\title{
ESTUDO DAS LIGAÇÕES CAVILHADAS IMPREGNADAS COM RESINAS ESTIRÊNICAS EMPREGADAS EM ESTRUTURAS DE MADEIRA
}

ORLANDO FERREIRA GOMES

Tese apresentada à Escola de Engenharia de São Carlos, da Universidade de São Paulo, como parte dos requisitos para obtenção do Título de Doutor em Engenharia Civil.

ORIENTADOR: Prof. Tit. Carlito Calil Jr

São Carlos

1997 
Ficha catalográfica preparada pela Seção de Tratamento da Informação do Serviço de Biblioteca - EESC-USP

G633e Estudo das ligações cavilhadas impregnadas com resinas estirênicas empregadas em estruturas de madeira / Orlando Ferreira Gomes. -- São Carlos, 1997.

Tese (Doutorado). -- Escola de Engenharia de São Carlos-Universidade de São Paulo, 1997. Orientador: Prof. Tit. Carlito Calil Júnior.

1. Ligações. 2. Cavilhas impregnadas.

3. Resinas estirênicas. 4. Estruturas de madeira.

I. Título 
"Se o Senhor não edificar a casa, em vão trabalham os que a edificam; se o Senhor não guardar a cidade, em vão vigia a sentinela."

SALMOS 127.

Ao meu Senhor e eterno

Salvador JESUS CRISTO, que me iluminou

para realizar esse trabalho.

À minha eterna companheira e esposa:

ROSALINA pelo apoio integral.

Aos meus filhos:KARINE E DANILO, que privei-me várias vezes de suas companhias para executar esse trabalho. Aos meus pais:DEODATO E ISABEL grandes professores da vida. Ao grande amigo e conselheiro PASTOR JARBAS A.VALENTIM, onde me inspirei em sua garra, ousadia e determinação para conseguir realizar seus ideais. 


\section{AGRADECIMENTOS}

Ao Professor Tit. Carlito Calil Jr. pela sua excelente orientação, pelo incentivo, amizade e dedicação profissional durante a elaboração e execução deste trabalho.

Aos Professores: José Agnelli, Sati Manrich, do Departamento de Engenharia de Materiais da UFSCar, pelas sugestões iniciais para montagem do processo de impregnação.

À Profa Dr.a Elizabete Frollini pelas sugestões e concessão do Laboratório de Físico-Química Orgânica do IQSC/USP, para os trabalhos de impregnação dos corpos de prova.

Ao Prof. Geraldo Lombardi do Departamento de Metrologia da EESC/USP, pelas sugestões para a confecção do equipamento de impregnação.

Ao Srs. Carlos A. Grandeza (DATIQUIM-Produtos Químicos Ltda.) e Luís Carlos Martins (COMPANHIA BRASILEIRA DE ESTIRENO), pelas doações dos produtos químicos: peróxido de benzoila e estireno para realização do processo de impregnação das madeiras.

Ao amigo e técnico José Francisco do Nascimento na operação da máquina universal de ensaios para execução dos ensaios nos modelos experimentais.

Ao técnico José Fernando Nascimento do Laboratório de FísicoQuímica Orgânica do IQSC/USP, pela cooperação dada no processo de impregnação dos corpos de prova de madeira. 
Aos técnicos: Aparecido, Arnaldo, Marivaldo e Sílvio da carpintaria do LaMEM/SET/USP, na confecção dos corpos de prova e os modelos finais de experimentação.

Aos Professores do Departamento de Estruturas da Escola de Engenharia Civil da Universidade Federal de Goiás pelo incentivo e apoio para realização da Pós- Graduação, e à FUNAPE/UFG .

A todos os amigos e colegas estudantes de pós-graduação pelo convívio universitário que jamais será esquecido.

Aos meus irmãos em Cristo da Igreja Batista de São Carlos, aos meus conterrâneos de Goiás e a sociedade brasileira. 


\section{SUMÁRIO}

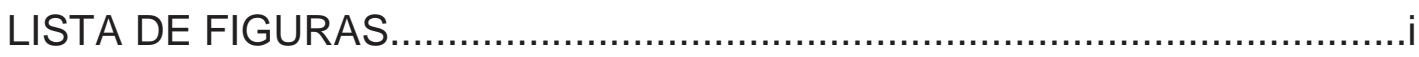

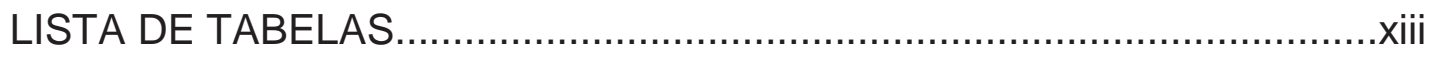

LISTA DE ABREVIATURAS, SIGLAS …...........................................xxviii

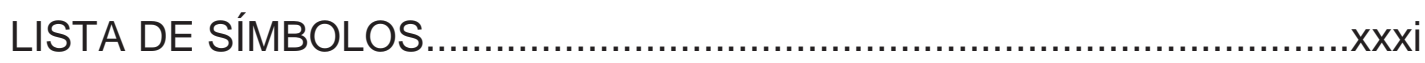

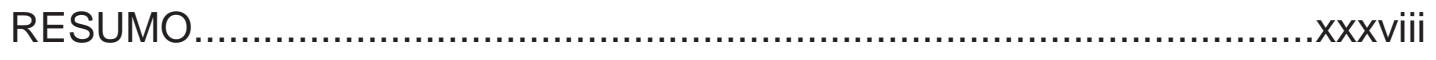

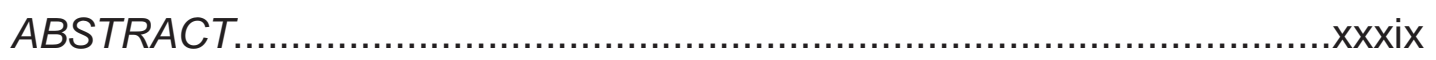

1 INTRODUÇÃO E CONCEITOS PRELIMINARES.....................................

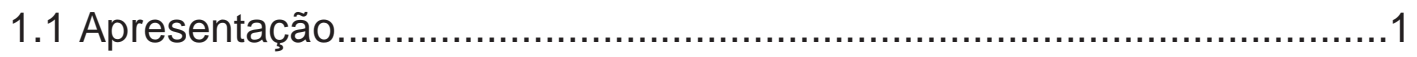

1.2 A madeira empregada como elemento estrutural..................................

1.2.1 Mecânica da madeira........................................................................

1.2.2 Relações entre tensões e deformações...........................................10

1.2.3 Propriedades mecânicas da madeira.............................................12

1.2.4 Madeira e produtos derivados da madeira.......................................13

2 HISTÓRICO E REVISÃO DA LITERATURA.........................................16

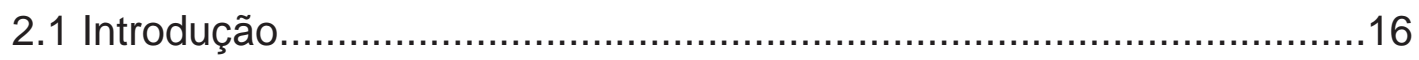

2.2 Principais contribuições da literatura.................................................17

3 LIGAÇÕES EM PEÇAS ESTRUTURAIS DE MADEIRA..........................24

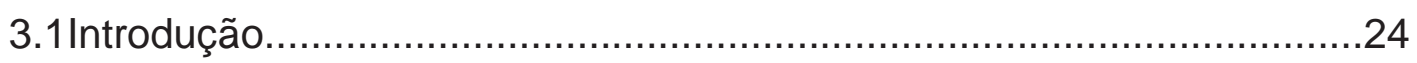

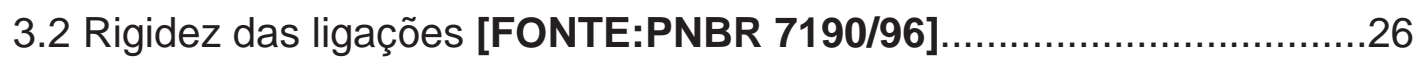

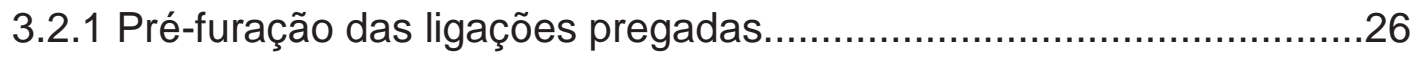

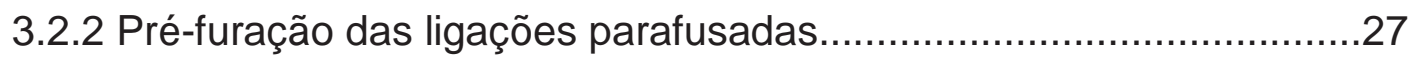

3.2.3 Pré-furação das ligações com cavilhas...........................................27 


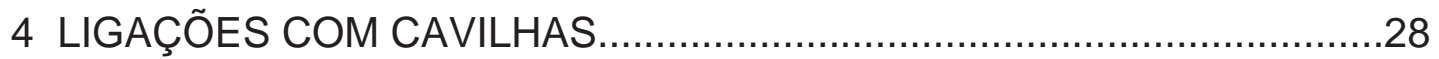

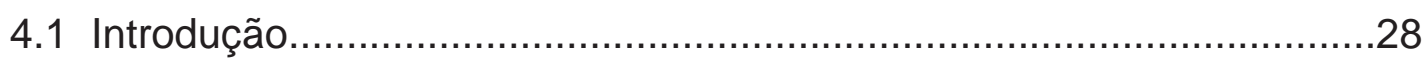

4.2 Fundamentos para a determinação das resistências das ligações cavilhadas em estruturas de madeira.....................................30

4.2.1 Comportamento básico das ligações cavilhadas..............................30

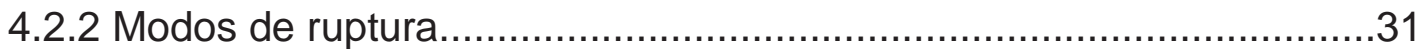

4.3 Esforços solicitantes nas ligações cavilhadas...................................33

4.4 Determinação teórica das cargas de primeiro e segundo limite das ligações cavilhadas...................................................37

4.4.1 Carga de Primeiro Limite...........................................................37

4.4.2 Cálculo da Carga de Segundo Limite.........................................44

4.5 Resistência total de uma cavilha com base no PNBR 7190/96.............51

4.6 Modos de ruptura segundo tratamento normativo.............................54

5 RECOMENDAÇÕES NORMATIVAS

PARA OS MÉTODOS DE ENSAIOS ..................................................59

5.1 Diâmetro das cavilhas e tamanho dos furos a serem utilizados nas peças de ligação.................................................................61

5.1.1 Associação Brasileira de Normas Técnicas NBR 7190/82................61

5.1.2 American Society for Testing and Materials-ASTM D 1761/77 ...........61

5.1.3 Deutsches Institut für normung DIN 68.150/1989- Parte 1...............62

5.1.4 British Standard Institution BS 6948/1989.................................62

5.1.5 National Design Especification for wood construction NDS/1991.......62

5.1 .6 Eurocode N.5/1991.............................................................62

5.1.7 Canadian Standards Association CAN/CSA-086.1-M89....................62

5.2 Espaçamentos mínimos..............................................................63

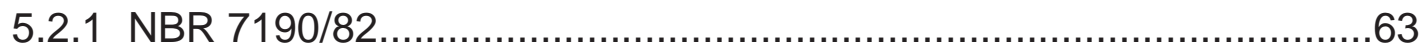

5.2.2 DIN 1052/88- Parte 2 ..................................................................63

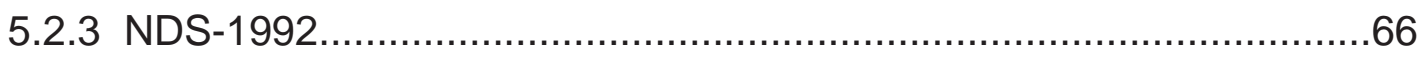

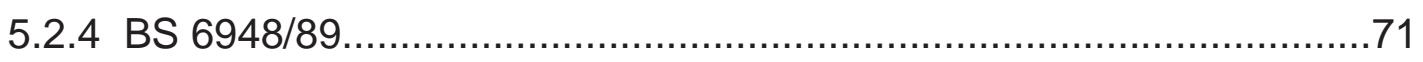

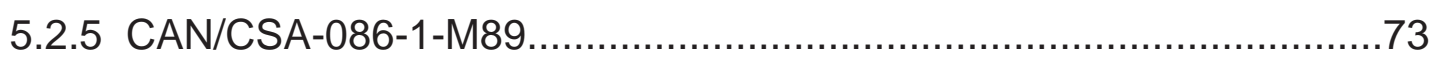

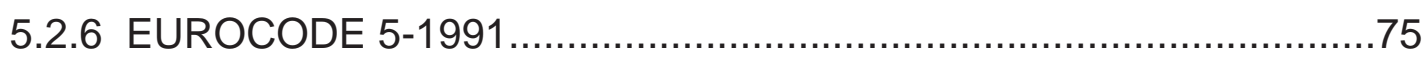


5.3 Espessura das peças a serem montadas nos ensaios de compressão paralela às fibras e compressão normal às fibras..........77

5.4 Procedimentos para realização de ensaios........................................77

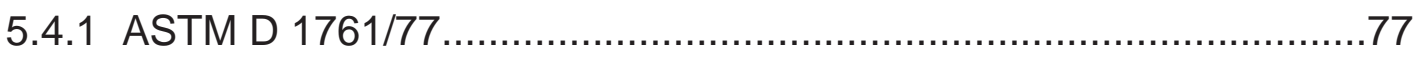

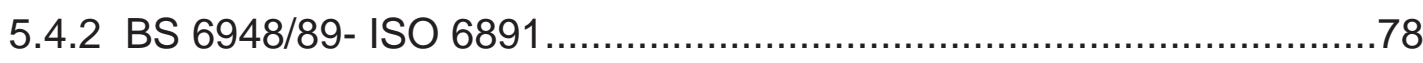

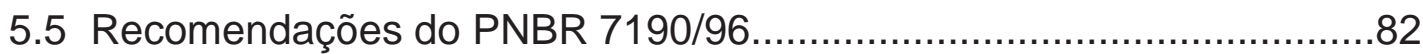

5.5.1 Espaçamentos entre elementos de ligação.......................................82

5.5.1.1 Espaçamentos em ligações com pinos (pregos com furação, parafusos e cavilhas)

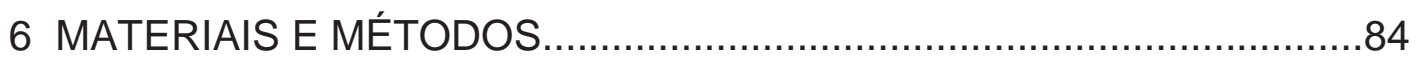

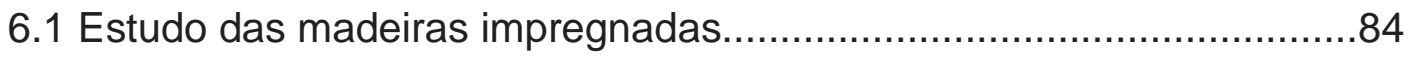

6.2 Produtos químicos utilizados na obtenção de resinas estirênicas........85

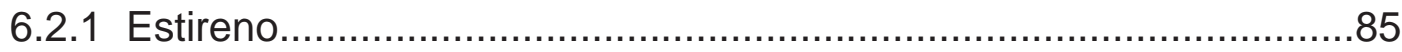

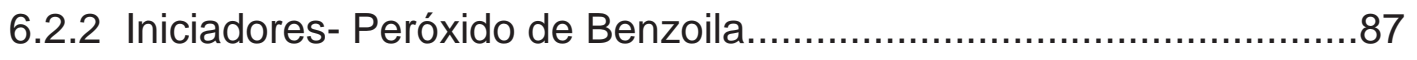

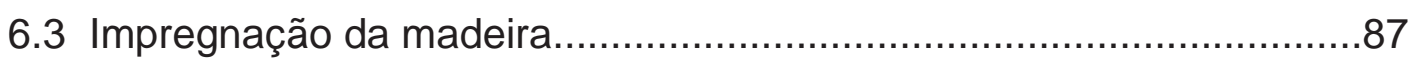

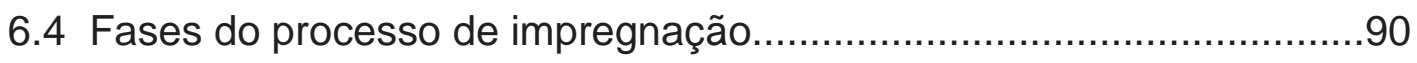

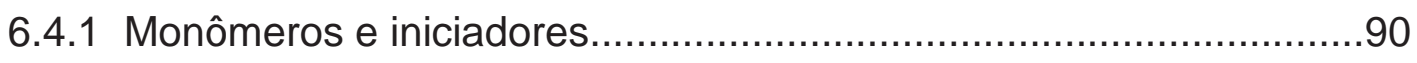

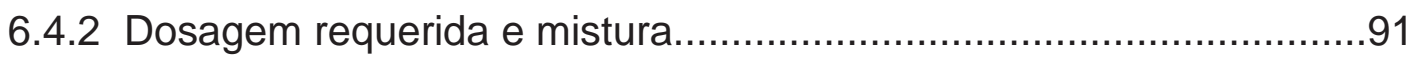

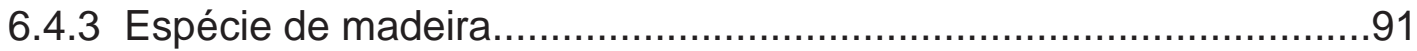

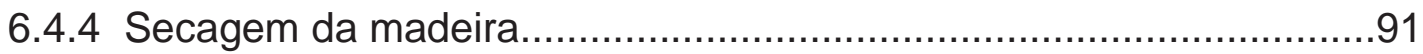

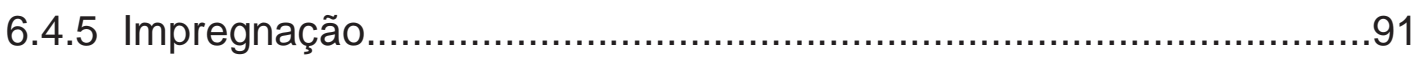

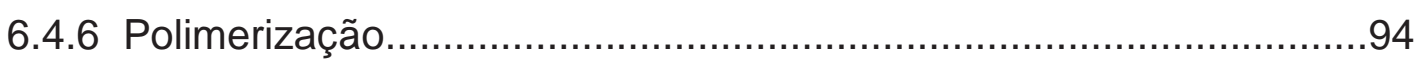

6.5 Ensaios para caracterização de madeiras impregnadas

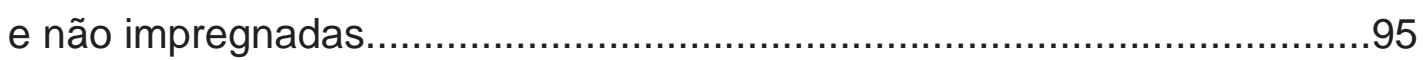

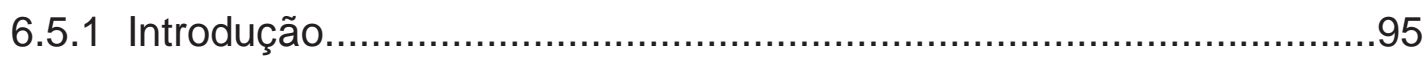

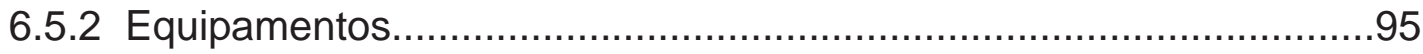

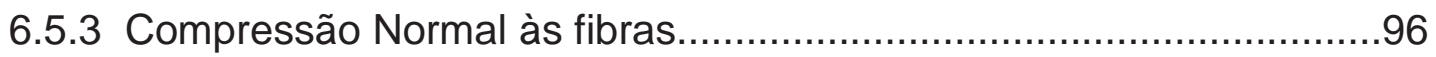

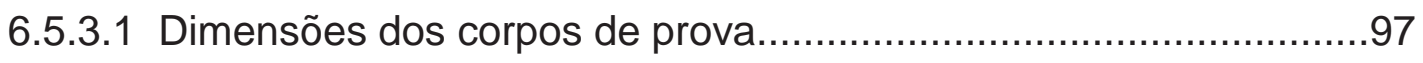

6.5.3.2 Programação de secagem dos corpos de prova.............................98

6.5.3.3 Impregnação dos corpos de prova.............................................99

6.5.3.4 Ensaios dos corpos de prova na compressão normal....................105 
6.5.4 Cisalhamento simples paralelo às fibras. 111

6.5.5 Cisalhamento na flexão em cavilhas..............................................116

6.5.5.1 Secagem e impregnação das cavilhas......................................117

6.5.5.2 Ensaio de cisalhamento na flexão das cavilhas...........................118

6.5.5.3 Tensões tangenciais devido à flexão nas cavilhas........................121

6.5.6 Compressão Paralela às Fibras.................................................123

6.5.6.1 Confecção dos corpos de prova-cavilhas $\mathrm{d}=2,0 \mathrm{~cm} ; l=8,0 \mathrm{~cm} \ldots . .125$

6.5.6.2 Programação de secagem e impregnação..................................126

6.5.6.3 Ensaio de compressão paralela- cavilhas $\mathrm{d}=2,0 \mathrm{~cm} ; \boldsymbol{l}=8,0 \mathrm{~cm} \ldots \ldots .128$

6.5.6.4 Confecção dos corpos de prova seção $5 \times 5 \times 20 \mathrm{~cm}$.......................132

6.5.6.5 Secagem e impregnação dos corpos de prova.............................133

6.5.6.6 Ensaio de compressão paralela às fibras...................................134

6.5.6.7 Análise dos ensaios de compressão paralela às fibras..................136

6.5.7 Tração Paralela às fibras..........................................................137

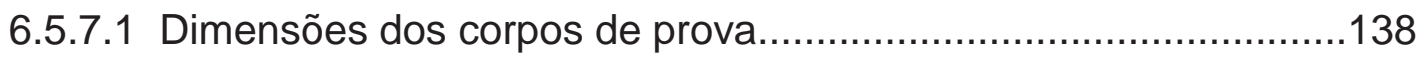

6.5.7.2 Secagem e impregnação dos corpos de prova.............................140

6.5.7.3 Ensaio de tração paralela às fibras..............................................141

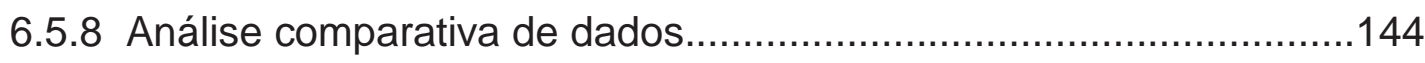

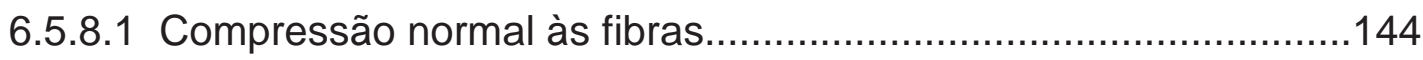

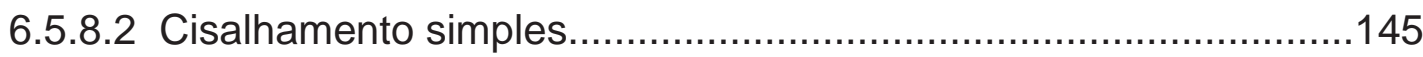

6.5.8.3 Ensaio de cisalhamento na flexão em cavilhas............................145

6.5.9 Compressão paralela às fibras...................................................147

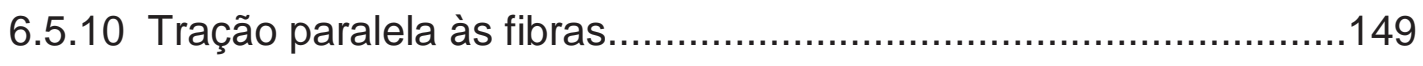

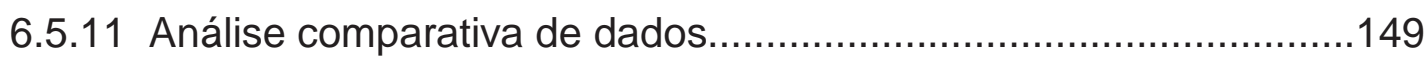

6.5.12 Consumo de materiais e estimativa de custo para o processo de impregnação de madeiras...................................................153

6.6 Ligações com cavilhas impregnadas e não impregnadas....................155

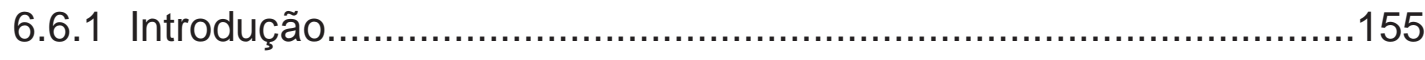

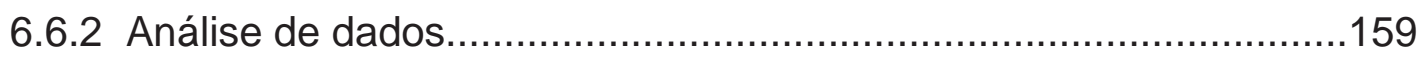

6.6.3 Resumo dos resultados finais dos valores de carga nos ensaios dos modelos das ligações com cavilhas...............................164 
6.6.4 Determinação das resistências das cavilhas utilizando o método proposto pelo PNBR 7190/96.

6.6.5 Considerações sobre os ensaios das ligações com cavilhas impregnadas e não impregnadas. 181

7 CONCLUSÕES E RECOMENDAÇÕES PARA FUTURAS PESQUISAS. 183

ANEXO A- Resultados parciais dos ensaios. 187

ANEXO B- Resultados dos ensaios de ligações com cavilhas impregnadas e não impregnadas. 201

ANEXO C- Cargas de primeiro e segundo limite das ligações cavilhadas .238

REFERÊNCIAS BIBLIOGRÁFICAS. .266

OBRAS CONSULTADAS 274 


\section{LISTA DE FIGURAS}

FIGURA 01-Peça de madeira mostrando os três eixos

principais. 05

FIGURA 02-Tensões atuantes num elemento cúbico de madeira segundo as direções dos eixos (L), ( R) e (T) .06

FIGURA 03-Madeira serrada representado modelo ortotrópico [FONTE:BODIG\&JAYNE(1982)].

FIGURA 04-Curvas carga-deslizamento para elementos de ligações dentro de uma conexão [FONTE:BLASS et al. (1984)].

FIGURA 05-Confecção de cavilhas no torno mecânico da carpintaria do LaMEM/SET/USP, e suas principais dimensões. 29

FIGURA 06-Diagrama carga-deslizamento típico das ligações cavilhadas. 31

FIGURA 07-Modos de ruptura das uniões com pinos de acordo com ALMEIDA (1990). 32

FIGURA 08-Esforços solicitantes no plano da seção transversal da união segundo ALMEIDA (1990) 33

FIGURA 09-Solicitação básica na ligação com cavilhas, adaptação feita de ALMEIDA (1990) .34

FIGURA 10-Solicitação simétrica da peça intermediária. .35 
FIGURA 11-Configuração do corpo de prova ensaiado sobre uma mesa rígida, onde o atrito entre o pátio e as peças altera a configuração de ruptura do corpo de prova....36

FIGURA 12-Distribuição de tensões na madeira-primeiro limite segundo ALMEIDA (1990).

FIGURA 13- Distribuição das pressões de contato para primeiro limite, $\sigma_{e, 0}=$ tensão de embutimento, d=diâmetro da cavilha, segundo ALMEIDA (1990). 39

FIGURA 14- Projeção do carregamento da cavilha para cálculo da força de primeiro limite.

FIGURA 15- Diagrama de distribuição de tensão na madeira, primeira hipótese [ALMEIDA (1990)] .45

FIGURA 16-Distribuição de tensões segunda hipótese [ALMEIDA(1990)]

FIGURA 17- Ligações com cavilhas. 52

FIGURA 18-Modos de ruptura para ligações com cavilhas sob corte simples e dispositivo de ligação com duas barras, FONTE:[WHALE et al (1987)] .55

FIGURA 19-Modos de ruptura para ligações com cavilhas sob corte duplo e dispositivo de ligação com três barras, FONTE:[WHALE et al (1987)]. 
FIGURA 20-Solicitação de compressão paralela e compressão normal às fibras. 60

FIGURA 21-Espaçamentos mínimos segundo a norma brasileira NBR 7190/82 para ligações com parafusos.

FIGURA 22-Distâncias de extremidades e espaçamentos mínimos para parafusos e pinos segundo a DIN 1052/88-Parte 2 65

FIGURA 23-Geometria de uma ligação por meio de parafusos com carregamento paralelo às fibras segundo NDS/1992. 66

FIGURA 24-Geometria de uma ligação por meio de parafusos com carregamento perpendicular às fibras segundo NDS/1992...67

FIGURA 25-Corpo de prova para ensaios paralelos as fibras sob carga lateral da categoria B dos elementos de ligação segundo BS 6948/89 .71

FIGURA 26-Ensaios de corpos de prova sob carga perpendiculares às fibras segundo BS 6948/89 .72

FIGURA 27-Espaçamentos dos parafusos nas ligações segundo CAN/CSA-086-1-M89. 74

FIGURA 28-Definição dos espaçamentos e distâncias dos elementos de ligação segundo o EUROCODE 5-1991. .75

FIGURA 29-Procedimentos de carregamento segundo a ISO 6891 80

FIGURA 30-Valores medidos da curva idealizada carga-deformação segundo a ISO 6891 81 
FIGURA 31-Espaçamentos em ligações pinos. .83

FIGURA 32-Fluxograma mostrando a fabricação do estireno segundo SHREVE \& BRINK (1980). .86

FIGURA 33- Ensaios de flexão estática de madeira e compósito polímero madeira da espécie tília americana (basswood), segundo MEYER apud ROWELL (1983). 89

FIGURA 34- Cilindro utilizado para o processo de impregnação montado no LaMEM/SET/USP. .92

FIGURA 35- Fluxograma mostrando o processo de impregnação da madeira nas dependências do IQSC/USP 93

FIGURA 36-Dimensões do corpo de prova para ensaio de compressão segundo PNBR 7190/96. .96

FIGURA 37-Valores comparativos de densidade de corpos de prova impregnados e não impregnados (Pinus). 104

FIGURA 38-Dados comparativos de resistência à compressão normal $\left(\mathfrak{f}_{c, 90}\right)$ de corpos de prova impregnados e não impregnados da espécie:Pinus 107

FIGURA 39-Dados comparativos de resistência à compressão normal $\left(\mathbf{f}_{c, 90}\right)$ de corpos de prova impregnados e não impregnados da espécie:Eucalipto citriodora 109

FIGURA 40-Corpo de prova $5 \times 5 \times 10 \mathrm{~cm}$ sendo ensaiado por solicitação de compressão normal 
FIGURA 41-Corpo de prova para ensaio de cisalhamento simples paralelo às fibras segundo o PNBR 7190/96

FIGURA 42-Dados comparativos de resistência no ensaio de cisalhamento simples paralelo às fibras.

FIGURA 43-Ensaio de cisalhamento na flexão em cavilhas

FIGURA 44-Ensaio de cisalhamento na flexão em cavilhas na máquina universal DARTEC do LaMEM/SET/USP....

FIGURA 45-Dados comparativos de resistência no ensaio de cisalhamento na flexão em cavilhas impregnadas e não impregnadas 122

FIGURA 46-Corpo de prova de compressão paralela (centímetros). 123

FIGURA 47-Modelo de cavilha para ensaio de compressão paralela às fibras idealizado no LaMEM/SET/USP 124

FIGURA 48-Esquema de ensaio de compressão paralela às fibras de cavilhas 128

FIGURA 49-Dados comparativos de resistência à compressão paralela às fibras de cavilhas. 130

FIGURA 50-Cavilha sendo ensaiada sob compressão paralela às fibras na máquina universal AMSLER do LaMEM/SET/USP. 131

FIGURA 51-Ensaio de compressão paralela às fibras executado na máquina universal AMSLER do LaMEM/SET/USP. 135 
FIGURA 52-Valores nominais das dimensões do corpo de prova para ensaio de tração paralela às fibras

FIGURA 53-Principais dimensões para confecção dos corpos de tração paralela às fibras.

FIGURA 54 -Corpo de prova de tração paralela às fibras sendo ensaiado na máquina universal do LaMEM/SET/USP

FIGURA 55-Corpo de prova de Ipê submetido a compressão normal.......144

FIGURA 56-Cavilhas de Ipê submetidas ao ensaio de cisalhamento na flexão 145

FIGURA 57-Corpos de prova de Ipê solicitados na compressão paralela às fibras.

FIGURA 58- Modos de ruptura dos corpos de prova de Pinus e Ipê, submetidos aos ensaios de caracterização completa das madeiras impregnadas e não impregnadas 152

FIGURA 59-Corpo de prova de ligação com cavilhas solicitados na compressão paralela às fibras, com relógio comparador 157

FIGURA 60-Corpo de prova de ligação com cavilhas solicitados na compressão normal às fibras, com relógio comparador 158

FIGURA 61- Corpo de prova preparado na carpintaria do LaMEM/SET/USP para o ensaio de compressão paralela às fibras. 160 
FIGURA 62- Corpo de prova preparado na carpintaria do

LaMEM/SET/USP para o ensaio de

compressão normal às fibras.

FIGURA 63- Corpo de prova ensaiado na máquina universal

Amsler do LaMEM/SET/USP para o ensaio de compressão paralela às fibras. 162

FIGURA 64- Corpo de prova ensaiado na máquina universal Amsler do LaMEM/SET/USP para o ensaio de compressão normal às fibras. 163

FIGURA 65-Dados comparativos de resistência de cálculo e cargas obtidas solicitadas na compressão paralela às fibras. 174

FIGURA 66-Dados comparativos de resistência de cálculo e cargas obtidas solicitadas na compressão normal às fibras.

FIGURA 67-Corpo de prova de ligação com cavilhas ao atingir a carga de ruptura no ensaio de compressão paralela às fibras. 177

FIGURA 68-Corpo de prova de ligação com cavilhas ao atingir a carga de ruptura no ensaio de compressão normal às fibras. 178

FIGURA 69-Gráfico $(\sigma-\varepsilon)$, para o corpo de prova 1 188

FIGURA 70-Gráfico $(\sigma-\varepsilon)$, para o corpo de prova 2 189

FIGURA 71-Gráfico $(\sigma-\varepsilon)$, para o corpo de prova 3 190 
FIGURA 72-Gráfico $(\sigma-\varepsilon)$, para o corpo de prova 4

FIGURA 73-Gráfico $(\sigma-\varepsilon)$, para o corpo de prova 5 192

FIGURA 74-Gráfico $(\sigma-\varepsilon)$, para o corpo de prova 6 193

FIGURA 75-Gráfico $(\sigma-\varepsilon)$, para o corpo de prova 7 194

FIGURA 76-Gráfico $(\sigma-\varepsilon)$, para o corpo de prova 8 195

FIGURA 77-Gráfico $(\sigma-\varepsilon)$, para o corpo de prova 9 196

FIGURA 78-Gráfico $(\sigma-\varepsilon)$, para o corpo de prova 10 197

FIGURA 79-Gráfico $(\sigma-\varepsilon)$, para o corpo de prova 11 198

FIGURA 80-Gráfico $(\sigma-\varepsilon)$, para o corpo de prova 12 199

FIGURA 81-Gráfico $(\sigma-\varepsilon)$, para o corpo de prova de Ipê 200

FIGURA 82-Gráfico F- $\varepsilon$ para o corpo de prova CP16. 202

FIGURA 83-Gráfico F- $\varepsilon$ para o corpo de prova CPI16 .203

FIGURA 84-Gráfico F- $\varepsilon$ para o corpo de prova CP18. .204

FIGURA 85-Gráfico F- $\varepsilon$ para o corpo de prova CPI18 .205

FIGURA 86-Gráfico F- $\varepsilon$ para o corpo de prova CP20 206 
FIGURA 87-Gráfico F- $\varepsilon$ para o corpo de prova CPI20.

FIGURA 88-Gráfico F- $\varepsilon$ para o corpo de prova CN16. 208

FIGURA 89-Gráfico F-E para o corpo de prova CNI16 .209

FIGURA 90-Gráfico F- $\varepsilon$ para o corpo de prova CN18 210

FIGURA 91-Gráfico F- $\varepsilon$ para o corpo de prova CNI18 211

FIGURA 92-Gráfico F- $\varepsilon$ para o corpo de prova CN20 212

FIGURA 93-Gráfico F- $\varepsilon$ para o corpo de prova CNI20 213

FIGURA 94-Gráfico F- $\varepsilon$ para o corpo de prova CN116. 214

FIGURA 95-Gráfico F-E para o corpo de prova CN2I16. 215

FIGURA 96-Gráfico F- $\varepsilon$ para o corpo de prova CN3 216

FIGURA 97-Gráfico F- $\varepsilon$ para o corpo de prova CN4 217

FIGURA 98-Gráfico F- $\varepsilon$ para o corpo de prova CVN16 218

FIGURA 99-Gráfico F- $\varepsilon$ para o corpo de prova CVNI16. 219

FIGURA 100-Gráfico F- $\varepsilon$ para o corpo de prova CVN18 220 
FIGURA 101-Gráfico F- $\varepsilon$ para o corpo de prova CVNI18. .221

FIGURA 102-Gráfico F- $\varepsilon$ para o corpo de prova CVN20 .222

FIGURA 103-Gráfico F- $\varepsilon$ para o corpo de prova CVNI20. .223

FIGURA 104-Gráfico F- $\varepsilon$ para o corpo de prova CT1 .224

FIGURA 105-Gráfico F- $\varepsilon$ para o corpo de prova CL1 .225

FIGURA 106-Gráfico F- $\varepsilon$ para o corpo de prova CT2. 226

FIGURA 107-Gráfico F- $\varepsilon$ para o corpo de prova CL2. .227

FIGURA 108-Gráfico F- $\varepsilon$ para o corpo de prova CT3. 228

FIGURA 109-Gráfico F- $\varepsilon$ para o corpo de prova CL3. .229

FIGURA 110-Gráfico F- $\varepsilon$ para o corpo de prova CPN18 .230

FIGURA 111-Gráfico F- $\varepsilon$ para o corpo de prova CPNI18. .231

FIGURA 112-Gráfico F- $\varepsilon$ para o corpo de prova P1 .232

FIGURA 113-Gráfico F- $\varepsilon$ para o corpo de prova P2 .233

FIGURA 114-Gráfico F- $\varepsilon$ para o corpo de prova P3. .234 
FIGURA 115-Gráfico F- $\varepsilon$ para o corpo de prova N1 .235

FIGURA 116-Gráfico F-E para o corpo de prova N2. .236

FIGURA 117-Gráfico F-ع para o corpo de prova N3. .237

FIGURA 118- Valores de c em função da excentricidade e no intervalo $t / 6 \leq e \leq t / 2$. 253

FIGURA 119- Diagrama $\xi_{0} \times \beta$ e valor $\beta_{\lim } \operatorname{com} \eta_{0}=0,75$ para Pinus sem impregnação. 253

FIGURA 120- Diagrama $\xi_{0} \times \beta$ e valor $\beta_{\lim } \operatorname{com} \eta_{0}=0,80$ para Pinus com impregnação. .254

FIGURA 121- Diagrama $\xi_{0} \times \beta$ e valor $\beta_{\lim } \operatorname{com} \eta_{0}=0,89$ para Ipê .254

FIGURA 122- Cálculo da carga de primeiro da ligação

Pinus sem impregnação. 255

FIGURA 123- Cálculo da carga de primeiro da ligação

Pinus com impregnação. 255

FIGURA 124- Cálculo da carga de primeiro limite da ligação Ipê 256

FIGURA 125- Comportamento de $\xi_{u}$ em função de $\beta$,

Carga de segundo limite Hipótese A. .256 
FIGURA 126-Comportamento das funções $\mathbf{F}_{\mathbf{w}, \mathbf{u}}$ e $\mathbf{F}_{\mathbf{c a v}, \mathbf{u}}$ para carga de segundo limite Hipótese A. .257

FIGURA 127- Comportamento de $\xi$ u em função de $\beta$ Carga de segundo limite Hipótese B. .258

FIGURA 128- Comportamento das funções $\mathbf{F}_{\mathbf{w}, \mathbf{u}}$ e $\mathbf{F}_{\mathbf{c a v}, \mathbf{u}}$ para carga de segundo limite Hipótese B .259 


\section{LISTA DE TABELAS}

Tabela 01-Valores aproximados de e e c obtidos por calibração.

Tabela 02- Valores de $\xi_{0}$ em função do parâmetro $\beta$

Tabela 03- Valores de $\mathbf{F}_{\mathbf{w}, \mathbf{o}}$ e $\mathbf{F}_{\mathbf{c a v}, \mathbf{o}}$ em função do parâmetro $\beta$.

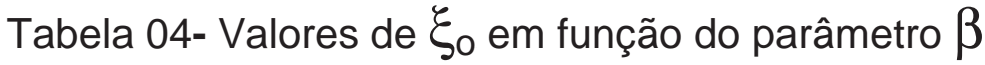
46

Tabela 05- Valores de $\mathrm{F}_{\mathrm{w}, \mathrm{u}}^{\mathrm{A}}, \mathrm{F}_{\mathrm{cav}, \mathrm{u}}^{\mathrm{A}}$ em função do parâmetro $\beta$ 47

Tabela 06 -Valores de $\xi_{\text {u }}$ em função do parâmetro $\beta$. 48.

Tabela 07- Valores de $\mathrm{F}_{\mathrm{w}, \mathrm{u}}^{\mathrm{B}}, \mathrm{F}_{\mathrm{cav}, \mathrm{u}}^{\mathrm{B}}$ em função do parâmetro $\beta$ 49

Tabela 08- Expressões para determinação das cargas limites

ESPÉCIE: Pinus sem impregnação .50

Tabela 09- Expressões para determinação das cargas limites

ESPÉCIE: Pinus com impregnação; $p=1 \mathrm{MPa}$ .50

Tabela 10- Expressões para determinação das cargas limites

ESPÉCIE: Ipê .51

Tabela 11- Distâncias de extremidade e espaçamentos mínimos para pinos e parafusos. 63 
Tabela 12 - Recomendações das distâncias de bordas para parafusos. 68

Tabela 13 -Recomendações de distância de extremidade para parafusos. .69

Tabela 14 -Espaçamentos requeridos para parafusos em uma linha. .70

Tabela 15 -Espaçamentos requeridos entre linhas de furos. .70

Tabela 16 - Espaçamentos mínimos e distâncias para pinos. 76

Tabela 17-Valores de $\mathrm{k}_{\mathrm{a}}$ .77

Tabela 18 - Valores das dimensões dos corpos de prova Espécie:Pinus 97

Tabela 19 - Valores das dimensões dos corpos de prova Espécie:Eucalipto citriodora

Tabela 20 - Peso dos corpos de prova verde e seco-Espécie:Pinus. .98

Tabela 21- Peso verde e seco de corpos de prova Espécie: Eucalipto citriodora. 99

Tabela 22- Tempo de impregnação, pressão de impregnação e temperatura de secagem em estufa por 48 horas Espécie: Pinus. 
Tabela 23- Tempo de impregnação, pressão de impregnação

e temperatura de secagem em estufa por 48 horas

Espécie: Eucalipto citriodora

Tabela 24 - Peso dos corpos impregnados e não impregnados

Espécie:Pinus 102

Tabela 25 - Peso dos corpos impregnados e não impregnados

Espécie:Eucalipto citriodora

Tabela 26 - Valores de densidade dos corpos

de prova impregnados e não impregnados-Espécie:Pinus 103

Tabela 27- Valores de densidade dos corpos

de prova impregnados e não impregnados

Espécie:Eucalipto citriodora

Tabela 28 - Pressão de impregnação, resistência à compressão normal às fibras e módulo de elasticidade de corpos de prova sem impregnação. Espécie:Pinus 105

Tabela 29 - Pressão de impregnação, resistência à compressão normal às fibras e módulo de elasticidade de corpos de prova com impregnação. Espécie:Pinus. 106

Tabela 30 - Pressão de impregnação, resistência

à compressão normal às fibras e módulo de elasticidade de corpos de prova sem impregnação. Espécie:Eucalipto citriodora. 108 
Tabela 31 - Pressão de impregnação, resistência à compressão normal às fibras e módulo de elasticidade normal às fibras de corpos de prova com impregnação ESPÉCIE: Eucalitpo citriodora. 108

Tabela 32 - Massa dos corpos de prova impregnados e não impregnados para o ensaio de cisalhamento simples paralelo às fibras Espécie:Pinus.

Tabela 33 - Carga e resistência dos corpos de prova não impregnados no ensaio de cisallhamento simples.Espécie:Pinus. 114

Tabela 34- Carga e resistência dos corpos de prova impregnados no ensaio de cisalhamento simples; $p=1$ MPa Espécie:Pinus. 114

Tabela 35- Dimensões principais das cavilhas -Espécie:Pinus. 116

Tabela 36- Massa das cavilhas impregnadas e não impregnadas Espécie:Pinus 117

Tabela 37- Cargas de ruptura no ensaio de cisalhamento na flexão de cavilhas Espécie:Pinus.

Tabela 38- Resistências médias em cavilhas impregnadas no ensaio de cisalhamento na flexão; $p=1 \mathrm{MPa}$-Espécie: Pinus

Tabela 39- Resistências médias em cavilhas não impregnadas no ensaio de cisalhamento na flexão

Tabela 40- Dimensões das cavilhas para ensaio de compressão paralela às fibras-Espécie:Pinus 
Tabela 41- Massa das cavilhas desde a etapa de confecção até a fase de impregnação -Espécie:Pinus.

Tabela 42- Resistência à compressão paralela às fibras das cavilhas não impregnadas-Espécie:Pinus. 129

Tabela 43- Resistência à compressão paralela às fibras das cavilhas impregnadas; $p=1 \mathrm{MPa}$-Espécie:Pinus.

Tabela 44 - Dimensões dos corpos de prova de compressão paralela às fibras-Espécie:Pinus 132

Tabela 45- Massa dos corpos de prova 5x5×20cm -Espécie:Pinus.

Tabela 46- Resistência à compressão paralela às fibras de corpos de prova $5 \times 5 \times 20 \mathrm{~cm}$,sem impregnação. Espécie:Pinus......136

Tabela 47- Resistência à compressão paralela às fibras de corpos de prova $5 \times 5 \times 20 \mathrm{~cm}$ com impregnação; $p=1 \mathrm{MPa}$. Espécie:Pinus. 136

Tabela 48- Dimensões dos corpos de prova para

o ensaio de tração paralela às fibras.Espécie:Pinus. 139

Tabela 48A- Dimensões dos corpos de prova 139

Tabela 49- Massa dos corpos de prova de tração paralela às fibras. 140

Tabela 50- Resultados do ensaio de tração paralela às fibras de corpos de prova não impregnados; Espécie:Pinus. 141 
Tabela 51- Resultados do ensaio de tração paralela às fibras de corpos de prova impregnados; $p=1 \mathrm{MPa}$; Espécie:Pinus

Tabela 52- Resultados de ensaios de cisalhamento na flexão em cavilhas.Espécie:Ipê 146

Tabela 53- Resultados dos ensaios de cavilhas de Ipê na compressão paralela às fibras-Espécie:Ipê. 148

Tabela 54- Ensaio de tração paralela às fibras- Espécie:Ipê 149

Tabela 55-Valores médios de densidade e resistência à compressão normal às fibras. 150

Tabela 56-Valores médios de resistência ao cisalhamento simples 150

Tabela 57-Valores médios de resistência à compressão paralela às fibras e módulo de elasticidade de corpos de prova $5 \times 5 \times 20 \mathrm{~cm}$. 150

Tabela 58-Valores médios de resistência à compressão paralela às fibras de cavilhas, $d=2,0 \mathrm{~cm} ; l=8,0 \mathrm{~cm}$

Tabela 59-Valores médios da resistência ao cisalhamento na flexão

Tabela 60-Valores médios de resistência à tração paralela às fibras

Tabela 61-Volume de madeira e quantidade de resina estirência absorvida. 153

Tabela 62-Consumo de produtos químicos por $\mathrm{m}^{3}$ de madeira 153 
Tabela 63-Estimativa do custo de impregnação de madeiras e cavilhas 154

Tabela 64- Grandezas obtidas nos ensaios de ligações com cavilhas......156

Tabela 65 - Resumo dos resultados no ensaio de ligações com cavilhas-Parte I -Espécie: Pinus Unidade:kN. 164

Tabela 65A - Resumo dos resultados no ensaio de ligações com cavilhas-parte II -Espécie: Pinus Unidade:kN 165

Tabela 65B - Resumo dos resultados no ensaio de ligações com cavilhas-parte III -Espécie: Ipê Unidade: kN .165

Tabela 66 -Valores de cálculo das resistências das cavilhas com base no PNBR 7190/96-Espécie: Pinus 169

Tabela 67- Valores de cálculo das resistências das cavilhas com base no PNBR 7190/96-Espécie:Ipê. 170

Tabela 68- Dados comparativos dos valores de cálculo das resistências das cavilhas baseados no PNBR 7190/96, em relação aos valores obtidos nos ensaios de ligações, solicitadas na compressão paralela às fibras-Espécie: Pinus

Tabela 69- Dados comparativos dos valores de cálculo das resistências das cavilhas baseados no PNBR 7190/96, em relação aos valores obtidos nos ensaios de ligações, solicitadas na compressão paralela às fibras.Espécie:Ipê 
Tabela 70- Dados comparativos dos valores de cálculo das resistências das cavilhas baseados no PNBR 7190/96, em relação aos valores obtidos nos ensaios de ligações, solicitadas na compressão normal às fibras- Espécie: Pinus.

Tabela 71- Dados comparativos dos valores de cálculo das resistências das cavilhas baseados no PNBR 7190/96, em relação aos valores obtidos nos ensaios de ligações, solicitadas na compressão normal às fibras- Espécie: Ipê. 173

Tabela 72- Valores dos coeficientes de resistência das cavilhas impregnadas e não impregnadas $\left(R_{v d, 1}\right) C l / R_{v d, 1}(S I)=r_{1}, F_{o}(C l) / F_{o}(S I)=r_{2}$; $\mathrm{F} /(\mathrm{Cl}) / \mathrm{F}_{/}(\mathrm{SI})=\mathrm{r}_{3} ; \mathrm{F}_{\max }(\mathrm{Cl}) / \mathrm{F}_{\max }(\mathrm{SI})=\mathrm{r}_{4}$ 176

Tabela 73-Dados comparativos de cargas e rigidez nos ensaios de ligações com cavilhas obtidas nos ensaios experimentais na compressão paralela às fibras com valores do PNBR 7190/96- Espécie:Pinus 179

Tabela 74-Dados comparativos de cargas e rigidez nos ensaios de ligações com cavilhas obtidas nos ensaios experimentais na compressão paralela às fibras com valores do PNBR 7190/96- Espécie:Ipê.

Tabela 75-Dados comparativos de cargas e rigidez nos ensaios de ligações com cavilhas obtidas nos ensaios experimentais na compressão normal às fibras com valores do PNBR 7190/96-Espécie:Pinus. 180 
Tabela 76-Dados comparativos de cargas e rigidez nos ensaios de ligações com cavilhas obtidas nos ensaios experimentais na compressão normal às fibras com valores do PNBR 7190/96 Espécie:Ipê.

Tabela 77- Características físicas e mecânicas das madeiras. 239

Tabela 78- Comparação dos valores das cargas de primeiro limite com os valores obtidos no ensaio de compressão paralela às fibras. ESPÉCIE:Pinus sem impregnação. 240

Tabela 79- Comparação dos valores das cargas de primeiro limite com os valores obtidos no ensaio de compressão paralela às fibras. ESPÉCIE:Pinus com impregnação. 240

Tabela 80- Comparação dos valores das cargas de primeiro limite com os valores obtidos no ensaio de compressão paralela às fibras. ESPÉCIE:Ipê. 240

Tabela 81- Comparação dos valores das cargas de segundo limite, hipótese A com os valores obtidos no ensaio de compressão paralela às fibras ESPÉCIE:Pinus sem impregnação. 241

Tabela 82- Comparação dos valores das cargas de segundo limite,hipótese $B$ com os valores obtidos no ensaio de compressão paralela às fibras. ESPÉCIE:Pinus sem impregnação. 
Tabela 83- Comparação dos valores das cargas

de segundo limite hipótese A,com os

valores obtidos no ensaio de compressão paralela às fibras.

ESPÉCIE:Pinus com impregnação.

Tabela 84- Comparação dos valores das

cargas de segundo limite hipótese B,com os

valores obtidos no ensaio de compressão paralela às fibras.

ESPÉCIE:Pinus com impregnação;

Tabela 85- Comparação dos valores das

cargas de segundo limite hipótese A,com os

valores obtidos no ensaio de compressão paralela às fibras.

ESPÉCIE:Ipê;

Tabela 86- Comparação dos valores das

cargas de segundo limite hipótese B,com os

valores obtidos no ensaio de compressão paralela às fibras.

ESPÉCIE:Ipê.

Tabela 87- Comparação dos valores das

cargas de primeiro limite com os valores obtidos no

ensaio de compressão normal às fibras.

ESPÉCIE:Pinus sem impregnação.

Tabela 88- Comparação dos valores das

cargas de primeiro limite com os

valores obtidos no ensaio de compressão normal às fibras.

ESPÉCIE:Pinus com impregnação. 
Tabela 89- Comparação dos valores das

cargas de segundo limite hipótese A,com os

valores obtidos no ensaio de compressão normal às fibras.

ESPÉCIE:Pinus com impregnação.

Tabela 90- Comparação dos valores das

cargas de segundo limite hipótese B,com os

valores obtidos no ensaio de compressão normal às fibras.

ESPÉCIE:Pinus com impregnação

Tabela 91- Comparação dos valores das

cargas de primeiro limite com os

valores obtidos no ensaio de compressão normal às fibras.

ESPÉCIE:Ipê;

Tabela 92- Comparação dos valores das

cargas de segundo limite hipótese A,com os

valores obtidos no ensaio de compressão normal às fibras.

ESPÉCIE:Ipê.

Tabela 93- Comparação dos valores das

cargas de segundo limite hipótese B,com os

valores obtidos no ensaio de compressão normal às fibras.

ESPÉCIE:Ipê.

Tabela 94- Expressões para determinação das

cargas limites ESPÉCIE: Pinus sem impregnação.

Tabela 95- Expressões para determinação das

cargas limites ESPÉCIE: Pinus com impregnação; $p=1 \mathrm{MPa}$ 248 
Tabela 96- Expressões para determinação das cargas limites

ESPÉCIE: Ipê.

Tabela 97-Simulação matemática para determinação

do valor da excentricidade e para

carga de primeiro limite das ligações cavilhadas

d=16mm; Espécie de Madeira: Pinus sem impregnação

Tabela 98-Simulação matemática para determinação

do valor da excentricidade e para

carga de segundo limite das ligações cavilhadas,

d=16mm; Espécie de Madeira: Pinus sem impregnação

Tabela 99-Simulação matemática para determinação

do valor da excentricidade e para

carga de primeiro limite das ligações cavilhadas,

$\mathrm{d}=16 \mathrm{~mm}$; Espécie de Madeira: Pinus com impregnação

Tabela100-Simulação matemática para determinação

do valor da excentricidade e para

carga de segundo limite das ligações cavilhadas,

d=16mm; Espécie de Madeira: Pinus com impregnação

Tabela 101-Simulação matemática para determinação

do valor da excentricidade e para

carga de primeiro limite das ligações cavilhadas

$\mathrm{d}=16 \mathrm{~mm}$; Espécie de Madeira: Ipê

Tabela 102-Simulação matemática para determinação

do valor da excentricidade e para

carga de segundo limite das ligações cavilhadas

, d=16mm; Espécie de Madeira: Ipê 
Tabela 103- Valores das cargas de primeiro limite em comparação com os resultados experimentais e com os valores normativos segundo a NBR 7190/96 das ligações cavilhadas impregnadas e não impregnadas no ensaio de compressão paralela às fibras. Espécie:Pinus. 260

Tabela 104- Valores das cargas de segundo limite Hipótese A, em comparação com os resultados experimentais e com os valores normativos segundo a NBR 7190/96 das ligações cavilhadas impregnadas e não impregnadas no ensaio de compressão paralela às fibras. Espécie:Pinus .260

Tabela 105- Valores das cargas de segundo limite Hipótese B, em comparação com os resultados experimentais e com os valores normativos segundo a NBR 7190/96 das ligações cavilhadas impregnadas e não impregnadas no ensaio de compressão paralela às fibras. Espécie:Pinus. 260

Tabela 106- Valores das cargas de primeiro limite em comparação com os resultados experimentais e com os valores normativos segundo a NBR 7190/96 das ligações cavilhadas impregnadas e não impregnadas no ensaio de compressão paralela às fibras. Espécie:Ipê .261

Tabela 107- Valores das cargas de segundo limite Hipótese A, em comparação com os resultados experimentais e com os valores normativos segundo a NBR 7190/96 das ligações cavilhadas impregnadas e não impregnadas no ensaio de compressão paralela às fibras. Espécie:Ipê 
Tabela 108- Valores das cargas de segundo limite Hipótese B, em comparação com os resultados experimentais e com os valores normativos segundo a NBR 7190/96 das ligações cavilhadas impregnadas e não impregnadas no ensaio de compressão paralela às fibras. Espécie:Ipê.

Tabela 109- Valores das cargas de primeiro limite em comparação com os resultados experimentais e com os valores normativos segundo a NBR 7190/96 das ligações cavilhadas impregnadas e não impregnadas no ensaio de compressão normal às fibras. Espécie:Pinus. 262

Tabela 110- Valores das cargas de segundo limite Hipótese A, em comparação com os resultados experimentais e com os valores normativos segundo a NBR 7190/96 das ligações cavilhadas impregnadas e não impregnadas no ensaio de compressão normal às fibras. Espécie:Pinus. 263

Tabela 111- Valores das cargas de segundo limite Hipótese B, em comparação com os resultados experimentais e com os valores normativos segundo a NBR 7190/96 das ligações cavilhadas impregnadas e não impregnadas no ensaio de compressão normal às fibras. Espécie:Pinus. 264

Tabela 112- Valores das cargas de primeiro limite em comparação com os resultados experimentais e com os valores normativos segundo a NBR 7190/96 das ligações cavilhadas impregnadas e não impregnadas no ensaio de compressão normal às fibras. Espécie:Ipê. 
Tabela 113- Valores das cargas de segundo limite Hipótese A, em comparação com os resultados experimentais e com os valores normativos segundo a NBR 7190/96 das ligações cavilhadas impregnadas e não impregnadas no ensaio de compressão normal às fibras. Espécie:Ipê.

Tabela 114- Valores das cargas de segundo limite Hipótese B, em comparação com os resultados experimentais e com os valores normativos segundo a NBR 7190/96 das ligações cavilhadas impregnadas e não impregnadas no ensaio de compressão normal às fibras Espécie:Ipê. 


\section{LISTA DE ABREVIATURAS E SIGLAS}

ABIMCI-Associação Brasileira da Indústria de Madeira Compensada e Industrializada

ABNT-Associação Brasileira de Normas Técnicas

AITC-American Institute of Timber Construction

ASCE-American Society of Civil Engineers

ASTM-American Society for Testing and Materials

BSI-British Standards Institution

CG-Centro de gravidade

Cl-Com impregnação

CP-Corpo de prova

CPI-Corpo de prova impregnado

CPM-Compósitos Polímero-Madeira

CPSI-Corpo de prova sem impregnação

CSA-Canadian Standard Association

DEMa-Departamento de Engenharia de Materiais da Universidade Federal de São Carlos 
DEST-Departamento de Estruturas da Escola de Engenharia da Universidade Federal de Goiás

DIN-Deustsches Institut für Normung

EESC-Escola de Engenharia de São Carlos da Universidade de São Paulo

EPUSP- Escola Politécnica da Universidade de São Paulo

FPL-Forest Products Laboratory

IBRAMEM-Instituto Brasileiro da Madeira e das Estruturas de Madeira

IFQSC-Instituto de Física e Química de São Carlos

IPT-Instituto de Pesquisas Tecnológicas do Estado de São Paulo

ISO-International Organization for Standardization

LaMEM-Laboratório de Madeiras e Estruturas de Madeira da Escola de Engenharia de São Carlos da USP.

LaMET-Laboratório de Metrologia da EESC/USP.

LEM- Laboratório de Estruturas e Materiais Estruturais da Escola Politécnica da USP.

LN-Linha Neutra.

NBR-Norma Brasileira Registrada

NDS-National Design Specification 
OBS-Observação

SET-Departamento de Estruturas da Escola de Engenharia de São Carlos da Universidade de São Paulo

TRADA-Timber Research \& Development Association

UFG-Universidade Federal de Goiás

UFSCar-Universidade Federal de São Carlos

USP-Universidade de São Paulo. 


\section{LISTA DE SÍMBOLOS}

\section{Letras romanas maiúsculas}

A - área

D - rigidez à flexão de placas ou cascas

E - módulo de deformação longitudinal

F - ação e força em geral

G - módulo de deformação transversal

$\mathrm{H}$ - componente horizontal de força

I - momento de inércia

K - qualquer grandeza com dimensões próprias, na ausência de símbolo específico

L - vão, comprimento (em substituição a 1 para evitar confusão com 0 número 1 )

M - momento (em geral, momento feltro)

$M_{r}$. - momento resistente

$M_{S}$ - momento solicitante

$M_{d}$ - valor de cálculo do momento $\left(M_{d}, M_{d}, M_{d}\right)$

$\mathrm{K}_{\mathrm{m}}$ - valor característico do momento $\left(\mathrm{K}_{\mathrm{m}}, \mathrm{M}_{\mathrm{rk}}, \mathrm{M}_{\mathrm{sk}}\right)$

$M_{u}$ - valor último do momento

$M_{\text {eng }}$ - momento fletor de engastamento perfeito

$\mathrm{N}$ - força normal $\left(\mathrm{N}_{\mathrm{d}}, \mathrm{N}_{\mathrm{k}}, \mathrm{N}_{\mathrm{u}}\right)$

P - força de proteção

Q - ação acidental (variável) $\left(Q_{d}, Q_{k}, Q_{u}\right)$

R - reação de apoio, resultante de tensões, resistência

$\mathrm{R}_{\mathrm{C}}$ - resultante de tensões de compressão

$R_{t} \quad$ - resultante das tensões de tração

S - solicitação, momento estático de área

$\mathrm{T}$ - momento de torção, temperatura, período de tempo 
U - umidade

$\mathrm{V} \quad$ - força cortante $\left(\mathrm{V}_{\mathrm{u}}, \mathrm{V}_{\mathrm{d}}, \mathrm{V}_{\mathrm{k}}\right)$, volume

W - carga do vento, módulo de resistência à flexão

Z - força (em geral) paralela ao eixo z, módulo de resistência à plastificação (na flexão)

\section{Letras romanas minúsculas}

a - distância, flecha

b - largura

$\mathrm{B}_{\mathrm{f}} \quad$ - largura da mesa das vigas de seção $\mathrm{T}$

$B_{w}$ - largura da alma das vigas

C - espaçamento

d - diâmetro

e - excentricidade

f $\quad$ - resistência de um material

$f_{d} \quad$ - valor de cálculo da resistência

$f_{k} \quad$ - valor característico da resistência

$f_{m} \quad$ - valor médio da resistência

$f_{w} \quad$ - resistência da madeira

$\mathrm{f}_{\text {wo }} \quad$ - resistência da madeira paralelamente às fibras

$f_{w c o}$ - resistência à compressão paralela às fibras

$\mathrm{f}_{\mathrm{wc} 90}$ - resistência à compressão normal às fibras

$f_{\text {wto }}$ - resistência à tração paralela às fibras

$\mathrm{f}_{\mathrm{wt90}}$ - resistência à tração normal às fibras

$f_{w v o}$ - resistência ao cisalhamento na presença de tensões tangenciais paralelas às fibras

$f_{\text {wv90 }}$ - resistência ao cisalhamento na presença exclusiva de tensões tangenciais normais às fibras

$f_{\text {weo }}$ - resistência de embutimento paralelo às fibras 
$f_{\text {we90 }}$ - resistência de embutimento normal às fibras

$f_{\text {wtM }}$ - resistência à tração na flexão

g - carga distribuída permanente (peso específico para evitar confusão com $\gamma$ coeficiente de segurança)

h - altura, espessura

i - raio de giração

k - coeficiente ( em geral)

$k_{\text {mod }}$ - coeficiente de modificação

$l$ - vão, comprimento

m - momento fletor por unidade de comprimento ou largura, massa, valor médio de um amostra

n - força normal por unidade de comprimento ou largura, número de elementos

p - pressão, densidade de probalidade

q - carga acidental distribuída

$r \quad$ - raio, índice de rigidez $=\mathrm{I} / \mathrm{L}$

s - espaçamento, desvio padrão de uma amostra

t - tempo em geral, espessura de elementos delgados

u - perímetro, componente de deslocamento de um ponto

v - força cortante por unidade de comprimento ou largura, velocidade, componente de deslocamento de um ponto

w - carga de vento distribuída, componente de deslocamento de um ponto

x - coordenada

y - coordenada

z - coordenada, braço de alavanca 


\section{Letras gregas minúsculas}

$\alpha$ (alfa) - ângulo, coeficiente

$\beta$ (beta) - ângulo, coeficiente, razão

$\gamma$ (gama) - coeficiente de segurança, peso específico (pode ser substituído por g), deformação tangencial específica

$\gamma_{f} \quad$ - coeficiente de ponderação das ações

$\gamma_{m}$ - coeficiente de ponderação das resistências dos materiais

$\gamma_{s} \quad$ - coeficiente de minoração da resistência do aço

$\gamma_{w} \quad$ - coeficiente de minoração da resistência da madeira

$\delta$ (delta) - coeficiente de variação

$\varepsilon$ (épsilon) - deformação normal específica

$\varepsilon_{\mathrm{w}} \quad$ - deformação específica da madeira

$\varepsilon_{\mathrm{wc}}$ - deformação específica da madeira comprimida

$\varepsilon_{\text {wcc }}$ - deformação específica por fluência da madeira comprimida

$\varepsilon_{\mathrm{wt}}$ - deformação específica da madeira tracionada

$\varepsilon_{\text {wtc }}$ - deformação específica por fluência da madeira tracionada

$\varepsilon_{\mathrm{wn}}\left(\varepsilon_{\mathrm{w} 90}\right)$ - deformação específica normal às fibras

$\varepsilon_{\mathrm{wp}}\left(\varepsilon_{\mathrm{wo}}\right)$ - deformação específica paralela às fibras

$\varepsilon_{\text {ws }}$ - deformação específica de retração por secagem da madeira

$\zeta$ (zeta) - coordenada adimensional ( $\mathrm{z} / \mathrm{L}$ )

$\eta$ (eta) - razão, coeficiente, coordenada adimensional $(\mathrm{Y} / \mathrm{L})$

$\theta$ (theta) - rotação, ângulo

$\lambda$ (lambda) - índice de esbeltez $=L_{0} / i$

$\mu$ (mü) - coeficiente de atrito, momento fletor relativo adimensional, média de uma população

$v$ (nü) - coeficiente de Poisson, força normal relativa adimensional

$\xi$ (csi) - coordenada relativa (x/L)

o (ómicron) - deve ser evitada 


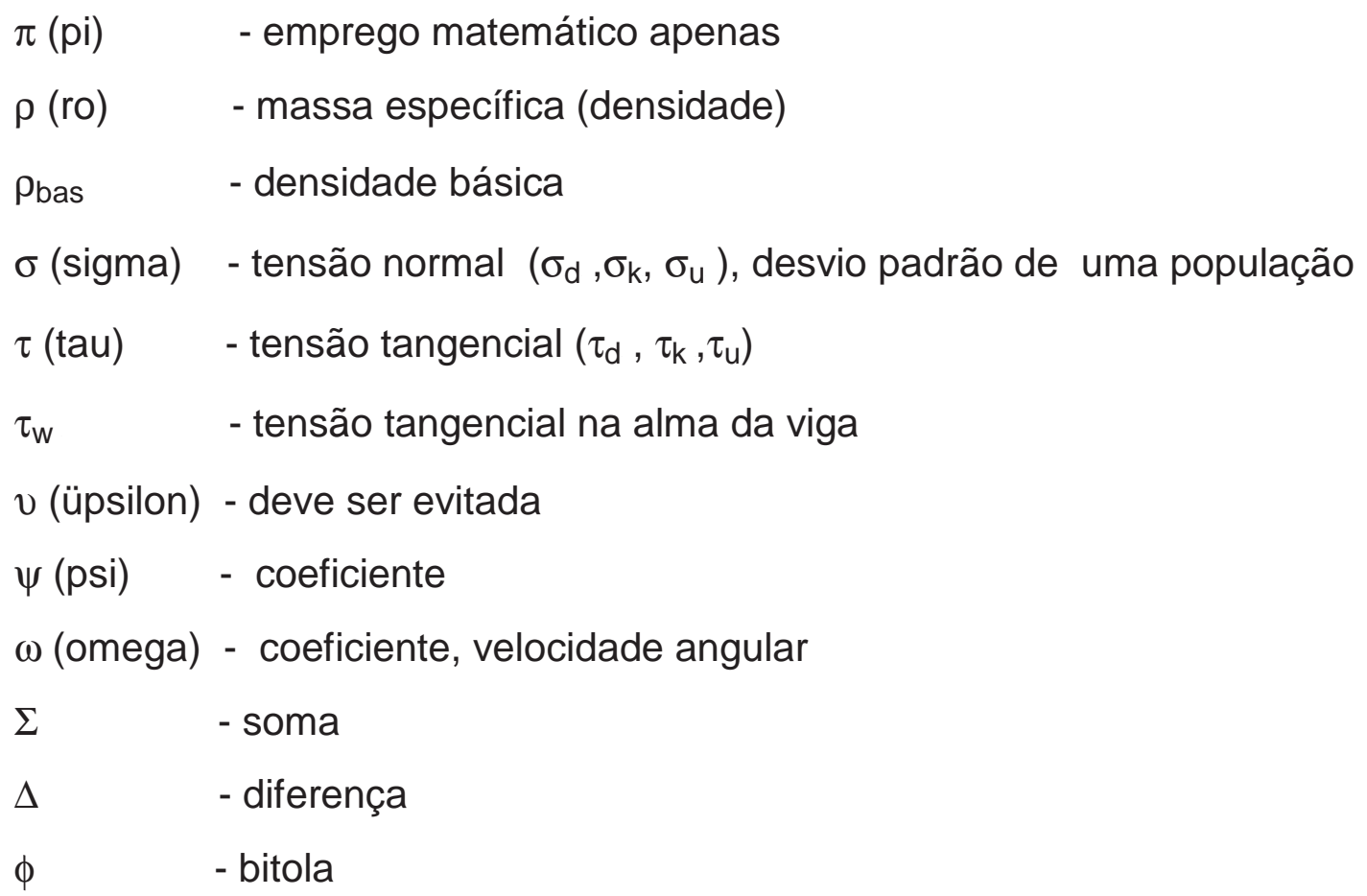

\section{Índices gerais}

a - aço estrutural

b - aderência

c - concreto, compressão, fluência

d - de cálculo

ef - efetivo

f - mesa da viga de seção T

i - inicial, núcleo

j - número

k - característico

m - material, média

p - pino, prego ou parafuso

S - aço, retração

t - tração, torção, transversal

u - último

v - cisalhamento

w - madeira, vento, alma das vigas

y - escoamento dos aços' 
Índices formados por abreviações

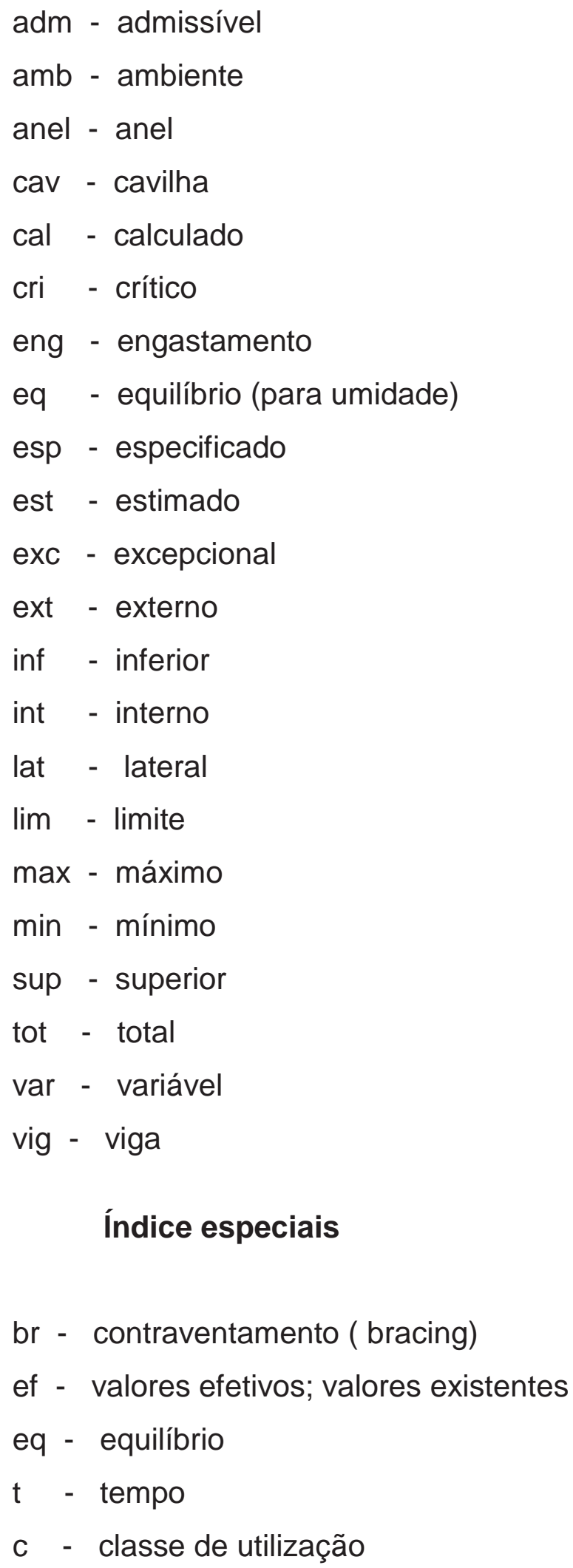


G - valores decorrentes de ações permanentes

m - valores na flexão

Q - valores decorrentes de ações variáveis

$\mathrm{R}$ - valores resistentes

S - valores solicitantes

$\mathrm{T}$ - temperatura 


\section{RESUMO}

GOMES, O. F. Estudo das ligações cavilhadas impregnadas com resinas estirênicas empregadas em estruturas de madeira. São Carlos, 1997. 281p. Tese (Doutorado)- Escola de Engenharia de São Carlos, Universidade de São Paulo.

O trabalho tem por finalidade o estudo teórico e experimental de ligações em estruturas de madeira com cavilhas de madeira de seção cilíndrica impregnadas com resinas estirênicas. A impregnação da madeira tem como objetivos: diminuir o processo de degradação, retardação ao fogo, melhorar a estabilidade dimensional e aumentar as propriedades de resistência e elasticidade da madeira.

Foram determinados experimentalmente as características de resistência e elasticidade do material e posteriormente realizados ensaios de ligações padronizados com solicitação paralela e normal às fibras.

Os resultados dos ensaios mostram aumento na resistência de compressão normal até $292 \%$ e aumento de $80 \%$ no limite de proporcionalidade da ligação.

A madeira utilizada para a impregnação foi 0 Pinus de reflorestamento.

Palavras-chave: Ligações, cavilhas, cavilhas de madeira, impregnação, resinas estirênicas, estruturas de madeira. 


\section{ABSTRACT}

GOMES, O. F. Study of timber dowels joints impregnated with commercial styrene resin to timber structures. São Carlos, 1997. 281 p.Tese (Doutorado )- Escola de Engenharia de São Carlos, Universidade de São Paulo.

The aim of this work is a theorytical and experimental studies of joints in timber structures with wooden dowels of circular cross section impregnated with styrenic resins.

The objetives of wood impregnation are to decrease the deterioration process, to promote fire retardation, to improve dimensional stability and mainly increase the compression strength and stiffiness of wood.

The strength and stiffness properties of the material are determined. Standard joints tests are carried out in compression both parallel and perpendicular to grains.

The test results increases of compression perpendicular strength up to $292 \%$ and the up to $80 \%$ proportional limit joint.

The wood used for impregnation was Pinus from reforestation sites.

Keywords: Connections, dowel, timber dowels, impregnation, resin styrene, timber structures. 


\section{INTRODUÇÃO E CONCEITOS PRELIMINARES}

\subsection{Apresentação}

A madeira é um material orgânico de origem vegetal, valorosíssimo, que hoje em dia, tem uma infinidade de aplicações. Ela esteve sempre presente ao longo de toda a história das edificações, desde as palafitas, nas casas de bambu ou de adobe, cúpulas em forma de bulbo, em templos religiosos, e até as modernas casas pré-fabricadas, dão testemunho eloqüente de que ela sendo bem escolhida e preparada pode-se ser empregada em vários tipos de construções e que poderão durar centenas de anos se for bem conservada.

A madeira foi provavelmente o primeiro tipo de material que o ser humano utilizou para construir uma ponte. Embora o concreto e o aço substituíram a madeira como os principais materiais para a construção de pontes no Século 20, o uso da madeira em pontes de pequenos vãos continua intenso como sempre.

No campo da engenharia de estruturas, desde a antigüidade a madeira, como material de construção, esteve presente nas construções das pontes, passarelas, veículos para transportes, habitações comuns, casas de bambu, embarcações, eclusas, silos agrícolas, igrejas, castelos medievais, construções rurais, hélices de aeronaves, de moinhos, dormentes das ferrovias, postes de energia elétrica, etc...,

Mesmo com a predominância de materiais tradicionais como a pedra, tijolo, o ferro fundido, o aço, concreto, a sua potencialidade como recurso renovável e sua capacidade de resistência às ações exteriores tem se destacado ao longo dos anos. 
No Brasil em um certo período predominou as construções de taipa de pilão, adobe e pau-a-pique, enquanto que a madeira tinha o seu emprego em menor escala principalmente na área rural, sendo muito utilizada na construção de: carro de bois, monjolos, estábulos, currais, carroças conduzidas por animais de tração, assoalhos, cercas, engenhos de cana-de-açúcar, pontes provisórias, canoas, instrumentos musicais, etc.

A desinformação e o despreparo de certas pessoas no nosso país levou a madeira a se tornar uma espécie de objeto na mão dos devastadores das nossas reservas florestais, colocando a sociedade sem nenhum conhecimento específico sobre o potencial que ela oferece, principalmente no campo estrutural.

Na região sul de nosso país é que se herdou da cultura européia a utilização racional da madeira para fins construtivos, onde podemos observar os belos chalés e edifícios construídos em linhas germânicas, tornando o ambiente agradável e aconchegante aos olhos dos visitantes de outras localidades.

Em outros países a madeira é um elemento forte que sempre esteve presente nas construções, visto o tratamento sério e profissional que foi dado a esse material, mesmo possuindo uma reserva de baixo potencial florestal.

Entretanto, são estes países os detentores do campo da informação, principalmente da investigação experimental, através de Institutos de Pesquisas como: o Laboratório de Produtos Florestais, de Madison (FPL), Associação para o Desenvolvimento e Pesquisa da Madeira da Inglaterra (TRADA), Centro Técnico de Aperfeiçoamento da Madeira de Paris (CTBA), Instituto Americano de Construção da Madeira( AITC), entre outros.

Felizmente, de uns anos para cá, no Brasil certos Institutos de Pesquisa como: Instituto de Pesquisas Tecnológicas do Estado de São Paulo (IPT), Laboratório de Madeiras e Estruturas de Madeiras, da Escola de Engenharia de São Carlos, da Universidade de São Paulo (LaMEM), Instituto Brasileiro da Madeira e das Estruturas de Madeira (IBRAMEM), 
Laboratório de Estruturas e Materiais, Estruturais da Escola Politécnica, da Universidade de São Paulo (LEM), dão o tratamento sério, profissional e adequado para a madeira no campo da investigação teórica e experimental, na utilização da mesma como elemento estrutural.

O controle tecnológico desses institutos permite, através dos requisitos de segurança, resistência, durabilidade e até mesmo de ordem econômica, selecionar espécies adequadas de madeiras a se empregar em certos tipos de estruturas, tais como:edifícios, construções habitacionais, escolas, igrejas, galpões, ginásios esportivos, coberturas, hangares, arcos, pontes rodoviárias, pontes ferroviárias, passarelas para pedestres, silos, construções rurais, formas, cimbramentos, anfiteatros, barcos, postes para transmissão de energia elétrica, dormentes das ferrovias, instalações militares, etc..

Com isso, a madeira torna-se uma alternativa importante como material para emprego nas estruturas convencionais, desde que se tome cuidados especiais de secagem, conteúdo de umidade, tratamento e preservação adequada contra o ataque de fungos e cupins, aumentando a durabilidade das mesmas.

Uma dificuldade peculiar de todo o projetista, seja qual for o seu campo de atuação se faz face ao projeto, detalhamento e montagem de campo da estrutura, principalmente do dimensionamento das ligações e também da escolha adequada dos elementos de ligação. Elementos de ligação como: pregos, parafusos, pinos, parafusos auto-atarraxantes, anéis metálicos, chapa de dentes estampados, têm sido os mais utilizados, diante da facilidade de fabricação e comercialização.

As cavilhas de madeira sem impregnação tem seu emprego normal nas ligações de peças estruturais de madeira, e as cavilhas impregnadas com resinas estirênicas serão, a partir deste trabalho, um elemento opcional de ligação, principalmente pela facilidade de confecção nas carpintarias. 
Também é importante que se faça um mecanismo para facilidade de aquisição, manipulação dos produtos que entram na composição das resinas de impregnação, sendo que para isto é necessário às indústrias de tratamento e preservação de madeiras adequar as suas instalações, para o processo em escala industrial da impregnação da madeira, a fim de que a cavilha impregnada possa ter facilidade de comercialização.

A utilização de cavilhas impregnadas está relacionada com o fato de certas estruturas de madeira serem projetadas em ambientes agressivos (edifícios construídos à beira mar, edifícios de indústrias químicas) ou à madeira ou aos elementos de ligação de aço, sofrendo o ataque constante da corrosão, comprometendo a vida útil da estrutura e fazendo com que se aumente $o$ trabalho de manutenção das estruturas.

\subsection{A Madeira empregada como elemento estrutural}

\subsubsection{Mecânica da madeira}

Em relação a uma estrutura a ser projetada, ZAGOTTIS (1974), chama a atenção que existem dois aspectos fundamentais que devem ser considerados: os de segurança e os de economia. Nessa direção a madeira trabalhada na forma de peças estruturais, passando pelos cuidados essenciais de seleção de espécies adequadas, secagem, tratamento e preservação, conhecimento íntimo de suas propriedades físicas e mecânicas como: densidade, umidade, retratibilidade, condutibilidade elétrica, condutibilidade térmica, isolamento acústico, compressão paralela às fibras, compressão normal às fibras, corte, tração, flexão, sendo utilizada numa determinada estrutura poderá se enquadrar dentro dos requisitos anteriores. 
A madeira, por conseguinte, é um material nobre, versátil, resistente e aconchegante, que faz parte do dia a dia da sociedade, desde a mais simples moradia até a mais sofisticada estrutura e, mesmo, com o progresso tecnológico através do aparecimento de novos materiais, ela tem o seu lugar de destaque ao longo dos tempos.

Diferente de certos materiais, ela é um material não homogêneo e anisotrópico sendo que para fins práticos, ela pode ser considerada como ortotrópica e em virtude de sua estrutura interna apresenta três planos de simetria elástica: (L) longitudinal, $(R)$ radial, $(T)$ tangencial, perpendiculares entre si.

O eixo longitudinal é paralelo às fibras, o eixo tangencial é tangente aos anéis de crescimento e radial na direção dos raios (figura 1). Entretanto devido a orientação das fibras apresenta do vista prático duas propriedades que são importantes e que devem merecer atenção especial,que são as propriedades na direção paralela às fibras (L) e na direção normal às fibras (R-radial ou T-tangencial).

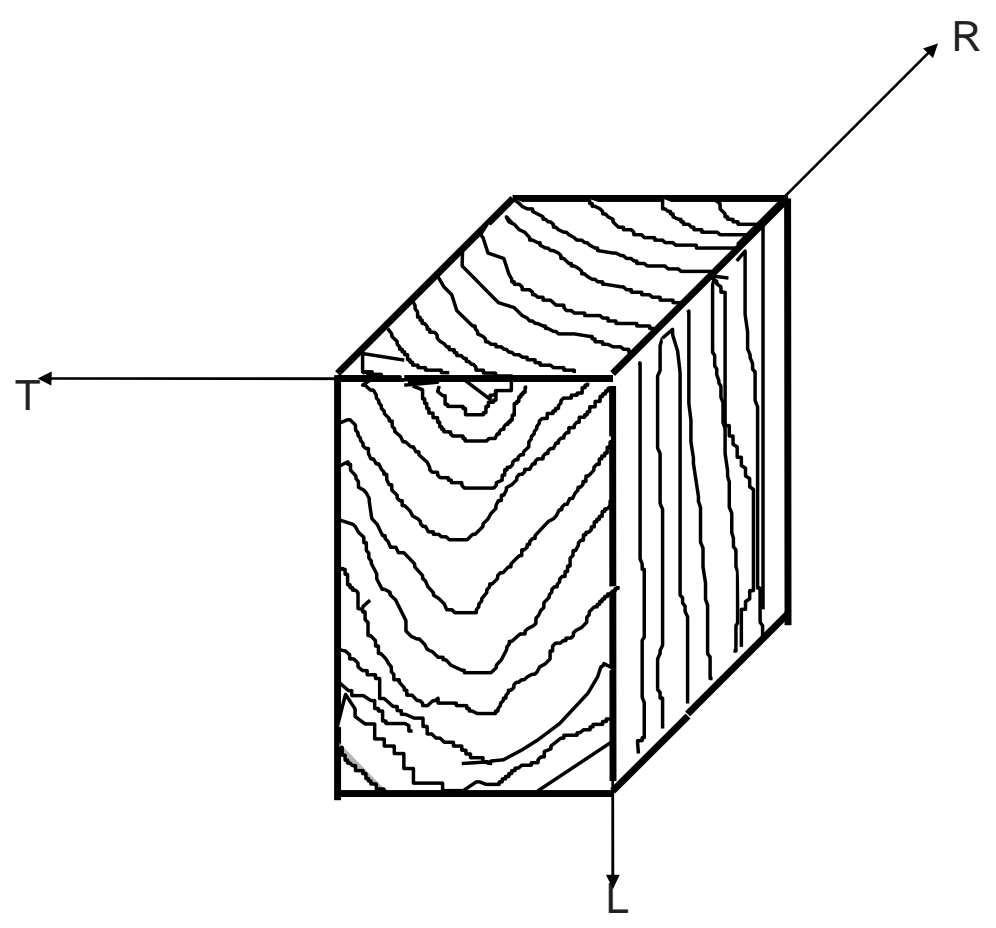

FIGURA 1 - Peça de madeira serrada, mostrando os três eixos principais. 
Dentro do aspecto de comportamento ortotrópico da madeira HANSEN (1961), BODIG \& JAYNE (1982) mostram que a lei de Hooke é a que melhor o retrata, considerando que a mesma pode ser estabelecida a partir de um simples experimento imaginário em que as tensões são aplicadas em um pequeno elemento de volume extraído de um bloco de madeira isenta de defeitos, conforme a figura 2. Os autores mostram que para este caso a aplicação da tensão normal $\sigma_{\mathrm{L}}$ isolada, resulta no aparecimento de três deformações $\varepsilon_{\mathrm{L}}, \varepsilon_{\mathrm{R}}, \boldsymbol{\varepsilon}_{\mathrm{T}}$, sendo que as duas últimas deformações laterais ocorrem em virtude do chamado efeito de Poisson.

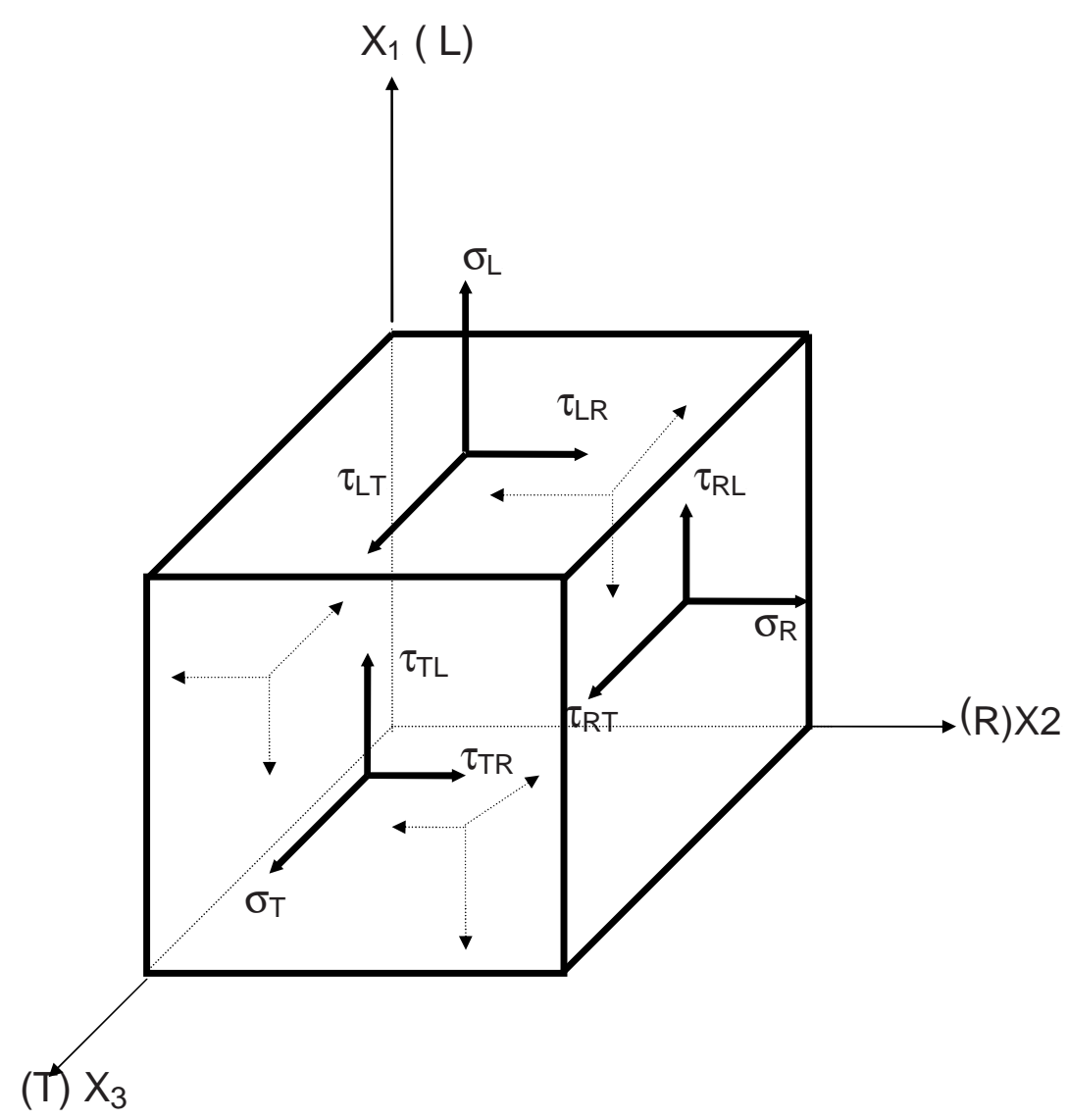

FIGURA 2 - Tensões atuantes num elemento cúbico de madeira, segundo as direções dos eixos (L),(R) e (T). 
BODIG \& JAYNE (1982), dentro do enfoque anterior eles chegam a uma expressão em forma matricial [1.1], que representa em termos particulares a lei de Hooke para materiais ortotrópicos, sendo que nessa expressão observa-se nove parâmetros que segundo a visão dos autores são suficientes para a descrição do comportamento elástico tridimensional dos referidos materiais. Nesta expressão os termos $\mathbf{S}_{\mathbf{i j}}$ representam as inclinações das tangentes às curvas tensões e deformações e os índices 1,2 e 3 representam a direção dos eixos coordenados; $\boldsymbol{\varepsilon}_{1}, \boldsymbol{\varepsilon}_{2}, \boldsymbol{\varepsilon}_{3}$ as deformações normais; $\sigma_{1}, \sigma_{2}, \sigma_{3}$, as tensões normais; $\tau_{12}, \tau_{13}, \tau_{23}$; as tensões tangenciais; $\gamma_{12}, \gamma_{13}, \gamma_{23}$; deformações produzidas por cisalhamento simples.

$$
\left[\begin{array}{l}
\varepsilon_{1} \\
\varepsilon_{2} \\
\varepsilon_{3} \\
\gamma_{23} \\
\gamma_{13} \\
\gamma_{12}
\end{array}\right]=\left[\begin{array}{cccccc}
S_{11} & S_{12} & S_{13} & 0 & 0 & 0 \\
S_{21} & S_{22} & S_{23} & 0 & 0 & 0 \\
S_{13} & S_{23} & S_{33} & 0 & 0 & 0 \\
0 & 0 & 0 & S_{44} & 0 & 0 \\
0 & 0 & 0 & 0 & S_{55} & 0 \\
0 & 0 & 0 & 0 & 0 & S 66
\end{array}\right]\left[\begin{array}{c}
\sigma_{1} \\
\sigma_{2} \\
\sigma_{3} \\
\tau_{23} \\
\tau_{13} \\
\tau_{12}
\end{array}\right]
$$

Um material ortotrópico é caracterizado por seis módulos de elasticidade, onde três são as relações entre as tensões normais e as deformações longitudinais nas direções dos eixos principais e três são as relações entre as tensões de cisalhamento e as deformações transversais, sendo que cada uma dessas relações são obtidas pela aplicação de tensões simples na direção em que são medidas as respectivas deformações, conforme as expressões, [1.2]. 


$$
\begin{array}{ll}
\frac{\sigma_{1}}{\varepsilon_{1}}=\mathrm{E}_{1}, & \frac{\sigma_{2}}{\varepsilon_{2}}=\mathrm{E}_{2}, \quad \frac{\sigma_{3}}{\varepsilon_{3}}=\mathrm{E}_{3} \\
\frac{\tau_{12}}{\gamma_{12}}=\mathrm{G}_{12}, & \frac{\tau_{13}}{\gamma_{13}}=\mathrm{G}_{13}, \quad \frac{\tau_{23}}{\gamma_{23}}=\mathrm{G}_{23}
\end{array}
$$

$E_{1}, E_{2}, E_{3}$, são chamados de módulos de elasticidade ou módulos de Young. $\mathrm{G}_{12}, \mathrm{G}_{13}, \mathrm{G}_{23}$ são chamados de módulos de rigidez ou módulo de elasticidade transversal.

Também BODIG \& JAYNE (1982), mostram que aplicando as tensões $\sigma_{1} \sigma_{2}, \sigma_{3}$ respectivamente, no experimento da figura 2 , obtém-se as relações entre as tensões e deformações envolvendo também os valores de $\mathrm{S}_{\mathrm{ij}}$, conforme as expressões [1.3] e [1.4]

$$
\begin{array}{lll}
\varepsilon_{1}=\mathrm{S}_{11} \sigma_{1} & \varepsilon_{2}=\mathrm{S}_{21} \sigma_{1} & \varepsilon_{3}=\mathrm{S}_{31} \sigma_{1} \\
\varepsilon_{1}=\mathrm{S}_{12} \sigma_{2} & \varepsilon_{2}=\mathrm{S}_{22} \sigma_{2} & \varepsilon_{3}=\mathrm{S}_{32} \sigma_{2} \\
\varepsilon_{1}=\mathrm{S}_{13} \sigma_{3} & \varepsilon_{2}=\mathrm{S}_{23} \sigma_{3} & \varepsilon_{3}=\mathrm{S}_{33} \sigma_{3}
\end{array}
$$

$$
\begin{array}{ll}
\varepsilon_{1}=\mathrm{S}_{11} \sigma_{1}+\mathrm{S}_{12} \sigma_{2}+\mathrm{S}_{13} \sigma_{3} & \gamma_{23}=\mathrm{S}_{44} \tau_{23} \\
\varepsilon_{2}=\mathrm{S}_{21} \sigma_{1}+\mathrm{S}_{22} \sigma_{2}+\mathrm{S}_{23} \sigma_{3} & \gamma_{13}=\mathrm{S}_{55} \tau_{13} \\
\varepsilon_{3}=\mathrm{S}_{31} \sigma_{1}+\mathrm{S}_{32} \sigma_{2}+\mathrm{S}_{33} \sigma_{3} & \gamma_{12}=\mathrm{S}_{66} \tau_{12}
\end{array}
$$

Comparando as expressões [1.2], [1.3] e [1.4] obtém-se as expressões [1.5].
$\mathrm{E} 1=\frac{1}{\mathrm{~S}_{11}}$
$\mathrm{E}_{2}=\frac{1}{\mathrm{~S}_{22}}$,
$\mathrm{E}_{3}=\frac{1}{\mathrm{~S}_{33}}$
$\mathrm{G}_{23}=\frac{1}{\mathrm{~S}_{44}}$
$\mathrm{G}_{13}=\frac{1}{\mathrm{~S} 55}$,
$\mathrm{G}_{12}=\frac{1}{\mathrm{~S} 66}$ 
Em relação ao coeficiente de Poisson os materiais ortotrópicos possuem seis coeficientes, sendo que o mesmo é definido na expressão [1.6]

$$
-v i j=\frac{\varepsilon_{j}}{\varepsilon_{i}}
$$

Fazendo $\mathrm{i}=1 ; \mathrm{j}=2$ tem-se:

$-\mathrm{V}_{12}=\frac{\varepsilon_{2}}{\varepsilon_{1}}=\frac{\mathrm{S}_{21}}{\mathrm{~S}_{11}}=\frac{\mathrm{S}_{21}}{1}=\mathrm{S}_{21} \mathrm{E}_{1}$, Extraindo o valor de $\mathrm{S}_{21}$ e com o mesmo E1

raciocínio para os demais casos, tem-se:
$\mathrm{S}_{21}=\frac{-\mathrm{V}_{12}}{\mathrm{E}_{1}}$,
$\mathrm{S}_{31}=\frac{-\mathrm{V} 13}{\mathrm{E} 1}$
$\mathrm{S}_{32}=\frac{-\mathrm{U} 23}{\mathrm{E}_{2}}$,
$\mathrm{S}_{12}=\frac{-\mathrm{v}_{21}}{\mathrm{E}_{2}}$,
$S_{13}=\frac{-v_{31}}{E_{3}}$,
$\mathrm{S}_{23}=\frac{-\mathrm{V}_{32}}{\mathrm{E}_{3}}$,

Das expressões [1.5], têm-se:
$\mathrm{S}_{11}=\frac{1}{\mathrm{E}_{1}}$
$\mathrm{S}_{22}=\frac{1}{\mathrm{E}_{2}}$,
$\mathrm{S}_{33}=\frac{1}{\mathrm{E} 3}$,
$\mathrm{S}_{44}=\frac{1}{\mathrm{G}_{23}}$,
$\mathrm{S} 55=\frac{1}{\mathrm{G} 13}$,
$\mathrm{S}_{66}=\frac{1}{\mathrm{G}_{12}}$,

Levando os valores das expressões [1.7] e [1.8] na expressão [1.1], tem-se a expressão da lei de Hooke em função dos chamados parâmetros elásticos de cálculo, tornando a mesma numa forma mais familiar nas aplicações práticas. 
$\left[\begin{array}{l}\boldsymbol{\varepsilon}_{1} \\ \boldsymbol{\varepsilon}_{2} \\ \boldsymbol{\varepsilon}_{3} \\ \cdots \\ \boldsymbol{\gamma}_{23} \\ \boldsymbol{\gamma}_{13} \\ \boldsymbol{\gamma}_{12}\end{array}\right]=\left[\begin{array}{cccccc}\frac{1}{\mathrm{E}_{1}} & \frac{-\boldsymbol{v}_{21}}{\mathrm{E}_{2}} & \frac{-\boldsymbol{v}_{31}}{\mathrm{E}_{3}} & 0 & 0 & 0 \\ \frac{-\boldsymbol{v}_{12}}{\mathrm{E}_{1}} & \frac{1}{\mathrm{E}_{2}} & \frac{-\boldsymbol{v}_{32}}{\mathrm{E}_{3}} & 0 & 0 & 0 \\ \frac{-\boldsymbol{v}_{13}}{\mathrm{E}_{1}} & \frac{-\boldsymbol{v}_{23}}{\mathrm{E}_{2}} & \frac{1}{\mathrm{E}_{3}} & 0 & 0 & 0 \\ 0 & 0 & 0 & \frac{1}{\mathrm{G}_{23}} & 0 & 0 \\ 0 & 0 & 0 & 0 & \frac{1}{\mathrm{G}_{13}} & 0 \\ 0 & 0 & 0 & 0 & 0 & \frac{1}{\mathrm{G}_{12}}\end{array}\right] \quad\left[\begin{array}{c}\sigma_{1} \\ \boldsymbol{\sigma}_{2} \\ \boldsymbol{\sigma}_{3} \\ \tau_{23} \\ \tau_{13} \\ \tau_{12}\end{array}\right]$

Desenvolvendo obtém-se uma forma mais simples da lei de Hooke, conforme as expressões abaixo:

$$
\begin{aligned}
& \varepsilon_{1}=\frac{1}{E_{1}}\left(\sigma_{1}-v_{12} \sigma_{2}-v_{13} \sigma_{3}\right) \\
& \varepsilon_{2}=\frac{1}{E_{2}}\left(\sigma_{2}-v_{21} \sigma_{1}-v_{23} \sigma_{3}\right) \\
& \varepsilon_{3}=\frac{1}{E_{3}}\left(\sigma_{3}-v_{31} \sigma_{1}-v_{32} \sigma_{2}\right) \\
& \gamma_{23}=\frac{1}{\mathrm{G}_{23}} \tau_{23}, \quad \gamma_{13}=\frac{1}{\mathrm{G}_{13}} \tau_{13}, \quad \gamma_{12}=\frac{1}{\mathrm{G}_{12}} \tau_{12},
\end{aligned}
$$

\subsubsection{Relações entre tensões e deformações}

A maior parte das seções das peças estruturais de madeira serrada isentas de defeitos são analisadas segundo BODIG \& JAYNE(1982), e HANSEN (1961), como materiais ortotrópicos com eixos geométricos $\left(\mathrm{X}_{1}, \mathrm{X}_{2}, \mathrm{X}_{3}\right)$ e eixos ortotrópicos $(\mathrm{L}, \mathrm{R}, \mathrm{T})$ coincidentes conforme a figura 3 . 
Com isso a equação matricial [1.9], ao substituir os subscritos 1 por L, 2 por $\mathrm{R}$, e 3 por $\mathrm{T}$ passa a ter a notação da lei de Hooke para a madeira da seguinte forma:

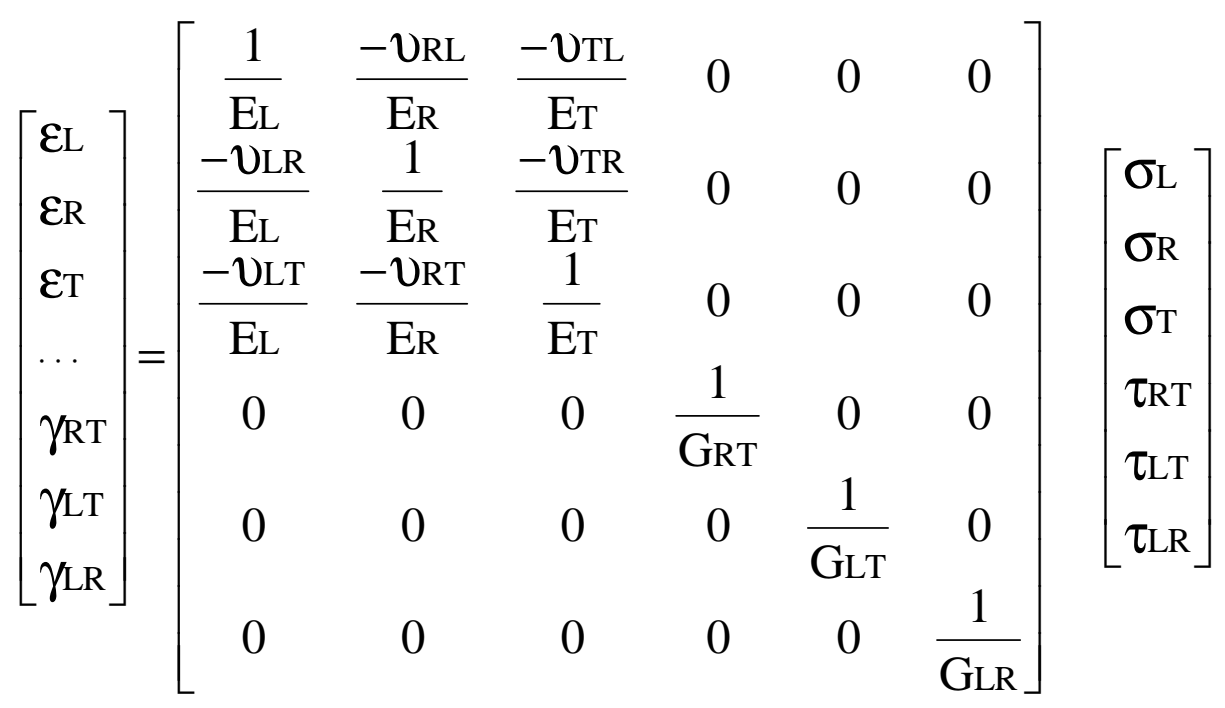

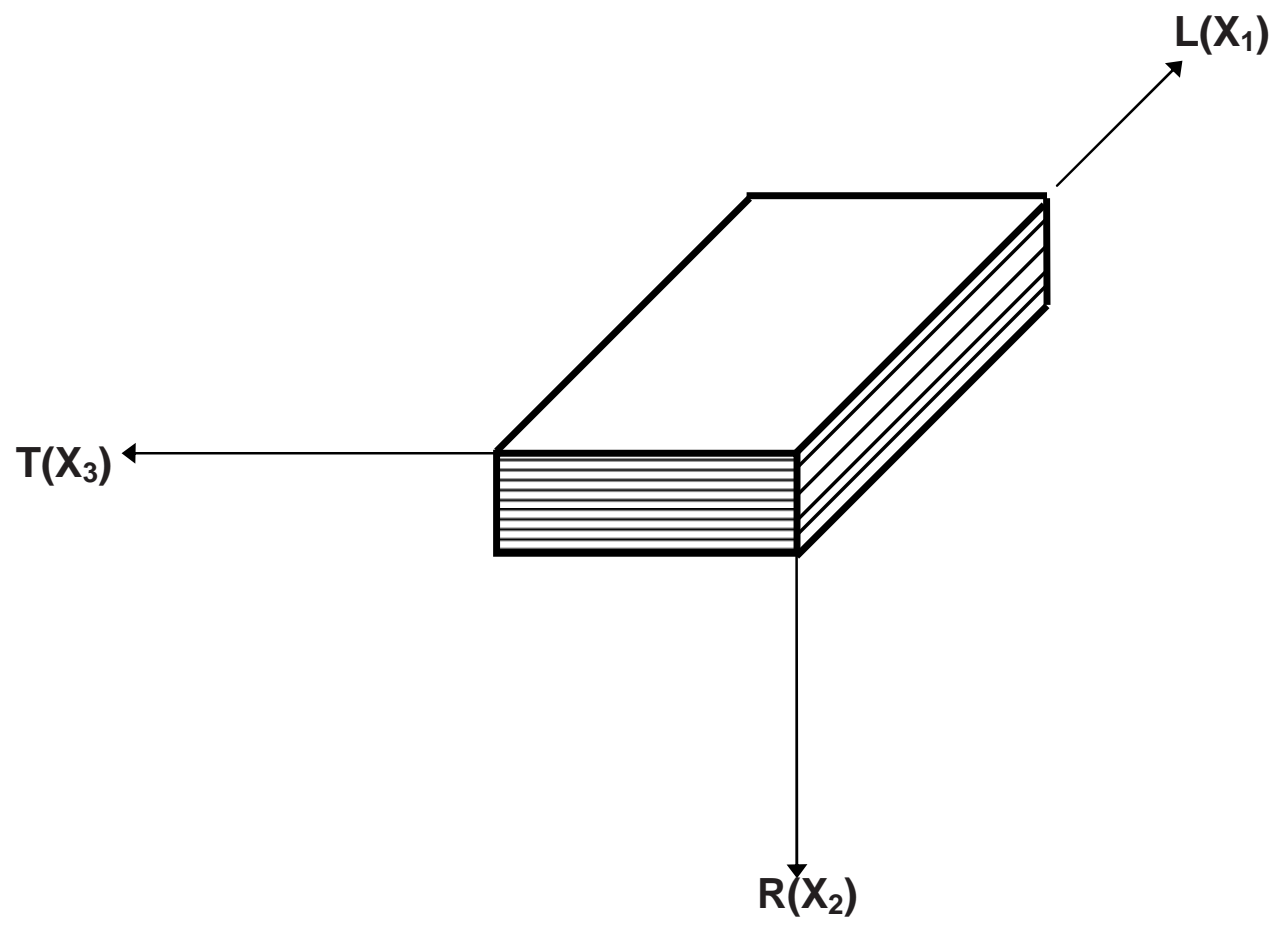

FIGURA 3- Madeira serrada representando modelo ortotrópico [FONTE: BODIG\&JAYNE(1982)]. 
Desenvolvendo a expressão [1.11] e aplicando a teoria matricial para mesma chegam-se aos valores das expressões [1.12], que relacionam as tensões e deformações, devido aos esforços que atuam segundo os eixos naturais da madeira: L- o eixo longitudinal paralelo às fibras, T- o eixo tangencial aos anéis de crescimento e $\mathrm{R}$ - o eixo radial paralelo aos raios medulares, o que mostra, portanto, a complexidade do comportamento estrutural da madeira, devido à natureza da sua constituição interna, de um material fibroso, quando solicitado por ações exteriores que desenvolvem tensões internas e suas correspondentes deformações.

$$
\begin{aligned}
& \varepsilon_{\mathrm{L}}=\frac{1}{\mathrm{EL}_{\mathrm{L}}}\left(\sigma_{\mathrm{L}}-v_{\mathrm{LR}} \sigma_{\mathrm{R}}-v_{\mathrm{LT}} \sigma_{\mathrm{T}}\right) \\
& \varepsilon_{\mathrm{R}}=\frac{1}{\mathrm{ER}_{\mathrm{R}}}\left(\sigma_{\mathrm{R}}-v_{\mathrm{RL}} \sigma_{\mathrm{L}}-v_{\mathrm{RT}} \sigma_{\mathrm{T}}\right) \\
& \varepsilon_{\mathrm{T}}=\frac{1}{\mathrm{ET}}\left(\sigma_{\mathrm{T}}-v_{\mathrm{TL}} \sigma_{\mathrm{L}}-v_{\mathrm{TR}} \sigma_{\mathrm{R}}\right) \\
& \gamma_{\mathrm{RT}}=\frac{1}{\mathrm{GRT}} \tau_{\mathrm{RT}}, \quad \gamma_{\mathrm{LT}}=\frac{1}{\mathrm{GLT}_{\mathrm{L}}} \tau_{\mathrm{LT}}, \quad \gamma_{\mathrm{LR}}=\frac{1}{\mathrm{GLR}_{\mathrm{L}}} \tau_{\mathrm{LR}},
\end{aligned}
$$

Para o cálculo das deformações devidas às tensões normais e às tensões de cisalhamento sobre os eixos $L, T$ e $R$, torna-se necessário 0 conhecimento de 9 constantes elásticas independentes para descrever 0 comportamento de um material ortotrópico. São as seguintes: $E_{L}, E_{R}, E_{T}$; $G_{L R}, G_{L T}, G_{R T} ; v_{L R}, v_{L T}, v_{R T}$.

\subsubsection{Propriedades mecânicas da madeira}

As propriedades mecânicas da madeira, determinadas para corpos de prova isentos de defeitos constitui a base para a elaboração das prescrições normativas. 
Destas propriedades, as de resistência e rigidez são de interesse em primeiro plano para o projetista estrutural, sendo que propriedades como: fluência, durabilidade, dureza, estabilidade dimensional, isolamento térmico, são também de interesse. As propriedades de resistência e rigidez de maior interesse ao projeto estrutural segundo o PNBR 7190/96,são:

a) Massa específica aparente a $12 \%$ de umidade: $\rho_{a p(12 \%)}$

b) Resistência à compressão paralela às fibras : $\mathbf{f}_{\mathrm{c} 0}$

c) Resistência à tração paralela às fibras : $\mathbf{f}_{\mathbf{t} 0}$

d) Resistência à tração normal às fibras : $\mathbf{f}_{\mathbf{t} 90}$

e) Resistência ao cisalhamento : $\mathbf{f}_{\mathrm{v}}$

f) Módulo de elasticidade longitudinal obtido no ensaio de compressão paralela às fibras : $\mathbf{E}_{\mathrm{c} 0}$

Essas propriedades de resistência e rigidez são determinadas com base numa série de ensaios padronizados pelas normas de ensaios, e dentro deste enfoque, diríamos mais ainda sob um rigoroso controle estatístico de qualidade [STALNAKER, HARRIS (1989)].

\subsubsection{Madeira e produtos derivados da madeira}

Uma das grandes dificuldades dos engenheiros civis, calculistas de Estruturas de Madeira, está relacionada ao fato de especificar, nos níveis de projeto, as peças estruturais a utilizar nas estruturas convencionais, com as espécies usualmente disponíveis em empresas fornecedoras de madeiras.

Numa tentativa de minimizar o problema, HELLMEISTER (1973), FURIATI(1981), BODIG \& JAYNE(1982), TONISSI(1985) e SALES(1991), procuraram minimizar este problema, na tentativa de classificar as madeiras do ponto de vista das características físicas, mecânicas e a sua utilização na construção civil.

Ao analisar estes trabalhos as madeiras são classificadas da seguinte forma: 


\section{a) Madeira Serrada}

As peças de madeira serrada mais utilizadas são as seguintes: Ripas, Ripões, Sarrafos, Caibros, Caibrões, Pontaletes, Vigotas, Tábuas, Pranchas, Pranchões, Postes.

\section{b) Chapas de Madeira}

Com o desenvolvimento industrial e uma melhor utilização racional da madeira, atualmente tem crescido a utilização dos materiais derivados da madeira, juntamente com outros materiais, na construção civil. $E$, dentro deste aspecto tem-se destacado as chapas de madeira obtidas através da transformação da madeira em seu estado natural.

De acordo com TONISSI(1985), chapas de madeira atualmente fabricadas no Brasil são de:madeira compensada, fibra de madeira, partículas de madeira, madeira laminada, mineralizada, sarrafos, papelão(chipboard), as principais, e ainda sem muita utilização no País destacam-se os compósitos de madeira, sendo que em outros países, esses produtos têm sido muito utilizados em virtude da sua capacidade resistente às ações exteriores e em, relação à madeira serrada, oferece requisitos de resistência e rigidez. Nessa linha de produtos destacam-se: chapas de aglomerado (particleboard- utilizadas na fabricação de móveis,cabinetes de cozinha e banheiro); chapas de lascas de madeira (flakeboard), placas(MDF-medium density fiber board-constituídas de aglomerantes adicionados às fibras de madeira, muita utilizadas na indústria moveleira,cabinetes de cozinha e banheiro, molduras, forros, divisórias); chapas de partículas aglomeradas (OBS-oriented strand board-utilizadas nas coberturas das casas de madeiras, estruturas, embalagens); lâminas paralelas ( LVL-Laminated Venner Lumber, utlizadas em construções civis como componentes estruturais principalmente como vigas em "I", vigas laminadas e coladas e vigas de lâminas paralelas). 


\section{c) Madeira laminada colada}

Embora pouco utilizada no Brasil, segundo LIMA(1994), a madeira laminada colada selecionada de espécies de reflorestamento como o Eucalipto e Pinus, quando coladas umas às outras formam peças estruturais retas ou curvas, leves e resistentes aos esforços solicitantes. Ela vem sendo objeto de estudo em alguns centros importantes de pesquisa do Brasil e pode ser usada em pontes de qualquer vão, galpões industriais, coberturas, hangares, ginásios, casas, torres de transmissão, elementos decorativos. Visto que êste tipo de madeira vem apresentando bons resultados de desempenho em algumas estruturas de madeira do nosso país, é importante que se faça uma maior divulgação do mesmo, a fim de que os usuários possam dispor desta nova tecnologia construtiva. 


\section{HISTÓRICO E REVISÃO DA LITERATURA}

\subsection{Introdução}

No passado, grande parte das ligações estruturais em madeira eram feitas preservando-se a idéia de continuidade, em virtude do tamanho das peças disponíveis na natureza. Com isso, se destacavam as chamadas junções (que ligavam as peças através dos seus extremos de modo que permitia o enlace de uma na outra), sambladuras, encaixes e entalhes . Nesta época, quando as peças eram curtas, estreitas ou delgadas, não era possível obter formas de estrutura com única peça, por isso utilizavam já os meios tradicionais de união que nós conhecemos como a cola, pregos e parafusos, a fim de obter um comportamento estrutural adequado. Dentre os meios de uniões então utilizados, destacavam-se aqueles feitos à base de madeira (espigas, tacos, cunhas, cavilhas e lingüetas), os metálicos (pregos, parafusos, grampos ) e as também utilizadas até os dias atuais, as uniões amarradas com cordas de couro, fibras naturais ou sintéticas e arame, principalmente quando se trabalha com madeiras roliças .

Cumpre salientar que a literatura sobre cavilhas tem se limitado à indústria de móveis, gabinetes de cozinhas, caixas de madeira para embalagens, portas, janelas, entretanto pouca informação existe a respeito de projeto de engenharia sobre esses elementos de ligação.

Com relação trabalhos específicos de impregnação da madeira, entretanto, queremos salientar que já existe uma quantidade razoável de trabalhos publicados sobre polimerização, que representa o ponto principal na questão do ponto de vista químico e que muito contribuirá para o enriquecimento do assunto de impregnação de madeiras. 


\subsection{Principais contribuições da literatura}

RAFF et al. (1965) apresentam um trabalho sobre as mudanças das propriedades da madeira como conseqüência local de polimerização por radiação de monômeros vinílicos na madeira, em experimentos comparados com o cobalto-60 (raios gama), iniciados com a polimerização do estireno e da mistura estireno-divinilbenzeno. Concluíram desses experimentos que a mistura de 95/5 estireno-divinilbenzeno aumenta a quantidade de resina formada na madeira, acima do que foi encontrado pelo uso somente do estireno. Verificaram aumento da densidade e diminuição da absorção de água.

LUCHESE \& STAMATO (1967) relatam resultados e conclusões extraídas de 264 ensaios, para determinar cargas admissíveis nas ligações de peças de Peroba Rosa com parafusos de aço.Ensaiaram 116 ligações alinhadas (com solicitação paralela às fibras) e 106 ligações cruzadas (com solicitação normal às fibras), que permitiram a fixação das cargas admissíveis através de expressões simples, com parâmetros determinados estatisticamente.

ECKELMAN (1969) desenvolveu experimentos em ligações cavilhadas constituídas de cavilhas simples solicitadas axialmente por esforços de tração, para determinar a resistência última e as relações forçadeslocamento. Foram testados dois modelos de corpos de prova, com um tipo de adesivo, a resina de uréia-formaldeído, e com várias combinações de espécies de madeiras(bétula branca, bordo, tulipeiro, carvalho). O autor conclui que ligações com cavilhas possuindo propriedades específicas podem ser calculadas utilizando a expressão [2.1], que fornece a resistência última ou arrancamento dessas ligações, onde as grandezas que aparecem na expressão são as seguintes: 
D é o diâmetro da cavilha; $\mathbf{L}$ é o comprimento da cavilha; $\mathbf{S}_{1}$ resistência ao corte do lado das fibras das barras que compõe a ligação; $\mathbf{S}_{2}$ é a resistência ao corte das cavilhas; a fator correspondente ao tipo de adesivo, com valores iguais a:1,0; 0,9; e 0,85 para uréia-formaldeído,poli(acetato de vinila), cola animal respectivamente; $\mathbf{b}=1,0-9,1 \mathbf{d} ; 1,0-17,1 \mathbf{d} ;$ e 1,0-1,8d; onde d é o gabarito do diâmetro do furo da cavilha para ureia-formaldeído, acetato de polivinila e cola animal respectivamente.

$$
\mathrm{F}=0,45 \mathrm{DL}^{0,89}(0,95 \mathrm{~S} 1+\mathrm{S} 2) \mathrm{a} \cdot \mathrm{b}
$$

PIEDADE (1972) chama a atenção que o uso de cavilhas de madeira em furos previamente preparados, continuam a ser dimensionadas de acordo com hipóteses simplistas e destituídas de apoio experimental. Em seu trabalho, realizou ensaios em 548 ligações de madeira com único furo, 144 com diversos furos e 36 ensaios com modelos de vigas laminadas, onde foi estudado o comportamento das cavilhas de madeira nas condições usuais em que este tipo de ligação é empregado. Foram utilizados corpos de prova de Pinho do Paraná e Peroba Rosa ligados com cavilhas de Eucalipto Citriodora.

ECKELMAN(1979) em outro trabalho realizou ensaios para avaliar a relação entre a força de arrancamento de cavilhas e a resistência ao corte paralela às fibras das madeiras conforme a expressão [2.2], onde $\mathbf{F}$ é a resistência ao arrancamento da cavilha; D é o diâmetro da cavilha; L é a profundidade do embutimento da cavilha; $\mathbf{S}_{1}$ a resistência ao corte paralela às fibras do material em que a cavilha é embutida; $\mathbf{S}_{2}$ resistência ao corte paralela às fibras em que a cavilha é construída; a é o fator relacionado ao tipo de adesivo; b é o fator relativo ao gabarito dos furos das cavilhas.

Os corpos de prova foram construídos tendo cavilhas de madeira da espécie denominada de bordo sacarino ou ácer campestre (sugar maple), sendo que também foram incluídas nos ensaios 15 espécies de madeiras típicas usadas na fabricação de móveis. 
O autor mostra que a resistência ao corte dessas madeiras variou de um valor mais baixo da ordem de $7 \mathrm{MPa}$ até um valor mais alto de $16,4 \mathrm{MPa}$ nos ensaios de arrancamento, e que a madeira denominada tília americana (basswood) mostrou pelos resultados é a de maior interesse para aplicação na indústria de fabricação de móveis visto a sua utilização apresentar maior regularidade e também por ser uma madeira mais flexível.

$$
\mathrm{F}=0,834 \mathrm{DL}^{0,89}(0,95 \mathrm{~S} 1-\mathrm{S} 2) \mathrm{a} \cdot \mathrm{b}
$$

AGNELLI(1981) apresentou um trabalho que estuda as propriedades físico-mecânicas e químicas de compostos polímero-madeira obtidos com as seguintes matérias primas: madeiras nacionais de baixa qualidade, porosas e com elevadas taxas de crescimento; monômeros estireno e metilmetacrilato, e as resinas oligopolímero-madeira empregando as resinas de poliéster insaturado. Os resultados obtidos mostraram que os compostos polímero-madeira empregando as resinas de poliéster insaturado, curadas à temperatura ambiente após impregnação à madeira, apresentaram maior porcentagem do polímero e melhores propriedades. Em relação à madeira pura, todos os compostos polímero-madeira apresentaram desempenho muito superior.

GESUALDO (1982 ) traz a idéia das cavilhas partidas a fim de que as mesmas possam facilitar a cravação nos elementos de fixação, fornecendo informações sobre os fundamentos teóricos e os critérios de cálculo para projeto e dimensionamento. $O$ estudo experimental foi feito através de solicitações de compressão paralela, compressão perpendicular às fibras, tração e flexão. As espécies utilizadas nos ensaios foram de Peroba Rosa ligadas por meio de cavilhas partidas ou roliças de Eucalipto Citriodora e Pinho do Paraná.

MANRICH (1984) estudou em seu trabalho o comportamento físicomecânico das madeiras caixeta(coerana) e de Pinus(elliotti), impregnadas com poliestireno e verificou aumento nas propriedades de flexão e de compressão paralela das madeiras impregnadas de caixeta e de pinus, 
onde se destacou o compósito pinus-poliestireno que apresentou um aumento aproximado de 132 \% na tensão máxima e no módulo de elasticidade em compressão paralela. Também descreve sobre os chamados compósitos polímero-madeira (CPM) que representa uma nova classe de materiais, os quais são resultantes da impregnação de madeiras por monômeros líquidos e que posteriormente são polimerizados. Sua pesquisa bibliográfica é bastante rica e destaca que os chamados CPM são obtidos em duas etapas: impregnação de monômeros e posteriormente a polimerização dos mesmos no interior da madeira.

MEYER (1984) publicou um trabalho onde descreve os processos de impregnação em madeiras sólidas: estabilização a quente da madeira, folheados de madeira tratados com fenol-formaldeído, o inchamento das paredes das células com polietileno glicol, tratamento de fase gás-ozônio, amônia líquida, tratamento de fase gás e radiação $\beta$ e $\gamma$.

Mostra que, geralmente, os compósitos polímeros-madeira implicam em um volume de polimerização de monômero do tipo vinílico nos espaços da madeira sólida. O volume de polimerização toma lugar nos vasos, capilares, e raios celulares, mas não nas paredes celulares ou lamelas médias. Também mostra que a impregnação da madeira tem dois objetivos: estabilização dimensional devido ao conteúdo de umidade e melhoria das características físicas e mecânicas.

EHLBECK \& EBERHART (1989) desenvolveram uma pesquisa para determinar a resistência e a deformação das ligações de laminados colados com pinos de madeira prensada impregnados com resinas fenólicas. Um dos objetivos específicos desta pesquisa foi verificar se a teoria de Johansen's para a determinação da resistência de ligações com elementos de fixação do tipo pino podem ser aplicados para tais tipos de materiais tendo acentuadas falhas frágeis.

Os dados de ensaios em princípio confirmaram a aplicabilidade do projeto do modelo que foi introduzido no código "Structural Timber Design Code" (CIB), bem como do projeto do EUROCODE 5 para os cálculos baseados nos estados limites. 
Foram confeccionados 128 corpos de prova e o comportamento da relação carga-deformação nos ensaios de compressão paralela às fibras em corte duplo, foram analisados. Os ensaios com pinos não metálicos em ligações com laminados colados desenvolveram um modo de ruptura adicional comparados com a teoria clássica de Johansen, que é a base para o cálculo da resistência de ligações com pinos no código CIB, e no projeto do EUROCODE-5.

ANDRIAMITANTSOA(1990) mostra a importância do comportamento mecânico das ligações em estruturas de madeira, principalmente no aspecto relacionado aos modos de deformação e ruptura. São apresentadas diversas conclusões preliminares práticas, relativas à determinação da resistência admissível e a resistência característica dessas ligações, tomando como referência as prescrições do projeto do EUROCODE-5.

CÉSAR(1991), fez uma investigação sobre os sistemas estruturais adotados pela empresa "Hauff", através de uma documentação gráfica, fotográfica e descritiva dos exemplos de estruturas para coberturas, como também estruturas para outras finalidades no período de 1925 a 1960 no Brasil. O sistema Hauff utiliza estruturas treliçadas com ligações cavilhadas que foram introduzidas no Brasil por esse engenheiro, o seu fundador em seus sistemas estruturais, descartava as soluções adotadas dos parafusos, conectores metálicos, barras de aço, pois sempre defendeu o emprego da madeira, por enxergar a potencialidade técnica desse material e por ver o Brasil como uma fonte de recursos naturais de madeira.

ZHANG \& ECKELMAN (1993) estudaram as de ligações de nó de pórtico em forma de $\mathrm{L}$, utilizando cavilhas simples em chapas de aglomerado e submeteram os modelos aos ensaios de compressão e tração, conseguindo determinar a resistência desses tipos de ligações que deram origem a esforços de flexão nas cavilhas e chegaram a duas expressões ,[2.3], que ligam o momento fletor ao diâmetro da cavilha e à profundidade de embutimento na face da barra. 
Também concluíram que para a obtenção do momento fletor máximo, a profundidade de $25 \mathrm{~mm}$ de embutimento é um ótimo valor para embutimento da cavilha na extremidade da barra. Portanto as expressões que ligam o momento fletor das ligações com cavilhas simples são as seguintes:

$$
\begin{aligned}
& Y c=460,4 x(D)^{0,452} x(E)^{1,140} \\
& Y t=614,6 x(D){ }^{0,591} x(E)^{1,180}
\end{aligned}
$$

Nas expressões anteriores as grandezas que nelas figuram tem o seguinte significado:

Y-Resistência ao momento fletor da ligação com cavilhas simples nas chapas de aglomerado. (Ib.in $\left.{ }^{1}\right)$

D-diâmetro da cavilha (in.)

$E=$ profundidade do embutimento na face da barra da ligação (in).

GALPERIN et al. (1995) fez uma pesquisa sobre o que chama de madeira modificada, definindo-a como sendo um material composto madeira-polímero em que suas propriedades são modificadas em comparação com a madeira natural através de processo termoquímico. Este processo consiste da impregnação da madeira através de monômeros, oligômeros ou resinas, e tratamento a quente da madeira impregnada por secagem e cura de catalisadores (fenol- formaldeído, ureia-formaldeído e resinas de poliéster). Os autores ao analisarem os dados obtidos desta pesquisa, concluíram que algumas propriedades são muito melhores na madeira modificada do que a madeira não modificada, tais como:propriedades físicas (dureza, resistência à abrasão, compressão perpendicular às fibras, inchamento na direção tangencial e absorção da água), capacidade de retenção da umidade, aumento da bioresistência (definida como a perda de peso da madeira natural depois que a mesma é submetida ao ensaio com fungos) e resistência ao fogo. 
Analisando os autores anteriores, podemos concluir que, dentro do enfoque deste trabalho, quem mais contribui para o seu desenvolvimento e permitiu que se estudasse um assunto ainda escasso dentro da nossa literatura na direção das ligações com cavilhas principalmente utilizadas na indústria de fabricação de móveis foi $\operatorname{ECKELMAN[21,22,59],~onde~êle~}$ avançou significativamente no aspecto de comportamento estrutural desses elementos de ligações.E nesta linha de pensamento juntam-se também aqui no Brasil as contribuições de PIEDADE (1972), GESUALDO(1982) e CÉSAR(1991), para o estudo de ligações com cavilhas em peças estruturais de madeiras.

Já em relação à de tecnologia de impregnação da madeira foi em seu trabalho que MEYER (1965) descreve os elementos essenciais que compõe o equipamento de impregnação da madeira por meio de monômeros vinílicos, utilizando o sistema de vácuo-pressão e que pela revisão da literatura uma boa parcela de trabalhos após essa data, delineiam seus experimentos com base nesse equipamento de impregnação.

As pesquisas realizadas por AGNELLI(1981) e MANRICH (1984), deram ao Brasil um avanço extraordinário nos processos de impregnação da madeira, utilizando espécies de madeiras e produtos químicos disponíveis no nosso mercado consumidor para aquisição comercial.Assim seguindo a conduta desta linha de trabalho destes dois últimos autores, esta pesquisa procurou seguir os mesmos fundamentos ora sugeridos pelos mesmos para impregnar cavilhas de madeira com a finalidade de utilizá-las nas ligações das peças estruturais de madeira e também viabilizar este processo de impregnação em escala industrial em nossas indústrias de tratamento e preservação. 


\section{LIGAÇÕES EM PEÇAS ESTRUTURAIS DE MADEIRA}

\subsection{Introdução}

Um dos aspectos importantes no cálculo e dimensionamento das Estruturas de Madeiras está relacionado com o conhecimento do comportamento das ligações entre as peças componentes da estrutura, e sua função principal é transmitir os esforços que atuam sobre elas.

As ligações mecânicas das peças de madeira podem ser divididas em dois grandes grupos:pinos ou conectores de superfície.

O tipo pinos, que são de forma cilíndrica e penetram profundamente na madeira, incluem as cavilhas, os pregos, parafusos passantes $\mathrm{e}$ parafusos auto-atarraxantes. Os conectores de superfície incluem os anéis metálicos e as chapas metálicas com dentes estampados.

Uma característica importante das ligações mecânicas está relacionada com a curva carga-deslizamento. As ligações com pré-furação muito maior que o diâmetro do pino ou conector sempre mostram uma deformação inicial sem carga até que o pino ou conector apoie firmemente na madeira. Devido às tolerâncias de fabricação a deformação inicial é prevista variar para os elementos de ligações simples de uma conexão. Quando a ligação é carregada, alguns elementos de ligação transmitem carga, enquanto outros ainda não estão carregados por causa de sua grande deformação inicial e ajuste dos seus elementos. 
A menos que as diferenças de carga entre os elementos de ligação ao corte simples estão submetidos a deformações plásticas, haverá uma diminuição da capacidade última de carga por elemento de ligação[veja figura 4]. Os exemplos de elementos de ligações com deformações iniciais são: parafusos, anéis metálicos e chapa de cisalhamento. Pregos, pregões, grampos, parafusos atarraxantes e chapas com dentes estampados, geralmente apresentam resistência desde o início do carregamento, a menos que eles sejam introduzidos em furos maiores.

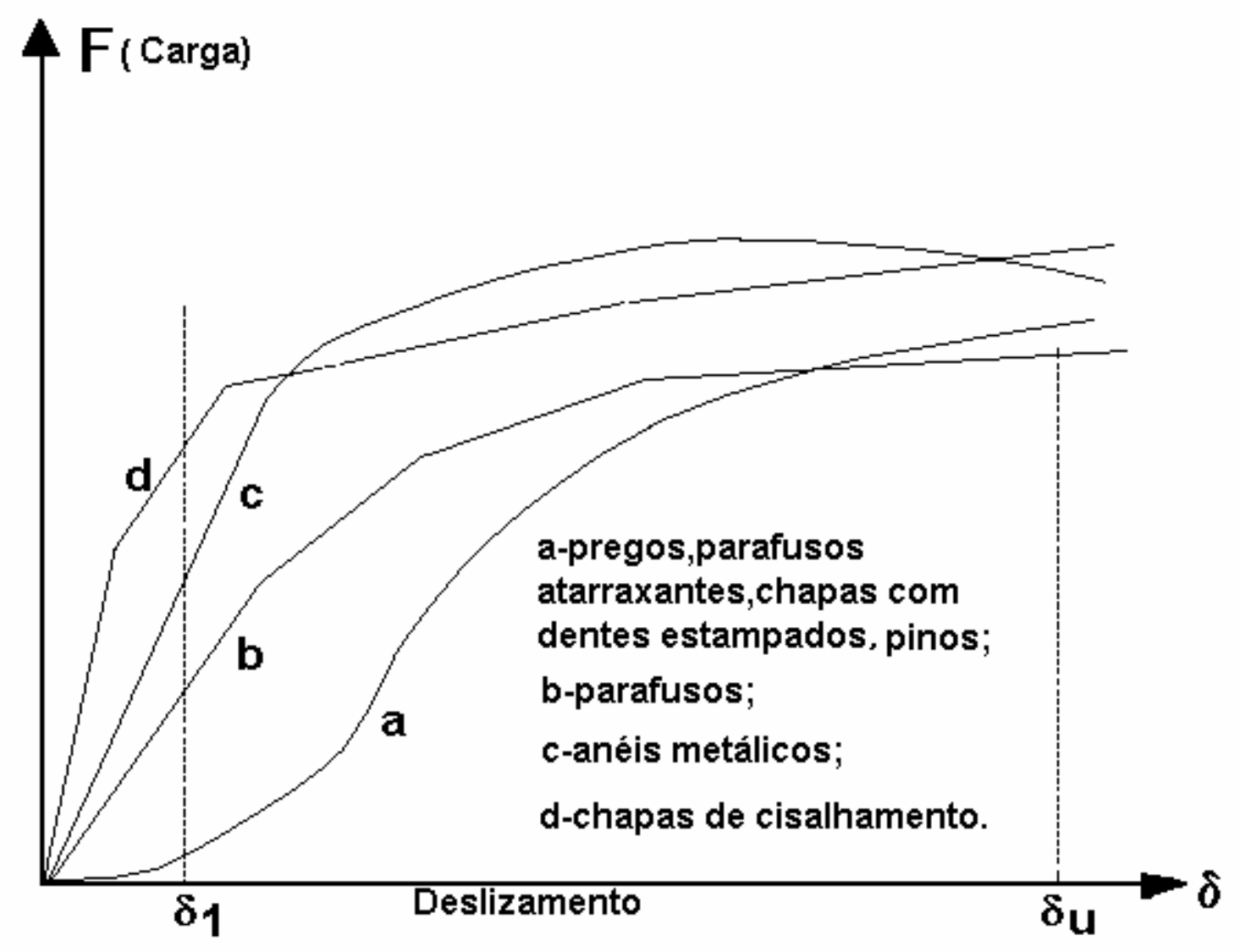

FIGURA 4- Curvas carga-deslizamento, para elementos de ligações dentro de uma conexão[Fonte:BLASS et al.(1994)]. 


\subsection{Rigidez das ligações [Fonte:PNBR 7190/96]}

"As ligações com 2 ou 3 pinos são consideradas deformáveis, permitindo-se o seu emprego exclusivamente em estruturas isostáticas. No projeto, estas ligações serão calculadas como se fossem rígidas, dando-se à estrutura isostática uma contra-flecha compensatória, de pelo menos $L / 100$, onde $L$ é o vão teórico da estrutura considerada".

Nunca serão utilizadas ligações com um único pino.

As ligações com 4 ou mais pinos podem ser consideradas rígidas nas condições seguintes.

As ligações pregadas com 4 ou mais pregos são consideradas rígidas, desde que respeitados os diâmetros de pré-furação especificados em 3.2.1 As ligações parafusadas com 4 ou mais parafusos são consideradas rígidas ou deformáveis, de acordo com o diâmetro de pré-furação adotado, conforme 3.2.2.

Para as ligações com cavilhas admitem-se as mesmas condições de rigidez especificadas anteriormente para as ligações com pinos metálicos.

\subsubsection{Pré-furação das ligações pregadas}

Em uniões pregadas será obrigatoriamente feita a pré-furação da madeira, com diâmetro $d_{o}$ não maior que o diâmetro $d_{\text {ef }}$ do prego, com os valores usuais:

$$
\begin{array}{ll}
\text { coníferas } & \mathrm{d}_{\mathrm{o}}=0,85 \mathrm{~d}_{\mathrm{ef}} \\
\text { dicotiledôneas } & \mathrm{d}_{\mathrm{o}}=0,95 \mathrm{~d}_{\mathrm{ef}}
\end{array}
$$

onde $d_{\text {ef }}$ é o diâmetro efetivo medido nos pregos a serem usados.

Em estruturas provisórias, admite-se o emprego de ligações pregadas sem a pré-furação da madeira, desde que se empreguem madeiras moles de baixa densidade, $\rho_{\mathrm{ap}} \leq 600 \mathrm{Kg} / \mathrm{m}^{3}$, que permitam a penetração dos pregos sem risco de fendilhamento, e pregos com diâmetro d não maior que 1/6 da espessura da madeira mais delgada e com espaçamento mínimo de $10 \mathrm{~d}$. 


\subsubsection{Pré-furação das ligações parafusadas}

Para que as ligações parafusadas sejam consideradas rígidas, a pré-furação deve ser feita com diâmetro $d_{0}$ não maior que o diâmetro $d$ do parafuso acrescido de 0,5 milímetro. Caso sejam empregados diâmetros $\mathrm{d}_{\mathrm{o}}$ maiores, a ligação deve ser considerada deformável.

\subsubsection{Pré-furação das ligações com cavilhas}

Nas ligações com cavilhas, a pré-furação deve ser feita com diâmetro $d_{0}$ igual ao diâmetro d da cavilha. 


\section{LIGAÇÕES COM CAVILHAS}

\subsection{Introdução:}

Atualmente as estruturas de madeira localizadas no mundo sofrem a agressão da poluição da atmosfera terrestre, através da corrosão atmosférica sobre os materiais constituintes de aço, especificamente os meios de ligações tradicionais como pregos, parafusos e anéis metálicos, aumentando o custo de manutenção dessas referidas estruturas e tornando as cavilhas de madeira e as cavilhas impregnadas elementos disponíveis e viáveis para serem utilizados nas ligações das peças estruturais;visto que as cavilhas impregnadas são importantes por serem na verdade, um novo material tendo como base a madeira, podendo inclusive apresentarem uma certa durabilidade, quando sujeitas à ação das intempéries.

Cavilhas são hastes cilíndricas (pinos) torneadas, de madeira dura, que se encaixam justa e gradualmente sob pressão, em furos abertos nas peças de madeira e utilizadas nas ligações de peças estruturais de madeira. Grande parte das aplicações das cavilhas, desde o passado, se faz na indústria de móveis:cadeiras, armários, caixas para embalagens, esquadrias de madeira, elementos decorativos e, especialmente construção naval.

Um dos aspectos importantes para a confecção de cavilhas está relacionado intimamente com a espécie de madeira a ser utilizada na construção. Outros fatores de importância fundamental são:espaçamento mínimo para evitar fendilhamento e tração normal na ligação, distância de extremidades, diâmetro das cavilhas, furação, cravação. 
As cavilhas devem ser torneadas e feitas ou com madeiras duras da classe C60, ou com madeiras moles de $\rho_{a p} \leq 600 \mathrm{Kg} / \mathrm{m}^{3}$ impregnadas com resinas que aumentem sua resistência.

Para emprego em cavilhas, as madeiras impregnadas devem ter resistência compatíveis com a classe C60. Admite-se o emprego de cavilhas estruturais apenas com os diâmetros de 16, 18 e 20 milímetros.[Fonte:PNBR 7190/96].

$\mathrm{Na}$ figura 05 podemos observar a confecção de cavilhas utilizando torno mecânico da carpintaria do LaMEM/SET/USP e o perfil de uma cavilha com suas dimensões principais ( $\boldsymbol{l = c o m p r i m e n t o ;} \mathbf{d}=$ diâmetro).
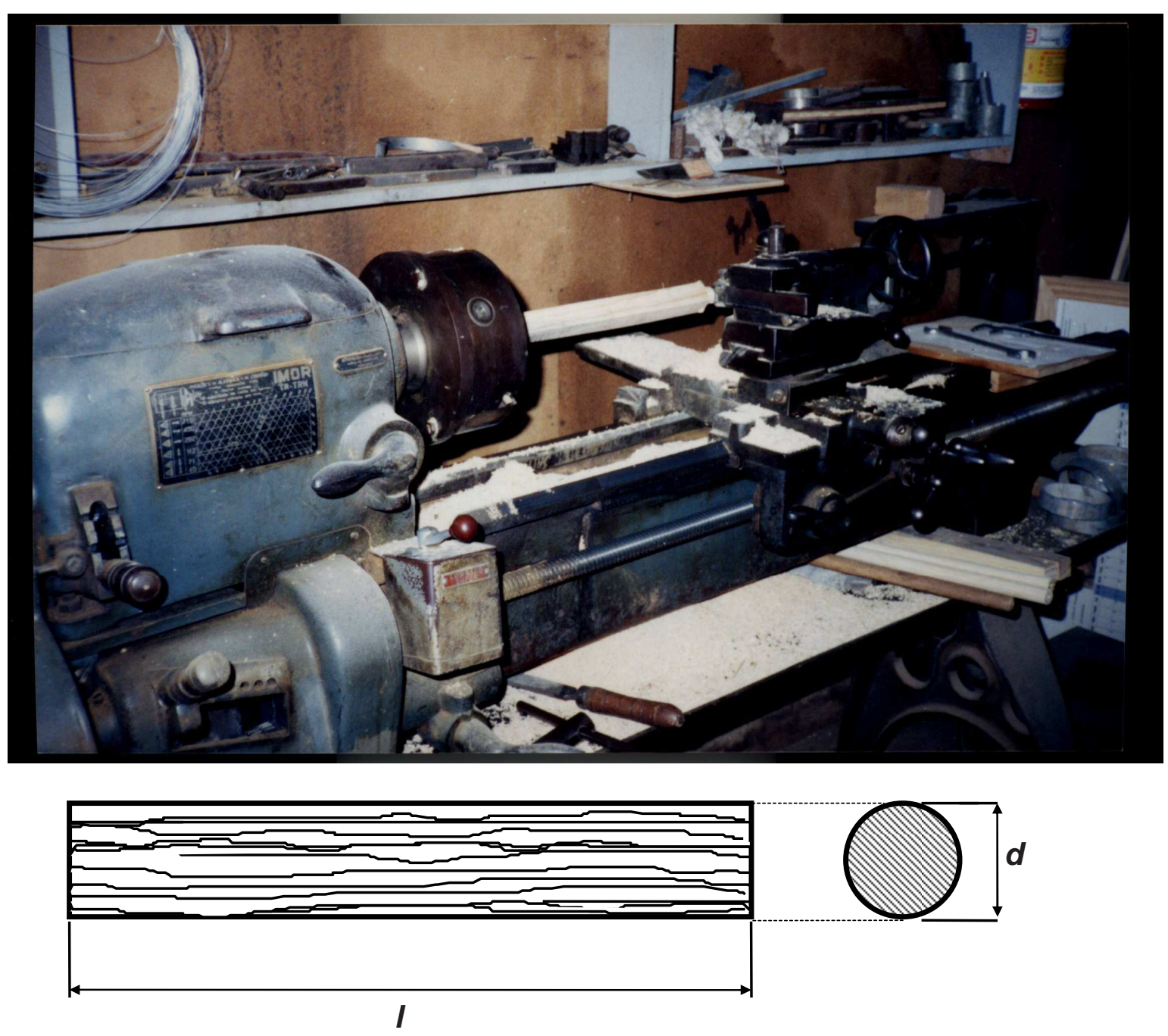

FIGURA 5- Confecção de cavilhas no torno mecânico da carpintaria do LaMEM/SET/USP, e suas principais dimensões. 


\subsection{Fundamentos para a determinação das resistências das ligações cavilhadas em estruturas de madeira.}

Os princípios básicos para a determinação das resistências das ligações cavilhadas de estruturas de madeira deste trabalho, serão feitos com base nos trabalhos de ALMEIDA (1987), ALMEIDA (1990); e ALMEIDA et al (1995); pois são os que mais contribuíram para a formulação dos referidos princípios na direção das ligações mecânicas, utilizando como elementos de ligações os pinos, pregos e parafusos, inclusive as formulações foram incorporadas no novo de projeto de revisão da nova norma brasileira para o Cálculo e Execução de Estruturas de Madeira, NBR 7190.

Neste trabalho sendo a cavilha um elemento de ligação mecânico do tipo pino de madeira, as formulações das expressões para este caso específico, serão uma tentativa de adaptação das que foram obtidas através dos trabalhos anteriores.

\subsubsection{Comportamento básico das ligações cavilhadas}

$\mathrm{Na}$ visão do autor dos trabalhos anteriores ele trata as ligações mecânicas (pinos,pregos,parafusos), tendo o mesmo comportamento dos elementos estruturais, ou seja estas ligações devem apresentar requisitos de segurança voltado para o mesmo tratamento que é dado pela norma brasileira de Ações e Segurança NBR 8681/1984, que é a questão de definir claramente os critérios de quantificação das ações e das resistências a serem consideradas no projeto das estruturas. Desse modo torna-se necessário o conhecimento dos modos de ruptura e os estados limites destas ligações.

Igualmente como é analisada nos trabalhos do autor mencionado anteriormente, aqui também as ligações cavilhadas apresentam excessivas deformações após a fase elástica conforme pode se observar na figura 6 , que mostra o diagrama carga - deslizamento típico de ligações de estruturas de madeira. 


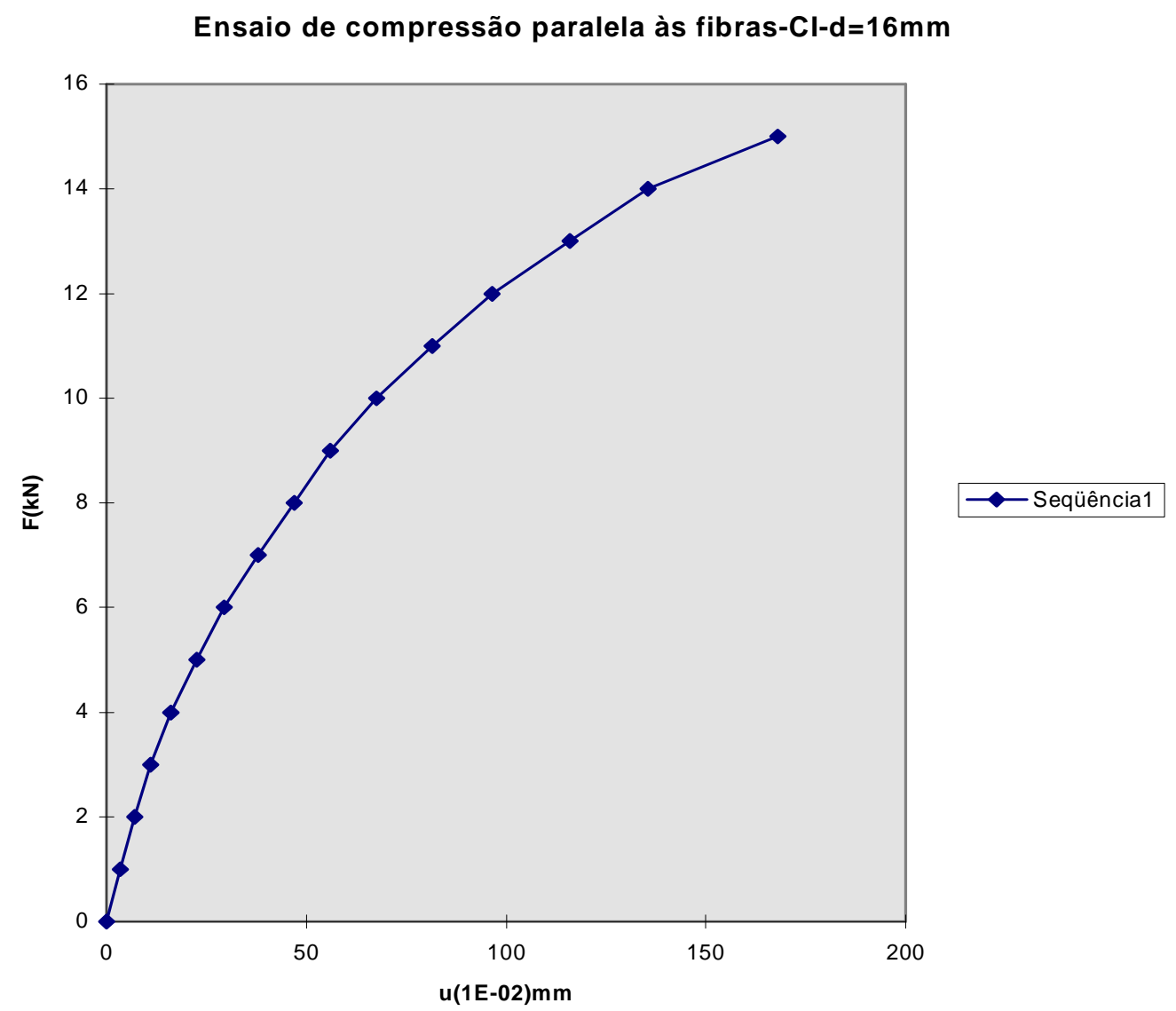

FIGURA 6- Diagrama carga - deslizamento típico das ligações cavilhadas.

\subsubsection{Modos de ruptura}

As investigações experimentais conduzidas por ALMEIDA(1990), permitiram identificar quatro modos de ruptura das ligações pregadas $\mathrm{e}$ parafusadas, que também podem ser estendidos as cavilhas de madeira:plastificação do pino $^{2}$ (cavilha de madeira) por flexão, embutimento da cavilha na madeira, cisalhamento da madeira e fendilhamento da madeira. Com isso o autor pôde desenvolver modelos de cálculo para determinar as chamadas cargas de primeiro e segundo limite, e seguindo o mesmo raciocínio estas cargas limites podem surgir do embutimento da cavilha na madeira ou da plastificação da mesma por flexão.Na figura 7 podem ser observados os referidos modos de ruptura.

\footnotetext{
${ }^{2}$ Pino -Peça, em geral cilíndrica e alongada, que se introduz em orifícios de duas ou mais peças para estabelecer entre elas uma união fixa ou articulada.
} 


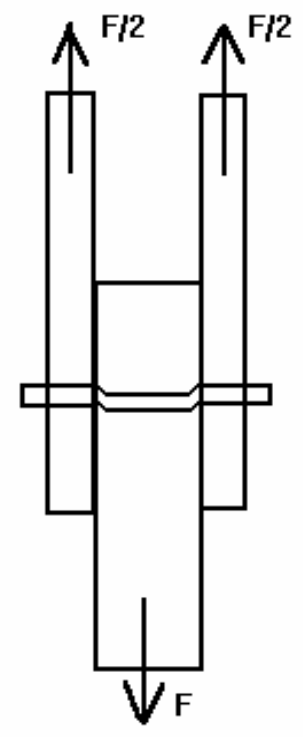

a) flexão do pino

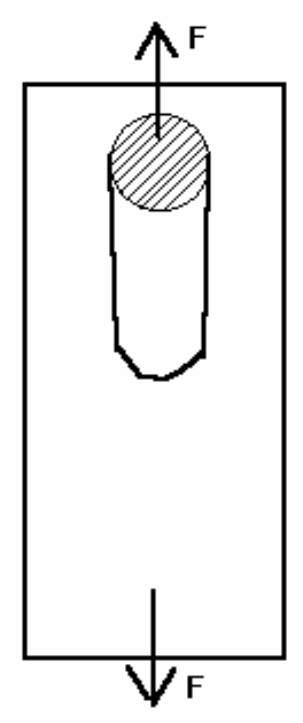

b) embutimento ou esmagamento da parede do furo

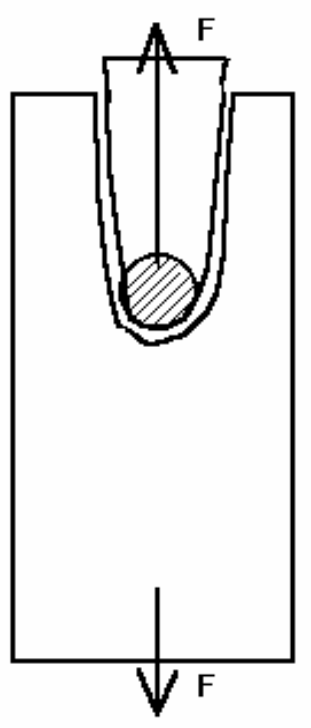

c] cisalhamento da madeira

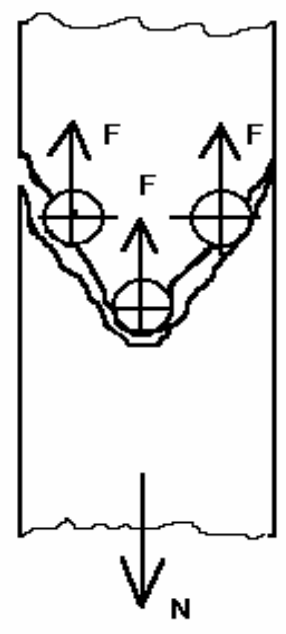

d) cisalhamento da peça de madeira
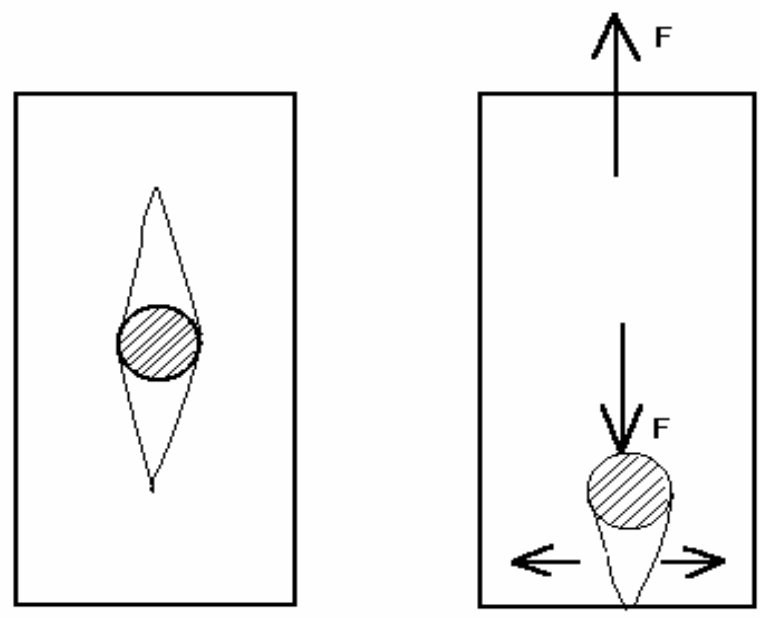

[ e ] e [f ] fendilhamento da madeira

FIGURA 7- Modos de ruptura das uniões com pinos de acordo com 


\subsection{Esforços solicitantes nas ligações cavilhadas}

Será considerado como ponto de partida que as ligações cavilhadas estão submetidas aos esforços solicitantes no plano principal da ligação, conforme a figura 8, seguindo o mesmo raciocínio de ALMEIDA (1987), e onde o mesmo parte do princípio que numa ligação estrutural são conhecidos os valores dos esforços a serem transmitidos, e a verificação dos esforços atuantes na madeira e na cavilha pode ser feita com o auxílio de hipóteses simplificadoras, desde que sejam respeitadas as condições do equilíbrio global da ligação, e esta conclusão ele chegou também no caso específico das ligações pregadas e parafusadas.

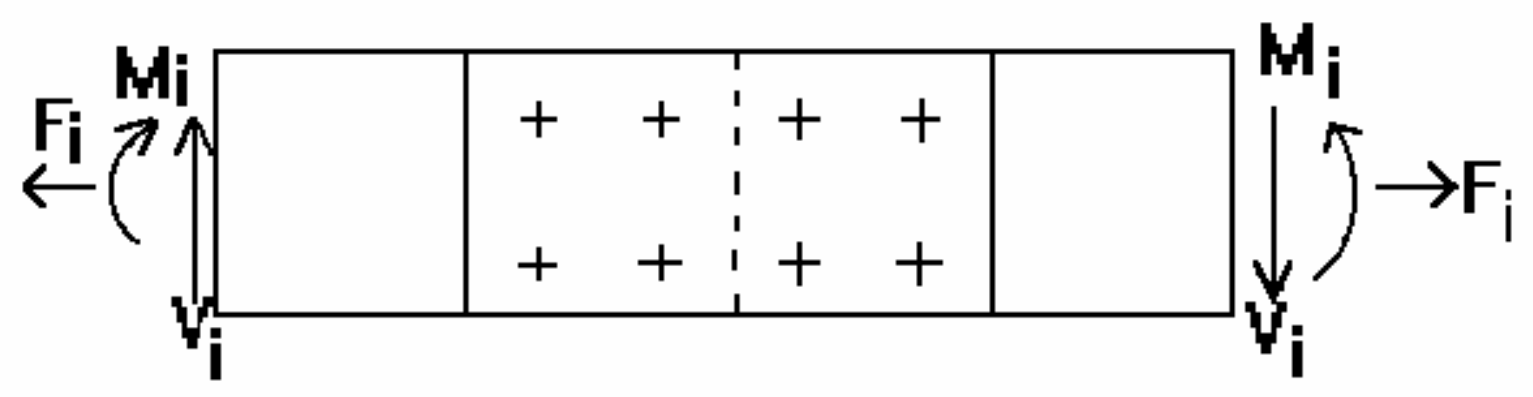

VISTA LATERAL

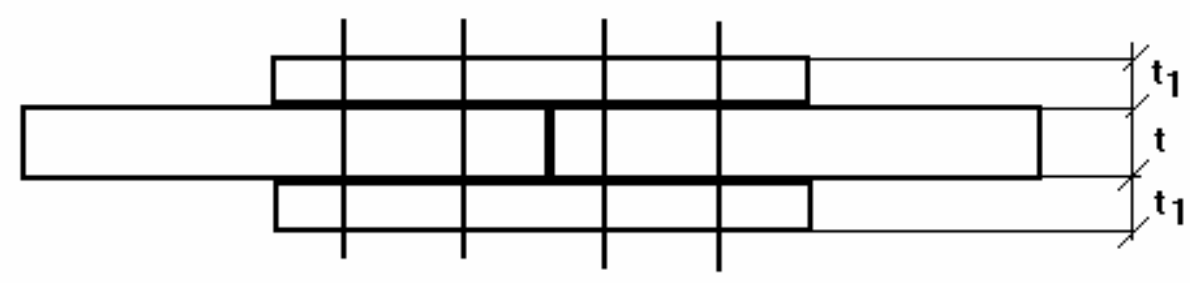

VISTA SUPERIOR

FIGURA 8- Esforços solicitantes no plano da seção transversal da união, segundo ALMEIDA ( 1990 ). 
Seja uma determinada ligação solicitada no caso mais geral conforme pode ser visto na figura 9, onde na investigação experimental de ALMEIDA (1990), ele conclui que as forças de natureza $H$ de tração paralela ao eixo dos pinos ${ }^{3}$ são desprezíveis, e neste trabalho os ensaios experimentais também comprovam esse fato conforme veremos posteriormente (veja figura11). No caso da prática de estruturas de madeira encontram-se com freqüência ligações simétricas onde as duas peças laterais possuem a mesma espessura e a mesma resistência, fazendo com que na peça central os esforços atuantes sejam também simétricos, conclusão esta obtida pelo autor e que será aplicada também neste trabalho, conforme a figura 9 .

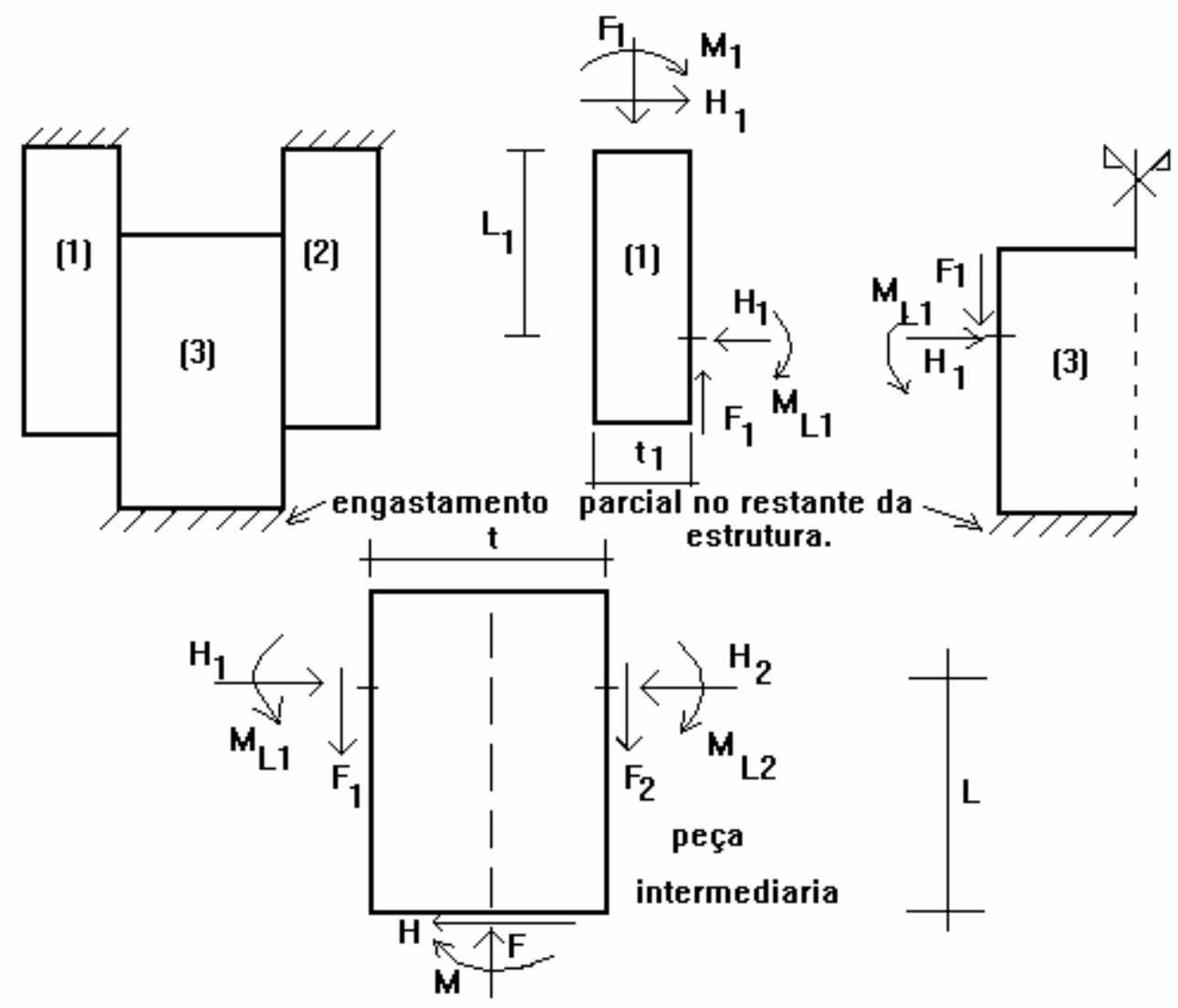

FIGURA 9-Solicitação básica na ligação com cavilhas, adaptação feita de ALMEIDA (1990).

${ }^{3}$ Daqui em diante o raciocínio será aplicado especificamente para o caso das cavilhas. 
Observando a figura 9, os esforços na peça central são simétricos e com isso tem-se a seguinte condição de equilíbrio da ligação:

$\mathrm{M}=0$ e $\mathrm{M}_{\mathrm{L} 1}=\mathrm{M}_{\mathrm{L} 2}=\mathrm{M}_{\mathrm{L}} ; \mathrm{F}_{1}=\mathrm{F}_{2} ; 2 \mathrm{~F}_{\mathrm{p}}=\mathrm{F} ;$ sendo $\mathrm{ML} \circ$ momento aplicado à cavilha, que pode ser visto na figura 10 .

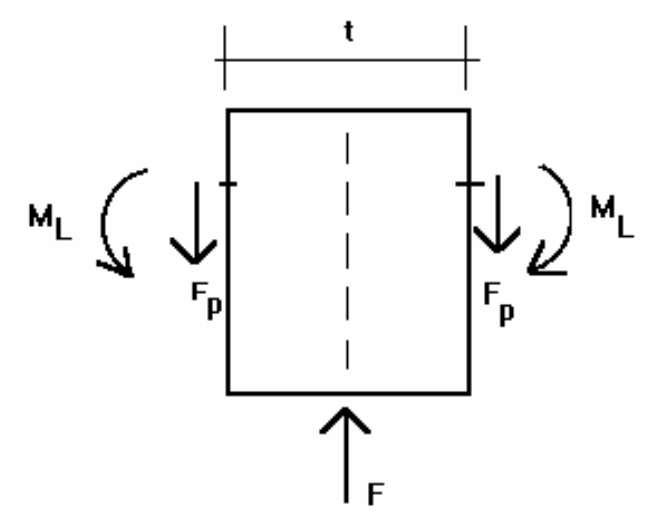

FIGURA 10-Solicitação simétrica da peça intermediária.

Os ensaios experimentais deste trabalho, indicaram que os modelos de ligações cavilhadas solicitadas na compressão paralela às fibras, mostram a configuração deformada das cavilhas conforme pode ser visto na figura 11, e confirma o mesmo raciocínio de ALMEIDA(1990), ao concluir que a transmissão da força cisalhante $\left(\mathbf{F}_{\mathbf{s}}\right)$ entre as peças da ligação provoca o mesmo tipo de solicitação de flexão simples na cavilha, e que para o cálculo das cargas limites será admitido que na transmissão dos esforços entre as peças a força cisalhante atuará na interface das mesmas. Com estas considerações passaremos para a determinação analítica das cargas limites nas ligações cavilhadas, onde se utilizará como elemento de ligação um pino de madeira ou a cavilha propriamente dita. 
Os corpos de prova da figura 11 foram ensaiados experimentalmente no LaMEM/SET/USP, onde se nota claramente as cavilhas deformadas e solicitadas por flexão simples (momento fletor e fôrça cortante).

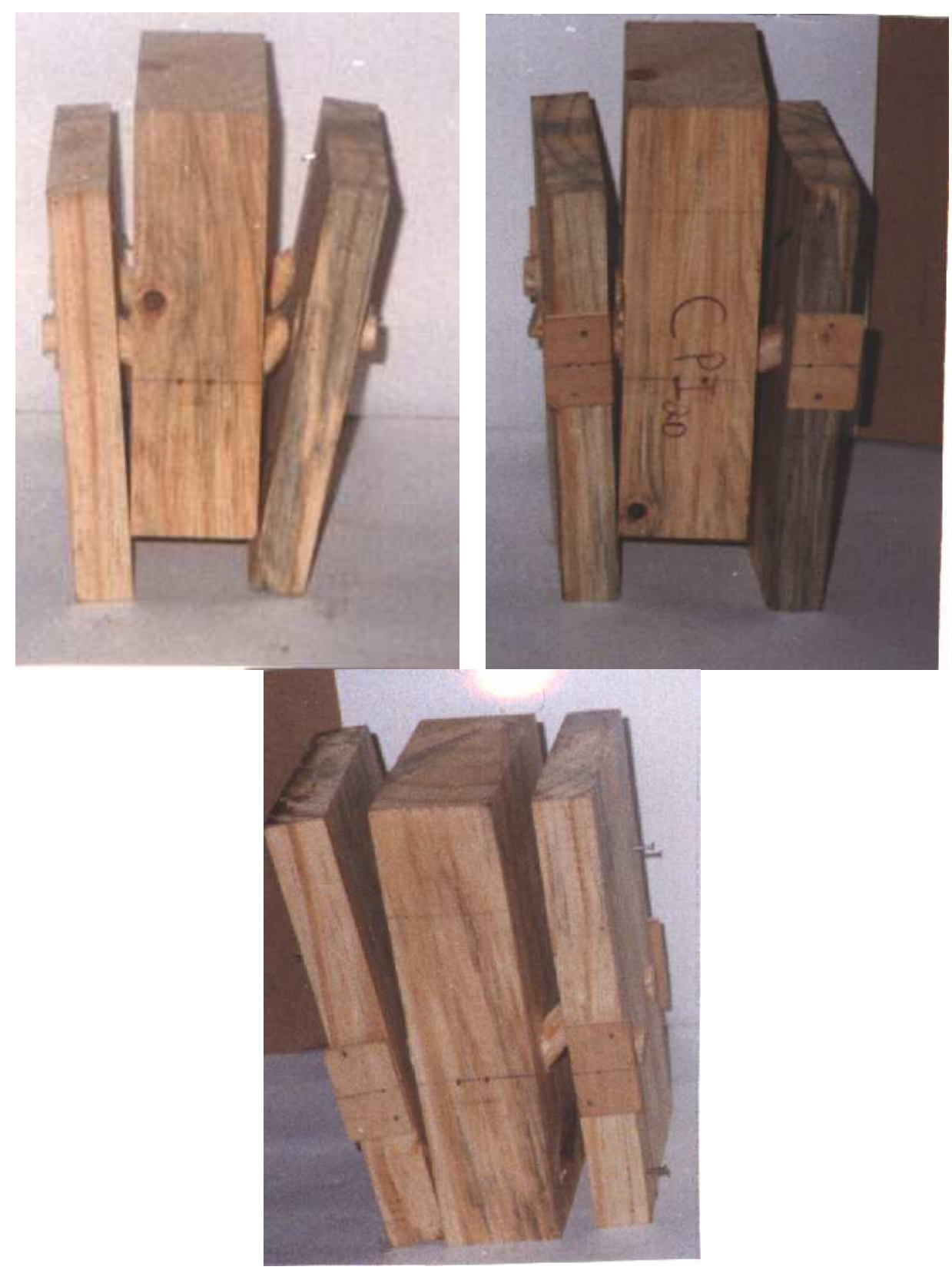

FIGURA 11- Configuração do corpo de prova ensaiado sobre uma mesa rígida, onde o atrito entre o pátio e as peças altera a configuração de ruptura do corpo de prova. 


\subsection{Determinação teórica das cargas de primeiro e segundo limite das ligações cavilhadas}

Para a determinação destas respectivas cargas limites serão adotadas as hipóteses sugeridas no trabalho de ALMEIDA(1990), nas seguintes situações:

\section{I- Hipóteses correspondentes à Carga de Primeiro Limite}

a) Início da plastificação da madeira-embutimento- com a cavilha em regime elástico;

b) Início da plastificação da cavilha por flexão ou por esmagamento normal às fibras, com a madeira ainda submetida a tensões inferiores à inicio de sua plastificação por embutimento;

c) Início da plastificação da cavilha e da madeira simultaneamente.

\section{II- Hipóteses Correspondentes à Carga de Segundo Limite}

a) plastificação completa da madeira-embutimento- com a cavilha em regime elástico;

b) plastificação da cavilha a flexão ou por esmagamento normal às fibras, com a madeira ainda em regime elástico;

c) plastificação da cavilha e da madeira simultaneamente.

\subsection{1-CARGA DE PRIMEIRO LIMITE}

Nesta fase admite-se que a madeira permanece em regime elástico, com distribuição linear de tensões ao longo da parede do furo.A tensão máxima atuante será igual ao limite de elasticidade $\sigma_{\text {we }}$, correspondente ao início do deslizamento controlado por embutimento.Na figura 12 é mostrado o respectivo diagrama extraído do trabalho de ALMEIDA(1987), e para manter o equilíbrio da ligação através do momento externo aplicado $\mathbf{M}_{\mathbf{L}}$ ,aparece uma excentricidade e dos pontos de aplicação das forças $\mathbf{F}$ que agem em cada uma das peças que será obtida por intermédio da calibração dos ensaios experimentais. 


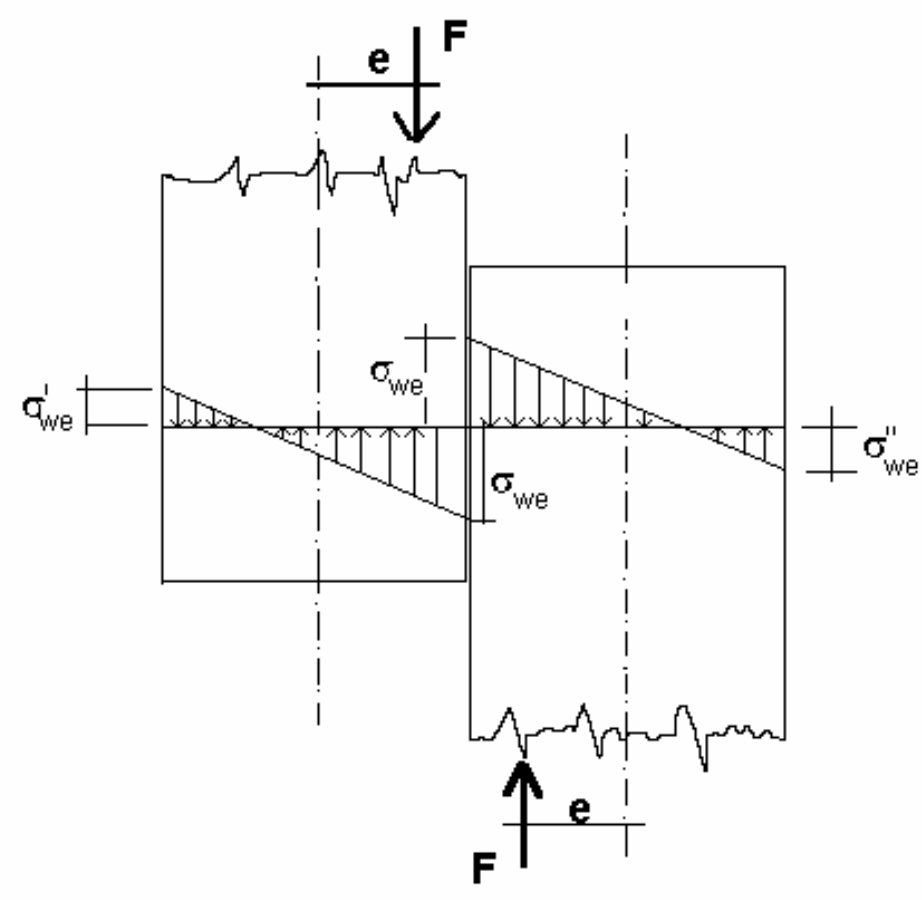

FIGURA 12-Distribuição de tensões na madeira-primeiro limite, segundo ALMEIDA(1987).

Para a determinação da carga de primeiro limite segundo as considerações de ALMEIDA (1987) e ALMEIDA (1990), utilizaremos inclusive as mesmas notações das grandezas utilizadas bem como as mesmas hipóteses nestes trabalhos,lembrando agora que utilizaremos como material do elemento de ligação as cavilhas de madeira com diâmetro da seção transversal d. A carga de primeiro limite correspondente ao início de embutimento da madeira é designada por $\left(\mathbf{F}_{\mathrm{w}, \mathrm{o}}\right)$ e de plastificação das cavilhas por flexão, $\left(F_{\text {cav,o }}\right)$. Para a determinação da carga $F_{w, o}$, admite-se que a cavilha permaneça em regime elástico $\left(\mathbf{M}_{\mathrm{act}, \mathrm{o}} \leq \mathbf{M}_{\mathrm{cav}, \mathrm{o}}\right)$ e $\left(\sigma_{\mathrm{e}, \mathrm{act}} \leq \sigma_{\mathrm{e}, \mathrm{o}}\right)$. A carga $\mathbf{F}_{\text {cav,o }}$, correspondente ao início de plastificação da cavilha por flexão, admite que a madeira permaneça em regime elástico $\left(\sigma_{\mathrm{e}, \mathrm{act}} \leq \sigma_{\mathrm{e}, \mathrm{o}}\right)$ e a cavilha em início de plastificação com $\left(\mathbf{M}_{\mathrm{act}, \mathrm{o}}=\mathbf{M}_{\mathrm{cav}, \mathrm{o}}\right)$. 
Com estas hipóteses adotadas baseadas no trabalho do autor citado ,admite-se que a distribuição de pressões ao longo do eixo da cavilha seja linear, o que será mantido também aqui no caso das cavilhas, pois a idéia já tinha sido amadurecida pelo mesmo autor em um outro trabalho seu no caso das ligações pregadas [ALMEIDA (1987)]. Na figura 13 pode ser observado o referido diagrama de distribuição de pressões ao longo da cavilha.
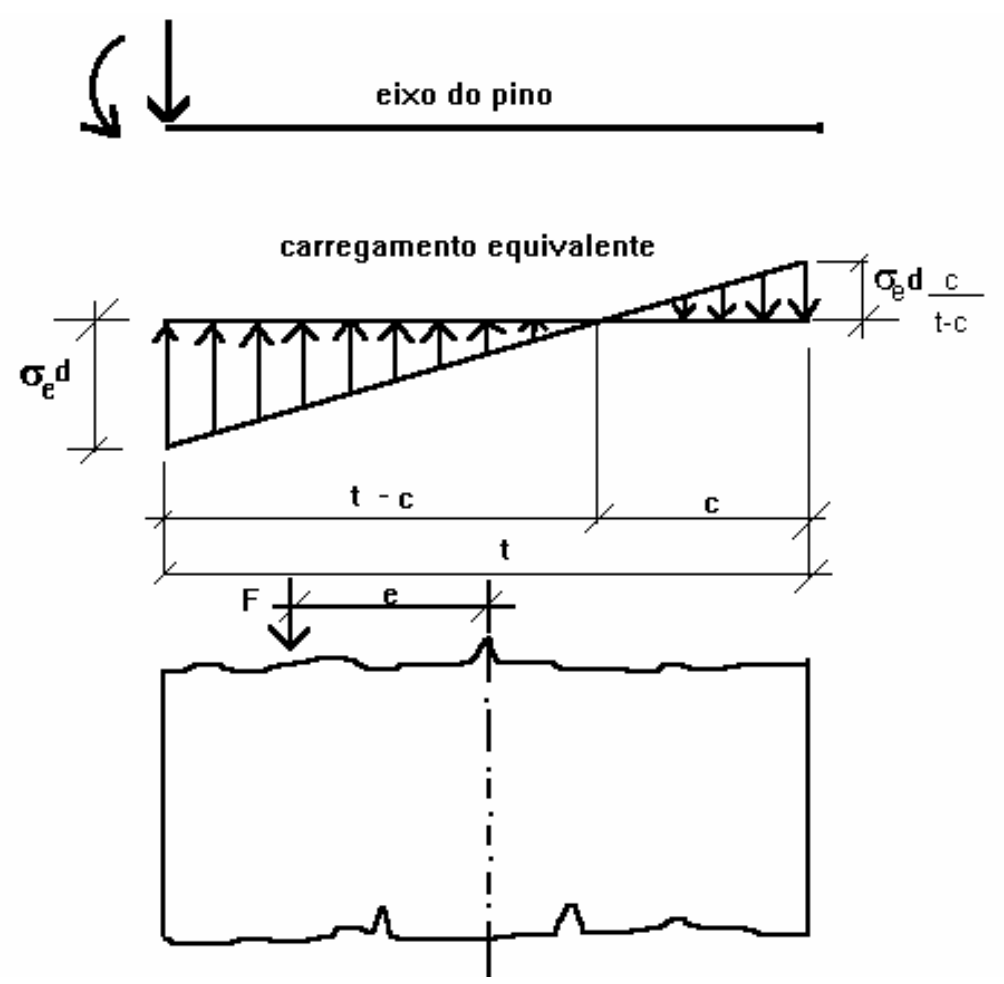

FIGURA 13-Distribuição das pressões de contato para primeiro limite,

$\sigma_{\mathrm{e}, \mathrm{o}}=$ tensão de embutimento, $\mathbf{d}=$ diâmetro da cavilha, segundo

\section{ALMEIDA ( 1990 ).}

Conforme visto anteriormente admite-se o momento externo $\mathbf{M}_{\mathrm{L}}$ seja equilibrado pelo momento resistente da ação $\mathbf{F}(\mathbf{F e})$, conforme a figura 14 . Igualmente como feito nos trabalhos experimentais de ALMEIDA(1987) e ALMEIDA(1990) , a excentricidade "e" da resultante das tensões será calibrada experimentalmente.Sob a ação do momento $\mathbf{M}_{\mathrm{L}}=\mathbf{R e}$ atuando, a tensão de contato $\sigma_{\mathrm{e}}$ atuante na madeira deve ser igual a tensão de início de embuti mento $\sigma_{\mathrm{e}, \mathrm{o}}$. 


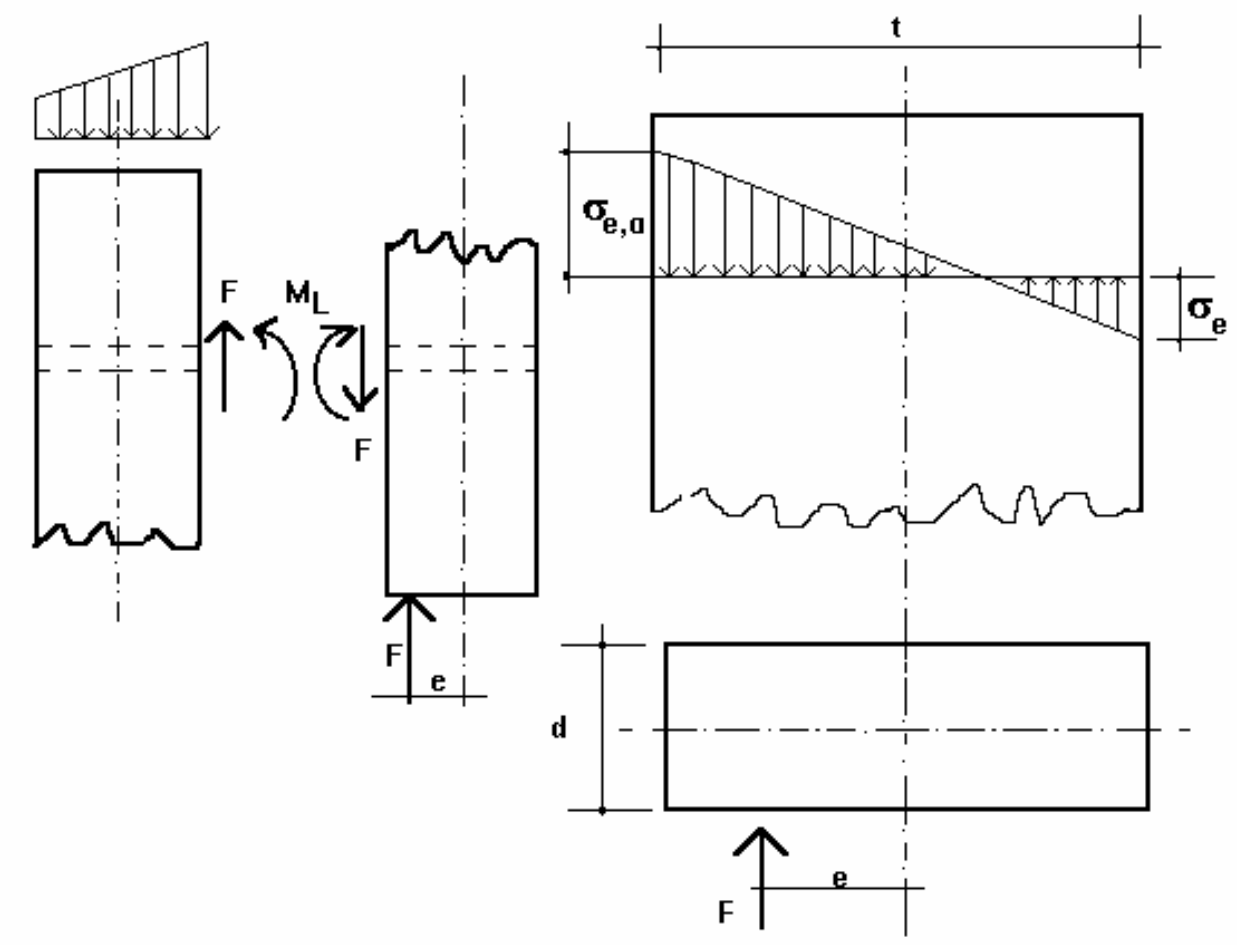

FIGURA 14-Projeção do carregamento da cavilha para cálculo da fôrça de primeiro limite.

A tensão de contato $\left(\sigma_{e}\right)$ atuante na fibra junto a interface da peça de madeira é determinada pela expressão:

$$
\sigma \mathrm{e}=\frac{\mathrm{F}}{\mathrm{A}}+\frac{\mathrm{M}}{\mathrm{W}}=\frac{\mathrm{F}}{\mathrm{d} \cdot \mathrm{t}}+\frac{6 . \mathrm{F} \cdot \mathrm{e}}{\mathrm{d} \cdot \mathrm{t}^{2}}
$$

A carga de primeiro limite da união por início do embutimento da madeira $\left(\mathbf{F}_{\mathbf{w}, \mathbf{o}}\right)$ será determinada com a igualdade $\sigma_{e}=\sigma_{e, 0}$ Da expressão 4.1,tem-se:

$$
F_{w, o}=\frac{d \cdot t^{2}}{t+6 \cdot e} \cdot \sigma_{e, 0}
$$

O momento fletor máximo que atua na cavilha será dado pela seguinte expressão:

$$
\operatorname{Mmax}=\frac{2}{3} \cdot \sigma e \cdot \frac{\mathrm{d} \cdot \mathrm{c}^{3}}{\mathrm{t}-\mathrm{c}}
$$


$\mathrm{Na}$ expressão anterior o valor de c, função da espessura $t$ e da excentricidade(e) é determinado pela expressão abaixo:

$$
c=\frac{6 . t \cdot e-t^{2}}{12 . e}
$$

Igualando o valor do momento máximo $\mathbf{M}_{\max }$, com o valor do momento de

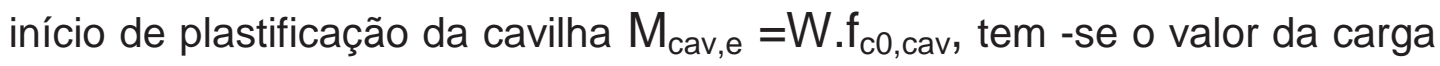

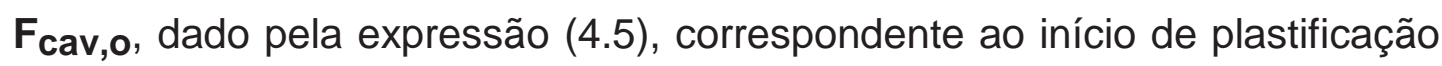
da cavilha.

$$
\frac{2}{3} \cdot \sigma \mathrm{e} \cdot \frac{\mathrm{d} \cdot \mathrm{c}^{3}}{\mathrm{t}-\mathrm{c}}=\frac{\pi}{32} \cdot \mathrm{d}^{3} \cdot \mathrm{fc} 0, \mathrm{cav} \quad \sigma \mathrm{e}=\frac{3 \pi \cdot \mathrm{d}^{2} \cdot(\mathrm{t}-\mathrm{c}) \cdot \mathrm{fc} 0, \mathrm{cav}}{64 \cdot \mathrm{c}^{3}}
$$

Levando o valor da expressão (4.5) em (4.2),teremos com a condição de $\sigma_{e, o}=\sigma_{e}$, o valor da carga $\boldsymbol{F}_{\text {cav }, o}$ será:

$$
\text { Fcav, } o=\frac{d \cdot t^{2}}{t+6 e} \cdot \frac{3 \pi}{64} \cdot d^{2} \cdot\left(\frac{t-c}{c^{3}}\right) \cdot f c 0, c a v
$$

Analisando novamente os trabalhos de ALMEIDA(1987) e ALMEIDA(1990), os mesmos concluem que a relação entre a espessura $(t)$ e 0 diâmetro da cavilha (d), chamada de $\beta=t / d$; interfere na resistência das ligações. Aqui com o mesmo raciocínio as expressões de $\mathbf{F}_{\mathbf{W}, \mathbf{o}}$ e $\mathbf{F}_{\mathbf{c a v}, \mathbf{o}}$ são desenvolvidas em função deste parâmetro $\beta$, onde será atribuído um certo valor para a excentricidade e, que deverá ser calibrado experimentalmente, conforme pode ser visto no ANEXO C.

Tal como foi feito nos trabalhos anteriores segue-se fazendo o mesmo procedimento , chamando de $\xi=\mathbf{F}_{\mathbf{w}, \mathbf{o}} / \mathbf{F}_{\mathbf{c a v}, \mathbf{o}}$ e $\eta_{\mathrm{o}}=\sigma_{\mathrm{e}, \mathrm{o}} / \mathbf{f}_{\mathbf{c 0}, \mathbf{c a v}}$,e dividindo membro a membro as expressões (4.2) e (4.6), têm-se: 


$$
\xi_{o}=\eta_{o} \cdot \frac{64 \cdot c^{3} \cdot \beta^{2}}{3 \cdot \pi \cdot t^{2} \cdot(t-c)}
$$

Para atender à hipótese básica de equilíbrio admitida no modelo os valores da excentricidade e, devem estar compreendidos no intervalo $t / 6 \leq e \leq t / 2$. Os valores de e e c estão mostrados em um gráfico do ANEXO C. Neste trabalho o valor da excentricidade foi calibrado para o caso das cavilhas impregnadas e não impregnadas conforme pode ser visto na Tabela 01 a seguir:

TABELA 01-Valores aproximados de e e c obtidos por calibração.

\begin{tabular}{|c|c|c|c|}
\hline $\begin{array}{c}\text { ESPÉCIE DE } \\
\text { MADEIRA }\end{array}$ & e & c & OBSERVAÇÃo \\
\hline Pinus & $0,28 \mathrm{t}$ & $0,20 \mathrm{t}$ & Sem impregnação \\
\hline Pinus & $0,42 \mathrm{t}$ & $0,30 \mathrm{t}$ & Com impregnação \\
\hline Ipê & $0,45 \mathrm{t}$ & $0,31 \mathrm{t}$ & Sem impregnação \\
\hline
\end{tabular}

Iremos nesta fase determinar os valores de $\xi_{0}$ em função do parâmetro $\beta$, substituindo o valor de c dado na tabela 01 para as diferentes condições de espécies de madeiras, conforme pode se ver na tabela 02. Substituindo também estes valores nas expressões (4.2) e (4.6) obteremos os valores de $\mathbf{F}_{\mathbf{w}, 0}$ e $\mathbf{F}_{\mathbf{c a v}, 0}$ respectivamente conforme poderá ser visto na tabela 03, sendo também utilizado o valor do diâmetro das cavilhas igual a $20 \mathrm{~mm}$, para o cálculo destas expressões. 


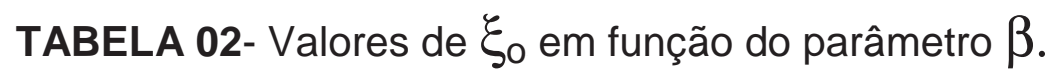

\begin{tabular}{|c|c|c|c|}
\hline ESPÉCIE & $\xi_{\mathrm{o}=\mathrm{f}(\boldsymbol{\beta})}$ & $\begin{array}{c}\beta_{\lim } \\
\left(\text { para } \xi_{\mathrm{o}=1)}\right.\end{array}$ & $\begin{array}{c}\text { NATUREZA DA } \\
\text { MADEIRA }\end{array}$ \\
\hline PINUS & $\xi_{\mathrm{o}=0,0673 \beta^{2} \eta_{\mathrm{o}}}$ & $\beta \lim =3,86 \sqrt{\frac{\mathrm{fc} 0, \mathrm{cav}}{\sigma_{\mathrm{e}, 0}}}$ & $\begin{array}{c}\text { SEM } \\
\text { IMPREGNAÇÃO }\end{array}$ \\
\hline PINUS & $\xi_{\mathrm{o}=0,26 \beta^{2} \eta_{\mathrm{o}}}$ & $\beta \lim =1,96 \sqrt{\frac{\mathrm{fc} 0, \mathrm{cav}}{\sigma_{\mathrm{e}, 0}}}$ & $\begin{array}{c}\text { COM } \\
\text { IMPREGNAÇÃO }\end{array}$ \\
\hline IPÊ & $\xi_{\mathrm{o}=0,29 \beta^{2} \eta_{\mathrm{o}}}$ & $\beta \lim =1,85 \sqrt{\frac{\mathrm{fc} 0, \mathrm{cav}}{\sigma_{\mathrm{e}}, \mathrm{o}}}$ & $\begin{array}{c}\text { SEM } \\
\text { IMPREGNAÇÃO }\end{array}$ \\
\hline
\end{tabular}

Para valores de $\beta$ menores que $\beta_{\text {lim ocorre embutimento da cavilha na }}$ madeira e a carga de primeiro limite será determinada por meio da expressão de $\mathbf{F}_{\mathrm{w}, \mathrm{o}}$ e para o caso de valores de $\beta$ maiores do que $\beta_{\lim } \circ$ primeiro limite ocorre por início da plastificação das cavilhas e carga de primeiro limite será determinada por meio da expressão de $\mathbf{F}_{\mathbf{c a v}, \mathbf{o}}$.Os gráficos das funções da Tabela 02 serão mostrados no ANEXO C, bem como das funções de $\mathbf{F}_{\mathbf{w}, \mathbf{o}}$ e $\mathbf{F}_{\mathbf{c a v}, \mathbf{o}}$ em função do parâmetro $\beta$.

$\mathrm{Na}$ Tabela 03 poderão ser vistos os valores de $\mathbf{F}_{\mathbf{W}, \mathbf{o}}$ e $\mathbf{F}_{\mathbf{c a v}, \mathbf{o}} \mathrm{em}$ função do parâmetro $\beta$. 
TABELA 03- Valores de $\mathbf{F}_{\mathbf{w}, 0}$ e $\mathbf{F}_{\mathbf{c a v}, 0}$ em função do parâmetro $\beta$.

\begin{tabular}{|c|c|c|c|}
\hline ESPÉCIE & $F_{W, 0}$ & $F_{\text {cav }, 0}$ & $\begin{array}{c}\text { NATUREZA DA } \\
\text { MADEIRA }\end{array}$ \\
\hline PINUS & $\frac{0,37 \cdot \mathrm{t}^{2} \cdot \sigma \mathrm{e}, 0}{\beta}$ & $\frac{5,5 \cdot \mathrm{t}^{2} \cdot \mathrm{fc} 0, \mathrm{cav}}{\beta^{3}}$ & Sem impregnação \\
\hline PINUS & $\frac{0,28 \cdot \mathrm{t}^{2} \cdot \sigma \mathrm{e}, 0}{\boldsymbol{\beta}}$ & $\frac{1,08 \cdot \mathrm{t}^{2} \cdot \mathrm{fc} 0, \mathrm{cav}}{\beta^{3}}$ & Com impregnação \\
\hline $\mathrm{IPE}$ & $\frac{0,27 \cdot \mathrm{t}^{2} \cdot \sigma_{\mathrm{e}, 0}}{\boldsymbol{\beta}}$ & $\frac{0,92 \cdot \mathrm{t}^{2} \cdot \mathrm{fc} 0, \mathrm{cav}}{\boldsymbol{\beta}^{3}}$ & Sem impregnação \\
\hline
\end{tabular}

\subsection{2-CÁLCULO DA CARGA DE SEGUNDO LIMITE}

Nesta fase consideraremos que a resistência à compressão paralela às fibras da madeira é suficiente para esmagar a cavilha, com a condição de que a tensão:( $\left.\boldsymbol{\sigma}_{\mathbf{e , o}, \mathbf{f}} \mathbf{f}\right)$, conforme podemos ver na figura 15.

A seguir ALMEIDA (1990) determina a carga de segundo limite em função da plastificação da madeira devida ao embutimento do pino, ou pela plastificação das cavilhas por flexão. Êle usa duas hipóteses de distribuição de tensões de embutimento ao longo da parede do furo, que utilizaremos também aqui neste trabalho.

\section{A) Primeira Hipótese: Comportamento elástico da madeira.}

Para determinação da carga de segundo limite com plastificação total da cavilha por flexão $\mathrm{F}_{\mathrm{W}, \mathrm{u}}^{\mathrm{A}}$, serão usados as mesmas equações deduzidas para o caso da carga de primeiro limite da ligação pela madeira $\left(\mathbf{F}_{\mathbf{w}, \mathbf{o}}\right)$, equação 4.2, substituindo o valor da tensão de embutimento de primeiro limite $\left(\sigma_{e, o}\right)$ pela resistência de embutimento $\left(\mathbf{f}_{\mathbf{e}}\right)$. 


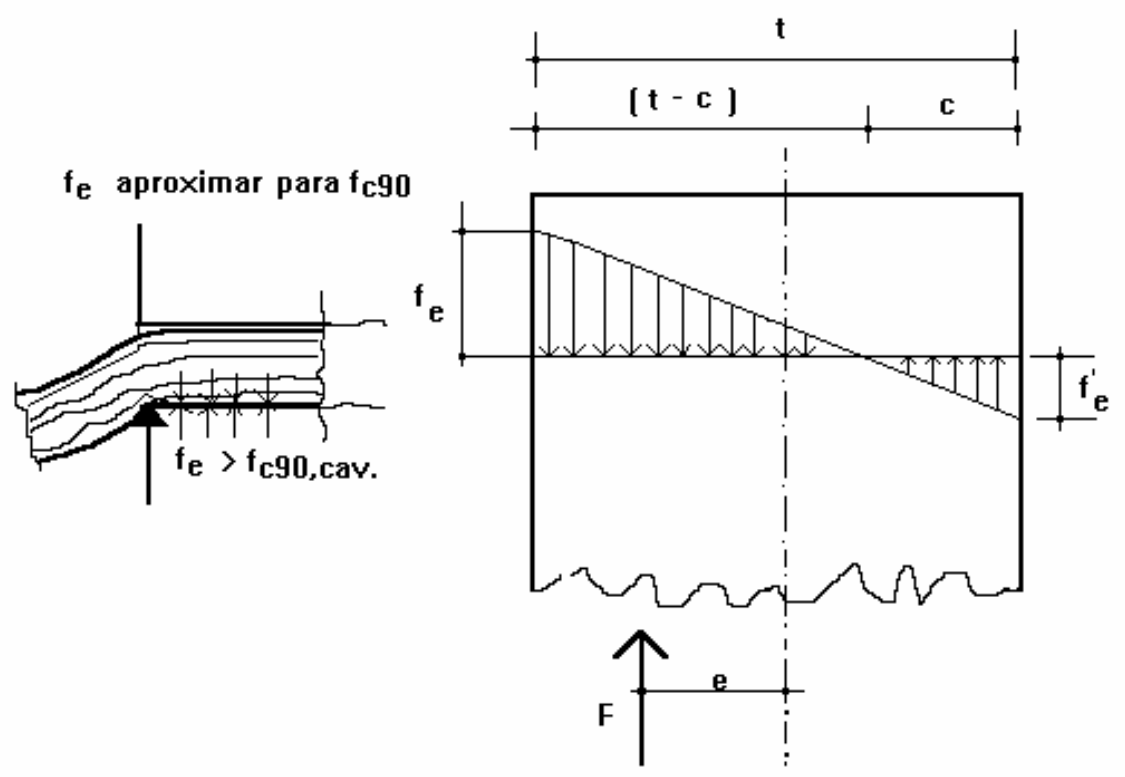

FIGURA 15-Diagrama de distribuição de tensão na madeira, primeira hipótese[ALMEIDA (1990)].

A resistência de embutimento da madeira pode ser determinada pela expressão (4.8) e com a condição básica que: $\left(\boldsymbol{\sigma}_{\mathbf{e}, \mathbf{0}=} \mathbf{f}_{\mathbf{e}}\right)$, para a madeira).

$$
\mathrm{F}_{\mathrm{W}, \mathrm{u}}^{\mathrm{A}}=\frac{\mathrm{d} \cdot \mathrm{t}^{2}}{\mathrm{t}+6 \mathrm{e}} \cdot \mathrm{fe}
$$

Para determinar a carga de segundo limite considerando a plastificação total $\left(\mathrm{F}_{\mathrm{cav}, \mathrm{u}}^{\mathrm{A}}\right)$ da cavilha por flexão, o momento fletor de plastificação da cavilha será $\mathbf{M}_{\mathbf{y}}=\mathbf{d}^{3} / 6 . \mathbf{f}_{\mathbf{c} 0, \text { cav }}$; e igualando esse valor com o valor do momento máximo atuante na cavilha, teremos:

$$
\frac{2}{3} \cdot f e \cdot \frac{d \cdot c^{3}}{t-c}=\frac{d^{3}}{6} \cdot f c 0, c a v \quad ; \quad f e=\frac{d^{2} \cdot(t-c)}{4 \cdot c^{3}} \cdot f c 0, c a v
$$

Substituindo o valor da expressão (4.9) em (4.8) obtemos: ( $\mathrm{F}_{\mathrm{cav}, \mathrm{u}}^{\mathrm{A}}$ ). 


$$
F_{c a v, u}^{A}=\left(\frac{d^{3} \cdot t^{2}}{t+6 e}\right) \cdot \frac{(t-c)}{4 \cdot c^{3}} \cdot f c o, c a v
$$

Aqui igualmente usaremos os mesmos valores da excentricidade e e o valor de c, conforme foi feito na Tabela 01.

Fazendo-se: $\quad \eta=f_{e} / f_{c 0, c a v} ; \quad$ e $\quad \xi_{u}^{\mathrm{A}}=\frac{F_{w}^{\mathrm{A}}}{\mathrm{F}_{\mathrm{cav}}^{\mathrm{A}}}$ e correspondente à primeira hipótese, obtermos a função $\xi=f(\beta)$, e com isso poderemos aplicar a expressão obtida para cada espécie de madeira conforme foi feito anteriormente na tabela 02 e que poderão ser vistos na Tabela 04.

TABELA 04- Valores de $\xi_{0}$ em função do parâmetro $\beta$.

\begin{tabular}{|c|c|c|c|}
\hline ESPÉCIE & $\xi_{\mathrm{u}=\mathrm{f}(\boldsymbol{\beta})}$ & $\begin{array}{c}\beta_{\lim } \\
\left(\mathrm{para} \xi_{\mathrm{u}}^{\mathrm{A}}=1\right)\end{array}$ & $\begin{array}{c}\text { NATUREZA DA } \\
\text { MADEIRA }\end{array}$ \\
\hline PINUS & $\xi_{\mathrm{u}}^{\mathrm{A}}=0,04 \cdot \beta^{2} \cdot \eta_{\mathrm{u}}$ & $\boldsymbol{\beta} \lim =5 \sqrt{\frac{\mathrm{fc} 0, \mathrm{cav}}{\mathrm{fe}}}$ & $\begin{array}{c}\text { SEM } \\
\text { IMPREGNAÇÃO }\end{array}$ \\
\hline PINUS & $\xi_{\mathrm{u}}^{\mathrm{A}}=0,16 \cdot \beta^{2} \cdot \eta_{\mathrm{u}}$ & $\boldsymbol{\beta}_{\lim =2,50 \sqrt{\frac{\mathrm{fc} 0, \mathrm{cav}}{\mathrm{fe}}}}$ & $\begin{array}{c}\text { COM } \\
\text { IMPREGNAÇÃO }\end{array}$ \\
\hline IPÊE & $\xi_{\mathrm{u}}^{\mathrm{A}}=0,17 \cdot \beta^{2} \cdot \eta_{\mathrm{u}}$ & $\beta_{\lim =2,40 \sqrt{\frac{\mathrm{fc} 0, \mathrm{cav}}{\mathrm{fe}}}}$ & $\begin{array}{c}\text { SEM } \\
\text { IMPREGNAÇÃO }\end{array}$ \\
\hline
\end{tabular}

Como no primeiro caso, são mostrados no ANEXO C os gráficos das funções $\xi_{u}=f(\beta)$.

Iremos calcular agora os valores de $\mathrm{F}_{\mathrm{w}, \mathrm{u}}^{\mathrm{A}}, \mathrm{F}_{\mathrm{cav}, \mathrm{u}}^{\mathrm{A}}$ em função do parâmetro $\beta$, cujos valores são mostrados na Tabela 5. 
TABELA 05- Valores de $\mathrm{F}_{\mathrm{w}, \mathrm{u}}^{\mathrm{A}}, \mathrm{F}_{\mathrm{cav}, \mathrm{u}}^{\mathrm{A}}$ em função do parâmetro $\beta$.

\begin{tabular}{|c|c|c|c|}
\hline ESPÉCIE & $\mathrm{F}_{\mathrm{w}, \mathrm{u}}^{\mathrm{A}}$ & $\mathrm{F}_{\mathrm{cav}, \mathrm{u}}^{\mathrm{A}}$ & $\begin{array}{c}\text { NATUREZA DA } \\
\text { MADEIRA }\end{array}$ \\
\hline PINUS & $\frac{0,37 . \mathrm{t}^{2} \cdot \mathrm{fe}}{\boldsymbol{\beta}}$ & $\frac{9,25 \cdot \mathrm{t}^{2} \cdot \mathrm{fc} 0, \mathrm{cav}}{\boldsymbol{\beta}^{3}}$ & Sem impregnação \\
\hline PINUS & $\frac{0,28 \cdot \mathrm{t}^{2} \cdot \mathrm{fe}}{\boldsymbol{\beta}}$ & $\frac{1,78 \cdot \mathrm{t}^{2} \cdot \mathrm{fc} 0, \mathrm{cav}}{\boldsymbol{\beta}^{3}}$ & Com impregnação \\
\hline IPẾ & $\frac{0,27 . \mathrm{t}^{2} \cdot \mathrm{fe}}{\boldsymbol{\beta}}$ & $\frac{0,92 \cdot \mathrm{t}^{2} \cdot \mathrm{fc} 0, \mathrm{cav}}{\boldsymbol{\beta}^{3}}$ & Sem impregnação \\
\hline
\end{tabular}

\section{B) SEGUNDA HIPÓTESE-Comportamento plástico da madeira}

Com 0 mesmo procedimento adotado no trabalho de ALMEIDA (1990), neste caso a ligação atinge o segundo limite com a plastificação da cavilha por flexão, e a distribuição de tensões está mostrada na figura 16.

Neste caso a expressão de $\mathrm{F}_{\mathrm{W}, \mathrm{u}}^{\mathrm{B}}$, será dada por:

$$
F_{w, u}^{B}=-2 . f e \cdot d \cdot e+\text { fe.d. } \sqrt{4 \cdot e^{2}+t^{2}}
$$

A carga de segundo limite com a plastificação total da cavilha por flexão, será usada o mesmo valor dado na expressão (4.10)

$$
F_{c a v, u}^{B}=\left(\frac{d^{3} \cdot t^{2}}{t+6 e}\right) \cdot \frac{(t-c)}{4 \cdot c^{3}} \cdot f c o, c a v
$$

Iremos agora calcular os valores da função $\xi_{u}=f(\beta)$, como nos casos anteriores. 


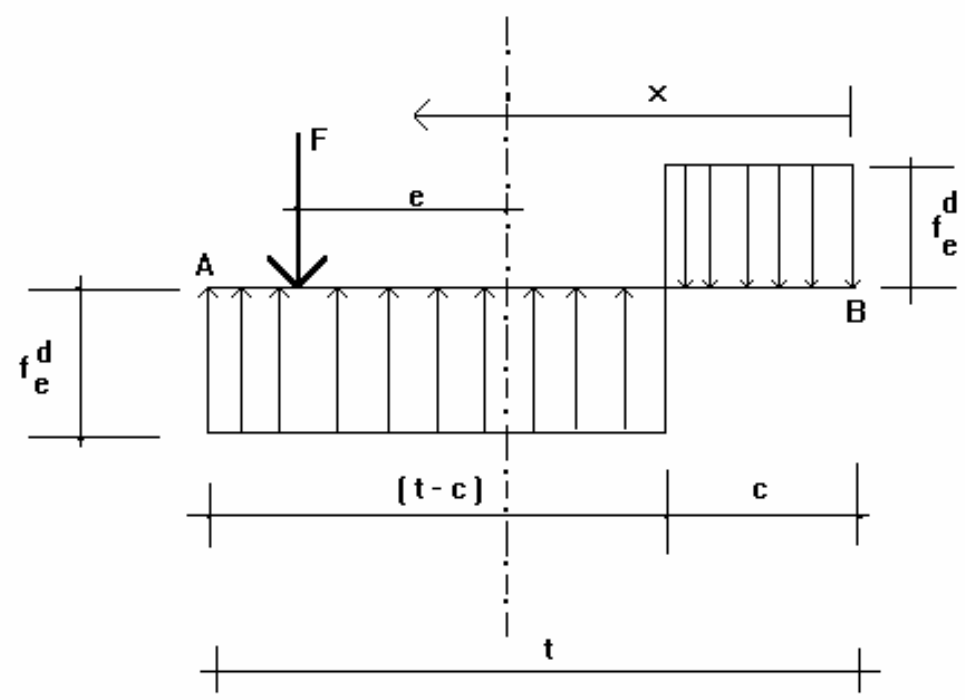

FIGURA 16- Distribuição de tensões-segunda hipótese,[ALMEIDA(1990)].

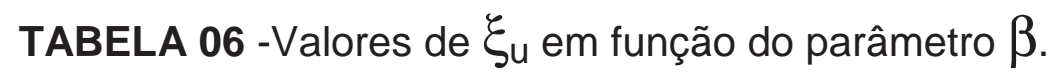

\begin{tabular}{|c|c|c|c|}
\hline ESPÉCIE & $\xi_{\mathrm{u}=\mathrm{f}(\boldsymbol{\beta})}$ & $\begin{array}{c}\beta_{\lim } \\
\left(\text { para } \xi_{\mathrm{u}}^{\mathrm{B}}=1\right)\end{array}$ & $\begin{array}{c}\text { NATUREZA DA } \\
\text { MADEIRA }\end{array}$ \\
\hline PINUS & $\xi_{\mathrm{u}}^{\mathrm{B}}=0,06 \cdot \beta^{2} \cdot \eta_{\mathrm{u}}$ & $\beta \lim =3,96 \sqrt{\frac{\mathrm{fc} 0, \mathrm{cav}}{\mathrm{fe}}}$ & $\begin{array}{c}\text { SEM } \\
\text { IMPREGNAÇÃO }\end{array}$ \\
\hline PINUS & $\xi_{\mathrm{u}}^{\mathrm{B}}=0,26 \cdot \beta^{2} \cdot \eta_{\mathrm{u}}$ & $\beta_{\lim =1,97 \sqrt{\frac{\mathrm{fc} 0, \mathrm{cav}}{\mathrm{fe}}}}$ & $\begin{array}{c}\text { COM } \\
\text { IMPREGNAÇÃO }\end{array}$ \\
\hline IPÊE & $\xi_{\mathrm{u}}^{\mathrm{B}}=0,28 \cdot \beta^{2} \cdot \eta_{\mathrm{u}}$ & $\beta \lim =1,88 \sqrt{\frac{\mathrm{fc} 0, \mathrm{cav}}{\mathrm{fe}}}$ & $\begin{array}{c}\text { SEM } \\
\text { IMPREGNAÇÃO }\end{array}$ \\
\hline
\end{tabular}

Como no primeiro caso, são mostrados no ANEXO C os gráficos das funções $\xi_{u}=f(\beta)$. 
Iremos calcular agora os valores de $\mathrm{F}_{\mathrm{w}, \mathrm{u}}^{\mathrm{B}}, \mathrm{F}_{\mathrm{cav}, \mathrm{u}}^{\mathrm{B}}$ em função do parâmetro $\beta$, cujos valores são mostrados na Tabela 7.

TABELA 07- Valores de $\mathrm{F}_{\mathrm{w}, \mathrm{u}}^{\mathrm{B}}, \mathrm{F}_{\mathrm{cav}, \mathrm{u}}^{\mathrm{B}}$ em função do parâmetro $\beta$.

\begin{tabular}{|c|c|c|l|}
\hline ESPÉCIE & $\mathrm{F}_{\mathrm{w}, \mathrm{u}}^{\mathrm{B}}$ & $\mathrm{F}_{\mathrm{cav}, \mathrm{u}}^{\mathrm{B}}$ & $\begin{array}{c}\text { NATUREZA DA } \\
\text { MADEIRA }\end{array}$ \\
\hline PINUS & $\frac{0,59 \cdot \mathrm{t}^{2} \cdot f e}{\beta}$ & $\frac{9,25 \cdot \mathrm{t}^{2} \cdot \mathrm{fc} 0, \mathrm{cav}}{\boldsymbol{\beta}^{3}}$ & Sem impregnação \\
\hline PINUS & $\frac{0,28 \cdot \mathrm{t}^{2} \cdot \mathrm{fe}}{\boldsymbol{\beta}}$ & $\frac{1,78 \cdot \mathrm{t}^{2} \cdot \mathrm{fc} 0, \mathrm{cav}}{\boldsymbol{\beta}^{3}}$ & \multirow{2}{*}{ Com impregnação } \\
\hline IPÊE & $\frac{0,44 \cdot \mathrm{t}^{2} \cdot \mathrm{fe}}{\boldsymbol{\beta}}$ & $\frac{1,56 \cdot \mathrm{t}^{2} \cdot \mathrm{fc} 0, \mathrm{cav}}{\boldsymbol{\beta}^{3}}$ & Sem impregnação \\
\hline
\end{tabular}

Finalmente iremos resumir os resultados finais teóricos das cargas de primeiro e segundo limite, para as espécies de madeiras que foram caracterizadas neste trabalho através das tabelas 8,9 e 10, a fim de permitir uma melhor visualização dos resultados. No ANEXO C deste trabalho iremos também desenvolver tabelas referente a determinação dos valores das cargas limites para os modelos ligações cavilhadas impregnadas ou não, solicitadas por esforços de compressão paralela às fibras e compressão normal às fibras, para efeito comparativo das cargas limites e as cargas máximas, que serão obtidas nos respectivos ensaios experimentais. 
TABELA 08- Expressões para determinação das cargas limites

ESPÉCIE: Pinus sem impregnação

\begin{tabular}{|c|c|c|c|}
\hline \multicolumn{2}{|c|}{ PRIMEIRO LIMITE } & \multicolumn{2}{c|}{ SEGUNDO LIMITE } \\
\hline$\beta_{\lim }$ & $3,86 \sqrt{\frac{\mathrm{fc} 0, \mathrm{cav}}{\sigma_{\mathrm{e}, 0}}}$ & $5 \sqrt{\frac{\mathrm{fc} 0, \mathrm{cav}}{\mathrm{fe}}}$ & $3,96 \sqrt{\frac{\mathrm{fc} 0, \mathrm{cav}}{\mathrm{fe}}}$ \\
\hline$F_{\mathrm{w}}$ & $\frac{0,37 \cdot \mathrm{t}^{2} \cdot \sigma_{\mathrm{e}, 0}}{\boldsymbol{\beta}}$ & $\frac{0,37 \cdot \mathrm{t}^{2} \cdot \mathrm{fe}}{\boldsymbol{\beta}}$ & $\frac{0,59 \cdot \mathrm{t}^{2} \cdot \mathrm{fe}}{\boldsymbol{\beta}}$ \\
\hline$F_{\mathrm{cav}}$ & $\frac{5,5 \cdot \mathrm{t}^{2} \cdot \mathrm{fc} 0, \mathrm{cav}}{\boldsymbol{\beta}^{3}}$ & $\frac{9,25 \cdot \mathrm{t}^{2} \cdot \mathrm{fc} 0, \mathrm{cav}}{\beta^{3}}$ & $\frac{9,25 \cdot \mathrm{t}^{2} \cdot \mathrm{fc} 0, \mathrm{cav}}{\boldsymbol{\beta}^{3}}$ \\
\hline$\eta$ & $\sigma_{\mathrm{e}, 0 / \mathrm{f}_{\mathrm{co}, \mathrm{cav}}}$ & $\mathrm{fe}_{\mathrm{e}} / \mathrm{f}_{\mathrm{co}, \mathrm{cav}}$ & $\mathrm{f}_{\mathrm{e}} / \mathrm{f}_{\mathrm{co}, \mathrm{cav}}$ \\
\hline
\end{tabular}

TABELA 09- Expressões para determinação das cargas limites

ESPÉCIE: Pinus com impregnação; $p=1 \mathrm{MPa}$.

\begin{tabular}{|c|c|c|c|}
\hline \multicolumn{2}{|c|}{ PRIMEIRO LIMITE } & \multicolumn{2}{c|}{ SEGUNDO LIMITE } \\
\hline$\beta_{\lim }$ & $1,96 \sqrt{\frac{\mathrm{fc} 0, \mathrm{cav}}{\sigma_{\mathrm{e}, 0}}}$ & $2,5 \sqrt{\frac{\mathrm{fc} 0, \mathrm{cav}}{\mathrm{fe}}}$ & $1,97 \sqrt{\frac{\mathrm{fc} 0, \mathrm{cav}}{\mathrm{fe}}}$ \\
\hline $\mathrm{F}_{\mathrm{w}}$ & $\frac{0,28 . \mathrm{t}^{2} \cdot \sigma_{\mathrm{e}, 0}}{\boldsymbol{\beta}}$ & $\frac{0,28 . \mathrm{t}^{2} \cdot \mathrm{fe}}{\boldsymbol{\beta}}$ & $\frac{0,46 . \mathrm{t}^{2} \cdot \mathrm{fe}}{\boldsymbol{\beta}}$ \\
\hline $\mathrm{F}_{\mathrm{cav}}$ & $\frac{1,08 . \mathrm{t}^{2} \cdot \mathrm{fc} 0, \mathrm{cav}}{\boldsymbol{\beta}^{3}}$ & $\frac{1,78 \cdot \mathrm{t}^{2} \cdot \mathrm{fc} 0, \mathrm{cav}}{\boldsymbol{\beta}^{3}}$ & $\frac{1,78 \cdot \mathrm{t}^{2} \cdot \mathrm{fc} 0, \mathrm{cav}}{\boldsymbol{\beta}^{3}}$ \\
\hline$\eta$ & $\sigma_{\mathrm{e}, 0} / \mathrm{f}_{\mathrm{co}, \mathrm{cav}}$ & $\mathrm{f}_{\mathrm{e}} / \mathrm{f}_{\mathrm{co}, \mathrm{cav}}$ & $\mathrm{f}_{\mathrm{e}} / \mathrm{f}_{\mathrm{co}, \mathrm{cav}}$ \\
\hline
\end{tabular}


TABELA 10- Expressões para determinação das cargas limites

ESPÉCIE: Ipê

\begin{tabular}{|c|c|c|c|}
\hline \multicolumn{2}{|c|}{ PRIMEIRO LIMITE } & \multicolumn{2}{c|}{ SEGUNDO LIMITE } \\
\hline$\beta_{\lim }$ & $1,85 \sqrt{\frac{\mathrm{fc} 0, \mathrm{cav}}{\sigma_{\mathrm{e}, 0}}}$ & $2,40 \sqrt{\frac{\mathrm{fc} 0, \mathrm{cav}}{\mathrm{fe}}}$ & $1,88 \sqrt{\frac{\mathrm{fc} 0, \mathrm{cav}}{\mathrm{fe}}}$ \\
\hline$F_{\mathrm{w}}$ & $\frac{0,27 \cdot \mathrm{t}^{2} \cdot \sigma_{\mathrm{e}, 0}}{\boldsymbol{\beta}}$ & $\frac{0,27 \cdot \mathrm{t}^{2} \cdot \mathrm{fe}}{\boldsymbol{\beta}}$ & $\frac{0,44 \cdot \mathrm{t}^{2} \cdot \mathrm{fe}}{\beta}$ \\
\hline$F_{\mathrm{cav}}$ & $\frac{0,92 \cdot \mathrm{t}^{2} \cdot \mathrm{fc} 0, \mathrm{ca}}{\boldsymbol{\beta}^{3}}$ & $\frac{1,56 \cdot \mathrm{t}^{2} \cdot \mathrm{fc} 0, \mathrm{cav}}{\beta^{3}}$ & $\frac{1,56 \cdot \mathrm{t}^{2} \cdot \mathrm{fc} 0, \mathrm{cav}}{\beta^{3}}$ \\
\hline$\eta$ & $\sigma_{\mathrm{e}, 0 / f_{\mathrm{co}, \mathrm{cav}}}$ & $\mathrm{f}_{\mathrm{e}} / \mathrm{f}_{\mathrm{co}, \mathrm{cav}}$ & $\mathrm{fe} / \mathrm{f}_{\mathrm{co}, \mathrm{cav}}$ \\
\hline
\end{tabular}

\subsection{Resistência total de uma cavilha com base no PNBR 7190/96}

A resistência total de uma cavilha é dada pela soma das resistências correspondentes às suas diferentes seções de corte.

O valor de cálculo da resistência de uma cavilha, correspondente a uma dada seção de corte entre duas peças de madeira, é determinada em função da resistência à compressão paralela $\mathbf{f}_{\mathrm{co}, \mathrm{d}}$ da cavilha, considerada em sua flexão, e da resistência à compressão normal $f_{c 90, d}$ da cavilha, considerada na segurança relativa a seu esmagamento, do diâmetro $\mathbf{d}$ da cavilha e da espessura $t$, tomada como a menor das espessuras $t_{1}$ e $t_{2}$ de penetração nos elementos interligados, como mostrado na figura 17.

As cavilhas em corte simples podem ser empregadas apenas em ligações secundárias. 
No caso de cavilhas em corte duplo, aplicam-se os mesmos critérios para a determinação da resistência correspondente a cada uma das seções de corte, considerando-se t com o menor dos valores entre $t_{1}$ e $t_{2} / 2$ em uma das seções, e entre $t_{2}$ e $t_{3}$ na outra.

A resistência de cálculo da cavilha $\mathbf{R}_{\mathbf{v d}, \mathbf{1}}$, correspondente a uma única seção de corte, é determinada de modo análogo ao empregado para os pinos metálicos.
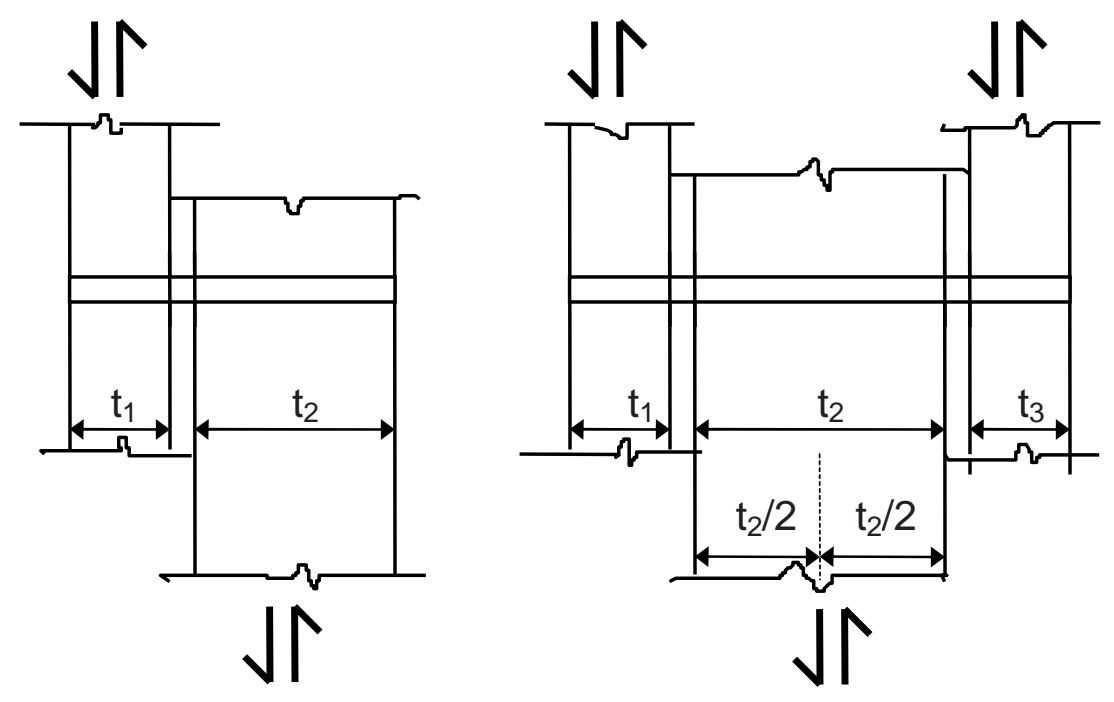

apenas em ligações secundárias

FIGURA 17- Ligações com cavilhas. 
Para as cavilhas, consideram-se:

$$
\begin{aligned}
& \beta=\frac{t}{d} \\
& \beta \lim =\sqrt{\frac{f c 0 d, c a v}{f c 90 d, c a v}}
\end{aligned}
$$

onde $\mathbf{f}_{\mathrm{cod}}$, cav é o valor de cálculo da resistência à compressão paralela, e

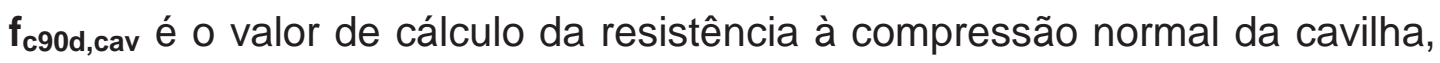
calculando-se a resistência pelas expressões seguintes:

I- Esmagamento da cavilha

$$
\begin{aligned}
& \beta \leq \beta_{\text {lim }} \\
& \mathrm{R}_{\mathrm{vd}, 1}=0,4 \frac{\mathrm{t}^{2}}{\beta} \mathrm{f}_{\mathrm{c} 90 \mathrm{~d}, \mathrm{cav}}
\end{aligned}
$$

II- Flexão de cavilha

$$
\begin{gathered}
\beta>\beta_{\text {lim }} \\
\operatorname{R}_{\mathrm{vd}, 1}=0,4 \frac{\mathrm{d}^{2}}{\beta_{\text {lim }}} \mathrm{fc}_{\mathrm{c} 0 \mathrm{~d}, \mathrm{cav}} \quad\left(\operatorname{com} \beta=\beta_{\text {lim }}\right)
\end{gathered}
$$




\subsection{Modos de Ruptura segundo tratamento normativo}

Alguns trabalhos publicados por autores, como WHALE et al.(1987), WHALE ( 1991 ), procuram dar um tratamento específico sobre as ligações em estruturas de madeira com intuito de direcioná-las para as prescrições normativas do COMMISION OF THE EUROPEAN COMMUNITIES (EUROCODE 5) de 1991, que no momento é uma norma técnica que tem procurado dar importância para as ligações do tipo pino, onde podemos adaptar as suas considerações para o caso das cavilhas. Os autores mostram que o parâmetro preponderante para determinar a capacidade de resistência lateral dessas ligações é feita com base na tensão última ou resistência de embutimento. As equações que os autores mostram estão relacionadas com a teoria do escoamento de JOHANSEN (1949) e com os modos de ruptura que, segundo este autor, dependem das propriedades e a geometria das barras que compõem a ligação em questão. Basicamente, as equações que serão mostradas a seguir são válidas para o caso de elementos de união do tipo pino, incluindo as cavilhas, pois, como foi definido anteriormente, a cavilha constitui um pino de madeira.

O cálculo da resistência $\mathbf{R}_{\mathbf{d}}$ expresso em $\mathbf{N}$ ( Newtons ), por plano de corte para ligações de madeira com madeira e painel com madeira sob carga lateral, pode ser tomado como o menor valor das expressões a seguir e, para cada uma das equações correspondentes, vem representado também o modo de ruptura, conforme se pode notar nas figuras 18 e 19. 


\section{CORTE SIMPLES}

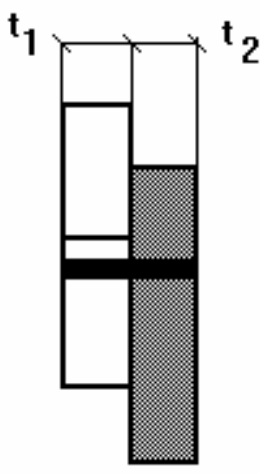

a

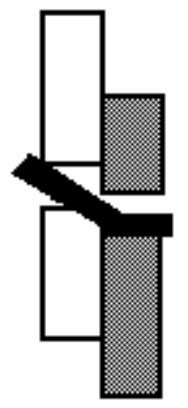

d

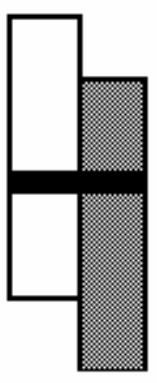

b

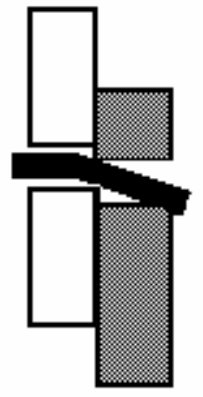

e

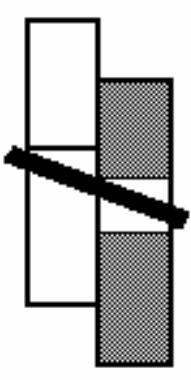

C

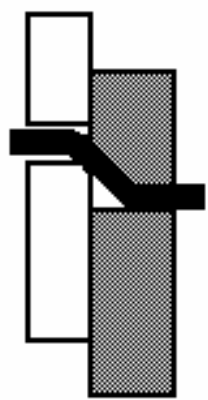

f

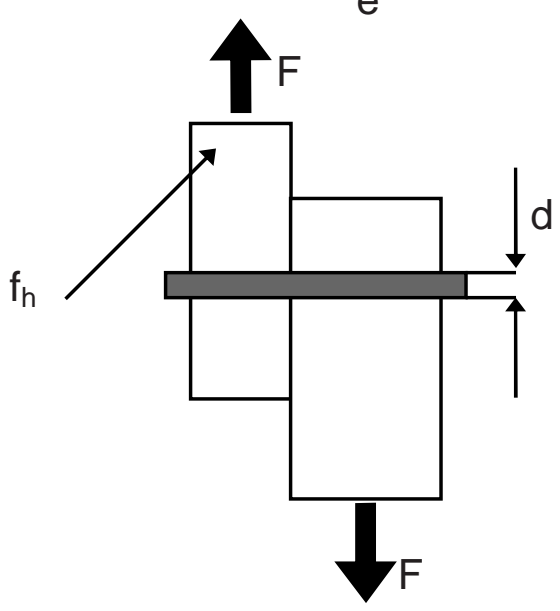

FIGURA 18- Modos de ruptura para ligações com cavilhas sob corte simples e dispositivo de ligação com duas barras,FONTE: [WHALE et al (1987)]. 


\section{I)EQUAÇÕES CORRESPONDENTES PARA CORTE SIMPLES}

$$
\operatorname{Rd}_{\mathrm{d}}=\min \left\{\begin{array}{l}
\text { a) } \mathrm{f}_{\mathrm{h}, 1, \mathrm{~d}} \times \mathrm{t}_{1} \times \mathrm{d} \\
\text { b) } \mathrm{f}_{\mathrm{h}, 1, \mathrm{~d}} \times \mathrm{t}_{2} \times \mathrm{d} \times \beta \\
\text { c) } \frac{\mathrm{f}_{\mathrm{h}, 1, \mathrm{~d}} \times \mathrm{t}_{1} \times \mathrm{d}}{1+\beta}\left[\sqrt{\beta+2 \beta^{2}\left(1+\frac{\mathrm{t}_{2}}{\mathrm{t}_{1}}+\left(\frac{\mathrm{t}_{2}}{\mathrm{t}_{1}}\right)^{2}\right)+\beta^{3}\left(\frac{\mathrm{t}_{2}}{\mathrm{t}_{1}}\right)^{2}}-\beta\left(1+\frac{\mathrm{t}_{2}}{\mathrm{t}_{1}}\right)\right] \\
\text { e) } \frac{\mathrm{f}_{\mathrm{h}, 1, \mathrm{~d}} \times \mathrm{t}_{2} \times \mathrm{d}}{1+2 \beta}\left[\sqrt{2 \beta(1+\beta)+\frac{4 \beta(2+\beta) \mathrm{M}_{\mathrm{y}, \mathrm{d}}}{\mathrm{f}_{\mathrm{h}, 1, \mathrm{~d}} \times \mathrm{d} \times \mathrm{t}_{1}{ }^{2}}}-\beta\right] \\
\text { f) } \left.\sqrt{\frac{2 \beta}{1+\beta}} \sqrt{2 \beta^{2}(1+\beta)+\frac{4 \beta(1+2 \beta) \mathrm{M}_{\mathrm{y}, \mathrm{d}}}{\mathrm{f}_{\mathrm{h}, 1, \mathrm{~d}} \times \mathrm{d} \times \mathrm{t}_{2}{ }^{2}}}-\beta\right]
\end{array}\right.
$$

Onde:

$t_{1}$ - Espessura das peças laterais em madeira,

$t_{2}$ - Espessura da peça central a ser unida por intermédio das cavilhas com as peças laterais,

$f_{h, 1}$ - Resistência de embutimento na espessura $t_{1}$, em N/mm ${ }^{2}$

$\mathrm{f}_{\mathrm{h}, 2^{-}}$Resistência de embutimento na espessura $t_{2}$, em N/mm ${ }^{2}$

$\beta$ - Relação entre $f_{h, 1} / f_{h, 2}, \quad \beta=f_{h 1} / f_{h 2}$

d- diâmetro do pino de fixação ou da cavilha,

$M_{y}$ - Momento de escoamento no elemento de fixação, $M_{y}=\left(f_{y} d^{3}\right) / 6$

$\mathrm{f}_{\mathrm{y}^{-}}$Tensão de escoamento no elemento de fixação ou da cavilha. 
CORTE DUPLO
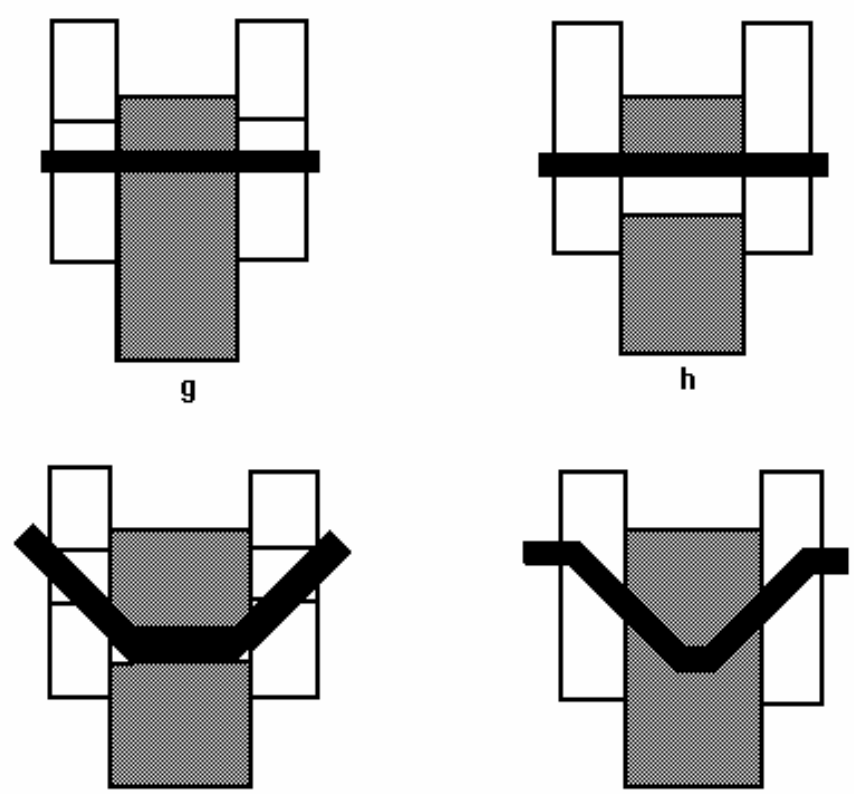

j

k

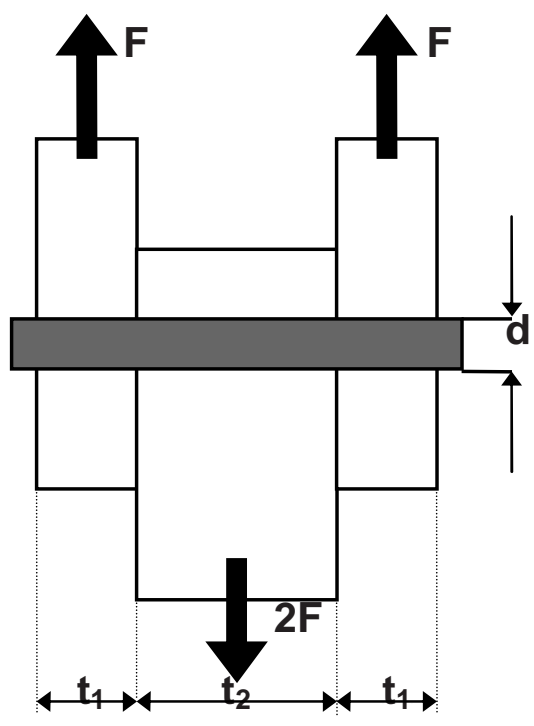

FIGURA 19- Modos de ruptura para ligações com cavilhas sob corte duplo e dispositivo de ligação com três barras, FONTE: [WHALE et al (1987)]. 


\section{II) EQUAÇÕES CORRESPONDENTES PARA CORTE DUPLO}

$$
\mathrm{R}_{\mathrm{d}}=\min \left\{\begin{array}{l}
\text { g) } \mathrm{f}_{\mathrm{h}, 1, \mathrm{~d}} \times \mathrm{t}_{1} \times \mathrm{d} \\
\text { h) } 0,5 \times \mathrm{f}_{\mathrm{h}, 1, \mathrm{~d}} \times \mathrm{t}_{2} \times \mathrm{d} \times \beta \\
\text { j) } \frac{\mathrm{f}_{\mathrm{h}, 1, \mathrm{~d}} \times \mathrm{t} \times \mathrm{d}}{2+\beta}\left[\sqrt{2 \beta(1+\beta)+\frac{4 \beta(2+\beta) \mathrm{M}_{\mathrm{y}, \mathrm{d}}}{\mathrm{f}_{\mathrm{h}, 1, \mathrm{~d}} \times \mathrm{d} \times \mathrm{t}_{1}{ }^{2}}}-\beta\right] \\
\text { k) } \sqrt{\frac{2 \beta}{1+\beta} \sqrt{2 \mathrm{M}_{\mathrm{y}, \mathrm{d}} \times \mathrm{f}_{\mathrm{h}, 1, \mathrm{~d}} \times \mathrm{d}}}
\end{array}\right.
$$

É importante notar que a teoria existente sobre o dimensionamento das ligações estruturais de madeira utilizando as cavilhas impregnadas, que se apresenta como proposta de elemento de fixação, deve-se aplicar teorias de dimensionamento das ligações com pinos e parafusos. Entretanto precisase caracterizar este novo material, fruto de uma pesquisa já existente no meio científico, o processo de polimerização da madeira através de resinas de estireno, e definir materiais empregados e os processos de impregnação, que serão abordados nas próximas páginas deste trabalho.

Com relação à questão construtiva, principalmente com a geometria dos espaçamentos mínimos entre cavilhas, diâmetros necessários para confecção das cavilhas, espessuras das madeiras a serem unidas, diâmetro dos furos das cavilhas, isto será fruto de análise posterior neste trabalho, que é a questão normativa de como o assunto é tratado, mas, com relação ao tratamento matemático para o cálculo das resistências necessárias, que as ligações com cavilhas devem oferecer às solicitações, os trabalhos de WHALE et al (1987) e WHALE (1991), que deram embasamento para as calibrações das expressões anteriores e que passaram a fazer parte do corpo da norma internacional EUROCODE N. 5, já significou um avanço profundo em direção ao assunto e será o ponto de partida desta análise. 


\section{RECOMENDAÇÕES NORMATIVAS PARA OS MÉTODOS DE ENSAIOS}

Nas normas nacionais e internacionais sobre ligações com cavilhas impregnadas e não impregnadas, não existe menção sobre 0 assunto. Trataremos aqui de alguns aspectos importantes concernentes a esse tipo de ligação buscando principalmente fatores relacionados aos seguintes assuntos:

a) diâmetro de cavilhas utilizadas e tamanho dos furos nas peças.

b) espaçamento mínimo de linha de furos e distâncias de extremidades.

c) espessuras das partes a serem unidas na montagem de ensaios de corpos de prova de compressão paralela às fibras e compressão normal às fibras.

d)dados sobre a relação carga-deformação, relação $F-u_{i}$ e $\sigma-\varepsilon$.

e)descrição do comportamento geral da ligação sob ação de carregamentos.

Vamos considerar para efeito de análise o esquema de uma peça com solicitação paralela às fibras e solicitação normal às fibras conforme a figura 20, e mostraremos portanto como é dado o tratamento normativo para cada caso acima especificado. 


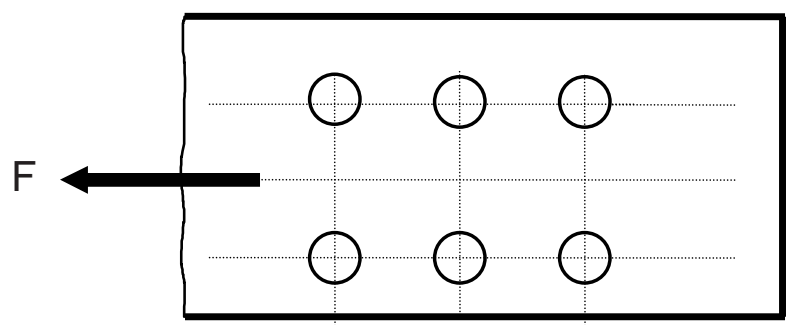

a) solicitação paralela às fibras

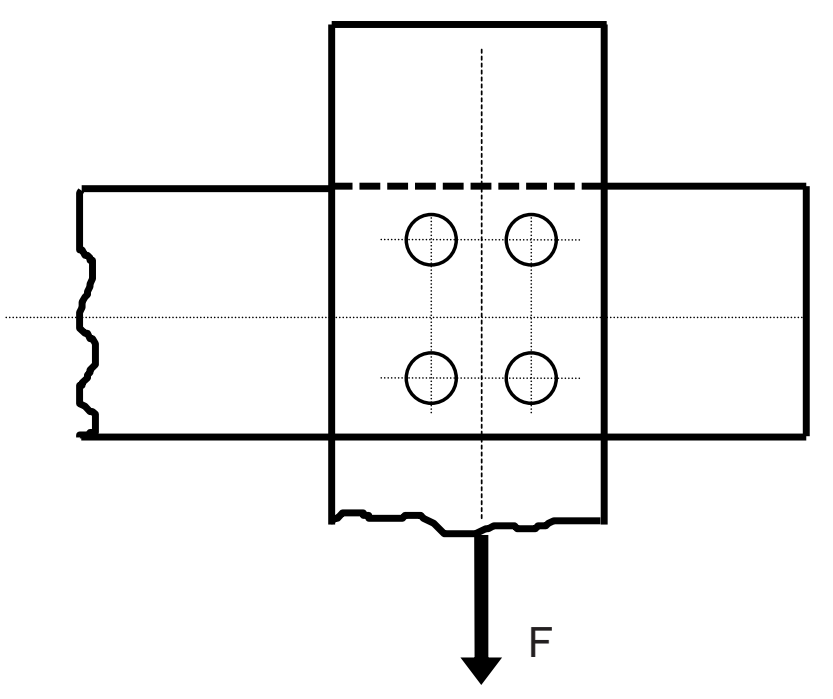

b) Solicitação normal às fibras.

FIGURA 20- Solicitação de compressão paralela e compressão normal às fibras. 
Discutiremos inicialmente sob o ponto de vista normativo cada um dos itens anteriores mencionados, lembrando que a maioria das normas nacionais e internacionais não fazem referências específicas sobre as ligações com cavilhas. O que discutiremos será uma tentativa de adaptar o que já existe tradicionalmente sobre parafusos e pinos de aço levando para o caso das cavilhas de madeiras.

\subsection{Diâmetro das cavilhas e tamanho dos furos a serem utilizados nas peças de ligação}

\subsubsection{ASSOCIAÇÃO BRASILEIRA DE NORMAS TÉCNICAS- NBR 7190/82}

Os diâmetros citados nessa norma correspondem aos seguintes:

$0.62 \mathrm{~cm} ; 0.95 \mathrm{~cm} ; 1,25 \mathrm{~cm} ; 1,9 \mathrm{~cm} ; 2,2 \mathrm{~cm} ; 2,5 \mathrm{~cm} ; 3,1 \mathrm{~cm} ; 3,8 \mathrm{~cm} ; 4,4 \mathrm{~cm}$; $5,0 \mathrm{~cm} ; 7,5 \mathrm{~cm}$.

No item 40c há apenas a recomendação de que os parafusos e pinos devem ser simetricamente dispostos em relação ao eixo da peça, e de tal maneira que seja reduzido ao mínimo o risco de afrouxarem simultaneamente em conseqüência de um possível fendilhamento da madeira.

\subsubsection{AMERICAN SOCIETY FOR TESTING AND MATERIALS ASTM D 1761-77}

Esta norma mostra no item 24.2.3 que os diâmetros dos furos para parafusos devem estarem compreendidos entre 1/32" e 1/16" $(0,8 \mathrm{~mm}$ e $1,6 \mathrm{~mm})$, maiores do que o diâmetro dos parafusos e os furos devem ser cuidadosamente pré-furados para a superfície, e esta é polida para assegurar bem o apoio do parafuso. 


\subsubsection{DEUTSCHES INSTITUT FÜR NORMUNG-DIN 68.150/1989 PARTE 1}

A DIN mostra uma tabela onde os diâmetros mais utilizados de cavilhas são: $5 \mathrm{~mm} ; 6 \mathrm{~mm}$; 8mm; $10 \mathrm{~mm}$; 12mm; 14mm; 16mm; 18 mm e 20 $\mathrm{mm}$. e a tolerância do furo é da ordem de $(\mathrm{d} \pm 0,2 \mathrm{~mm})$, para acabamentos calculados.

\subsubsection{BRITISH STANDARD INSTITUTION-BS 6948/1989}

Descreve os métodos de ensaios em ligações em estruturas de madeira utilizando diversos tipos de elementos de fixação, mas não há indicação sobre o item em questão.

\subsubsection{NATIONAL DESIGN ESPECIFICATION FOR WOOD CONSTRUCTION-NDS/1992}

Especifica que para parafusos os furos devem ser de no mínimo 1/32" $(0,8 \mathrm{~mm})$ e um máximo de 1/16"(1,6 mm) seguindo o mesmo padrão da ASTM D 1761 e o diâmetros utilizados na faixa de 1/2" (12,5mm) a $1 "(25 \mathrm{~mm})$.

\subsubsection{EUROCODE N. 5/1991}

O diâmetro mínimo para pinos é $8 \mathrm{~mm}$. A tolerância para os diâmetros de cavilhas são da ordem de $\pm 0.1 \mathrm{~mm}$ e os furos pré-executados nas barras de madeira devem ter um diâmetro não maior do que o diâmetro do pino.

5.1.7 CANADIAN STANDARDS ASSOCIATION- CAN/CSA-086.1-M89

Em relação aos parafusos especifica que os furos para parafusos na madeira devem ser exatamente alinhados não menos do que 1,0 mm e não mais do que 2,0 mm do que o diâmetro do parafuso. 


\subsection{Espaçamentos mínimos:}

\subsubsection{NBR 7190/82}

Na figura 21 temos que esta norma especifica as seguintes distâncias:

a) t $\geq 4 \mathrm{~d}$; t" $\geq 7 \mathrm{~d}$; t' $\geq 1,5 \mathrm{~d}$; (peças tracionadas)

b) $\mathrm{t} \geq 4 \mathrm{~d}$; t" $\geq 4 \mathrm{~d}$; t' $\geq 1,5 \mathrm{~d}$; (peças comprimidas)

5.2.2 DIN 1052/88- Parte 2

Especifica as distâncias mínimas de borda e as distâncias mínimas de extremidades para pinos de aço, conforme a figura 22.

Apresenta também uma tabela com os espaçamentos mínimos conforme podemos ver na tabela 11.

TABELA 11-Distâncias de extremidade e espaçamentos mínimos para pinos e parafusos.

\begin{tabular}{|c|c|c|c|}
\hline & & $\begin{array}{c}\text { Espaçamento } \\
\text { Mínimo } \\
\text { para Pinos }\end{array}$ & $\begin{array}{l}\text { 1)Paralela à linha de } \\
\text { força } \\
\text { Parafusos }\end{array}$ \\
\hline Espaçamento & $\begin{array}{c}\text { Paralela às fibras } \\
\text { Perpendicular às } \\
\text { fibras }\end{array}$ & $3 d$ & $7 \mathrm{~d} \geq 100 \mathrm{~mm}$ \\
\hline $\begin{array}{c}\text { Distância da } \\
\text { extremidade } \\
\text { carregada }\end{array}$ & $\begin{array}{c}\text { Paralela às fibras } \\
\text { ferpendicular às }\end{array}$ & $3 \mathrm{~d}$ & $5 \mathrm{~d}$ \\
\hline $\begin{array}{c}\text { Distância da } \\
\text { extremidade } \\
\text { não carregada }\end{array}$ & $\begin{array}{c}\text { Paralela às fibras } \\
\text { Perpendicular às } \\
\text { fibras }\end{array}$ & $3 \mathrm{~d}$ & $7 \mathrm{~d} \geq 100 \mathrm{~mm}$ \\
& & & $3 \mathrm{~d}$ \\
\hline Para mad & & $3 \mathrm{~d}$ \\
\hline
\end{tabular}

1) Para madeiras inclinadas de extremidade, os valores intermediários serão obtidos por interpolação linear. 

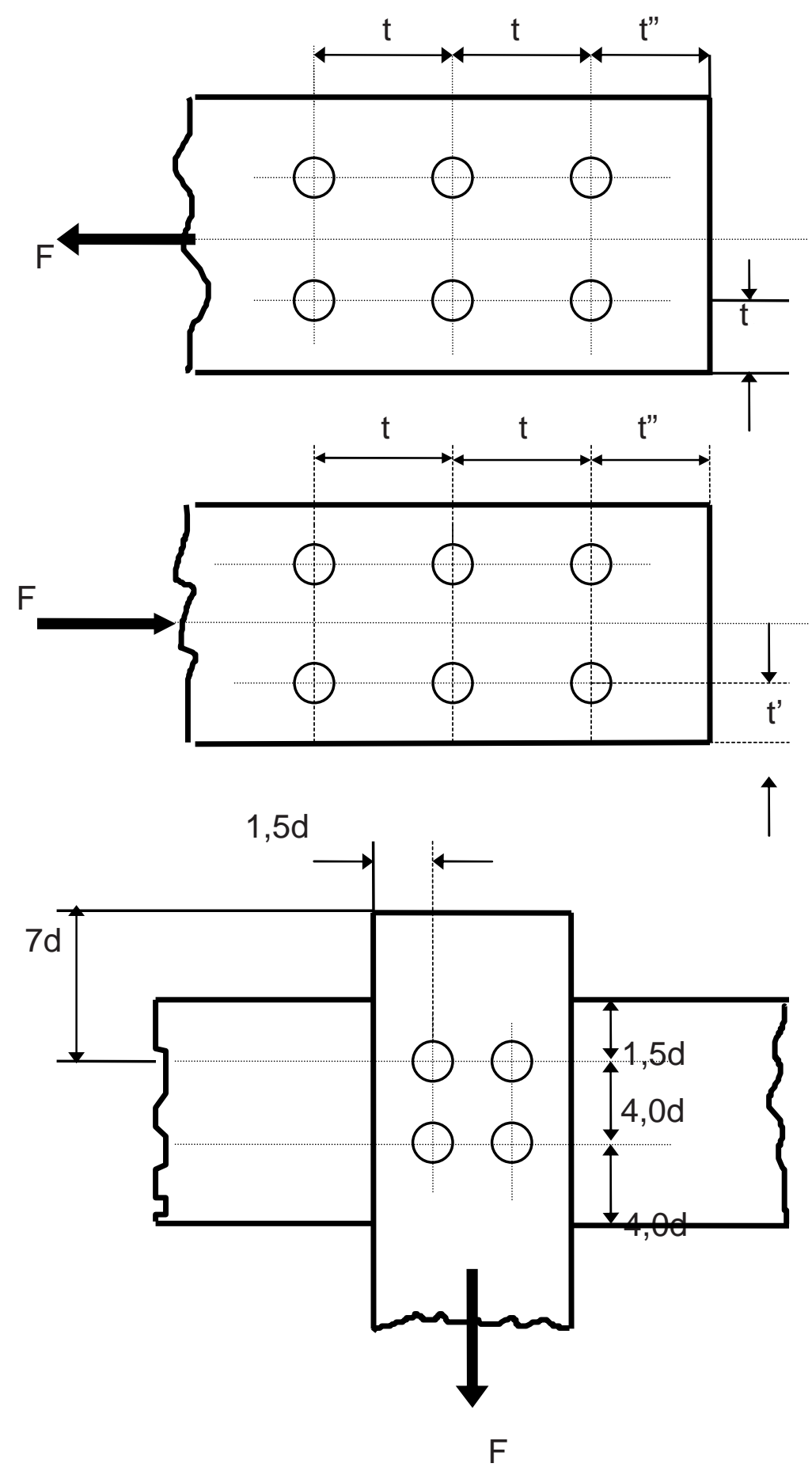

FIGURA 21- Espaçamentos mínimos segundo a norma brasileira NBR 7190/82 para ligações com parafusos. 


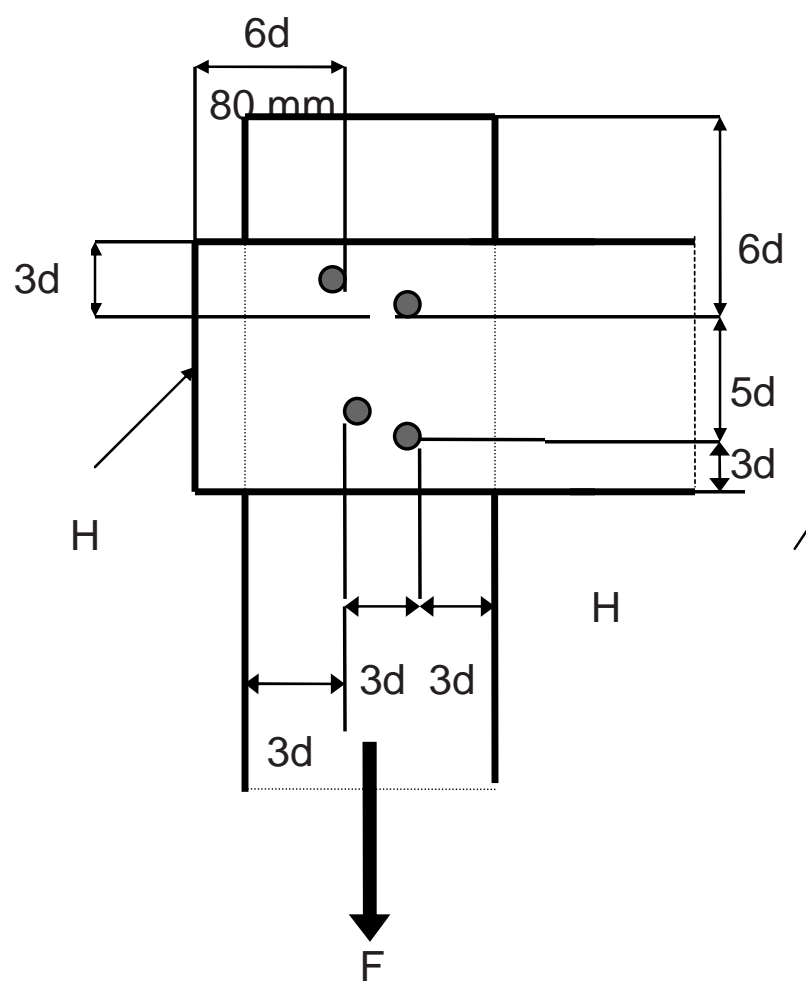

$6 d$

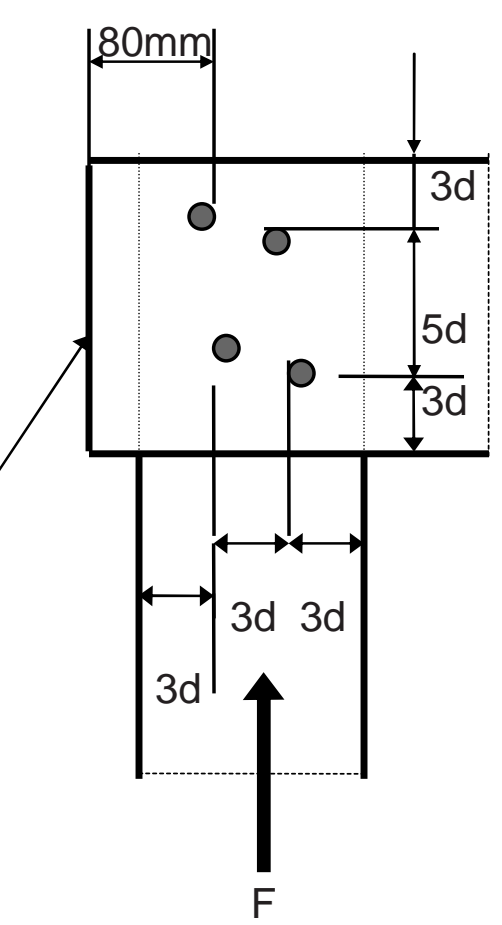

$\mathrm{H}$ : extremidade das fibras

FIGURA 22- Distâncias de extremidades e espaçamentos mínimos para parafusos e pinos segundo a DIN 1052/88-Parte 2. 


\subsubsection{NDS-1992}

Essa norma define claramente o que é distância de extremidade e distância de borda na geometria da ligação carregada paralelamente a direção das fibras e perpendicularmente à direção das fibras conforme se pode observar simultaneamente nas figuras 23 e 24 , relativo aos parafusos.

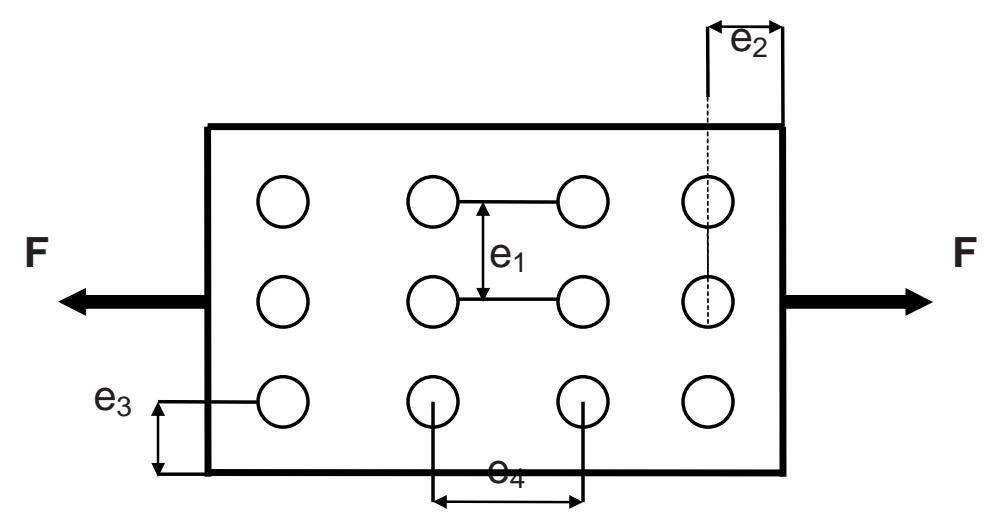

Carregamento paralelo às fibras

$\mathrm{e}_{1}$-Espaçamento entre linhas de parafusos

$\mathrm{e}_{2}$ - Distância de extremidade

$\mathrm{e}_{3}$ - Distância de borda

e e $^{-}$Distância entre parafusos em linha

FIGURA 23- Geometria de uma ligação por meio de parafusos com carregamento paralelo às fibras segundo NDS/1992. 
$\mathrm{F} / 2$
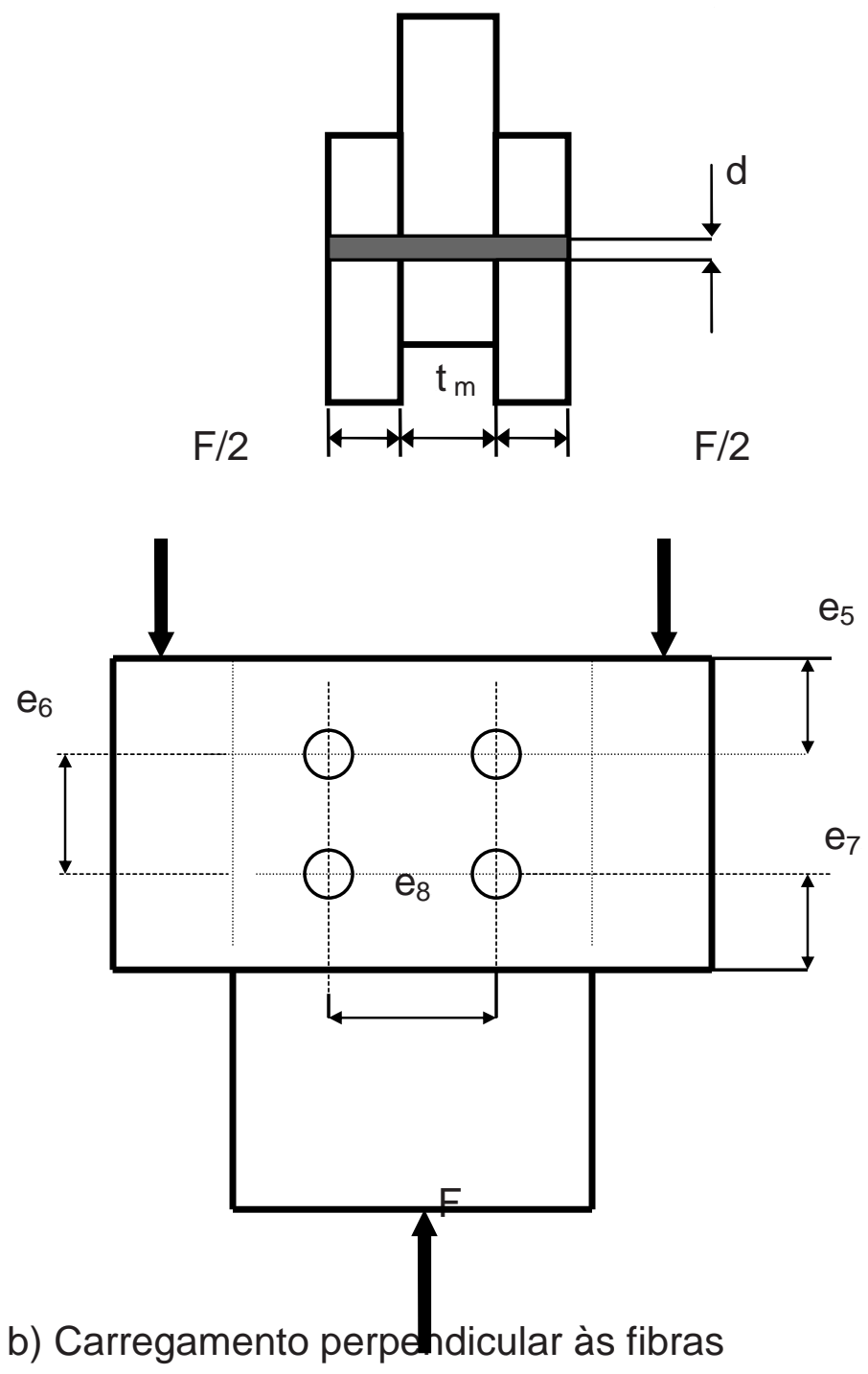

$e_{5}$ - Distância da borda carregada

$\mathrm{e}_{6}$ - Espaçamento entre parafusos em linha

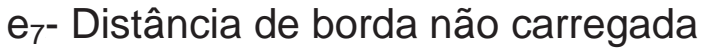

$e_{8}$-Espaçamento entre linhas de parafusos

FIGURA 24-Geometria de uma ligação por meio de parafusos com carregamento perpendicular às fibras segundo NDS/1992. 
Nas tabelas seguintes poderemos observar os requisitos necessários para os espaçamentos mínimos.

TABELA 12- Recomendações das distâncias de bordas para parafusos.

\begin{tabular}{|c|c|c|}
\hline Direção do carregamento & Espaçamento & Distância mínima de borda \\
\hline $\begin{array}{c}\text { Paralela às fibras } \\
\text { Quando //D } \leq 6 \\
\text { Quando //D>6 }\end{array}$ & $\begin{array}{l}e_{3} \\
e_{3}\end{array}$ & $\begin{array}{c}1,5 \mathrm{D} \\
1,5 \mathrm{D} \text { ou } 1 / 2 \text { espaçamento entre } \\
\text { linhas, } \\
\text { adotar o maior dos dois } \\
\text { valores }\end{array}$ \\
\hline $\begin{array}{c}\text { Perpendicular às fibras } \\
\text { borda carregada } \\
\text { borda não carregada }\end{array}$ & $\begin{array}{l}e_{5} \\
e_{7}\end{array}$ & $\begin{array}{c}4 \mathrm{D} \\
1,5 \mathrm{D}\end{array}$ \\
\hline
\end{tabular}

Nota: A relação //D é usada para determinar a distância mínima de extremidade que deve ser o menor dos valores de:

(a) comprimento do parafuso na barra principal da madeira/D $=I_{m} / D$

(b) comprimento total do parafuso nas extremidades das barras de madeira $=I_{\mathrm{s}} / \mathrm{D}$

Observando a figura 24 temos: $t_{m}=I_{m} ; t_{s}+t_{s}=I_{s}$ 
TABELA 13- Recomendações de distância de extremidade para parafusos.

\begin{tabular}{|l|c|c|}
\hline \multicolumn{1}{|c|}{ Direção do carregamento } & Espaçamento & $\begin{array}{l}\text { Distância } \\
\text { mínima de } \\
\text { extremidade }\end{array}$ \\
\hline \multicolumn{1}{|c|}{ Perpendicular às fibras } & $\mathrm{e}_{2}$ & 4D \\
\hline $\begin{array}{l}\text { Compressão:(parafuso apoiado ao às Fibras } \\
\text { longo da extremidade da barra) }\end{array}$ & $\mathrm{e}_{2}$ & 4D \\
\hline $\begin{array}{l}\text { Paralela às fibras, Tração: } \\
\text { (parafuso apoiado em } \\
\text { direção da extremidade da barra) } \\
\text { Para madeiras moles } \\
\text { Para madeiras duras }\end{array}$ & & 7D \\
& $\mathrm{e}_{2}$ & $5 \mathrm{D}$ \\
\hline
\end{tabular}


TABELA 14- Espaçamentos requeridos para parafusos em uma linha.

\begin{tabular}{|c|c|c|}
\hline $\begin{array}{c}\text { Direção do } \\
\text { carregamento }\end{array}$ & $\begin{array}{c}\text { Espaçamento } \\
\text { e }\end{array}$ & $\begin{array}{c}\text { Espaçamento } \\
\text { mínimo }\end{array}$ \\
\hline $\begin{array}{c}\text { Paralela às } \\
\text { fibras }\end{array}$ & $\mathrm{e}_{4}$ & $4 \mathrm{D}$ \\
\hline $\begin{array}{c}\text { Perpendicular } \\
\text { às fibras }\end{array}$ & $\mathrm{e}_{6}$ & $\begin{array}{c}\text { espaçamento } \\
\text { requerido para } \\
\text { barras ligadas. }\end{array}$ \\
\hline
\end{tabular}

TABELA 15- Espaçamentos requeridos entre linhas de furos.

\begin{tabular}{|c|c|c|}
\hline $\begin{array}{c}\text { Direção do } \\
\text { carregamento }\end{array}$ & Espaçamento & Espaçamento mínimo \\
\hline $\begin{array}{c}\text { Paralela às } \\
\text { fibras }\end{array}$ & $\mathrm{e}_{1}$ & $1,5 \mathrm{D}$ \\
\hline $\begin{array}{c}\text { Perpendicular } \\
\text { ás Fibras: }\end{array}$ & & \\
Quando //D $\leq 2$ & $\mathrm{e}_{8}$ & $2,5 \mathrm{D}$ \\
Quando & $\mathrm{e}_{8}$ & $(5 /+10 \mathrm{D}) / 8$ \\
$2</ / \mathrm{D}<6$ & $\mathrm{e}_{8}$ & $5 \mathrm{D}$ \\
Quando //D $\geq 6$ & & \\
& & \\
\hline
\end{tabular}

A relação //D usada para determinar o espaçamento mínimo entre linhas de parafusos deve ser o menor dos dois valores:

(a)comprimento do parafuso na peça principal :/D $=I_{\mathrm{m}} / \mathrm{D}$

(b)comprimento total do parafuso na madeira do lado das barras: $/ D=I_{S} / D$ 


\subsubsection{BS 6948/89}

A Norma distingue claramente o que é parafuso ou pino e mostra também em uma tabela os padrões para distâncias de bordas e de extremidade para o que chama de elementos de fixação de categoria $\mathrm{B}$ (vejamos a figuras 25 e 26).
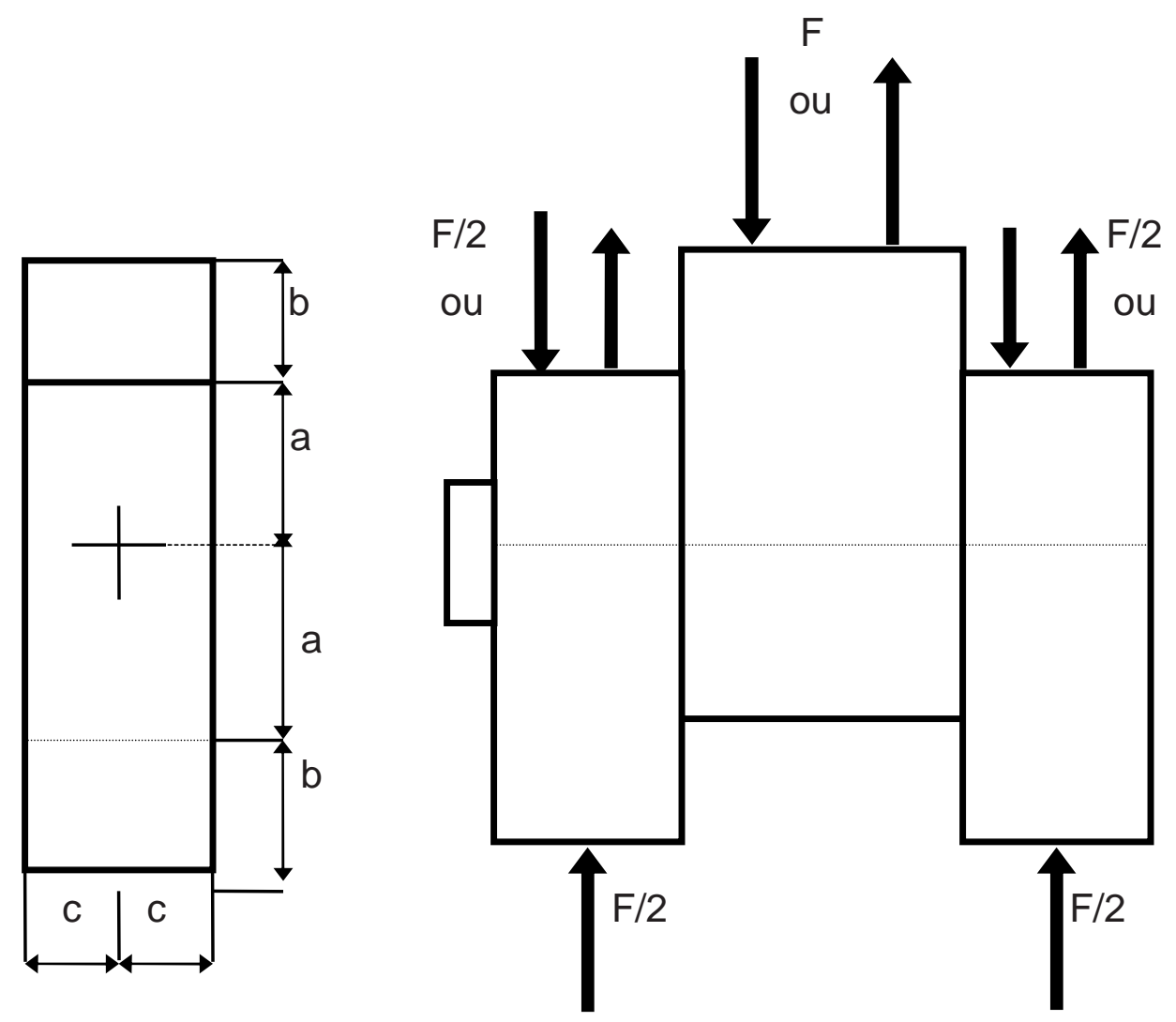

a) Ensaios paralelos as fibras (corpos de prova de tração ou compressão).

FIGURA 25- Corpo de prova para ensaios paralelos as fibras sob carga lateral da categoria B dos elementos de ligação segundo BS 6948/89. 


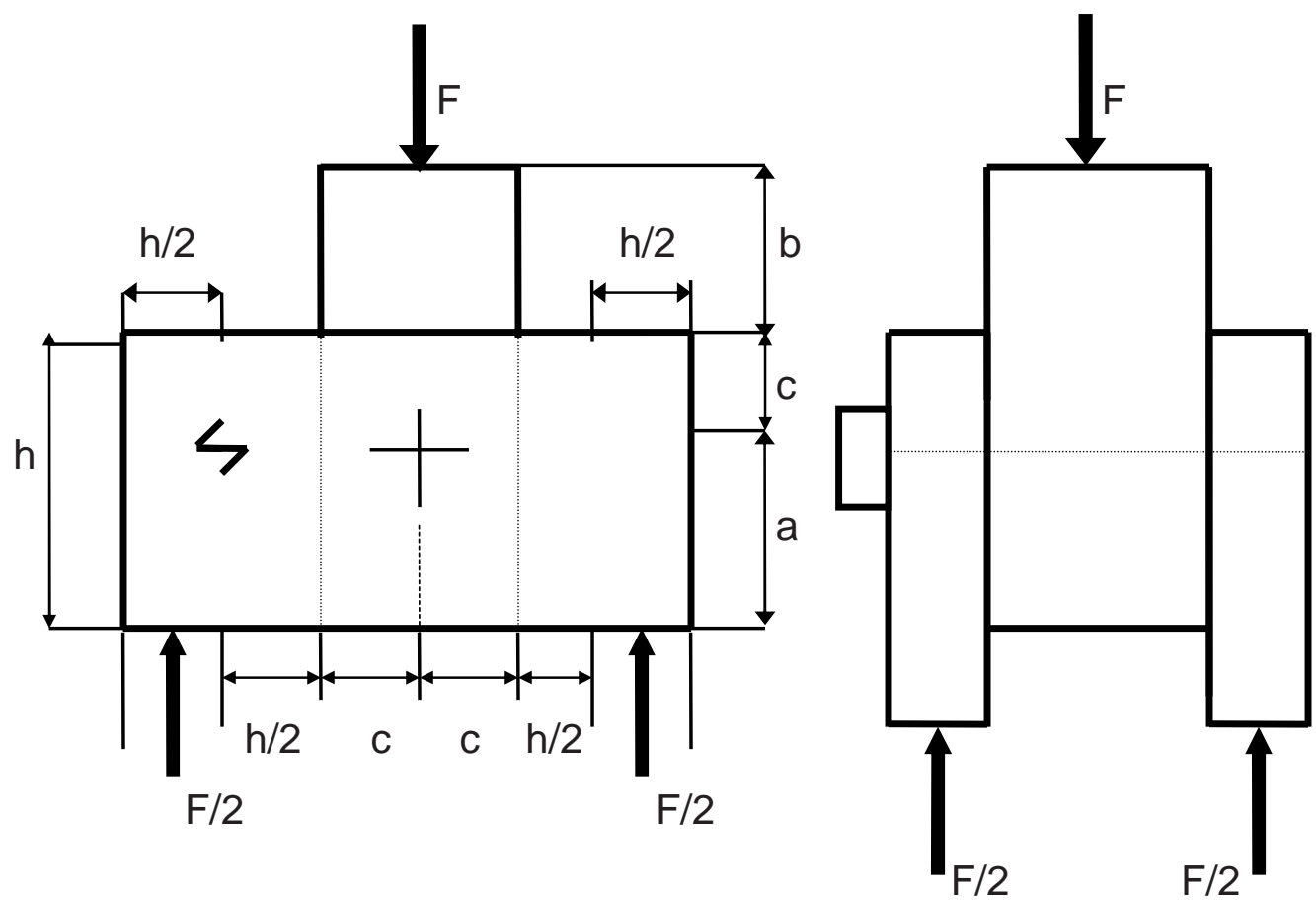

b)Ensaios perpendiculares as fibras

( ensaios de corpos de prova de compressão somente).

NOTA 1.

Direção das fibras da madeira.

NOTA 2. $a=$ Para elementos de fixação instalados sem pré-furação: $20 \mathrm{~d}$, mas não menos do que $25 \mathrm{~mm}$.

$\mathbf{a}=$ Para elementos de fixação instalados em furos pré-executados: 10d, mas não menos do que $25 \mathrm{~mm}$.

$\mathbf{b}=10 \mathrm{~d}$, mas não menos do que $25 \mathrm{~mm}$.

$\mathbf{c}=5 \mathrm{~d}$, mas não menos do que $12 \mathrm{~mm}$.

$\mathbf{F}=$ carga .

$\mathbf{h}=$ altura da peça de madeira.

$\mathbf{h} / \mathbf{2}=$ metade da largura da peça de madeira

(mas não menos do que $50 \mathrm{~mm}$ ).

FIGURA 26- Ensaios de Corpos de prova sob carga perpendiculares às fibras segundo BS 6948/89. 
Temos portanto as seguintes tolerâncias para os espaçamentos mínimos:

a)Carregamento Paralelo às fibras:

$\mathrm{a}=4 \mathrm{~d}$ (compressão) ; $\mathrm{a}=7 \mathrm{~d}$ (tração); $\mathrm{b}=50 \mathrm{~mm}$ (compressão)

$\mathrm{C}=1,5 \mathrm{~d}$.

b)Carregamento Normal às fibras:

$a=4 d$ (compressão); $b=50 \mathrm{~mm} ; \mathrm{c}=1,5 \mathrm{~d}$

\subsubsection{CAN/CSA -086.1-M89}

Para esta norma podemos observar a figura 27 que mostra 0 espaçamento para parafusos nos elementos de ligação para carregamento paralelo às fibras e carregamento normal às fibras.

a) Espaçamento de parafusos em uma linha $\left(\mathbf{e}_{2}, \mathbf{e}_{3}\right.$ e $\left.\mathbf{e}_{7}\right)$

Para carregamento paralelo às fibras: $4 d$

Para carregamento normal às fibras: $\geq 3 d$

\section{b) Espaçamento entre linhas $\left(\mathbf{e}_{6}\right)$}

Para carregamento paralelo às fibras o espaçamento entre linhas não deve ser menor que $2 \mathrm{~d}$.

Para carregamento perpendicular às fibras, o espaçamento deve ser pelo menos 2,5d para b/d =2, e 5d para b/d $\geq 6$. Para relações de b/d entre 2 e 6 o espaçamento deverá ser obtido por interpolação linear.

\section{c) Distância de topo ou de extremidade $\left(\mathbf{e}_{4}\right)$}

Essa distância deve ser pelo menos:

$7 d$, para uma barra em tração

4d, ou $50 \mathrm{~mm}$, seja qual for o maior, para uma barra de alguma espécie na compressão para uma barra perpendicular às fibras. 
d) Distância de Extremidade $\left(e_{1}\right)$

Para barras perpendiculares as fibras, a distância de extremidade carregada deve ser pelo menos $4 d$ e a extremidade não carregada deve ser pelo menos 1,5d. Para barras carregadas paralelamente às fibras, a distância deve ser pelo menos 1,5 d, ou a metade da distância entre linha de parafusos, qualquer um dos dois o maior.

Carga paralela às fibras

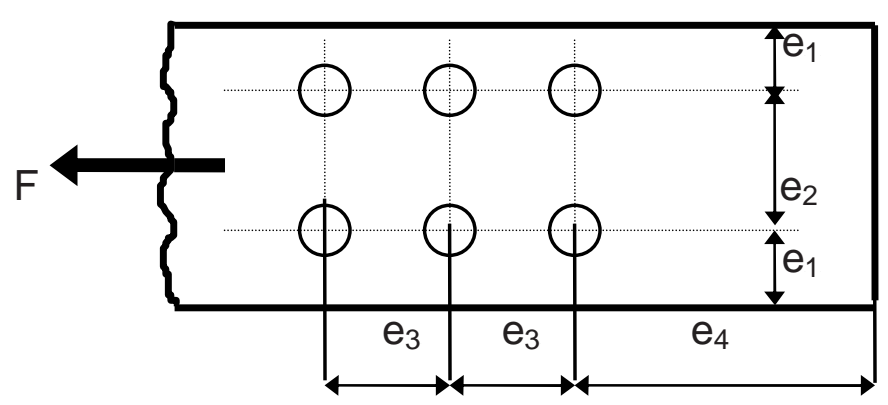

Carga perpendicular às fibras

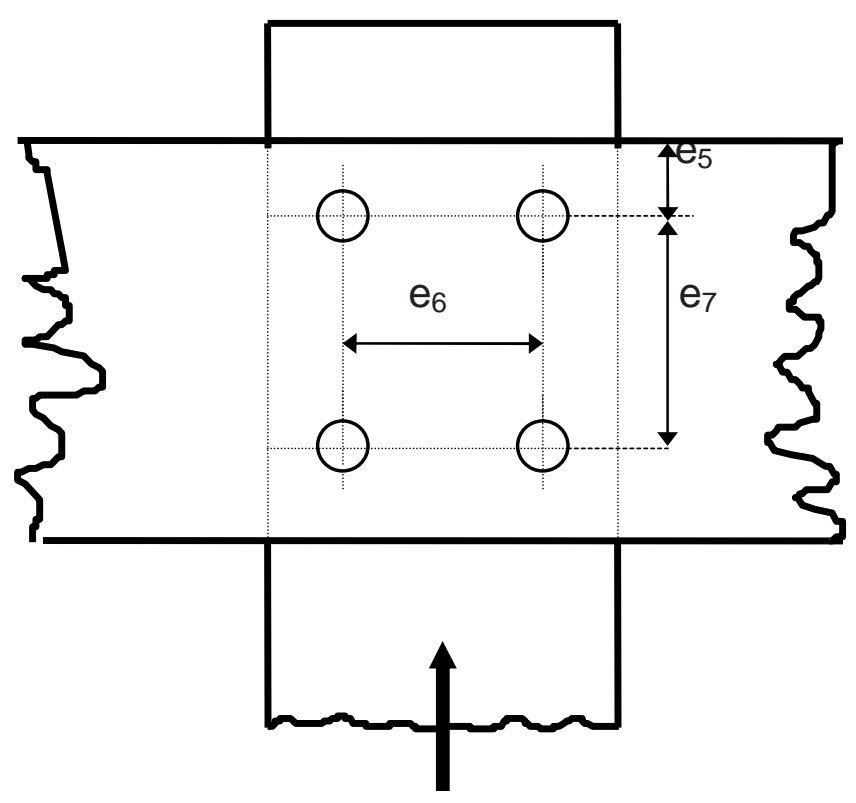

F

FIGURA 27-Espaçamentos dos parafusos nas ligações segundo CAN/CSA-086.1-M89. 


\subsubsection{EUROCODE 5 -1991}

Na figura 28 podemos ver como é tratado por essa norma o caso específico de pinos com os espaçamentos mínimos.

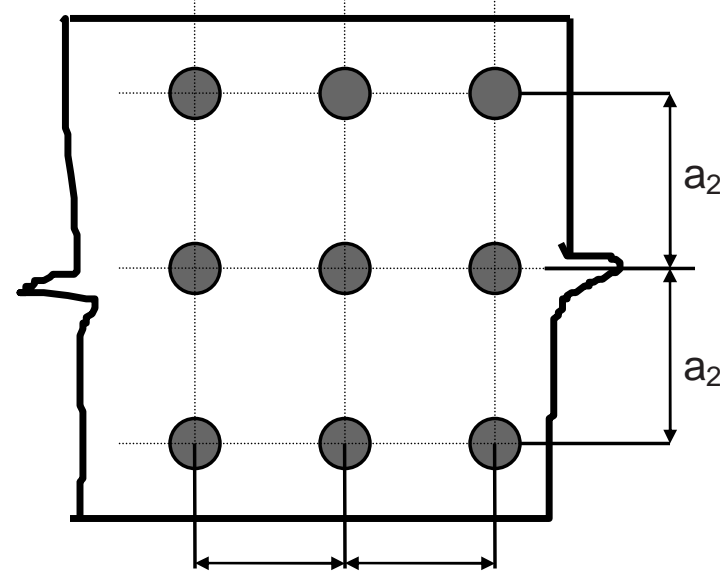

$\mathrm{a}_{1} \mathrm{a}_{1}$

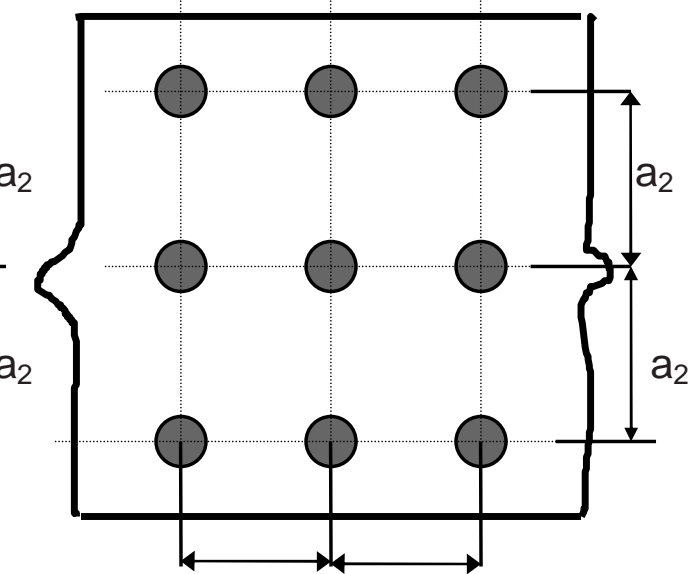

$a_{1} a_{1}$

Espaçamento

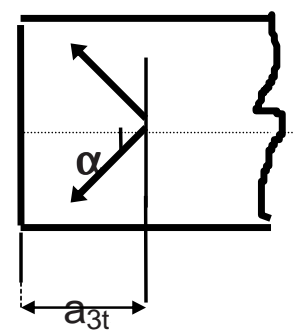

$90^{\circ} \leq \alpha \leq 90^{\circ}$

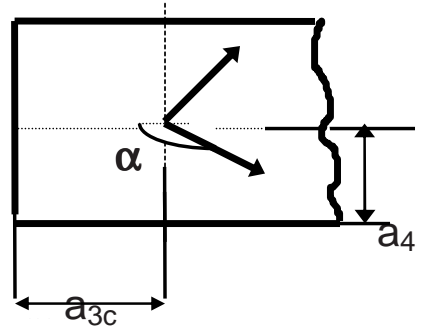

$90^{\circ} \leq \alpha \leq 270^{\circ}$

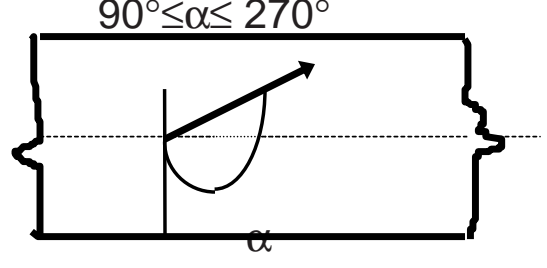

$180^{\circ} \leq \alpha \leq 360^{\circ}$

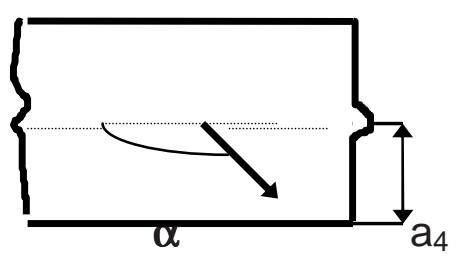

$0^{\circ} \leq \alpha \leq 180^{\circ}$

Extremidade carregada/Extremidade não carregada/Distâncias de borda Onde $\alpha$ é o ângulo entre a força e a direção das fibras.

Figura 28-Definição dos espaçamentos e distâncias dos elementos de ligação segundo o EUROCODE 5-1991. 
TABELA 16- Espaçamentos mínimos e distâncias para pinos

\begin{tabular}{|c|c|c|}
\hline$a_{1}$ & $\begin{array}{c}\text { Espaçamento } \\
\text { paralelo às fibras }\end{array}$ & $3 d+$ A. $\mid \cos \alpha$ \\
\hline$a_{2}$ & $\begin{array}{c}\text { Espaçamento } \\
\text { perpendicular às } \\
\text { fibras }\end{array}$ & $3 d$ \\
\hline$a_{3, t}$ & $\begin{array}{l}\qquad-90^{\circ} \leq \alpha \leq 90 \\
\text { (extremidade carregada } \\
\text { extremidades das fibras) }\end{array}$ & $\mathrm{B} \geq 80 \mathrm{~mm}$ \\
\hline$a_{3, c}$ & $\begin{array}{l}\qquad 150^{\circ} \leq \alpha \leq 210^{\circ} \\
\text { todos outros ângulos }\end{array}$ & $\begin{array}{c}3 d \\
\text { B. }|\operatorname{sen} \alpha| \geq 3 d\end{array}$ \\
\hline$a_{4}$ & $\begin{array}{c}30^{\circ} \leq \alpha \leq 150^{\circ} \\
\text { (extremidade } \\
\text { carregada) } \\
\text { todos outros ângulos }\end{array}$ & $(2+2 \cdot \operatorname{sen} \alpha) d$ \\
\hline
\end{tabular}

Existe um aspecto importante que é o cálculo da resistência de embutimento cujo valor a ser usado é dado pela expressão:

$$
\mathrm{f}_{\mathrm{h}, \mathrm{k}}^{\alpha}=\mathrm{ka} \frac{0.082(1-0,01 \mathrm{~d}) \rho_{\mathrm{k}}}{2,3 \operatorname{sen}^{2} \alpha+\cos ^{2} \alpha}, \quad \mathrm{N} / \mathrm{mm}^{2}
$$

sendo $\rho_{\mathrm{k}}$ a densidade característica da madeira em $\mathrm{Kg} / \mathrm{m}^{3}$ e d em $\mathrm{mm}$.

O fator $\mathrm{k}_{\mathrm{a}}$ depende dos valores de $\mathrm{a}_{1}, \mathrm{a}_{3, \mathrm{t}}, \mathrm{a}_{3, \mathrm{c}}$ vistos na tabela 16. Os valores de $\mathrm{k}_{\mathrm{a}}$ podem ser extraídos da tabela 17. 
TABELA 17- Valores do fator $k_{a}$

\begin{tabular}{|c|c|c|c|c|}
\hline $\begin{array}{c}a_{1} \\
\alpha=0^{\circ}\end{array}$ & $5 d$ & $6 d$ & $7 d$ \\
\hline $5 d$ & $2 d$ & 0,70 & 0,85 & 0,88 \\
\hline $6 d$ & $3 d$ & 0,72 & 0,87 & 0.92 \\
\hline 7d & 4d & 0,75 & 0,90 & 1,00 \\
\hline
\end{tabular}

$\mathrm{a} 1=3 \mathrm{~d}+\mathrm{A} \cdot|\cos \alpha| \quad \mathrm{a} 3, \mathrm{t}=\mathrm{B} ; \mathrm{a} 3, \mathrm{c}=\mathrm{B} \cdot \mid \operatorname{sen} \alpha$

5.3 Espessura das peças a serem montadas nos ensaios de compressão paralela às fibras e compressão normal às fibras.

Algumas normas tratam especificamente o assunto, outras não, mas de uma maneira geral o que temos observado é que a largura da peça central é normalmente o dobro das peças laterais.

\subsection{Procedimentos para realização de ensaios:}

\subsubsection{ASTM D 1761/77}

\section{a)Tipos de ensaios}

Deve-se realizar ensaios de compressão paralela às fibras e compressão normal às fibras baseados em modelos semelhantes aos das figuras 25 e 26.No ensaio de compressão paralela às fibras medem-se as deformações para aumentos sucessivos de carga usando relógios comparadores com exatidão de 0,025 mm. 


\section{b)Medida da deformação}

Faz-se as leituras com suficiente intervalos de carga para estabelecer com exatidão a curva tensão-deformação.

\section{c) Velocidade do carregamento}

A velocidade de carregamento recomendada é de $0,9 \mathrm{~mm} / \mathrm{min} ., \pm 50 \%$.

Essa norma recomenda que se faça os chamados ensaios menores como a determinação da densidade específica e o conteúdo de umidade de cada peça de madeira da ligação que vai ser testada. Em outros casos determina-se também a resistência à compressão paralela as fibras das peças de madeira.

\subsubsection{BS 6948/89 e ISO 6891}

Essas normas sobre o assunto em questão são tecnicamente equivalentes e mostram que o objetivo primordial são os princípios gerais para determinação da resistência e deformação (deslizamento) característicos de uniões executadas com elementos de ligação mecânicos usados em estruturas de madeira carregados estaticamente.

\section{a) Máquina de ensaio}

A máquina de ensaio deve ser capaz de aplicar e registrar carga com precisão de $\pm 1 \%$ de $F_{\text {est }}$ (Carga máxima estimada em Newtons).

\section{b)Deslizamento da União}

Devem ser aparelhos com $1 \%$ de precisão ou para deslizamentos com menos de $2 \mathrm{~mm}$ ou $\pm 0,02 \mathrm{~mm}$. 


\section{c)Máxima carga}

Deve ser feita a estimativa da máxima carga $F_{\text {est }}$ com base em experiência.

\section{d)Aplicação da carga}

O procedimento de carregamento é mostrado na figura 29 obedecendo a seguinte seqüência:

d.1) A carga deverá ser aplicada até $0,4 \mathrm{~F}_{\text {est }}$ e mantida durante $30 \mathrm{~s}$.

d.2) Reduzir a carga para $0,1 \mathrm{~F}_{\text {est }}$ e mantida por 30 s.

d.3) Aumentar até a carga última ou quando for atingido o deslizamento de $15 \mathrm{~mm}$.

d.4) Interromper o ensaio quando for atingido a carga última ou quando o deslizamento for de $15 \mathrm{~mm}$.

\section{e)Registro das medições}

Podem ser observadas nas figuras 29 e 30.

Se forem considerados relevantes para cada ensaio deverão ser registrados os seguintes valores:
e.1) Carga máxima:
$\mathrm{F}_{\max }$

e.2) Carga máxima estimada:

$F_{\text {est }}$

e.3) Deslizamento inicial:

$$
v_{i}=v_{04}
$$

e.4) Deslizamento inicial modificado:

$$
v_{i, \bmod }=\frac{4}{3}\left(v_{04}-v_{01}\right)
$$

e.5) Acomodação da união:

$$
v_{s}=v_{i}-v_{i, \bmod }
$$

e.6) Deslizamento elástico: $\quad v_{0}=\frac{2}{3}\left(v_{14}-v_{24}-v_{11}-v_{21}\right)$

e.7) Módulo inicial de deslizamento : $\quad \mathrm{k}_{\mathrm{i}}=0,4 \mathrm{~F}_{\mathrm{est}} / \mathrm{v}_{\mathrm{i}}$

e.8) Módulo de deslizamento: $\quad \mathrm{k}_{\mathrm{s}}=0,4 \mathrm{~F}_{\mathrm{est}} / \mathrm{v}_{\mathrm{i}, \mathrm{mod}}$
e.9) Deslizamento para 0,6 $F_{\max }$
$v_{0,6, \bmod }=v_{0.6}-v_{24}+v_{i, \bmod }$ 
e.10) Deslizamento modificado para 0,6 $F_{\max }: \quad v_{i, \bmod }$

e.11) Deslizamento para 0,8 $F_{\max }: \quad v_{0,8}$

e.12) Deslizamento modificado para 0,8 $F_{\max }: v_{0,8 \bmod }=v_{0,8}-v_{24}+v_{i, \bmod }$

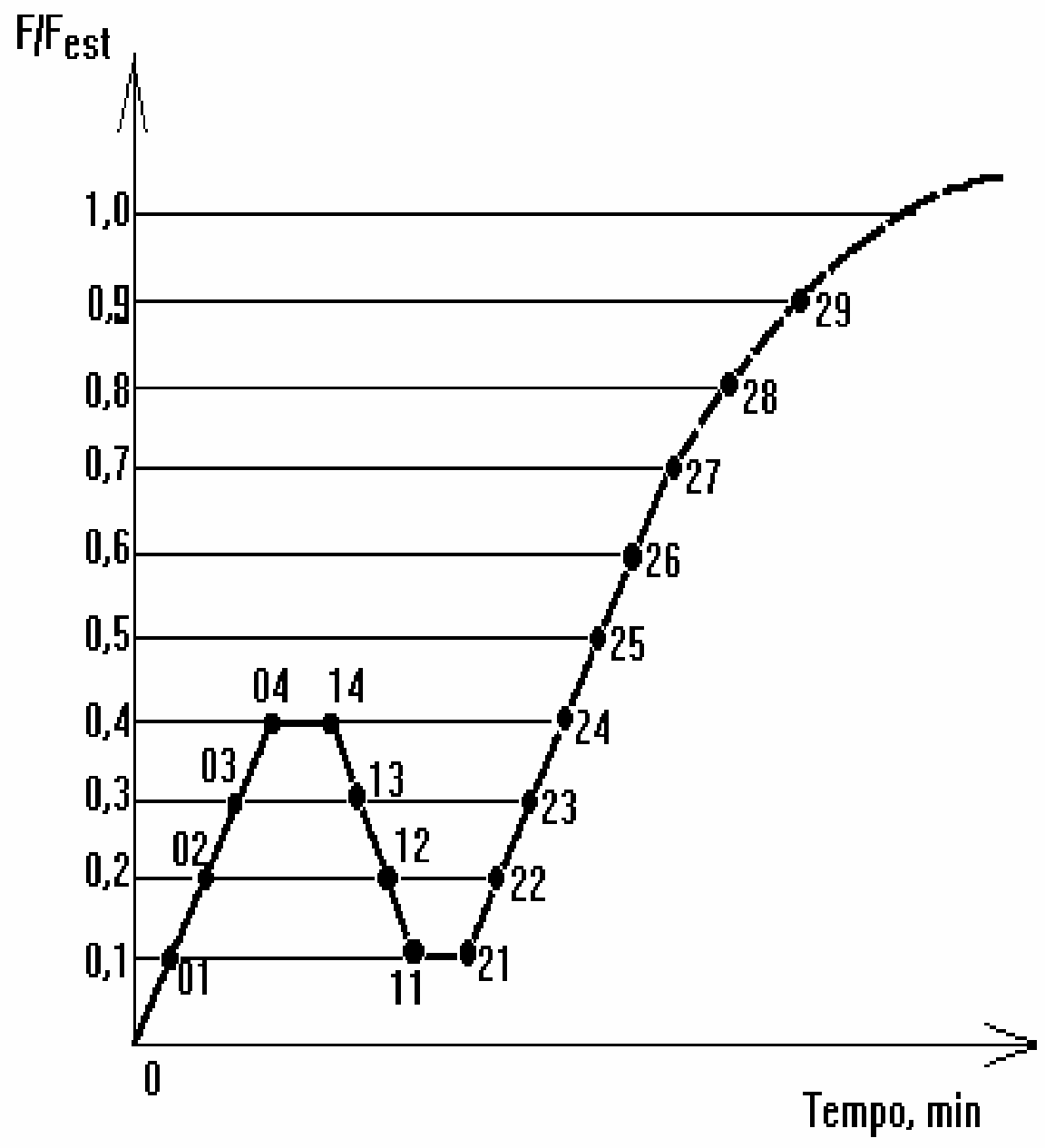

FIGURA 29 - Procedimento de carregamento segundo a ISO 6891. 


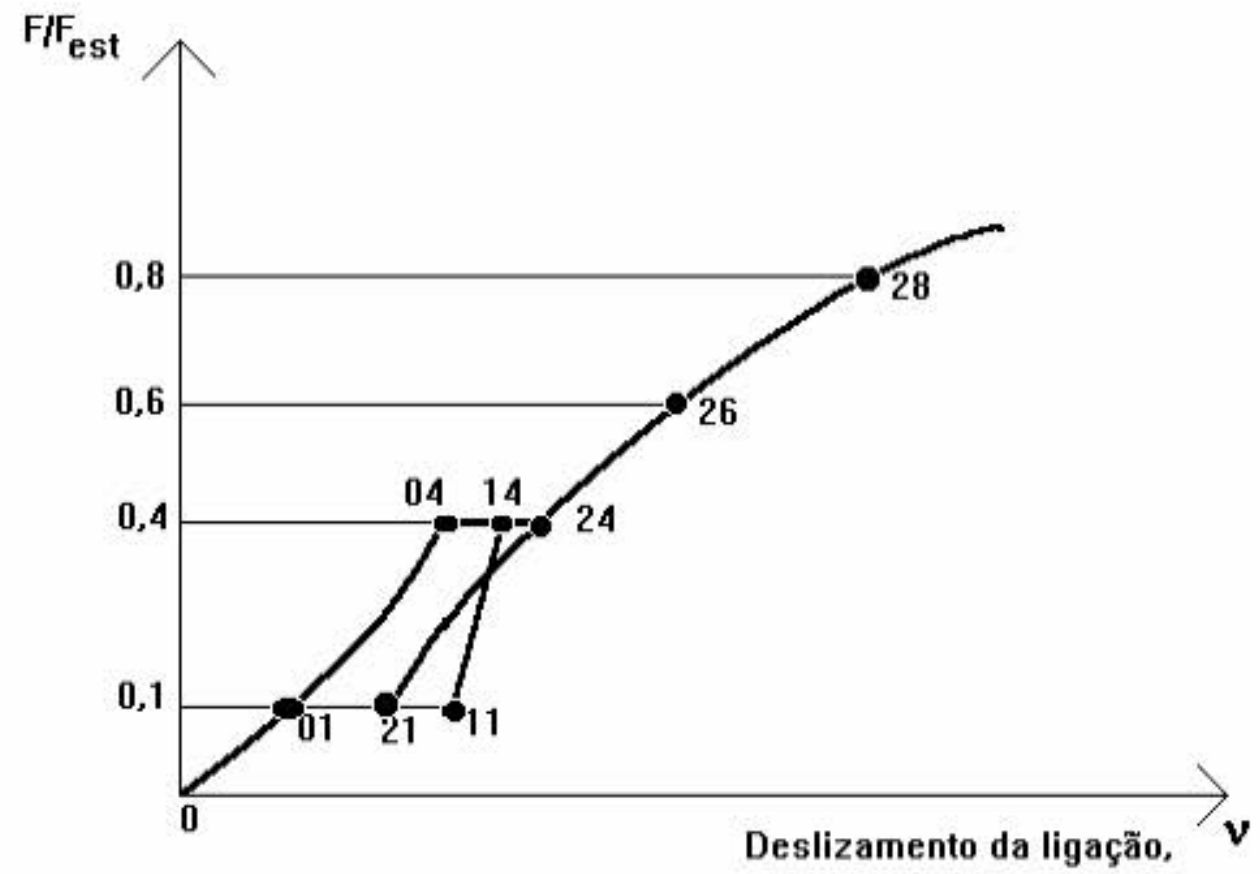

FIGURA 30- Valores medidos da curva idealizada carga-deformação segundo a ISO 6891. 


\subsection{Recomendações do PNBR 7190/96}

\subsubsection{Espaçamentos entre elementos de ligação}

\subsubsection{Espaçamentos em ligações com pinos (pregos com pré- furação, parafusos e cavilhas )}

Os espaçamentos mínimos recomendados são os seguintes:

a) entre o centro de dois pinos situados em uma mesma linha paralela à direção das fibras: pregos, cavilhas e parafusos afastados $6 \mathrm{~d}$; parafusos $4 \mathrm{~d}$;

b) do centro do último pino à extremidade de peças tracionadas: 7d;

c) do centro do último pino à extremidade de peças comprimidas:4d;

d) entre os centros de dois pinos situados em duas linhas paralelas à direção das fibras, medido perpendicularmente às fibras: 3d;

e) do centro de qualquer pino à borda lateral da peça, medido perpendicularmente às fibras, quando o esforço transmitido for paralelo às fibras: 1,5d;

f) do centro de qualquer pino à borda lateral da peça, medido perpendicularmente às fibras, quando o esforço transmitido for normal às fibras, do lado onde atuam tensões de tração normal: 1,5d;

g) do centro de qualquer pino à borda lateral da peça, medido perpendicularmente às fibras, quando o esforço transmitido for normal às fibras, do lado onde atuam tensões de compressão normal: 4d.

Estes espaçamentos estão representados na figura 31. 


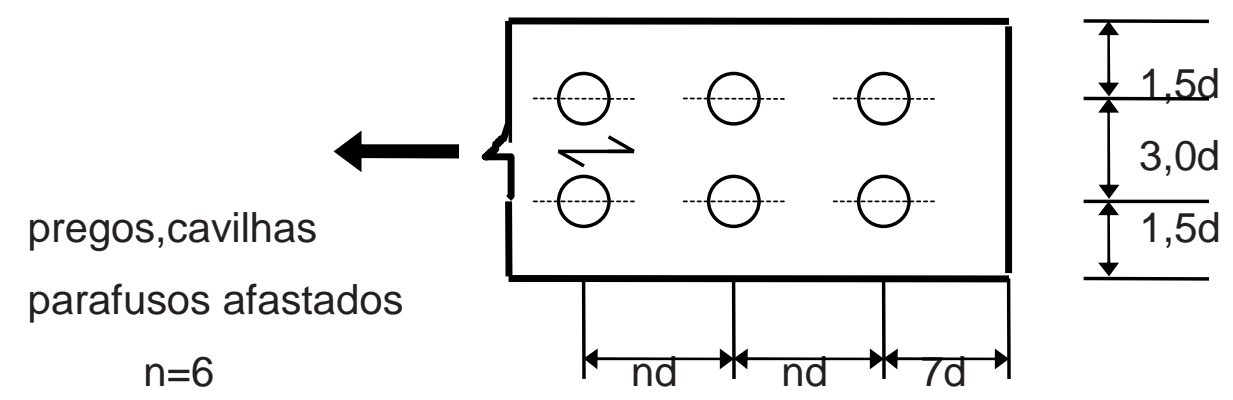

parafusos

$n=4$
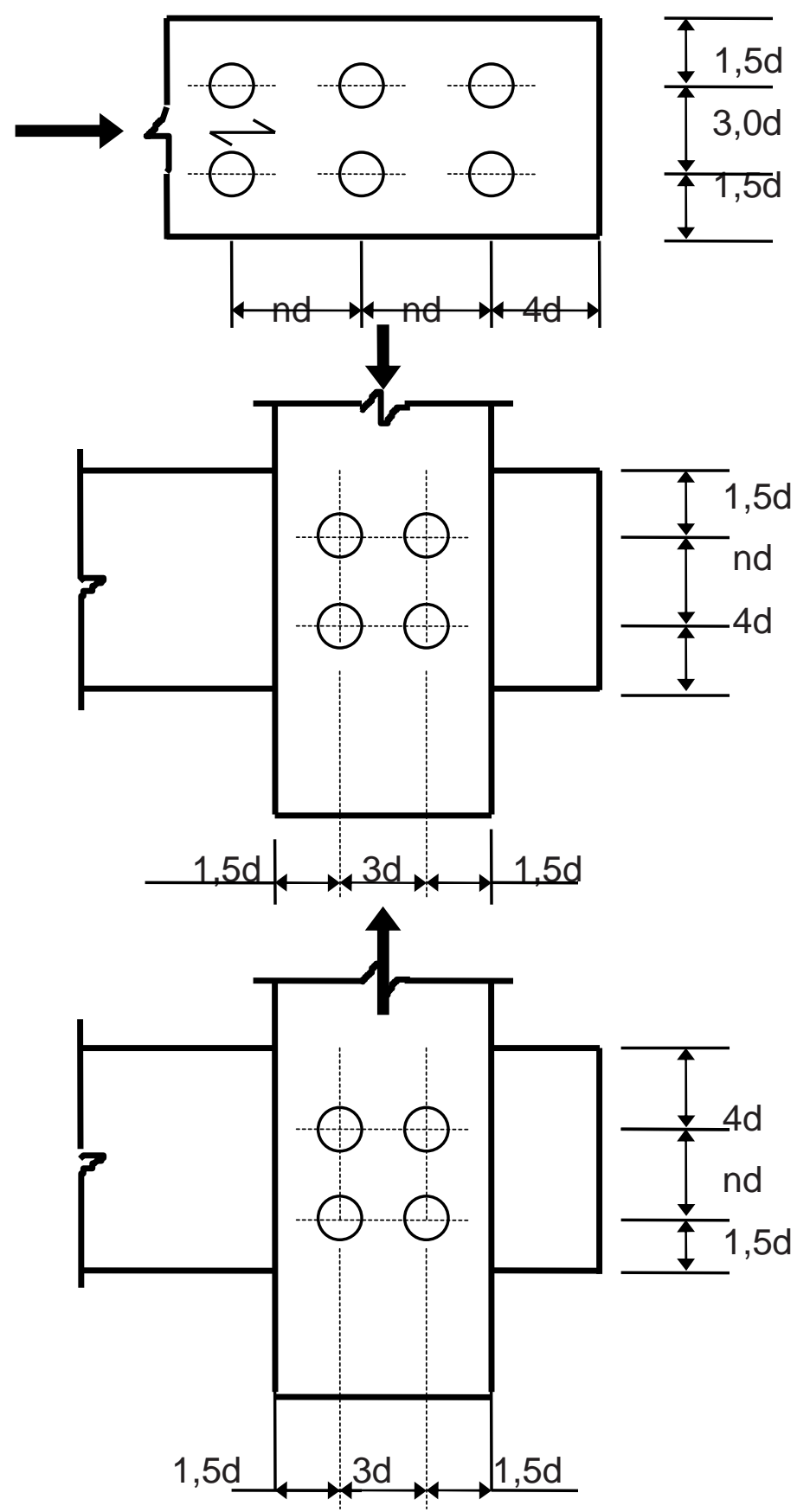

FIGURA 31- Espaçamentos em ligações com pinos. 


\section{MATERIAIS E MÉTODOS}

\subsection{Estudo das madeiras impregnadas}

Os materiais e métodos empregados no desenvolvimento deste trabalho foram idealizados a partir de sugestões extraídas dos trabalhos de MANRICH(1984) e MANRICH \& AGNELLI(1989), principalmente com relação aos seguintes aspectos: equipamento de impregnação da madeira, proporção de mistura dos componentes da resina de impregnação, tempo de impregnação, pressão de impregnação, espécie de madeira, e a metodologia dos ensaios.

Inicialmente será mostrada uma visão geral da teoria sobre os materiais empregados na confecção dos modelos finais de experimentação que são as ligações com cavilhas impregnadas e não impregnadas. $O$ delineamento do modelo final de experimentação foi feito com base em normas nacionais e internacionais de ensaios sobre ligações de peças estruturais de madeira.

Antes da montagem dos modelos finais para os ensaios das ligações sob compressão paralela às fibras e compressão normal às fibras foi feito uma série de ensaios de caracterização das madeiras com impregnação e sem impregnação. 


\subsection{Produtos químicos utilizados na obtenção de resinas estirênicas:}

\subsubsection{Estireno}

O estireno $\left(\mathrm{C}_{6} \mathrm{H}_{5} \mathrm{CH}=\mathrm{CH}_{2}\right)$ um hidrocarboneto aromático que possui um anel benzênico constitui um dos produtos petroquímicos mais utilizados em grande quantidade na atualidade, principalmente na produção de resinas e elastômeros.

Segundo SHREVE \& BRINK(1980), ele é proveniente da pirólise e desidrogenação do etilbenzeno $\left(\mathrm{C}_{6} \mathrm{H}_{5} \mathrm{CH}_{2} \mathrm{CH}_{3}\right)$, que se obtém pela síntese do eteno $\left(\mathrm{C}_{2} \mathrm{H}_{4}\right)$ e benzeno $\left(\mathrm{C}_{6} \mathrm{H}_{6}\right)$. Na figura 32 pode-se observar $\mathrm{O}$ fluxograma de produção do estireno.

ALLINGER et al.(1978), traduz o fluxograma anterior em termos de equação química mostrando que isso representa a maior parte dos processos disponíveis para a produção do estireno baseada na alquilação e polialquilação do benzeno com o etileno na fase líquida, utilizando-se o cloreto de alumínio a 90ํ e com pressão moderada. É usado o excesso de benzeno para evitar a poliaquilação. Também se utiliza um processo na fase de vapor com o auxílio de um catalisador de ácido fosfórico ou sílica-alumina a temperaturas mais elevadas.O etil-benzeno é desidrogenado a temperaturas superiores a $600^{\circ} \mathrm{C}$, produzindo estireno na presença de vapor de água e catalisadores à base de óxidos metálicos. A mistura de reação é purificada por destilação a vácuo na presença de inibidores de polimerização. Na equação [6.1] são traduzidos as considerações anteriores.

$$
\begin{array}{r}
\mathrm{C}_{6} \mathrm{H}_{6}+\mathrm{C}_{2} \mathrm{H}_{4} \underset{\mathrm{A} / \mathrm{Cl}_{3} \longrightarrow}{\longrightarrow} \mathrm{C}_{6} \mathrm{H}_{5} \mathrm{CH}_{2} \mathrm{CH} \frac{600 \text { - } \mathrm{C}}{\text { Catalisador }} \\
\text { O estireno utilizado neste trabalho foi fornecido a título de cortesia }
\end{array}
$$
pela empresa CIA. BRASILEIRA DE ESTIRENO, numa lata com capacidade de 20 litros. 


\section{PRODUÇÃO DE ESTIRENO}

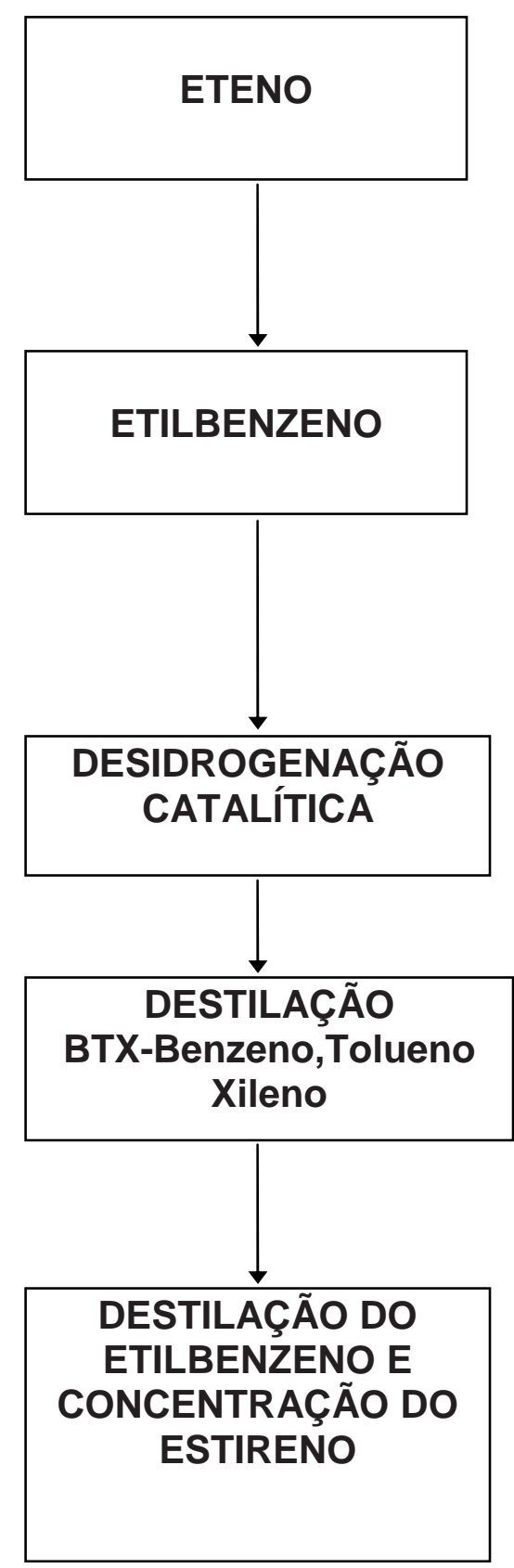

FIGURA 32- Fluxograma mostrando a fabricação do estireno segundo SHREVE \& BRINK (1980). 


\subsubsection{Iniciadores-Peróxido de Benzoila}

Os peróxidos constituem compostos orgânicos iniciadores de reações químicas destinados a decomposição de moléculas, dando origem aos chamados radicais livres. O peróxido de benzoila no campo dos polímeros é largamente utilizado para iniciar o processo de polimerização para a formação dos radicais livres, destacando-se o caso das resinas estirênicas e dos acrilatos e acetato de vinilia, ele é produzido quando o benzoil clorídrico mais o peróxido de sódio são misturados na água, conforme pode ser visto na equação química [6.2].

\section{$2 \mathrm{C}_{6} \mathrm{H}_{5} \mathrm{COCl}+\mathrm{Na}_{2} \mathrm{O}_{2} \longrightarrow 2 \mathrm{-2NaCl} \longrightarrow 2 \mathrm{C}_{6} \mathrm{H}_{5} \mathrm{CO}_{2}$ \\ Cloreto de Peróxido de Peróxido de Benzoila \\ Benzoila Sódio}

O peróxido de benzoila neste trabalho foi fornecido pela empresa DATIQUIM Produtos Químicos Ltda, sob a forma de $50 \%$ de concentração do elemento ativo, em um frasco de $500 \mathrm{ml}$ contendo $1 \mathrm{Kg}$ do produto.

\subsection{Impregnação da Madeira}

A impregnação consiste num processo de injeção de determinados produtos químicos (líquidos) nas madeiras para permitir uma melhor conservação ao longo do tempo, e melhorar suas propriedades físicas e mecânicas principalmente do ponto de vista da resistência estrutural, e também permitir um melhor aspecto do ponto de vista estético.

De um modo geral os processos de modificações das propriedades físicas e mecânicas da madeira tem sido feitas através dos anos utilizando certos tipos de tratamentos tradicionais utilizando alcatrão, piches, creosotos, resinas, pintura da superfície e preenchimento dos poros. 
Recentes desenvolvimentos efetuados por: MEYER (1965), RAFF et al.(1965), MEYER apud ROWELL(1983) ${ }^{4}$, MEYER apud BEVER(1986), MANRICH(1989), MANRICH \& AGNELLI (1989), GALPERIN et al.(1995), tem sido empreendidos neste campo utilizando-se os processos de impregnação da madeira utilizando monômeros líquidos, (compostos que podem ser transformados em polímeros ou resinas através da combinação com outros compostos similares) dando origem aos chamados compósitos polímero- madeira (CPM), cujas propriedades aumentam significativamente como: resistência à compressão, dureza e abrasão, e do mesmo modo há um melhoramento na estética, durabilidade do material e na estabilidade dimensional.

Em relação aos trabalhos anteriores podemos dizer que houve um avanço significativo no campo da impregnação de madeiras, por isso é que pensando na hipótese de se melhorar o desempenho das ligações tradicionais de cavilhas é que se pensou em impregnar as mesmas para avaliar o seu comportamento estrutural dentro do campo das ligações estruturais de madeira.

$\mathrm{Na}$ figura 33 pode-se observar o comportamento da madeira e do compósito polímero-madeira da espécie chamada de tília americana (basswood), ensaiados sob flexão estática ilustrados do trabalho de MEYER apud ROWELL(1983), notando-se a eficácia do processo de impregnação da madeira, usando monômeros (MMA) metil metacrilato.

\footnotetext{
${ }^{4}$ ROWELL, R. Advances in chemistry series-the chemistry of solid wood. Washington, American Chemical Society, 1983.

${ }^{5}$ BEVER, M.B. Encyclopedia of materials science and engineering. Oxford, Pergamon Press, vol.7 7, T-Z, 1986.
} 


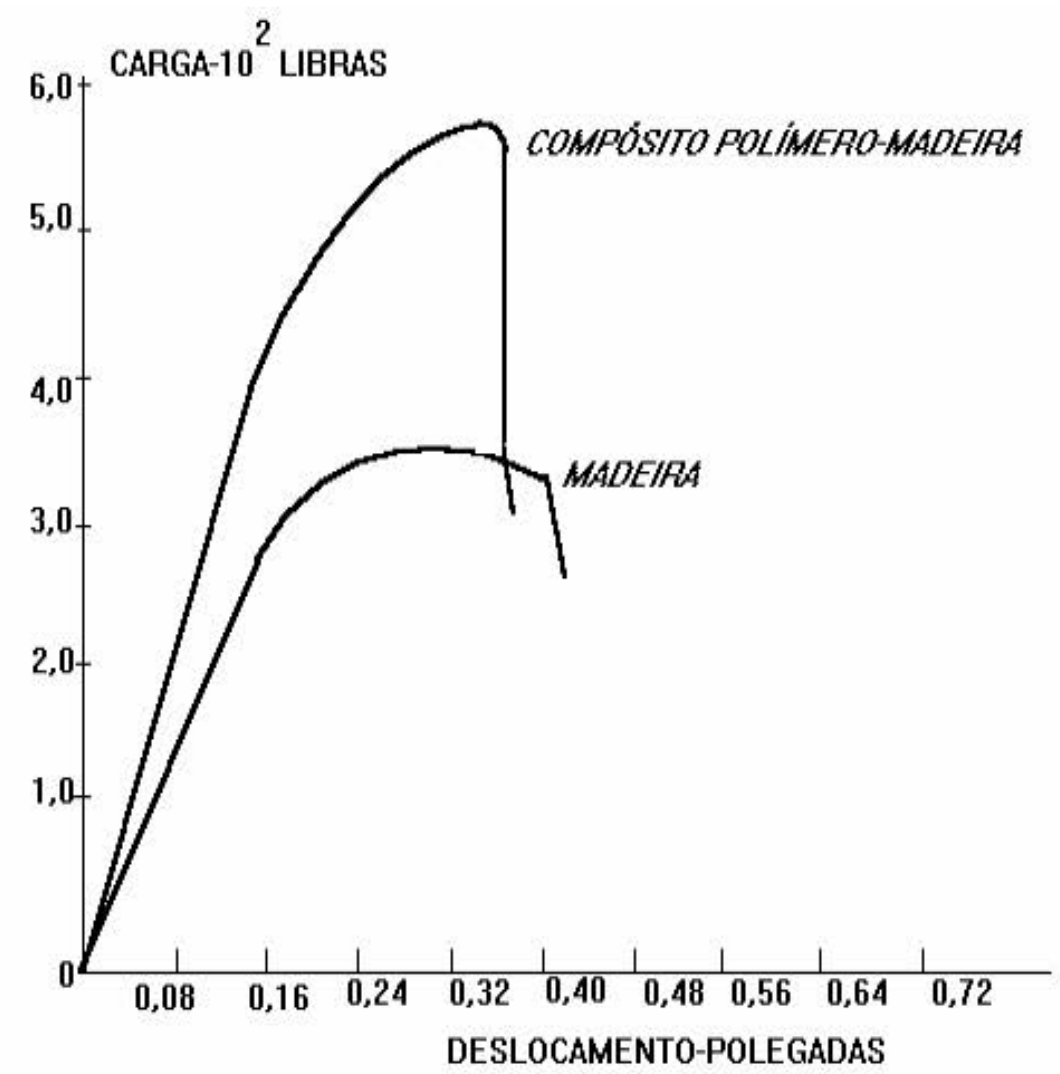

FIGURA 33- Ensaios de flexão estática de madeira e compósito polímero madeira da espécie tília americana (basswood), segundo MEYER apud ROWELL (1983). 
Um aspecto também muito importante com relação ao processo de impregnação está relacionado com a utilização de concreto impregnado com polímeros em tabuleiro de pontes, pesquisa essa realizada por

MANSON et al (1978), onde foram verificados os seguintes passos: seleção de monômeros, desenvolvimento das técnicas e aparelho para impregnação da superfície do concreto, avaliação da técnica de impregnação, preparação do concreto para impregnação, propriedades do concreto impregnado com polímeros (durabilidade, resistência a abrasão, resistência, permeabilidade,etc). Nesse trabalho os autores mostram que as propriedades mecânicas e a durabilidade do concreto impregnado, melhoraram significativamente em comparação com o concreto não impregnado,utilizando-se um sistema de monômeros na proporção de 100: 10 de metil metacrilato (MMA) - trimetilpropano trimetacrilato (TMPTMA) e um iniciador azobisisobutironitrila (AIBN) na mistura contendo 0,5\%. Os resultados que esses autores chegaram foram surpreendentes tais como: $A$ resistência à compressão foi triplicada, a resistência à tração foi duplicada, a penetração a cloretos foi reduzida a menos de 1/6, a absorção a umidade foi reduzida em média de $85 \%$, a resistência ao ataque químico foi dramaticamente aumentada.

Dentro dessa linha de raciocínio e seguindo os mesmos passos para o caso das madeiras é que se utilizará o processo de impregnação obedecendo os seguintes passos importantes: Escolha dos Monômeros e iniciadores, Dosagem requerida e mistura, Espécie de madeira, Secagem da madeira, Impregnação, Polimerização.

\subsection{Fases do processo de impregnação}

\subsubsection{Monômeros e iniciadores}

Neste trabalho optou-se pela utilização do estireno líquido e do peróxido de benzoila em $50 \%$ de pasta. 


\subsubsection{Dosagem requerida e mistura}

A proporção dos elementos químicos utilizados no preparo da resina estirênica é da seguinte ordem: $1,5 \%$ de peróxido de benzoila mais $98,5 \%$ de estireno, sendo os componentes misturados em volume.

\subsubsection{Espécie de Madeira}

As madeiras escolhidas para receberem o processo de impregnação foram aquelas que possuem um bom grau de absorção de resinas estirênicas, sendo que a idéia inicial foi se utilizar as madeiras de reflorestamento, pensando principalmente naquelas de baixa densidade. Nos ensaios preliminares para caracterização das madeiras impregnadas e não impregnadas utilizou-se o Pinus e Eucalipto citriodora. Essas espécies de madeira são provenientes de uma serraria localizada no município da cidade de São Carlos (SP). Os resultados finais são comparados com a espécie Ipê.

\subsubsection{Secagem da madeira}

Antes da madeira ser impregnada com um monômero é necessário a remoção de água dos poros, em virtude do teor de umidade contido na mesma. Daí a necessidade de se colocar a madeira na estufa a $100^{\circ} \mathrm{C}$ para a evaporação de toda a água contida na mesma, para permitir o ingresso do monômero e facilitar o processo de impregnação.

\subsubsection{Impregnação}

Inicialmente foi idealizado e montado no LaMEM/SET/USP, um recipiente cilíndrico de aço destinado a realizar os trabalhos de impregnação com capacidade igual a $4800 \mathrm{ml}$, conforme a figura 34, onde no seu interior coloca-se o monômero, o iniciador e a madeira a ser impregnada. Em seguida é feita a retirada do ar contido no interior do reservatório para que o mesmo não interfira no processo de impregnação, através do borbulhamento com nitrogênio líquido $\left(\mathrm{N}_{2}\right)$ durante 10 minutos, e a seguir aplica-se uma pressão de impregnação durante 30 minutos para efetivar o processo durante um certo período. 
Nos ensaios preliminares para caracterização de madeiras impregnadas e não impregnadas foram aplicadas pressões de impregnação da ordem de 0,$25 ; 0,5 ; 0,75$ e $1 \mathrm{MPa}$.

Em seguida a madeira é retirada do reservatório de impregnação e feita a retirada do excesso de resina de impregnação sendo a mesma embrulhada em papel alumínio e levada na estufa para polimerização e evaporação por um período de 48 horas a uma temperatura de $60^{\circ} \mathrm{C}$, e nessa fase é que se efetua o trabalho e a formação do processo de polimerização da madeira. $\mathrm{Na}$ figura 35 pode-se observar o fluxograma do processo de impregnação executado nas dependências do Laboratório de Físico-Química Orgânica do IQSC/USP.

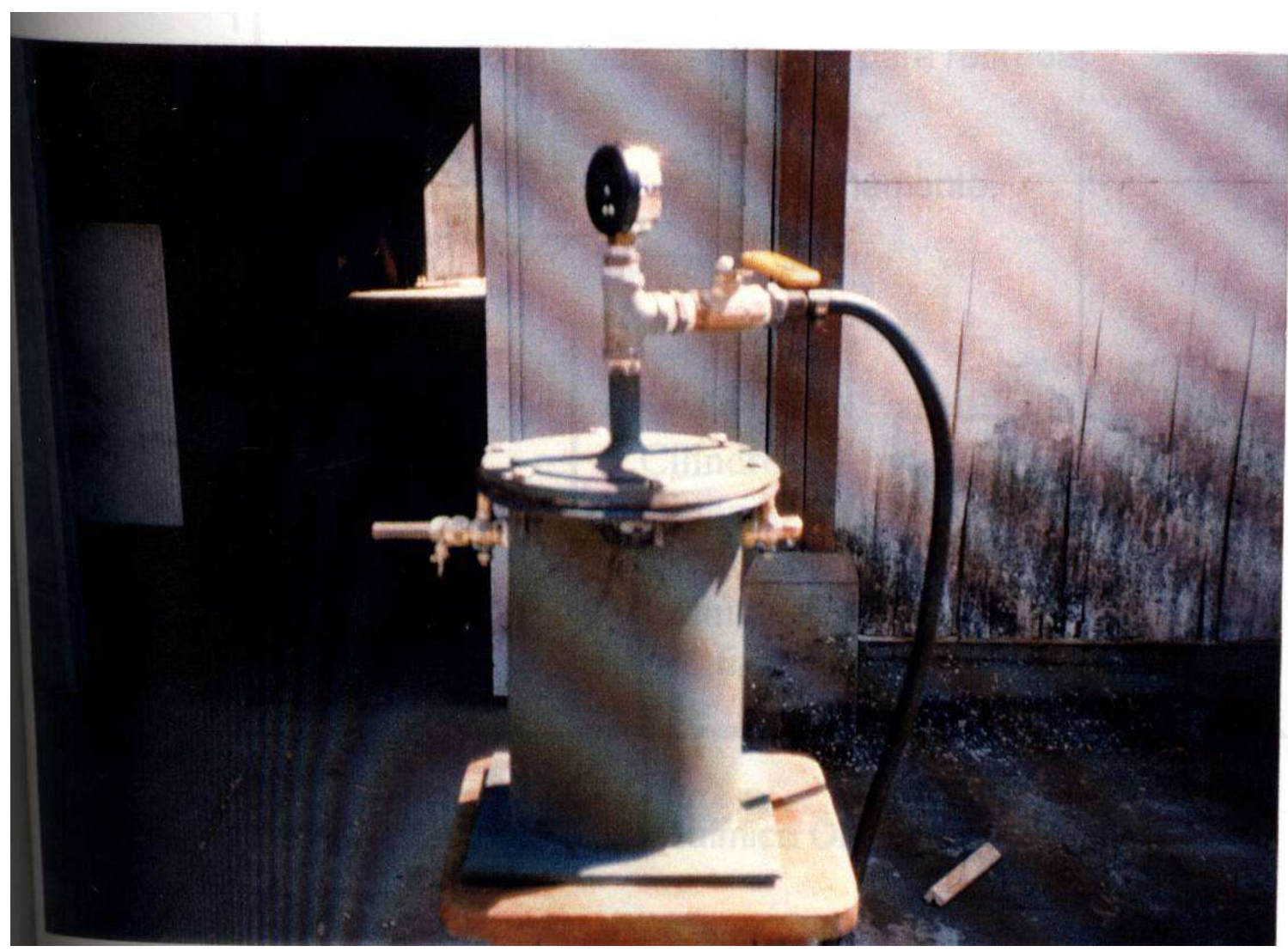

FIGURA 34- Cilindro utilizado para o processo de impregnação montado no LaMEM/SET/USP. 

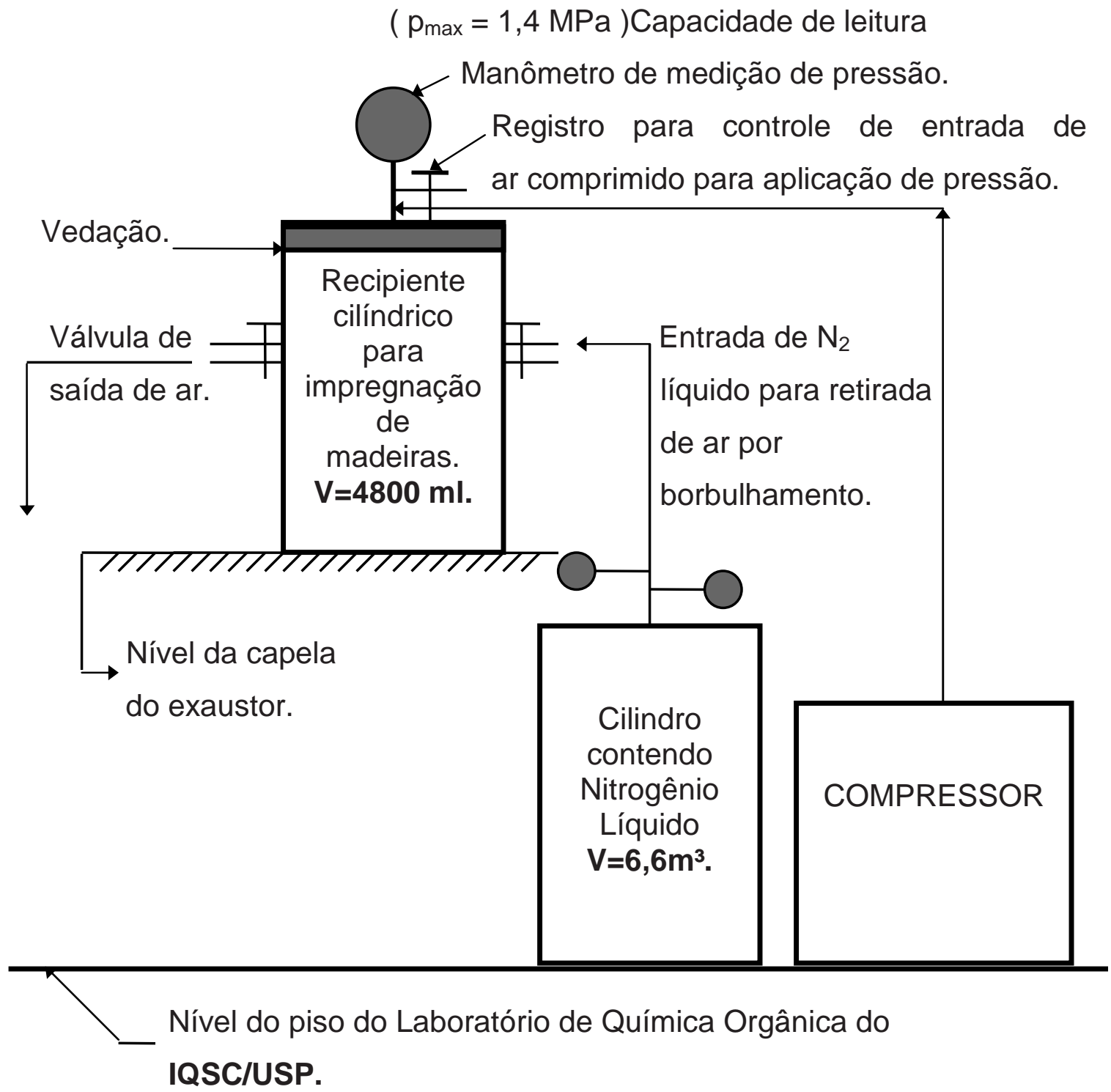

FIGURA 35- Fluxograma mostrando o processo de impregnação da madeira nas dependências do IQSC/USP. 


\subsubsection{Polimerização}

Na etapa de impregnação da madeira quando os corpos de prova são retirados do reservatório de impregnação e embrulhados em papel alumínio e colocados na estufa a $60^{\circ} \mathrm{C}$ para secagem, é nessa fase que se verifica o processo de polimerização do estireno no interior da madeira.

A polimerização é um conjunto de reações químicas, onde as moléculas dos monômeros se unem umas as outras para formar os polímeros, constituindo portanto num dos processos mais comuns de polimerização denominada de polimerização por adição. Basicamente a impregnação da madeira se dá pela polimerização via radicais livres do monômero (estireno), através de um iniciador (peróxido de benzoila), que foi o mecanismo de reação química utilizado neste trabalho para a obtenção da resina estirênica.

Em termos de equação química para a reação anterior podemos seguir o raciocínio de PRYOR (1970), para o caso de polimerização por adição.

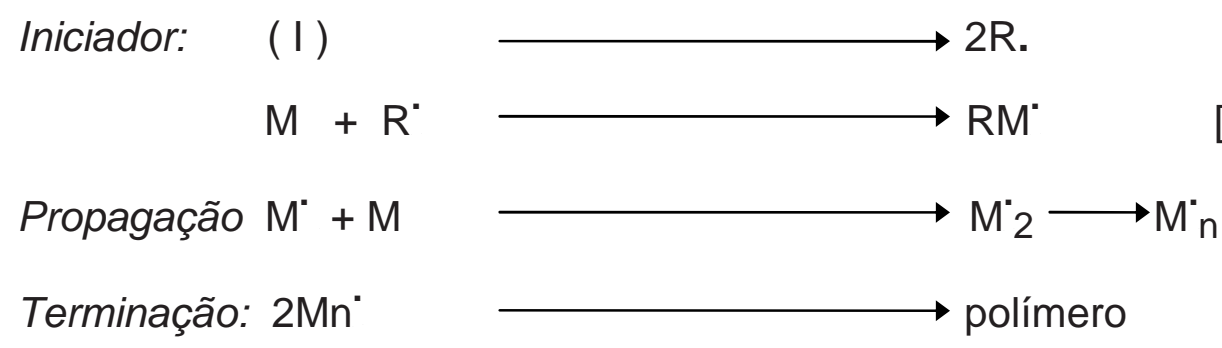

M é a molécula de monômero.

$\mathrm{M}_{\mathrm{n}}$ 'é um radical contendo $\mathrm{n}$ unidades de repetição (mesos). 


\subsection{Ensaios para caracterização de madeiras impregnadas e não Impregnadas}

\subsubsection{Introdução:}

Para avaliar o comportamento das ligações cavilhadas foram programados vários ensaios de caracterização das madeiras impregnadas e não impregnadas e feita a determinação da resistência última das ligações.

Inicialmente foram realizados os ensaios de impregnação da madeira, variando: Pressão de impregnação, Tempo de impregnação e Espécies de madeiras ( Pinus, Eucalipto citriodora ).

Serão determinadas os valores das resistências mecânicas da madeira tais como: resistência à compressão paralela às fibras $\left(f_{c o}\right)$, resistência à compressão normal $\left(f_{c 90}\right)$, resistência ao cisalhamento simples $\left(f_{v}\right)$, resistência ao cisalhamento na flexão $\left(f_{v M}\right)$ e resistência à tração paralela às fibras $\left(\mathfrak{f}_{\mathrm{to}}\right)$, principalmente para avaliar o comportamento das cavilhas impregnadas e não impregnadas na composição dos modelos finais das ligações. Um aspecto importante é que nesses ensaios iniciais faz-se a impregnação de um determinado grupo de corpos de prova e também comparam-se os valores dessas respectivas resistências dos corpos de prova impregnados e não impregnados, a fim de que se possa testar a eficiência da resina estirênica, bem como do processo de impregnação utilizado e também verificar a porcentagem de aumento na resistência da madeira em relação as propriedades mecânicas citadas anteriormente.

\subsubsection{Equipamentos}

Os equipamentos utilizados para realização dos ensaios são os seguintes:a) Máquina Universal de ensaios DARTEC de capacidade $100 \mathrm{kN}$;

b)Máquina Universal de ensaios AMSLER de capacidade 250 kN; Balança Eletrônica ACATEC BDC 3300 de capacidade máxima $500 \mathrm{~g}$ e precisão 0,01 ; d) Estufa de Secagem dos corpos de prova; e) Estufa de climatização; f) Relógios comparadores de precisão 0,01 mm e 0,001mm;

g) Paquímetro de precisão de $0,1 \%$ ou seja $0,02 \mathrm{~mm} / 20 \mathrm{~mm}$. 
Os ensaios de caracterização de madeiras impregnadas e não impregnadas foram realizados nas dependências do LaMEM/SET/USP.

\subsubsection{COMPRESSÃO NORMAL ÀS FIBRAS}

Inicialmente foram preparados os corpos de prova baseados na metodologia do BOLETIM TÉCNICO DA ESCOLA POLITÉCNICA DA USP (BT/PEF/9604).Os corpos de prova para este tipo de ensaio possuem seção transversal $5 \times 5 \mathrm{~cm}$ e o comprimento do corpo de prova é de $10 \mathrm{~cm}$, conforme a figura 36, sendo que estas dimensões na hora do ensaio foram tiradas as médias de duas medidas das arestas correspondentes utilizandose para isso o paquímetro digital.

Foram confeccionados inicialmente 21 corpos de prova da espécie Pinus e 08 corpos de prova de Eucalipto citriodora.

Os corpos de prova foram marcados inicialmente e em seguida determinados suas medidas das principais dimensões e logo após foram colocados para programação de secagem na estufa durante 48 horas a $100^{\circ} \mathrm{C}$.

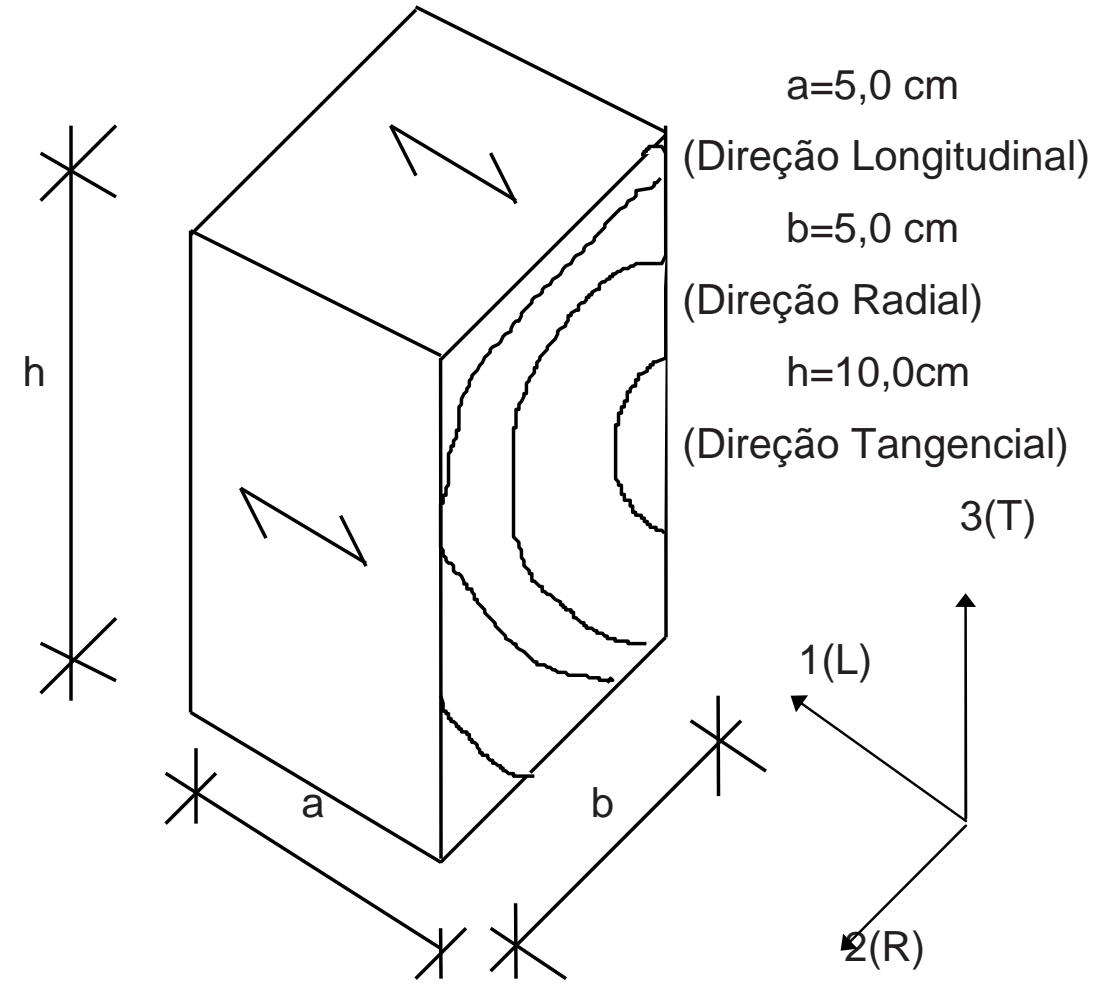

FIGURA 36-Dimensões do corpo de prova para ensaio de compressão normal às fibras segundo o PNBR 7190/96. 


\subsubsection{Dimensões dos corpos de prova}

TABELA 18-Valores das dimensões dos corpos de prova Espécie :Pinus

\begin{tabular}{|c|c|c|c|c|c|}
\hline SÉRIE & $\mathrm{a}(\mathrm{mm})$ & $\mathrm{b}(\mathrm{mm})$ & $\mathrm{h}(\mathrm{mm})$ & $\mathrm{A}\left(\mathrm{cm}^{2}\right)$ & $\mathrm{V}\left(\mathrm{cm}^{3}\right)$ \\
\hline 1 & 50,91 & 49,36 & 95,78 & 25 & 241 \\
\hline 2 & 50,75 & 49,56 & 97,12 & 25 & 244 \\
\hline 3 & 50,62 & 49,54 & 96,64 & 25 & 242 \\
\hline 4 & 50,26 & 49,55 & 95,81 & 25 & 239 \\
\hline 5 & 50,67 & 49,24 & 97,36 & 25 & 243 \\
\hline 6 & 50,51 & 49,36 & 97,13 & 25 & 242 \\
\hline 7 & 51,32 & 51,01 & 97,21 & 26 & 254 \\
\hline 8 & 50,45 & 49,81 & 97,58 & 25 & 245 \\
\hline 9 & 50,99 & 49,84 & 96,96 & 25 & 246 \\
\hline 10 & 50,41 & 49,94 & 98,08 & 25 & 247 \\
\hline 11 & 50,82 & 49,84 & 98,34 & 25 & 249 \\
\hline 12 & 49,9 & 50,61 & 97,34 & 25 & 246 \\
\hline 13 & 49,98 & 51,1 & 97,25 & 26 & 248 \\
\hline 14 & 51,14 & 50,15 & 97,06 & 26 & 249 \\
\hline 15 & 51 & 49,96 & 97,87 & 25 & 249 \\
\hline 16 & 50,78 & 49,7 & 96,94 & 25 & 245 \\
\hline 17 & 50,91 & 49,79 & 97,36 & 25 & 247 \\
\hline 18 & 50,78 & 49,71 & 97,06 & 25 & 245 \\
\hline 19 & 50,76 & 50,66 & 93,32 & 26 & 240 \\
\hline 20 & 50,55 & 50,44 & 92,53 & 25 & 236 \\
\hline 21 & 50,22 & 50,52 & 94,42 & 25 & 240 \\
\hline
\end{tabular}

TABELA 19-Valores das dimensões dos corpos de prova

Espécie :Eucalipto citriodora

\begin{tabular}{|c|c|c|c|c|c|}
\hline SÉRIE & $\mathrm{a}(\mathrm{mm})$ & $\mathrm{b}(\mathrm{mm})$ & $\mathrm{c}(\mathrm{mm})$ & $\mathrm{A}\left(\mathrm{cm}^{2}\right)$ & $\mathrm{V}\left(\mathrm{cm}^{3}\right)$ \\
\hline 1 & 49,06 & 49,12 & 99,68 & 24 & 240 \\
\hline 2 & 49,34 & 49,25 & 99,35 & 24 & 241 \\
\hline 3 & 49,79 & 49,12 & 99,95 & 24 & 244 \\
\hline 4 & 49,62 & 49,47 & 99,47 & 25 & 244 \\
\hline 5 & 49,87 & 48,82 & 99,45 & 24 & 242 \\
\hline 6 & 49,48 & 49,11 & 99,33 & 24 & 241 \\
\hline 7 & 49,67 & 49,6 & 99,18 & 25 & 244 \\
\hline 8 & 49,75 & 49,59 & 99,43 & 25 & 245 \\
\hline & & & & & \\
\hline
\end{tabular}

Dimensões dos corpos de prova:

a(Direção Longitudinal); b(Direção Radial); h(Direção Tangencial);

A(Área ); V(Volume). 


\subsubsection{Programação de secagem dos corpos de prova}

Os corpos de prova passam pelo processo de secagem para determinação do teor de umidade da madeira, sendo que os corpos de prova da série 1 a 6 não serão impregnados visto que serão submetidos aos ensaios de compressão normal cujos resultados serão comparados com os demais corpos de prova impregnados. Os corpos de prova da série 7 a 18 foram colocados na estufa a uma temperatura de $40{ }^{\circ} \mathrm{C}$ durante 88 horas, e também com eles foi colocado um corpo de prova de referência(CP-Ref.) para controle da umidade. A seguir estão listados os respectivos pesos da madeira verde e peso seco dos corpos de prova.

TABELA 20-Peso dos corpos de prova verde e seco. ESPÉCIE:Pinus

\begin{tabular}{|c||c|c|c|}
\hline SÉRIE & $\mathrm{Mn}(\mathrm{g})$ & $\mathrm{Mo}(\mathrm{g})$ & $\mathrm{U}(\%)$ \\
\hline 7 & 81,9 & 76,5 & 7 \\
\hline 8 & 90,5 & 84,8 & 7 \\
\hline 9 & 81,2 & 76,5 & 6 \\
\hline 10 & 89,2 & 83,4 & 7 \\
\hline 11 & 94,6 & 89,7 & 5 \\
\hline 12 & 85,9 & 80,8 & 6 \\
\hline 13 & 84,7 & 79,3 & 7 \\
\hline 14 & 80,7 & 75,5 & 7 \\
\hline 15 & 81,6 & 77,1 & 6 \\
\hline 16 & 91,2 & 85,6 & 7 \\
\hline 17 & 88,1 & 82,1 & 7 \\
\hline 18 & 81,2 & 75,9 & 7 \\
\hline CP-Ref. & 108,1 & 101,2 & 7 \\
\hline MÉDIA & 88 & 82 & 7 \\
\hline DESVIO PADRÃO & 8 & 7 & 1 \\
\hline & & & \\
\hline
\end{tabular}

$M_{n}$ - Massa da madeira verde, $M_{0}$ - massa da madeira seca, $\mathrm{U}$ - Teor de umidade 
Igualmente foram colocados na estufa para secagem os corpos de prova de Eucalipto citriodora, a uma temperatura de secagem de $100{ }^{\circ} \mathrm{C}$ durante um período de 48 horas, e as respectivas massas estão listadas a seguir:

TABELA 21-Peso dos corpos de prova verde e seco.

\section{ESPÉCIE:Eucalipto Citriodora}

\begin{tabular}{|c|c|c|c|}
\hline SÉRIE & $\mathrm{M}_{\mathrm{n}}(\mathrm{g})$ & $\mathrm{M}_{\mathrm{o}}(\mathrm{g})$ & $\mathrm{U}(\%)$ \\
\hline 1 & 275 & 222 & 23,87 \\
\hline 2 & 265,7 & 211,8 & 25,45 \\
\hline 3 & 265,4 & 215,3 & 23,27 \\
\hline 4 & 267,4 & 211,8 & 26,25 \\
\hline 5 & 294,8 & 232,4 & 26,85 \\
\hline 6 & 262,3 & 213,3 & 22,97 \\
\hline 7 & 273,1 & 217 & 25,85 \\
\hline 8 & 272,9 & 214,44 & 27,26 \\
\hline & & & \\
\hline MÉDIA & $\mathbf{2 7 2}$ & $\mathbf{2 1 7}$ & $\mathbf{2 5}$ \\
\hline
\end{tabular}

\subsubsection{Impregnação dos corpos de prova}

A impregnação dos corpos de prova teve como objetivo testar a eficiência da resina estirênica(peróxido de benzoila + estireno).Os trabalhos de impregnação da madeira foram realizados nas dependências do Laboratório de Química Orgânica do IQSC/USP. O cilindro utilizado para impregnação dos corpos de prova possui uma capacidade de $4800 \mathrm{ml}$, sendo que inicialmente foram impregnados tres grupos de 04 corpos de prova que ocupam um volume de $1000 \mathrm{ml}$ e portanto foram gastos inicialmente $3800 \mathrm{ml}$ de resina estirênica $(3740 \mathrm{ml}$ de estireno + $60 \mathrm{ml}$ de peróxido de benzoila ). 
As pressões para o trabalho de impregnação variaram de 0,25 a $1 \mathrm{MPa}$, sendo aplicadas após a solução ser borbulhada com nitrogênio inerte para expulsar do ar no interior do cilindro de impregnação, a fim de que o mesmo não prejudique o processo de polimerização do monômero no interior da madeira. Inicialmente foram impregnados os corpos de prova da série 7 a 10 e gastos um total de $3800 \mathrm{ml}$ de resina estirênica, sendo que a pressão de impregnação para este caso foi de 0,25 $\mathrm{MPa}$. Os corpos de prova foram borbulhados no nitrogênio inerte por 10 minutos e em seguida foi aplicada a referida pressão durante 30 minutos.

A seguir os corpos de prova foram retirados do cilindro e enxugados para retirada do excesso de resina e embrulhados em papel alumínio para serem pesados e colocados na estufa para secagem a uma temperatura de $600^{\circ} \mathrm{C}$. Em relação aos demais corpos de prova foi adotado o mesmo procedimento, apenas o que variou foi a pressão de impregnação, conforme poderemos ver na tabela 22.

Quando os corpos de prova são retirados da estufa e desembrulhados os mesmos são pesados e imediatamente são colocados na estufa de climatização a uma temperatura de $50^{\circ} \mathrm{C}$ a fim de eli minar todo o aspecto de evaporação e consolidar o processo de polimerização do monômero no interior da madeira, e quando são retirados os corpos de prova são novamente pesados.

$\mathrm{Na}$ tabelas 22 e 23 também podem-se observar os valores da temperatura de secagem dos corpos de prova impregnados embrulhados em papel alumínio e na tabela 24 são listados os respectivos pesos dos corpos de prova impregnados e posteriormente secos impregnados. 
TABELA 22- Tempo de impregnação, pressão de impregnação e temperatura de secagem em estufa por 48 horas.

\section{ESPÉCIE:Pinus}

\begin{tabular}{|c|c|c|c|}
\hline SÉRIE & $\mathrm{t}_{\mathrm{ap}}(\mathrm{min})$ & $\mathrm{p}(\mathrm{MPa})$ & $\mathrm{T}\left({ }^{\circ} \mathrm{C}\right)$ \\
\hline 7 & 30 & 0,25 & 60 \\
\hline 8 & 30 & 0,25 & 60 \\
\hline 9 & 30 & 0,25 & 60 \\
\hline 10 & 30 & 0,25 & 60 \\
\hline 11 & 30 & 0,5 & 60 \\
\hline 12 & 30 & 0,5 & 60 \\
\hline 13 & 30 & 0,5 & 60 \\
\hline 14 & 30 & 0,5 & 60 \\
\hline 15 & 30 & 0,75 & 60 \\
\hline 16 & 30 & 0,75 & 60 \\
\hline 17 & 30 & 0,75 & 60 \\
\hline 18 & 30 & 0,75 & 60 \\
\hline 19 & 30 & 1 & 60 \\
\hline 20 & 30 & 1 & 60 \\
\hline 21 & 30 & 1 & 60 \\
\hline & & & \\
\hline & & & \\
\hline
\end{tabular}

TABELA 23- Tempo de impregnação, pressão de impregnação e temperatura de secagem em estufa por 48 horas.

ESPÉCIE:Eucalipto citriodora

\begin{tabular}{|c|c|c|c|}
\hline SÉRIE & $\mathrm{t}_{\mathrm{ap}}(\mathrm{min})$ & $\mathrm{p}(\mathrm{MPa})$ & $\mathrm{T}\left({ }^{0} \mathrm{C}\right)$ \\
\hline 5 & 30 & 1 & 60 \\
\hline 6 & 30 & 1 & 60 \\
\hline 7 & 30 & 1 & 60 \\
\hline 8 & 30 & 1 & 60 \\
\hline & & & \\
\hline
\end{tabular}

Nesta tabelas $t_{a p}$ representa o tempo de aplicação da pressão no reservatório de impregnação, $\mathbf{p}$ a pressão aplicada através de ar comprimido e $\mathbf{T}$ a temperatura de secagem em estufa. 
TABELA 24- Peso dos corpos impregnados e não impregnados ESPÉCIE:Pinus

\begin{tabular}{|c|c|c|c|c|c|c|}
\hline SÉRIE & $\mathrm{p}(\mathrm{MPa})$ & $\mathrm{M}_{\mathrm{n}}(\mathrm{g})$ & $\mathrm{M}_{\mathrm{o}}(\mathrm{g})$ & $\mathrm{M}_{\mathrm{ni}}(\mathrm{g})$ & $\mathrm{M}_{\text {oi }}(\mathrm{g})$ & $\mathrm{M}_{\text {oica }}(\mathrm{g})$ \\
\hline & & & & & & \\
\hline 7 & 0,25 & 81,9 & 76,5 & 188,4 & 159,4 & 157,3 \\
\hline 8 & 0,25 & 90,5 & 84,8 & 197,1 & 170,6 & 169,4 \\
\hline 9 & 0,25 & 81,2 & 76,5 & 187,2 & 163,3 & 161,4 \\
\hline 10 & 0,25 & 89,2 & 83,4 & 210,7 & 179,2 & 178,6 \\
\hline 11 & 0,5 & 94,6 & 89,7 & 209,5 & 194,4 & 195,4 \\
\hline 12 & 0,5 & 85,9 & 80,8 & 195,8 & 181,6 & 182,4 \\
\hline 13 & 0,5 & 84,7 & 79,3 & 193,4 & 178,3 & 178,9 \\
\hline 14 & 0,5 & 80,7 & 75,5 & 179,7 & 168,4 & 168,8 \\
\hline 15 & 0,75 & 91,2 & 85,6 & 243,5 & 199,1 & 196,6 \\
\hline 16 & 0,75 & 81,6 & 77,1 & 233,4 & 197,1 & 194,1 \\
\hline 17 & 0,75 & 88,1 & 82,1 & 241,9 & 202,3 & 200,3 \\
\hline 18 & 0,75 & 81,2 & 75,9 & 228,5 & 191,4 & 190 \\
\hline 19 & 1 & 115,1 & 107 & 234,4 & 208,15 & 208,1 \\
\hline 20 & 1 & 115 & 107 & 231,18 & 207,2 & 206,9 \\
\hline 21 & 1 & 114,5 & 107,2 & 238,1 & 216,72 & 216,4 \\
\hline
\end{tabular}

TABELA 25- Peso dos corpos impregnados e não impregnados ESPÉCIE:Eucalipto citriodora

\begin{tabular}{|c|c|c|c|c|c|c|}
\hline SÉRIE & $\mathrm{p}(\mathrm{MPa})$ & $\mathrm{M}_{\mathrm{n}}(\mathrm{g})$ & $\mathrm{M}_{\mathrm{o}}(\mathrm{g})$ & $\mathrm{M}_{\mathrm{ni}}(\mathrm{g})$ & $\mathrm{M}_{\mathrm{oi}}(\mathrm{g})$ & $\mathrm{M}_{\text {oica }}(\mathrm{g})$ \\
\hline 5 & 1 & 294,8 & 232,4 & 242,7 & 235,12 & 234,5 \\
\hline 6 & 1 & 262,3 & 213,3 & 226,6 & 220,7 & 220,2 \\
\hline 7 & 1 & 273,1 & 217 & 229 & 223,37 & 223 \\
\hline 8 & 1 & 272,9 & 214,44 & 229 & 221,62 & 221,5 \\
\hline
\end{tabular}

p-pressão de impregnação;

$M_{n}$ - Peso Verde; $M_{0}$ - Peso Seco; $M_{n i}$ - Peso Impregnado

$M_{o i}$ - Peso Seco impregnado

$M_{\text {oica- }}$ Peso seco impregnado na Estufa de Climatização

Com os dados das tabelas 24 e 25 pode-se calcular as respectivas densidades para cada fase do trabalho de impregnação dos corpos de prova, e com isso oferecerá condições de analisar a questão da absorção da resina estirênica pela madeira. Esses valores poderão ser vistos na tabela 26. 
TABELA 26- Valores de densidade dos corpos de prova impregnados e não impregnados.

ESPÉCIE:Pinus

\begin{tabular}{|c|c|c|c|c|c|c|}
\hline SÉRIE & $\mathrm{p}$ (MPa) & $\operatorname{Dv}(\mathrm{g} / \mathrm{cm} 3)$ & $D s(g / c m 3)$ & $\mathrm{Di}(\mathrm{g} / \mathrm{cm} 3)$ & Dsi(g/cm3) & Dsia(g/cm3) \\
\hline 7 & 0,25 & 0,32 & 0,30 & 0,74 & 0,63 & 0,62 \\
\hline 8 & 0,25 & 0,37 & 0,34 & 0,80 & 0,70 & 0,69 \\
\hline 9 & 0,25 & 0,33 & 0,31 & 0,76 & 0,66 & 0,65 \\
\hline 10 & 0,25 & 0,36 & 0,34 & 0,85 & 0,73 & 0,72 \\
\hline \multicolumn{2}{|c|}{ Média } & 0,35 & 0,32 & 0,79 & 0,68 & 0,67 \\
\hline \multicolumn{2}{|c|}{ Desvio Padrão } & 0,02 & 0,02 & 0,05 & 0,04 & 0,04 \\
\hline & & & & & & \\
\hline 12 & $\begin{array}{l}0,5 \\
0,5\end{array}$ & $\begin{array}{l}0,38 \\
0,35\end{array}$ & 0,36 & 0,84 & 0,78 & 0,78 \\
\hline 13 & 0.5 & 0.34 & 0.32 & 078 & 072 & 072 \\
\hline 14 & 0,5 & 0,32 & 0,3 & 0,72 & 0,68 & 0,68 \\
\hline \multicolumn{2}{|c|}{ Média } & 0,35 & 0,33 & 0,78 & 0,73 & 0,73 \\
\hline \multicolumn{2}{|c|}{ Desvio Padrão } & 0,02 & 0,02 & 0,05 & 0,04 & 0,04 \\
\hline & & & & & & \\
\hline 15 & 0,75 & 0,36 & 0,34 & 0,98 & 0,8 & 0,79 \\
\hline 16 & 0,75 & 0,33 & 0,32 & 0,95 & 0,81 & 0,79 \\
\hline 17 & 0,75 & 0,36 & 0,33 & 0,98 & 0,82 & 0,81 \\
\hline 18 & 0,75 & 0,33 & 0,31 & 0,93 & 0,78 & 0,78 \\
\hline \multicolumn{2}{|c|}{ Média } & 0,35 & 0,33 & 0,96 & 0,80 & 0,79 \\
\hline \multicolumn{2}{|c|}{ Desvio Padrão } & 0,02 & 0,01 & 0,02 & 0,02 & 0,01 \\
\hline & & & & & & \\
\hline 19 & 1 & 0,48 & 0,44 & 0,98 & 0,86 & 0,86 \\
\hline 20 & 1 & 0,49 & 0,45 & 0,98 & 0,88 & 0,88 \\
\hline 21 & 1 & 0,48 & 0,45 & 0,99 & 0,9 & 0,9 \\
\hline \multicolumn{2}{|c|}{ Média } & 0,48 & 0,45 & 0,98 & 0,88 & 0,88 \\
\hline \multicolumn{2}{|c|}{ Desvio Padrão } & 0,01 & 0,01 & 0,01 & 0,02 & 0,02 \\
\hline
\end{tabular}

TABELA 27- Valores de densidade dos corpos de prova impregnados e não impregnados.

ESPÉCIE:Eucalipto Citriodora

\begin{tabular}{|c|c|c|c|c|c|c|}
\hline SÉRIE & $\mathbf{p}(\mathbf{M P a})$ & $\mathbf{D v}(\mathbf{g} / \mathbf{c m} 3)$ & $\mathbf{D s}(\mathbf{g} / \mathbf{c m} 3)$ & $\mathbf{D i}(\mathbf{g} / \mathbf{c m} 3)$ & Dsi(g/cm3) & Dsia(g/cm3) \\
\hline 5 & 1 & 1,22 & 0,96 & 1 & 0,97 & 0,97 \\
\hline 6 & 1 & 1,09 & 0,88 & 0,94 & 0,91 & 0,91 \\
\hline 7 & 1 & 1,12 & 0,88 & 0,94 & 0,92 & 0,91 \\
\hline 8 & 1 & 1,11 & 0,87 & 0,93 & 0,9 & 0,9 \\
\hline Média & & $\mathbf{1 , 1 4}$ & $\mathbf{0 , 9 0}$ & $\mathbf{0 , 9 5}$ & $\mathbf{0 , 9 3}$ & $\mathbf{0 , 9 2}$ \\
\hline \multicolumn{2}{|l}{ Desvio Padrão } & $\mathbf{0 , 0 6}$ & $\mathbf{0 , 0 4}$ & $\mathbf{0 , 0 3}$ & $\mathbf{0 , 0 3}$ & $\mathbf{0 , 0 3}$ \\
\hline
\end{tabular}


Nas tabelas anteriores tem-se:

p-pressão de impregnação

$D_{v}$ - Densidade madeira verde

$D_{s}$ - Densidade madeira seca em estufa

$D_{i}$ - Densidade madeira impregnada com resina estirênica

$\mathrm{D}_{\mathrm{si}}$ - Densidade madeira impregnada seca em estufa

$D_{\text {sia- }}$ Densidade madeira impregnada seca em estufa de climatização.

$\mathrm{Na}$ figura 37 pode-se observar o gráfico de desempenho da densidade da madeira impregnada em relação à madeira não impregnada.

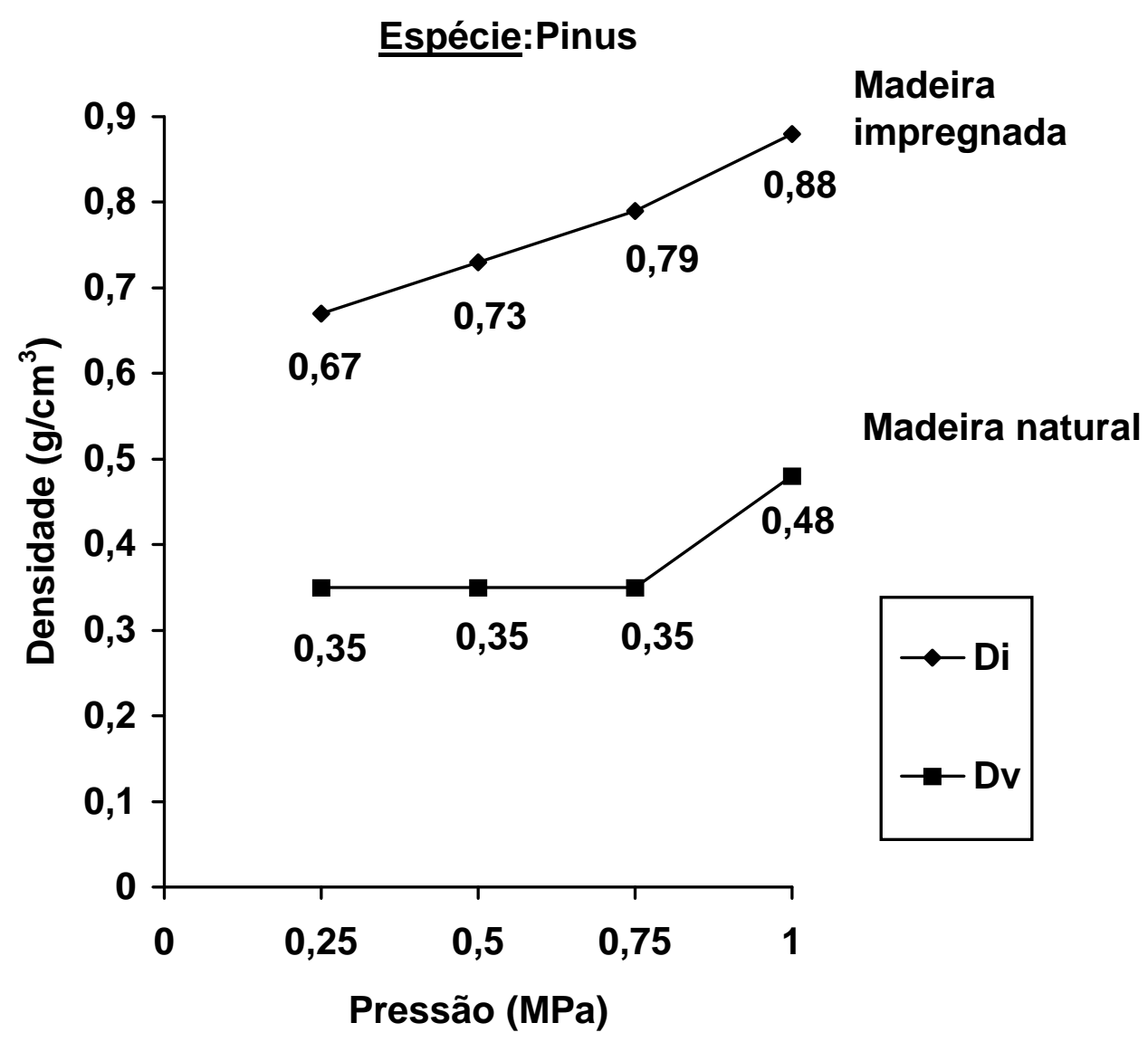

FIGURA 37- Valores comparativos de densidade de corpos de prova impregnados e não impregnados (Pinus). 


\subsubsection{Ensaios dos corpos de prova na compressão normal}

Os corpos de prova foram ensaiados por solicitação de compressão normal na máquina universal DARTEC de capacidade $100 \mathrm{kN}$, localizada nas dependências do LaMEM/SET/USP. Foram ensaiados inicialmente os corpos de prova da série 1 a 6 , e os resultados comparados com os corpos de prova impregnados da série 7 a 21 . Os métodos de ensaios foram propostos pelo PNBR 7190/96.

$\mathrm{Na}$ tabela 28 podem-se notar alguns dados importantes dos ensaios de compressão dos corpos de prova impregnados e não impregnados tais como:Carga de ruptura, tensão de ruptura e módulo de elasticidade. Nessa tabela os corpos de prova de Pinus, tiveram um desempenho satisfatório com o processo de impregnação.

TABELA 28- Pressão de impregnação, resistência à compressão normal às fibras e módulo de elasticidade normal às fibras de corpos de prova sem impregnação.

ESPÉCIE: Pinus

\begin{tabular}{|c|c|c|}
\hline C.P. & $\mathbf{f}_{\mathbf{c}, \mathbf{9 0}(\mathbf{M P a})}$ & $\mathbf{E}_{\mathbf{c}, \mathbf{9 0}(\mathbf{M P a})}$ \\
\hline 1 & 1 & 65 \\
\hline 2 & 3 & 249 \\
\hline 3 & 2 & 106 \\
\hline 4 & 2 & 91 \\
\hline 5 & 3 & 108 \\
\hline 6 & 4 & \\
\hline & & \\
\hline Média & $\mathbf{3}$ & $\mathbf{1 2 4}$ \\
\hline Desv Pad & $\mathbf{0 , 9 5}$ & $\mathbf{7 2}$ \\
\hline
\end{tabular}


TABELA 29- Pressão de impregnação, resistência à compressão normal às fibras, módulo de elasticidade normal às fibras de corpos de prova impregnados.

ESPÉCIE: Pinus

\begin{tabular}{|c|c|c|c|}
\hline C.P. & $\mathrm{p}(\mathrm{MPa})$ & $\mathrm{f}_{\mathrm{c}, 90}(\mathrm{MPa})$ & $E_{c, 90}(M P a)$ \\
\hline 7 & 0,25 & 5 & 323 \\
\hline 8 & 0,25 & 8 & 362 \\
\hline 9 & 0,25 & 8 & 374 \\
\hline 10 & 0,25 & 8 & 327 \\
\hline Média & & 8 & 346 \\
\hline \multicolumn{2}{|c|}{ Desvio Padrão } & 1 & 25 \\
\hline 11 & 0,5 & 7 & 290 \\
\hline 12 & 0,5 & 11 & 506 \\
\hline 13 & 0,5 & 9 & 419 \\
\hline 14 & 0,5 & 11 & 385 \\
\hline Média & & 9 & 400 \\
\hline \multicolumn{2}{|c|}{ Desvio Padrão } & 2 & 89 \\
\hline 15 & 0,75 & 7 & 289 \\
\hline 16 & 0,75 & 15 & 591 \\
\hline 17 & 0,75 & 16 & 249 \\
\hline 18 & 0,75 & 16 & 570 \\
\hline Média & & 14 & 425 \\
\hline \multicolumn{2}{|c|}{ Desvio Padrão } & 4 & 181 \\
\hline 1 & 1 & 16 & \\
\hline 20 & 1 & 16 & $\bar{\square}$ \\
\hline 21 & 1 & 17 & $\overline{-}$ \\
\hline Média & & 16 & $\bar{E}$ \\
\hline \multicolumn{2}{|c|}{ Desvio Padrão } & 1 & - \\
\hline & & & \\
\hline
\end{tabular}

$\mathrm{Na}$ figura 38 estão relacionados os valores médios da resistência à compressão normal às fibras obtidos na execução dos ensaios dos corpos de prova solicitados por compressão normal. 
Valores médios da resistência à compressão normal às fibras

ESPÉCIE:Pinus

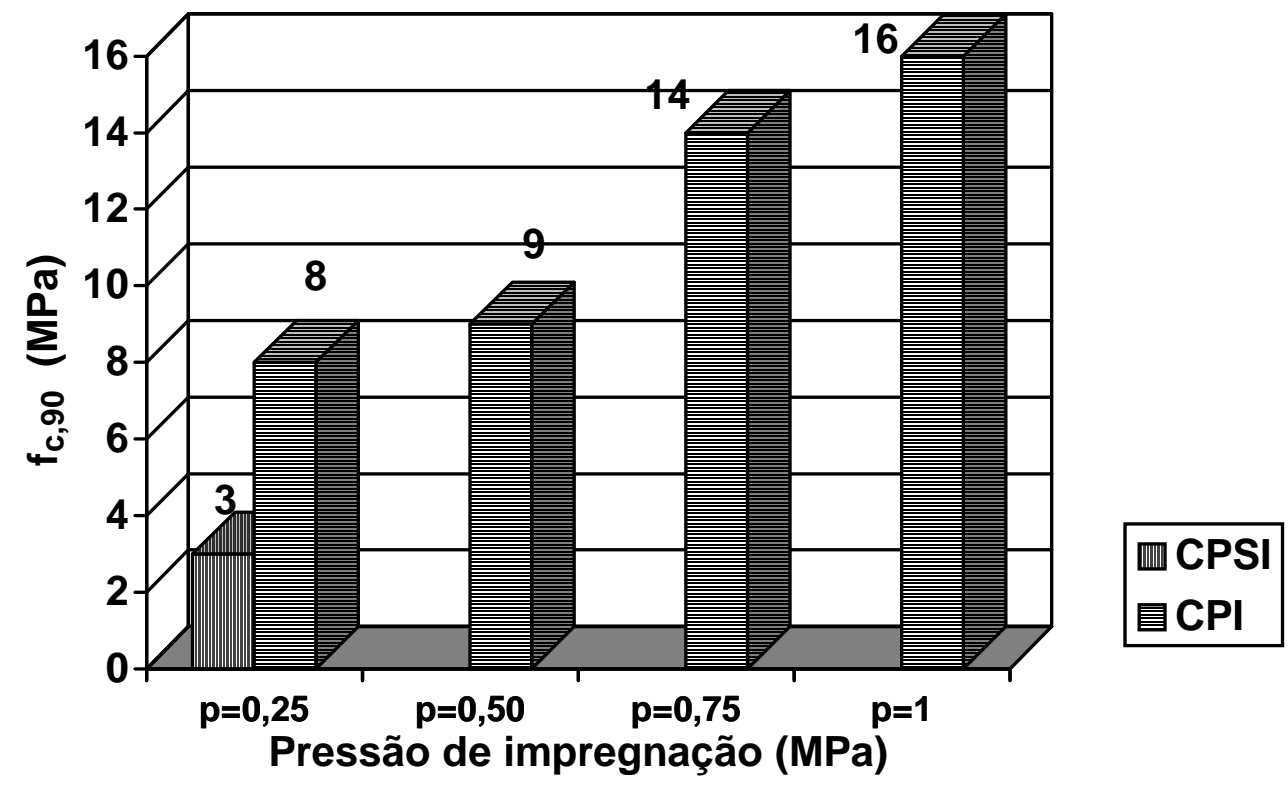

CPSI-Corpo de prova sem impregnação

CPI-Corpo de prova impregnado

FIGURA 38- Dados comparativos de resistência à compressão normal às fibras $\left(\mathbf{f}_{c, 90}\right)$ de corpos de prova impregnados e não impregnados da espécie :Pinus. 
TABELA 30- Pressão de impregnação, resistência à compressão normal às fibras e módulo de elasticidade normal às fibras de corpos de prova sem impregnação.

ESPÉCIE: Eucalipto citriodora

\begin{tabular}{|c|c|c|}
\hline C.P. & $\mathbf{f}_{\mathbf{c}, \mathbf{9 0}}(\mathbf{M P a})$ & $\mathbf{E}_{\mathbf{c}, \mathbf{9 0}(\mathbf{M P a})}$ \\
\hline 1 & 14 & 375 \\
\hline 2 & 13 & 399 \\
\hline 3 & 18 & 581 \\
\hline 4 & 21 & 487 \\
\hline Média & $\mathbf{1 7}$ & $\mathbf{4 6 1}$ \\
\hline Desv Pad & $\mathbf{4}$ & $\mathbf{9 4}$ \\
\hline & & \\
\hline & & \\
\hline & & \\
\hline
\end{tabular}

TABELA 31- Pressão de impregnação, resistência à compressão normal às fibras e módulo de elasticidade normal às fibras de corpos de prova com impregnação.

ESPÉCIE: Eucalipto citriodora

\begin{tabular}{|c|c|c|c|}
\hline C.P. & $\mathrm{p}(\mathrm{MPa})$ & $f_{c, 90}(M P a)$ & $E_{c, 90}(\mathrm{MPa})$ \\
\hline 5 & 1 & 23 & \\
\hline 6 & 1 & 16 & \\
\hline 7 & 1 & 17 & \\
\hline 8 & 1 & 19 & \\
\hline Média & & 19 & \\
\hline \multicolumn{2}{|c|}{ Desvio Padrão } & 3 & \\
\hline & & & \\
\hline
\end{tabular}


Valores médios da resistência à compressão normal às fibras

ESPÉCIE:Eucalipto citriodora

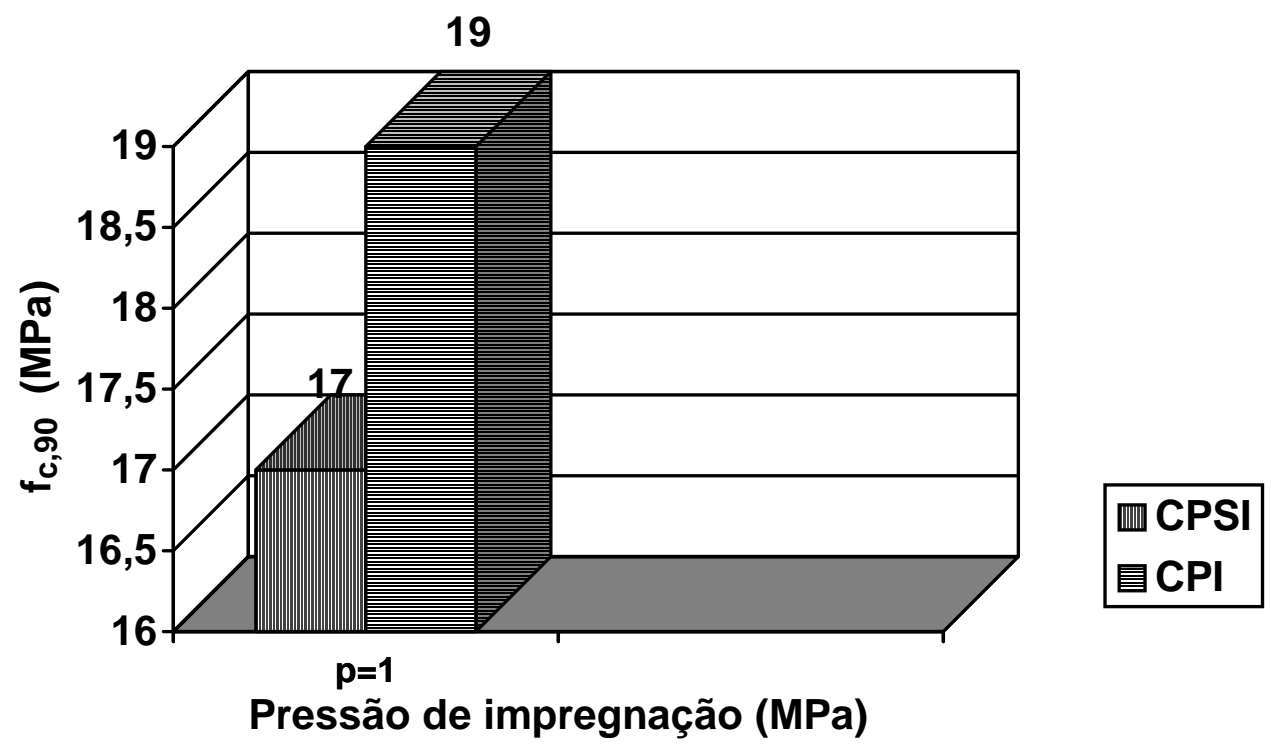

CPSI-Corpo de prova sem impregnação

CPI-Corpo de prova impregnado

FIGURA 39- Dados comparativos de resistência à compressão normal às fibras $\left(\mathbf{f}_{c, 90}\right)$ de corpos de prova impregnados e não impregnados da espécie :Eucalipto citriodora. 
Dois aspectos importantes são extraídos do ensaio anterior, é que a pressão de impregnação apresentou melhores resultados para valores de $1 \mathrm{MPa}$ e a madeira de Pinus apresenta melhores condições de impregnação do que o Eucalipto citriodora, por ser uma madeira de baixa densidade sendo que foi decidido adotar para os próximos ensaios esses dois parâmetros. Na figura 40 pode-se observar o corpo de prova de compressão normal $5 \times 5 \times 10 \mathrm{~cm}$ sendo ensaiado na máquina universal DARTEC.

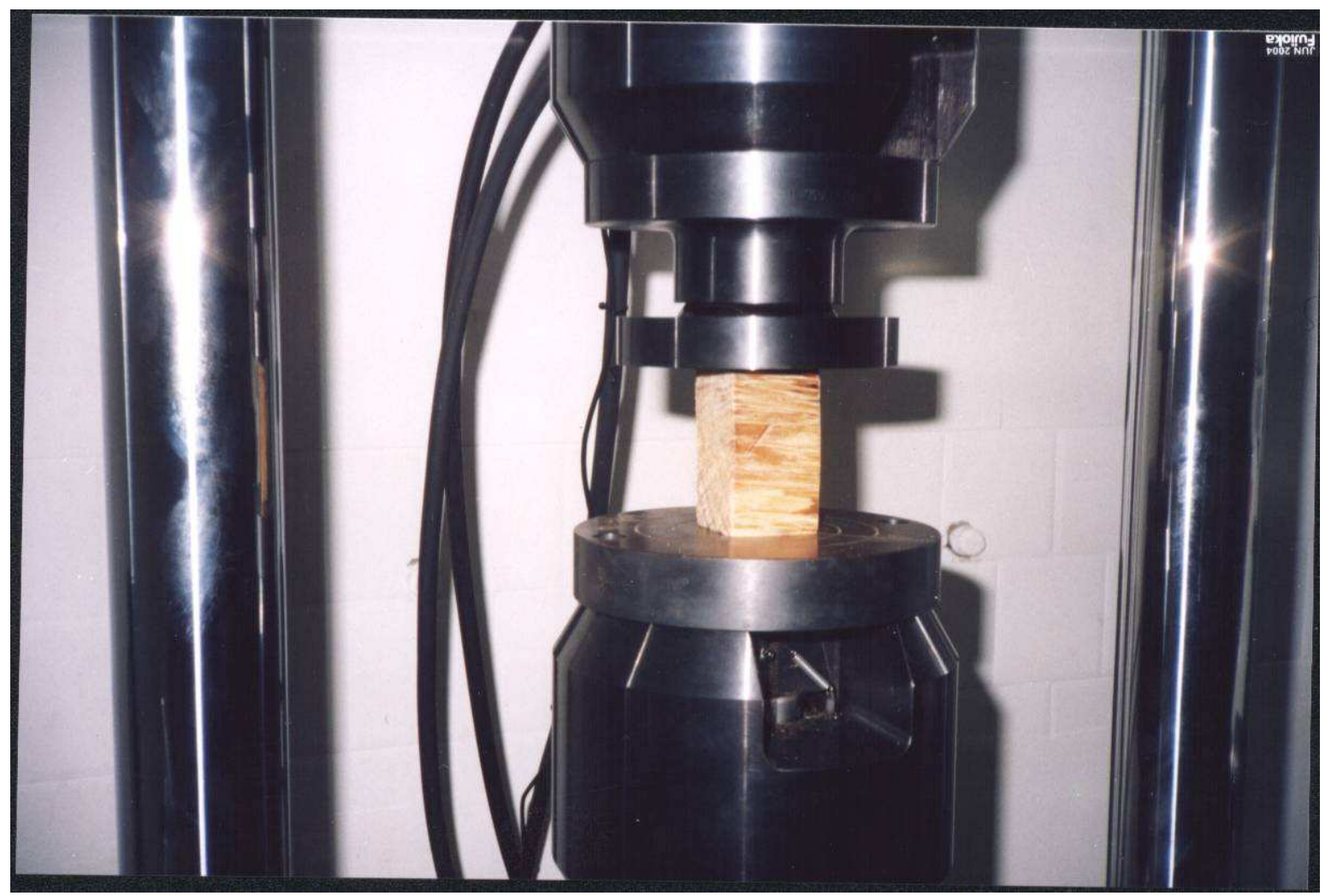

FIGURA 40- Corpo de prova $5 \times 5 \times 10 \mathrm{~cm}$ sendo ensaiado por solicitação de compressão normal. 


\subsubsection{CISALHAMENTO SIMPLES PARALELO ÀS FIBRAS}

Os corpos de prova foram confeccionados de acordo com o PNBR $7190 / 96$. Foram confeccionados um total de 24 corpos de prova conforme a figura 41 , sendo numerados desde a série 1 até 24 e comparados 02 grupos de 12 corpos de prova, uma série com impregnação e a outra sem impregnação. Os corpos de prova foram confeccionados da espécie Pinus e em seguida os mesmos foram marcados e medidos através do paquímetro digital, sendo posteriormente pesados e colocados na estufa para secagem a $100{ }^{\circ} \mathrm{C}$ durante um período de 48 horas. Os corpos de prova foram impregnados a uma pressão de $1 \mathrm{MPa}$ e os mesmos foram embrulhados em papel alumínio para secagem em estufa por um período de 48 horas a $60^{\circ} \mathrm{C}$. Em seguida os corpos de prova foram colocados na estufa de climatização durante um período de 48 horas a uma temperatura de $50^{\circ} \mathrm{C}$ para consolidação do processo de polimerização no interior da madeira.

$\mathrm{Na}$ tabela 32 pode-se notar os dados das respectivas massas dos corpos de prova da série 1 a 24 durante todo o processo de preparação e confecção até o processo de impregnação, e na tabelas 33 e 34 podem ser vistos os valores das cargas e tensões de ruptura durante o ensaio de cisalhamento simples paralelo às fibras. 


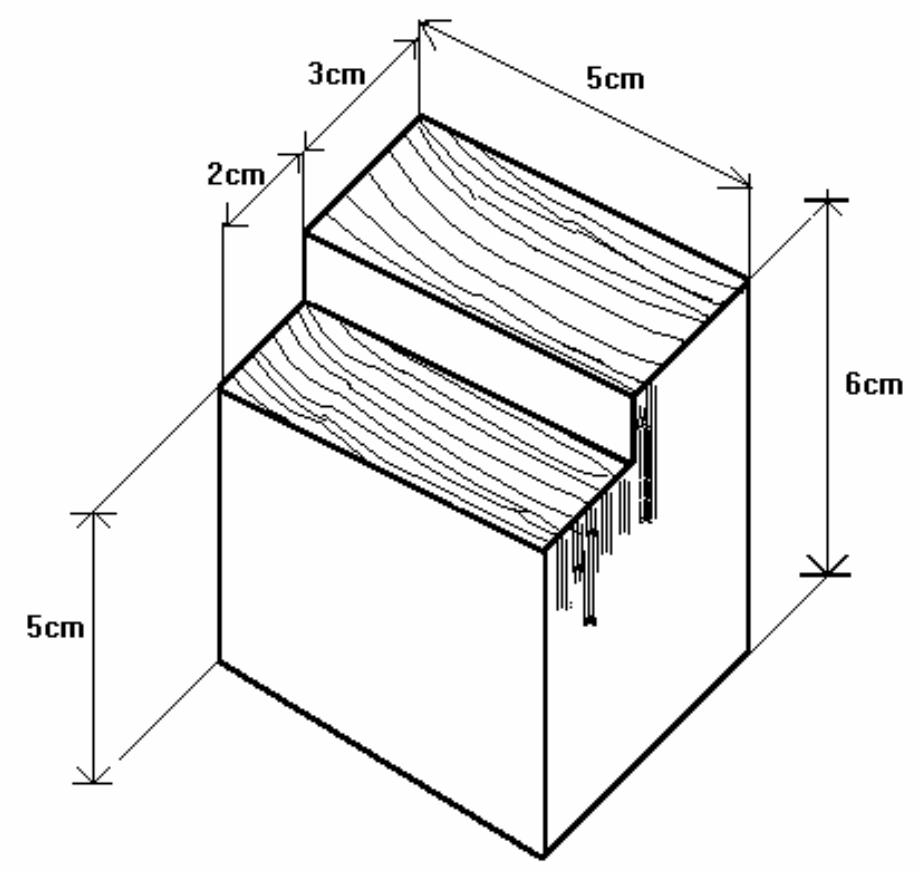

FIGURA 41 - Corpo de prova para ensaio de cisalhamento simples paralelo às fibras segundo o PNBR 7190/96. 
TABELA 32- Massa dos corpos de prova impregnados e não impregnados para o ensaio de cisalhamento simples paralelo às fibras.

ESPÉCIE:Pinus

\begin{tabular}{|c|c|c|c|c|c|}
\hline C.P. & Mn(g) & Mo(g) & Mni(g) & Moi(g) & Moica(g) \\
\hline 1 & 62,5 & 55,83 & - & - & - \\
\hline 2 & 61,8 & 55,25 & - & - & - \\
\hline 3 & 68,2 & 61,3 & - & - & - \\
\hline 4 & 63,4 & 57,23 & - & - & - \\
\hline 5 & 63,8 & 57,74 & - & - & - \\
\hline 6 & 61,1 & 54,86 & - & - & - \\
\hline 7 & 69,2 & 62,34 & - & - & - \\
\hline 8 & 64,6 & 58,79 & - & - & - \\
\hline 9 & 61,2 & 55,41 & - & - & - \\
\hline 10 & 61,3 & 55,27 & - & - & - \\
\hline 11 & 64,7 & 58,46 & - & - & - \\
\hline 12 & 62,7 & 56,47 & - & - & - \\
\hline 13 & 61,2 & 55,09 & 120,61 & 102,1 & 102,19 \\
\hline 14 & 64,2 & 58,17 & 114,86 & 99,57 & 99,6 \\
\hline 15 & 62,1 & 56,1 & 86 & 76,44 & 76,6 \\
\hline 16 & 65 & 58,76 & 118,56 & 99 & 99,05 \\
\hline 17 & 61,8 & 55,5 & 90,29 & 81,21 & 81,18 \\
\hline 18 & 65,2 & 58,62 & 73,11 & 68,3 & 68,35 \\
\hline 19 & 65,9 & 59,02 & 88,83 & 81,25 & 81,19 \\
\hline 20 & 61,1 & 55,19 & 109,07 & 93,98 & 93,88 \\
\hline 21 & 66 & 59,02 & 70,68 & 66,65 & 66,94 \\
\hline 22 & 61,6 & 55,15 & 66,95 & 62,74 & 62,9 \\
\hline 23 & 65,9 & 59,13 & 73,83 & 68,97 & 69,05 \\
\hline 24 & 66,3 & 59,63 & 79,1 & 74,92 & 75,13 \\
\hline Média & $\mathbf{6 3 , 7 8}$ & $\mathbf{5 7 , 4 3}$ & & & \\
\hline Desv.Pad. & $\mathbf{2 , 3 4 5 8 8 8}$ & $\mathbf{2 , 1 2 0 5 0 7}$ & & & \\
\hline Um(\%)= & $\mathbf{1 1 , 0 6 1 9 4}$ & & & & \\
\hline
\end{tabular}

$\mathbf{U}_{\mathrm{m}^{-}}$Umidade média $=(\mathrm{Mn}-\mathrm{Mo}) / \mathrm{Mo}^{*} 100$

$\mathbf{M}_{\mathbf{n}}$-Massa da madeira verde; $\mathbf{M}_{\mathbf{0}}$ - Massa da madeira seca

$\mathbf{M}_{\mathbf{n i}^{-}}$Massa da madeira impregnada; $\mathbf{M}_{\mathbf{o i}^{-}}$Massa da madeira seca impregnada; $\mathbf{M}_{\text {oica- }}$ Massa da madeira seca impregnada em estufa de climatização. 
TABELA 33- Carga e resistência dos corpos de prova não impregnados no ensaio de cisalhamento simples

ESPÉCIE:Pinus

\begin{tabular}{|c|c|c|c|}
\hline C.P. & $\mathbf{F}_{\mathbf{u}}(\mathbf{k N})$ & $\mathbf{A v}\left(\mathbf{c m}^{2}\right)$ & $\left.\mathbf{f}_{\mathbf{v}} \mathbf{( M P a}\right)$ \\
\hline 1 & 23,95 & 25,49 & 9 \\
\hline 2 & 21,7 & 25,64 & 9 \\
\hline 3 & 28 & 25,86 & 11 \\
\hline 4 & 20,4 & 25,76 & 8 \\
\hline 5 & 22,6 & 25,83 & 9 \\
\hline 6 & 23,8 & 25,95 & 9 \\
\hline 7 & 24,9 & 25,69 & 10 \\
\hline 8 & 19,6 & 25,63 & 8 \\
\hline 9 & 22,8 & 25,75 & 9 \\
\hline 10 & 24,1 & 25,83 & 9 \\
\hline 11 & 25,7 & 25,54 & 10 \\
\hline 12 & 22,6 & 25,86 & 9 \\
\hline & & & \\
\hline Média & $\mathbf{2 3}$ & $\mathbf{2 6}$ & $\mathbf{9}$ \\
\hline Desv.Pad. & $\mathbf{2}$ & $\mathbf{0 , 1 4}$ & $\mathbf{0 , 8 9}$ \\
\hline
\end{tabular}

TABELA 34- Carga e resistência dos corpos de prova impregnados no ensaio de cisalhamento simples; $p=1 \mathrm{MPa}$.

ESPÉCIE:Pinus

\begin{tabular}{|c|c|c|c|}
\hline $\mathbf{C .} \mathbf{P}$ & $\mathbf{F}_{\mathbf{u}}(\mathbf{k N})$ & $\mathbf{A}_{\mathbf{v}}\left(\mathbf{c m}^{\mathbf{2}}\right)$ & $\mathbf{f}_{\mathbf{v}}(\mathbf{M P a})$ \\
\hline 1 & 21,1 & 25,69 & 8 \\
\hline 2 & 25,5 & 25,89 & 10 \\
\hline 3 & 27,6 & 25,74 & 11 \\
\hline 4 & 13,7 & 25,64 & 5 \\
\hline 5 & 24,9 & 25,91 & 10 \\
\hline 6 & 33,1 & 25,85 & 13 \\
\hline 7 & 33 & 25,86 & 13 \\
\hline 8 & 36,6 & 25,84 & 14 \\
\hline 9 & 35,5 & 25,97 & 14 \\
\hline 10 & 28,4 & 25,78 & 11 \\
\hline 11 & 28,6 & 26,07 & 11 \\
\hline 12 & 36,4 & 25,9 & 14 \\
\hline Média & $\mathbf{2 9}$ & $\mathbf{2 6}$ & $\mathbf{1 1}$ \\
\hline DesvPad & $\mathbf{7}$ & $\mathbf{0 , 1 2}$ & $\mathbf{2 , 6 5}$ \\
\hline
\end{tabular}


Nas tabelas anteriores tem-se:

p-pressão de impregnação;

$\mathbf{F}_{\mathbf{u}}$ - Carga de Ruptura;

Av-Área de cisalhamento;

$\mathbf{f}_{\mathrm{v}}$ - resistência ao cisalhamento

$\mathrm{Na}$ figura 42 pode-se notar os dados comparativos das resistências dos corpos de prova no ensaio de cisalhamento simples.

VALORES MÉDIOS DAS RESISTÊNCIAS NO ENSAIO DE CISALHAMENTO SIMPLES; $\mathrm{p}=1 \mathrm{MPa}$

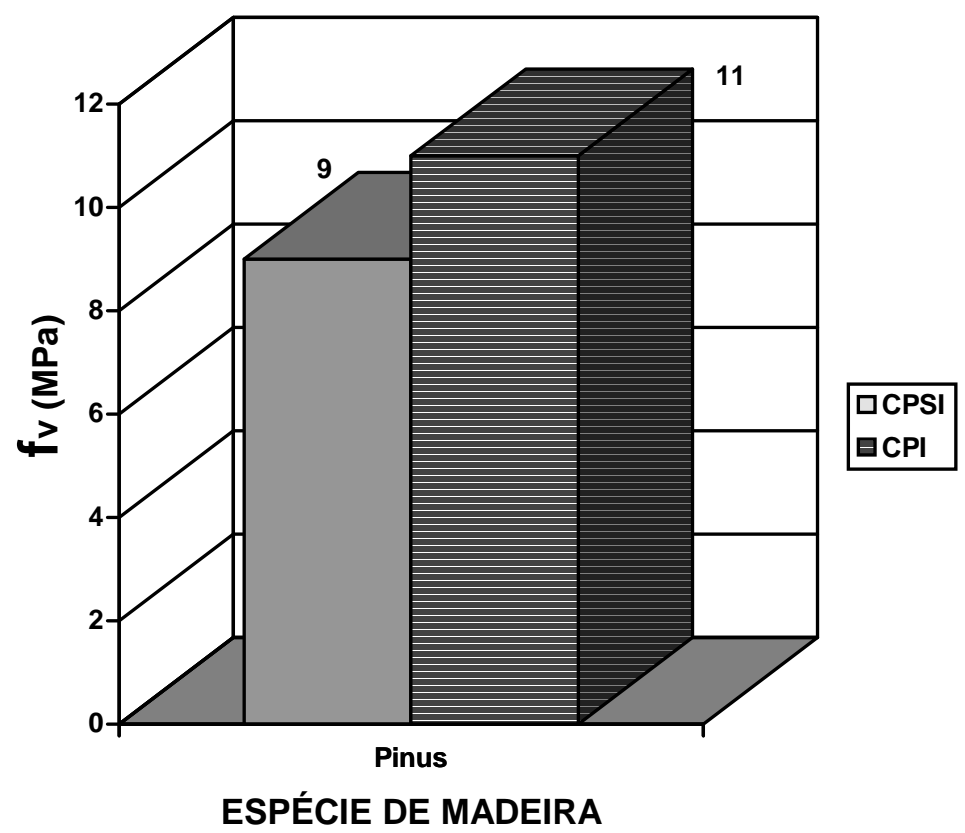

Aumento Percentual:

$\mathbf{f}_{\mathrm{v}}(\mathbf{C P I}) / \mathbf{f}_{\mathrm{v}}(\mathbf{C P S I})=11 / 9=1,22(22 \%) \boldsymbol{\uparrow}$

CPSI- Corpo de prova sem impregnação

CPI- Corpo de prova impregnado.

FIGURA 42- Dados comparativos de resistência no ensaio de cisalhamento simples paralelo às fibras. 


\subsubsection{CISALHAMENTO NA FLEXÃO EM CAVILHAS}

Em virtude dos modelos finais serem compostos de ligações com cavilhas impregnadas e não impregnadas solicitadas por compressão paralela e compressão normal às fibras, foi idealizado o ensaio de cisalhamento na flexão em cavilhas com os seguintes diâmetros:16 mm;18 $\mathrm{mm} ; 20 \mathrm{~mm}$ e o comprimento das mesmas da ordem de: $l=10 \mathrm{~d}$, onde $\mathbf{d}$ é 0 diâmetro da seção transversal da cavilha. As cavilhas foram confeccionadas da espécie Pinus no torno mecânico da carpintaria do LaMEM/SET/USP. $\mathrm{Na}$ tabela 35 pode-se observar as dimensões das cavilhas após a sua confecção.

TABELA 35- Dimensões principais das cavilhas ESPÉCIE:Pinus

\begin{tabular}{|c|c|c|}
\hline C.P. & $\mathbf{d}(\mathbf{c m})$ & $\boldsymbol{l}(\mathbf{c m})$ \\
\hline 1 & 1,522 & 16,2 \\
\hline 2 & 1,671 & 14,52 \\
\hline 3 & 1,624 & 16 \\
\hline 4 & 1,636 & 16 \\
\hline 5 & 1,631 & 16 \\
\hline 6 & 1,631 & 16,1 \\
\hline 7 & 1,894 & 18,1 \\
\hline 8 & 1,894 & 18,2 \\
\hline 9 & 1,795 & 18,2 \\
\hline 10 & 1,875 & 18,3 \\
\hline 11 & 1,911 & 18,2 \\
\hline 12 & 1,892 & 18,3 \\
\hline 13 & 2,07 & 20 \\
\hline 14 & 2,069 & 19,98 \\
\hline 15 & 2,061 & 19,9 \\
\hline 16 & 2,086 & 20 \\
\hline 17 & 2,014 & 20 \\
\hline 18 & 2,124 & 19,9 \\
\hline
\end{tabular}




\subsubsection{Secagem e impregnação das cavilhas}

Os corpos de prova foram colocados para secagem na estufa a uma temperatura de $100^{\circ} \mathrm{C}$ no período de 48 horas e em seguida os corpos de prova foram impregnados a uma pressão de impregnação $1 \mathrm{MPa}$ durante 30 minutos, e os mesmos foram colocados para secagem a uma temperatura de $60^{\circ} \mathrm{C}$ durante 48 horas. Em seguida os corpos de prova foram colocados na estufa de climatização a uma temperatura de $50^{\circ} \mathrm{C}$ durante 48 horas para retirar o excesso de resina de impregnação. Na tabela 36 pode-se notar os valores das massas dos corpos de prova desde a etapa de confecção até a fase final de impregnação.

TABELA 36- Massa das cavilhas impregnadas e não impregnadas ESPÉCIE:Pinus

\begin{tabular}{|c|c|c|c|c|}
\hline C.P. & Mn(g) & Mo(g) & Mni(g) & Moi(g) \\
\hline 1 & 15,82 & 14,25 & & \\
\hline 2 & 14,52 & 13,03 & & \\
\hline 3 & 16,72 & 15,03 & & \\
\hline 4 & 15,95 & 14,3 & 32,67 & 28,09 \\
\hline 5 & 12,96 & 11,72 & 31,73 & 27,71 \\
\hline 6 & 15,04 & 13,49 & 32,42 & 26,83 \\
\hline 7 & 21,96 & 19,69 & & \\
\hline 8 & 20,26 & 18,22 & & \\
\hline 9 & 18,42 & 16,56 & & \\
\hline 10 & 20,13 & 18,11 & 41,42 & 37,81 \\
\hline 11 & 24,29 & 21,93 & 48,63 & 44,23 \\
\hline 12 & 21,01 & 18,89 & 47,21 & 42,53 \\
\hline 13 & 27,86 & 24,92 & & \\
\hline 14 & 24,94 & 22,35 & & \\
\hline 15 & 30,74 & 27,51 & & \\
\hline 16 & 26,92 & 24,13 & 64,35 & 60,17 \\
\hline 17 & 24,33 & 21,85 & 58,62 & 52,44 \\
\hline 18 & 44,42 & 39,81 & 65,3 & 59,65 \\
\hline
\end{tabular}




\subsubsection{Ensaio de cisalhamento na flexão das cavilhas}

Os corpos de prova foram ensaiados na Máquina Universal DARTEC do LaMEM/SET/USP com capacidade nominal de 100 kN.Na figura 43 observa-se como foi idealizado o ensaio de flexão das cavilhas no referido equipamento e na figura 44 pode-se notar uma dada cavilha sendo ensaiada na máquina Universal DARTEC.

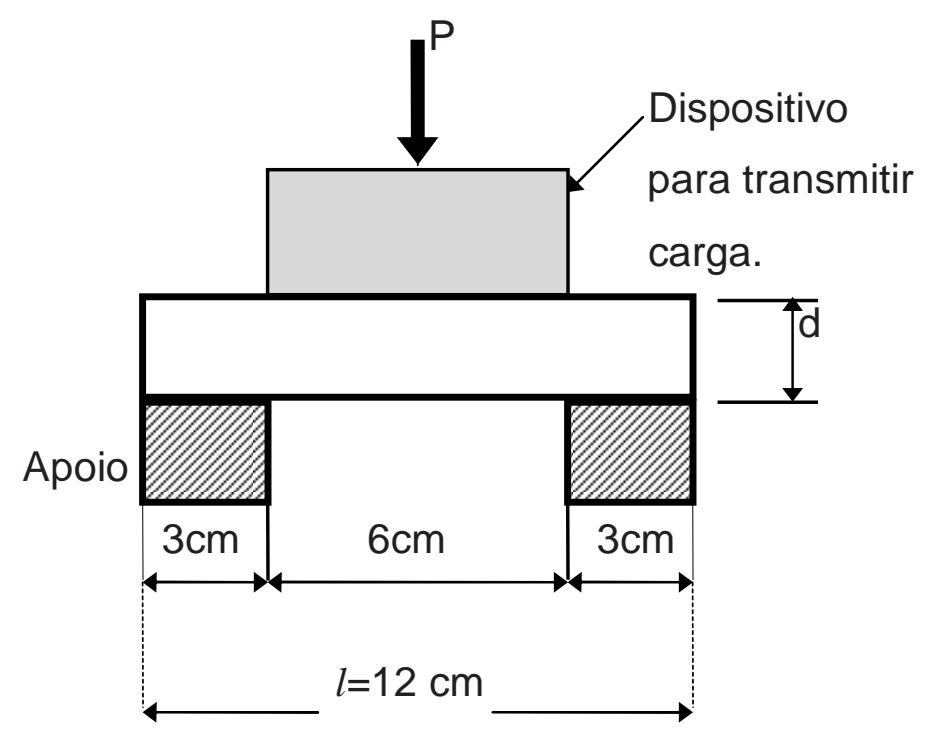

FIGURA 43- Ensaio de cisalhamento na flexão em cavilhas. 


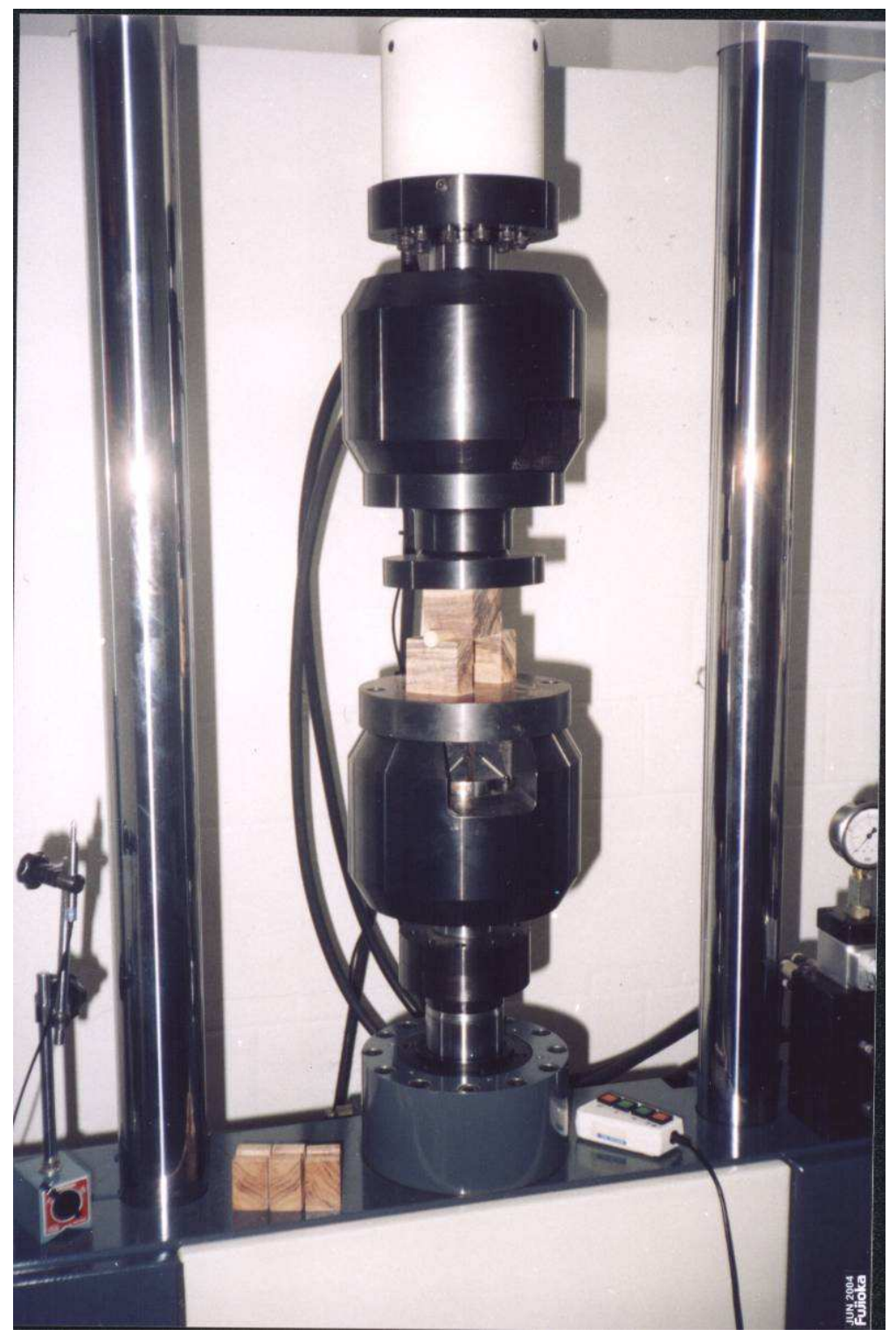

FIGURA 44- Ensaio de cisalhamento na flexão em cavilhas na máquina universal DARTEC do LaMEM/SET/USP. 
$\mathrm{Na}$ tabela 37 podemos observar os resultados dos ensaios de cisalhamento na flexão nas cavilhas através da máquina DARTEC.

TABELA 37- Cargas de ruptura no ensaio cisalhamento na flexão de cavilhas

ESPÉCIE:Pinus

\begin{tabular}{|c|c|c|c|}
\hline C.P. & $\mathbf{d}(\mathbf{m m})$ & $\mathbf{F}_{\mathbf{u}}(\mathbf{k N})$ & $\mathbf{O B S}$. \\
\hline 13 & 20,7 & 7 & $\mathrm{CPSI}$ \\
\hline 14 & 20,69 & 6 & $\mathrm{CPSI}$ \\
\hline 15 & 20,61 & 6,3 & $\mathrm{CPSI}$ \\
\hline Média & & $\mathbf{6 , 4 3}$ & $\mathbf{C P S I}$ \\
\hline Desv.Pad. & & $\mathbf{0 , 5 1}$ & $\mathbf{C P S I}$ \\
\hline 16 & 20,86 & 13 & $\mathrm{CPI}$ \\
\hline 17 & 20,14 & 11,15 & $\mathrm{CPI}$ \\
\hline 18 & 21,24 & 20 & $\mathrm{CPI}$ \\
\hline Média & & $\mathbf{1 4 , 7 2}$ & $\mathbf{C P I}$ \\
\hline Desv.Pad & & $\mathbf{4 , 6 7}$ & $\mathbf{C P I}$ \\
\hline 9 & 17,95 & 5 & $\mathrm{CPSI}$ \\
\hline 8 & 18,94 & 5 & $\mathrm{CPSI}$ \\
\hline 7 & 18,94 & 6 & $\mathrm{CPSI}$ \\
\hline Média & & $\mathbf{5 , 3 3}$ & $\mathbf{C P S I}$ \\
\hline Desv.Pad. & & $\mathbf{0 , 5 7 7 3 5}$ & $\mathbf{C P S I}$ \\
\hline 12 & 18,92 & 15 & $\mathrm{CPI}$ \\
\hline 10 & 18,75 & 7 & $\mathrm{CPI}$ \\
\hline 11 & 19,11 & 4,5 & $\mathrm{CPI}$ \\
\hline Média & & $\mathbf{8 , 8 3}$ & $\mathbf{C P I}$ \\
\hline Desv.Pad. & & $\mathbf{5 , 4 8}$ & $\mathbf{C P I}$ \\
\hline 3 & 16,24 & 5 & $\mathrm{CPSI}$ \\
\hline 2 & 16,71 & 4 & $\mathrm{CPSI}$ \\
\hline 1 & 15,22 & 4,5 & $\mathrm{CPSI}$ \\
\hline Média & & $\mathbf{4 , 5}$ & $\mathbf{C P S I}$ \\
\hline Desv.Pad. & & $\mathbf{0 , 5}$ & $\mathbf{C P S I}$ \\
\hline 4 & 16,36 & 3,5 & $\mathrm{CPI}$ \\
\hline 5 & 16,31 & 6 & $\mathrm{CPI}$ \\
\hline 6 & 16,31 & 5,8 & $\mathrm{CPI}$ \\
\hline Média & & $\mathbf{5 , 1}$ & $\mathbf{C P I}$ \\
\hline Desv.Pad. & & $\mathbf{1 , 3 8 9 2 4 4}$ & $\mathbf{C P I}$ \\
\hline & & & \\
\hline & & & \\
\hline
\end{tabular}

$\mathbf{F}_{\mathbf{u}}$-Carga de ruptura

d - Diâmetro da seção transversal da cavilha

CPSI -Corpo de prova sem impregnação

CPI -Corpo de prova impregnado 


\subsubsection{Tensões tangenciais devido à flexão nas cavilhas}

O cálculo das tensões tangenciais devido à flexão nas cavilhas impregnadas e não impregnadas pode ser expressa conforme a expressão abaixo:

$$
\begin{gathered}
\tau_{u}=\frac{\mathrm{Vu} \times \mathrm{Sx}}{\mathrm{b} \times \mathrm{Ix}}=\frac{\mathrm{Vu} \times \frac{2 \mathrm{r}^{3}}{3}}{\mathrm{~d} \times \frac{\pi \mathrm{r}^{4}}{4}}=\frac{\frac{2 \mathrm{Vur}^{3}}{3}}{\frac{\mathrm{d} \pi \mathrm{r}^{4}}{4}}=\frac{2 \mathrm{Vur}^{3}}{3} \times \frac{4}{\pi \mathrm{dr} r^{4}}=\frac{8 \times \mathrm{Vu} \times \mathrm{r}^{3}}{3 \pi 2 \times \mathrm{r} \times \mathrm{r}^{4}}= \\
=\frac{8 \mathrm{Vur}^{3}}{6 \pi \mathrm{r}^{5}}=\frac{8 \mathrm{Vu}}{6 \pi \mathrm{r}^{2}}=\frac{8 \mathrm{Vu}}{6 \pi \times \frac{\mathrm{d}^{2}}{4}}=\frac{32 \mathrm{Vu}}{6 \pi \mathrm{d}^{2}}=\frac{16 \mathrm{Vu}}{3 \pi \mathrm{d}^{2}} \\
\tau_{\mathrm{u}}=\frac{16 \mathrm{Vu}}{3 \pi \mathrm{d}^{2}}
\end{gathered}
$$

Na tabelas 38 e 39 estão os valores das resistências ao cisalhamento na flexão das cavilhas impregnadas e não impregnadas para os respectivos diâmetros de 16; 18; e 20 mm.

TABELA 38- Resistências médias em cavilhas impregnadas no ensaio de cisalhamento na flexão; $p=1 \mathrm{MPa}$.

ESPÉCIE: Pinus

\begin{tabular}{|c|c|c|c|c|}
\hline SÉRIE & $\mathbf{d}(\mathbf{c m})$ & $\mathbf{F}_{\mathbf{u}}(\mathbf{k N})$ & $\mathbf{V}_{\mathbf{u}}(\mathbf{k N})$ & $\mathbf{f}_{\mathbf{v M}}(\mathbf{M P a})$ \\
\hline 1 & 1,6 & 5,1 & 2,55 & 17 \\
\hline & & & & \\
\hline 2 & 1,8 & 8,83 & 4,415 & 23 \\
\hline & & & & \\
\hline 3 & 2 & 14,72 & 7,36 & 31 \\
\hline & & & & \\
\hline
\end{tabular}

Nesta tabela $V_{\mathrm{u}}=\mathrm{F}_{\mathrm{u}} / 2$ ( $\mathrm{F}_{\mathrm{u}}$ é o valor obtido do ensaio) 
TABELA 39- Resistências médias em cavilhas não impregnadas no ensaio de cisalhamento na flexão.

ESPÉCIE: Pinus

\begin{tabular}{|c|c|c|c|c|}
\hline SÉRIE & $\mathbf{d}(\mathbf{c m})$ & $\mathbf{F}_{\mathbf{u}}(\mathbf{k N})$ & $\mathbf{V}_{\mathbf{u}}(\mathbf{k N})$ & $\mathbf{f}_{\mathbf{v M}}(\mathbf{M P a})$ \\
\hline 1 & 1,6 & 4,5 & 2,25 & 15 \\
\hline 2 & & & & \\
\hline & 1,8 & 5,33 & 2,665 & 14 \\
\hline 3 & 2 & 6,43 & 3,215 & 14 \\
\hline & & & & \\
\hline
\end{tabular}

$\mathrm{Na}$ figura 45 pode-se notar um gráfico comparativo dos dados da resistência ao cisalhamento na flexão das cavilhas impregnadas e não impregnadas para os respectivos diâmetros de 16; 18 e 20 mm.

\section{Valores médios das resistências no ensaio de cisalhamento na flexão de cavilhas. ESPÉCIE:Pinus}

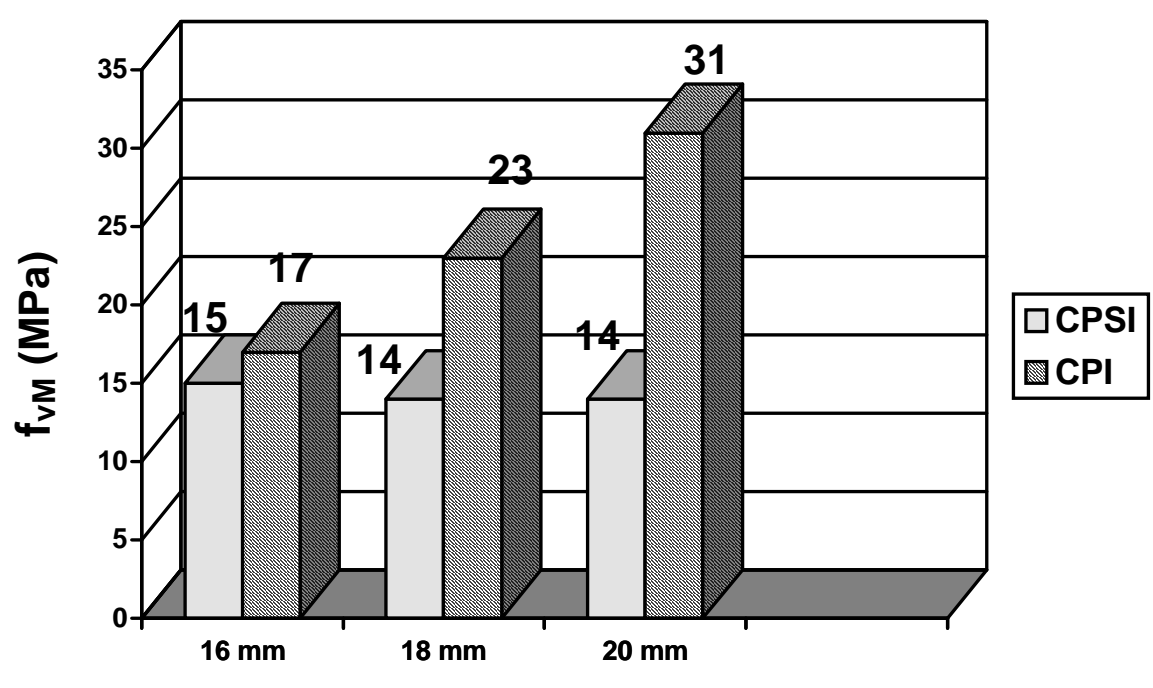

Diâmetro das cavilhas

Aumento Percentual:a) $f_{v M}(C P I) / f_{v M}(C P S I)=17 / 15=1,133(13,33 \%), d=16 \mathrm{~mm}$;

b) $f_{v M}(C P I) / f_{v M}(C P S I)=23 / 14=1,643(64,30 \%), d=18 \mathrm{~mm}$;

c) $f_{v M}(C P I) / f_{v M}(C P S I)=31 / 14=2,2143(121,43 \%) d=20 \mathrm{~mm}$;

FIGURA 45- Dados comparativos de resistência no ensaio de cisalhamento na flexão em cavilhas impregnadas e não impregnadas. 


\subsubsection{COMPRESSÃO PARALELA ÀS FIBRAS}

A idéia central sobre a determinação da resistência à compressão paralela às fibras da madeira utilizada na confecção das ligações com cavilhas impregnadas e não impregnadas constou de duas alternativas, sendo que a primeira foi realizar os ensaios em corpos de prova padronizados segundo o método do IBRAMEM(PNBR 7190/96), conforme a figura 46 e a segunda foi tentar uma aproximação de se obter a resistência a compressão paralela às fibras das cavilhas através de um modelo de corpo de prova mostrado na figura 47. O objetivo central desse ensaio foi principalmente verificar a questão dimensional dos corpos de prova para serem trabalhados no processo de impregnação levando em conta a questão da teoria da semelhança dos modelos, se isso afetaria com relevância a resistência dos corpos de prova na compressão paralela às fibras.

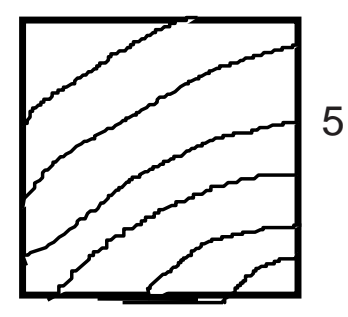

$5 \mathrm{~cm}$

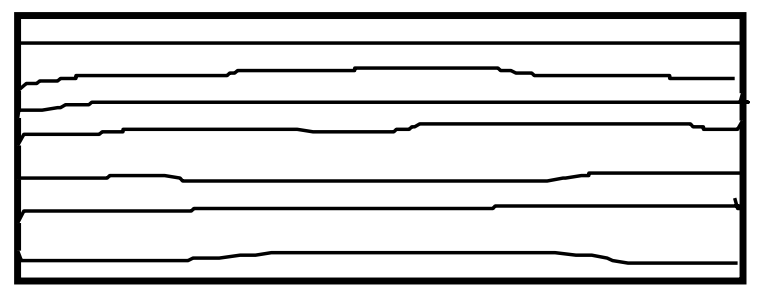

$20 \mathrm{~cm}$

FIGURA 46- Corpo de prova de compressão paralela (centímetros). 


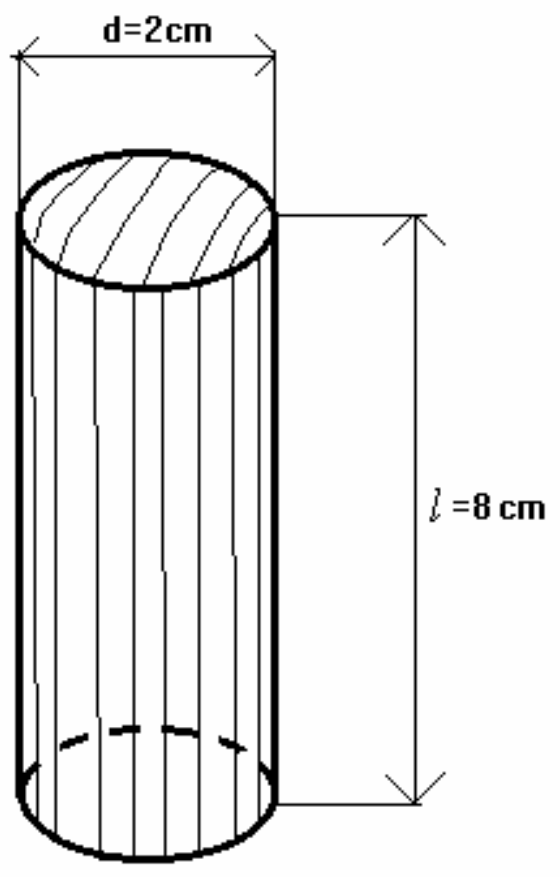

FIGURA 47- Modelo de cavilha para ensaio de compressão paralela às fibras idealizado no LaMEM/SET/USP. 
6.5.6.1 Confecção dos corpos de prova -Cavilhas: $d=2,0 \mathrm{~cm} ; l=8,0 \mathrm{~cm}$.

Inicialmente foram confeccionados 24 corpos de prova conforme a figura 47, e em seguida os mesmos foram marcados conforme a tabela 40, e extraídas as suas principais dimensões.

TABELA 40- Dimensões das cavilhas para ensaio de compressão paralela às fibras.

\section{ESPÉCIE:Pinus}

\begin{tabular}{|c|c|c|c|c||}
\hline $\mathbf{C . P .}$ & $\mathbf{d}(\mathbf{m m})$ & $\boldsymbol{l}(\mathbf{m m})$ & $\mathbf{A}\left(\mathbf{c m}^{\mathbf{2}}\right)$ & $\mathbf{V}\left(\mathbf{c m}^{\mathbf{3}} \mathbf{)}\right.$ \\
\hline 1 & 20,07 & 79,89 & 3,16 & 25,27 \\
\hline 2 & 19,97 & 79,79 & 3,13 & 24,99 \\
\hline 3 & 20,27 & 80,08 & 3,23 & 25,84 \\
\hline 4 & 20,13 & 79,59 & 3,18 & 25,33 \\
\hline 5 & 20,1 & 79,88 & 3,17 & 25,35 \\
\hline 6 & 19,78 & 79,97 & 3,07 & 24,57 \\
\hline 7 & 20,05 & 80,06 & 3,16 & 25,28 \\
\hline 8 & 20,12 & 78,68 & 3,18 & 25,02 \\
\hline 9 & 20,17 & 79,83 & 3,20 & 25,51 \\
\hline 10 & 20,16 & 79,71 & 3,19 & 25,44 \\
\hline 11 & 20,16 & 80,06 & 3,19 & 25,56 \\
\hline 12 & 20,1 & 79,95 & 3,17 & 25,37 \\
\hline 13 & 20,16 & 80,55 & 3,19 & 25,71 \\
\hline 14 & 20,09 & 79,91 & 3,17 & 25,33 \\
\hline 15 & 20,23 & 79,85 & 3,21 & 25,67 \\
\hline 16 & 20,06 & 80,11 & 3,16 & 25,32 \\
\hline 17 & 20,09 & 79,91 & 3,17 & 25,33 \\
\hline 18 & 20,18 & 79,59 & 3,20 & 25,46 \\
\hline 19 & 20,18 & 80,27 & 3,20 & 25,67 \\
\hline 20 & 20,1 & 79,91 & 3,17 & 25,36 \\
\hline 21 & 19,91 & 80 & 3,11 & 24,91 \\
\hline 22 & 20,08 & 80,17 & 3,17 & 25,39 \\
\hline 23 & 20,03 & 80,32 & 3,15 & 25,31 \\
\hline 24 & 20,07 & 79,97 & 3,16 & 25,30 \\
\hline
\end{tabular}




\subsubsection{Programação de secagem e impregnação}

Os corpos de prova foram colocados para secagem a uma temperatura de $100^{\circ} \mathrm{C}$, durante um período de 48 horas.Em seguida os mesmos foram impregnados a uma pressão de impregnação de $1 \mathrm{MPa}$.

$\mathrm{Na}$ tabela 41 pode-se observar os valores das massas dos referidos corpos de prova desde a fase de preparação até a fase final do processo de impregnação.

Depois que os corpos de prova passaram pelo processo de impregnação os mesmos foram colocados em estufa para secagem a uma temperatura de $60^{\circ} \mathrm{C}$ durante 48 horas e em seguida os mesmos foram pesados e colocados na estufa de climatização a uma temperatura de $5^{\circ} \mathrm{C}$ durante 48 horas, estando os mesmos aptos para serem ensaiados na compressão paralela às fibras conforme o esquema da figura 48.

$\mathrm{Na}$ tabelas 42 e 43 podem ser observados os resultados obtidos no ensaio de compressão paralela às fibras. 
TABELA 41- Massa das cavilhas desde a etapa de confecção até a fase de impregnação

ESPÉCIE:Pinus

\begin{tabular}{|c|c|c|c|c|c|}
\hline $\mathbf{C . P .}$ & $\mathbf{M}_{\mathbf{n}} \mathbf{( g )}$ & $\mathbf{M}_{\mathbf{o}}(\mathbf{g})$ & $\mathbf{M}_{\mathbf{n i}} \mathbf{( g )}$ & $\mathbf{M}_{\mathbf{~} \mathbf{i}}(\mathbf{g})$ & $\mathbf{M}_{\text {oica }} \mathbf{( g )}$ \\
\hline 1 & 13,67 & 11,9 & - & - & - \\
\hline 2 & 11,82 & 10,24 & - & - & - \\
\hline 3 & 12,73 & 11,13 & - & - & - \\
\hline 4 & 13,06 & 11,34 & - & - & - \\
\hline 5 & 14,25 & 12,37 & - & - & - \\
\hline 6 & 11,81 & 10,22 & - & - & - \\
\hline 7 & 14,2 & 12,28 & - & - & - \\
\hline 8 & 12,98 & 11,31 & - & - & - \\
\hline 9 & 13,16 & 11,44 & - & - & - \\
\hline 10 & 13,36 & 11,63 & - & - & - \\
\hline 11 & 13,3 & 11,63 & - & - & - \\
\hline 12 & 14,57 & 12,73 & & - & \\
\hline 13 & 13,23 & 11,53 & 14,23 & 13,04 & 13,1 \\
\hline 14 & 12,7 & 10,99 & 14,1 & 12,77 & 12,9 \\
\hline 15 & 13 & 11,25 & 14,16 & 12,85 & 12,9 \\
\hline 16 & 13,61 & 11,83 & 14,62 & 13,38 & 13,5 \\
\hline 17 & 13,98 & 12,11 & 15,36 & 13,91 & 14 \\
\hline 18 & 13,69 & 11,93 & 15,15 & 13,62 & 13,8 \\
\hline 19 & 12,3 & 10,68 & 21,65 & 17,62 & 17,6 \\
\hline 20 & 13,16 & 11,47 & 14,1 & 13,02 & 13 \\
\hline 21 & 14,38 & 12,49 & 16,3 & 14,28 & 14,5 \\
\hline 22 & 15,04 & 13,07 & 15,87 & 14,61 & 14,8 \\
\hline 23 & 12,73 & 11,1 & 15,18 & 12,59 & 12,8 \\
\hline 24 & 14,4 & 12,55 & 15,04 & 13,97 & 14 \\
\hline Média & $\mathbf{1 3 , 3 8}$ & $\mathbf{1 1 , 6 3}$ & $\mathbf{1 5 , 4 8}$ & $\mathbf{1 3 , 8 1}$ & $\mathbf{1 3 , 9 1}$ \\
\hline Desv.Pad. & $\mathbf{0 , 8 4}$ & $\mathbf{0 , 7 4}$ & $\mathbf{2 , 0 7}$ & $\mathbf{1 , 3 6}$ & $\mathbf{1 , 3 4}$ \\
\hline & & & & & \\
\hline & & & & & \\
\hline Umidade & $\mathbf{1 5 , 0 1}$ & & & & \\
\hline & & & & & \\
\hline
\end{tabular}


6.5.6.3 Ensaio de compressão paralela - Cavilhas $d=2,0 \mathrm{~cm} ; l=8,0 \mathrm{~cm}$.

$O$ ensaio tem como objetivo determinar a resistência à compressão paralela às fibras das cavilhas, e as mesmas são ensaiadas na Máquina Universal Amsler do LaMEM/SET/USP de capacidade $250 \mathrm{kN}$. Na figura 48 pode-se notar o esquema de ensaio da cavilha para determinação da carga de ruptura.

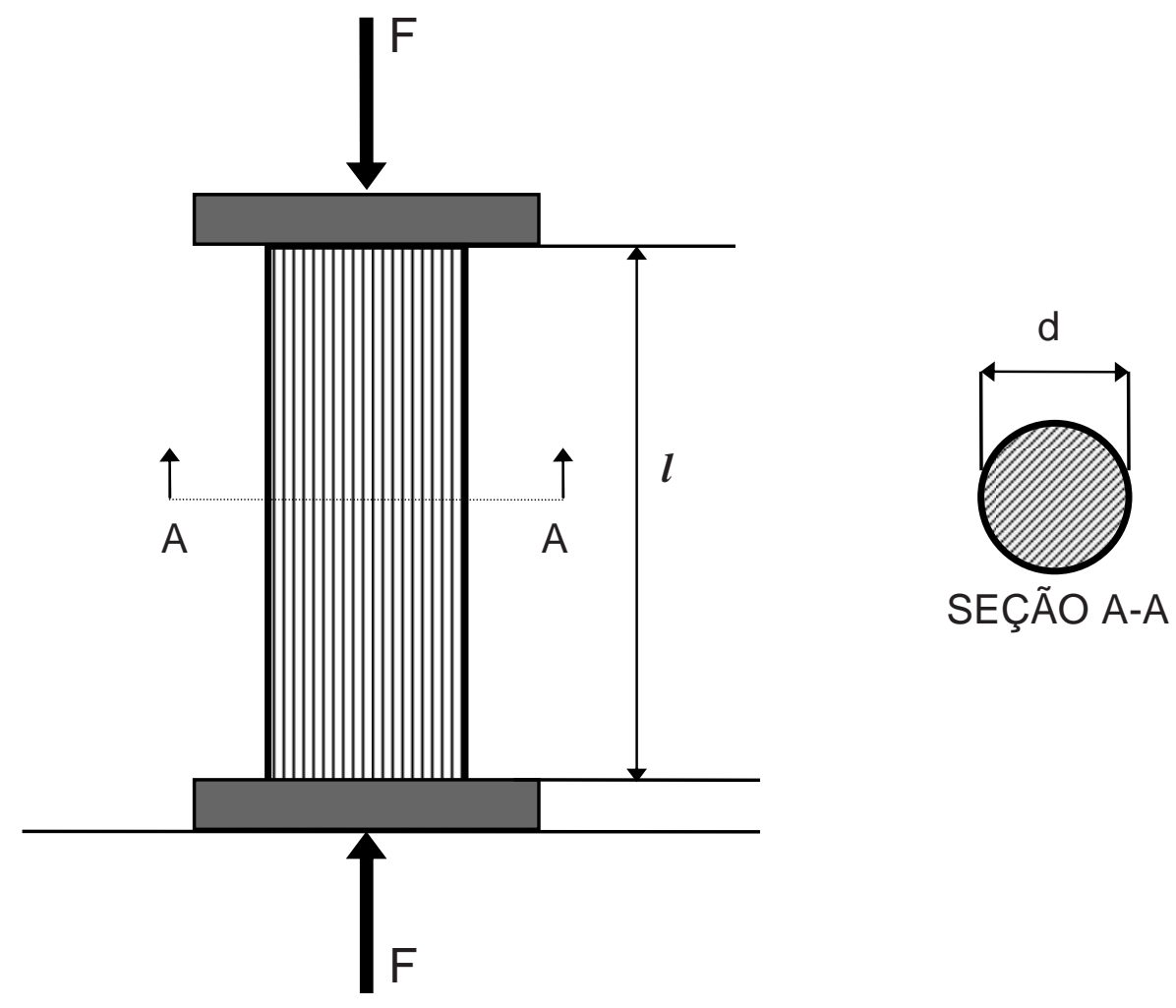

FIGURA 48- Esquema de ensaio de compressão paralela às fibras das cavilhas. 
TABELA 42- Resistência à compressão paralela às fibras das cavilhas não impregnadas.

ESPÉCIE:Pinus

\begin{tabular}{|c|c|c|c||}
\hline $\mathbf{C P}$ & $\mathbf{F}_{\mathbf{u}}(\mathbf{k N})$ & $\mathbf{A}(\mathbf{c m} \mathbf{)})$ & $\left.\mathbf{f}_{\mathbf{c}, \mathbf{0}} \mathbf{( M P a}\right)$ \\
\hline 1 & 16,6 & 3,16 & 53 \\
\hline 2 & 14,2 & 3,13 & 45 \\
\hline 3 & 14,7 & 3,23 & 46 \\
\hline 4 & 15,4 & 3,18 & 48 \\
\hline 5 & 16,5 & 3,17 & 52 \\
\hline 6 & 13,25 & 3,07 & 43 \\
\hline 7 & 15,35 & 3,16 & 49 \\
\hline 8 & 15,2 & 3,18 & 48 \\
\hline 9 & 15,1 & 3,2 & 47 \\
\hline 10 & 15 & 3,19 & 47 \\
\hline 11 & 14,7 & 3,19 & 46 \\
\hline 12 & 17,2 & 3,17 & 54 \\
\hline Média & $\mathbf{1 5}$ & $\mathbf{3}$ & $\mathbf{4 8}$ \\
\hline Desv.Pad. & $\mathbf{1 , 0 9}$ & $\mathbf{0 , 0 4}$ & $\mathbf{3 , 2 8}$ \\
\hline
\end{tabular}

TABELA 43- Resistência à compressão paralela às fibras das cavilhas impregnadas; $\mathrm{p}=1 \mathrm{MPa}$.

ESPÉCIE:Pinus

\begin{tabular}{|c|c|c|c|}
\hline C.P. & $\mathbf{F}_{\mathbf{u}}(\mathbf{k N})$ & $\mathbf{A}\left(\mathbf{c m}^{\mathbf{2}}\right)$ & $\left.\mathbf{f}_{\mathbf{c}, \mathbf{0}} \mathbf{( M P a}\right)$ \\
\hline 1 & 19,45 & 3,19 & 61 \\
\hline 2 & 17,5 & 3,17 & 55 \\
\hline 3 & 17,8 & 3,21 & 55 \\
\hline 4 & 19,35 & 3,16 & 61 \\
\hline 5 & 22,7 & 3,17 & 72 \\
\hline 6 & 18,6 & 3,2 & 58 \\
\hline 7 & 20,1 & 3,2 & 63 \\
\hline 8 & 19 & 3,17 & 60 \\
\hline 9 & 21,4 & 3,11 & 69 \\
\hline 10 & 20,9 & 3,17 & 66 \\
\hline 11 & 17,8 & 3,15 & 57 \\
\hline 12 & 18,1 & 3,16 & 57 \\
\hline Média & $\mathbf{1 9}$ & $\mathbf{3}$ & $\mathbf{6 1}$ \\
\hline Desv.Pad. & $\mathbf{1 , 6 2}$ & $\mathbf{0 , 0 3}$ & $\mathbf{5 , 3 0}$ \\
\hline
\end{tabular}


Na figura 49 pode-se notar os dados comparativos de resistências no ensaio de compressão paralela às fibras das cavilhas.

VALORES MÉDIOS DAS RESISTÊNCIAS À COMPRESSÃO PARALELA Às FIBRAS $\left(f_{c, o}\right)$ DAS CAVILHAS.

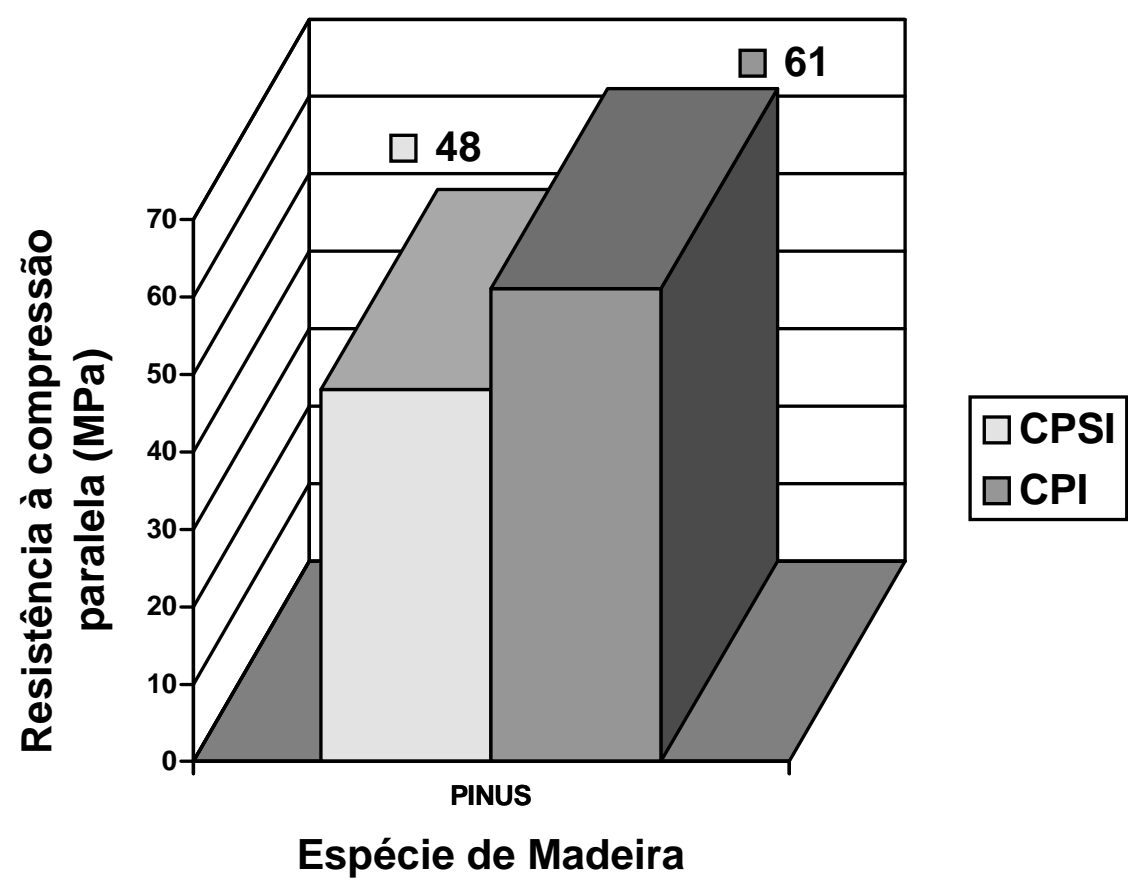

Aumento Percentual:

$\mathbf{f}_{\mathrm{c}, \mathrm{o}}(\mathrm{CPI}) \mathbf{f}_{\mathrm{c}, \mathrm{o}}(\mathrm{CPSI})=61 / 48=1,2708(27,08 \%) \uparrow$.

CPSI- Corpo de prova sem impregnar

CPI- Corpo de prova impregnado.

FIGURA 49- Dados comparativos de resistência à compressão paralela às fibras de cavilhas. 
$\mathrm{Na}$ figura 50 pode-se observar uma cavilha sendo ensaiada na máquina universal do LaMEM/SET/USP, sendo submetida à compressão paralela às fibras.

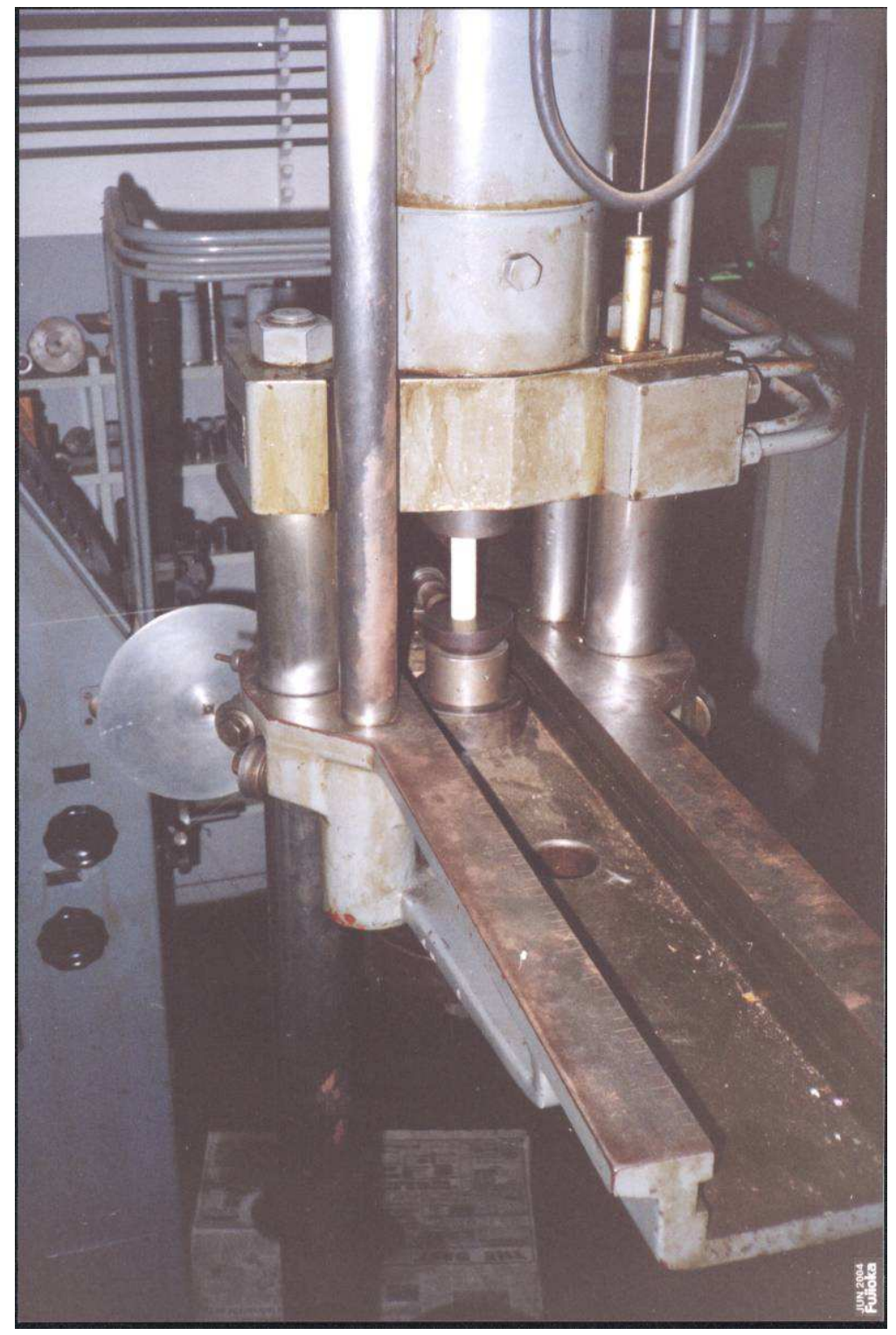

FIGURA 50- Cavilha sendo ensaiada sob compressão paralela às fibras na máquina universal Amsler do LaMEM/SET/USP. 


\subsubsection{Confecção dos corpos de prova - Seção nominal de 5x5x20cm}

Os corpos de prova foram confeccionados obedecendo ao esquema da metodologia de ensaios do PNBR 7190/96, conforme consta a figura 51, onde chamaremos de $: \mathbf{a}_{\mathbf{1}}, \mathbf{b}_{\mathbf{1}}$ as dimensões da seção transversal do corpo de prova e $\mathbf{c}_{1}$ o comprimento do mesmo. Foram confeccionados um total de 12 corpos de prova e na tabela 44 podem ser observadas as dimensões dos mesmos que foram extraídas através de um paquímetro digital.

TABELA 44 - Dimensões dos corpos de prova de compressão paralela às fibras.

\section{ESPÉCIE:Pinus}

\begin{tabular}{|c|c|c|c|c|c|}
\hline C.P. & $\mathbf{a}_{\mathbf{1}}(\mathbf{m m})$ & $\mathbf{b}_{\mathbf{1}}(\mathbf{m m})$ & $\mathbf{c}_{\mathbf{1}}(\mathbf{m m})$ & $\mathbf{A}\left(\mathbf{c m}^{2}\right)$ & $\mathbf{V}\left(\mathbf{c m}^{\mathbf{3}}\right)$ \\
\hline 1 & 50,33 & 50,16 & 201 & 25,25 & 507,44 \\
\hline 2 & 50,25 & 50,29 & 202 & 25,27 & 510,47 \\
\hline 3 & 50,27 & 50,29 & 202 & 25,28 & 510,67 \\
\hline 4 & 50,51 & 50,59 & 202 & 25,55 & 516,17 \\
\hline 5 & 50,36 & 50,34 & 203 & 25,35 & 514,63 \\
\hline 6 & 50,43 & 50,37 & 202 & 25,40 & 513,11 \\
\hline 7 & 50,89 & 50,15 & 201 & 25,52 & 512,98 \\
\hline 8 & 50 & 50,19 & 202 & 25,10 & 506,92 \\
\hline 9 & 50,04 & 50 & 202 & 25,02 & 505,40 \\
\hline 10 & 50,33 & 50,26 & 203 & 25,30 & 513,51 \\
\hline 11 & 50,71 & 50,22 & 204 & 25,47 & 519,52 \\
\hline 12 & 51,05 & 50,35 & 201 & 25,70 & 516,64 \\
\hline & & & & & \\
\hline
\end{tabular}




\subsubsection{Secagem e impregnação dos corpos de prova}

Os corpos de prova foram pesados e imediatamente colocados na estufa para o processo de secagem a uma temperatura de $100^{\circ} \mathrm{C}$ durante um período de 48 horas. Os corpos de prova da série 7 a 12 foram impregnados a uma pressão de impregnação de $1 \mathrm{MPa}$ e logo depois colocados para secagem a uma temperatura de $60^{\circ} \mathrm{C}$ d urante 48 horas, e a seguir foram colocados na estufa de climatização, a uma temperatura de $50^{\circ} \mathrm{C}$ durante 48 horas, e foram retirados para estarem preparados para 0 ensaio de compressão paralela às fibras.

$\mathrm{Na}$ tabela 45 pode-se notar os valores das massas dos corpos de prova durante todo o processo de secagem até a impregnação.

TABELA 45- Massa dos corpos de prova $5 \times 5 \times 20 \mathrm{~cm}$ ESPÉCIE:Pinus

\begin{tabular}{|c|c|c|l|l|l|}
\hline C.P. & $\mathbf{M}_{\mathbf{n}}(\mathbf{g})$ & $\mathbf{M}_{\mathbf{o}}(\mathbf{g})$ & $\mathbf{M}_{\mathbf{n i}}(\mathbf{g})$ & $\mathbf{M}_{\text {oi }}(\mathbf{g})$ & $\mathbf{M}_{\text {oica }}(\mathbf{g})$ \\
\hline 1 & 271,74 & 232,07 & - & - & - \\
\hline 2 & 273,12 & 235,64 & - & - & - \\
\hline 3 & 273,57 & 235,84 & - & - & - \\
\hline 4 & 272,91 & 234,92 & - & - & - \\
\hline 5 & 265,04 & 229,76 & - & - & - \\
\hline 6 & 257,9 & 221,51 & - & - & - \\
\hline 7 & 278,53 & 240,1 & 262,2 & 255,48 & 253,02 \\
\hline 8 & 279,97 & 239,7 & 265,1 & 258,53 & 258,84 \\
\hline 9 & 245,84 & 212,08 & 234,6 & 227,25 & 226,98 \\
\hline 10 & 275,67 & 236,85 & 260,5 & 254,62 & 255,55 \\
\hline 11 & 257,03 & 222,18 & 238,5 & 230,9 & 233,3 \\
\hline 12 & 249,4 & 216,21 & 237,5 & 230,31 & 230,45 \\
\hline Média & $\mathbf{2 6 6 , 7 3}$ & $\mathbf{2 2 9 , 7 4}$ & $\mathbf{2 4 9 , 7 3}$ & $\mathbf{2 4 2 , 8 5}$ & $\mathbf{2 4 3 , 0 2}$ \\
\hline Desv.Pad & $\mathbf{1 1 , 5 1}$ & $\mathbf{9 , 4 4}$ & $\mathbf{1 4 , 2 3}$ & $\mathbf{1 4 , 7 5}$ & $\mathbf{1 4 , 2 6}$ \\
\hline U\% & $\mathbf{1 6 , 1 0}$ & & & & \\
\hline
\end{tabular}




\subsubsection{Ensaio de compressão paralela às fibras}

Os corpos de prova são ensaiados na máquina universal AMSLER do LaMEM/SET/USP de capacidade nominal 250 kN, sob a aplicação de carga de compressão paralela às fibras e instalados relógios comparadores com precisão de $0,001 \mathrm{~mm}$, sendo registrados os valores de carga e os respectivos de deslocamentos, seguindo a metodologia de ensaios do LaMEM/SET/USP, e que pode ser visto na figura 51.

No ANEXO A pode-se observar os dados registrados de carga e deslocamento dos respectivos corpos de prova da série 1 a 12 , e os respectivos gráficos relacionando as tensões e deformações obtidas nos ensaios de compressão paralela às fibras. 


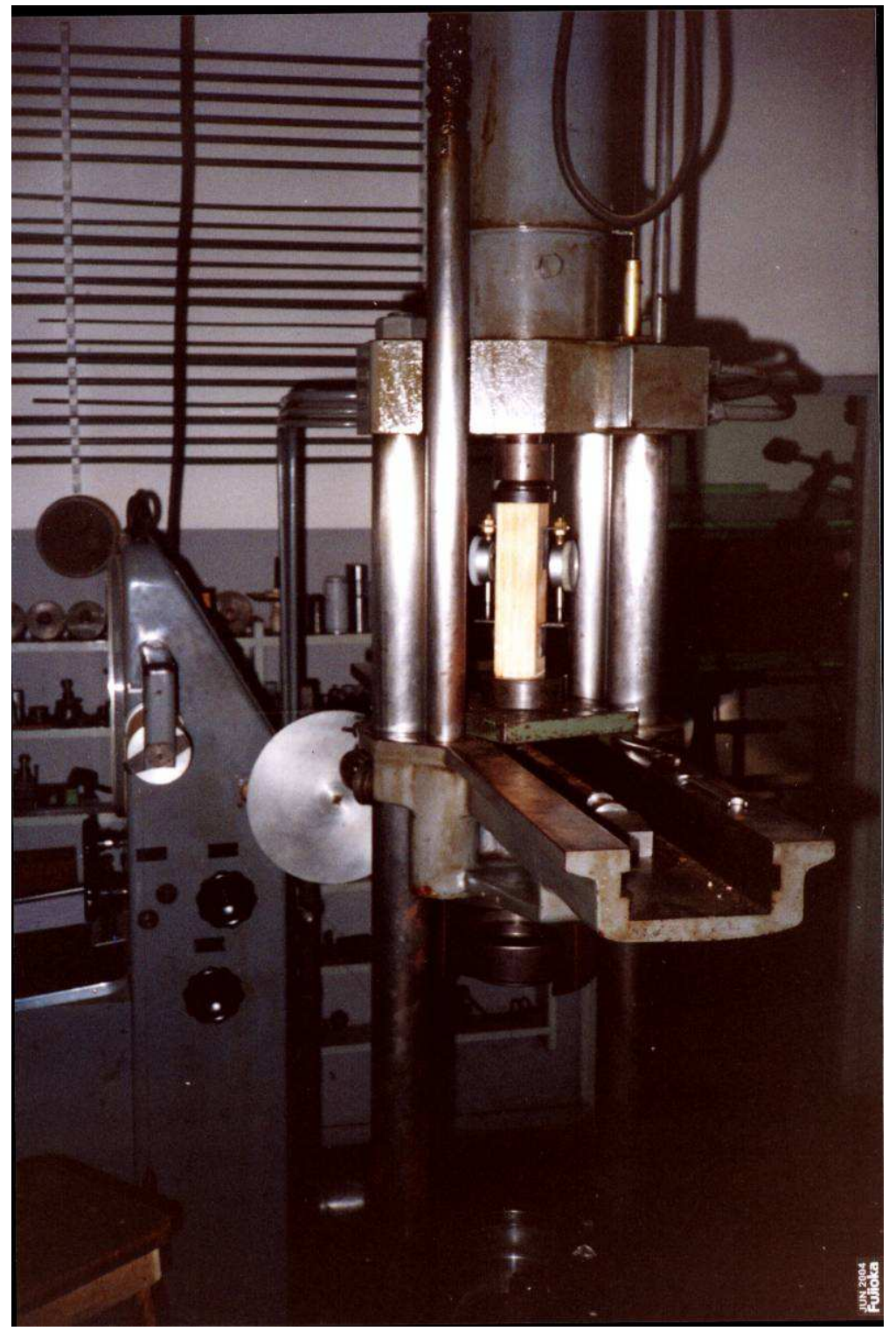

FIGURA 51- Ensaio de compressão paralela às fibras executado na máquina universal Amsler do LaMEM/SET/USP. 


\subsubsection{Análise dos ensaios de compressão paralela às fibras}

Nas tabelas 46 e 47 podem-se observar o resumo final dos resultados dos ensaios de compressão paralela às fibras, conforme o Anexo A, para caracterização das madeiras impregnadas e não impregnadas dos corpos de prova $5 \times 5 \times 20 \mathrm{~cm}$.

TABELA 46- Resistência à compressão paralela às fibras de corpos de prova $5 \times 5 \times 20 \mathrm{~cm}$,sem impregnação. Espécie:Pinus

\begin{tabular}{|c|c|c|c|c|}
\hline $\mathbf{C P}$ & EQUAÇÃO & $\mathbf{F}_{\mathbf{u}}(\mathbf{k N})$ & $\mathbf{f}_{\mathbf{c}, \mathbf{o}}(\mathbf{M P a})$ & $\mathbf{E}(\mathbf{M P a})$ \\
\hline 1 & $\sigma=5100,7 \varepsilon$ & 55 & $22^{*}$ & 5101 \\
\hline 2 & $\sigma=4012,9 \varepsilon$ & 49 & $20^{*}$ & 4013 \\
\hline 3 & $\sigma=8828,2 \varepsilon$ & 129,5 & 52 & 8828 \\
\hline 4 & $\sigma=5529,4 \varepsilon$ & 97 & 39 & 5529 \\
\hline 5 & $\sigma=7505,3 \varepsilon$ & 108,5 & 43 & 7505 \\
\hline 6 & $\sigma=8221,3 \varepsilon$ & 118 & 47 & 8221 \\
\hline Média & $\sigma=7521 \varepsilon$ & $\mathbf{1 1 3}$ & $\mathbf{4 5}$ & $\mathbf{7 5 2 1}$ \\
\hline Desv.Pad. & $\mathbf{1 4 3 4}$ & $\mathbf{1 4}$ & $\mathbf{6}$ & $\mathbf{1 4 3 4}$ \\
\hline
\end{tabular}

*Os resultados dos corpos de prova 1 e 2 foram abandonados.

TABELA 47- Resistência à compressão paralela às fibras de corpos de prova $5 \times 5 \times 20 \mathrm{~cm}, c o m$ impregnação; $\mathrm{p}=1 \mathrm{MPa}$. Espécie:Pinus

\begin{tabular}{|c|c|c|c|c|}
\hline $\mathbf{C P}$ & EQUAÇÃO & $\mathbf{F}_{\mathbf{u}}(\mathbf{k N})$ & $\mathbf{f}_{\mathbf{c}, \mathbf{o}}(\mathbf{M P a})$ & $\mathbf{E}(\mathbf{M P a})$ \\
\hline 1 & $\sigma=11576 \varepsilon$ & 154 & 62 & 11576 \\
\hline 2 & $\sigma=9827,3 \varepsilon$ & 172,5 & 69 & 9827 \\
\hline 3 & $\sigma=7074,6 \varepsilon$ & 139 & 56 & 7075 \\
\hline 4 & $\sigma=11226 \varepsilon$ & 172,5 & 69 & 11226 \\
\hline 5 & $\sigma=8615,9 \varepsilon$ & 143,5 & 57 & 8616 \\
\hline 6 & $\sigma=6583 \varepsilon$ & 125,5 & 50 & 6583 \\
\hline Média & $\sigma=9150 \varepsilon$ & $\mathbf{1 5 1}$ & $\mathbf{6 1}$ & $\mathbf{9 1 5 0}$ \\
\hline Desv.Pad. & $\mathbf{2 0 9 0}$ & $\mathbf{1 9}$ & $\mathbf{8}$ & $\mathbf{2 0 9 0}$ \\
\hline
\end{tabular}


Nas tabelas anteriores observa-se o seguinte aumento percentual da resistência à compressão paralela às fibras:

a) $f_{c, o}(C P I) / f_{c, o}(C P S I)=61 / 45=1,3556(35,56 \%) \uparrow$.

b) $E_{c, o}(C P I) / E_{c, o}(C P S I)=9150 / 7521=1,2166(21,66 \%) \uparrow$.

\subsubsection{TRAÇÃO PARALELA ÀS FIBRAS}

Os corpos de prova foram confeccionados seguindo a metodologia de ensaios do LaMEM/SET/USP, entretanto o comprimento do corpo de prova foi reduzido para adequar com as dimensões do reservatório de impregnação e as dimensões nominais de acordo com a figura 52. Inicialmente foram confeccionados 16 corpos de prova sendo que deste total 8 corpos sofreram o processo de impregnação.

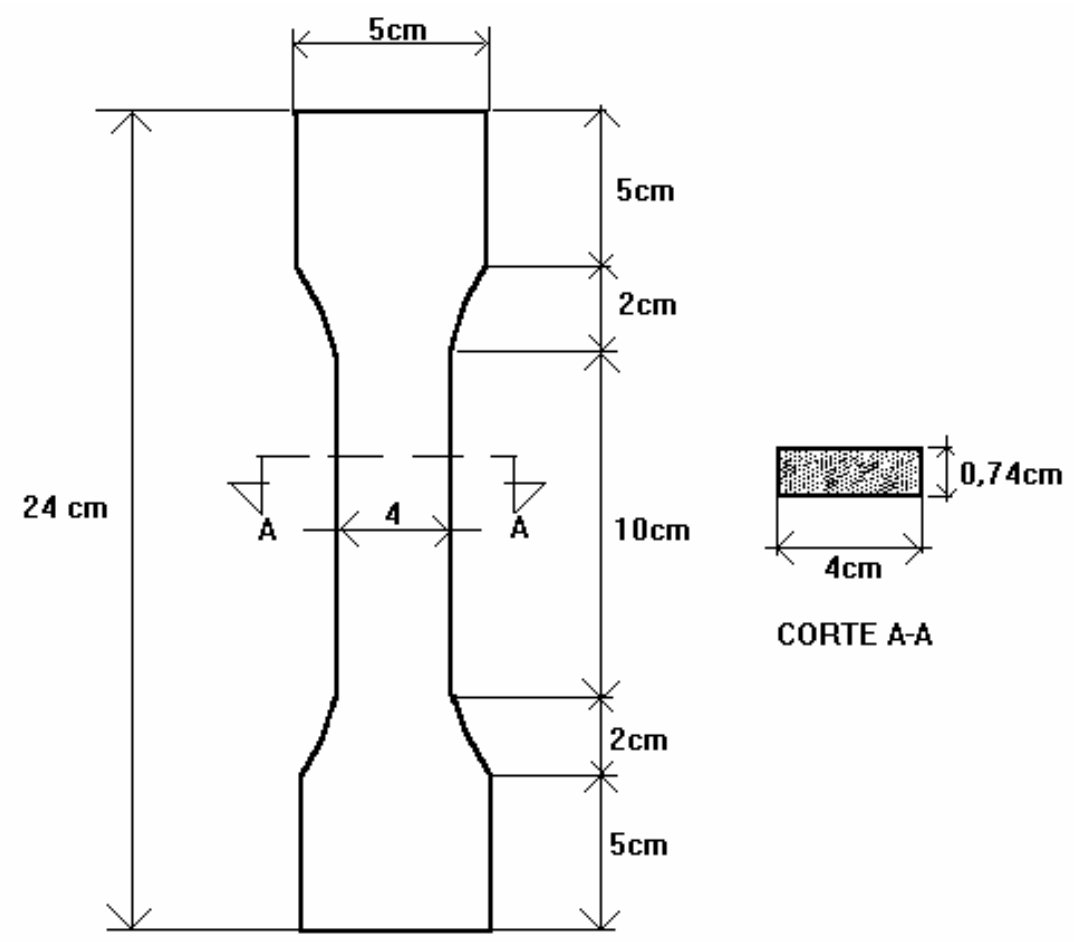

FIGURA 52-Valores nominais das dimensões do corpo de prova para ensaio de tração paralela às fibras. 


\subsubsection{Corpos de prova}

Os corpos de prova foram confeccionados da espécie de madeira de Pinus, obedecendo ao esquema da figura 53 e em seguida os corpos de prova foram marcados, pesados e medidos.
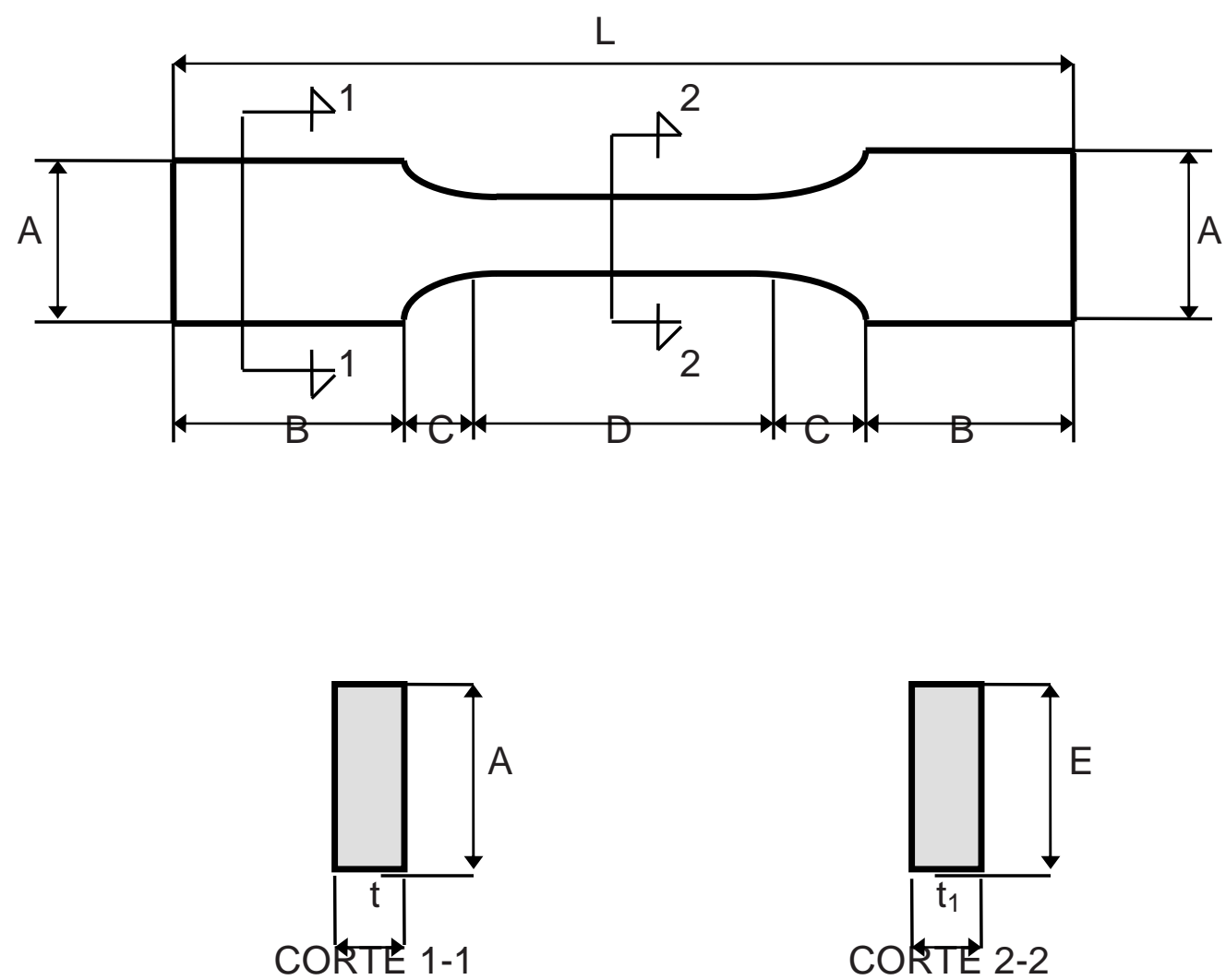

FIGURA 53- Principais dimensões para confecção dos corpos de prova de tração paralela às fibras. 
TABELA 48- Dimensões dos corpos de prova para o ensaio de tração paralela às fibras.

ESPÉCIE:Pinus

\begin{tabular}{|c|c|c|c|c|c|c|}
\hline $\mathbf{C P}$ & $\mathbf{A}(\mathbf{c m})$ & $\mathbf{B}(\mathbf{c m})$ & $\mathbf{C}(\mathbf{c m})$ & $\mathbf{D}(\mathbf{c m})$ & $\mathbf{L}(\mathbf{c m})$ & $\mathbf{t}(\mathbf{c m})$ \\
\hline T1 & 4,773 & 5 & 2 & 10 & 24 & 0,766 \\
\hline T2 & 5,038 & 5 & 2 & 10 & 24 & 0,646 \\
\hline T3 & 4,818 & 5 & 2 & 10 & 24 & 0,733 \\
\hline T4 & 4,869 & 5 & 2 & 10 & 24,1 & 0,766 \\
\hline T5 & 4,769 & 5 & 2 & 10 & 24,1 & 0,732 \\
\hline T6 & 4,753 & 5 & 2 & 10 & 24,1 & 0,775 \\
\hline T7 & 4,754 & 5 & 2 & 10 & 24 & 0,752 \\
\hline T8 & 5,042 & 5 & 2 & 10 & 24,2 & 0,688 \\
\hline TI1 & 5,046 & 5 & 2 & 10 & 24 & 0,687 \\
\hline TI2 & 5,079 & 5 & 2 & 10 & 24,2 & 0,653 \\
\hline TI3 & 5,038 & 5 & 2 & 10 & 24,1 & 0,691 \\
\hline TI4 & 5,032 & 5 & 2 & 10 & 24 & 0,693 \\
\hline TI5 & 5,038 & 5 & 2 & 10 & 23,9 & 0,619 \\
\hline TI6 & 5,02 & 5 & 2 & 10 & 24 & 0,706 \\
\hline TI7 & 4,976 & 5 & 2 & 10 & 24 & 0,758 \\
\hline TI8 & 5,031 & 5 & 2 & 10 & 24 & 0,658 \\
\hline & & & & & & \\
\hline
\end{tabular}

TABELA 48A- Dimensões dos corpos de prova.

\begin{tabular}{|c|c|c|c|}
\hline $\mathbf{C P}$ & $\mathbf{E}(\mathbf{m m})$ & $\mathbf{t}_{\mathbf{1}}(\mathbf{m m})$ & $\mathbf{A}(\mathbf{c m} \mathbf{2})$ \\
\hline $\mathrm{T} 1$ & 3,87 & 0,766 & 2,96 \\
\hline $\mathrm{T} 2$ & 4,008 & 0,757 & 3,03 \\
\hline $\mathrm{T} 3$ & 3,825 & 0,756 & 2,89 \\
\hline $\mathrm{T} 4$ & 3,861 & 0,795 & 3,07 \\
\hline T5 & 3,812 & 0,735 & 2,80 \\
\hline T6 & 3,831 & 0,778 & 2,98 \\
\hline T7 & 3,801 & 0,776 & 2,95 \\
\hline T8 & 3,992 & 0,788 & 3,15 \\
\hline TI1 & 4,001 & 0,776 & 3,10 \\
\hline TI2 & 4,023 & 0,777 & 3,13 \\
\hline TI3 & 3,972 & 0,698 & 2,77 \\
\hline TI4 & 4,017 & 0,663 & 2,66 \\
\hline TI5 & 3,984 & 0,698 & 2,78 \\
\hline TI6 & 4,009 & 0,772 & 3,09 \\
\hline TI7 & 3,978 & 0,802 & 3,19 \\
\hline TI8 & 3,993 & 0,74 & 2,95 \\
\hline
\end{tabular}




\subsubsection{Secagem e impregnação dos corpos de prova}

Os corpos de prova foram colocados na estufa para secagem para controle de umidade a uma temperatura de $100{ }^{\circ} \mathrm{C}$, dur ante o período de 48 horas.

Os corpos de prova foram impregnados a uma pressão de $1 \mathrm{MPa}$ durante 30 minutos e foram colocados na estufa para o processo de secagem a uma temperatura de $60^{\circ} \mathrm{C}$ durante 48 horas. Na tabela 49 podem ser observados os valores das massas dos corpos de prova desde a fase inicial de confecção, impregnação, até a fase de preparo para o ensaio de determinação da resistência dos mesmos aos esforços de tração paralela às fibras.

TABELA 49- Massa dos corpos de prova de tração paralela às fibras.

\begin{tabular}{|c|c|c|c|c|}
\hline CP & $\operatorname{Mn}(g)$ & Mo(g) & Mni(g) & Moi(g) \\
\hline $\mathrm{T} 1$ & 36 & 34,32 & 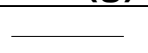 & 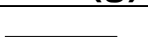 \\
\hline T2 & 37,93 & 35,16 & 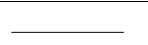 & 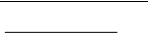 \\
\hline T3 & 37,14 & 34,43 & 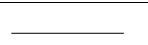 & 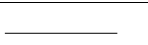 \\
\hline T4 & 35,12 & 32,82 & 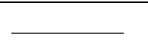 & 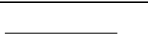 \\
\hline T5 & 34,78 & 32,13 & 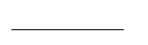 & - \\
\hline T6 & 37,23 & 34,53 & 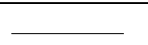 & 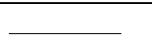 \\
\hline T7 & 33,14 & 30,66 & 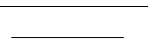 & 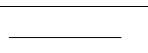 \\
\hline T8 & 33,31 & 30,9 & 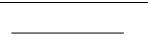 & 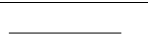 \\
\hline T9 & 40,9 & 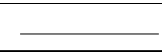 & $\bar{u}$ & 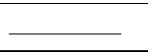 \\
\hline T10 & 42 & 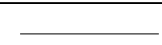 & 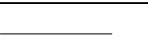 & 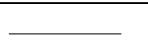 \\
\hline T11 & 42,88 & & - & \\
\hline TI1 & 33,63 & 30,04 & 48,2 & 44,76 \\
\hline TI2 & 37 & 33,28 & 53,55 & 49,67 \\
\hline TI3 & 31,86 & 28,37 & 45,35 & 40,82 \\
\hline $\mathrm{TI} 4$ & 31,84 & 28,5 & 45,58 & 40,98 \\
\hline TI5 & 32,78 & 29,16 & 44,8 & 39,94 \\
\hline TI6 & 37,65 & 33,95 & 58,41 & 52,94 \\
\hline TI7 & 38,19 & 34,36 & 53,23 & 48,66 \\
\hline TI8 & 32,4 & 29,18 & 48,34 & 43,09 \\
\hline TI9 & - & 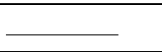 & 52,95 & 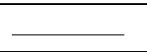 \\
\hline TI10 & - & 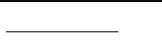 & 47,93 & 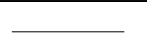 \\
\hline TI11 & 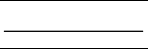 & 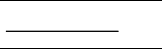 & 50,61 & 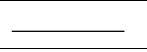 \\
\hline TI12 & 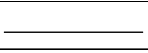 & 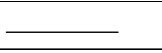 & 57,37 & 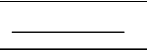 \\
\hline TI13 & 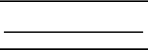 & 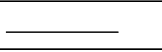 & 47,24 & 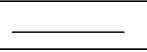 \\
\hline TI14 & 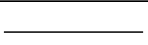 & 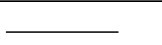 & 46,93 & - \\
\hline
\end{tabular}




\subsubsection{Ensaio de Tração Paralela às Fibras}

Os corpos de prova foram ensaiados na máquina universal DARTEC do LaMEM/SET/USP, de capacidade nominal de $100 \mathrm{kN}$, onde foram determinadas as resistências à tração dos corpos de prova impregnados e não impregnados.

TABELA 50- Resultados do ensaio de tração paralela às fibras de corpos de prova não impregnados; Espécie:Pinus.

\begin{tabular}{|c|c|c|c||}
\hline $\mathbf{C P}$ & $\mathbf{F}_{\mathrm{u}}(\mathbf{k N})$ & $\mathbf{A}\left(\mathbf{c m}^{\mathbf{2}}\right)$ & $\mathbf{f}_{\mathrm{t}, \mathrm{o}}(\mathbf{M P a} \mathbf{)}$ \\
\hline 1 & 5,97 & 2,96 & 20 \\
\hline 2 & 4,20 & 3,03 & 14 \\
\hline 3 & 9,60 & 2,89 & 32 \\
\hline 4 & 3,60 & 3,07 & 12 \\
\hline 5 & 3,47 & 2,8 & 12 \\
\hline 6 & 3,50 & 2,98 & 12 \\
\hline 7 & 4,26 & 2,95 & 14 \\
\hline 8 & 4,56 & 3,15 & 15 \\
\hline 9 & 6,34 & 3,01 & 21 \\
\hline 10 & 9,29 & 3 & 31 \\
\hline Média & $\mathbf{5 , 4 8}$ & $\mathbf{3}$ & $\mathbf{1 8}$ \\
\hline Desv.Pad. & $\mathbf{2 , 3 1}$ & $\mathbf{0 , 1 0}$ & $\mathbf{7 , 7 3}$ \\
\hline
\end{tabular}

TABELA 51- Resultados do ensaio de tração paralela às fibras de corpos de prova impregnados; $p=1 \mathrm{MPa}$; Espécie:Pinus

\begin{tabular}{|c|c|c|c|}
\hline $\mathbf{C P}$ & $\left.\mathbf{F}_{\mathbf{u}} \mathbf{( k N}\right)$ & $\mathbf{A}\left(\mathbf{c m}^{2}\right)$ & $\mathbf{f}_{\mathrm{t}, \mathrm{o}}(\mathbf{M P a} \mathbf{)}$ \\
\hline 1 & 9,85 & 2,98 & 33 \\
\hline 2 & 9,95 & 3,1 & 32 \\
\hline 3 & 8,3 & 2,44 & 34 \\
\hline 4 & 11 & 2,77 & 40 \\
\hline 5 & 8,73 & 2,66 & 33 \\
\hline 6 & 6,86 & 2,78 & 25 \\
\hline 7 & 10,64 & 3,09 & 34 \\
\hline 8 & 11,16 & 3,19 & 35 \\
\hline 9 & 7,56 & 2,95 & 26 \\
\hline 10 & 11,83 & 3,03 & 39 \\
\hline 11 & 10,94 & 2,96 & 37 \\
\hline 12 & 10,75 & 2,98 & 36 \\
\hline 13 & 8,83 & 3,04 & 29 \\
\hline 14 & 13,01 & 3,02 & 43 \\
\hline 15 & 13,2 & 3 & 44 \\
\hline 16 & 10,13 & 2,98 & 34 \\
\hline Média & $\mathbf{1 0}$ & $\mathbf{3}$ & $\mathbf{3 5}$ \\
\hline Desv.Pad. & $\mathbf{1 , 7 9}$ & $\mathbf{0 , 1 9}$ & $\mathbf{5 , 4 2}$ \\
\hline
\end{tabular}


Os resultados indicaram o seguinte desempenho de resistência à tração paralela às fibras:

$\mathbf{F}_{\mathbf{u}}(\mathrm{CPI}) / \mathbf{F}_{\mathbf{u}}(\mathrm{CPSI})=1017 / 548=1,8558(85,60 \%) \boldsymbol{\uparrow}$.

$\mathbf{f}_{\mathrm{t}, \mathrm{o}}(\mathrm{CPI}) / \mathbf{f}_{\mathrm{t}, \mathrm{o}}(\mathrm{CPSI})=35 / 18=1,944(94,44 \%) \boldsymbol{\uparrow}$.

Com a realização dos ensaios anteriores para caracterização das madeiras impregnadas e não impregnadas utilizando-se o Pinus, fica portanto determinado as propriedades de resistência das madeiras para permitir a montagem dos modelos de ligações com cavilhas impregnadas e não impregnadas solicitadas por compressão paralela às fibras e compressão normal às fibras, objeto de estudo do item 6.6. Neste caso também se fazer uma espécie de análise comparativa desses resultados das madeiras impregnadas com os valores dos mesmos ensaios anteriores utilizando para esses fins a espécie de madeira o Ipê.

$\mathrm{Na}$ figura 54 pode ser observado o corpo de prova de tração paralela às fibras sendo ensaiado na máquina Universal de ensaios DARTEC do LaMEM/SET/USP. 


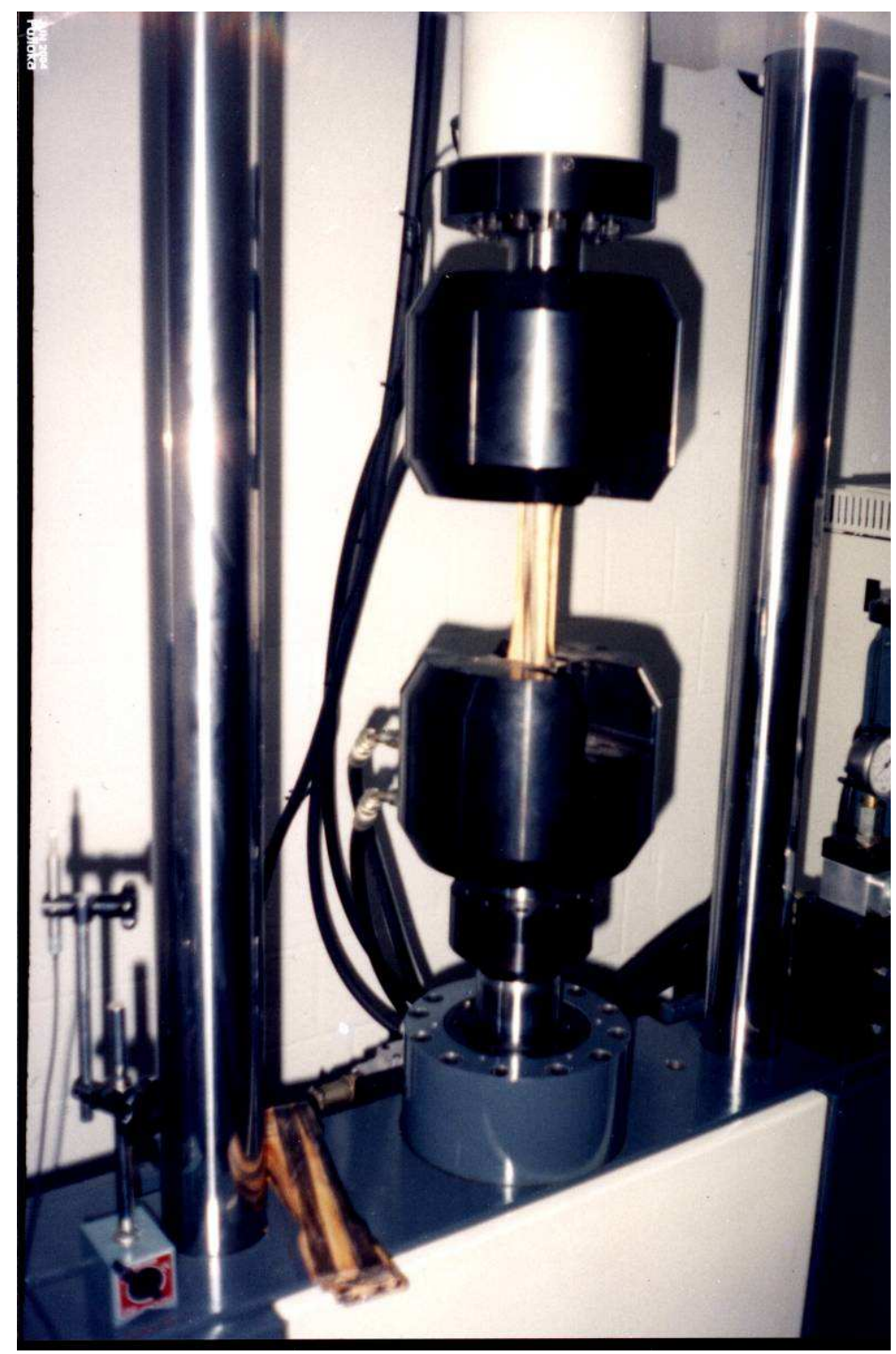

FIGURA 54- Corpo de prova de tração paralela às fibras sendo ensaiado na máquina Universal do LaMEM/SET/USP. 


\subsubsection{ANÁLISE COMPARATIVA DE DADOS}

Essa análise foi feita repetindo os mesmos ensaios anteriores para caracterização das madeiras impregnadas e não impregnadas, porém foi utilizada uma espécie de madeira classe 60(PNBR 7190/96), muito utilizada em cavilhas.

\subsubsection{Compressão normal às fibras}

Foi confeccionado um corpo de prova $5 \times 5 \times 10 \mathrm{~cm}$, e submetido ao ensaio de compressão normal às fibras, de acordo com a figura 55.

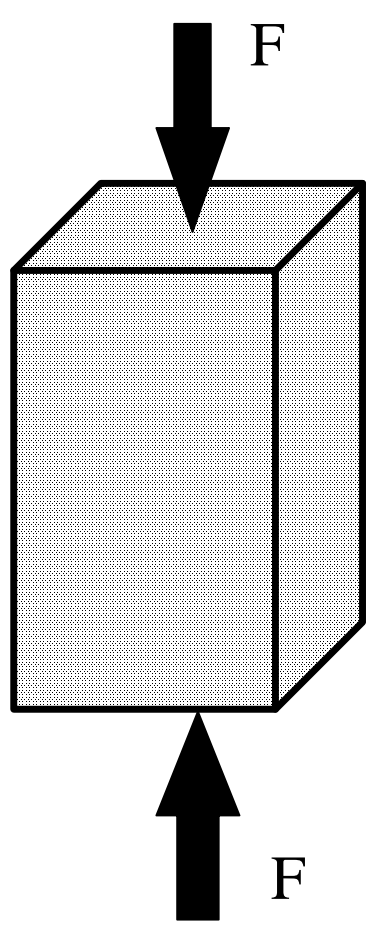

FIGURA 55- Corpo de prova de Ipê submetido a compressão normal. 
O corpo de prova da figura 55 foi ensaiado e determinado o valor da resistência à compressão normal, $\mathrm{f}_{\mathrm{c}, 90}$ tendo obtido os seguintes resultados:

$$
F_{u}=59,50 \mathrm{kN} ; f_{c, 90}=24 \mathrm{MPa} \text {. }
$$

\subsubsection{Cisalhamento simples}

O corpo de prova foi confeccionado de acordo com a figura 41 e submetido ao ensaio de cisalhamento simples e determinado a sua resistência. Os valores obtidos foram os seguintes:

$$
F_{u}=40,50 \mathrm{kN} ; f_{v}=16 \mathrm{MPa}
$$

\subsubsection{Ensaio de cisalhamento na flexão em cavilhas}

Foram confeccionadas cavilhas de Ipê, com diâmetros variando de 16; 18 e $20 \mathrm{~mm}$ e submetidas ao ensaio de cisalhamento na flexão conforme a figura 56.

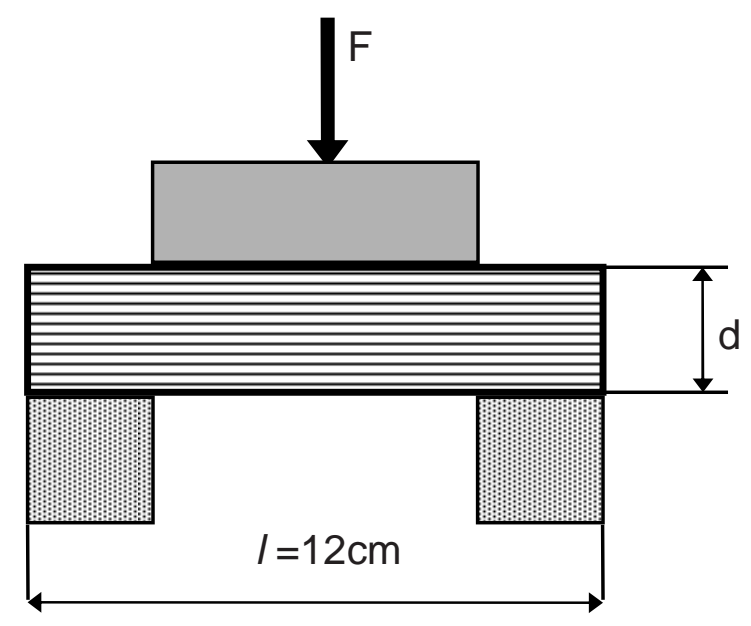

FIGURA 56- Cavilhas de Ipê submetidas ao ensaio de cisalhamento na flexão. 
$\mathrm{Na}$ tabela 52 podem ser observados os resultados do ensaio de cisalhamento na flexão.

TABELA 52- Resultados de ensaios de cisalhamento na flexão em cavilhas.

ESPÉCIE:Ipê.

\begin{tabular}{|c|c|c|c|c|}
\hline C.P. & $\mathrm{d}(\mathrm{cm})$ & $\mathrm{F}_{\mathrm{u}}(\mathrm{kN})$ & $\mathrm{V}_{\mathrm{u}}=\mathrm{F}_{\mathrm{u}} / 2(\mathrm{kN})$ & $\mathrm{f}_{\mathrm{vM}}(\mathrm{MPa})$ \\
\hline 1 & 1,6 & 5,35 & 2,68 & 18 \\
\hline 2 & 1,6 & 5,35 & 2,68 & 18 \\
\hline 3 & 1,6 & 5,70 & 2,85 & 19 \\
\hline 4 & 1,6 & 5,90 & 2,95 & 20 \\
\hline 5 & 1,6 & 6,00 & 3,00 & 20 \\
\hline 6 & 1,6 & 6,05 & 3,03 & 20 \\
\hline Média & 1,60 & 5,73 & 2,86 & 19 \\
\hline \multicolumn{2}{|c|}{ Desvio Padrão } & $\underline{0,31}$ & $\overline{0,16}$ & 1 \\
\hline 7 & $1,1,8$ & 8,70 & 4,35 & $\overline{23}$ \\
\hline 8 & 1,8 & 8,40 & 4,20 & 22 \\
\hline 9 & 1,8 & 7,50 & 3,75 & 20 \\
\hline 19 & 1,8 & 9,05 & 4,53 & 24 \\
\hline 11 & 1,8 & 9,00 & 4,50 & 24 \\
\hline 12 & 1,8 & 8,15 & 4,08 & 21 \\
\hline Média & 1,8 & 8,47 & $\underline{4,23}$ & $\underline{22}$ \\
\hline \multicolumn{2}{|c|}{ Desvio Padrão } & $\overline{0,59}$ & $\overline{0,29}$ & $\overline{2}$ \\
\hline 13 & 2 & $\overline{9,40}$ & $\overline{4,70}$ & $\overline{20}$ \\
\hline 14 & 2 & 10,10 & 5,05 & 21 \\
\hline 15 & 2 & 8,85 & 4,43 & 19 \\
\hline 16 & 2 & 8,55 & 4,28 & 18 \\
\hline 17 & 2 & 9,25 & 4,63 & 20 \\
\hline 18 & 2 & 9,70 & 4,85 & 21 \\
\hline Média & 2 & 9,31 & 4,65 & 20 \\
\hline \multicolumn{2}{|c|}{ Desvio Padrão } & $\overline{0,56}$ & $\overline{0,28}$ & 1 \\
\hline
\end{tabular}




\subsubsection{Compressão Paralela às Fibras}

Foram confeccionados os corpos de prova $5 \times 5 \times 20 \mathrm{~cm}$ e cavilha com $\mathrm{d}=2,0 \mathrm{~cm}$; e $l=8,0 \mathrm{~cm}$, para serem ensaiados e determinados os valores das resistências à compressão paralela às fibras. Na figura 57 podemos observar os corpos de prova sendo submetidos ao ensaio de compressão paralela às fibras.
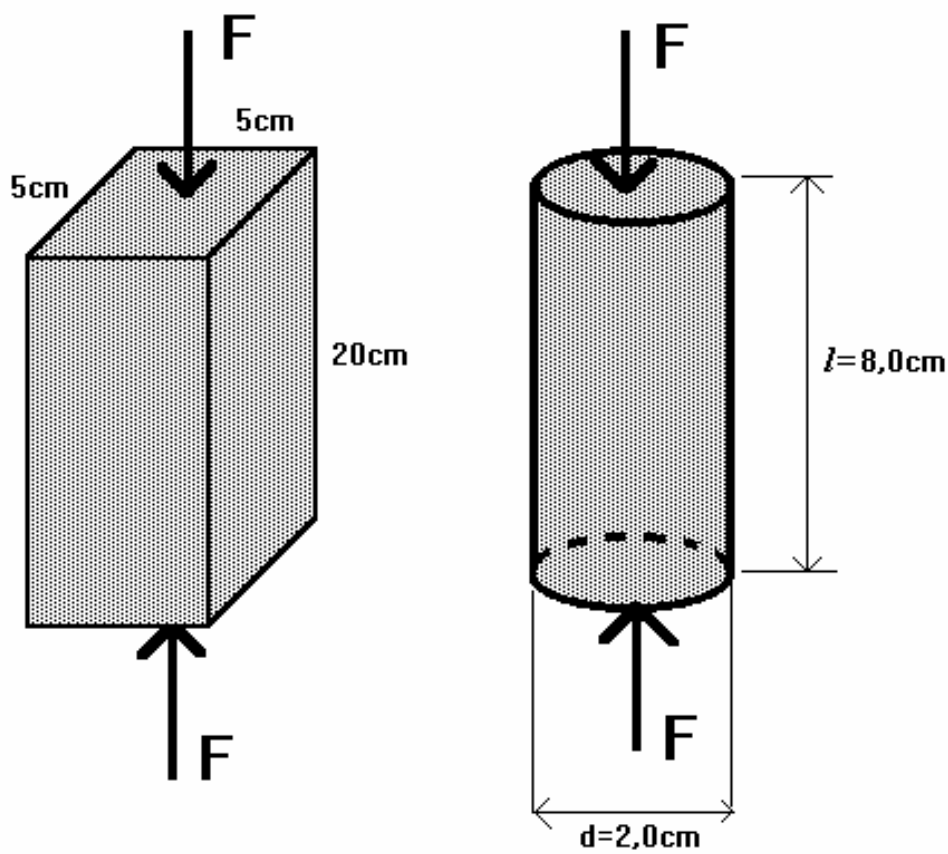

FIGURA 57- Corpos de prova de Ipê solicitados na compressão paralela às fibras. 
O resultado obtido para o corpo de prova de $5 \times 5 \times 20 \mathrm{~cm}$ foi igual a: $\mathrm{f}_{\mathrm{C}, \mathrm{O}}=91 \mathrm{MPa}$ e o módulo de elasticidade: $\mathrm{E}_{\mathrm{C}, \mathrm{o}}=20798 \mathrm{MPa}$, conforme o Anexo A.

Foram confeccionadas 12 cavilhas de Ipê de 2,0 cm de diâmetro e 8,0 $\mathrm{cm}$ de comprimento, para serem ensaiadas na compressão paralela às fibras. Na tabela 53 podemos notar os resultados dos respectivos na máquina universal DARTEC do LaMEM/SET/USP.

TABELA 53- Resultados dos ensaios de cavilhas de Ipê na compressão paralela às fibras.

ESPÉCIE:Ipê

\begin{tabular}{|c|c|c|c|c|c|}
\hline C.P. & $\mathrm{d}(\mathrm{cm})$ & $l(\mathrm{~cm})$ & $F_{u}(k N)$ & $\mathrm{A}\left(\mathrm{cm}^{2}\right)$ & $\mathbf{f}_{\mathbf{c}, \mathbf{o}}(\mathrm{MPa})$ \\
\hline 1 & 2,012 & 7,809 & 30,30 & 3,1794 & 95 \\
\hline 2 & 2,05 & 7,777 & 25,70 & 3,3006 & 78 \\
\hline 3 & 2,026 & 7,739 & 26,60 & 3,2257 & 82 \\
\hline 4 & 2,014 & 7,764 & 26,40 & 3,1857 & 83 \\
\hline 5 & 2,022 & 7,745 & 27,20 & 3,2111 & 85 \\
\hline 6 & 2,031 & 7,745 & 26,30 & 3,2397 & 81 \\
\hline 7 & 2,016 & 7,702 & 25,60 & 3,1921 & 80 \\
\hline 8 & 2,027 & 7,81 & 27,25 & 3,227 & 84 \\
\hline 9 & 2,013 & 7,729 & 24,63 & 3,1826 & 77 \\
\hline 10 & 2,014 & 7,788 & 23,80 & 3,1857 & 75 \\
\hline 11 & 2,011 & 7,962 & 26,60 & 3,1762 & 84 \\
\hline 12 & 2,017 & 7,762 & 26,00 & 3,1952 & 81 \\
\hline Média & & & 26 & 3,21 & 82 \\
\hline Desvio $\mathrm{F}$ & rão & & $\overline{2}$ & 0,04 & $\overline{5}$ \\
\hline
\end{tabular}




\subsubsection{Tração Paralela às Fibras}

Foram confeccionados 08 corpos de prova conforme o mesmo modelo da figura 52 e ensaiados sob o carregamento de tração através da máquina universal DARTEC do LaMEM/SET/USP. Na tabela 54 pode-se observar os resultados do referido ensaio.

TABELA 54- Ensaio de tração paralela às fibras.

ESPÉCIE:Ipê.

\begin{tabular}{|c|c|c|c|c|}
\hline $\mathrm{CP}$ & Dimensões $(\mathrm{cm})$ & $\mathrm{A}\left(\mathrm{cm}^{2}\right)$ & $\mathrm{F}_{\mathrm{u}}(\mathrm{kN})$ & $\mathrm{f}_{\mathrm{t}, \mathrm{o}}(\mathrm{MPa})$ \\
\hline 2 & 3,$920 ; 0,765$ & 2,98 & 17,85 & 60 \\
\hline 3 & 3,$945 ; 0,726$ & 2,98 & 36,80 & 123 \\
\hline 4 & 3,$954 ; 0,768$ & 2,98 & 38,96 & 131 \\
\hline 5 & 3,$935 ; 0,671$ & 2,98 & 28,26 & 95 \\
\hline 6 & 3,$938 ; 0,722$ & 2,98 & 29,85 & 100 \\
\hline 8 & 3,$963 ; 0,704$ & 2,98 & 23,14 & 78 \\
\hline & & & & \\
\hline \multicolumn{2}{|l|}{ Média } & $\underline{3}$ & $\underline{29}$ & $\underline{98}$ \\
\hline \multicolumn{2}{|l|}{ Desvio Padrão } & $\underline{0}$ & $\underline{8}$ & $\underline{27}$ \\
\hline
\end{tabular}

\subsubsection{Análise comparativa de dados}

Os ensaios anteriores tiveram como objetivo principal a caracterização das madeiras impregnadas e não impregnadas para utilização em ligações por pinos.

Os resultados finais comparativos dos diversos tipos de resistências estão reunidos nas tabelas de 55 a 60 .

Por intermédio destes ensaios verificou-se que a espécie Pinus, como madeira de reflorestamento é a mais adequada para sofrer o processo de impregnação com resinas estirênicas. Os resultados finais de resistência para essa espécie são comparadas com uma espécie de madeira no caso o Ipê, muito utilizada na confecção de cavilhas estruturais. 
Nas tabelas 55 a 60 tem-se:

$\mathrm{f}^{\mathrm{n}}$ - resistência da madeira natural.

f '- resistência da madeira impregnada.

* Os corpos de prova da espécie Ipê não sofreram processo de impregnação.

TABELA 55-Valores médios de densidade e resistência à compressão normal às fibras.

\begin{tabular}{|c|c|c|c|c|}
\hline Nome comum & $\begin{array}{c}\rho^{n} \\
\left(K g / m^{3}\right)\end{array}$ & $\begin{array}{c}\rho^{i} \\
\left(\mathrm{Kg} / \mathrm{m}^{3}\right)\end{array}$ & $\begin{array}{l}f_{c, 90}{ }^{n} \\
(\mathrm{MPa})\end{array}$ & $\begin{array}{c}\mathbf{f}_{c, 90}{ }^{i} \\
(\mathrm{MPa})\end{array}$ \\
\hline Pinus & 480 & 880 & 3 & 16 \\
\hline Eucalipto Citriodora & 1140 & 930 & 17 & 19 \\
\hline Ipê ${ }^{*}$ & 1068 & - & 24 & - \\
\hline
\end{tabular}

TABELA 56-Valores médios de resistência ao cisalhamento simples.

\begin{tabular}{|c|c|c|}
\hline Nome comum & $\begin{array}{c}\mathbf{f}_{\mathrm{v}, \mathrm{o}}{ }^{\mathbf{n}} \\
(\mathrm{MPa})\end{array}$ & $\begin{array}{c}\mathbf{f}_{\mathrm{v}, \mathrm{o}}{ }^{\mathrm{i}} \\
(\mathbf{M P a})\end{array}$ \\
\hline Pinus & 9 & 11 \\
\hline Ipế $^{*}$ & 16 & - \\
\hline
\end{tabular}

TABELA 57-Valores médios de resistência à compressão paralela às fibras e módulo de elasticidade de corpos de prova $5 \times 5 \times 20 \mathrm{~cm}$.

\begin{tabular}{|c|c|c|c|c|}
\hline Nome comum & $\begin{array}{l}\mathrm{f}_{\mathrm{c}, \mathrm{o}}{ }^{\mathrm{n}} \\
(\mathrm{MPa})\end{array}$ & $\begin{array}{c}\mathrm{f}_{\mathrm{c}, \mathrm{o}}{ }^{\mathrm{i}} \\
(\mathrm{MPa})\end{array}$ & $\begin{array}{l}E_{c, o}{ }^{n} \\
(\mathrm{MPa})\end{array}$ & $\begin{array}{c}E_{c, 0}{ }^{i} \\
(\mathrm{MPa})\end{array}$ \\
\hline Pinus & 45 & 61 & 7521 & 9150 \\
\hline Ipêt & 91 & - & 20798 & - \\
\hline
\end{tabular}


TABELA 58-Valores médios de resistência à compressão paralela às fibras de cavilhas, $d=2,0 \mathrm{~cm} ; l=8,0 \mathrm{~cm}$.

\begin{tabular}{|c|c|c|}
\hline Nome comum & $\begin{array}{c}\mathbf{f}_{\mathrm{c}, \mathrm{o}}{ }^{\mathbf{n}} \\
(\mathrm{MPa})\end{array}$ & $\begin{array}{c}\mathbf{f}_{\mathrm{c}, \mathrm{o}}{ }^{\mathrm{i}} \\
(\mathbf{M P a})\end{array}$ \\
\hline Pinus & 48 & 61 \\
\hline $\mathrm{Ip} \hat{\mathrm{e}}^{*}$ & 82 & - \\
\hline
\end{tabular}

TABELA 59-Valores médios da resistência ao cisalhamento na flexão.

\begin{tabular}{|c|c|c|c|}
\hline Nome comum & $\begin{array}{c}d \\
\text { (cm) }\end{array}$ & $\begin{array}{l}f_{\mathrm{vM}}{ }^{n} \\
(\mathrm{MPa})\end{array}$ & $\begin{array}{l}f_{\mathrm{vM}}{ }^{\prime} \\
(\mathrm{MPa})\end{array}$ \\
\hline Pinus & 1,6 & 15 & 17 \\
\hline Pinus & 1,8 & 14 & 23 \\
\hline Pinus & 2,0 & 14 & 31 \\
\hline Ipêt* & 1,6 & 19 & - \\
\hline Ipê & 1,8 & 22 & - \\
\hline Ipêt ${ }^{*}$ & 2,0 & 20 & - \\
\hline
\end{tabular}

TABELA 60-Valores médios de resistência à tração paralela às fibras.

\begin{tabular}{|c|c|c|}
\hline Nome comum & $\begin{array}{c}\mathbf{f}_{\mathrm{t}, \mathrm{o}}{ }^{\mathbf{}} \\
(\mathbf{M P a})\end{array}$ & $\begin{array}{c}\mathbf{f}_{\mathrm{t}, \mathrm{o}}{ }^{\mathrm{i}} \\
(\mathbf{M P a})\end{array}$ \\
\hline Pinus & 18 & 35 \\
\hline Ipê $^{*}$ & 98 & - \\
\hline
\end{tabular}


Na figura 58 pode-se observar os modos de ruptura dos corpos de prova de Pinus e Ipê, submetidos aos ensaios para caracterização das propriedades das madeiras impregnadas e não impregnadas.

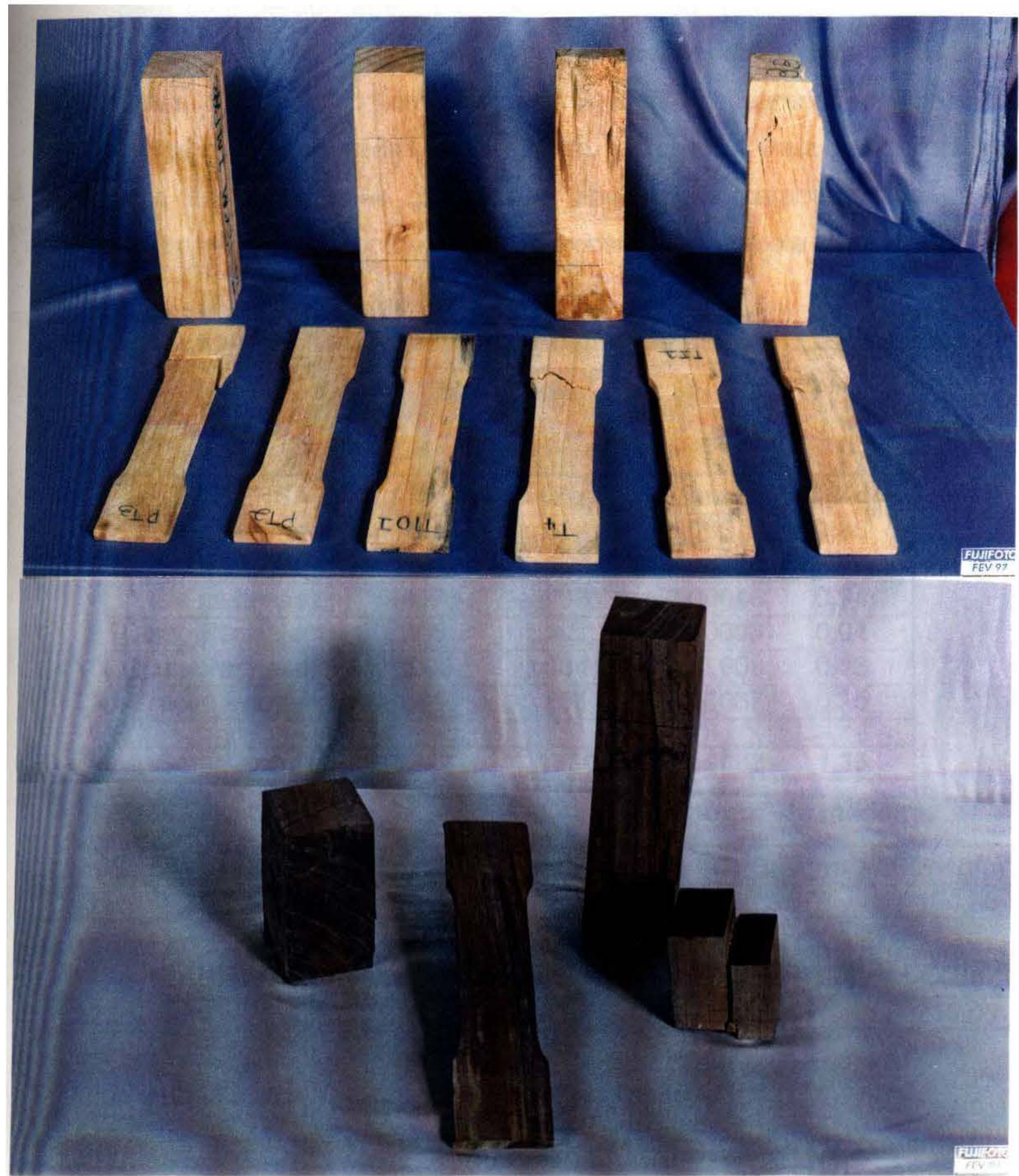

FIGURA 58-Modos de ruptura dos corpos de prova de Pinus e Ipê , submetidos aos ensaios de caracterização completa das madeiras impregnadas e não impregnadas 
6.5.12 Consumo de materiais e estimativa de custo para o processo de impregnação de madeiras

Será considerado apenas o levantamento da quantidade de resina estirênica gasta no processo de impregnação das madeiras, bem como das quantidades de peróxido de benzoila(iniciador) e estireno(monômero), produtos químicos utilizados no referido processo. Para isso foram levantadas as quantidades gastas nos ensaios de caracterização das madeiras impregnadas, conforme pode-se observar na tabela abaixo.

TABELA 61-Volume de madeira e quantidade de resina estirência absorvida.

\begin{tabular}{|c|c|c|r|c|}
\hline TIPO DE ENSAIO & $\mathbf{V ( c m})^{\mathbf{3}}$ & $\mathbf{Q ( g )}$ & $\mathbf{V ( m})^{\mathbf{3}}$ & $\mathbf{Q ( K g )}$ \\
\hline Comp.Normal & 715 & 382 & 0,00072 & 0,38 \\
\hline Cis.SImples & 1680 & 403 & 0,00168 & 0,40 \\
\hline Cis.na flexão & 457 & 238 & 0,00046 & 0,24 \\
\hline Comp.Paralela(1) & 305 & 45 & 0,0003 & 0,04 \\
\hline Comp.Paralela(2) & 3000 & 131 & 0,003 & 0,13 \\
\hline Tração Paralela & 665 & 151 & 0,00067 & 0,15 \\
\hline & & & & \\
\hline Soma total & $\mathbf{6 8 2 3}$ & $\mathbf{1 3 5 0}$ & $\mathbf{0 , 0 0 6 8 2}$ & $\mathbf{1 , 3 5}$ \\
\hline
\end{tabular}

TABELA 62-Consumo de produtos químicos por $\mathrm{m}^{3}$ de madeira.

\begin{tabular}{|c|c|c|c|c|c|c|}
\hline $\mathrm{V}\left(\mathbf{m}^{3}\right)$ & $\mathbf{Q}(\mathrm{Kg})$ & $\mathbf{1 , 5} \%(\mathrm{~PB})$ & $\mathbf{9 8 , 5} \%(\mathrm{E})$ & $\mathbf{C R}\left(\mathrm{Kg} / \mathbf{m}^{3}\right)$ & $\mathrm{CPB}\left(\mathrm{Kg} / \mathbf{m}^{3}\right)$ & $\mathrm{CE}\left(\mathrm{Kg} / \mathbf{m}^{3}\right)$ \\
\hline 0,01 & 1,35 & 0,02 & 1,33 & 197,95 & 2,97 & 194,98 \\
\hline & & & & & & \\
\hline $\mathbf{V}(l)$ & $\mathbf{Q}(\mathbf{K g})$ & $\rho_{\mathrm{PB}}(\mathrm{Kg} / l)$ & $\rho_{\mathrm{E}}(\mathrm{Kg} / l)$ & $\mathbf{C R}\left(l / \mathbf{m}^{3}\right)$ & $\mathrm{CPB}\left(l / \mathbf{m}^{3}\right)$ & $\mathrm{CE}\left(l / \mathbf{m}^{3}\right)$ \\
\hline 6,823 & 1,35 & 1,14 & 0,91 & 218,00 & 2,61 & 215,00 \\
\hline
\end{tabular}

V-Volume de madeira; Q-Quantidade de resina absorvida PB-Peróxido de benzoila; E-Estireno; CR-Consumo de resina por $\mathrm{m}^{3}$ de madeira; CPB-Consumo de peróxido de benzoila por $\mathrm{m}^{3}$ de madeira; $\mathrm{CE}$ Consumo de estireno por $\mathrm{m}^{3}$ de madeira ; $\rho_{\mathrm{PB}}$-Densidade do peróxido de benzoila; $\rho_{\mathrm{E}}$-Densidade do estireno; 
TABELA 63-Estimativa do custo de impregnação de madeiras e cavilhas.

\begin{tabular}{|c|c|c|c|c|}
\hline $\mathrm{CPB}\left(\mathrm{Kg} / \mathrm{m}^{3}\right)$ & $\mathrm{CE}\left(\mathrm{Kg} / \mathrm{m}^{3}\right)$ & Preço(PB)*/Kg & Preço(E) ${ }^{*} / \mathrm{Kg}$ & $\mathrm{C} / \mathrm{m}^{3}$ \\
\hline 2,97 & 194,98 & 10,05 & 1,31 & 285 \\
\hline \multicolumn{5}{|c|}{ Obs. ${ }^{*}$ Os precos foram fornecidos pelo fabricante em moeda } \\
\hline & rrente do paí & & & \\
\hline
\end{tabular}

Portanto conclui-se que para impregnar $\mathbf{1} \mathbf{m}^{3}$ de madeira utilizando resina estirênica, utilizando na sua composição peróxido de benzoila e estireno, consome-se um total de 3 litros $(3 \mathrm{Kg})$ de peróxido de benzoila e 215 litros $(195 \mathrm{Kg})$ de estireno, que do ponto de vista comercial seria um total de 3 embalagens de $1 \mathrm{Kg}$ de PB, 1 Tambor de $180 \mathrm{Kg}$ e uma lata de $16 \mathrm{Kg}$ de estireno.

OBSERVAĈ̃A: O custo do peróxido de benzoila e do estireno foram fornecidos pela empresas: DATIQUIM PRODUTOS QUÍMICOS LTDA. e CIA. BRASILEIRA DE ESTIRENO, que foram os fornecedores dos produtos. 


\subsection{Ensaios de ligações com cavilhas impregnadas e não impregnadas.}

\subsubsection{Introdução:}

A confecção dos modelos dos corpos de prova de ligações com cavilhas impregnadas e não impregnadas solicitados por compressão paralela às fibras e compressão normal às fibras, foi feita com base na norma internacional BS 6948/89 e adequadas as dimensões para se compatibilizar com as espécies de madeiras nacionais com dimensões padronizadas das vigas serradas de seção transversal $(6 \times 12 \mathrm{~cm})$ e contendo cada ligação 02 cavilhas com diâmetros que variaram da ordem de 16,18, 20 mm de diâmetro conforme pode-se observar nas figuras 59 e 60 .

Foram realizados em torno de 36 ensaios, sendo 09 modelos de ligações solicitados por compressão paralela às fibras e 27 por compressão normal às fibras. São aplicadas cargas em intervalos constantes e para cada valor são lidos os respectivos deslocamentos através de relógios comparadores com precisão de $10^{-2} \mathrm{~mm}$ e $10^{-3} \mathrm{~mm}$ convenientemente instalados nos modelos.

Em seguida os dados são analisados através de análise de regressão e traçam-se os gráficos do tipo:Carga x deformação( F-e).

Para traçar os gráficos dos resultados dos ensaios são levados em conta os valores lidos através de relógios comparadores instalados nos corpos de prova das ligações e feita as leituras correspondentes para uma variação constante de carga tal como pode ser visto na tabela 64. 
TABELA 64- Grandezas obtidas nos ensaios de ligações com cavilhas.

\begin{tabular}{|c|c|c|}
\hline $\begin{array}{c}\text { Carga } \\
\mathbf{F}(\mathbf{k N})\end{array}$ & $\begin{array}{c}\text { Deslizamento } \\
\mathbf{u}(\mathbf{m m})\end{array}$ & $\begin{array}{c}\text { Deformação } \\
\text { Específica } \boldsymbol{\varepsilon}_{\mathbf{i}}\end{array}$ \\
\hline 0 & 0 & 0 \\
\hline $\mathrm{F}_{1}$ & $\mathrm{u}_{1}$ & $\mathrm{u}_{1} / \mathrm{Lo}$ \\
\hline $\mathrm{F}_{2}$ & $\mathrm{u}_{2}$ & $\mathrm{U}_{2} / \mathrm{Lo}$ \\
\hline $\mathrm{F}_{3}$ & $\mathrm{u}_{3}$ & $\mathrm{U}_{3} / \mathrm{Lo}$ \\
\hline--- & --- & --- \\
\hline $\mathrm{F}_{\mathrm{i}}$ & $\mathrm{u}_{\mathrm{i}}$ & $\mathrm{u}_{\mathrm{i}} / \mathrm{LO}$ \\
\hline--- & --- & --- \\
\hline $\mathrm{F}_{\mathrm{n}}$ & $\mathrm{u}_{\mathrm{n}}$ & $\mathrm{U}_{\mathrm{n}} / \mathrm{Lo}$ \\
\hline
\end{tabular}

Com esses valores obtém-se portanto a relação entre $F$ e $\varepsilon$ e uma equação do tipo $F=F(\varepsilon)$, através da análise de regressão para cada ensaio realizado. 


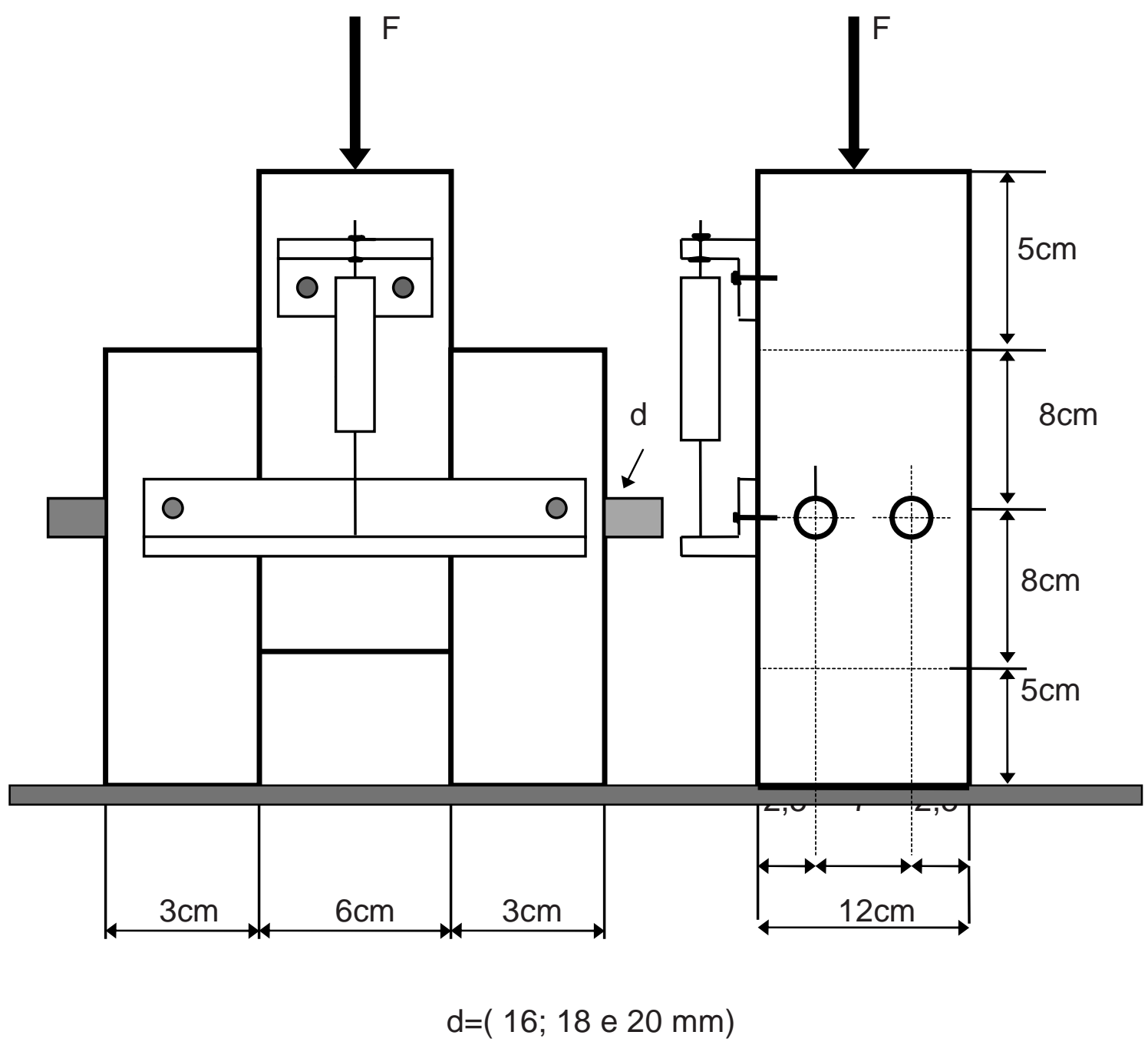

FIGURA 59- Corpo de prova de ligação com cavilhas solicitado na compressão paralela às fibras, com relógio comparador. 


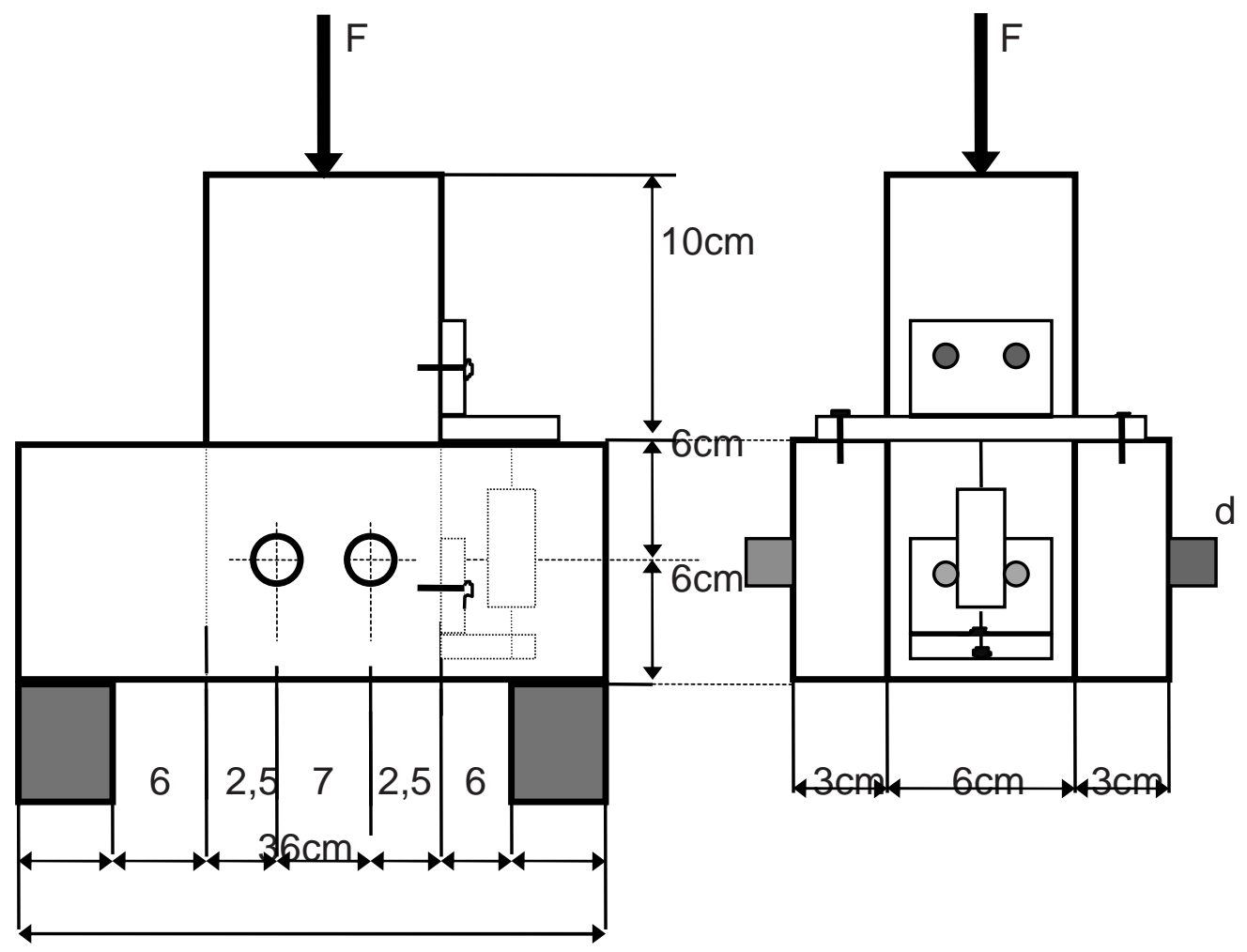

d( diâmetro da seção transversal da cavilha) $\mathrm{d}(16 ; 18$ e $20 \mathrm{~mm})$. compressão normal às fibras, com relógio comparador. 


\subsubsection{Análise dos dados}

No Anexo B são analisados para cada ensaio os gráficos mostrando os pares de valores de $\mathbf{F}$ e $\boldsymbol{\varepsilon}$, bem como traçadas as respectivas curvas para cada caso através de análise de regressão, tentando ajustar as curvas que mais se aproximam da realidade dos valores dos ensaios.

Nas figuras 61, 62, 63 e 64 podem ser vistos os respectivos modelos de ligações com cavilhas sendo preparadas para serem ensaiadas bem como solicitadas na compressão paralela às fibras e compressão normal às fibras.

A carga limite última $\left(\mathbf{F}_{\mathbf{L}}\right)$ da ligação, é o valor de carregamento correspondente à deformação específica da ligação de 0,2\% (2/1000), segundo o PNBR 7190/96.

Para a análise de regressão dos dados foi utilizada a versão 5.0 do software Microsoft Excel. 


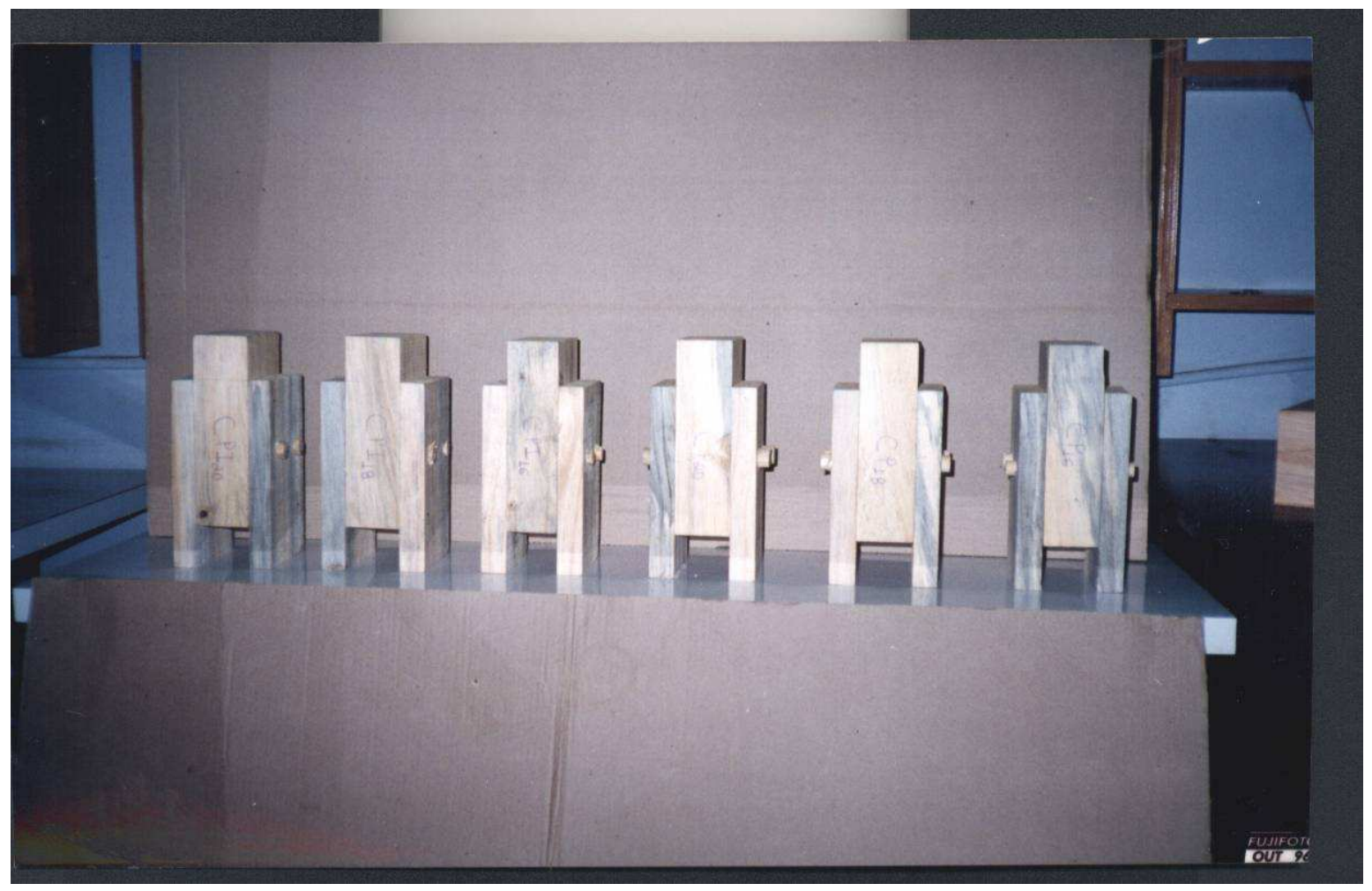

FIGURA 61- Corpo de prova preparado na carpintaria do LaMEM/SET/USP para o ensaio de compressão paralela às fibras. 


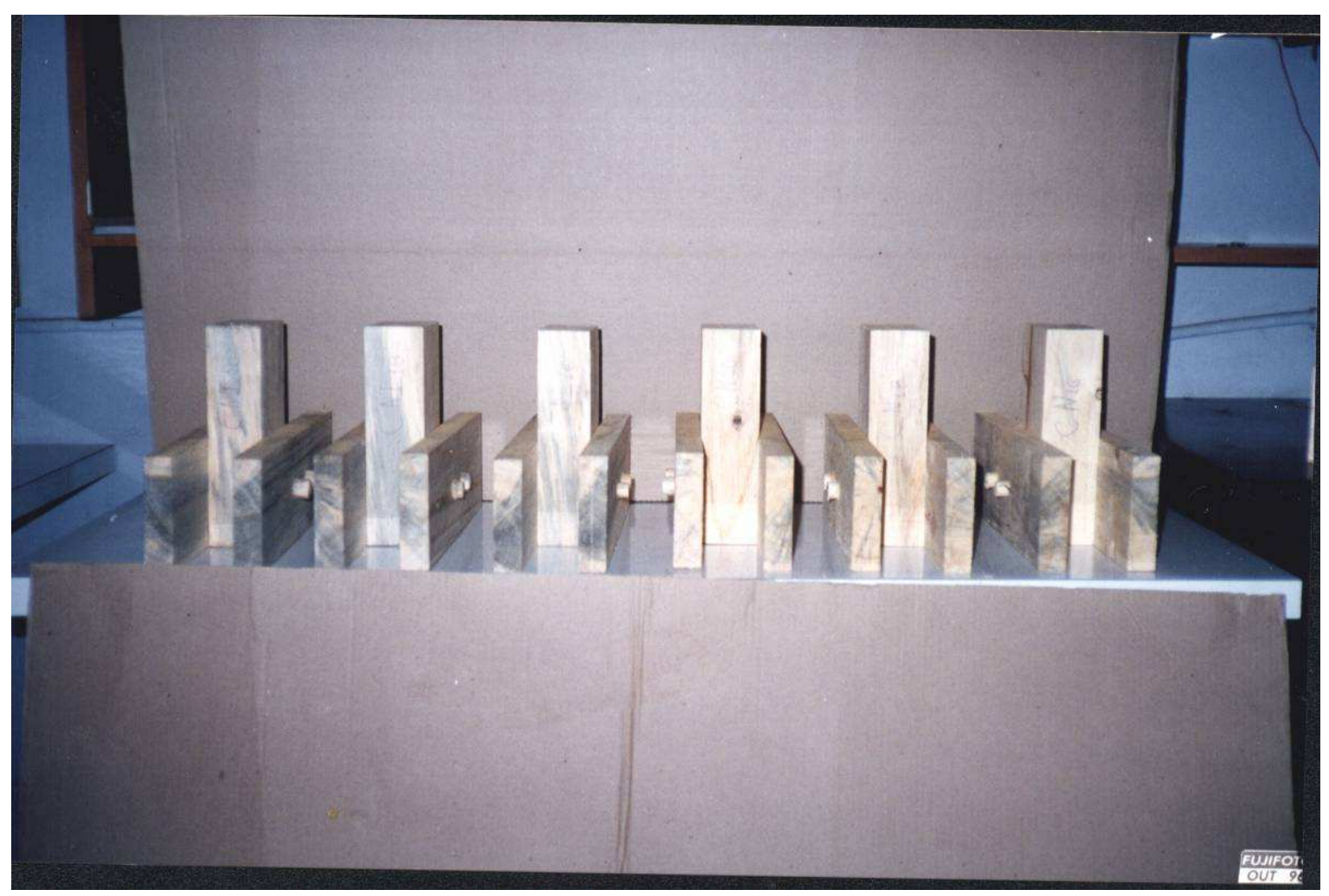

FIGURA 62- Corpo de prova preparado na carpintaria do LaMEM/SET/USP para o ensaio de compressão normal às fibras. 


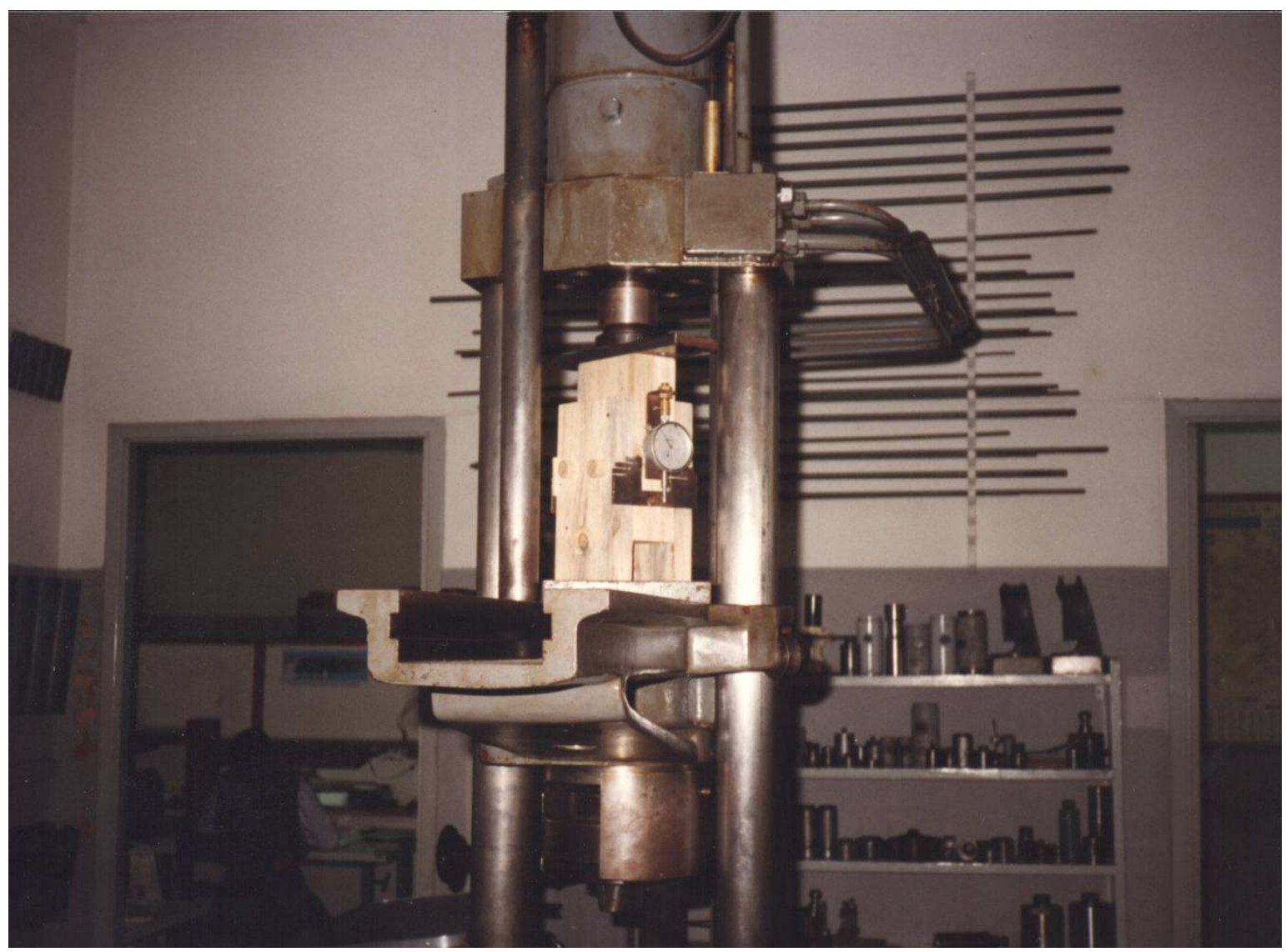

FIGURA 63- Corpo de prova ensaiado na máquina universal Amsler do LaMEM/SET/USP para o ensaio de compressão paralela às fibras. 


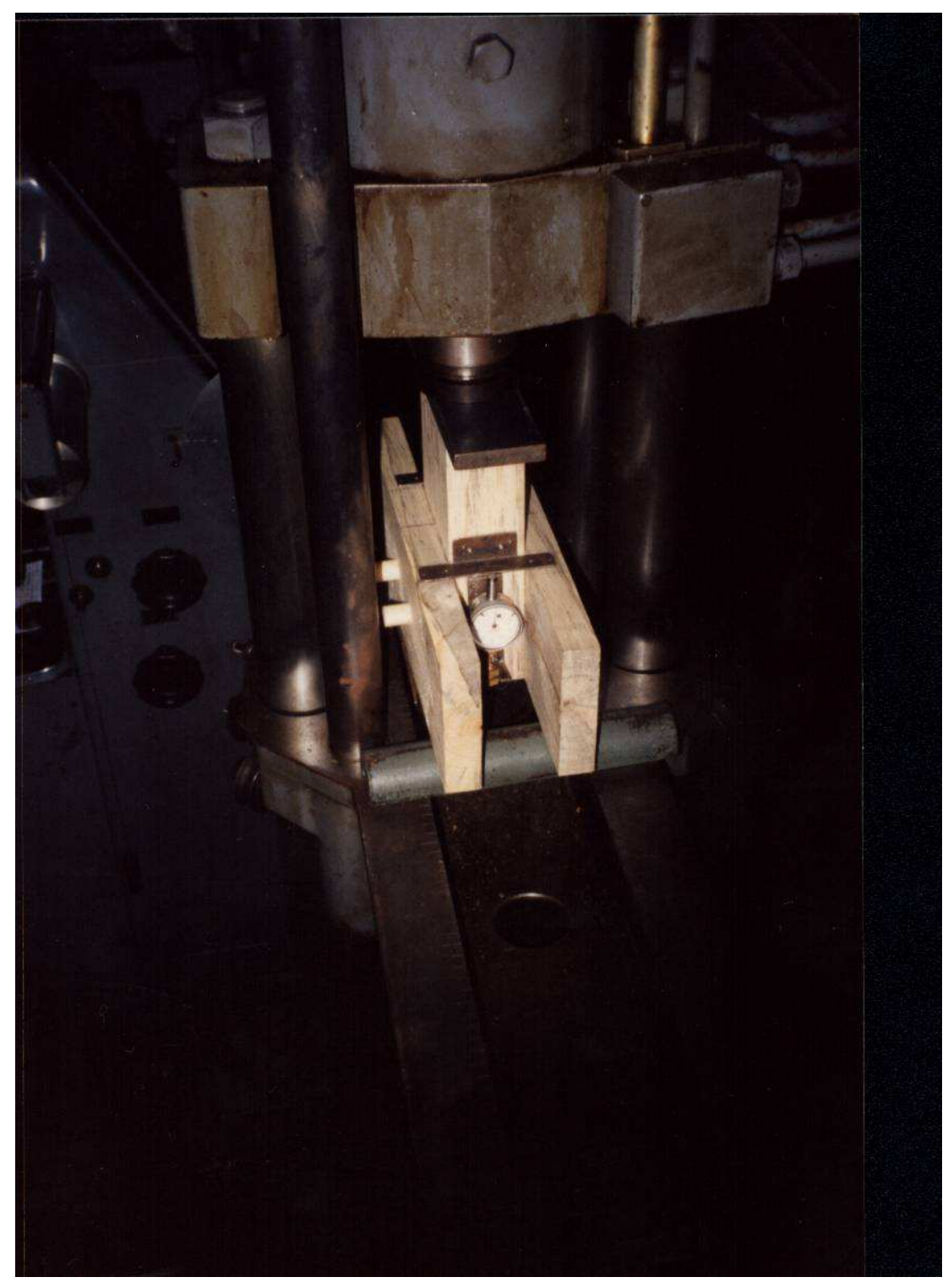

FIGURA 64- Corpo de prova ensaiado na máquina universal Amsler do LaMEM/SET/USP para o ensaio de compressão normal às fibras. 
6.6.3 Resumo dos resultados finais dos valores de cargas nos ensaios dos modelos das ligações com cavilhas.

No encerramento dos ensaios dos modelos das ligações com base nos resultados do ANEXO B, confeccionamos a tabela 65 mostrando os dados que são importantes para análise tais como:

$\mathbf{F}_{\mathbf{0}^{-}}$Limite de Proporcionalidade

$F_{L}$ - Carga Limite correspondente a uma deformação específica de 0,2\%.

$\mathbf{F}_{\max }-$ Carga de ruptura do ensaio do modelo.

TABELA 65- Resumo dos resultados no ensaio de ligações com cavilhas-Parte I

ESPÉCIE: Pinus UNIDADE:kN

\begin{tabular}{|c|c|c|c|c|c|c|}
\hline CP & Ensaio & $\mathrm{d}(\mathrm{cm})$ & $\mathrm{F}_{\mathrm{o}}$ & $\mathrm{F}_{l}$ & $\mathrm{~F}_{\max }$ & OBSERVAÇÃo \\
\hline CP16 & Comp.Paralela & 1,6 & 6,00 & 8,12 & 11,20 & $\mathrm{SI}$ \\
\hline CPI16 & Comp.Paralela & 1,6 & 8,00 & 11,71 & 15,90 & $\mathrm{Cl}$ \\
\hline CP18 & Comp.Paralela & 1,8 & 9,00 & 11,15 & 16,40 & $\mathrm{SI}$ \\
\hline CPI18 & Comp.Paralela & 1,8 & 11,00 & 16,19 & 21,40 & $\mathrm{Cl}$ \\
\hline CP20 & Comp.Paralela & 2 & 10,00 & 12,06 & 19,20 & $\mathrm{SI}$ \\
\hline CPI20 & Comp.Paralela & 2 & 15,00 & 21,62 & 29,40 & $\mathrm{Cl}$ \\
\hline CN16 & Comp. Normal & 1,6 & 6,00 & 9,95 & 13,50 & $\mathrm{SI}$ \\
\hline CN116 & Comp. Normal & 1,6 & 6,00 & 9,80 & 12,80 & $\mathrm{Cl}$ \\
\hline CN18 & Comp. Normal & 1,8 & 9,00 & 11,13 & 15,60 & $\mathrm{SI}$ \\
\hline CNI18 & Comp.Normal & 1,8 & 9,00 & 14,62 & 17,50 & $\mathrm{Cl}$ \\
\hline CN20 & Comp.Normal & 2 & 9,00 & 11,57 & 16,20 & $\mathrm{SI}$ \\
\hline CNI20 & Comp.Normal & 2 & 7,00 & 12,85 & 19,70 & $\mathrm{Cl}$ \\
\hline CN1-16 & Comp.Normal & 1,6 & 5,00 & 7,15 & 10,40 & $\mathrm{SI}$ \\
\hline CN12-16 & Comp.Normal & 1,6 & 8,00 & 11,31 & 14,70 & $\mathrm{Cl}$ \\
\hline CN3-16 & Comp.Normal & 1,6 & 5,00 & 6,58 & 10,00 & $\mathrm{SI}$ \\
\hline CN4-18 & Comp.Normal & 1,8 & 7,00 & 8,86 & 12,70 & $\mathrm{SI}$ \\
\hline
\end{tabular}

CP-Corpo de Prova ;SI-Sem impregnação; Cl-Com impregnação 
Tabela 65A - Resumo dos resultados no ensaio de ligações com cavilhas-parte II ESPÉCIE: Pinus UNIDADE:kN.

\begin{tabular}{|c|c|c|c|c|c|c|}
\hline CP & Ensaio & $\mathrm{d}$ & $\mathrm{F}_{\mathrm{O}}$ & $\mathrm{Fl}$ & $\mathrm{F}_{\max }$ & Observação \\
\hline CVN16 & Comp. Normal & 1,6 & 5,00 & 7,76 & 12,00 & $\mathrm{SI}$ \\
\hline CVN16 & Comp. Normal & 1,6 & 9,00 & 11,16 & 14,35 & $\mathrm{Cl}$ \\
\hline CVN18 & Comp. Normal & 1,8 & 13,00 & 17,06 & 24,80 & $\mathrm{SI}$ \\
\hline CVN18 & Comp. Normal & 1,8 & 10,00 & 15,41 & 21,80 & $\mathrm{Cl}$ \\
\hline CVN20 & Comp. Normal & 2 & 8,00 & 11,65 & 17,00 & $\mathrm{SI}$ \\
\hline CVNI20 & Comp. Normal & 2 & 13,00 & 17,66 & 23,10 & $\mathrm{Cl}$ \\
\hline CT1 & Comp. Normal & 1,6 & 4,00 & 6,10 & 11,30 & $\mathrm{SI}$ \\
\hline CL1 & Comp. Normal & 1,6 & 6,00 & 7,71 & 14,80 & $\mathrm{SI}$ \\
\hline CT2 & Comp. Normal & 1,8 & 5,00 & 8,06 & 14,10 & $\mathrm{SI}$ \\
\hline CL2 & Comp. Normal & 1,8 & 5,00 & 6,94 & 13,20 & $\mathrm{SI}$ \\
\hline CT3 & Comp. Normal & 2 & 6,00 & 7,94 & 14,60 & $\mathrm{SI}$ \\
\hline CL3 & Comp. Normal & 2 & 7,00 & 7,94 & 13,20 & $\mathrm{SI}$ \\
\hline CPN18 & Comp. Normal & 1,8 & 10,00 & 12,93 & 18,30 & $\mathrm{SI}$ \\
\hline CPN18 & Comp. Normal & 1,8 & 13,00 & 14,86 & 18,60 & $\mathrm{Cl}$ \\
\hline
\end{tabular}

TABELA 65B - Resumo dos resultados no ensaio de ligações com cavilhas-parte III ESPÉCIE: Ipê UNIDADE: kN.

\begin{tabular}{|c|c|c|c|c|c|c|}
\hline CP & Ensaio & $\mathrm{d}$ & $\mathrm{F}_{\mathrm{o}}$ & $\mathrm{F}_{l}$ & $\mathrm{~F}_{\max }$ & Observação \\
\hline P1 & Comp.Paralela & 1,6 & 5,00 & 10,58 & 26,00 & $\mathrm{SI}$ \\
\hline P2 & Comp.Paralela & 1,8 & 9,00 & 16,40 & 26,00 & $\mathrm{SI}$ \\
\hline P3 & Comp.Paralela & 2 & 11,00 & 19,84 & 30,30 & $\mathrm{SI}$ \\
\hline N1 & Comp.Normal & 1,6 & 8,00 & 12,84 & 24,00 & $\mathrm{SI}$ \\
\hline N2 & Comp.Normal & 1,8 & 10,00 & 16,57 & 21,50 & $\mathrm{SI}$ \\
\hline N3 & Comp.Normal & 2 & 13,00 & 20,41 & 25,60 & $\mathrm{SI}$ \\
\hline
\end{tabular}




\subsubsection{Determinação das resistências das cavilhas utilizando o método proposto pelo PNBR 7190/96}

A determinação analítica da resistência das cavilhas será feita com base no projeto de revisão da norma brasileira PNBR 7190/96 em seu item 7.4.3 que mostra o seguinte:

Para as cavilhas, considera-se:

$$
\beta=\frac{\mathrm{t}}{\mathrm{d}} \quad ; \quad \boldsymbol{\beta}_{\mathrm{lim}}=\sqrt{\frac{\mathrm{f}_{\mathrm{cod}, \mathrm{cav}}}{\mathrm{fc90 \textrm {d } , \mathrm { cav }}}}
$$

A resistência da cavilha será dada pelas seguintes expressões:

a) Esmagamento da cavilha

$$
\beta \leq \beta_{\lim } ; \quad \mathrm{R}_{\mathrm{vd}, 1}=0,4 \frac{\mathrm{t}^{2}}{\boldsymbol{\beta}} \mathrm{f}_{\mathrm{c} 90 \mathrm{~d}, \mathrm{cav}}
$$

b) Flexão da cavilha

$$
\begin{aligned}
\beta>\beta_{\lim } ; \quad \operatorname{Rvd}, 1=0,4 \frac{d^{2}}{\beta \lim } \mathrm{fcod}, \mathrm{cav} \\
\left(\operatorname{com} \beta=\beta_{\lim )}\right.
\end{aligned}
$$

Com estas considerações montaremos a tabela 66 onde estão realizados os cálculos das resistências das cavilhas para permitir a comparação com os dados de cargas obtidas na execução dos ensaios experimentais.

Para a montagem da tabela 66 lançamos os dados obtidos nos ensaios experimentais com relação a resistência à compressão paralela às fibras e compressão normal às fibras dos corpos de prova impregnados e não impregnados, conforme pode ser visto a seguir. 
Nas expressões anteriores $f_{c 0 d}$,cav e $f_{c} 90 d$,cav representam os valores de cálculo da resistência à compressão paralela e compressão normal da cavilha. Segundo o item 6.2.6 do PNBR 7190/96 os valores de cálculo da resistência são dados por:

$$
\mathrm{fwd}_{\mathrm{w}}=\mathrm{k} \bmod \frac{\mathrm{f}_{\mathrm{wk}}}{\gamma}
$$

Portanto têm-se:

$$
\begin{aligned}
& \mathrm{fco}_{\mathrm{c}} \mathrm{d}=\mathrm{k} \bmod \frac{\mathrm{f}_{\mathrm{co}, \mathrm{k}}}{\gamma_{\mathrm{wc}}}
\end{aligned}
$$

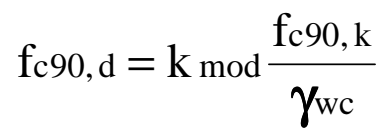

Os valores obtidos nos ensaios de caracterização são:

Corpos de prova sem impregnação- $\mathrm{SI} \quad \mathrm{f}_{\mathrm{Co}, \mathrm{k}}=31,5 \mathrm{MPa}$

Corpos de prova com impregnação-Cl $\quad \mathrm{f}_{\mathrm{co}, \mathrm{k}}=42,70 \mathrm{MPa}$

Corpos de prova sem impregnação- $S I \quad f_{C} 90, k=2,10 \mathrm{MPa}$

Corpos de prova com impregnação- $\mathrm{Cl} \quad \mathrm{f}_{\mathrm{C} 90, \mathrm{k}}=11,20 \mathrm{MPa}$

O coeficiente de modificação kmod segundo o item 5.4.4 do PNBR 7190/96 que afeta os valores de cálculo das propriedades da madeira em função da classe de carregamento da estrutura é dado pela expressão [6.11].

$$
\mathrm{k}_{\bmod }=\mathrm{k}_{\bmod .1} \cdot \mathrm{k}_{\bmod .2} \cdot \mathrm{k}_{\bmod .3}
$$

Serão adotados os seguintes valores:

$\mathbf{k}_{\text {mod.1 }}=0,90$ (Madeira serrada e classe de carregamento de curta duração)

$\mathbf{k}_{\text {mod.2 }}=1,00$ [Madeira serrada e classes de umidade (1) e (2)]

$\mathbf{k}_{\text {mod.3 }}=1,00$ (Madeira de 1ㄹ categoria) 
$\mathrm{k}_{\bmod }=0,90 \cdot 1,00 \cdot 1,00=0,90$

$\gamma_{w c}=1,0$ (Coeficiente de ponderação)

Substituindo os valores nas expressões [6.9] e [6.10], teremos:

a)Madeira sem impregnação (Pinus)

$\mathrm{f}_{\mathrm{co}, \mathrm{d}}=\mathrm{k} \bmod \frac{\mathrm{f}_{\mathrm{co}, \mathrm{k}}}{\boldsymbol{\gamma}_{\mathrm{wc}}}=0,90 \frac{315}{1,0}=283,50 \mathrm{daN} / \mathrm{cm}^{2}$

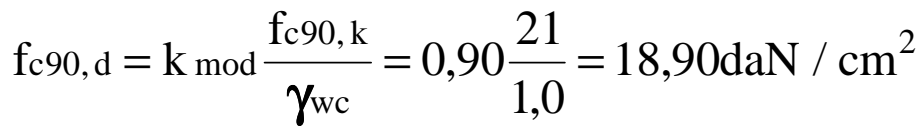

b) Madeira com impregnação(Pinus)

$\mathrm{f}_{\mathrm{co}, \mathrm{d}}=\mathrm{k} \bmod \frac{\mathrm{f}_{\mathrm{co}, \mathrm{k}}}{\boldsymbol{\gamma}_{\mathrm{wc}}}=0,90 \frac{427}{1,0}=384,30 \mathrm{daN} / \mathrm{cm}^{2}$

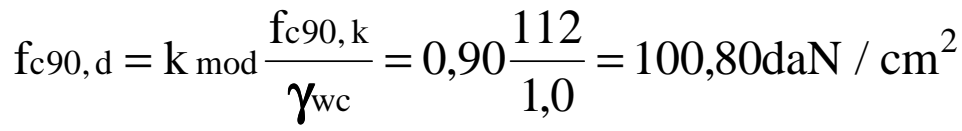

c)Madeira sem impregnação (Ipê)

$\mathrm{f}_{\mathrm{co}, \mathrm{d}}=\mathrm{k} \bmod \frac{\mathrm{f}_{\mathrm{co}, \mathrm{k}}}{\gamma_{\mathrm{wc}}}=0,90 \frac{637}{1,0}=573,30 \mathrm{daN} / \mathrm{cm}^{2}$

$\mathrm{f}_{\mathrm{c} 90, \mathrm{~d}}=\mathrm{k} \bmod \frac{\mathrm{f}_{\mathrm{c} 90, \mathrm{k}}}{\gamma_{\mathrm{wc}}}=0,90 \frac{168}{1,0}=151,20 \mathrm{daN} / \mathrm{cm}^{2}$

$\underline{\text { Valores de } \beta_{\lim }}$

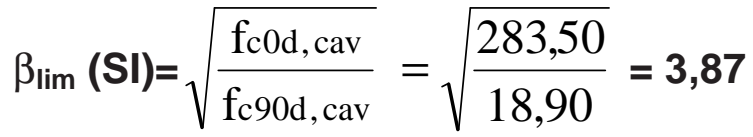

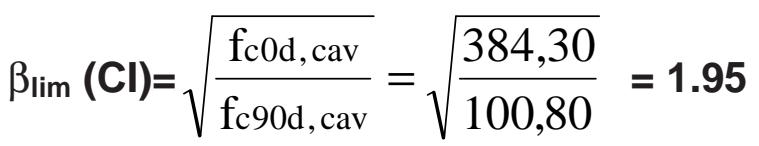

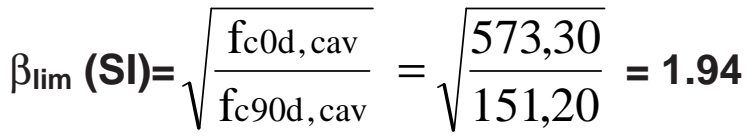


TABELA 66 -Valores de cálculo das resistências das cavilhas com base no PNBR 7190/96.

ESPÉCIE: Pinus

\begin{tabular}{|c|c|c|c|c|c|c|}
\hline CP & $\mathrm{f}_{\mathrm{c} 90 \mathrm{~d}, \mathrm{cav}}$ & $\mathrm{d}(\mathrm{cm})$ & $\mathrm{t}(\mathrm{cm})$ & $\beta$ & $\beta_{\text {lim }}$ & $\mathrm{R}_{\mathrm{vd}, 1}(\mathrm{kN})$ \\
\hline CP16 & 0,19 & 1,6 & 2,5 & 1,56 & 3,87 & 0,30 \\
\hline CPI16 & 1,01 & 1,6 & 2,7 & 1,69 & 1,95 & 1,74 \\
\hline CP18 & 0,19 & 1,8 & 2,6 & 1,44 & 3,87 & 0,35 \\
\hline CPI18 & 1,01 & 1,8 & 2,6 & 1,44 & 1,95 & 1,89 \\
\hline CP20 & 0,19 & 2 & 2,5 & 1,25 & 3,87 & 0,38 \\
\hline CPI20 & 1,01 & 2 & 2,6 & 1,30 & 1,95 & 2,10 \\
\hline CN16 & 0,19 & 1,6 & 2,6 & 1,63 & 3,87 & 0,31 \\
\hline CNI16 & 1,01 & 1,6 & 2,6 & 1,63 & 1,95 & 1,68 \\
\hline CN18 & 0,19 & 1,8 & 2,6 & 1,44 & 3,87 & 0,35 \\
\hline CNI18 & 1,01 & 1,8 & 2,6 & 1,44 & 1,95 & 1,89 \\
\hline CN20 & 0,19 & 2 & 2,6 & 1,30 & 3,87 & 0,39 \\
\hline CNI20 & 1,01 & 2 & 2,6 & 1,30 & 1,95 & 2,10 \\
\hline CN1-16 & 0,19 & 1,6 & 2,8 & 1,75 & 3,87 & 0,34 \\
\hline CNI2-16 & 1,01 & 1,6 & 2,75 & 1,72 & 1,95 & 1,77 \\
\hline CN3-16 & 0,19 & 1,6 & 2,6 & 1,63 & 3,87 & 0,31 \\
\hline CN4-18 & 0,19 & 1,8 & 2,6 & 1,44 & 3,87 & 0,35 \\
\hline CVN16 & 0,19 & 1,6 & 2,5 & 1,56 & 3,87 & 0,30 \\
\hline CVNI16 & 1,01 & 1,6 & 2,4 & 1,50 & 1,95 & 1,55 \\
\hline CVN18 & 0,19 & 1,8 & 2,374 & 1,32 & 3,87 & 0,32 \\
\hline CVNI18 & 1,01 & 1,8 & 2,48 & 1,38 & 1,95 & 1,80 \\
\hline CVN20 & 0,19 & 2 & 2,6 & 1,30 & 3,87 & 0,39 \\
\hline CVNI20 & 1,01 & 2 & 2,6 & 1,30 & 1,95 & 2,10 \\
\hline CT1 & 0,19 & 1,6 & 2,6 & 1,63 & 3,87 & 0,31 \\
\hline CL1 & 0,19 & 1,6 & 2,5 & 1,56 & 3,87 & 0,30 \\
\hline CT2 & 0,19 & 1,8 & 2,7 & 1,50 & 3,87 & 0,37 \\
\hline CL2 & 0,19 & 1,8 & 2,6 & 1,44 & 3,87 & 0,35 \\
\hline CT3 & 0,19 & 2 & 2,6 & 1,30 & 3,87 & 0,39 \\
\hline CL3 & 0,19 & 2 & 2,7 & 1,35 & 3,87 & 0,41 \\
\hline CPN18 & 0,19 & 1,8 & 2,5 & 1,39 & 3,87 & 0,34 \\
\hline CPNI18 & 1,01 & 1,8 & 2,2 & 1,22 & 1,95 & 1,60 \\
\hline & & & & & & \\
\hline
\end{tabular}

OBS. Os valores de $\mathbf{f}_{\mathrm{c} 90 \mathrm{~d}, \mathrm{cav}}$, estão expressos em $\mathbf{k N} / \mathbf{c m}^{2}$. 
TABELA 67- Valores de cálculo das resistências das cavilhas com base no PNBR 7190/96.

ESPÉCIE: Ipê

\begin{tabular}{|c|c|c|c|c|c|c|}
\hline $\mathbf{C P}$ & $\mathbf{f}_{\mathbf{c 9 0 d}, \mathbf{c a v}}$ & $\mathbf{d}(\mathbf{c m})$ & $\mathbf{t}(\mathbf{c m})$ & $\beta$ & $\beta_{\text {lim }}$ & $\mathbf{R}_{\mathbf{v d}, \mathbf{1}}(\mathbf{k N})$ \\
\hline P1 & 1,51 & 1,6 & 2,3 & 1,438 & 1,94 & 2,22 \\
\hline P2 & 1,51 & 1,8 & 2,4 & 1,333 & 1,94 & 2,61 \\
\hline P3 & 1,51 & 2 & 2,45 & 1,225 & 1,94 & 2,96 \\
\hline N1 & 1,51 & 1,6 & 2,4 & 1,5 & 1,94 & 2,32 \\
\hline N2 & 1,51 & 1,8 & 2,4 & 1,333 & 1,94 & 2,61 \\
\hline N3 & 1,51 & 2 & 2,45 & 1,225 & 1,94 & 2,96 \\
\hline
\end{tabular}

Em seguida iremos comparar os valores obtidos de resistência de cálculo das cavilhas com os valores das cargas limites obtidas nos ensaios experimentais, lembrando que os valores de ensaios serão divididos por quatro em virtude de apresentarem quatro seções de corte, ou seja na tabela 65 os valores de $\mathbf{F}_{\mathbf{0}}$, $\mathbf{F}_{\text {/ }} \mathbf{e} \mathbf{F}_{\max }$ serão transcritos para a tabelas 68 a 71 na forma $F_{0} / 4, F_{/} / 4$ e $F_{\max } / 4$. 
TABELA 68- Dados comparativos dos valores de cálculo das resistências das cavilhas baseados no PNBR 7190/96, em relação aos valores obtidos nos ensaios de ligações,solicitadas na compressão paralela às fibras.

ESPÉCIE: Pinus

\begin{tabular}{|c|c|c|c|c|c|c|}
\hline $\mathrm{CP}$ & $\mathrm{d}(\mathrm{cm})$ & $\mathrm{R}_{\mathrm{vd}, 1}(\mathrm{kN})$ & $\mathrm{F}_{\mathrm{o}} / 4(\mathrm{kN})$ & $\mathrm{F}_{l} / 4(\mathrm{kN})$ & $\mathrm{F}_{\mathrm{max}} / 4(\mathrm{kN})$ & $\mathrm{OBS}$. \\
\hline CP16 & 1,6 & 0,30 & 1,50 & 2,03 & 2,80 & $\mathrm{SI}$ \\
\hline CPI16 & 1,6 & 1,74 & 2,00 & 2,93 & 3,98 & $\mathrm{Cl}$ \\
\hline CP18 & 1,8 & 0,35 & 2,25 & 2,78 & 4,10 & $\mathrm{SI}$ \\
\hline CPI18 & 1,8 & 1,89 & 2,75 & 4,05 & 5,35 & $\mathrm{Cl}$ \\
\hline CP20 & 2 & 0,38 & 2,50 & 3,01 & 4,80 & $\mathrm{SI}$ \\
\hline CPI20 & 2 & 2,10 & 3,75 & 5,40 & 7,35 & $\mathrm{Cl}$ \\
\hline
\end{tabular}

TABELA 69- Dados comparativos dos valores de cálculo das resistências das cavilhas baseados no PNBR 7190/96, em relação aos valores obtidos nos ensaios de ligações,solicitadas na compressão paralela às fibras.

ESPÉCIE:Ipê

\begin{tabular}{|c|c|c|c|c|c|c|}
\hline $\mathrm{CP}$ & $\mathrm{d}(\mathrm{cm})$ & $\mathrm{R}_{\mathrm{vd}, 1}(\mathrm{kN})$ & $\mathrm{F}_{\mathrm{o}} / 4(\mathrm{kN})$ & $\mathrm{F}_{l} / 4(\mathrm{kN})$ & $\mathrm{F}_{\mathrm{max}} / 4(\mathrm{kN})$ & OBS. \\
\hline $\mathrm{P} 1$ & 1,6 & 2,22 & 1,25 & 2,64 & 6,5 & $\mathrm{SI}$ \\
\hline P2 & 1,8 & 2,61 & 2,25 & 4,1 & 6,5 & $\mathrm{SI}$ \\
\hline P3 & 2 & 2,96 & 2,75 & 4,96 & 7,58 & $\mathrm{SI}$ \\
\hline
\end{tabular}

SI-Sem impregnação

Cl-Com impregnação 
TABELA 70- Dados comparativos dos valores de cálculo das resistências das cavilhas baseados no PNBR 7190/96, em relação aos valores obtidos nos ensaios de ligações,solicitadas na compressão normal às fibras.

ESPÉCIE: Pinus

\begin{tabular}{|c|c|c|c|c|c|c|}
\hline $\mathrm{CP}$ & $\mathrm{d}(\mathrm{cm})$ & $\mathrm{R}_{\mathrm{vd}, 1}(\mathrm{kN})$ & $\mathrm{F}_{\mathrm{o}} / 4(\mathrm{kN})$ & $\mathrm{F}_{l} / 4(\mathrm{kN})$ & $\mathrm{F}_{\mathrm{max}} / 4(\mathrm{kN})$ & $\mathrm{OBS}$. \\
\hline CN16 & 1,6 & 0,31 & 1,5 & 2,48 & 3,38 & $\mathrm{SI}$ \\
\hline CN16 & 1,6 & 1,68 & 1,5 & 2,45 & 3,2 & $\mathrm{Cl}$ \\
\hline CN18 & 1,8 & 0,35 & 2,25 & 2,78 & 3,9 & $\mathrm{SI}$ \\
\hline CNI18 & 1,8 & 1,89 & 2,25 & 3,65 & 4,38 & $\mathrm{Cl}$ \\
\hline CN20 & 2 & 0,39 & 2,25 & 2,89 & 4,05 & $\mathrm{SI}$ \\
\hline CNI20 & 2 & 2,1 & 1,75 & 3,21 & 4,92 & $\mathrm{Cl}$ \\
\hline CN1-16 & 1,6 & 0,34 & 1,25 & 1,78 & 2,6 & $\mathrm{SI}$ \\
\hline CNI2-16 & 1,6 & 1,77 & 2 & 2,82 & 3,67 & $\mathrm{Cl}$ \\
\hline CN3-16 & 1,6 & 0,31 & 1,25 & 1,64 & 2,5 & $\mathrm{SI}$ \\
\hline CN4-18 & 1,8 & 0,35 & 1,75 & 2,21 & 3,17 & $\mathrm{SI}$ \\
\hline CVN16 & 1,6 & 0,3 & 1,25 & 1,94 & 3 & $\mathrm{SI}$ \\
\hline CVNI16 & 1,6 & 1,55 & 2,25 & 2,79 & 3,58 & $\mathrm{Cl}$ \\
\hline CVN18 & 1,8 & 0,32 & 3,25 & 4,26 & 6,2 & $\mathrm{SI}$ \\
\hline CVNI18 & 1,8 & 1,8 & 2,5 & 3,85 & 5,45 & $\mathrm{Cl}$ \\
\hline CVN20 & 2 & 0,39 & 2 & 2,91 & 4,25 & $\mathrm{SI}$ \\
\hline CVNI20 & 2 & 2,1 & 3,25 & 4,41 & 5,78 & $\mathrm{Cl}$ \\
\hline CT1 & 1,6 & 0,31 & 1 & 1,52 & 2,83 & $\mathrm{SI}$ \\
\hline CL1 & 1,6 & 0,3 & 1,5 & 1,92 & 3,7 & $\mathrm{SI}$ \\
\hline CT2 & 1,8 & 0,37 & 1,25 & 2,01 & 3,52 & $\mathrm{SI}$ \\
\hline CL2 & 1,8 & 0,35 & 1,25 & 1,73 & 3,3 & $\mathrm{SI}$ \\
\hline CT3 & 2 & 0,39 & 1,5 & 1,98 & 3,65 & $\mathrm{SI}$ \\
\hline CL3 & 2 & 0,41 & 1,75 & 1,98 & 3,3 & $\mathrm{SI}$ \\
\hline CPN18 & 1,8 & 0,34 & 2,5 & 3,23 & 4,58 & $\mathrm{SI}$ \\
\hline CPNI18 & 1,8 & 1,6 & 3,25 & 3,71 & 4,65 & $\mathrm{Cl}$ \\
\hline
\end{tabular}

SI-Sem impregnação Cl-Com impregnação 
TABELA 71- Dados comparativos dos valores de cálculo das resistências das cavilhas baseados no PNBR 7190/96, em relação aos valores obtidos nos ensaios de ligações,solicitadas na compressão normal às fibras.

ESPÉCIE: Ipê

\begin{tabular}{|c|c|c|c|c|c|c|}
\hline $\mathrm{CP}$ & $\mathrm{d}(\mathrm{cm})$ & $\mathrm{R}_{\mathrm{vd}, 1}(\mathrm{kN})$ & $\mathrm{F}_{\mathrm{o}} / 4(\mathrm{kN})$ & $\mathrm{F}_{l} / 4(\mathrm{kN})$ & $\mathrm{F}_{\max } / 4(\mathrm{kN})$ & OBS. \\
\hline $\mathrm{N} 1$ & 1,6 & 2,32 & 2 & 3,21 & 6 & $\mathrm{SI}$ \\
\hline $\mathrm{N} 2$ & 1,8 & 2,61 & 2,5 & 4,14 & 5,38 & $\mathrm{SI}$ \\
\hline $\mathrm{N} 3$ & 2 & 2,96 & 3,25 & 5,1 & 6,4 & $\mathrm{SI}$ \\
\hline
\end{tabular}

SI-Sem impregnação

Cl-Com impregnação

Nas figuras 65 e 66 podem ser observados gráficos comparativos das resistências de cálculo, e dos valores de cargas obtidos nos ensaios de ligações com cavilhas impregnadas e não impregnadas, solicitadas na compressão paralela e compressão normal às fibras. 
Ensaio de ligações com cavilhas solicitadas na compressão paralela às fibras; $d=2,0 \mathrm{~cm}$.

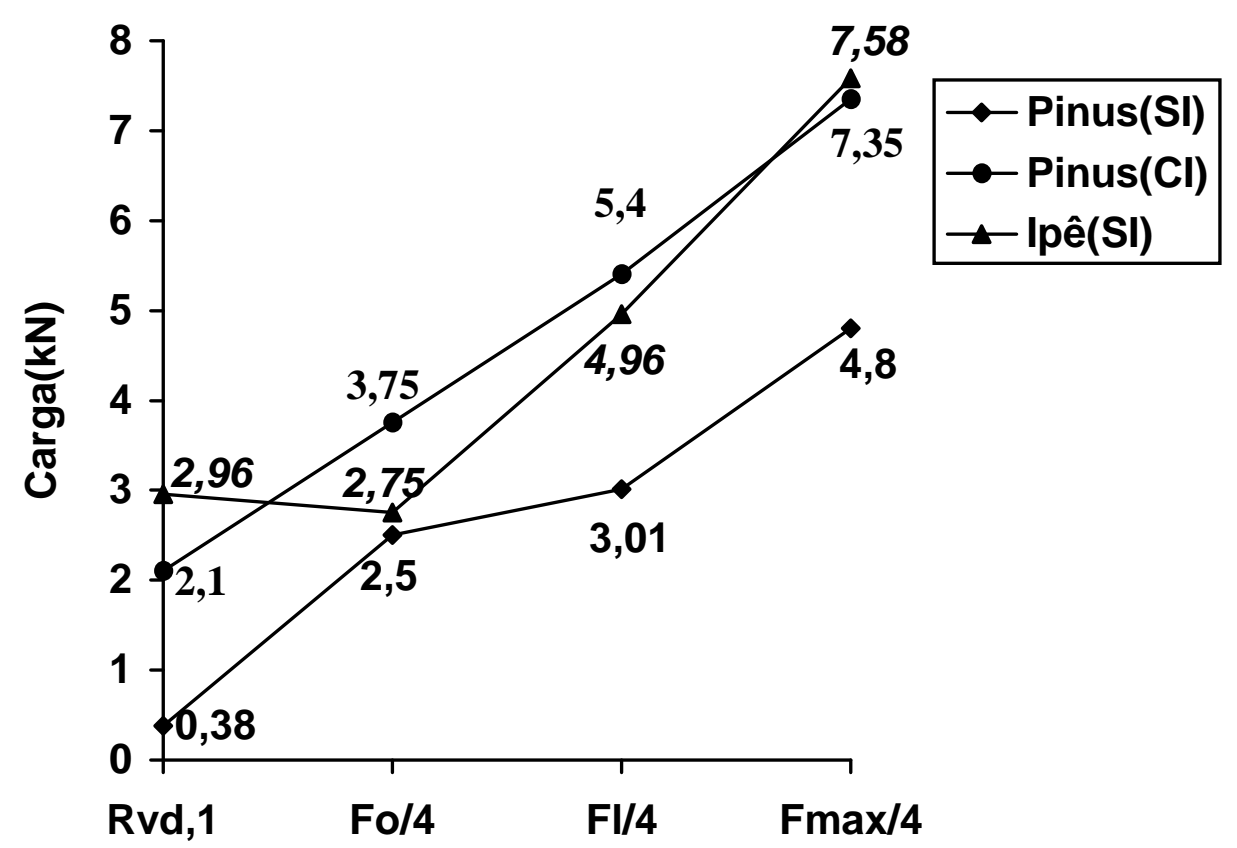

FIGURA 65- Dados comparativos de resistência de cálculo e cargas obtidas no ensaio de ligações com cavilhas solicitadas na compressão paralela às fibras. 
Ensaio de ligações com cavilhas solicitadas na compressão normal às fibras; $d=2,0 \mathrm{~cm}$.

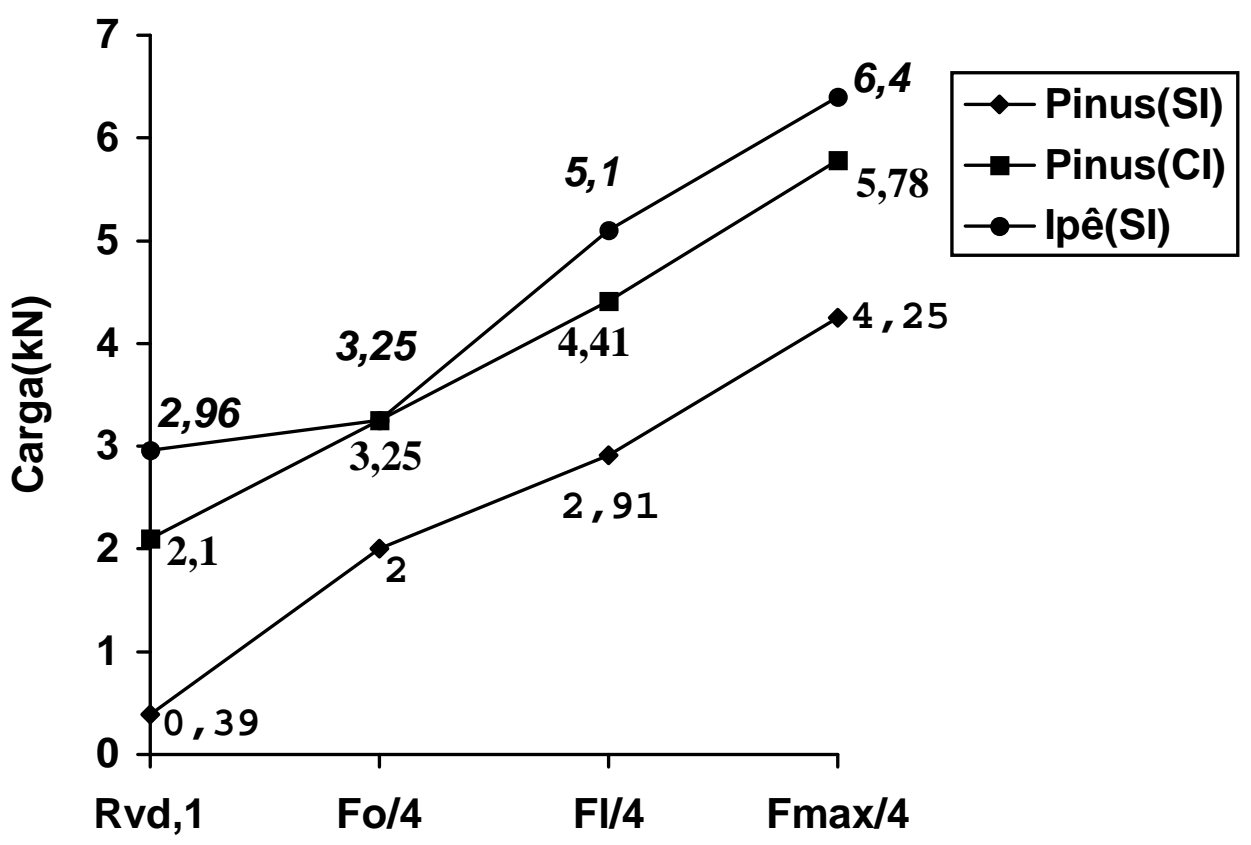

FIGURA 66- Dados comparativos de resistência de cálculo e cargas obtidas no ensaio de ligações com cavilhas solicitadas na compressão normal às fibras. 
Finalmente podemos observar na tabela 72 os coeficientes das respectivas resistências da cavilhas com relação a resistência de cálculo, ao limite de proporcionalidade e a carga máxima, tendo portanto a noção do aumento percentual da resistência das cavilhas impregnadas em relação às cavilhas não impregnadas.

Nas tabelas $73,74,75$ e 76 podem-se observar os valores da rigidez das ligações com cavilhas impregnadas e não impregnadas.

TABELA 72- Valores dos coeficientes de resistência das cavilhas impregnadas e não impregnadas $\left(R_{v d, 1}\right) C l / R_{v d, 1}(S I)=r_{1}, F_{0}(C I) / F_{0}(S I)=r_{2}$;

$$
F_{(}(\mathrm{Cl}) / \mathrm{F}(\mathrm{SI})=r_{3} ; F_{\max }(\mathrm{Cl}) / \mathrm{F}_{\max }(\mathrm{SI})=\mathrm{r}_{4} \text {. }
$$

\section{ESPÉCIE:Pinus}

\begin{tabular}{|c|c|c|c|c|c|}
\hline ENSAIO & $\mathbf{d}(\mathbf{c m})$ & $\mathbf{r}_{1}$ & $\mathbf{r}_{2}$ & $\mathbf{r}_{3}$ & $\mathbf{r}_{4}$ \\
\hline Compressão paralela & 1,6 & 5,8 & 1,34 & 1,44 & 1,42 \\
\hline Compressão paralela & 1,8 & 5,4 & 1,22 & 1,46 & 1,3 \\
\hline Compressão paralela & 2 & 5,52 & 1,5 & 1,79 & 1,53 \\
\hline Compressão normal & 1,6 & 5,17 & 1,8 & 1,44 & 1,2 \\
\hline Compressão normal & 1,8 & 4,71 & 1,3 & 1,15 & 1,02 \\
\hline Compressão normal & 2 & 5,38 & 1,62 & 1,52 & 1,36 \\
\hline
\end{tabular}

SI-Cavilhas sem impregnação; Cl- Cavilhas Impregnadas.

Nas figuras 67 e 68 podem ser observados os modelos de ligações com cavilhas ensaiadas na compressão paralela às fibras e na compressão normal às fibras após serem ensaiadas, ou seja quando atingiram a carga de ruptura nos respectivos ensaios, mostrando assim seu modo de ruptura. 


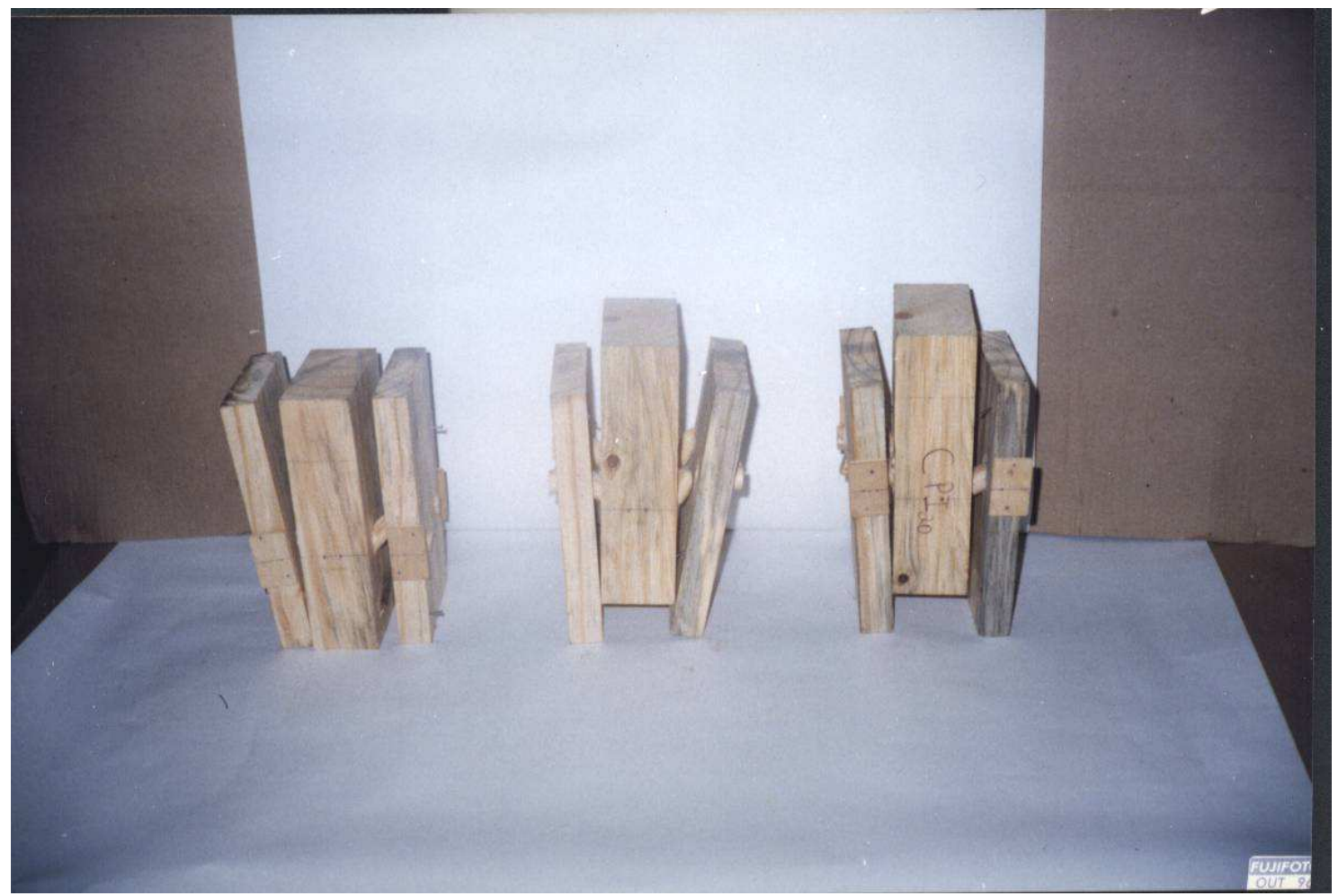

FIGURA 67- Corpo de prova de ligação com cavilhas ao atingir a carga de ruptura no ensaio de compressão paralela às fibras. 

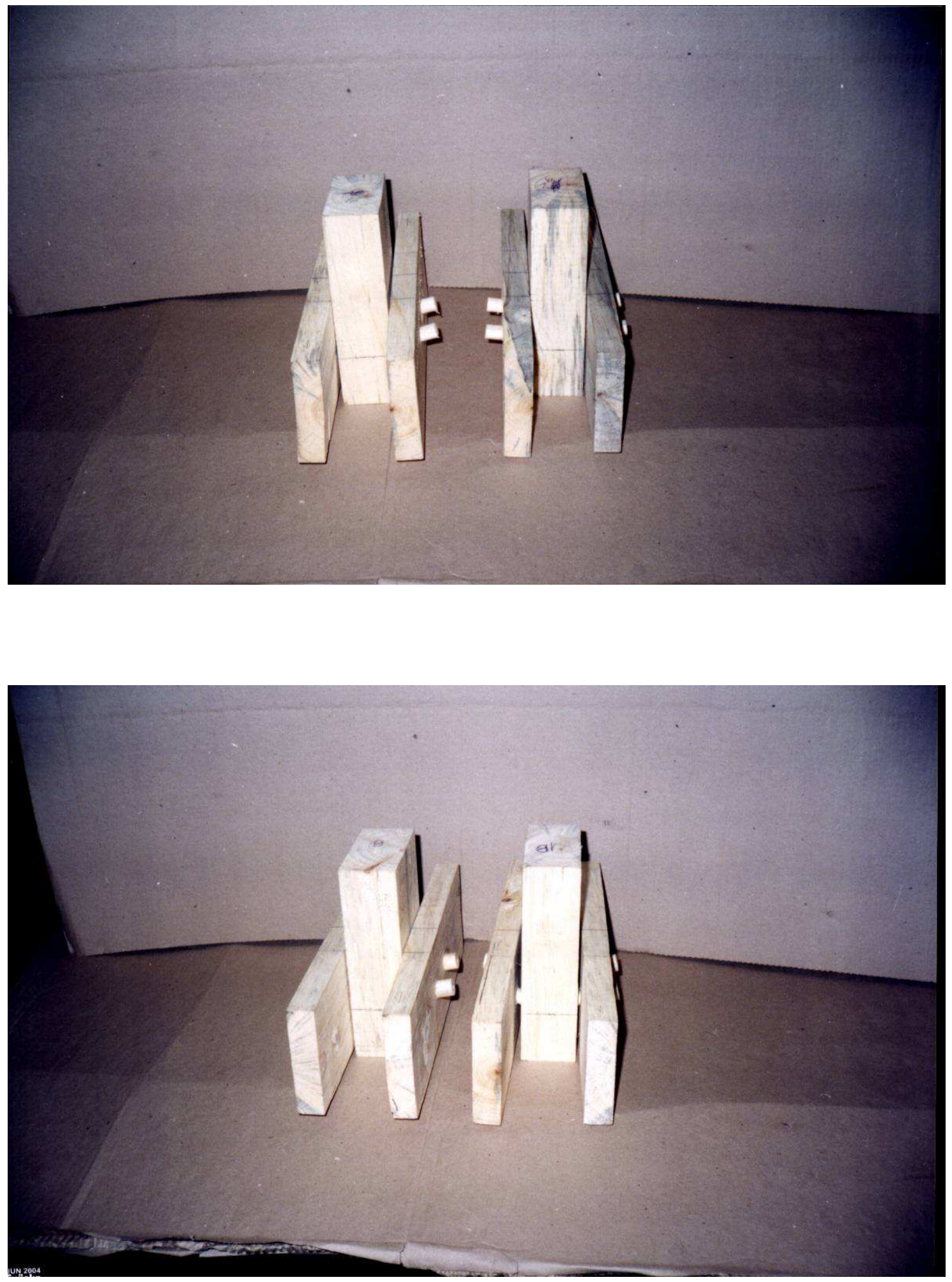

FIGURA 68- Corpo de prova de ligação com cavilhas ao atingir a carga de ruptura no ensaio de compressão normal às fibras. 
TABELA 73-Dados comparativos de cargas e rigidez nos ensaios de ligações com cavilhas obtidas nos ensaios experimentais na compressão paralela às fibras com valores do PNBR 7190/96.

ESPÉCIE:Pinus

\section{VALORES EXPRESSOS EM kN, e kN/mm}

\begin{tabular}{|c|c|c|c|c|c|c|c|}
\hline $\mathbf{N}$. & $\mathbf{d}(\mathbf{c m})$ & $\mathbf{R}_{\mathbf{v d}} \mathbf{1}^{\mathbf{1}^{(\mathbf{n})}}$ & $\mathbf{R}_{\mathbf{v d}} \mathbf{1}^{\mathbf{( i )}^{(\mathbf{)}}}$ & $\mathbf{F}_{\mathbf{L}}{ }^{(\mathbf{n})}$ & $\mathbf{F}_{\mathbf{L}}{ }^{(\mathbf{i})}$ & $\mathbf{k}^{(\mathbf{n})}$ & $\mathbf{k}^{(\mathbf{i})}$ \\
\hline 1 & 1,6 & 0,30 & 1,74 & 2,03 & 2,93 & 12,96 & 15,96 \\
\hline 2 & 1,8 & 0,35 & 1,89 & 2,78 & 4,05 & 30,80 & 34,59 \\
\hline 3 & 2,0 & 0,38 & 2,10 & 3,01 & 5,40 & 20,75 & 45,61 \\
\hline
\end{tabular}

TABELA 74-Dados comparativos de cargas e rigidez nos ensaios de ligações com cavilhas obtidas nos ensaios experimentais na compressão paralela às fibras com valores do PNBR 7190/96.

ESPÉCIE:Ipê

\section{VALORES EXPRESSOS EM kN, e kN/mm}

\begin{tabular}{|c|c|c|c|c|c|c|c|}
\hline $\mathbf{N}$. & $\mathbf{d}(\mathbf{c m})$ & $\mathbf{R}_{\mathbf{v d}}, \mathbf{1}^{(\mathbf{n})}$ & $\mathbf{R}_{\mathbf{v d}}, \mathbf{1}^{(\mathbf{i}}$ & $\mathbf{F}_{\mathbf{L}}^{(\mathbf{n})}$ & $\mathbf{F}_{\mathbf{L}}^{(\mathbf{i})}$ & $\mathbf{k}^{(\mathbf{n})}$ & $\mathbf{k}^{(\mathbf{i})}$ \\
\hline 1 & 1,6 & 2,22 & - & 2,64 & - & 33,90 & - \\
\hline 2 & 1,8 & 2,61 & - & 4,1 & - & 28,62 & - \\
\hline 3 & 2,0 & 2,96 & - & 4,96 & - & 27,26 & - \\
\hline
\end{tabular}


TABELA 75-Dados comparativos de cargas e rigidez nos ensaios de ligações com cavilhas obtidas nos ensaios experimentais na compressão normal às fibras com valores do PNBR 7190/96. ESPÉCIE:Pinus

\section{VALORES EXPRESSOS EM kN , e kN/mm}

\begin{tabular}{|c|c|c|c|c|c|c|c|}
\hline $\mathbf{N}$. & $\mathbf{d}(\mathbf{c m})$ & $\mathbf{R}_{\mathbf{v d}}, \mathbf{1}^{(\mathbf{n})}$ & $\mathbf{R}_{\mathbf{v d}, \mathbf{1}^{(\mathbf{i}}}$ & $\mathbf{F}_{\mathbf{L}}{ }^{(\mathbf{n})}$ & $\mathbf{F}_{\mathbf{L}}{ }^{(\mathbf{i})}$ & $\mathbf{k}^{(\mathbf{n})}$ & $\mathbf{k}^{(\mathbf{i})}$ \\
\hline 1 & 1,6 & 0,31 & 1,68 & 2,48 & 2,45 & 14,73 & 9,68 \\
\hline 2 & 1,8 & 0,35 & 1,89 & 2,78 & 3,65 & 18,00 & 18,22 \\
\hline 3 & 2,0 & 0,39 & 2,10 & 2,89 & 3,21 & 15,22 & 14,31 \\
\hline 4 & 1,6 & 0,34 & 1,77 & 1,78 & 2,82 & 7,96 & 7,82 \\
\hline 5 & 1,6 & 0,31 & - & 1,64 & - & 6,83 & - \\
\hline 6 & 1,8 & 0,35 & - & 2,21 & - & 13,59 & - \\
\hline 7 & 1,6 & 0,30 & 1,55 & 1,94 & 2,79 & 12,50 & 14,47 \\
\hline 8 & 1,8 & 0,32 & 1,80 & 4,26 & 3,85 & 25,77 & 17,43 \\
\hline 9 & 2,0 & 0,39 & 2,10 & 2,91 & 4,41 & 15,16 & 25,77 \\
\hline 10 & 1,6 & 0,31 & - & 1,52 & - & 5,84 & - \\
\hline 11 & 1,6 & 0,30 & - & 1,92 & - & 3,34 & - \\
\hline 12 & 1,8 & 0,37 & - & 2,01 & - & 8,13 & - \\
\hline 13 & 1,8 & 0,35 & - & 1,73 & - & 7,41 & - \\
\hline 14 & 2,0 & 0,39 & - & 1,98 & - & 7,93 & - \\
\hline 15 & 2,0 & 0,41 & - & 1,98 & - & 11,76 & - \\
\hline 16 & 1,8 & 0,34 & 1,60 & 3,23 & 3,71 & 11,97 & 9,12 \\
\hline
\end{tabular}


TABELA 76-Dados comparativos de cargas e rigidez nos ensaios de ligações com cavilhas obtidas nos ensaios experimentais na compressão normal às fibras com valores do PNBR 7190/96.

ESPÉCIE:Ipê

\section{VALORES EXPRESSOS EM kN , e kN/mm}

\begin{tabular}{|c|c|c|c|c|c|c|c|}
\hline $\mathbf{N}$. & $\mathbf{d}(\mathbf{c m})$ & $\mathbf{R}_{\mathbf{v d}}, \mathbf{1}^{(\mathbf{n})}$ & $\mathbf{R}_{\mathbf{v d}, \mathbf{1}^{(\mathbf{i}}}$ & $\mathbf{F}_{\mathbf{L}}^{(\mathbf{n})}$ & $\mathbf{F}_{\mathbf{L}}^{(\mathbf{i})}$ & $\mathbf{k}^{(\mathbf{n})}$ & $\mathbf{k}^{(\mathbf{i})}$ \\
\hline 1 & 1,6 & 2,32 & - & 3,21 & - & 20.28 & - \\
\hline 2 & 1,8 & 2,61 & - & 4,14 & - & 16.78 & - \\
\hline 3 & 2,0 & 2,96 & - & 5,1 & - & 28.47 & - \\
\hline
\end{tabular}

OBS. Os índices (n) e (i) referem-se respectivamente a madeira natural e madeira impregnada.

\subsubsection{Considerações sobre os ensaios de ligações com cavilhas impregnadas e não impregnadas}

a)A resistência $\mathbf{R}$ de uma ligação é determinada convencionalmente pela força aplicada a um corpo -de- prova padronizado que provoca na ligação uma deformação específica residual de $2 \%$.

b)Baseados nos dados obtidos da tabela 72, nos ensaios de ligações com cavilhas solicitadas na compressão paralela às fibras os melhores resultados obtidos foram: um aumento percentual da ordem de $\mathbf{5 0} \%$ no limite de proporcionalidade $\left(\mathbf{F}_{0}\right), 79 \%$ na carga limite $\left(\mathbf{F}_{\mathbf{l}}\right)$ e $\mathbf{5 3} \%$ na carga máxima $\left(\boldsymbol{F}_{\text {max }}\right)$, da espécie Pinus, para cavilhas com diâmetro igual a $20 \mathrm{~mm}$. 
c)Já para os ensaios de ligações com cavilhas solicitadas na compressão normal às fibras, observou-se um aumento percentual da ordem de $\mathbf{8 0} \%$ no limite de proporcionalidade $\left(\mathbf{F}_{\mathrm{o}}\right)$ para cavilhas com diâmetro igual a $16 \mathrm{~mm}$, entretanto em relação a carga limite $\left(\mathbf{F}_{\boldsymbol{l}}\right)$, e a carga máxima $\left(F_{\text {max }}\right)$, um aumento de $52 \%$ e $36 \%$,da espécie Pinus, para cavilhas com diâmetro igual a $20 \mathrm{~mm}$.

d) Com os resultados acima especificados nota-se portanto a eficiência do processo de impregnação das cavilhas para permitir a sua utilização como elemento de ligação nas ligações convencionais dos projetos estruturais de madeira.

e) Os corpos de prova intitulados de CT1, CL1, CT2, CL2, CT3 e CL3, ensaiados na solicitação de compressão normal às fibras teve como objetivo principal definir a melhor posição em relação aos apoios transversais e laterais dos corpos de provas, no respectivo ensaio, entretanto nota-se que em relação aos resultados finais dos valores de $\boldsymbol{F}_{\mathbf{0}}, \mathbf{F}_{\boldsymbol{l}} \mathbf{e} \mathbf{F}_{\max }$ não houve mudança significativa, decidindo portanto adotar nos ensaios convencionais solicitados na compressão normal às fibras, o esquema de apoio transversal dos corpos de prova CT1, CT2 e CT3, que é o modelo padrão seguido pela normal internacional BS 6948/89 descrito em sua página 28 e que foi adotado nesta pesquisa.

f)As cavilhas impregnadas ao serem utilizadas como elementos de ligações nas ligações de estruturas de madeira poderão propiciar uma maior durabilidade das mesmas em relação aos meios tradicionais de ligações em ambientes agressivos. 


\section{CONCLUSÕES E RECOMENDAÇÕES PARA FUTURAS PESQUISAS}

Do trabalho realizado podemos fazer algumas recomendações que julgamos de extrema importância para a utilização deste tipo de ligação: 1)É importante selecionar as espécies adequadas de madeira para se confeccionar as cavilhas impregnadas.Para isso é importante realizar um estudo anatômico adequado para que se possa escolher qual a espécie de madeira mais adequada para essa finalidade.

2)O trabalho de preparação das resinas de impregnação bem como o processo de impregnação devem ser executados em locais apropriados para permitir a máxima segurança dos usuários bem como ser acompanhado de pessoal especializado e equipamentos de segurança já que os produtos químicos a serem manipulados são tóxicos e explosivos.

3)Recomenda-se para impregnação de cavilhas a utilização do produto químico estireno bem como das seguintes variáveis:tempo de impregnação (30 min.), pressão de impregnação (1MPa), tempo e temperatura de polimerização (48 horas a $60^{\circ} \mathrm{C}$ ).

4)Não se tem dado nenhuma importância na literatura vigente sobre a questão das ligações com cavilhas bem como do ponto de vista normativo. Acredita-se com esse tipo de estudo possa se colocar no campo estrutural da madeira uma nova alternativa de emprego em escala até industrial desse elemento de ligação o que poderá ser um boa opção em relação a outros elementos utilizados principalmente os fabricados em aço devido ao problema da corrosão. 
O novo projeto de revisão da norma brasileira NBR 7190/96, já apresenta critérios de dimensionamento de ligações por cavilhas, baseados nesta pesquisa.

5) Com os resultados deste trabalho pode-se pensar, a nível de escala industrial, a impregnação de peças de madeira com dimensões comerciais para o emprego nas estruturas de madeira convencionais.

6) Espécies de madeira de reflorestamento como o Pinus apresentam uma boa facilidade de absorção de resinas de estireno, já o Eucalipto Citriodora não se comporta muito bem para esse tipo de trabalho de impregnação, devido a sua alta densidade e baixa permeabilidade.

7) É importante que se continue a realizar pesquisas nesse assunto utilizando outras espécies de madeira de baixa densidade (classe 20).

8) Em relação a esse trabalho espera-se ter uma contribuição nos critérios de dimensionamento de ligações estruturais de madeira e também no campo normativo ampliar a liberdade para o calculista optar pelas cavilhas impregnadas quando se puder substituir os elementos tradicionais de ligação, desde que examinado com cuidado quando o projeto der essa opção.

Também em relação a cavilhas impregnadas pretende-se solucionar um velho problema que ocorre nas ligações com pregos, parafusos, pinos de aço, etc. em que se torna necessário uma manutenção preventiva em face do problema da corrosão e com isso optar pelo uso desse novo material opcional de fixação nas ligações em estruturas de madeira, principalmente às respostas às intempéries como tabuleiro de pontes de madeira.

9)Os resultados preliminares comparando-se as resistências de cavilhas de Pinus impregnadas com resinas e madeiras tropicais de alta resistência, mostram que a resistência de algumas madeiras tropicais ainda é maior que o Pinus impregnado.

As grandes vantagens observadas com a utilização da impregnação são a estabilidade dimensional com relação a umidade, diminuição da variabilidade das características de resistência e elasticidade, e aumento significativo no limite de proporcionalidade na ordem de $80 \%$ na 
compressão normal, como $50 \%$ na compressão paralela, tanto de peças isoladas como na ligação.

10) Analisando os resultados das Tabelas 78 a 93 , de $\mathbf{F}_{\mathbf{W}}$ e $\mathbf{F}_{\mathbf{c a v}}$, para as cargas de primeiro e segundo limite das ligações cavilhadas, conclui-se que pelos valores calculados de $\beta$ e $\beta_{\lim }$, sempre ocorreu o fato de que $\beta<\beta_{\lim }$, ou seja ocorreu embutimento da cavilha na madeira e as cargas limites dos modelos das ligações cavilhadas que foram ensaiadas, para todos os casos foi caracterizada sempre pelo valor de $\mathbf{F}_{\mathbf{w}}$.

11) Igualmente os valores calculados das expressões de $\mathbf{F}_{\mathbf{W}}$ e $\mathbf{F}_{\mathbf{c a v}}$, das ligações cavilhadas nas tabelas 94,95 e 96 em função da resistência à compressão normal as fibras $\mathbf{f}_{\mathbf{c} 90}$, e $\mathbf{f}_{\mathbf{c 0} \mathbf{0} \text {,cav }}$, e que permitiram a determinação dos valores anteriores nas tabelas 103 e 114 em comparação com os valores experimentais, mostram também que tanto para madeiras nativas quanto para madeiras impregnadas sempre ocorreu 0 embutimento da cavilha na madeira, ou seja daí a razão de se utilizar nêste trabalho para a determinação de $\mathbf{R}_{\mathbf{v d}, \mathbf{1}}$ (Resistência de uma cavilha),segundo os princípios normativos da NBR 7190/96, o seu valor expresso no item 7.4.3, conforme a expressão (7.1).

$$
\operatorname{Rvd}, 1=0,4 \cdot \frac{\mathrm{t}^{2}}{\beta} \text {.fc90d,cav } \quad \mathrm{p} / \beta \leq \beta_{\lim } \quad \text { [7.1] }
$$

12) Nas tabelas 94 a 96 os valores de $\mathbf{F}_{\mathbf{w}}$ e $\mathbf{F}_{\text {cav }}$ para o caso das madeiras impregnadas e para madeiras nativas, mostram que os seus respectivos valores para o caso da carga de segundo limite nas hipóteses $A$ e $B$, foram os que mais se aproximaram da expressão de $\mathbf{R}_{\mathbf{v d}, \mathbf{1}}$ prescrita no item 7.4.3 da NBR 7190/96.

13) Para os novos ensaios de caracterização de resistência e elasticidade das madeiras e das ligações em estruturas de madeira, recomenda-se a utilização do método proposto pela NBR 7190/96. 
14)Somente como informativo, o custo do tratamento de madeiras impregnadas por $\mathrm{m}^{3}$, conforme o capítulo 6 no item 6.5.12, é da ordem de $\mathrm{R} \$ 285 / \mathrm{m}^{3}$, apenas do material, sendo a madeira impregnada a uma pressão de $1 \mathrm{MPa}$, com um consumo estimado de 3litros de peróxido de benzoila como iniciador e 215 litros do monômero estireno.

15)As perspectivas para novas pesquisas são as seguintes:

-Utilizar novas espécies de madeiras.

-Utilização de produtos químicos diferentes como por exemplo: estireno de qualidade inferior, estireno com limoneno, resina de mamona,etc.

-Análise de viabilidade técnica e econômica de impregnação de peças estruturais a nível industrial. 


\section{ANEXO A \\ RESULTADOS PARCIAIS DOS ENSAIOS EXPERIMENTAIS \\ 1 Ensaios de caracterização de madeiras impregnadas e não impregnadas}

\subsection{Ensaios de compressão paralela às fibras}

Apresentam-se a seguir os resultados do ensaio de compressão paralela às fibras de corpos de prova impregnados e não impregnados da espécie Pinus e Ipê de dimensões $5 \times 5 \times 20 \mathrm{~cm}$, conforme o item 6.5 .6 .6 do capitulo 6 .

Os referidos resultados são transcritos em forma de gráficos do tipo tensão versus deformação( $\sigma-\varepsilon)$, sendo que cada um vem apresentando as respectivas equações relacionando essas duas variáveis.

Para chegar aos resultados dos referidos gráficos foi utilizado a técnica de análise de regressão linear, através de programa de microcomputador utilizando-se o software denominado de Microsof Excel versão 5.0 .

Os ensaios foram realizados na máquina universal AMSLER do LaMEM/SET/USP de capacidade nominal $250 \mathrm{kN}$, sendo que as duas variáveis importantes obtidas desses ensaios foram: carga e deslocamentos. 
Ensaio de compressão paralela às fibrascorpo de prova sem impregnação-CP 1-Pinus

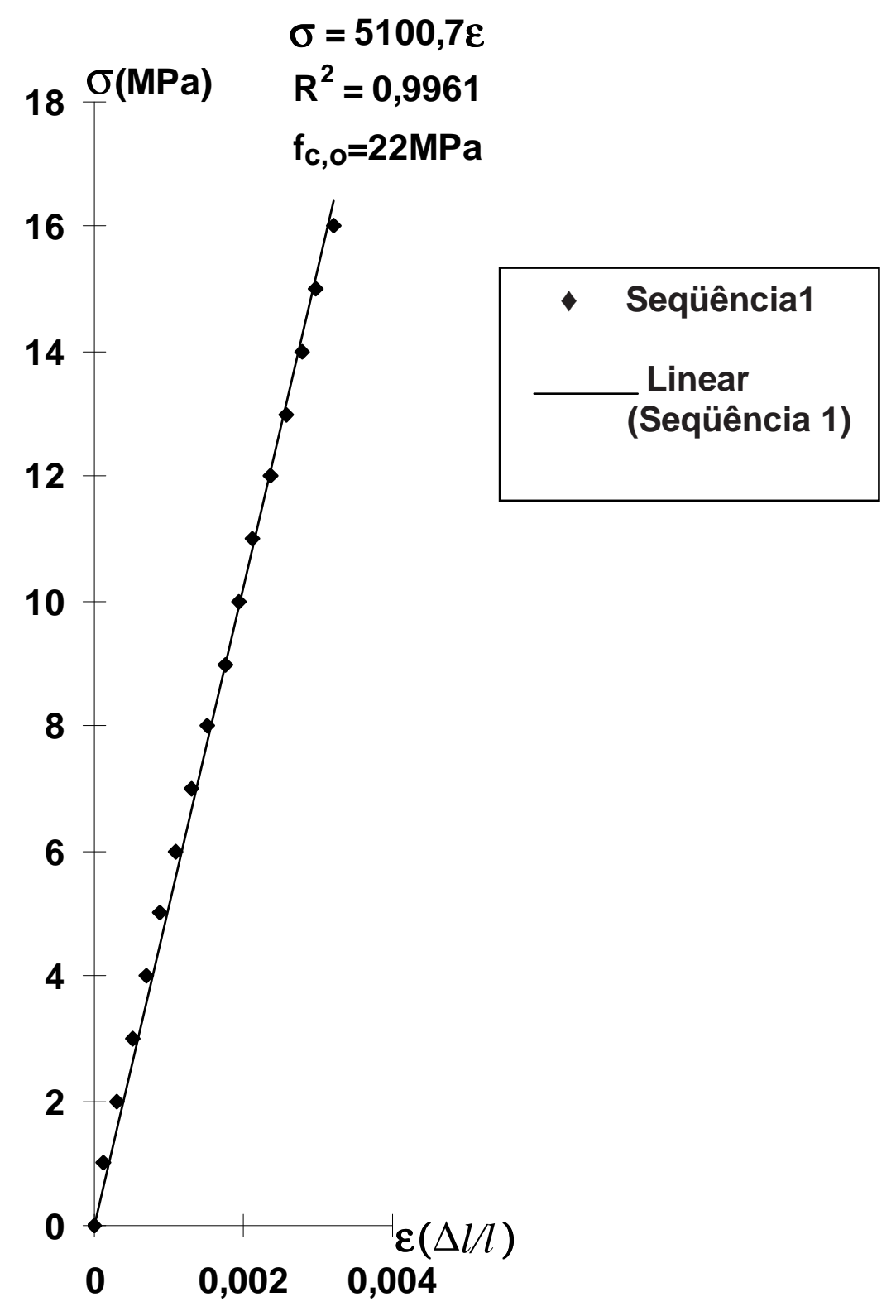

FIGURA 69 - Gráfico $(\sigma-\varepsilon)$, para o corpo de prova 1. 
Ensaio de compressão paralela às fibrascorpo de prova sem impregnar-CP 2-Pinus

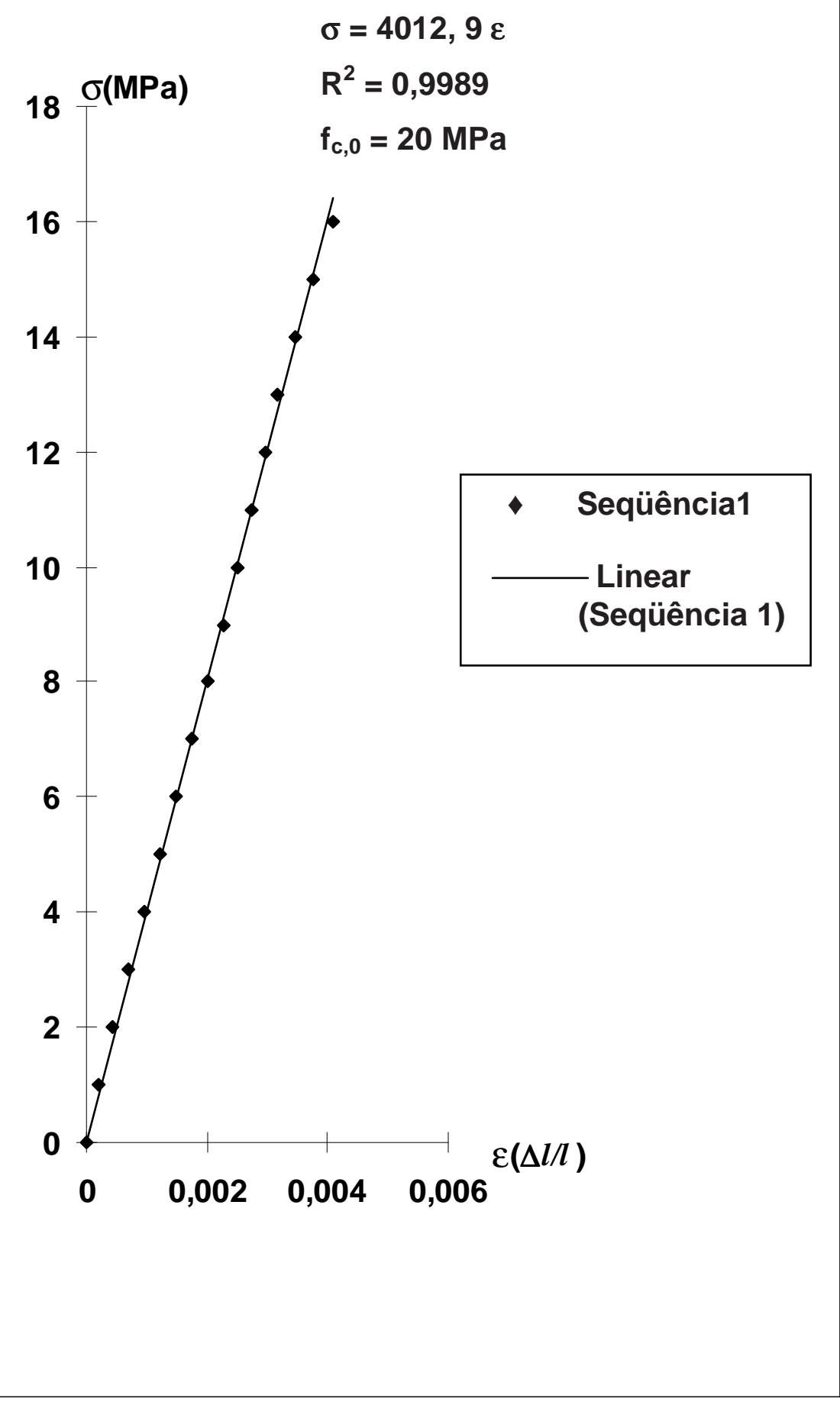

FIGURA 70 - Gráfico $(\sigma-\varepsilon)$, para o corpo de prova 2. 
Ensaio de compressão paralela às fibrascorpo de prova sem impregnação-CP 3- Pinus

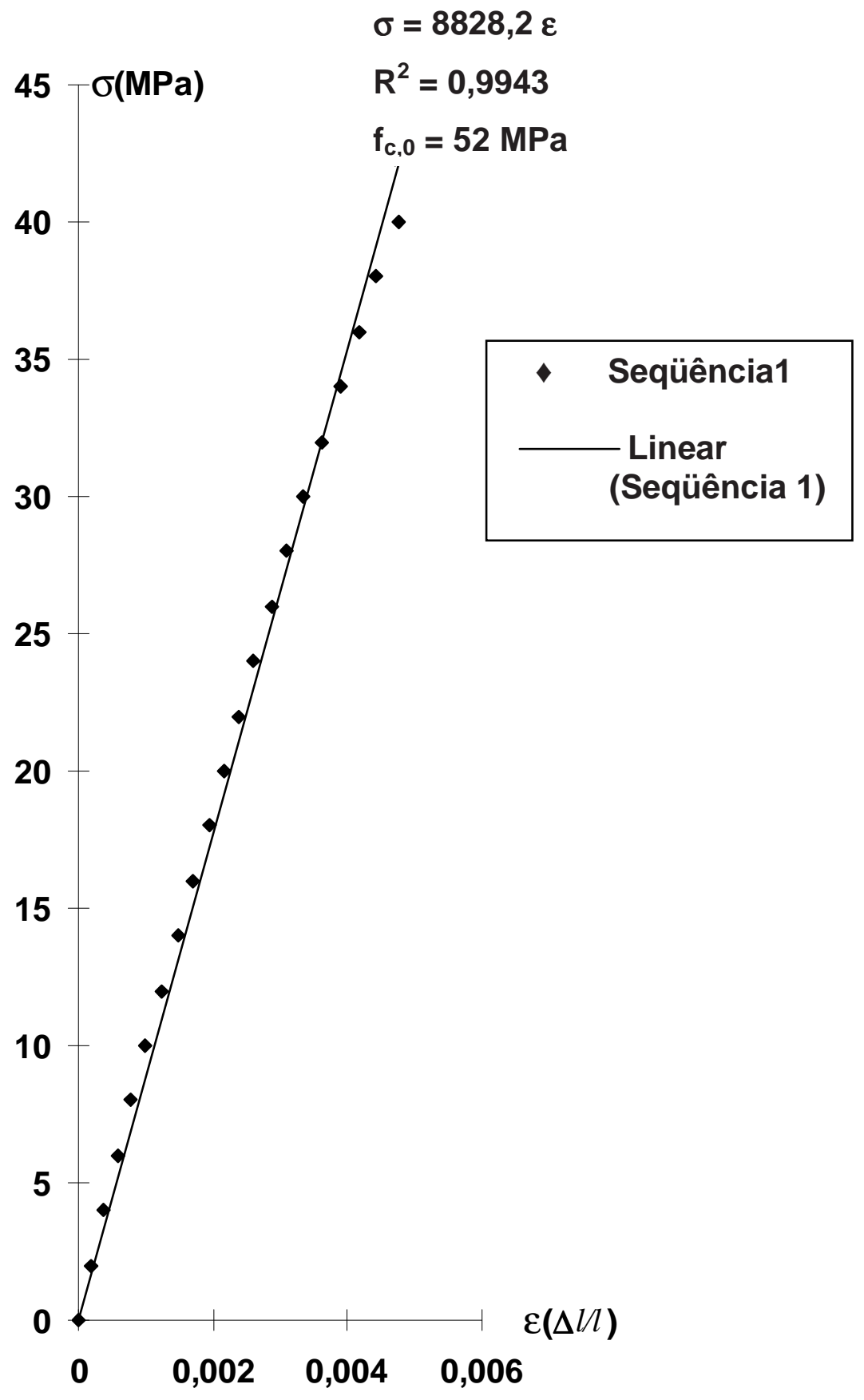

FIGURA 71 - Gráfico $(\sigma-\varepsilon)$, para o corpo de prova 3. 
Ensaio de compressão paralela às fibrascorpo de prova sem impregnação-CP 4-Pinus

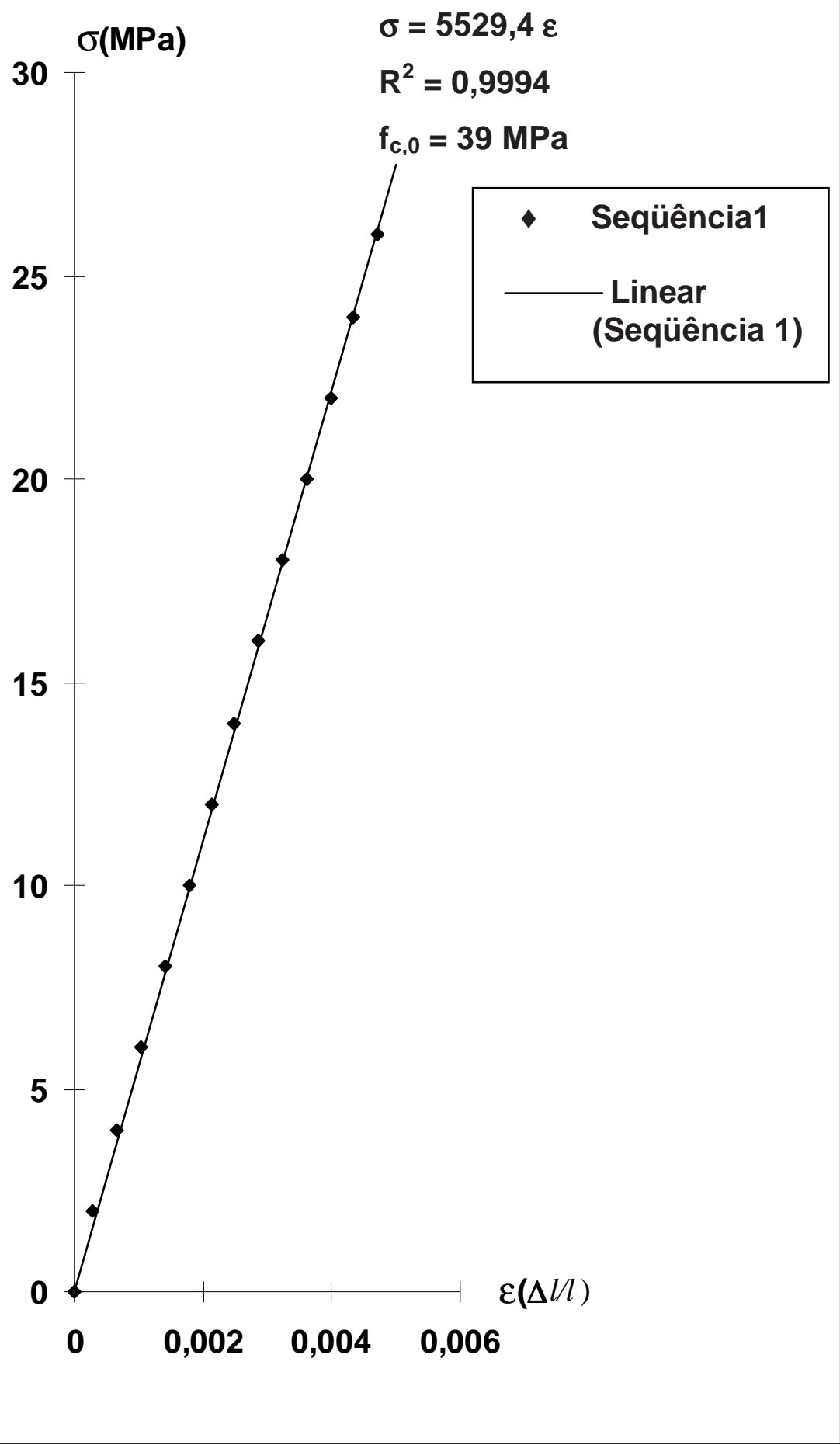

FIGURA 72 - Gráfico $(\sigma-\varepsilon)$, para o corpo de prova 4. 
Ensaio de compressão paralela às fibras-corpo de prova sem impregnação-CP 5-Pinus

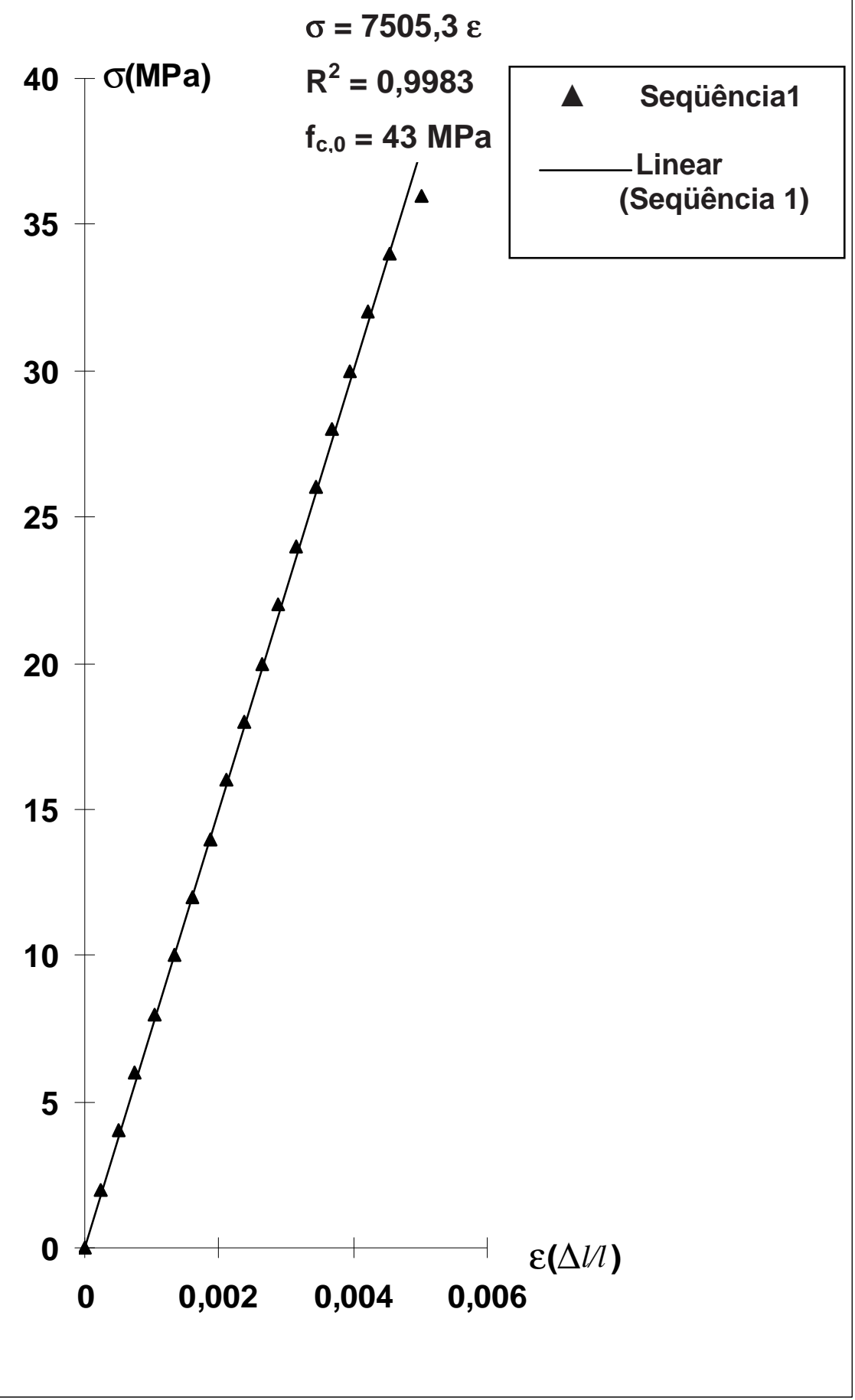

FIGURA 73- Gráfico $(\sigma-\varepsilon)$, para o corpo de prova 5. 


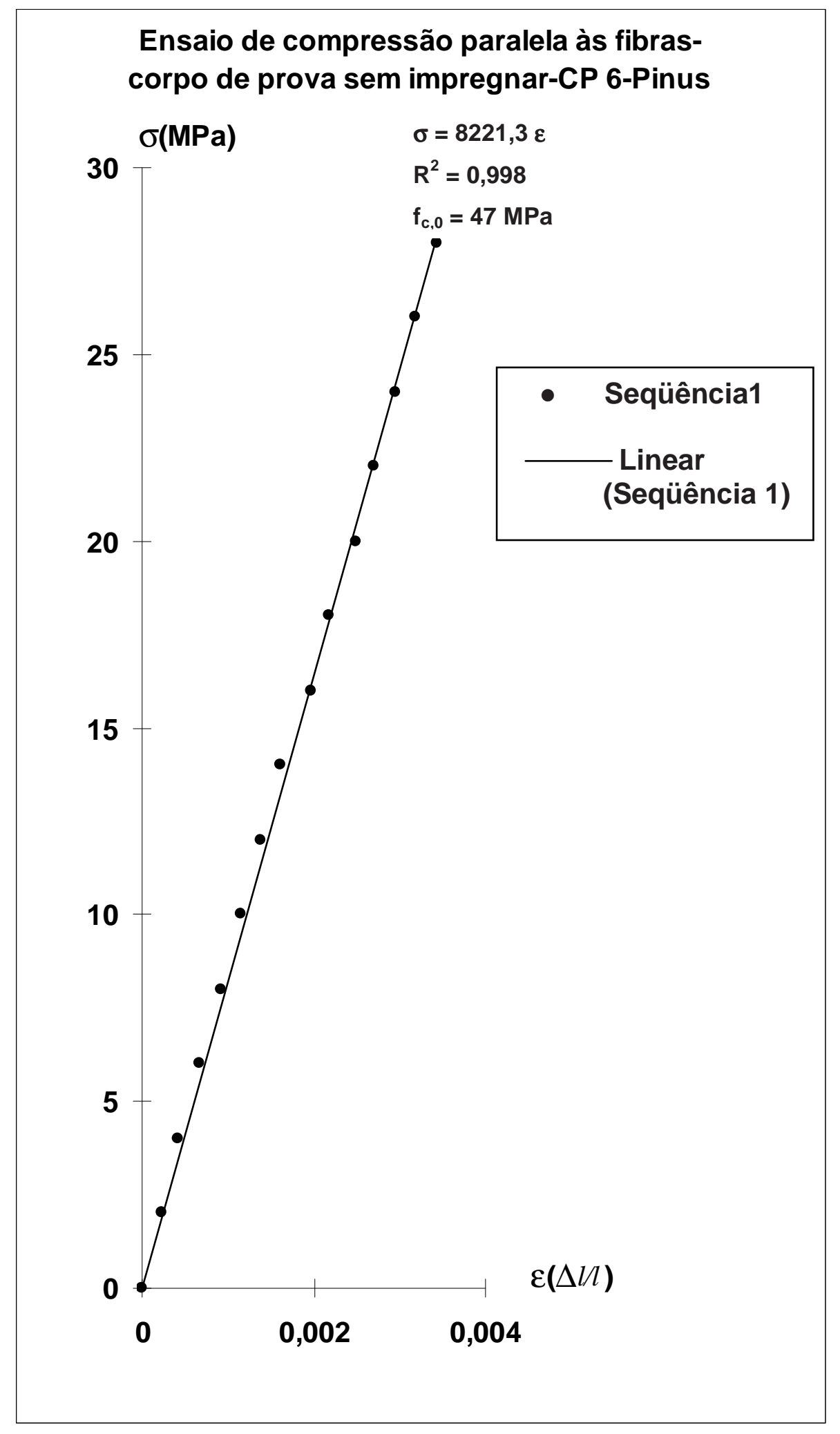

FIGURA 74 - Gráfico $(\sigma-\varepsilon)$, para o corpo de prova 6. 


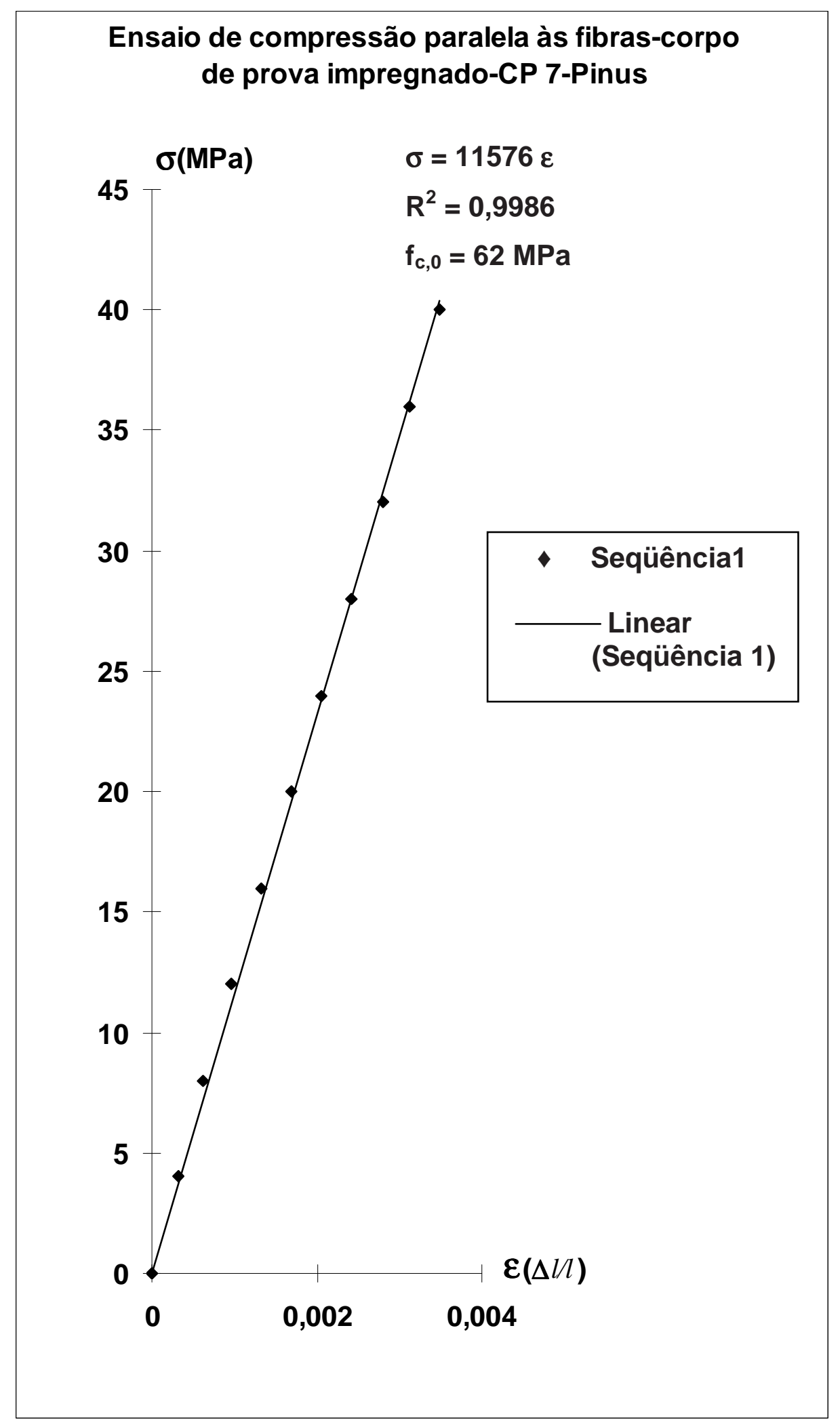

FIGURA 75 - Gráfico $(\sigma-\varepsilon)$, para o corpo de prova 7. 


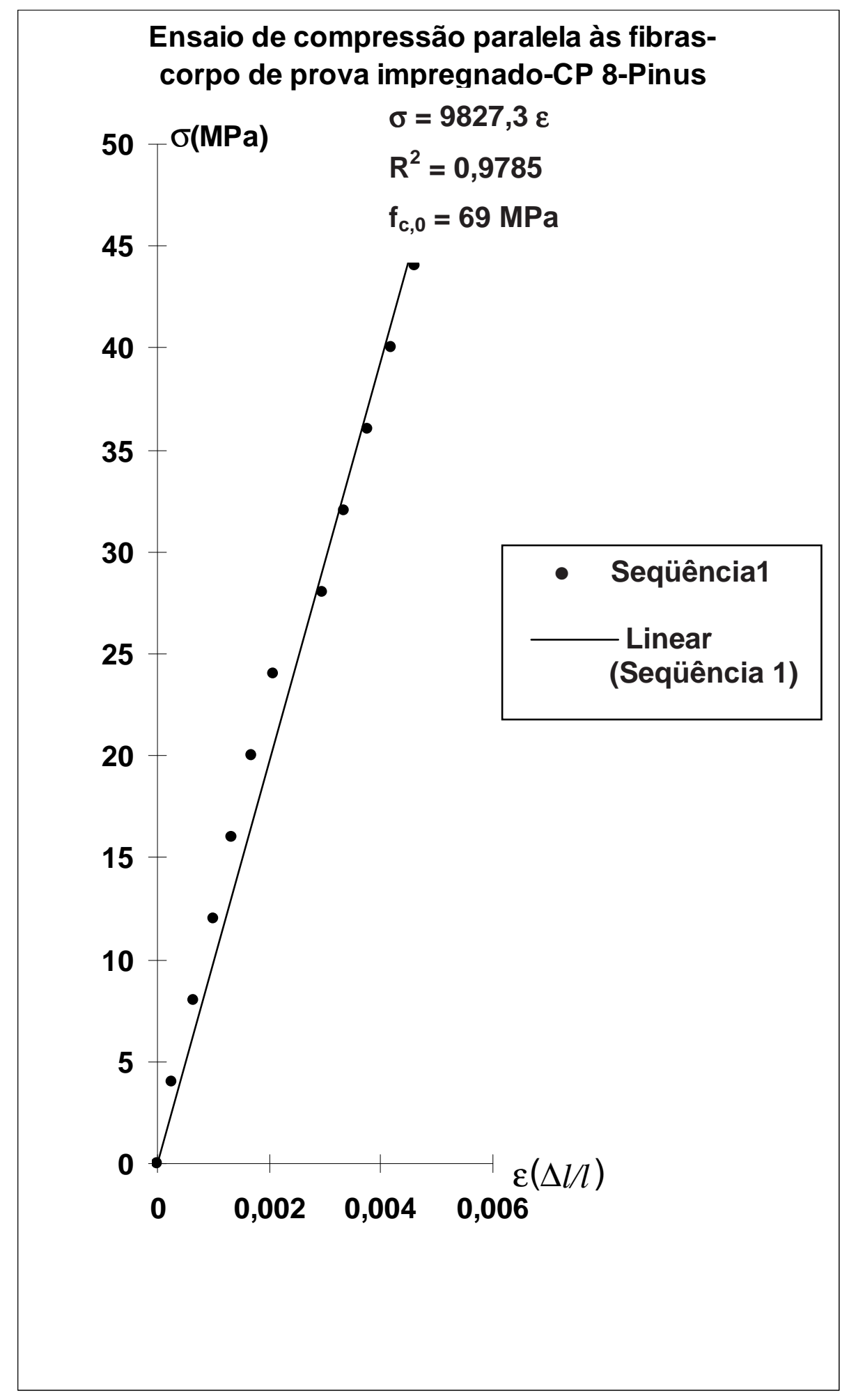

FIGURA 76 - Gráfico $(\sigma-\varepsilon)$, para o corpo de prova 8. 


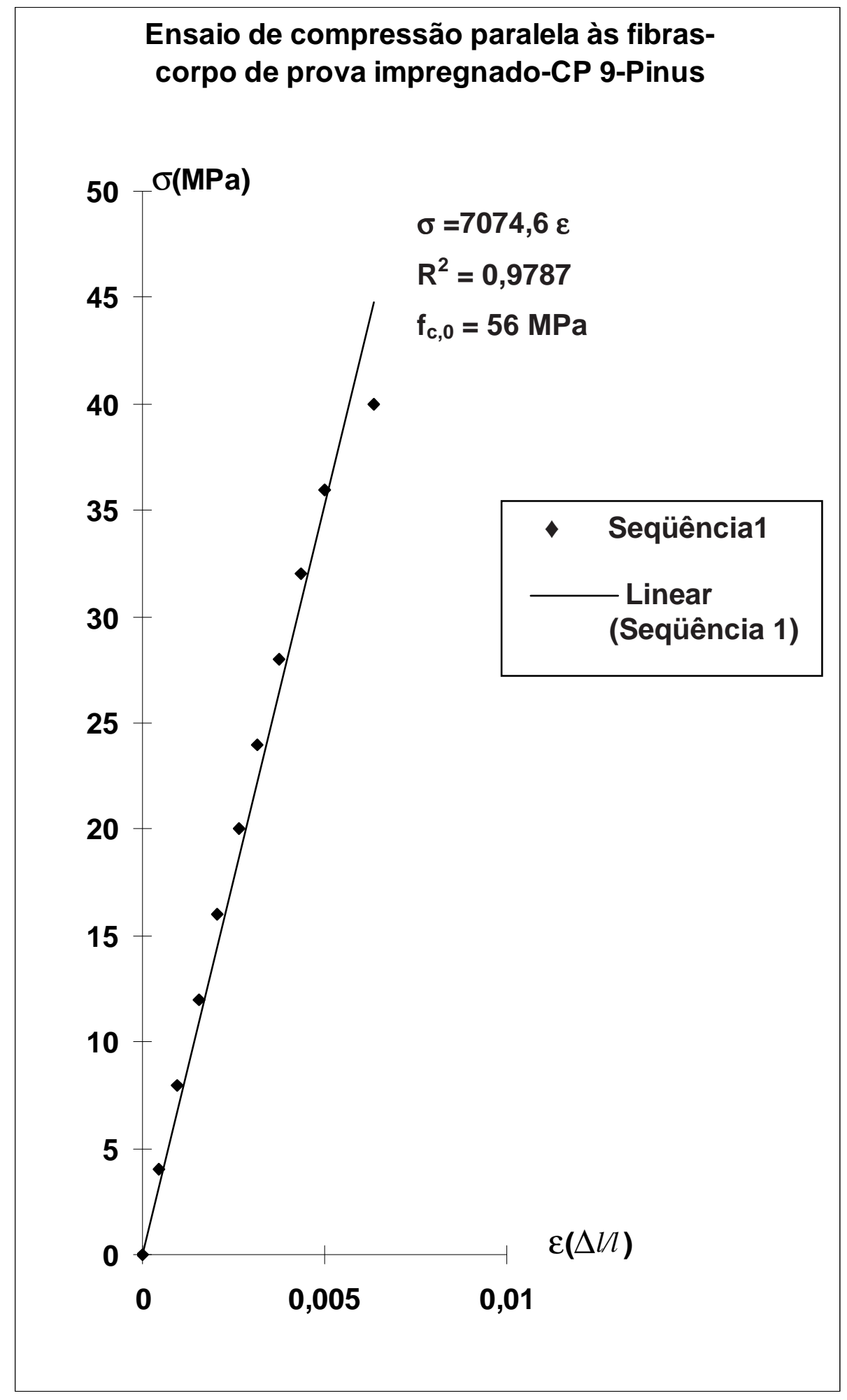

FIGURA 77- Gráfico $(\sigma-\varepsilon)$, para o corpo de prova 9. 
Ensaio de compressão paralela às fibrascorpo de prova impregnado-CP 10-Pinus

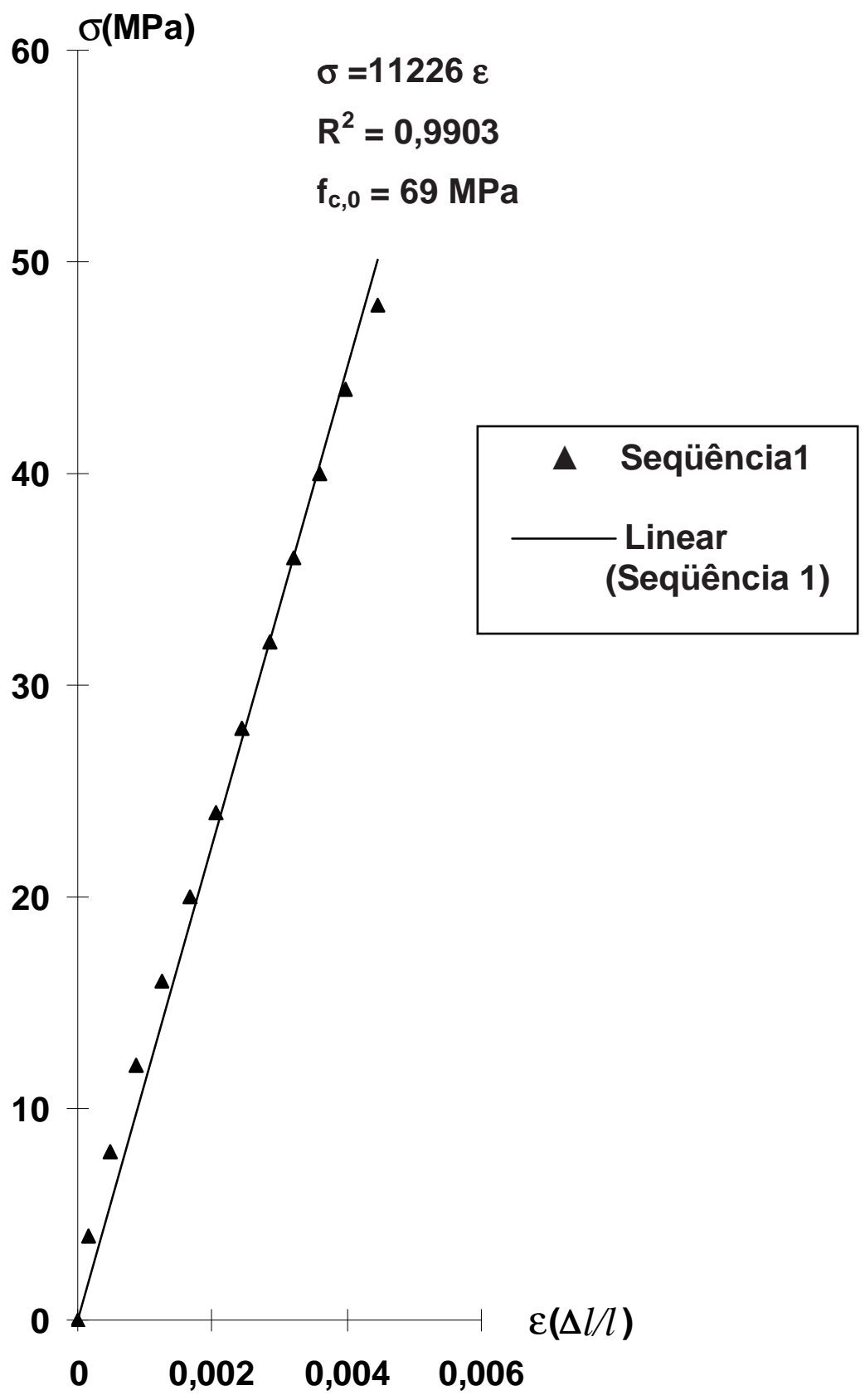

FIGURA 78 - Gráfico $(\sigma-\varepsilon)$, para o corpo de prova 10. 
Ensaio de compressão paralela às fibrascorpo de prova impregnado-CP 11-Pinus

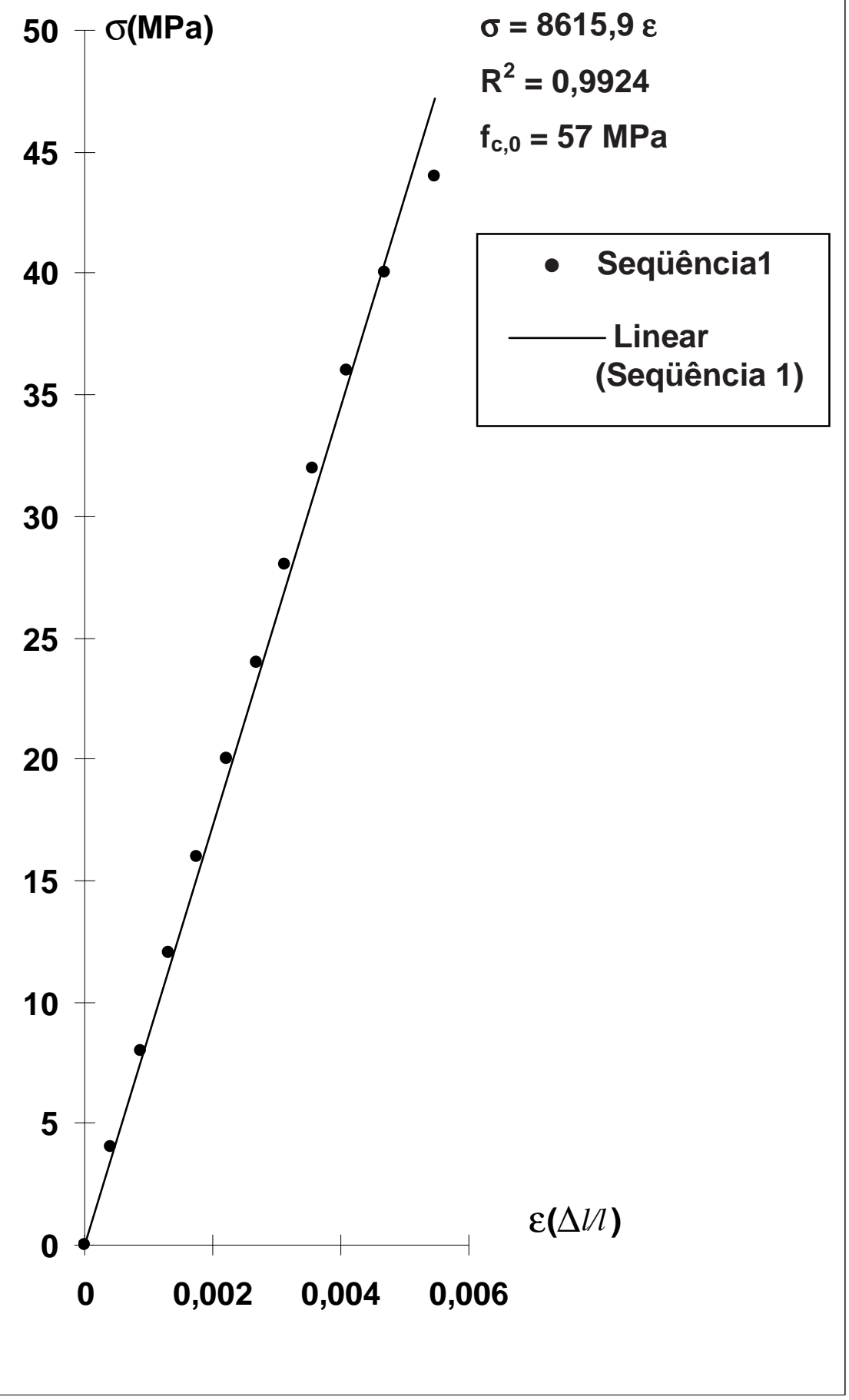

FIGURA 79 - Gráfico $(\sigma-\varepsilon)$, para o corpo de prova 11. 
Ensaio de compressão paralela às fibrascorpo de prova impregnado-CP 12-Pinus

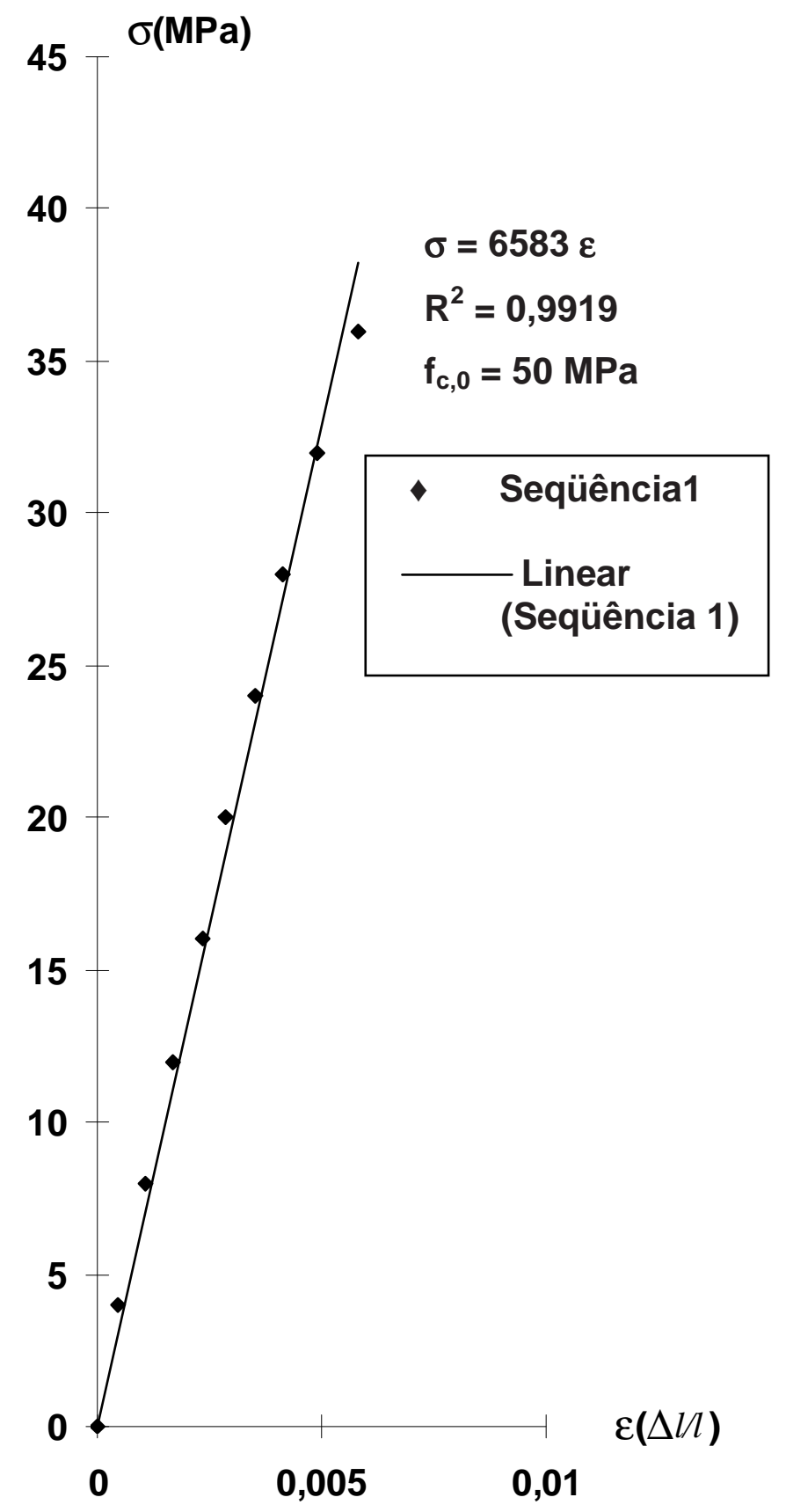

FIGURA 80 - Gráfico $(\sigma-\varepsilon)$, para o corpo de prova 12. 
Ensaio de compressão paralela às fibras-Ipê

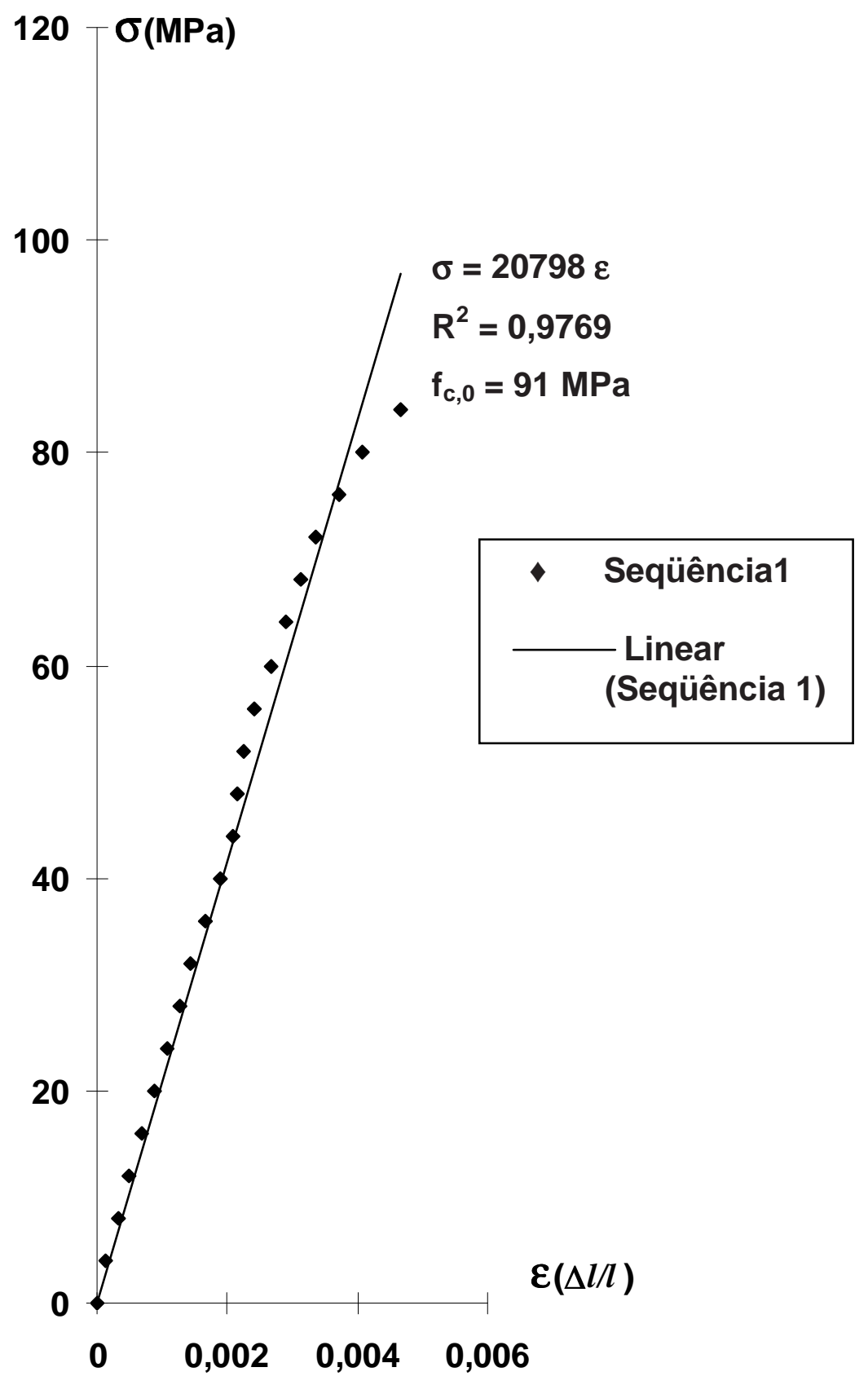

FIGURA 81 - Gráfico $(\sigma-\varepsilon)$, para o corpo de prova de Ipê. 


\section{ANEXO B \\ RESULTADOS DOS ENSAIOS DE LIGAÇÕES COM CAVILHAS IMPREGNADAS E NÃO IMPREGNADAS}

\subsection{Ensaios de compressão paralela ás fibras}

Inicialmente são registrados os dados de leitura de $\operatorname{carga}\left(\mathbf{F}_{\mathbf{i}}\right)$ e deslocamentos $\left(\mathbf{u}_{\mathbf{i}}\right)$, são traçados gráficos relacionando as variáveis de carga (F) e deformação específica $(\varepsilon)$, para permitir a determinação da carga limite da ligação e da sua respectiva rigidez. Os relógios comparadores para leitura de deslocamentos foram da ordem de precisão de $0,01 \mathrm{~mm}$ e os detalhes de instalação dos mesmos podem ser vistos na figura 59 do capítulo 6 .

Os ensaios foram executados na máquina universal Amsler do LaMEM/SET/USP, de capacidade 250kN.

São traçados gráficos envolvendo relações entre as variáveis $\mathbf{F}$ e $\boldsymbol{\varepsilon}$, cujas equações são obtidas através da análise de regressão utilizando o software da Microsoft Excel versão 5.0.

\subsection{Ensaio de compressão normal às fibras}

Os ensaios de compressão normal foram realizados observando principalmente a questão do suporte dos mesmos para aplicação de carga, e também foram lidos os valores de cargas $(\mathbf{F})$ e deslocamentos $\left(\mathbf{u}_{\mathbf{i}}\right)$. Os relógios comparadores utilizados para leitura de deslocamentos foram da ordem de precisão de $0,01 \mathrm{~mm}$. Na figura 60 podem ser vistos os detalhes de fixação dos relógios comparadores. 
Ensaio de compressão paralela às fibras-CP16-

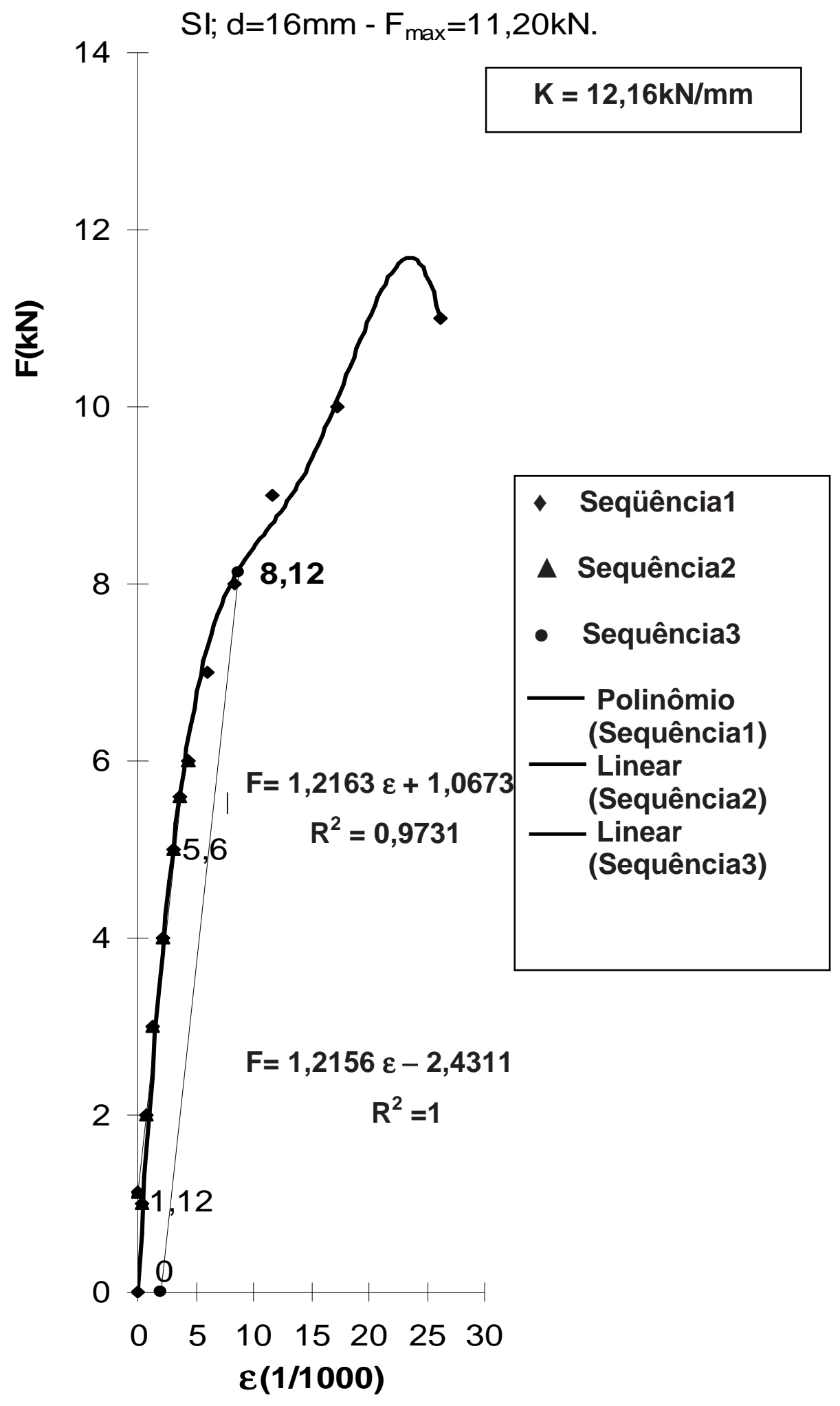

FIGURA 82- Gráfico, F- $\varepsilon$, para o corpo de prova CP16. 


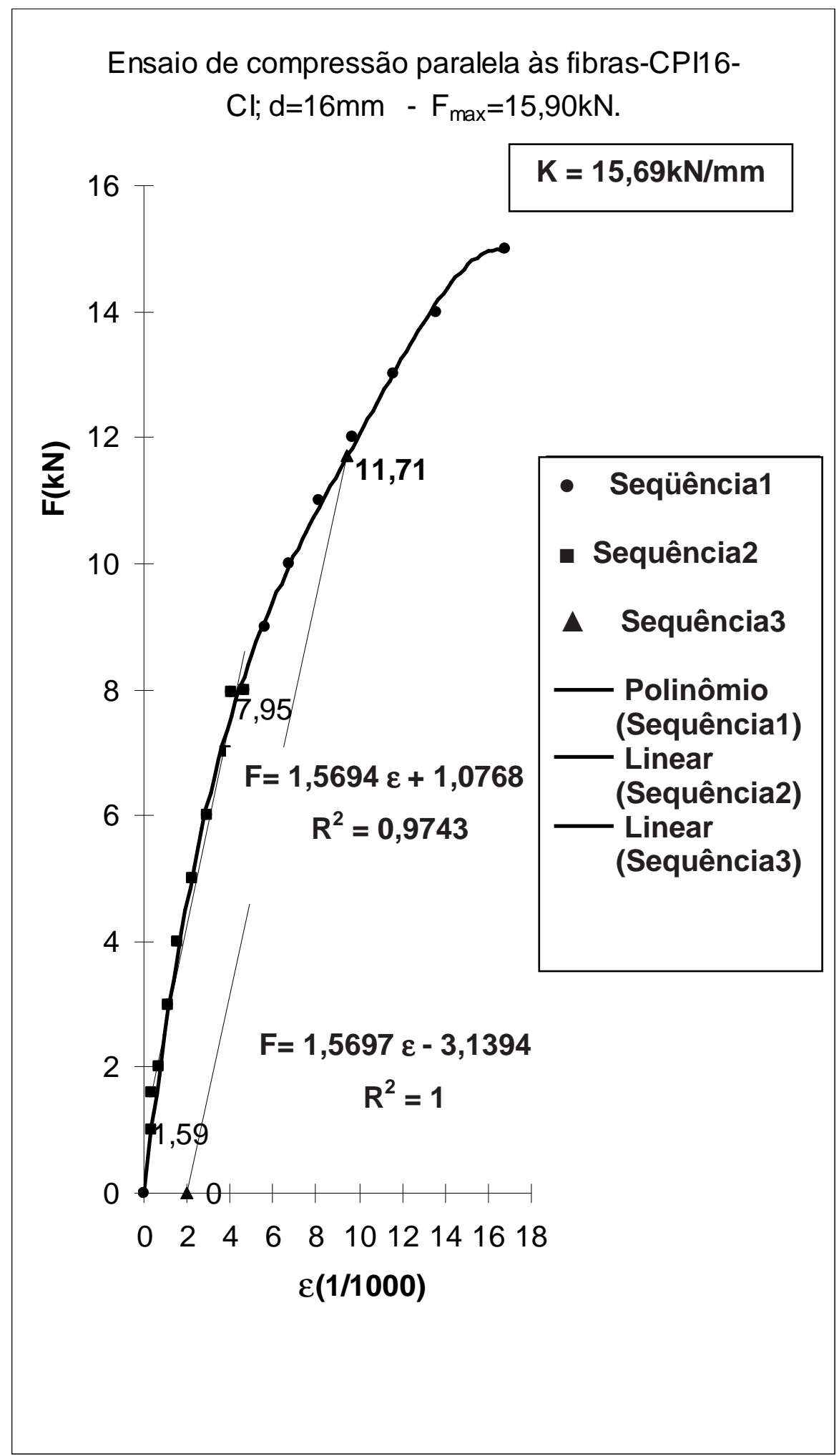

FIGURA 83 Gráfico, F-e, para o corpo de prova CPI16. 


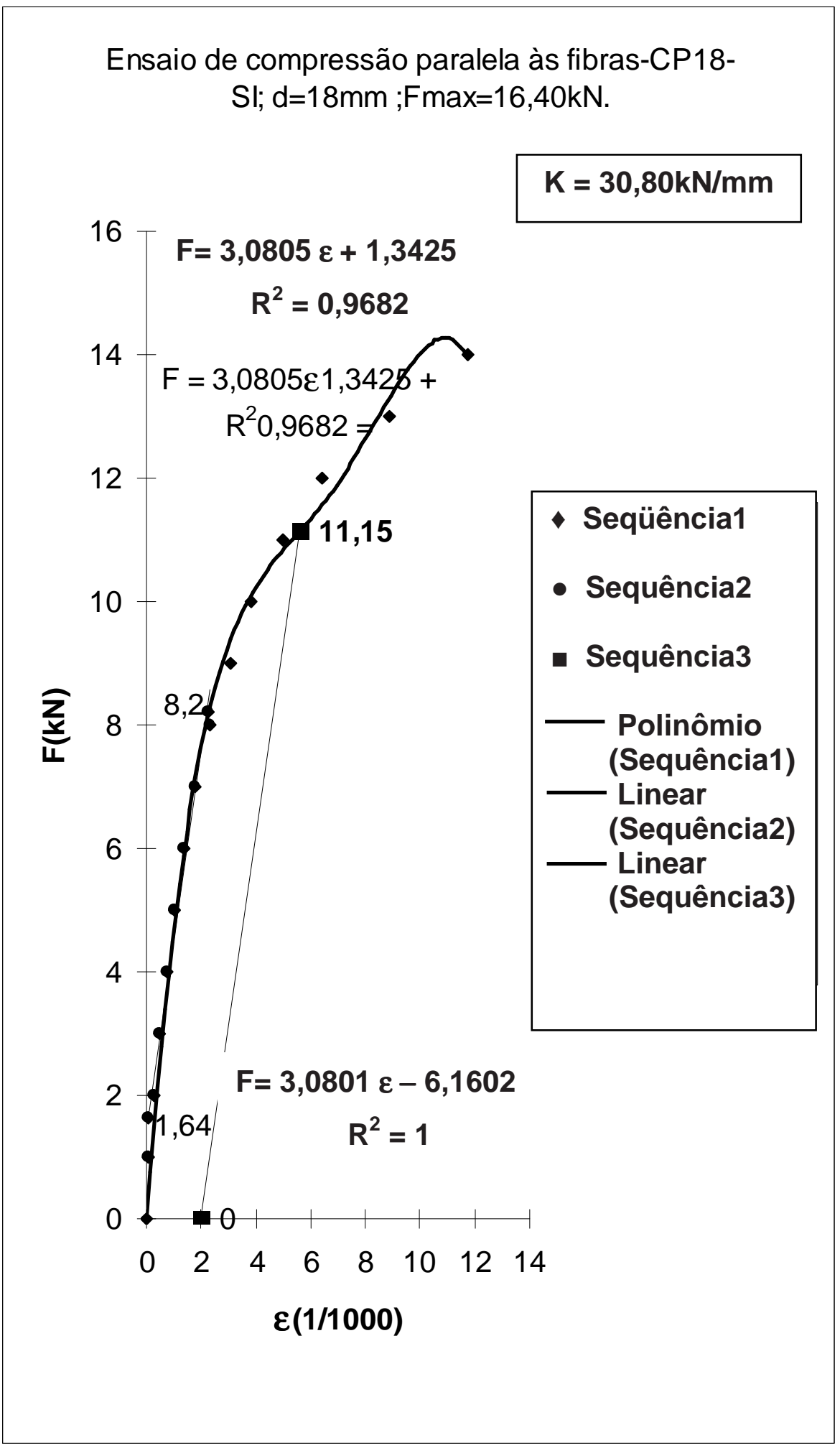

FIGURA 84-Gráfico F- $\varepsilon$ para o corpo de prova CP18. 


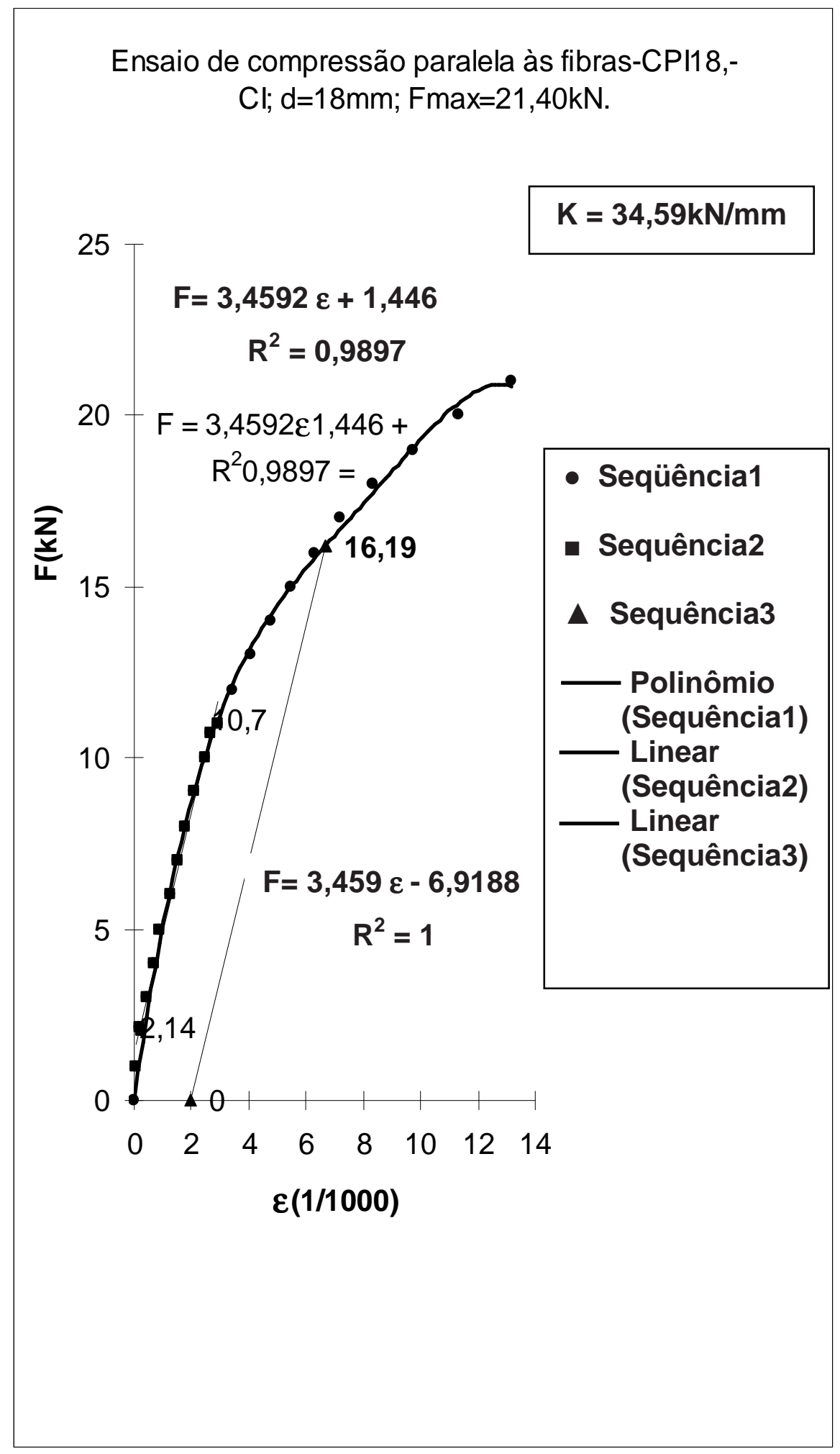

FIGURA 85-Gráfico F- $\varepsilon$ para o corpo de prova CPI18. 


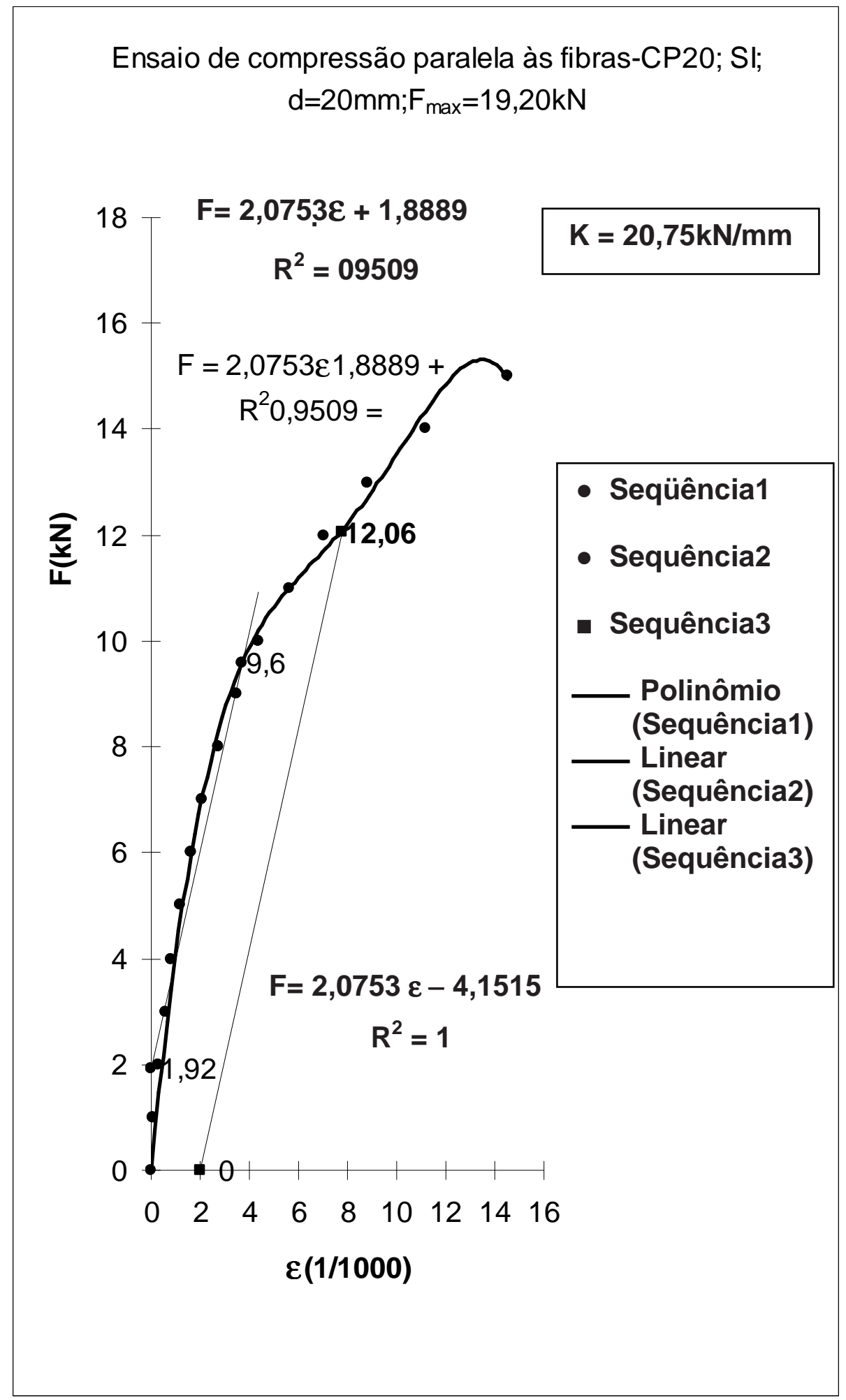

FIGURA 86 - Gráfico F- $\varepsilon$ para o corpo de prova CP20. 


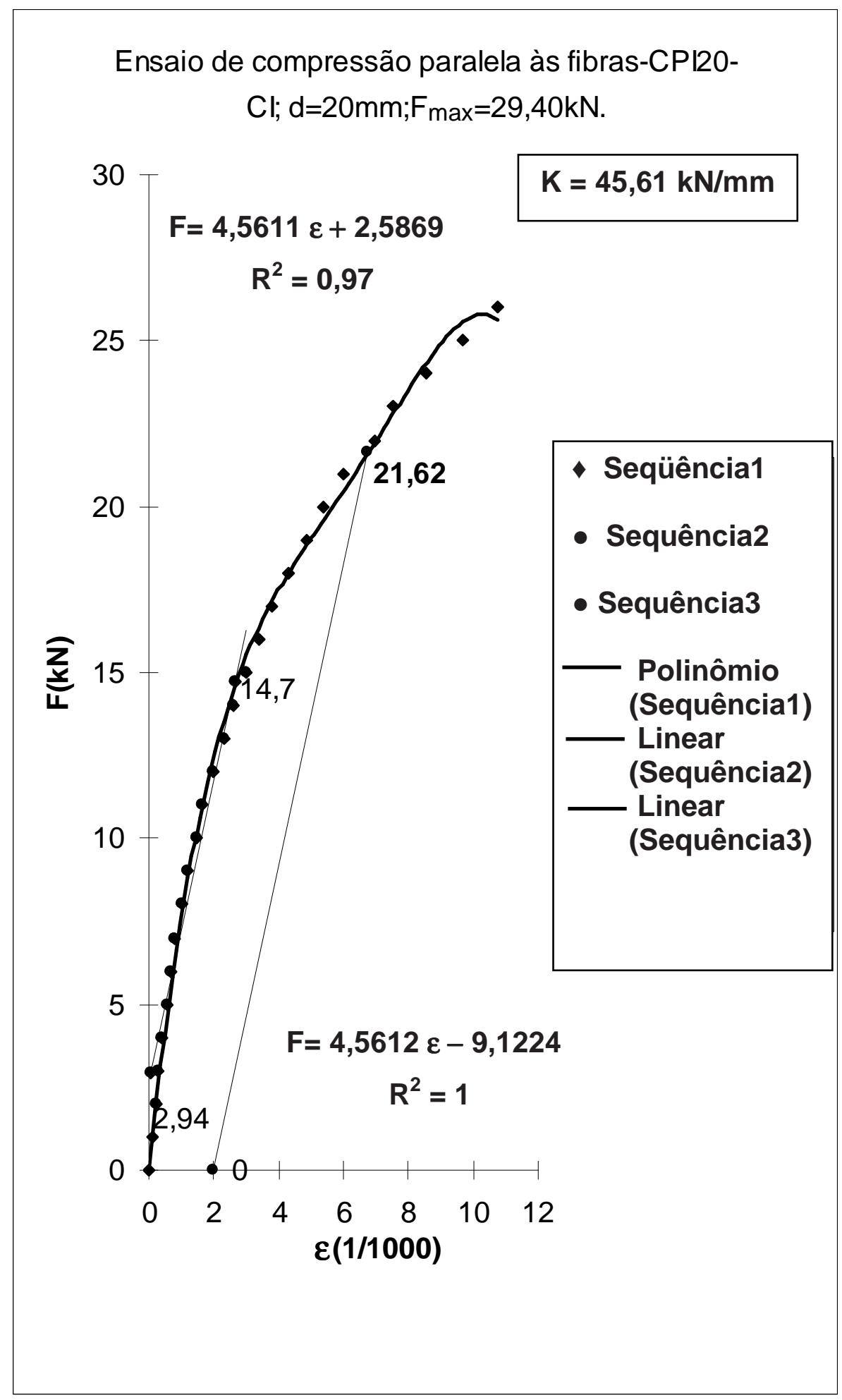

FIGURA 87 - Gráfico F- $\varepsilon$ para o corpo de prova CPI20. 


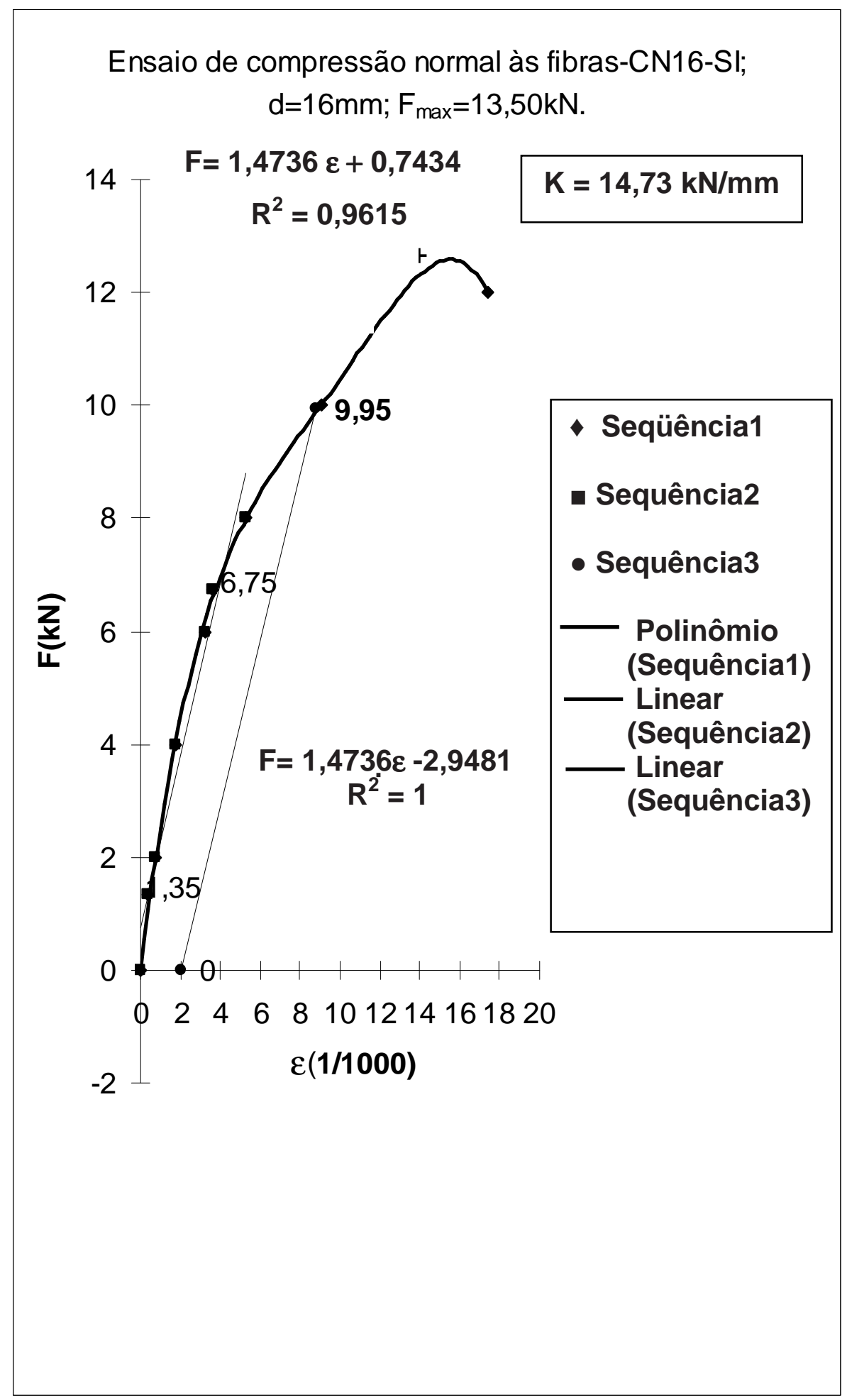

FIGURA 88 - Gráfico F- $\varepsilon$ para o corpo de prova CN16. 
Ensaio de compressão normal às fibras-CNI16-Cl; $\mathrm{d}=16 \mathrm{~mm} ; \mathrm{F}_{\text {max }}=12,80 \mathrm{kN}$.

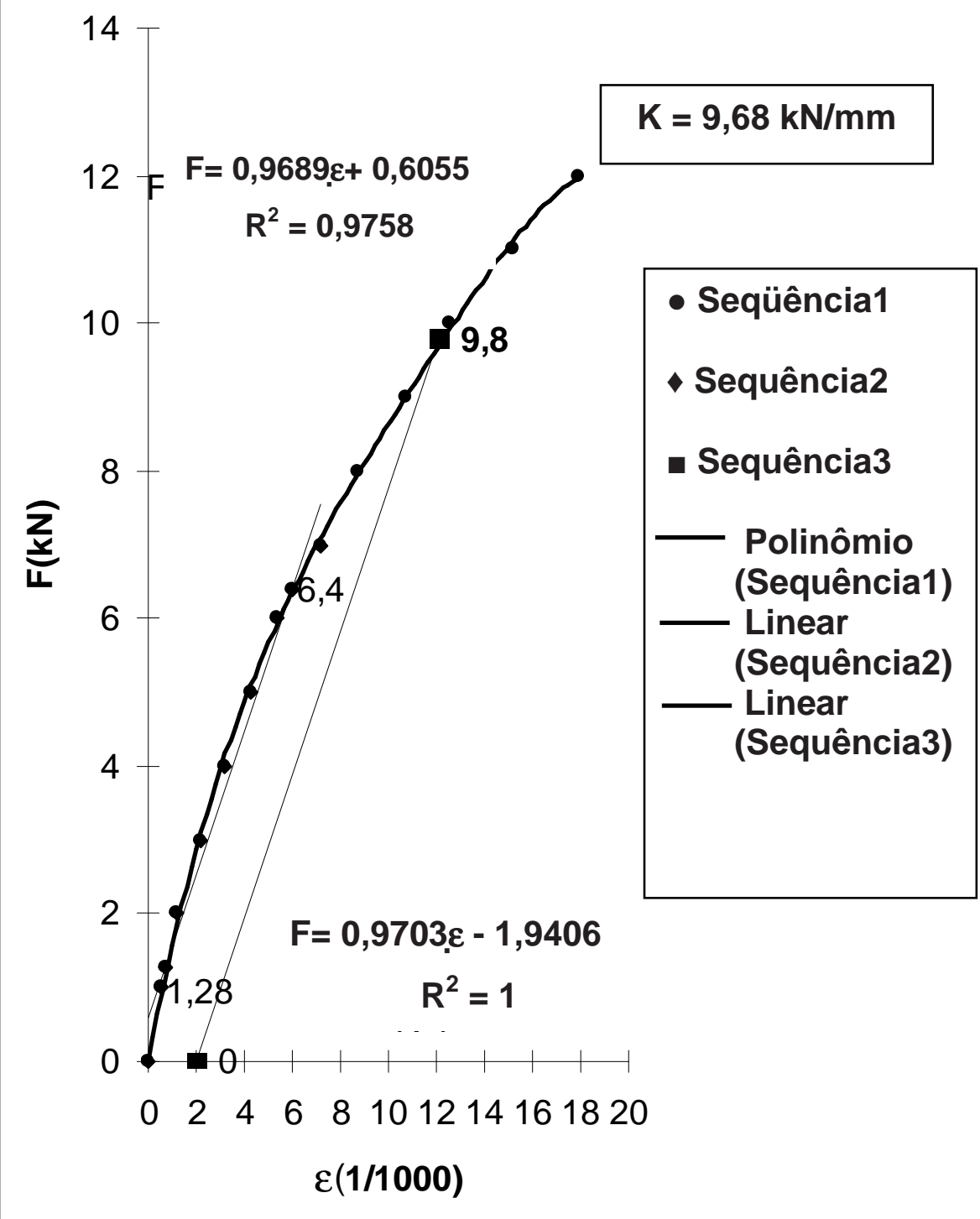

FIGURA 89 - Gráfico F- $\varepsilon$ para o corpo de prova CNI16. 


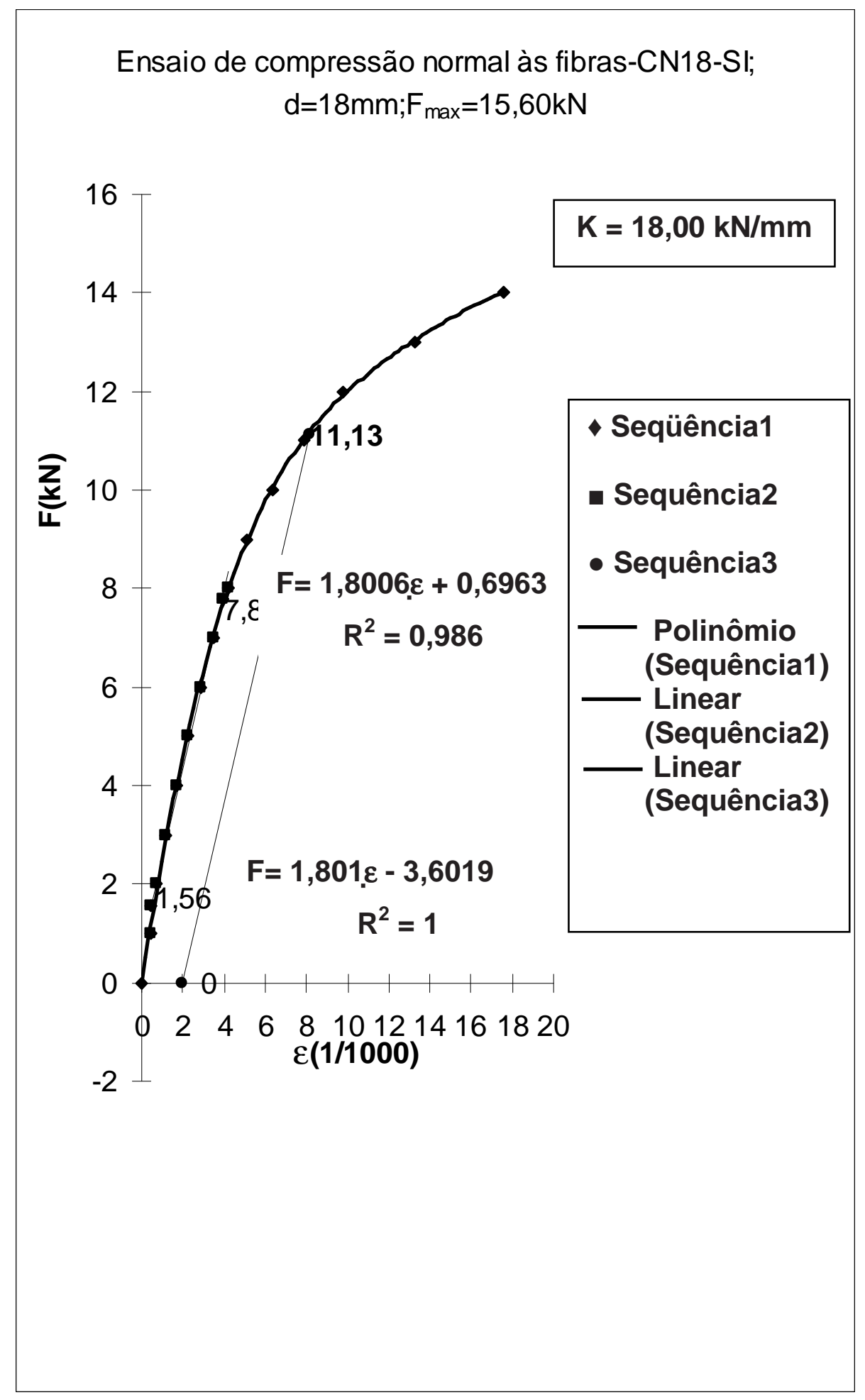

FIGURA 90 - Gráfico F- $\varepsilon$ para o corpo de prova CN18. 


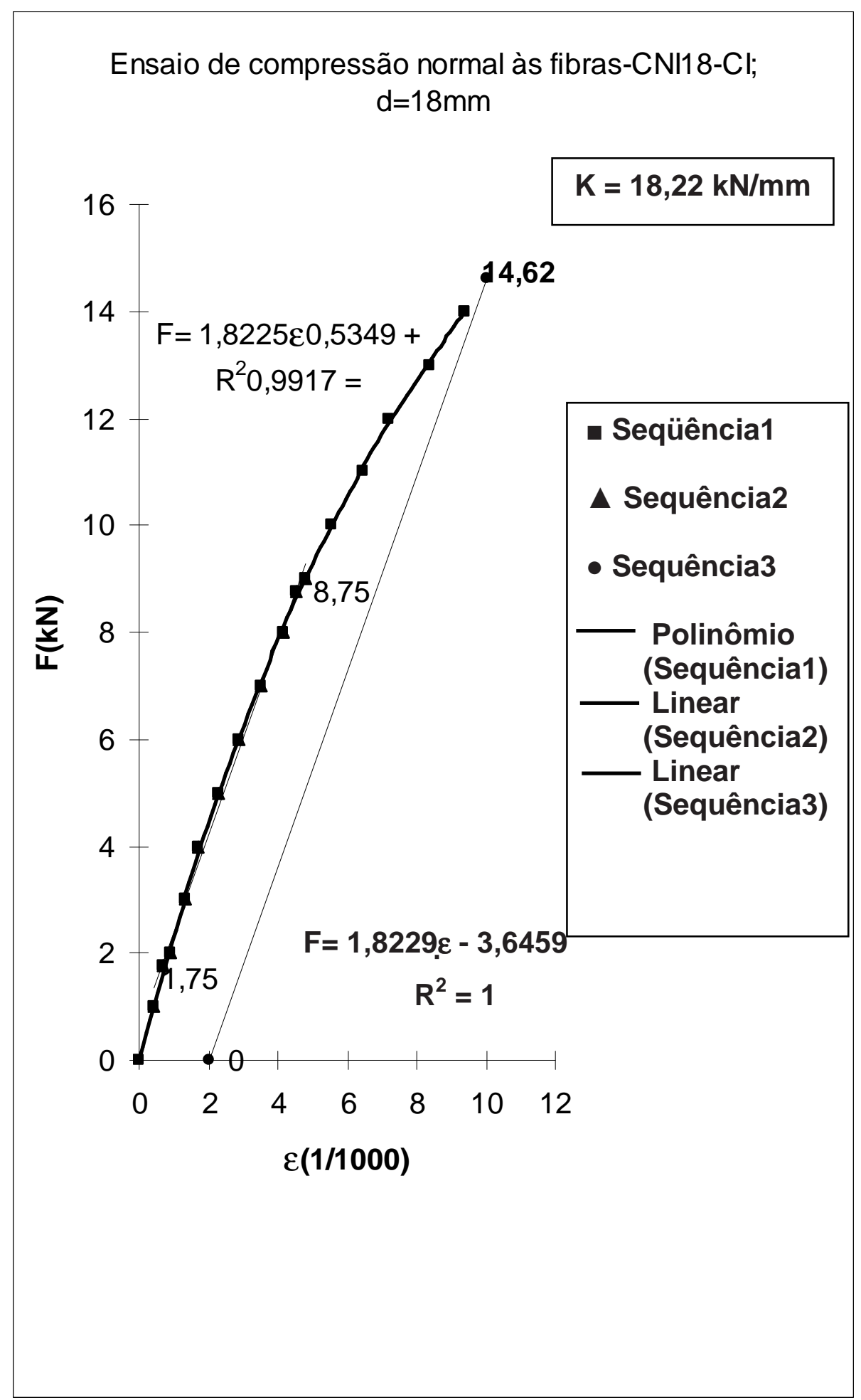

FIGURA 91 - Gráfico F- $\varepsilon$ para o corpo de prova CNI18. 


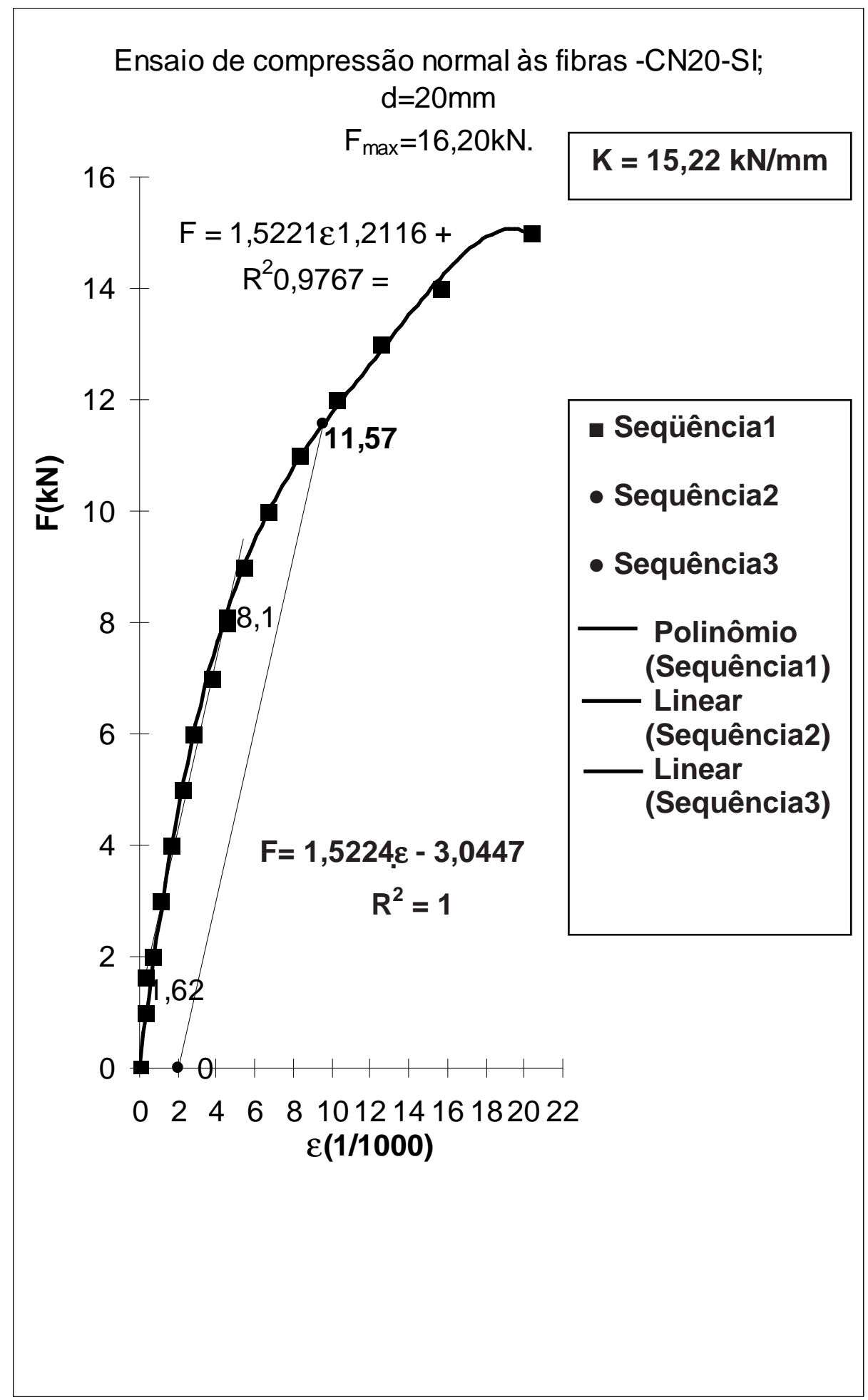

FIGURA 92 - Gráfico F- $\varepsilon$ para o corpo de prova CN20. 


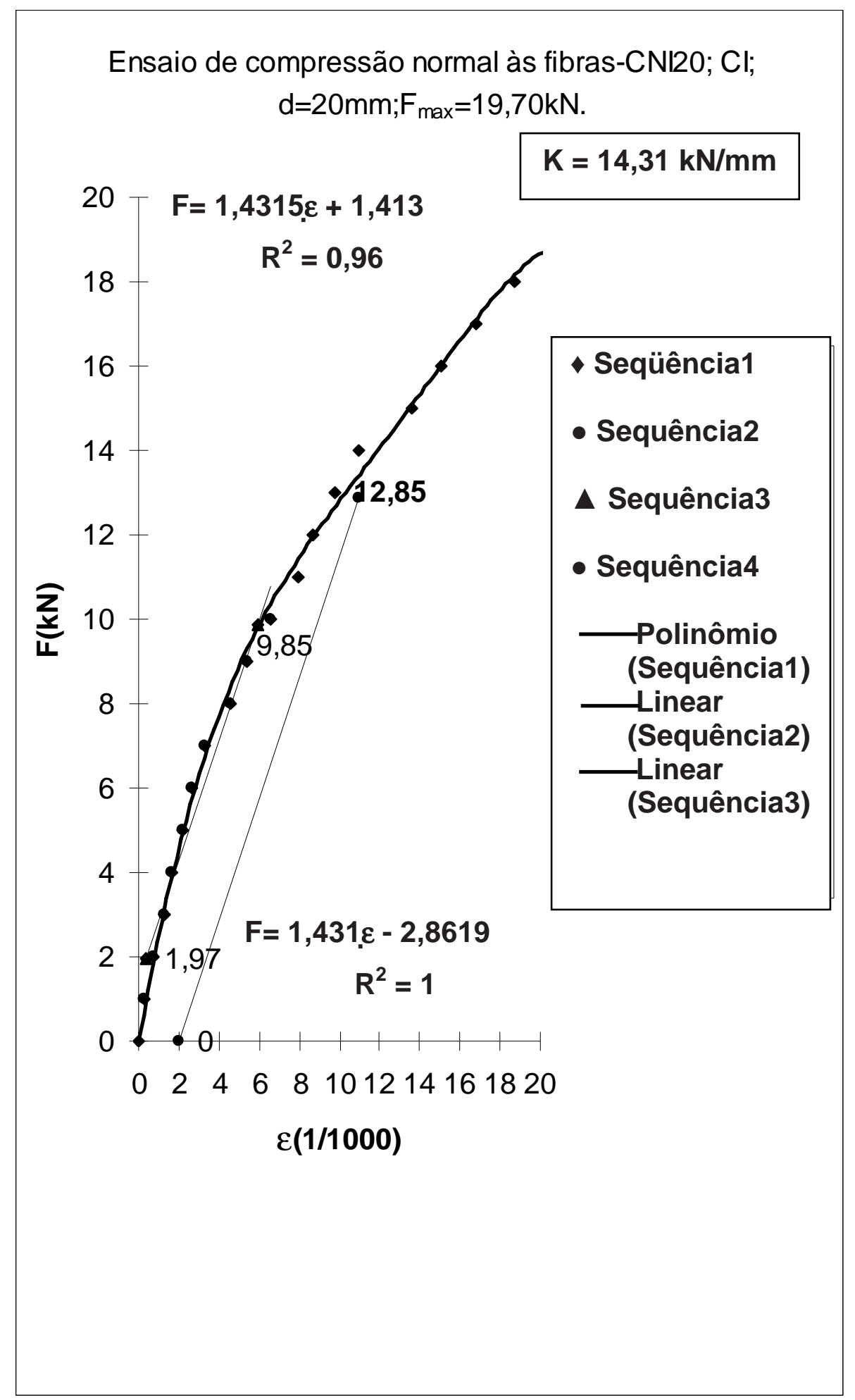

FIGURA 93 - Gráfico F-e para o corpo de prova CNI20. 


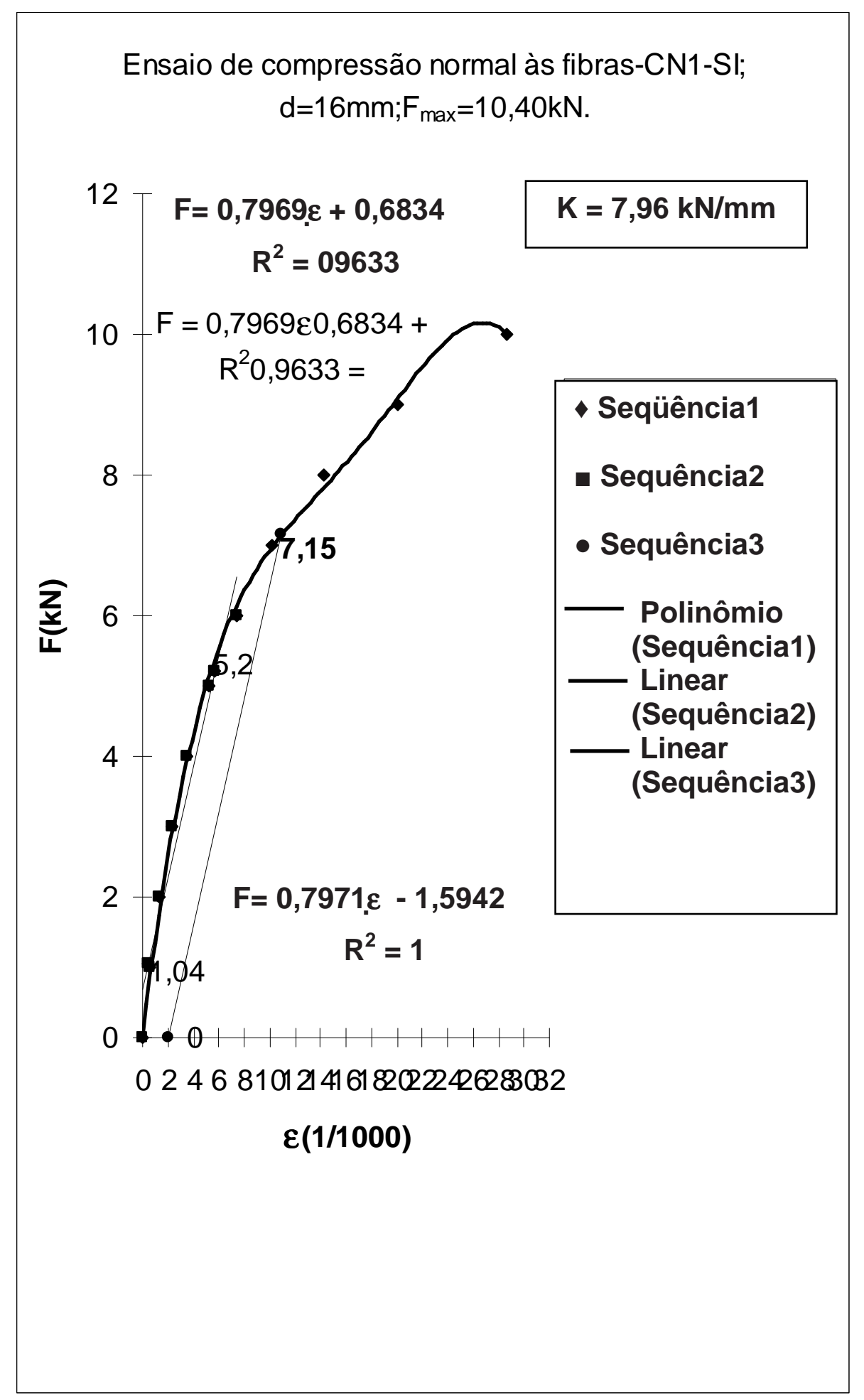

FIGURA 94- Gráfico F-ع para o corpo de prova CN116. 


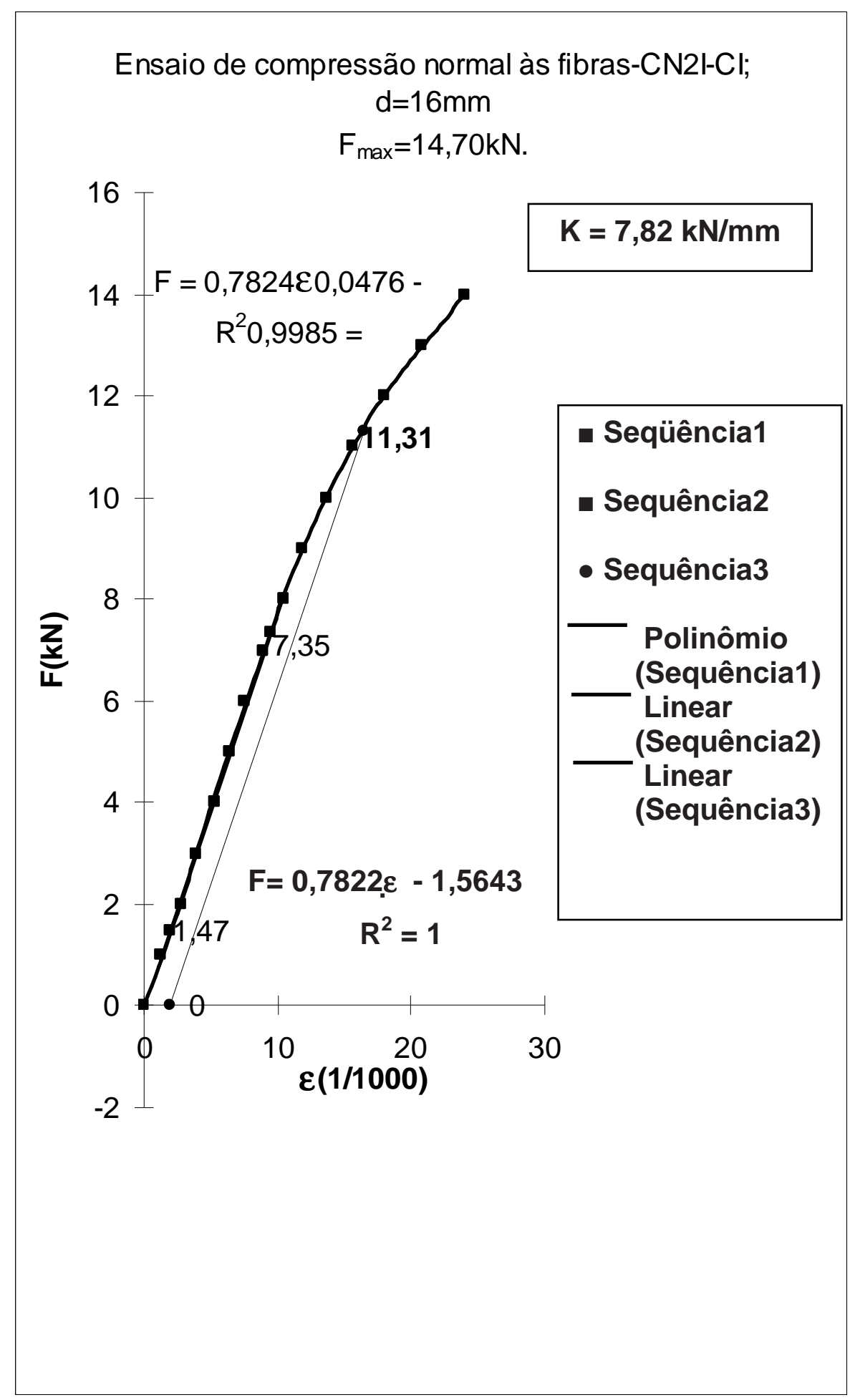

FIGURA 95 - Gráfico F-e para o corpo de prova CN2l16. 


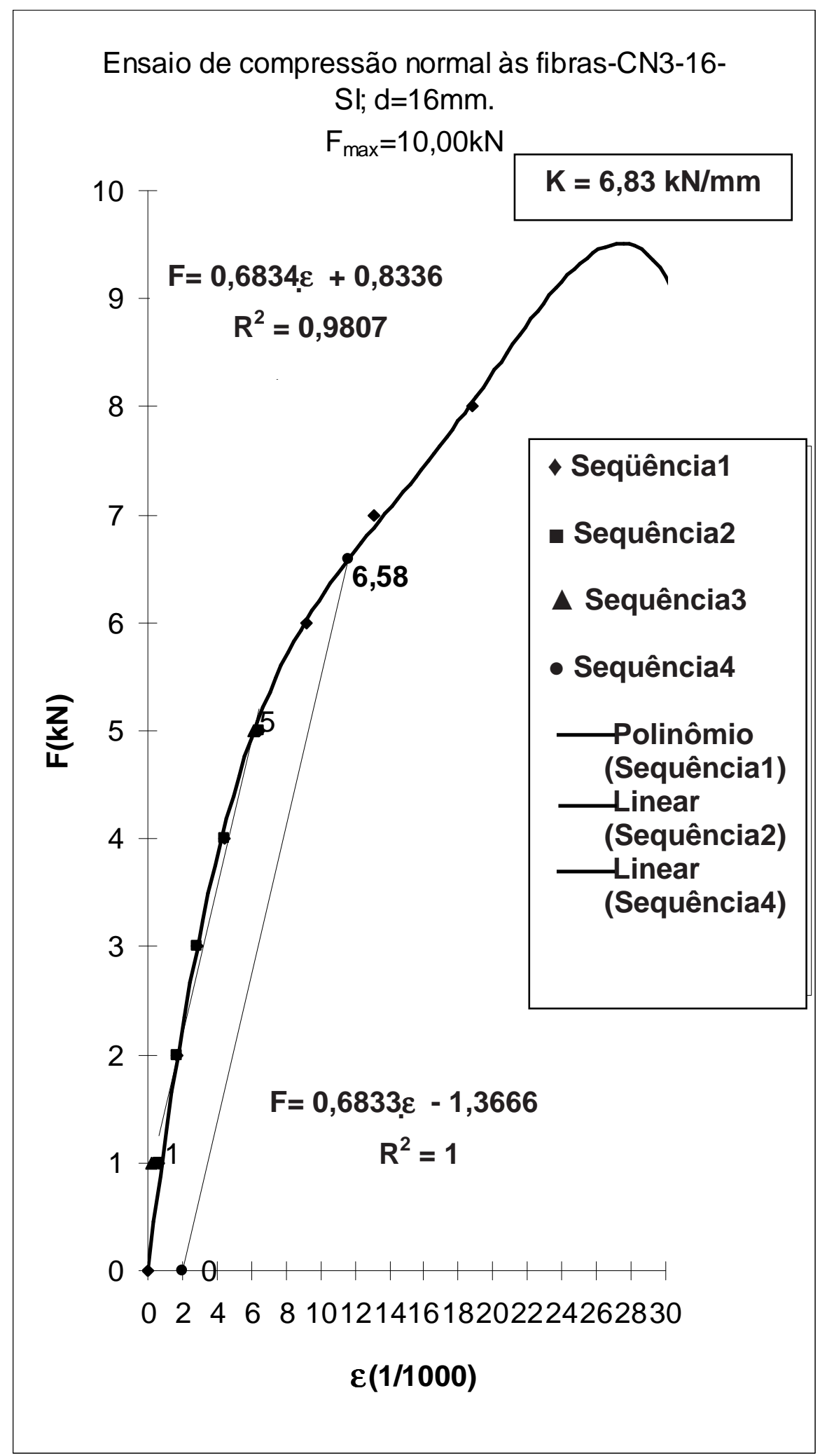

FIGURA 96 - Gráfico F-ع para o corpo de prova CN3. 


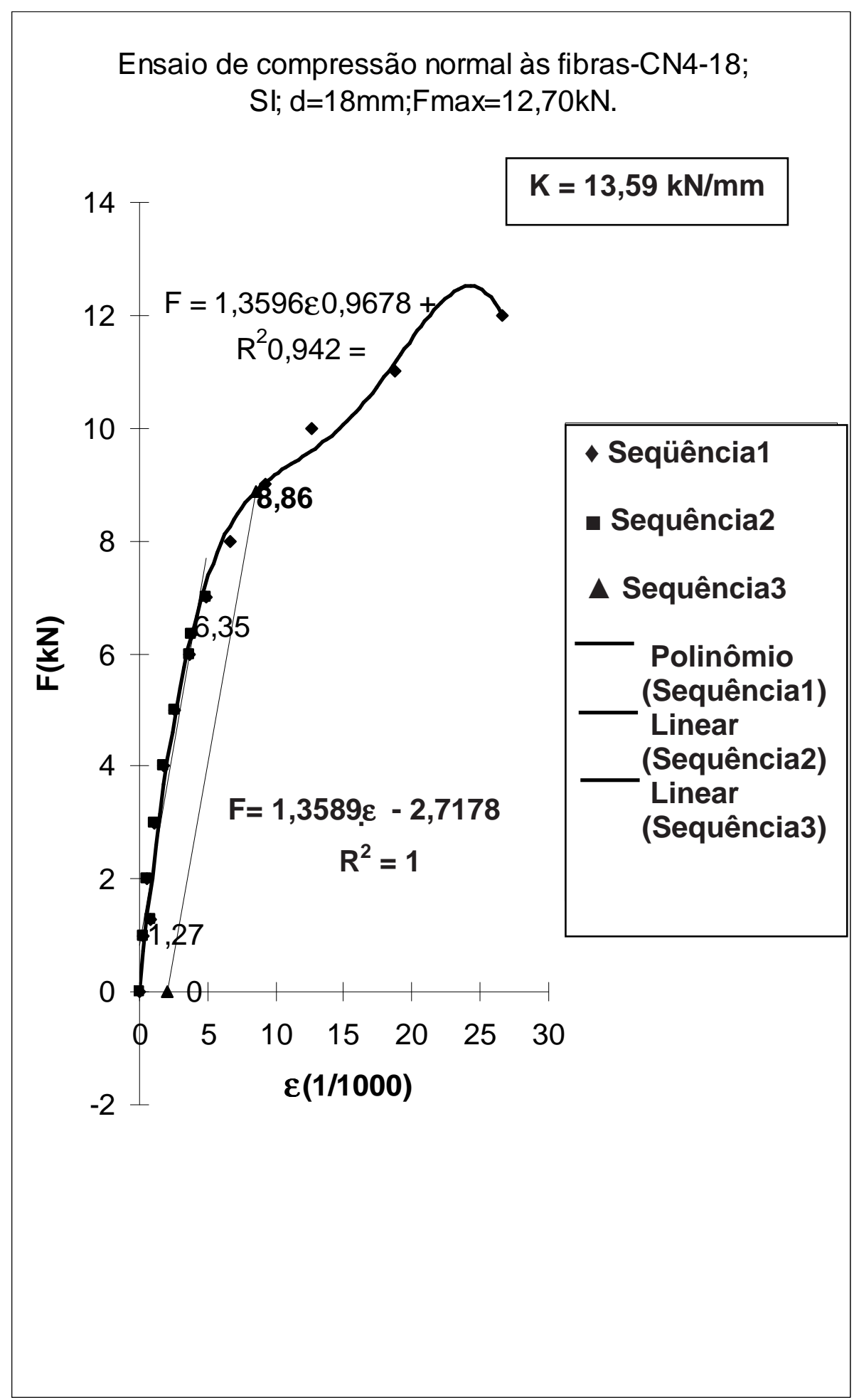

FIGURA 97 - Gráfico F-E para o corpo de prova CN4. 
Ensaio de compressão normal às fibras-CVN16-

$\mathrm{Sl} ; \mathrm{d}=16 \mathrm{~mm} ; \mathrm{F}_{\max }=12,00 \mathrm{kN}$.

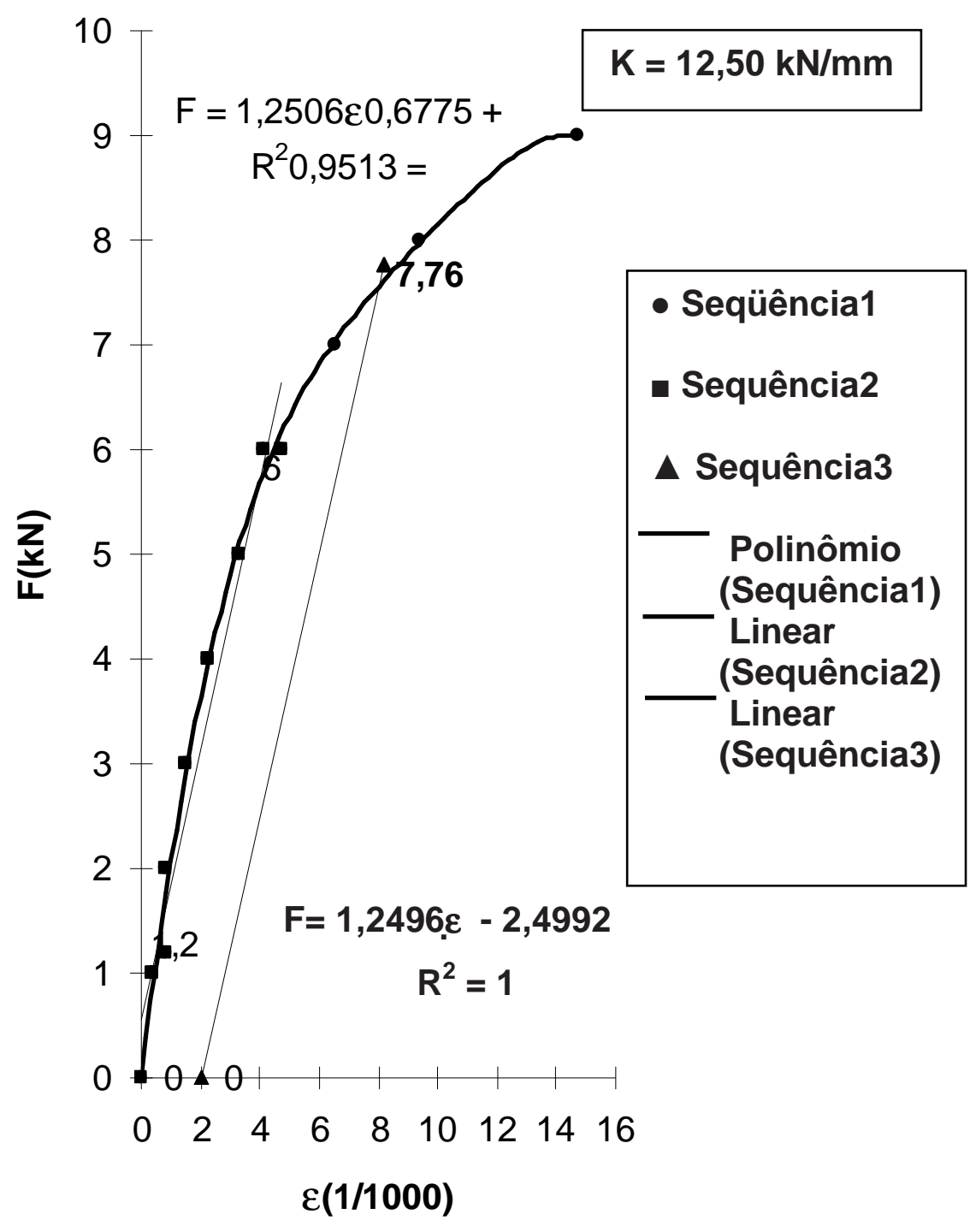

FIGURA 98 - Gráfico F-ع para o corpo de prova CVN16. 


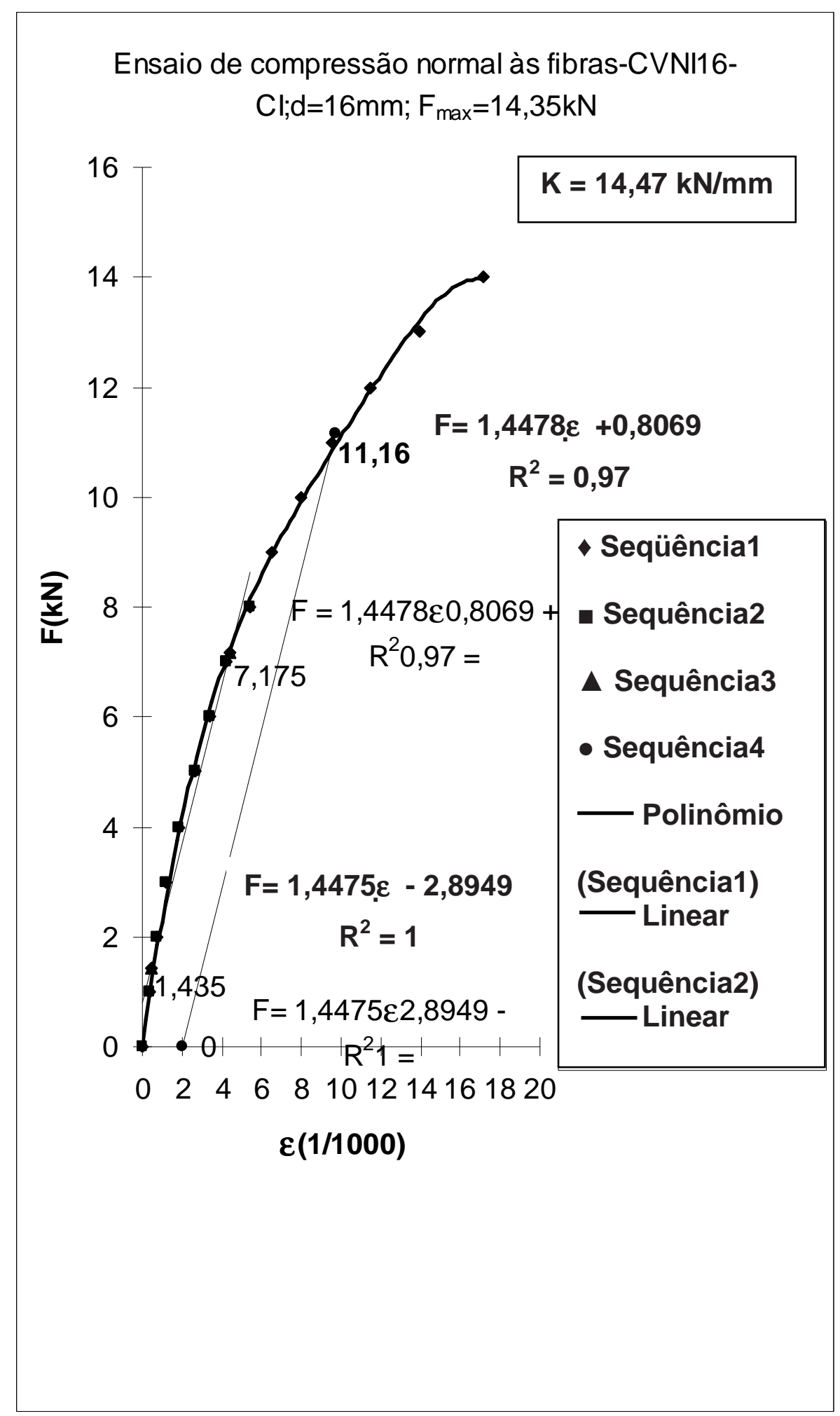

FIGURA 99 - Gráfico F-ع para o corpo de prova CVNI16. 


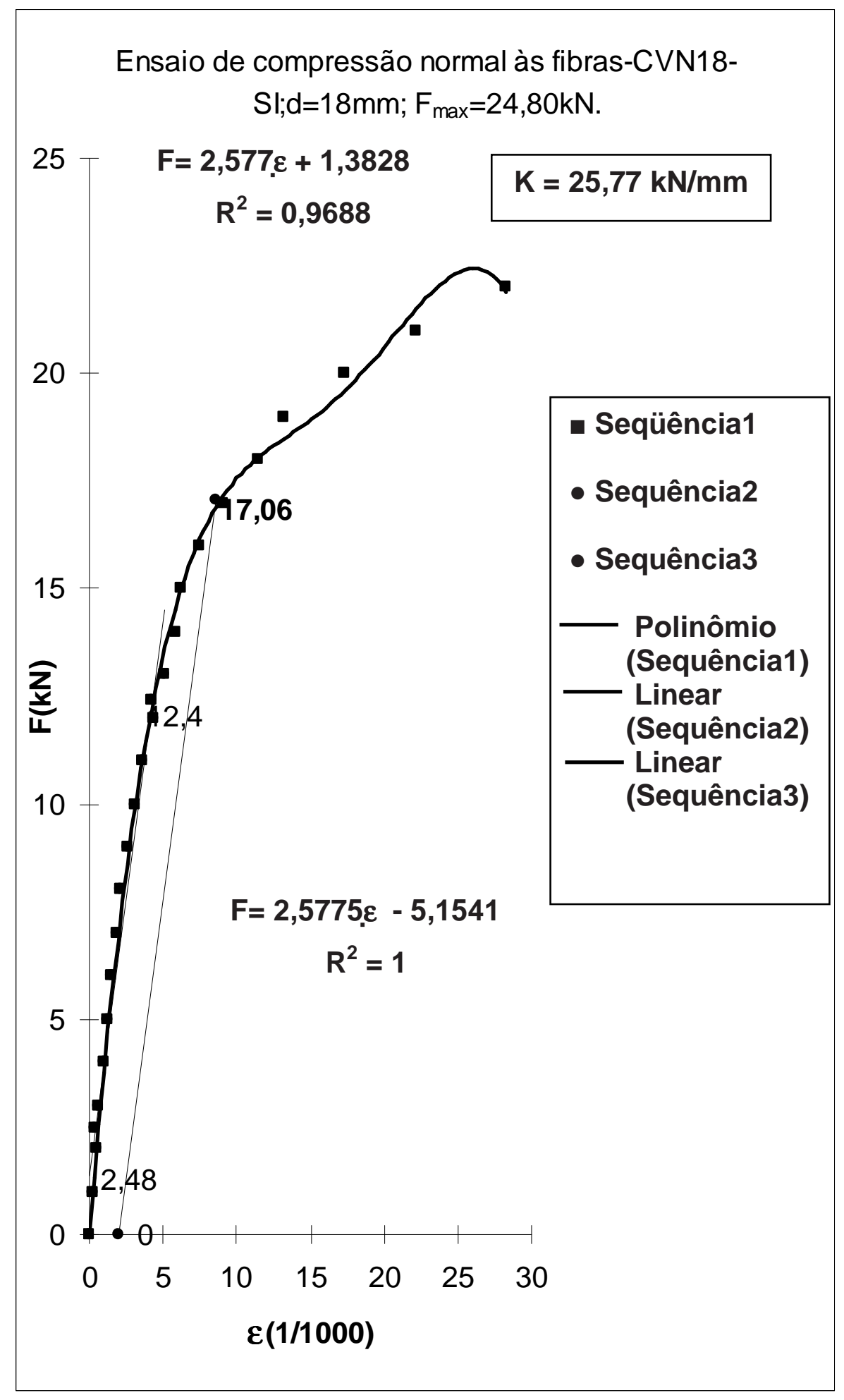

FIGURA 100 - Gráfico F-E para o corpo de prova CVN18. 


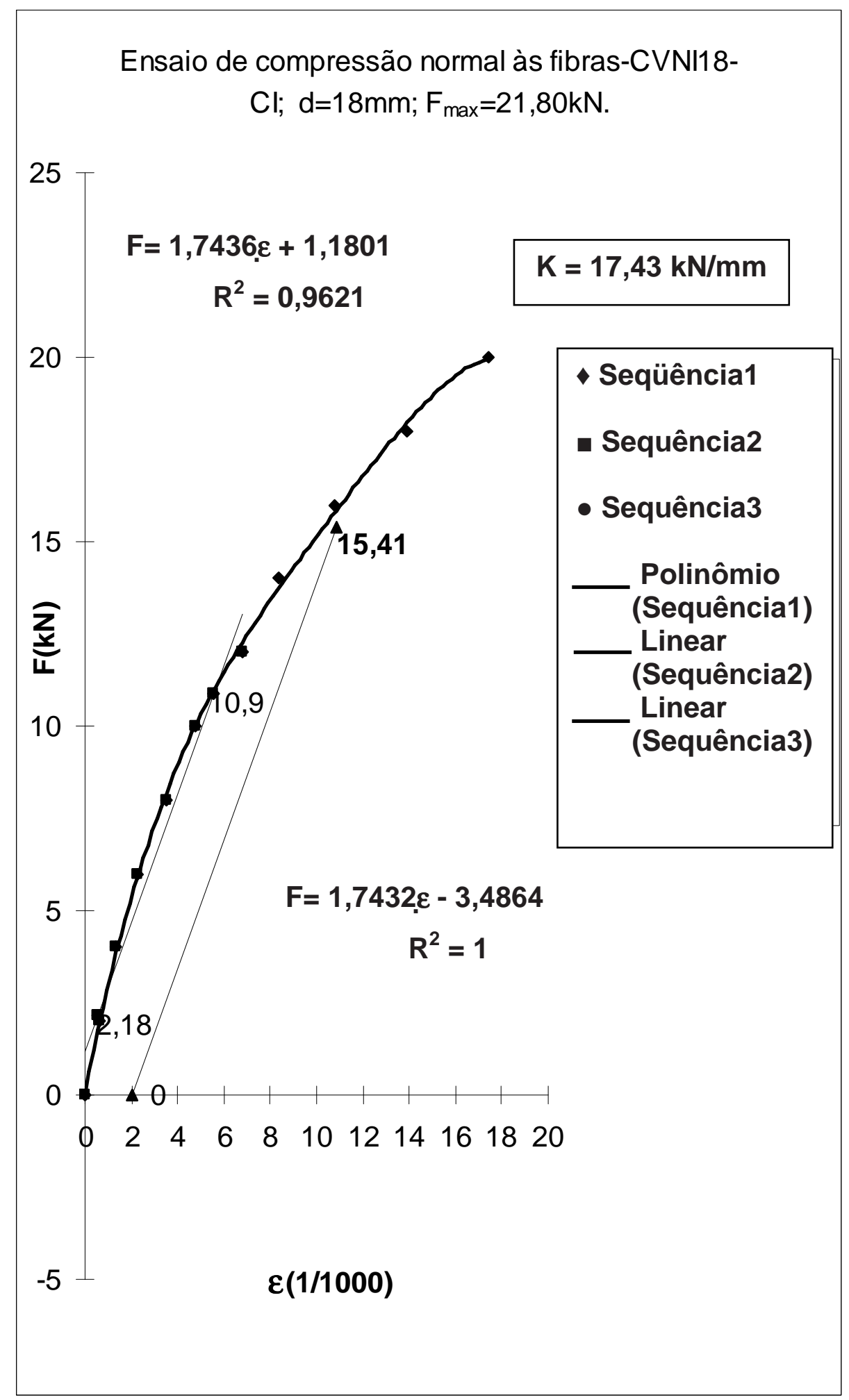

FIGURA 101 - Gráfico F- $\varepsilon$ para o corpo de prova CVNI18. 


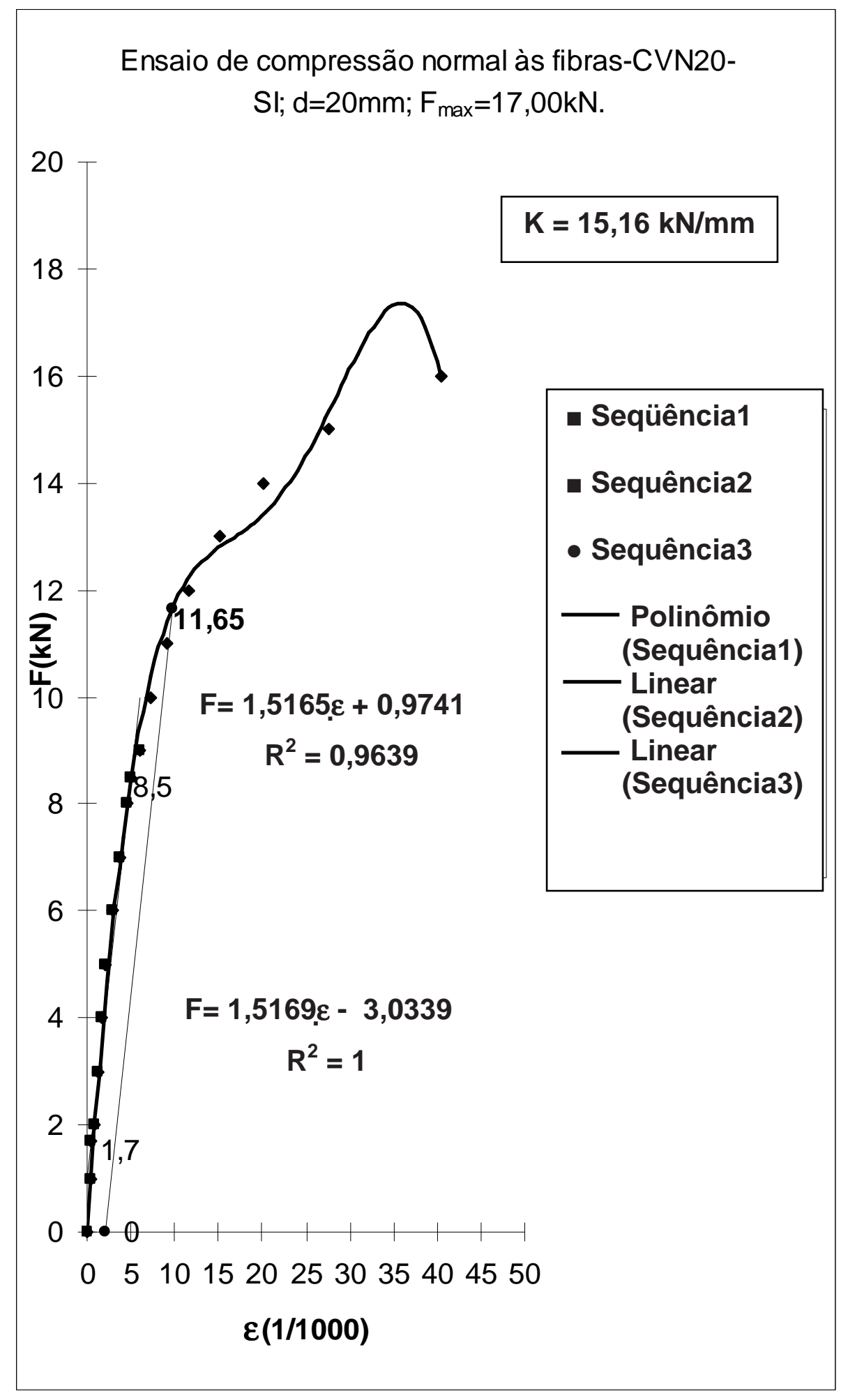

FIGURA 102 - Gráfico F- $\varepsilon$ para o corpo de prova CVN20. 


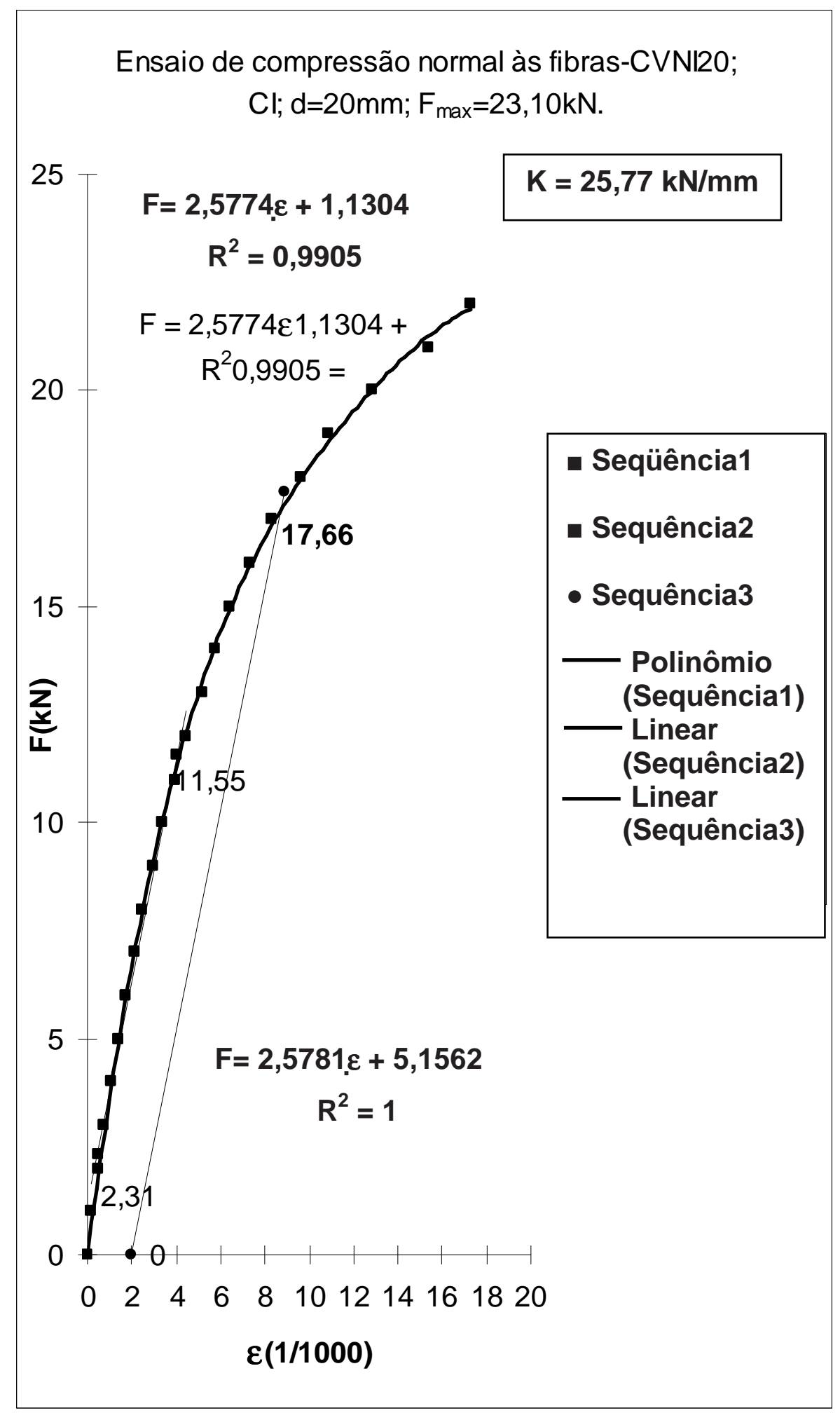

FIGURA 103 - Gráfico F-ع para o corpo de prova CVNI20. 


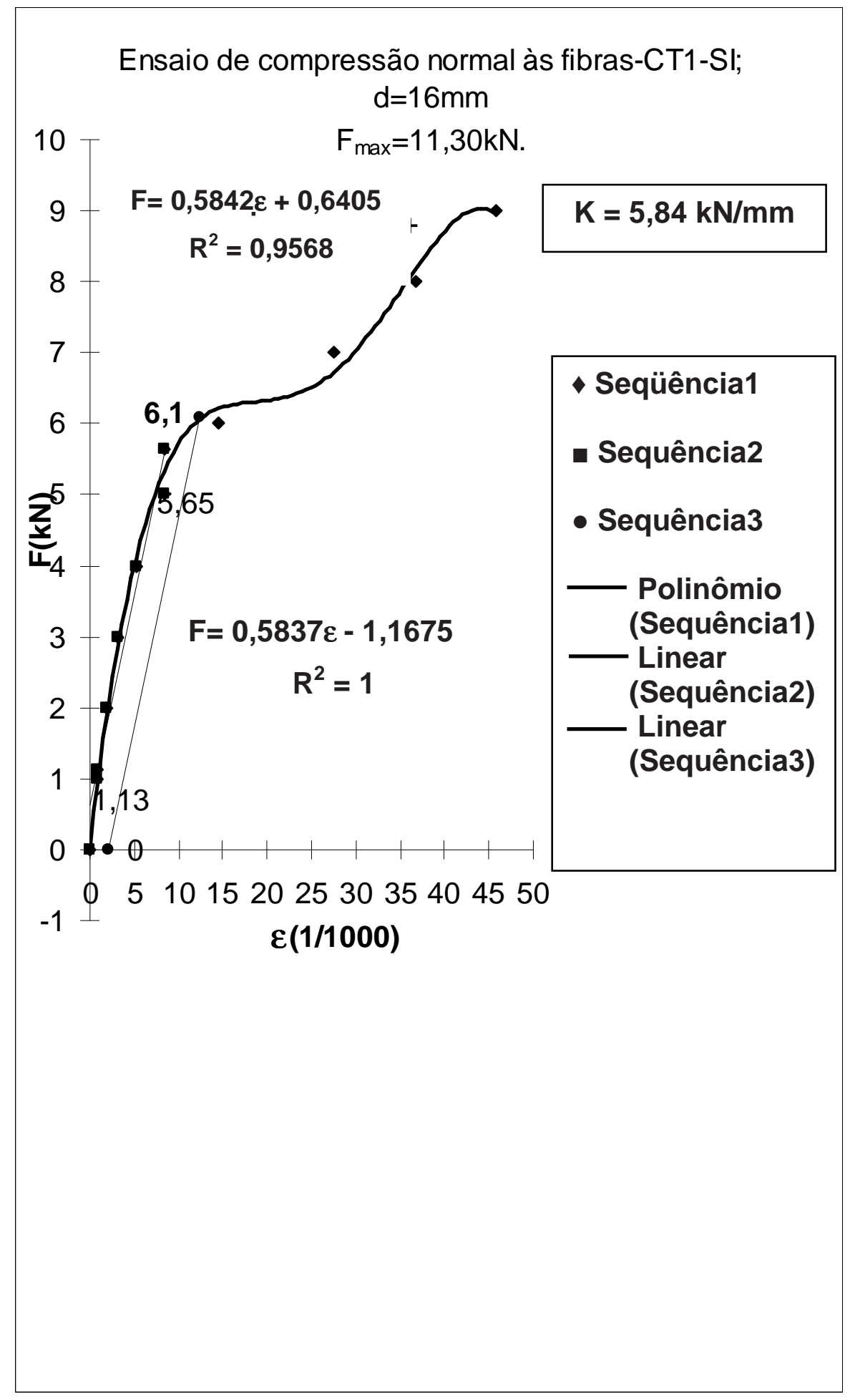

FIGURA 104 - Gráfico F-E para o corpo de prova CT1. 


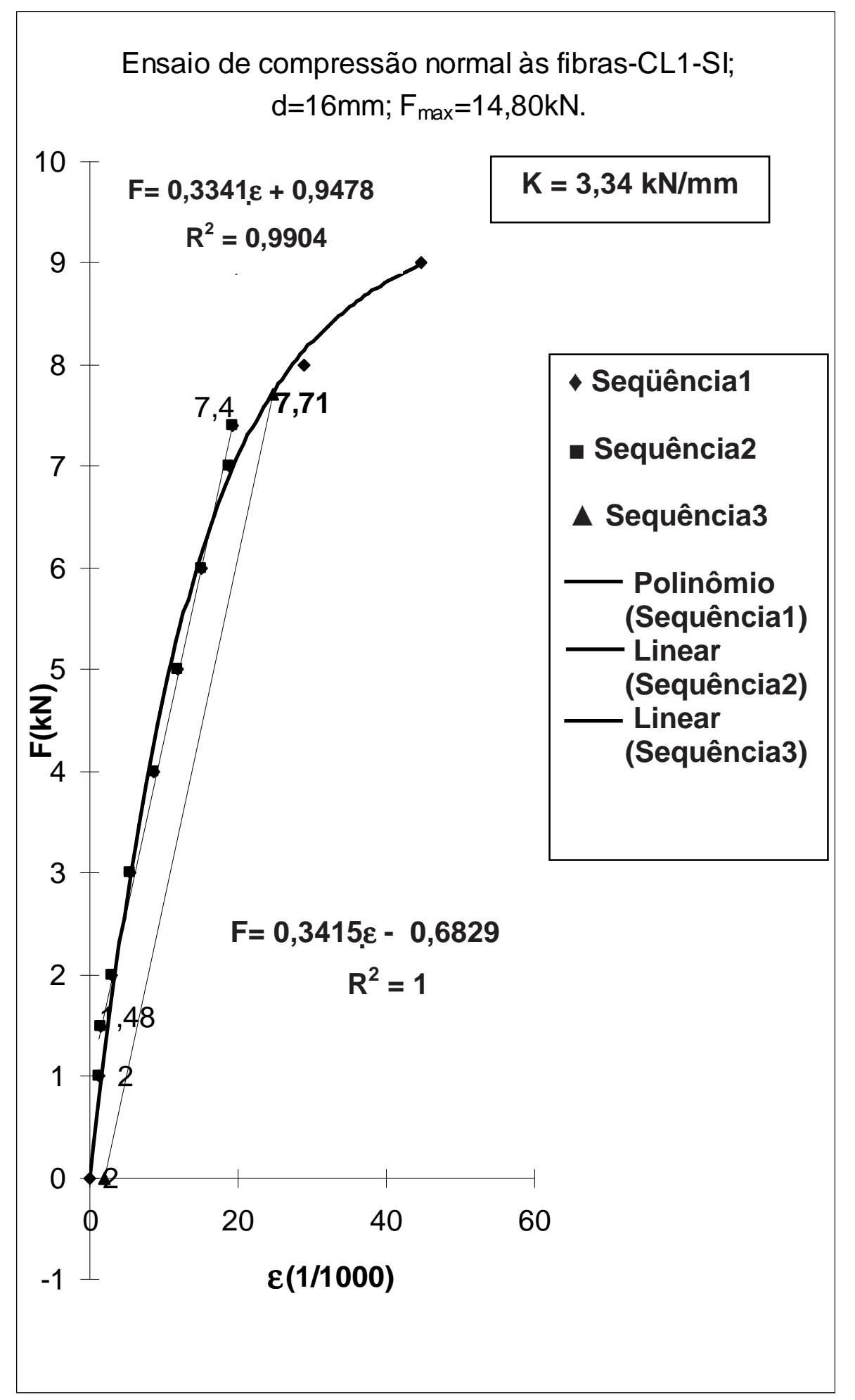

FIGURA 105 - Gráfico F-E para o corpo de prova CL1. 


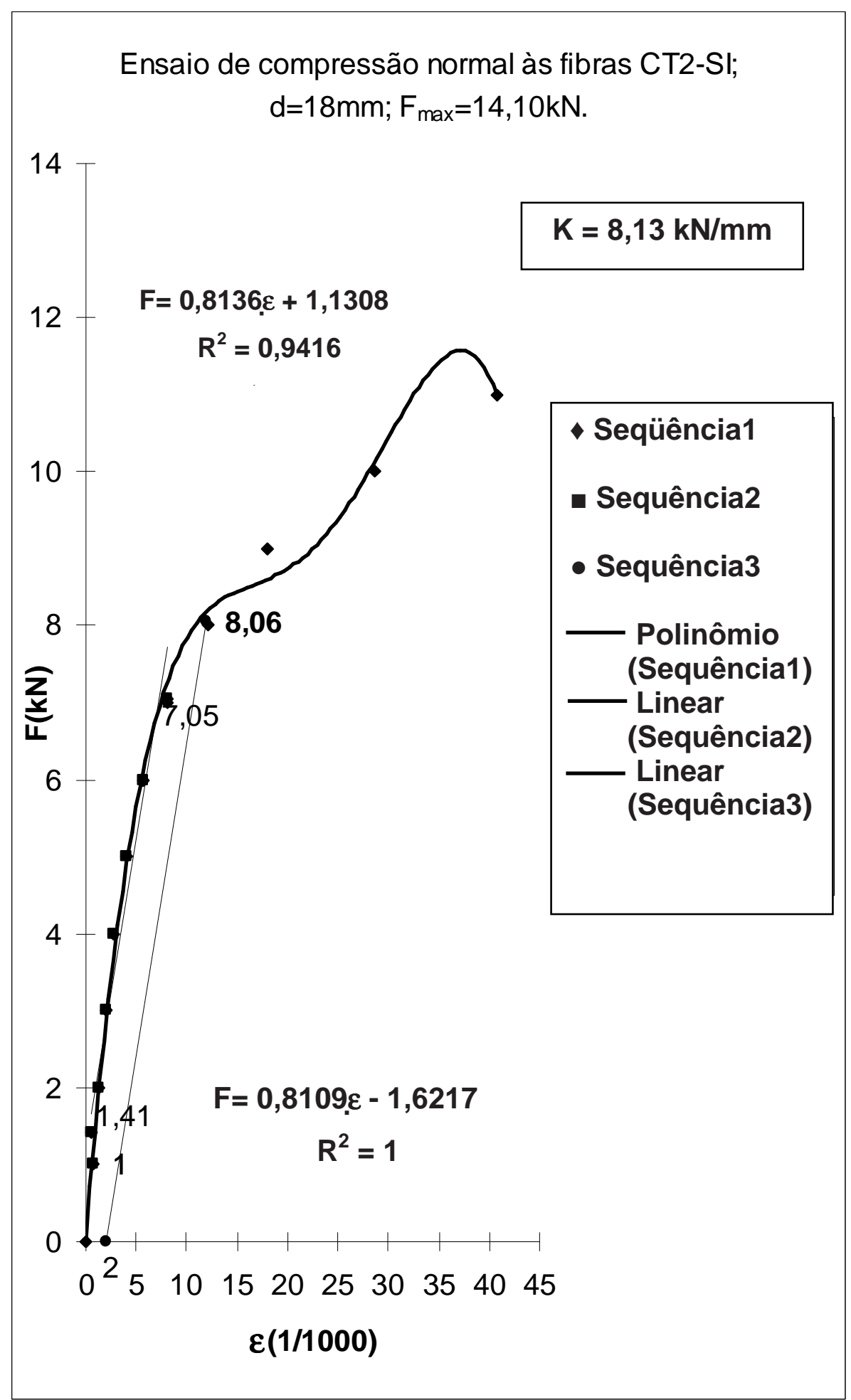

FIGURA 106 - Gráfico F- $\varepsilon$ para o corpo de prova CT2. 
Ensaio de compressão normal às fibras-CL2-Sl; $\mathrm{d}=18 \mathrm{~mm}$; Fmax $=13,20 \mathrm{kN}$.

$$
\mathrm{K}=7,41 \mathrm{kN} / \mathrm{mm}
$$

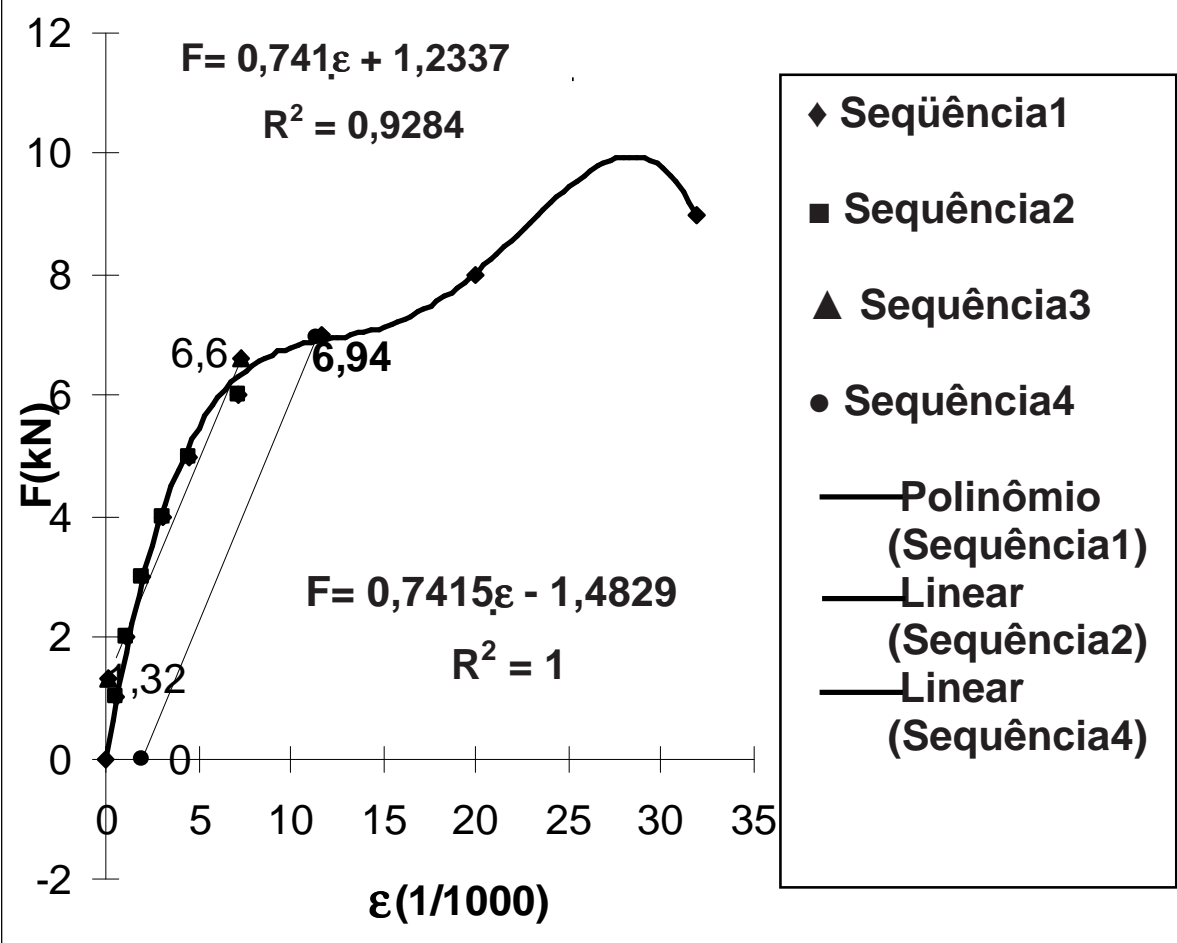

FIGURA 107 - Gráfico F-E para o corpo de prova CL2. 


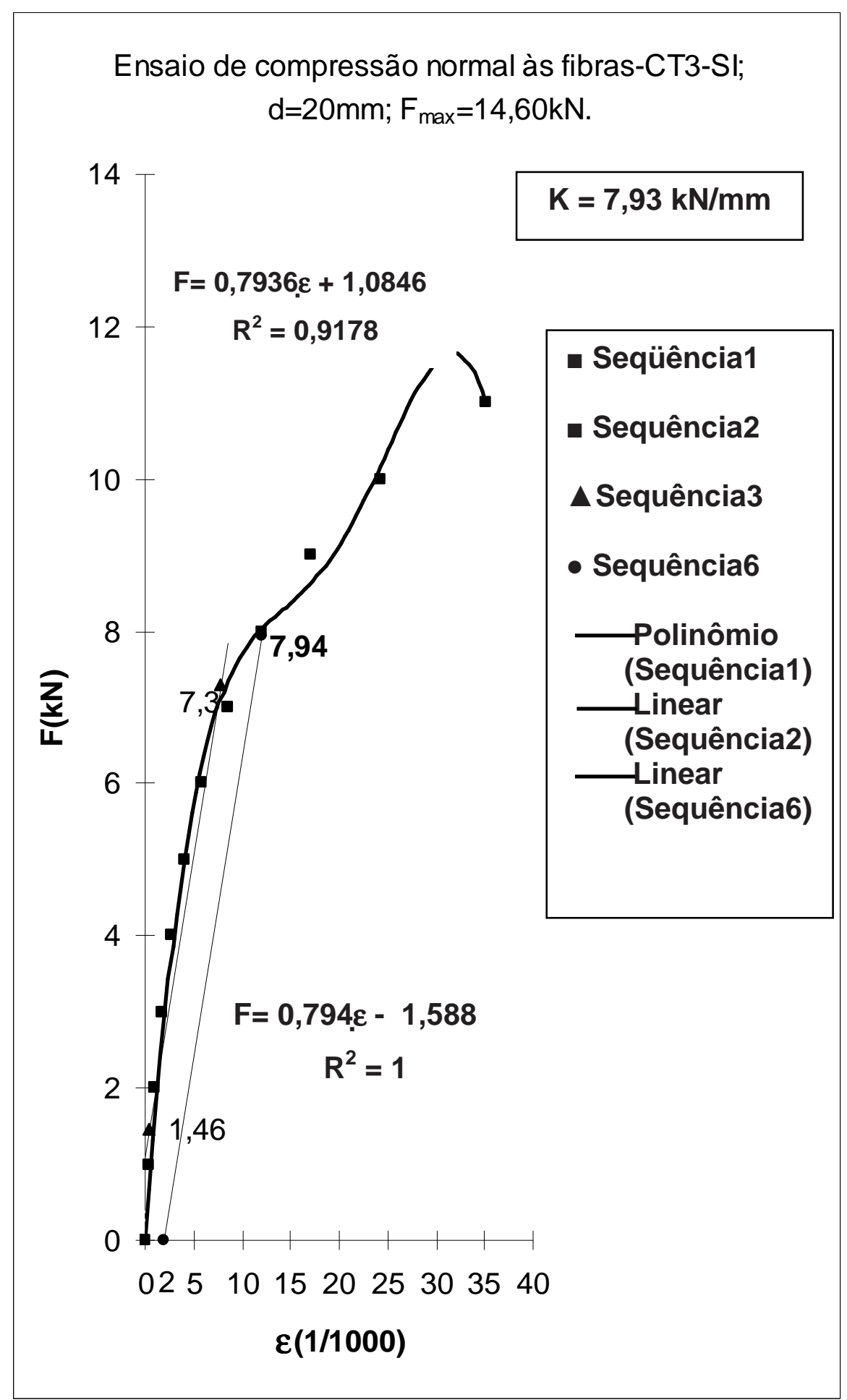

FIGURA 108 - Gráfico F- $\varepsilon$ para o corpo de prova CT3. 
Ensaio de compressão normal às fibras- CL3-SI; $\mathrm{d}=20 \mathrm{~mm} ; \mathrm{F}_{\max }=13,20 \mathrm{kN}$.

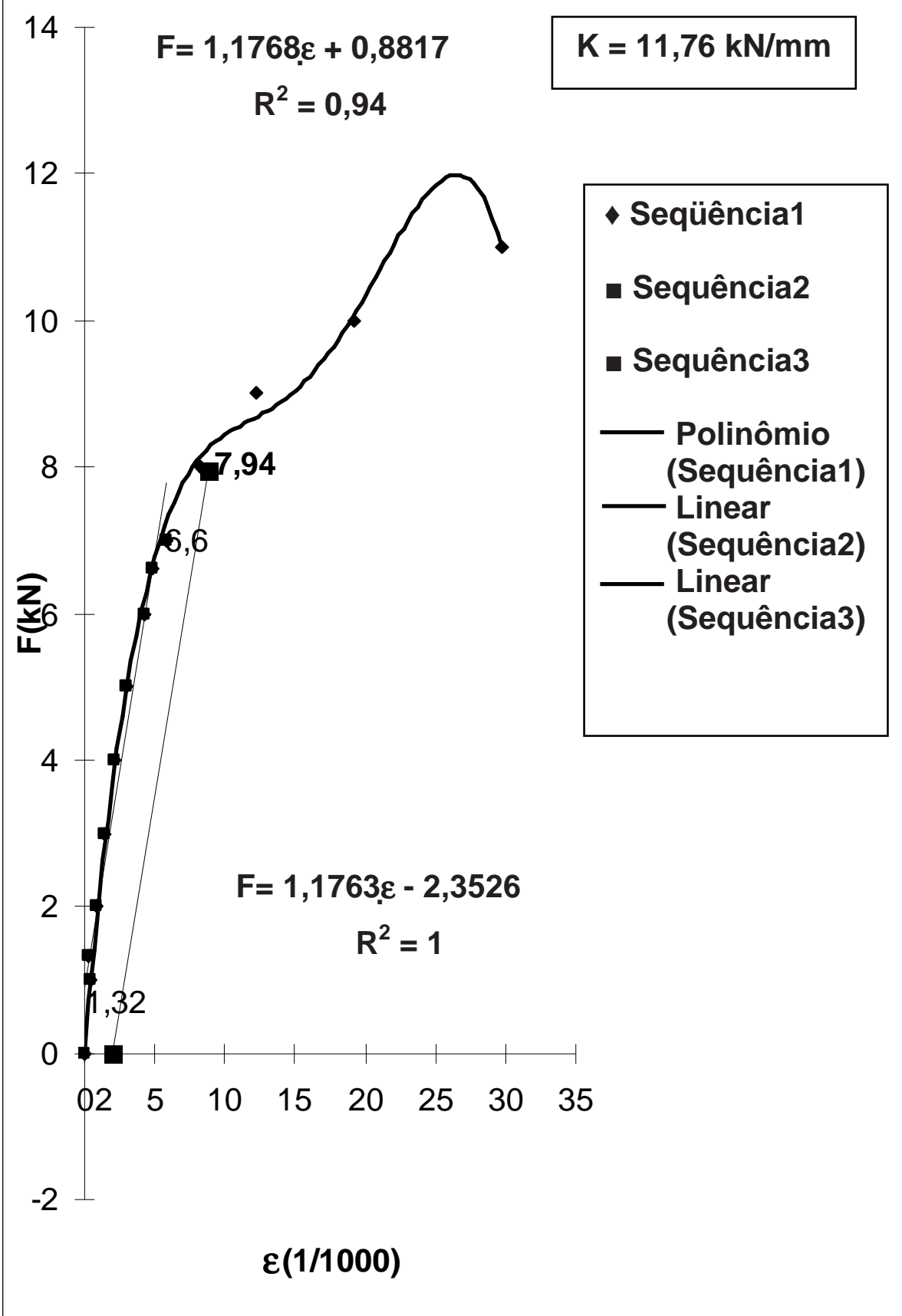

FIGURA 109 - Gráfico F-ع para o corpo de prova CL3. 


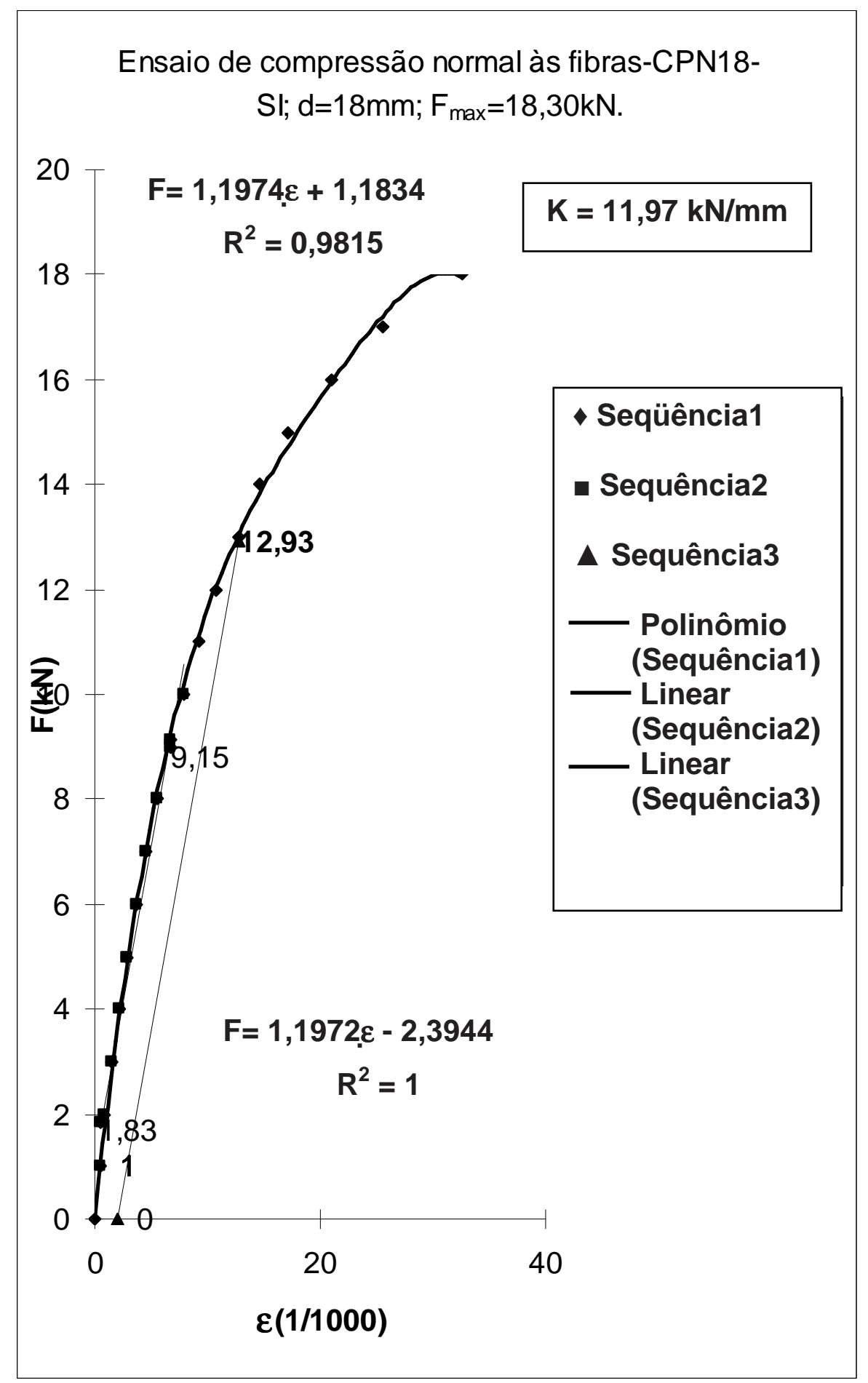

FIGURA 110 - Gráfico F- $\varepsilon$ para o corpo de prova CPN18. 


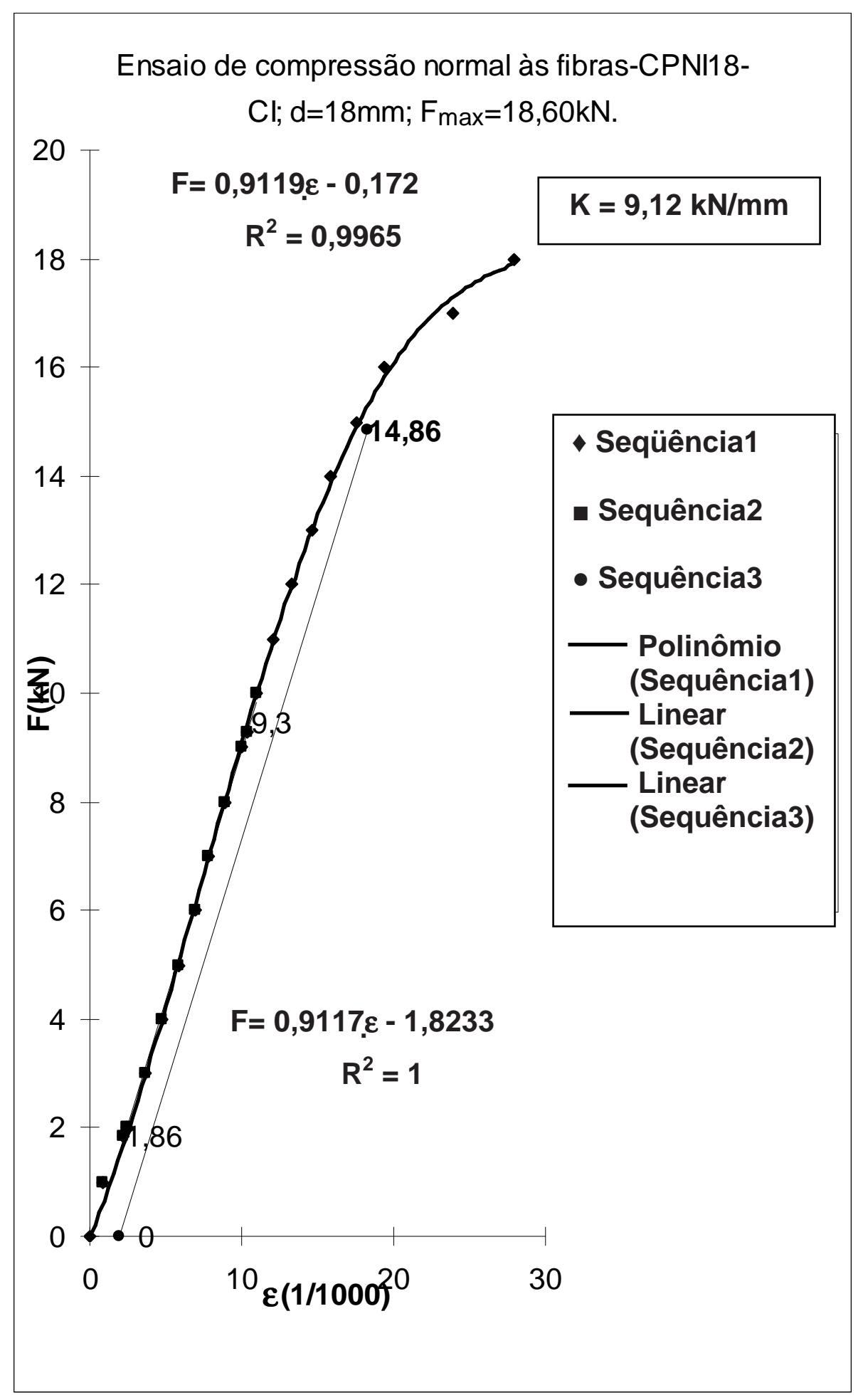

FIGURA 111 - Gráfico F-e para o corpo de prova CPNI18. 


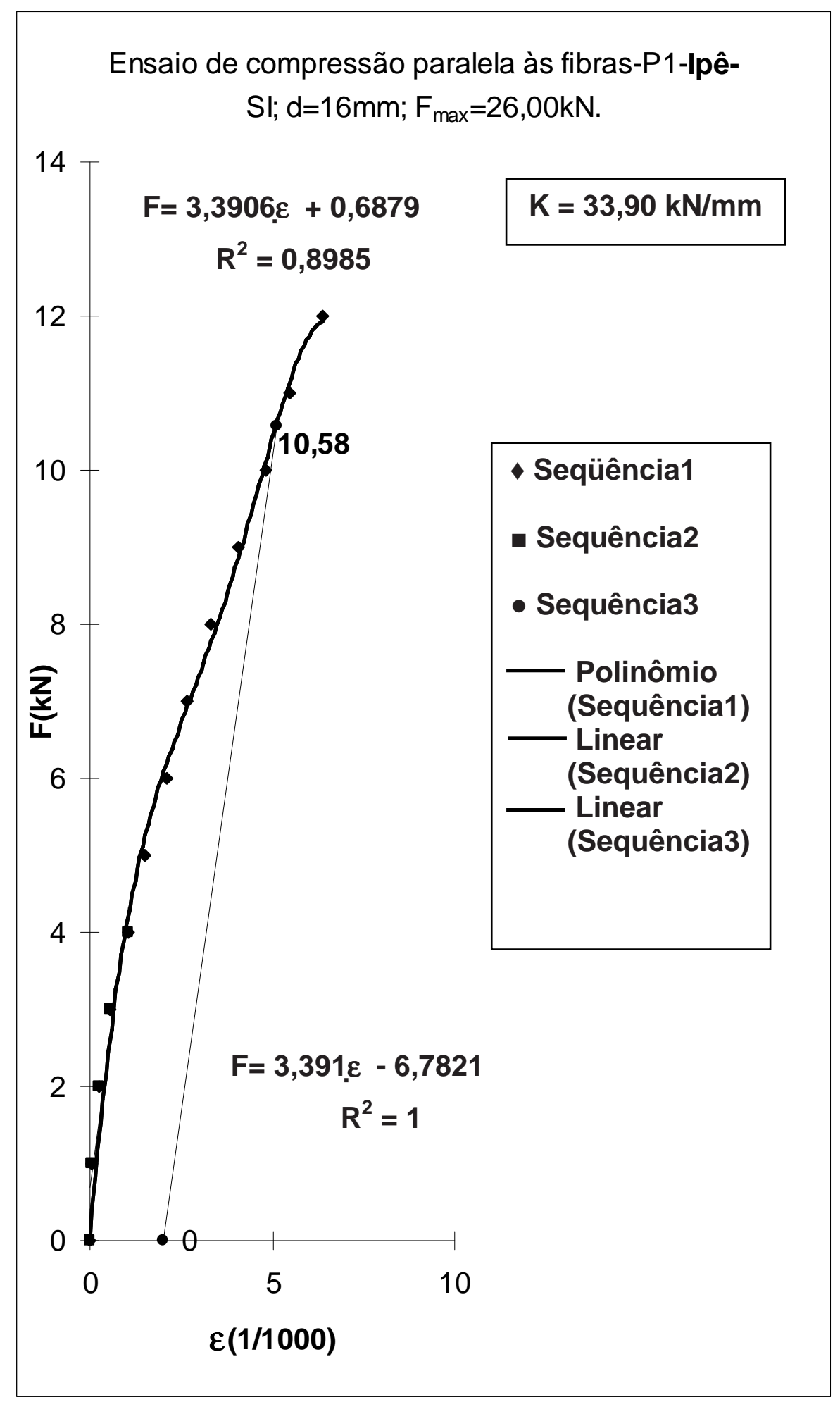

FIGURA 112 - Gráfico F- $\varepsilon$ para o corpo de prova P1. 


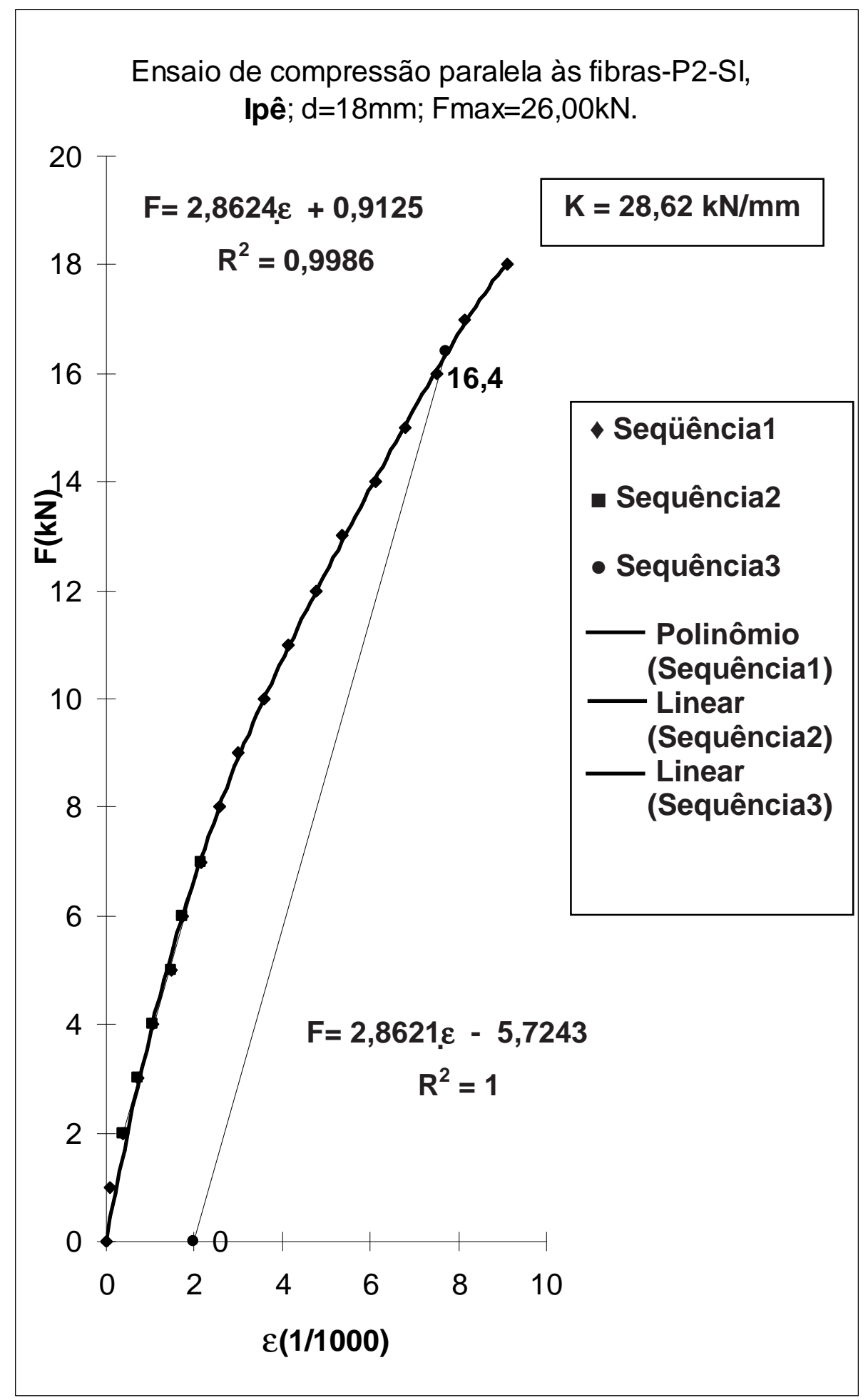

FIGURA 113 - Gráfico F- $\varepsilon$ para o corpo de prova P2. 


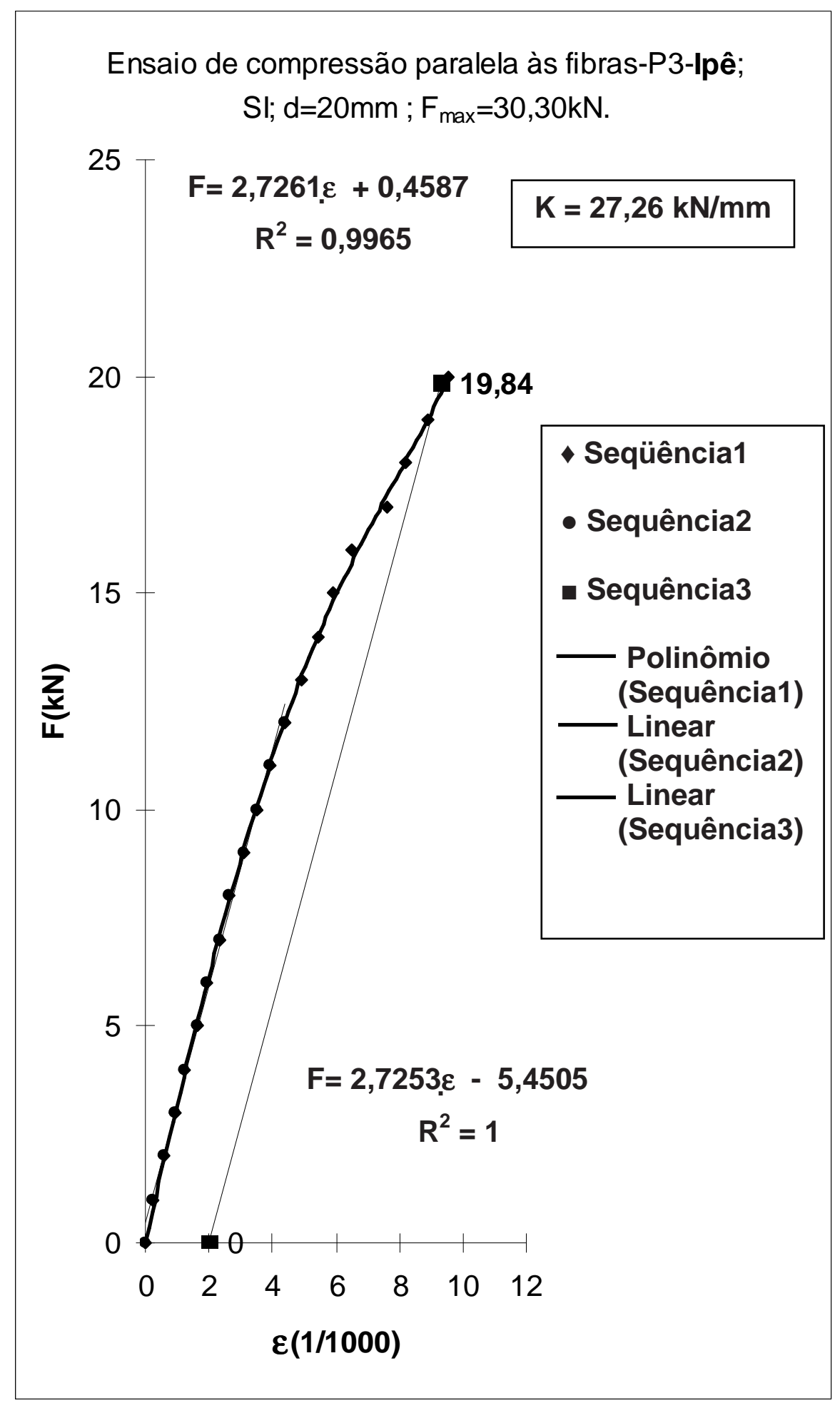

FIGURA 114 - Gráfico F-ع para o corpo de prova P3. 


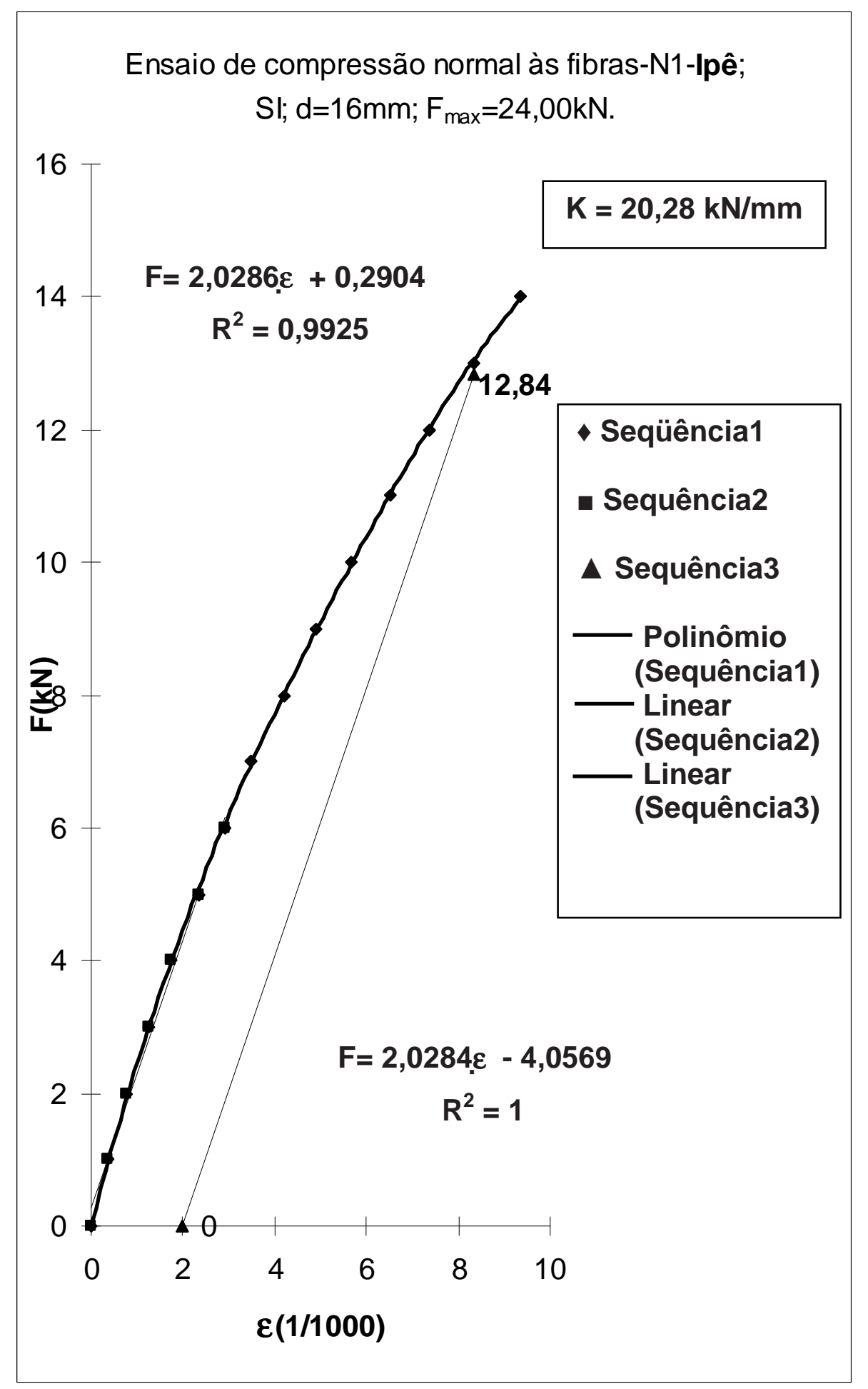

FIGURA 115 - Gráfico F-ع para o corpo de prova N1. 


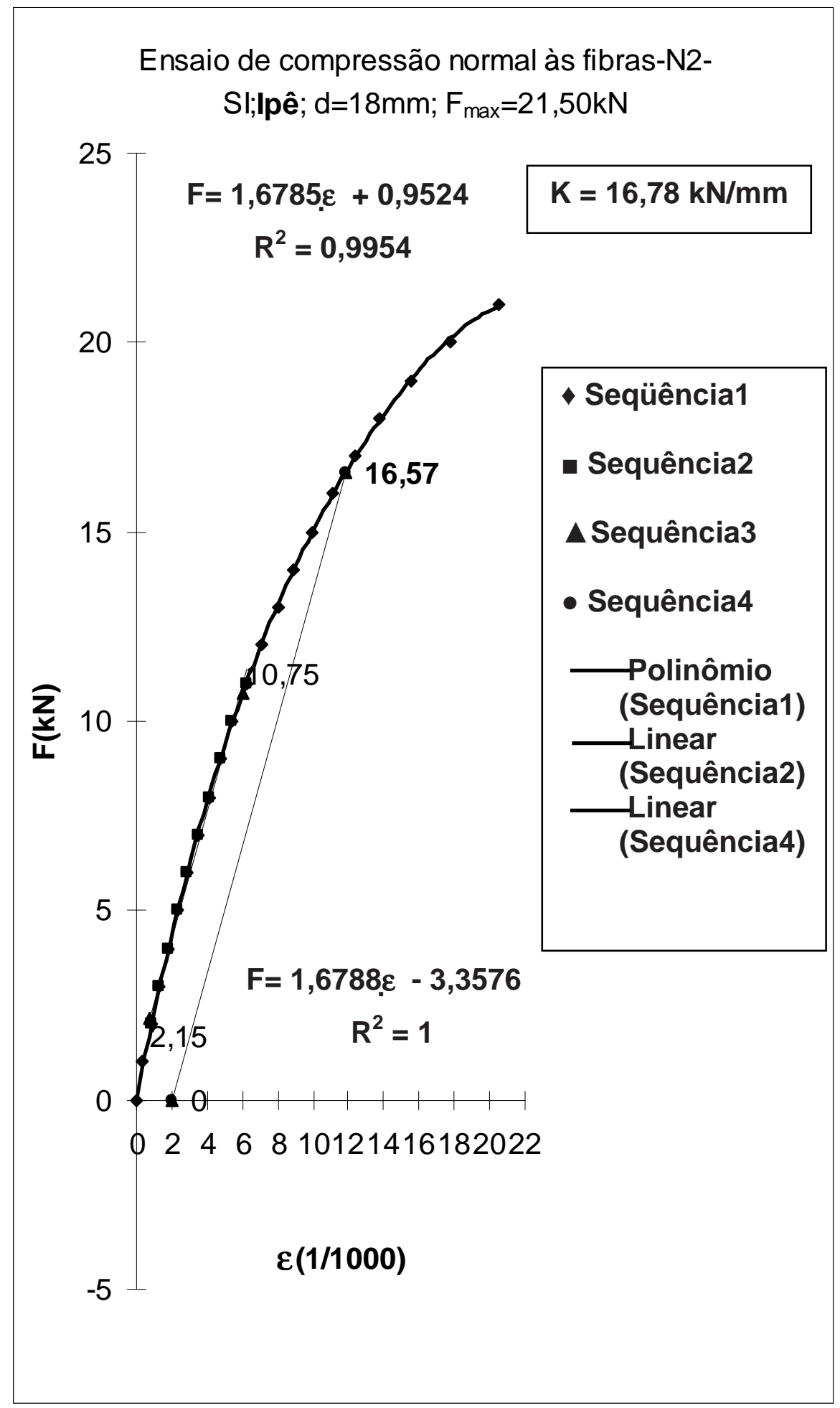

FIGURA 116 - Gráfico F-e para o corpo de prova N2. 


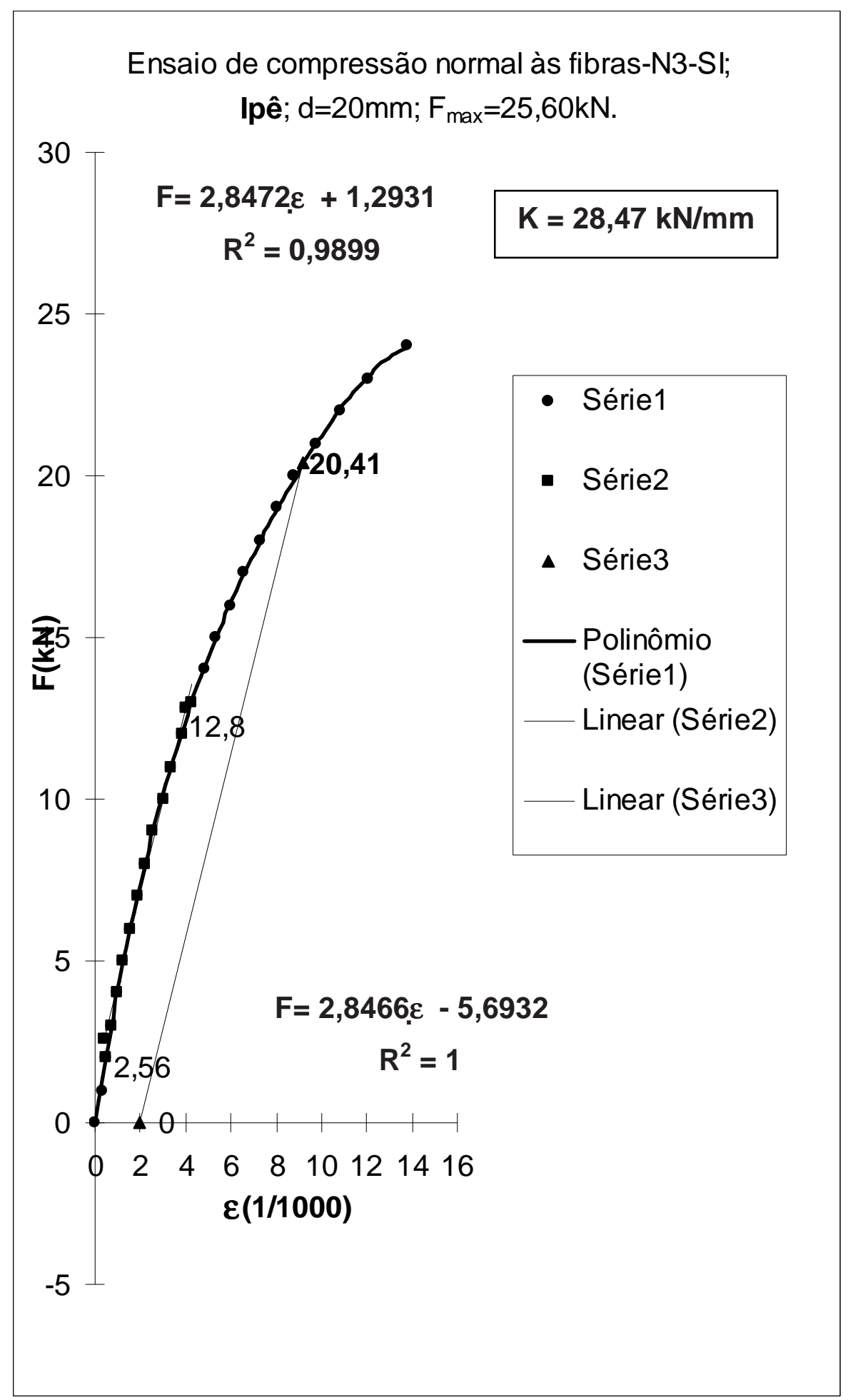

FIGURA 117 - Gráfico F-E para o corpo de prova N3. 


\section{ANEXO C}

\section{CARGAS DE PRIMEIRO E SEGUNDO LIMITE DAS LIGAÇÕES CAVILHADAS.}

Este anexo tem como objetivo mostrar os resultados através de gráficos e tabelas do método de cálculo das cargas limites que são propostos no trabalho de ALMEIDA (1990), e que aqui no caso específico desta tese são aplicadas as formulações para o caso das ligações cavilhadas impregnadas ou não cujos modelos podem ser vistos no capítulo 06.

Foram realizados um total de 36 ensaios, sendo 09 corpos de prova solicitados na compressão paralela às fibras e 27 por compressão normal às fibras, sendo as cavilhas submetidas a corte duplo. Para cada corpo de

prova foi determinado o parâmetro $\boldsymbol{\beta}$ em função da espessura $\mathbf{t}$ das peças $e$ o diâmetro d das cavilhas conforme as tabelas 78 a 93 As cargas teóricas foram determinadas de acordo com as expressões (4.1) a (4.12) desenvolvidas no capítulo 4 deste trabalho.

Os valores das propriedades físicas dos materiais foram determinados de acordo com normas de ensaio correspondentes a cada material e os valores podem ser vistos na Tabela 77 .

Para empregar as expressões para determinação das cargas de primeiro e segundo limite, calcula-se o parâmetro $\beta$ efetivo ( $\beta$ ef) e o valor de

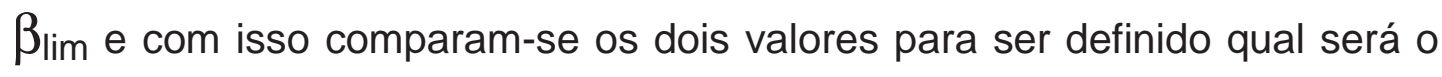
valor da carga limite a ser determinada, sendo que os referidos valores são mostrados nas Tabela 78 a 93. 


\section{TABELA 77- CARACTERÍSTICAS FÍSICAS E MECÂNICAS DAS MADEIRAS.}

SI-Sem impregnação; Cl-com impregnação.

\begin{tabular}{|c|c|c|c|c|c|}
\hline ESPÉCIE & U\% & $\mathbf{N}$ & $\begin{array}{c}\text { PARÂMETRO } \\
\mathbf{S}\end{array}$ & $\begin{array}{c}\text { VALORES } \\
\text { MÉDIOS } \\
\text { (MPa) }\end{array}$ & $\begin{array}{l}\text { RELAÇÃO } \\
\mathrm{f}_{\mathrm{CO}} / \mathrm{f}_{\mathrm{C}} \mathrm{O} 0\end{array}$ \\
\hline PINUS SI & - & - & $\sigma_{e, 0}$ & 36 & - \\
\hline PINUS Cl & - & - & $\sigma_{e, 0}$ & 49 & - \\
\hline $\mathrm{IPE}$ & - & - & $\sigma_{e, 0}$ & 73 & - \\
\hline PINUS SI & - & - & $f_{e}$ & 47 & - \\
\hline PINUS Cl & - & - & $f_{e}$ & 65 & - \\
\hline $\mathrm{IPE}$ & - & - & $f_{e}$ & 96 & - \\
\hline PINUS SI & 16,10 & 4 & $f_{\mathrm{C} 0, w}$ & 45 & $\mathrm{f}_{\mathrm{C} 0} / \mathrm{f}_{\mathrm{C} 90}=15$ \\
\hline PINUS Cl & 16,10 & 6 & $f_{c 0, w}$ & 61 & $\mathrm{f}_{\mathrm{C} O} / \mathrm{f}_{\mathrm{C}} 90=3,81$ \\
\hline $\mathrm{IPE}$ & 12,00 & 1 & $\mathrm{f}_{\mathrm{C} 0, \mathrm{w}}$ & 91 & $\mathrm{f}_{\mathrm{C} 0} / \mathrm{f}_{\mathrm{C} 90}=3,79$ \\
\hline PINUS SI & 7.30 & 3 & $\mathrm{f}_{\mathrm{c} 90}$ & 3 & - \\
\hline PINUS Cl & 7.30 & 3 & $f_{c 90}$ & 16 & - \\
\hline IPE & 12,00 & 1 & $\mathrm{f}_{\mathrm{c} 90}$ & 24 & - \\
\hline PINUS SI & 15,01 & 6 & $\mathrm{f}_{\mathrm{c} 0 \text {, cav }}$ & 48 & $\mathrm{f}_{\mathrm{c} 0, \text { cav }} / \mathrm{f}_{\mathrm{c} 90=16}$ \\
\hline PINUS Cl & 15,01 & 6 & $\mathrm{f}_{\mathrm{c} 0 \text {, cav }}$ & 61 & $f_{c 0, \text { cav }} / f_{c 90}=3,81$ \\
\hline$\overline{I P E}$ & 12,00 & 12 & $\mathrm{f}_{\mathrm{c} 0 \text {, cav }}$ & 82 & $f_{c 0, \text { cav }} / f_{c 90}=3,41$ \\
\hline
\end{tabular}

Passaremos a seguir para a determinação dos valores teóricos das cargas de primeiro e segundo limite e iremos comparar estes valores com os resultados obtidos nos ensaios experimentais das ligações cavilhadas. Os diâmetros das cavilhas adotados foram de 16,18 e $20 \mathrm{~mm}$ e de acordo com a NBR 7190/96, tanto para cavilhas impregnadas e não impregnadas. 
TABELA 78- Comparação dos valores das cargas de primeiro limite com os valores obtidos no ensaio de compressão paralela às fibras.

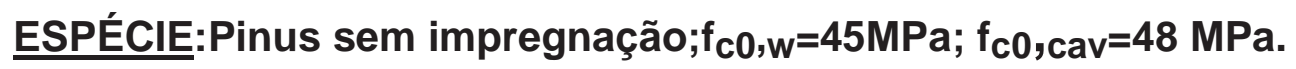

$$
\sigma_{\mathrm{e}, 0}=\mathrm{k}_{1} \cdot \mathrm{f}_{\mathrm{c} 0, \mathrm{w}}=0,80.45=36 \mathrm{MPa} \text {. }
$$

UNIDADE: $F(k N) ; \sigma\left(k N / \mathrm{cm}^{2}\right)$

\begin{tabular}{|c|c|c|c|c|c|c|}
\hline $\mathbf{t}$ & $\boldsymbol{\beta}$ & $\boldsymbol{\beta}_{\lim }$ & $\boldsymbol{\sigma}_{\mathbf{e}, \mathbf{0}}$ & $\mathbf{F}_{\mathbf{W}, \mathbf{0}}$ & $\mathbf{F}_{\text {cav } \mathbf{0} \mathbf{0}}$ & $\mathbf{F}_{\text {oexp. }}$ \\
\hline 2,5 & 1,56 & 4,46 & 3,6 & 5,34 & - & 6 \\
\hline 2,6 & 1,44 & 4,46 & 3,6 & 6,25 & - & 9 \\
\hline 2,5 & 1,25 & 4,46 & 3,6 & 6,66 & - & 10 \\
\hline
\end{tabular}

TABELA 79- Comparação dos valores das cargas de primeiro limite com os valores obtidos no ensaio de compressão paralela às fibras.

ESPÉCIE: Pinus com impregnação; $f_{c 0, w}=61 \mathrm{MPa} ; f_{c 0}$,cav=61 MPa;

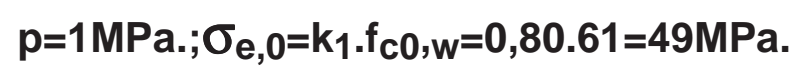

UNIDADE: $F(k N) ; \sigma\left(k N / \mathrm{cm}^{2}\right)$

\begin{tabular}{|c|c|c|c|c|c|c|}
\hline $\mathbf{t}$ & $\boldsymbol{\beta}$ & $\boldsymbol{\beta}_{\text {lim }}$ & $\boldsymbol{\sigma}_{\mathbf{e}, \mathbf{0}}$ & $\mathbf{F}_{\mathbf{W}, \mathbf{0}}$ & $\mathbf{F}_{\text {cav }, \mathbf{0}}$ & $\mathbf{F}_{\text {oexp. }}$ \\
\hline 2,7 & 1,69 & 2,19 & 4,9 & 5,92 & - & 8 \\
\hline 2,6 & 1,44 & 2,19 & 4,9 & 6,44 & - & 11 \\
\hline 2,6 & 1,3 & 2,19 & 4,9 & 7,13 & - & 15 \\
\hline
\end{tabular}

TABELA 80- Comparação dos valores das cargas de primeiro limite com os valores obtidos no ensaio de compressão paralela às fibras.

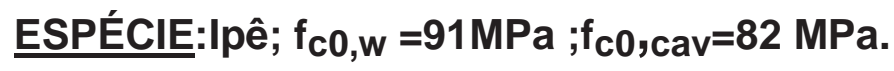

$\sigma_{e, 0}=k_{1} \cdot f_{c 0, w}=0,80.91=73 \mathrm{MPa}$.

UNIDADE: $F(k N) ; \sigma\left(k N / \mathrm{cm}^{2}\right)$

\begin{tabular}{|c|c|c|c|c|c|c|}
\hline $\mathbf{t}$ & $\boldsymbol{\beta}$ & $\boldsymbol{\beta}_{\text {lim }}$ & $\boldsymbol{\sigma}_{\mathbf{e}, \mathbf{0}}$ & $\mathbf{F}_{\mathbf{W}, \mathbf{0}}$ & $\mathbf{F}_{\text {cav }, \mathbf{0}}$ & $\mathbf{F}_{\text {oexp. }}$ \\
\hline 2,3 & 1,44 & 1,96 & 7,3 & 7,24 & - & 5 \\
\hline 2,4 & 1,33 & 1,96 & 7,3 & 8,54 & - & 9 \\
\hline 2,45 & 1,22 & 1,96 & 7,3 & 9,70 & - & 11 \\
\hline
\end{tabular}


TABELA 81- Comparação dos valores das cargas de segundo limite,hipótese $A$ com os valores obtidos no ensaio de compressão paralela às fibras.

ESPÉCIE:Pinus sem impregnação; $\mathrm{f}_{\mathrm{co}, \mathrm{w}}=45 \mathrm{MPa} ; \mathrm{f}_{\mathrm{c} 0, \mathrm{cav}=48 \mathrm{MPa}}$. $f_{e}=k_{2} \cdot f_{c 0, w}=1,05.45=47 \mathrm{MPa} ; F(k N) ; f\left(k N / \mathrm{cm}^{2}\right)$.

\begin{tabular}{|c|c|c|c|c|c|c|}
\hline $\mathbf{t}$ & $\boldsymbol{\beta}$ & $\boldsymbol{\beta}_{\text {lim }}$ & $\mathbf{f}_{\mathbf{e}}$ & $\mathbf{F}_{\mathbf{w}, \mathbf{o}}$ & $\mathbf{F}_{\text {cav }, \mathbf{0}}$ & $\mathbf{F}_{\text {uexp. }}$ \\
\hline 2,5 & 1,56 & 5,05 & 4,7 & 6,97 & - & 8,12 \\
\hline 2,6 & 1,44 & 5,05 & 4,7 & 8,16 & - & 11,15 \\
\hline 2,5 & 1,25 & 5,05 & 4,7 & 8,70 & - & 12,06 \\
\hline
\end{tabular}

TABELA 82- Comparação dos valores das cargas de segundo limite,hipótese $B$ com os valores obtidos no ensaio de compressão paralela às fibras.

ESPÉCIE:Pinus sem impregnação; $f_{c 0, w}=45 \mathrm{MPa} ; f_{c 0},{ }_{c a v}=48 \mathrm{MPa}$. $f_{e,}=k_{2} \cdot f_{c 0, w}=1,05 \cdot 45=47 \mathrm{MPa} ; F(k N) ; f\left(k N / \mathrm{cm}^{2}\right)$.

\begin{tabular}{|c|c|c|c|c|c|c|}
\hline $\mathbf{t}$ & $\boldsymbol{\beta}$ & $\boldsymbol{\beta}_{\lim }$ & $\mathbf{f}_{\mathbf{e}}$ & $\mathbf{F}_{\mathbf{w}, \mathbf{0}}$ & $\mathbf{F}_{\text {cav }, \mathbf{0}}$ & $\mathbf{F}_{\mathbf{m a x} .}$ \\
\hline 2,5 & 1,56 & 4,04 & 4,7 & 11,11 & - & 11,2 \\
\hline 2,6 & 1,44 & 4,04 & 4,7 & 13,02 & - & 16,4 \\
\hline 2,5 & 1,25 & 4,04 & 4,7 & 13,87 & - & 19,2 \\
\hline
\end{tabular}

TABELA 83- Comparação dos valores das cargas de segundo limite hipótese $A, c o m$ os valores obtidos no ensaio de compressão paralela às fibras.

ESPÉCIE:Pinus com impregnação; $\mathrm{f}_{\mathrm{c} 0, \mathrm{w}}=61 \mathrm{MPa} ; \mathrm{f}_{\mathrm{c} 0, \mathrm{cav}=61 \mathrm{MPa}}$. $f_{e}=k_{2} \cdot f_{c 0, w}=1,05.61=65 M P a . ; p=1 M P a ; F(k N) ; f\left(k N / \mathrm{cm}^{2}\right)$.

\begin{tabular}{|c|c|c|c|c|c|c|}
\hline $\mathbf{t}$ & $\boldsymbol{\beta}$ & $\boldsymbol{\beta}_{\text {lim }}$ & $\mathbf{f}_{\mathbf{e}}$ & $\mathbf{F}_{\mathbf{w}, \mathbf{o}}$ & $\mathbf{F}_{\text {cav }, \mathbf{0}}$ & $\mathbf{F}_{\text {uexp. }}$ \\
\hline 2,7 & 1,69 & 2,42 & 6,5 & 7,85 & - & 11,71 \\
\hline 2,6 & 1,44 & 2,42 & 6,5 & 8,54 & - & 16,19 \\
\hline 2,6 & 1,3 & 2,42 & 6,5 & 9,46 & - & 21,62 \\
\hline
\end{tabular}


TABELA 84- Comparação dos valores das cargas de segundo limite hipótese B,com os valores obtidos no ensaio de compressão paralela às fibras.

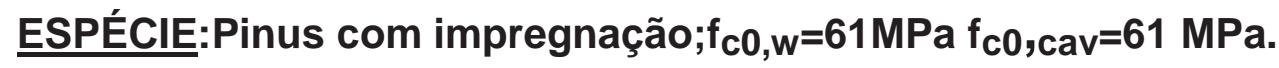

$f_{e}=k_{2} \cdot f_{c 0, w}=1,05.61=65 M P a . ; p=1 \mathrm{MPa} ; F(k N) ; f\left(k N / \mathrm{cm}^{2}\right)$.

\begin{tabular}{|c|c|c|c|c|c|c|}
\hline $\mathbf{t}$ & $\boldsymbol{\beta}$ & $\boldsymbol{\beta}_{\text {lim }}$ & $\mathbf{f}_{\mathbf{e}}$ & $\mathbf{F}_{\mathbf{w}, \mathbf{0}}$ & $\mathbf{F}_{\text {cav }, \mathbf{0}}$ & $\mathbf{F}_{\text {max. }}$ \\
\hline 2,7 & 1,69 & 1,9 & 6,5 & 12,90 & - & 15,9 \\
\hline 2,6 & 1,44 & 1,9 & 6,5 & 14,04 & - & 21,4 \\
\hline 2,6 & 1,3 & 1,9 & 6,5 & 15,55 & - & 29,4 \\
\hline
\end{tabular}

TABELA 85- Comparação dos valores das cargas de segundo limite hipótese $A, c o m$ os valores obtidos no ensaio de compressão paralela às fibras.

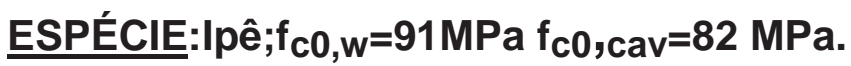

$f_{e}=k_{2} \cdot f_{c 0, w}=1,05.91=96 M P a . ; p=1 M P a ; F(k N) ; f\left(k N / c^{2}\right)$.

\begin{tabular}{|c|c|c|c|c|c|c|}
\hline $\mathbf{t}$ & $\boldsymbol{\beta}$ & $\boldsymbol{\beta}_{\text {lim }}$ & $\mathbf{f}_{\mathbf{e}}$ & $\mathbf{F}_{\mathbf{W}, \mathbf{0}}$ & $\mathbf{F}_{\text {cav } \mathbf{0}}$ & $\mathbf{F}_{\text {uexp. }}$ \\
\hline 2,3 & 1,44 & 2,21 & 9,6 & 9,52 & - & 10,58 \\
\hline 2,4 & 1,33 & 2,21 & 9,6 & 11,23 & - & 16,4 \\
\hline 2,45 & 1,22 & 2,21 & 9,6 & 12,75 & - & 19,84 \\
\hline
\end{tabular}

TABELA 86- Comparação dos valores das cargas de segundo limite hipótese B,com os valores obtidos no ensaio de compressão paralela às fibras.

ESPÉCIE:Ipê; $f_{C 0, w}=91 \mathrm{MPa} \mathrm{f}_{\mathrm{C} 0, \mathrm{cav}=82 \mathrm{MPa}}$.

$f_{e}=k_{2} \cdot f_{c 0, w}=1,05.91=96 M P a . ; p=1 M P a ; F(k N) ; f\left(k N / c^{2}\right)$.

\begin{tabular}{|c|c|c|c|c|c|c|}
\hline $\mathbf{t}$ & $\boldsymbol{\beta}$ & $\boldsymbol{\beta}_{\lim }$ & $\mathbf{f}_{\mathbf{e}}$ & $\mathbf{F}_{\mathbf{w}, \mathbf{o}}$ & $\mathbf{F}_{\text {cav }, \mathbf{0}}$ & $\mathbf{F}_{\mathbf{m a x} .}$ \\
\hline 2,3 & 1,44 & 1,74 & 9,6 & 15,52 & - & 26 \\
\hline 2,4 & 1,33 & 1,74 & 9,6 & 18,29 & - & 26 \\
\hline 2,45 & 1,22 & 1,74 & 9,6 & 20,78 & - & 30,3 \\
\hline
\end{tabular}


TABELA 87- Comparação dos valores das cargas de primeiro limite com os valores obtidos no ensaio de compressão normal às fibras.

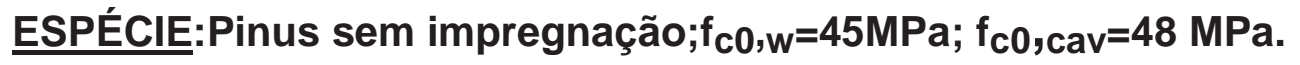

$$
\sigma_{\mathrm{e}, 0}=\mathrm{k}_{1} \cdot \mathrm{f}_{\mathrm{c} 0, \mathrm{w}}=0,80.45=36 \mathrm{MPa} \text {. }
$$

UNIDADE: $F(k N) ; \sigma\left(k N / \mathrm{cm}^{2}\right)$

\begin{tabular}{|c|c|c|c|c|c|c|}
\hline $\mathbf{t}$ & $\boldsymbol{\beta}$ & $\beta_{\lim }$ & $\boldsymbol{\sigma}_{\mathbf{e}, \mathbf{0}}$ & $\mathbf{F}_{\mathbf{w}, \mathbf{0}}$ & $\mathbf{F}_{\text {cav }, \mathbf{0}}$ & $\mathbf{F}_{\text {oexp. }}$ \\
\hline 2,5 & 1,56 & 4,46 & 3,6 & 5,34 & - & 5 \\
\hline 2,37 & 1,39 & 4,46 & 3,6 & 5,38 & - & 10 \\
\hline 2,6 & 1,3 & 4,46 & 3,6 & 6,93 & - & 8 \\
\hline
\end{tabular}

TABELA 88- Comparação dos valores das cargas de primeiro limite com os valores obtidos no ensaio de compressão normal às fibras. ESPÉCIE: Pinus com impregnação; $f_{c 0, w}=61 \mathrm{MPa} ; f_{c 0}$,cav=61 MPa;

$$
\begin{gathered}
\mathrm{p}=1 \mathrm{MPa} . \\
\sigma_{\mathrm{e}, 0=k_{1} . \mathrm{f}_{\mathrm{c} 0, w}=0,80.61=49 \mathrm{MPa} .} \\
\text { UNIDADE: } \mathrm{F}(\mathrm{kN}) ; \sigma\left(\mathrm{kN} / \mathrm{cm}^{2}\right)
\end{gathered}
$$

\begin{tabular}{|c|c|c|c|c|c|c|}
\hline $\mathbf{t}$ & $\boldsymbol{\beta}$ & $\boldsymbol{\beta}_{\lim }$ & $\boldsymbol{\sigma}_{\mathbf{e}, \mathbf{0}}$ & $\mathbf{F}_{\mathbf{W}, \mathbf{0}}$ & $\mathbf{F}_{\text {cav } \mathbf{0}}$ & $\mathbf{F}_{\text {oexp. }}$ \\
\hline 2,4 & 1,5 & 2,18 & 4,9 & 5,27 & - & 9 \\
\hline 2,2 & 1,22 & 2,18 & 4,9 & 5,44 & - & 13 \\
\hline 2,6 & 1,3 & 2,18 & 4,9 & 7,13 & - & 13 \\
\hline
\end{tabular}

TABELA 89- Comparação dos valores das cargas de segundo limite hipótese $A, c o m$ os valores obtidos no ensaio de compressão normal às fibras.

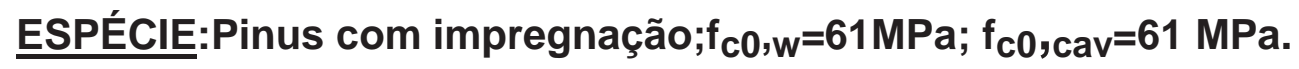

$$
f_{e}=k_{2} \cdot f_{c 0, w}=1,05 \cdot 61=65 M P a . ; p=1 M P a ; F(k N) ; f\left(k N / c^{2}\right) \text {. }
$$

\begin{tabular}{|c|c|c|c|c|c|c|}
\hline $\mathbf{t}$ & $\boldsymbol{\beta}$ & $\boldsymbol{\beta}_{\lim }$ & $\mathbf{f}_{\mathbf{e}}$ & $\mathbf{F}_{\mathbf{W}, \mathbf{0}}$ & $\mathbf{F}_{\text {cav } \mathbf{0}}$ & $\mathbf{F}_{\text {uexp. }}$ \\
\hline 2,4 & 1,5 & 2,42 & 6,5 & 6,99 & - & 11,16 \\
\hline 2,2 & 1,22 & 2,42 & 6,5 & 7,22 & - & 14,86 \\
\hline 2,6 & 1,3 & 2,42 & 6,5 & 9,46 & - & 17,66 \\
\hline
\end{tabular}


TABELA 90- Comparação dos valores das cargas de segundo limite hipótese $B$, com os valores obtidos no ensaio de compressão normal às fibras.

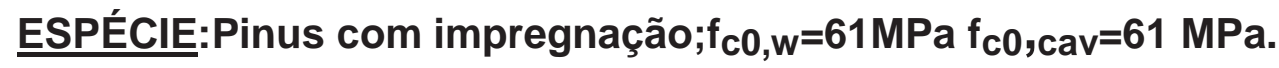

$f_{e}=k_{2} \cdot f_{c 0, w}=1,05.61=65 M P a . ; p=1 \mathrm{MPa} ; F(k N) ; f\left(k N / \mathrm{cm}^{2}\right)$.

\begin{tabular}{|c|c|c|c|c|c|c|}
\hline $\mathbf{t}$ & $\boldsymbol{\beta}$ & $\boldsymbol{\beta}_{\lim }$ & $\mathbf{f}_{\mathbf{e}}$ & $\mathbf{F}_{\mathbf{w}, \mathbf{o}}$ & $\mathbf{F}_{\text {cav } \mathbf{0}}$ & $\mathbf{F}_{\text {max. }}$ \\
\hline 2,4 & 1,5 & 1,91 & 6,5 & 11,48 & - & 14,35 \\
\hline 2,2 & 1,22 & 1,91 & 6,5 & 11,86 & - & 18,6 \\
\hline 2,6 & 1,3 & 1,91 & 6,5 & 15,55 & - & 23,1 \\
\hline
\end{tabular}

TABELA 91- Comparação dos valores das cargas de primeiro limite com os valores obtidos no ensaio de compressão normal às fibras.

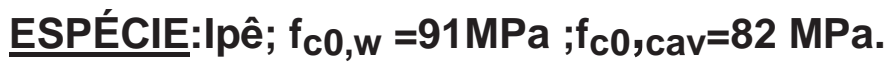

$\sigma_{e, 0}=k_{1} \cdot f_{c 0, w}=0,80.91=73 \mathrm{MPa}$.

UNIDADE: $F(k N) ; \sigma\left(k N / \mathrm{cm}^{2}\right)$

\begin{tabular}{|c|c|c|c|c|c|c|}
\hline $\mathbf{t}$ & $\boldsymbol{\beta}$ & $\boldsymbol{\beta}_{\lim }$ & $\boldsymbol{\sigma}_{\mathbf{e}, \mathbf{0}}$ & $\mathbf{F}_{\mathbf{w}, \mathbf{0}}$ & $\mathbf{F}_{\text {cav } \mathbf{0}}$ & $\mathbf{F}_{\text {oexp. }}$ \\
\hline 2,4 & 1,5 & 1,96 & 7,3 & 7,57 & - & 8 \\
\hline 2,4 & 1,33 & 1,96 & 7,3 & 8,54 & - & 10 \\
\hline 2,45 & 1,22 & 1,96 & 7,3 & 9,70 & - & 13 \\
\hline
\end{tabular}

TABELA 92- Comparação dos valores das cargas de segundo limite hipótese $A, c o m$ os valores obtidos no ensaio de compressão normal às fibras.

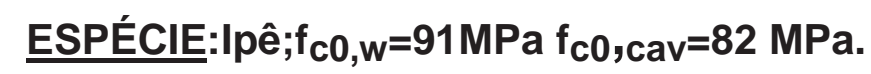

$f_{e}=k_{2} \cdot f_{c 0, w}=1,05.91=96 \mathrm{MPa}$.; $p=1 \mathrm{MPa} ; F(k N) ; f\left(k N / \mathrm{cm}^{2}\right)$.

\begin{tabular}{|c|c|c|c|c|c|c|}
\hline $\mathbf{t}$ & $\boldsymbol{\beta}$ & $\boldsymbol{\beta}_{\text {lim }}$ & $\mathbf{f}_{\mathbf{e}}$ & $\mathbf{F}_{\mathbf{w}, \mathbf{o}}$ & $\mathbf{F}_{\text {cav }, \mathbf{0}}$ & $\mathbf{F}_{\text {uexp. }}$ \\
\hline 2,4 & 1,5 & 2,22 & 9,6 & 9,95 & - & 12,84 \\
\hline 2,4 & 1,33 & 2,22 & 9,6 & 11,23 & - & 16,57 \\
\hline 2,45 & 1,22 & 2,22 & 9,6 & 12,75 & - & 20,41 \\
\hline
\end{tabular}


TABELA 93- Comparação dos valores das cargas de segundo limite hipótese $B, c o m$ os valores obtidos no ensaio de compressão normal às fibras.

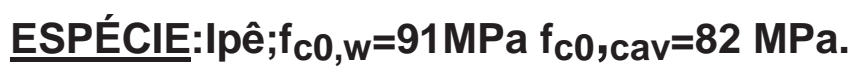

$f_{e}=k_{2} \cdot f_{c 0, w}=1,05.91=96 M P a . ; p=1 M P a ; F(k N) ; f\left(k N / c^{2}\right)$.

\begin{tabular}{|c|c|c|c|c|c|c|}
\hline $\mathbf{t}$ & $\boldsymbol{\beta}$ & $\boldsymbol{\beta}_{\text {lim }}$ & $\mathbf{f}_{\mathbf{e}}$ & $\mathbf{F}_{\mathbf{w}, \mathbf{o}}$ & $\mathbf{F}_{\text {cav }, \mathbf{0}}$ & $\mathbf{F}_{\text {max. }}$ \\
\hline 2,4 & 1,5 & 1,74 & 9,6 & 16,22 & - & 24 \\
\hline 2,4 & 1,33 & 1,74 & 9,6 & 18,29 & - & 21,5 \\
\hline 2,45 & 1,22 & 1,74 & 9,6 & 20,78 & - & 25,6 \\
\hline
\end{tabular}

Neste trabalho como não foi feito ensaio de embutimento de cavilhas, tal como foi idealizado no trabalho de ALMEIDA(1987), para o caso específico das uniões pregadas, para determinação dos valores de $\sigma_{e, 0}$ (primeiro limite) e $f_{e}$ (segundo limite), onde no referido trabalho o autor chegou a conclusão que essas respectivas tensões são funções da resistência à compressão paralela às fibras $\mathbf{f}_{c, 0}$, , sendo dadas por:

$$
\begin{array}{ll}
\mathrm{k} 1=\frac{\sigma_{\mathrm{e}, 0}}{\mathrm{fc}, 0} ; & \sigma_{\mathrm{e}, 0}=\mathrm{k} 1 . \mathrm{fc}_{\mathrm{c}, 0} \\
\mathrm{k} 2=\frac{\mathrm{fe}, 0}{\mathrm{fc}, 0} \quad ; \quad \mathrm{fe}=\mathrm{k} 2 . \mathrm{fc}, 0
\end{array}
$$

Neste trabalho foram adotados para $\mathbf{k}_{\mathbf{1}}$ e $\mathbf{k}_{\mathbf{2}}$ os valores de 0,80 e 1,05; respectivamente, ao se analisar os trabalhos de ALMEIDA (1987) e ALMEIDA (1990), onde o mesmo conclui que para madeiras com baixa resistência à compressão os respectivos coeficientes tendem um valor menor do que unidade. 
Observando a Tabela 77 iremos analisar as seguintes relações: $\mathbf{f}_{\mathbf{c o}} / \mathbf{f}_{\mathbf{c} 90} \mathbf{e}$

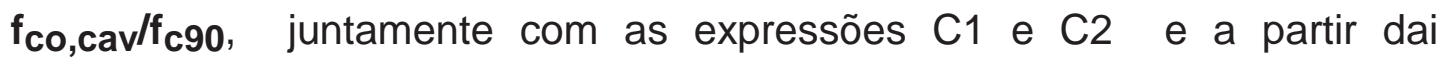
determinar expressões da carga de primeiro limite e segundo limite e analisá-las com os valores que são prescritos no item 7.4.3 da NBR 7190/96 e também comparar os valores calculados com os resultados obtidos nos ensaios experimentais dos modelos de ligações cavilhadas impregnadas e não impregnadas.

a) Seja, $f_{c 0} / f_{c 90}=15$; para madeira de Pinus não impregnada

Nesse caso as expressões C1 e C2 passariam a apresentar o seguinte aspecto:

$$
\begin{aligned}
& \sigma_{\mathrm{e}}, 0=\mathrm{k} 1 . \mathrm{fc} 0=0,80 \cdot 15 \cdot \mathrm{fc} 90=12 \cdot \mathrm{fc} 90 \\
& \mathrm{fe}=\mathrm{k} 2 \cdot \mathrm{fc} 0=1,05 \cdot 15 \cdot \mathrm{fc} 90=15,75 \cdot \mathrm{fc} 90
\end{aligned}
$$

a) Seja, $f_{c 0} / f_{c} 90=3,81$; para madeira de Pinus impregnada.

Nesse caso as expressões C1 e C2 passariam a apresentar o seguinte aspecto:

$$
\begin{aligned}
& \sigma_{\mathrm{e}, 0}=\mathrm{k} 1 . \mathrm{fc} 0=0,80 \cdot 3,81 \cdot \mathrm{fc} 90=3,05 \cdot \mathrm{fc} 90 \\
& \mathrm{fe}=\mathrm{k} 2 . \mathrm{fc} 0=1,05 \cdot 3,81 . \mathrm{fc} 90=4 \cdot \mathrm{fc} 90
\end{aligned}
$$

a) Seja, $f_{\mathrm{co}} / f_{\mathrm{c} 90}=3,79$; para madeira de Ipê.

Nesse caso as expressões C1 e C2 passariam a apresentar o seguinte aspecto:

$$
\begin{aligned}
& \sigma_{\mathrm{e}, 0}=\mathrm{k} 1 . \mathrm{fc} 0=0,80 \cdot 3,79 \cdot \mathrm{fc} 90=3,03 \cdot \mathrm{fc} 90 \\
& \mathrm{fe}=\mathrm{k} 2 \cdot \mathrm{fc} 0=1,05 \cdot 3,79 \cdot \mathrm{fc} 90=3,98 \cdot \mathrm{fc} 90
\end{aligned}
$$


Com os valores anteriores substituindo os mesmos nas expressões das tabelas 8,9 e 10 do capítulo 4 , e lembrando que neste trabalho os modelos experimentais foram executados com ligações cavilhadas em corte duplo e com duas cavilhas por modelo.Com esta consideração as referidas expressões apresentarão novos valores que serão comparadas com os valores prescritos na nova norma de Projeto de estruturas de madeira a NBR 7190/96.

TABELA 94- Expressões para determinação das cargas limites ESPÉCIE: Pinus sem impregnação

\begin{tabular}{|c|c|c|c|c|}
\hline \multicolumn{2}{|c|}{ PRIMEIRO LIMITE } & \multicolumn{2}{|c|}{ SEGUNDO LIMITE } & \multirow{2}{*}{$\begin{array}{c}\text { VALOR } \\
\text { NORMATIVO } \\
\text { NBR } 7190 / 96 \\
\end{array}$} \\
\hline & & HIPÓTESE A & HIPÓTESE B & \\
\hline \multirow[t]{2}{*}{$\beta$} & $\mathrm{t}$ & $\frac{\mathrm{t}}{\mathrm{s}}$ & t & $\mathrm{t}$ \\
\hline & d & d & $\frac{\mathrm{d}}{\mid c \rho}$ & $\frac{\mathrm{d}}{\mathrm{d}}$ \\
\hline Blim & $1,11 . \sqrt{\frac{\mathrm{fc} 0}{\mathrm{fc} 90}}$ & 1,26. $\sqrt{\frac{\mathrm{fc} 0}{\mathrm{fc} 90}}$ & $\sqrt{\frac{\mathrm{fc} 0}{\mathrm{fc} 90}}$ & $\sqrt{\frac{\text { fc0d,cav }}{\text { fc90d,cav }}}$ \\
\hline \multirow{2}{*}{$F_{w}$} & $1,11 . \mathrm{t}^{2}$.fc 90 & 1,46. $\mathrm{t}^{2} . \mathrm{fc} 90$ & $2,32 \cdot \mathrm{t}^{2} \cdot \mathrm{fc} 90$ & $0,4 \cdot \mathrm{t}^{2} \cdot \mathrm{fc} 90 \mathrm{~d}, \mathrm{cav}$ \\
\hline & $\beta$ & $\beta$ & $\beta$ & $\begin{array}{c}\beta_{*} \\
\beta \leq \beta_{\lim }\end{array}$ \\
\hline \multirow{2}{*}{ Fcav } & 1,37.d $\mathrm{d}^{2}$.fol,cav & $231 . d^{2} \cdot f o 0, c a v$ & 2,31.d $\mathrm{d}^{2} \mathrm{fo} 0, \mathrm{cav}$ & $0,4 \cdot \mathrm{d}^{2} \cdot \mathrm{fc} 0 \mathrm{~d}, \mathrm{cav}$ \\
\hline & $\beta$ & $\beta$ & $\beta$ & $\begin{array}{c}\overline{\boldsymbol{\beta} \lim \left(\boldsymbol{\beta}=\boldsymbol{\beta}_{\lim }\right)} \\
\beta>\beta_{\lim }\end{array}$ \\
\hline$\eta$ & $12 . f_{\mathrm{c} 90} / f_{\mathrm{co}, \mathrm{cav}}$ & $15,75 f_{\mathrm{c} 90} / f_{\mathrm{co}, \mathrm{cav}}$ & $12 f_{c 90} / f_{\text {co,cav }}$ & - \\
\hline
\end{tabular}

* Éstes valores correspondem ao valor de cálculo da resistência de uma cavilha, correspondente a uma dada seção de corte, conforme o item 7.4.3 da NBR 7190/96. 
TABELA 95- Expressões para determinação das cargas limites

ESPÉCIE: Pinus com impregnação; $p=1 \mathrm{MPa}$.

\begin{tabular}{|c|c|c|c|c|}
\hline \multirow{2}{*}{\multicolumn{2}{|c|}{ PRIMEIRO LIMITE }} & \multicolumn{2}{|c|}{ SEGUNDO LIMITE } & $\begin{array}{c}\text { VALOR } \\
\text { NORMATIVO }\end{array}$ \\
\hline & & HIPÓTESE A & HIPÓTESE B & NBR 7190/96 \\
\hline$\beta$ & $\frac{t}{d}$ & $\frac{t}{d}$ & $\frac{t}{d}$ & $\frac{\mathrm{t}}{\mathrm{d}}$ \\
\hline Blim & $1,12 \cdot \sqrt{\frac{\mathrm{fc} 0}{\mathrm{fc} 90}}$ & $1,25 . \sqrt{\frac{\mathrm{fc} 0}{\mathrm{fc} 90}}$ & $1,01 \cdot \sqrt{\frac{\mathrm{fc} 0}{\mathrm{fc} 90}}$ & $\sqrt{\frac{\text { fc0d,cav }}{\text { fc90d,cav }}}$ \\
\hline$F_{w}$ & $\frac{0,21 \cdot \mathrm{t}^{2} \cdot \mathrm{fc} 90}{\boldsymbol{\beta}}$ & $\frac{0,28 \cdot \mathrm{t}^{2} \cdot \mathrm{fc} 90}{\beta}$ & $\frac{0,46 \cdot \mathrm{t}^{2} \cdot \mathrm{fc} 90}{\boldsymbol{\beta}}$ & $\begin{array}{c}\frac{0,4 \cdot \mathrm{t}^{2} \cdot \mathrm{fc} 90 \mathrm{~d}, \mathrm{cav}}{\beta} \\
\beta \\
\beta \leq \beta_{\lim }\end{array}$ \\
\hline Fcav & $\frac{0,27 \cdot \mathrm{d}^{2} \cdot \mathrm{fo} 0, \mathrm{cav}}{\beta}$ & $\frac{0,44 \cdot \mathrm{d}^{2} \cdot \mathrm{fo} 0, \mathrm{cav}}{\beta}$ & $\frac{0,44 \cdot \mathrm{d}^{2} \cdot \mathrm{fo} 0, \mathrm{cav}}{\beta}$ & $\begin{array}{c}\frac{0,4 \cdot d^{2} . \mathrm{fc} 0 \mathrm{~d}, \mathrm{cav}}{\boldsymbol{\beta}_{\lim }\left(\boldsymbol{\beta}=\boldsymbol{\beta}_{\text {lim }}\right)} \\
\beta>\beta_{\lim }\end{array}$ \\
\hline$\eta$ & $3,05 . f_{c 90} / f_{c o, c a v}$ & $4 . f_{\mathrm{c} 90} / f_{\mathrm{co}, \mathrm{cav}}$ & $4 . f_{c 90} / f_{c o, c a v}$ & \\
\hline
\end{tabular}

* Êstes valores correspondem ao valor de cálculo da resistência de uma cavilha, correspondente a uma dada seção de corte, conforme o item 7.4.3 da NBR 7190/96.

Aqui da mesma forma iremos calcular os valores teóricos das cargas de primeiro e segundo limite compara-las com os valores obtidos nos ensaios experimentais das ligações cavilhadas e também com a nova norma de Projeto de Estruturas de Madeira a NBR 7190/96, cujos resultados poderão serem vistos nas Tabelas 103 a 114. 
TABELA 96- Expressões para determinação das cargas limites

ESPÉCIE: Ipê

\begin{tabular}{|c|c|c|c|c|}
\hline \multirow{2}{*}{\multicolumn{2}{|c|}{ PRIMEIRO LIMITE }} & \multicolumn{2}{|c|}{ SEGUNDO LIMITE } & \multirow{2}{*}{$\begin{array}{c}\text { VALOR } \\
\text { NORMATIVO } \\
\text { NBR } 7190 / 96 \\
\end{array}$} \\
\hline & & HIPÓTESE A & HIPÓTESE B & \\
\hline$\beta$ & $\mathrm{t}$ & t & $\frac{\mathrm{t}}{\mathrm{t}}$ & $\frac{\mathrm{t}}{-}$ \\
\hline & $\overline{\mathrm{d}}$ & $\overline{\mathrm{d}}$ & $\mathrm{d}$ & $\overline{\mathrm{d}}$ \\
\hline Blim & $1,06 . \sqrt{\frac{\mathrm{fc} 0}{\mathrm{fc} 90}}$ & $1,20 \cdot \sqrt{\frac{\mathrm{fc} 0}{\mathrm{fc} 90}}$ & $0,94 \cdot \sqrt{\frac{f c 0}{f c 90}}$ & $\sqrt{\frac{\text { fc0d,cav }}{\text { fc90d,cav }}}$ \\
\hline $\mathrm{F}_{\mathrm{w}}$ & $\frac{0,20 \cdot \mathrm{t}^{2} \cdot \mathrm{fc} 90}{\boldsymbol{\beta}}$ & $\frac{0,27 \cdot \mathrm{t}^{2} \cdot \mathrm{fc} 90}{\boldsymbol{\beta}}$ & $\frac{0,44 \cdot \mathrm{t}^{2} \cdot \mathrm{fc} 90}{\boldsymbol{\beta}}$ & $\begin{array}{c}\frac{0,4 \cdot \mathrm{t}^{2} \cdot \mathrm{fc} 90 \mathrm{~d}, \mathrm{cav}}{\beta} \\
\beta \leq \beta_{\lim }\end{array}$ \\
\hline Fcav & $\frac{0,23 \mathrm{~d}^{2} \cdot \mathrm{fo} 0, \mathrm{cav}}{\beta}$ & $\frac{0,40 \cdot \mathrm{d}^{2} \cdot \mathrm{fo} 0, \mathrm{cav}}{\beta}$ & $\frac{0,40 \cdot \mathrm{d}^{2} \cdot \mathrm{fo} 0, \mathrm{cav}}{\beta}$ & $\begin{array}{c}\frac{0,4 \cdot d^{2} . \mathrm{fc} 0 \mathrm{~d}, \mathrm{cav}}{\boldsymbol{\beta} \lim \left(\boldsymbol{\beta}=\boldsymbol{\beta}_{\lim }\right)} \\
\beta>\beta_{\lim }\end{array}$ \\
\hline$\eta$ & $3,03 . f_{c 90} / f_{c o, c a v}$ & $3,98 . f_{c 90} / f_{c o, c a v}$ & $3,98 . f_{c 90} / f_{c o, c a v}$ & - \\
\hline
\end{tabular}

* Êstes valores correspondem ao valor de cálculo da resistência de uma cavilha, correspondente a uma dada seção de corte, conforme o item 7.4.3 da NBR 7190/96.

Nas próximas páginas, poderemos observar nas tabelas 97 a 102, uma espécie de simulação matemática, para permitir a determinação dos valores da excentricidade e e também o valor de $\mathbf{c}$, que entram no cálculo das expressões das cargas de primeiro e segundo limite das ligações cavilhadas e também esses valores destas cargas são calculados utilizando os valores das expressões que foram desenvolvidas nas tabelas 94,95e 96. Igualmente do ponto de vista matemático poderão ser vistos em formas de gráficos, os comportamentos das funções: $\xi=f(\beta), F_{\mathbf{w}}=f(\beta)$ e $F_{\text {cav }}=f(\beta)$, para as respectivas cargas de primeiro e segundo limite. 
TABELA 97-Simulação matemática para determinação do valor da excentricidade e para carga de primeiro limite das ligações cavilhadas, d=16mm; Espécie de Madeira: Pinus sem impregnação

\begin{tabular}{|c|c|c|c|c|c|c|c|c|c|c|c|}
\hline$t(\mathrm{~cm})$ & $\mathrm{d}(\mathrm{cm})$ & $\beta_{\mathrm{ef}}=\mathrm{t} / \mathrm{d}$ & $\mathrm{e}(\mathrm{cm})$ & $\begin{array}{c}\sigma_{\mathrm{e}, \mathrm{o}} \\
\mathrm{kN} / \mathrm{cm} \\
2\end{array}$ & $\mathrm{~F}_{\mathrm{w}}(\mathrm{kN})$ & $\mathrm{c}(\mathrm{cm})$ & $\begin{array}{l}\mathbf{f}_{\mathrm{c}, 0(\mathrm{cav})} \\
\mathrm{kN} / \mathrm{cm}^{2}\end{array}$ & $\mathrm{~F}_{\mathrm{s}}(\mathbf{k N})$ & $\sigma_{e, 0} / f_{y=} \eta_{o}$ & $\beta^{2}$ & $\beta$ \\
\hline 2,5 & 1,6 & 1,5625 & 0,42 & 3,6 & 7,20 & 0,00 & 4,8 & $9,1 \mathrm{E}+12$ & 0,75 & $\begin{array}{c}3,07 \mathrm{E} \\
+12 \\
\end{array}$ & 1751737 \\
\hline 2,5 & 1,6 & 1,5625 & 0,49 & 3,6 & 6,64 & 0,18 & 4,8 & 1334,54 & 0,75 & $\begin{array}{c}490,3 \\
9\end{array}$ & 22,14 \\
\hline 2,5 & 1,6 & 1,5625 & 0,56 & 3,6 & 6,16 & 0,31 & 4,8 & 218,37 & 0,75 & 86,46 & 9,30 \\
\hline 2,5 & 1,6 & 1,5625 & 0,63 & 3,6 & 5,75 & 0,42 & 4,8 & 82,00 & 0,75 & 34,80 & 5,90 \\
\hline 2,5 & 1,6 & 1,5625 & 0,70 & 3,6 & 5,39 & 0,50 & 4,8 & 42,76 & 0,75 & 19,36 & 4,40 \\
\hline 2,5 & 1,6 & 1,5625 & 0,77 & 3,6 & 5,07 & 0,57 & 4,8 & 26,51 & 0,75 & 12,76 & 3,57 \\
\hline 2,5 & 1,6 & 1,5625 & 0,84 & 3,6 & 4,79 & 0,63 & 4,8 & 18,27 & 0,75 & 9,31 & 3,05 \\
\hline 2,5 & 1,6 & 1,5625 & 0,91 & 3,6 & 4,54 & 0,68 & 4,8 & 13,51 & 0,75 & 7,27 & 2,70 \\
\hline 2,5 & 1,6 & 1,5625 & 0,98 & 3,6 & 4,31 & 0,72 & 4,8 & 10,50 & 0,75 & 5,95 & 2,44 \\
\hline 2,5 & 1,6 & 1,5625 & 1,05 & 3,6 & 4,10 & 0,75 & 4,8 & 8,47 & 0,75 & 5,04 & 2,25 \\
\hline 2,5 & 1,6 & 1,5625 & 1,12 & 3,6 & 3,91 & 0,78 & 4,8 & 7,03 & 0,75 & 4,38 & 2,09 \\
\hline 2,5 & 1,6 & 1,5625 & 1,19 & 3,6 & 3,74 & 0,81 & 4,8 & 5,96 & 0,75 & 3,89 & 1,97 \\
\hline 2,5 & 1,6 & 1,5625 & 1,26 & 3,6 & 3,59 & 0,84 & 4,8 & 5,15 & 0,75 & 3,51 & 1,87 \\
\hline
\end{tabular}

TABELA 98-Simulação matemática para determinação do valor da excentricidade e para carga de segundo limite das ligações cavilhadas, d=16mm; Espécie de Madeira: Pinus sem impregnação

\begin{tabular}{|c|c|c|c|c|c|c|c|c|c|c|c|}
\hline$t(\mathrm{~cm})$ & $\mathrm{d}(\mathrm{cm})$ & $\beta_{\mathrm{ef}}=\mathrm{t} / \mathrm{d}$ & $\mathrm{e}(\mathrm{cm})$ & $\begin{array}{c}\mathrm{f}_{\mathrm{e}} \\
\mathrm{kN} / \mathrm{cm} \\
2\end{array}$ & $\mathrm{~F}_{\mathrm{w}}(\mathrm{kN})$ & $\mathrm{c}(\mathrm{cm})$ & $\begin{array}{l}f_{c, 0 \text { (cav) }} \\
\mathbf{k N} / \mathbf{c m}^{2}\end{array}$ & $\mathrm{~F}_{\mathrm{s}}(\mathrm{kN})$ & $\sigma_{e, 0} / f_{y=} \eta_{o}$ & $\beta^{2}$ & $\beta$ \\
\hline 2,5 & 1,6 & 1,5625 & 0,42 & 4,7 & 9,40 & 0,00 & 4,8 & $9,1 \mathrm{E}+12$ & 0,98 & $\begin{array}{c}2,35 \mathrm{E} \\
+12\end{array}$ & 1533103 \\
\hline 2,5 & 1,6 & 1,5625 & 0,49 & 4,7 & 8,67 & 0,18 & 4,8 & 1334,54 & 0,98 & $\begin{array}{c}375,6 \\
2\end{array}$ & 19,38 \\
\hline 2,5 & 1,6 & 1,5625 & 0,56 & 4,7 & 8,05 & 0,31 & 4,8 & 218,37 & 0,98 & 66,22 & 8,14 \\
\hline 2,5 & 1,6 & 1,5625 & 0,63 & 4,7 & 7,51 & 0,42 & 4,8 & 82,00 & 0,98 & 26,66 & 5,16 \\
\hline 2,5 & 1,6 & 1,5625 & 0,70 & 4,7 & 7,04 & 0,50 & 4,8 & 42,76 & 0,98 & 14,83 & 3,85 \\
\hline 2,5 & 1,6 & 1,5625 & 0,77 & 4,7 & 6,62 & 0,57 & 4,8 & 26,51 & 0,98 & 9,77 & 3,13 \\
\hline 2,5 & 1,6 & 1,5625 & 0,84 & 4,7 & 6,25 & 0,63 & 4,8 & 18,27 & 0,98 & 7,13 & 2,67 \\
\hline 2,5 & 1,6 & 1,5625 & 0,91 & 4,7 & 5,92 & 0,68 & 4,8 & 13,51 & 0,98 & 5,57 & 2,36 \\
\hline 2,5 & 1,6 & 1,5625 & 0,98 & 4,7 & 5,62 & 0,72 & 4,8 & 10,50 & 0,98 & 4,56 & 2,13 \\
\hline 2,5 & 1,6 & 1,5625 & 1,05 & 4,7 & 5,35 & 0,75 & 4,8 & 8,47 & 0,98 & 3,86 & 1,96 \\
\hline 2,5 & 1,6 & 1,5625 & 1,12 & 4,7 & 5,11 & 0,78 & 4,8 & 7,03 & 0,98 & 3,36 & 1,83 \\
\hline 2,5 & 1,6 & 1,5625 & 1,19 & 4,7 & 4,89 & 0,81 & 4,8 & 5,96 & 0,98 & 2,98 & 1,73 \\
\hline 2,5 & 1,6 & 1,5625 & 1,26 & 4,7 & 4,68 & 0,84 & 4,8 & 5,15 & 0,98 & 2,68 & 1,64 \\
\hline
\end{tabular}


TABELA 99-Simulação matemática para determinação do valor da excentricidade e para carga de primeiro limite das ligações cavilhadas, $\mathrm{d}=16 \mathrm{~mm}$; Espécie de Madeira: Pinus com impregnação

\begin{tabular}{|c|c|c|c|c|c|c|c|c|c|c|c|}
\hline $\mathbf{t}(\mathbf{c m})$ & $\mathbf{d}(\mathbf{c m})$ & $\boldsymbol{\beta}_{\mathrm{ef}}=\mathbf{t} / \mathbf{d}$ & $\mathbf{e}(\mathbf{c m})$ & $\begin{array}{c}\sigma_{\mathrm{e}, 0} \\
\mathrm{kN} / \mathbf{c m} \\
2\end{array}$ & $\mathbf{F}_{\mathbf{w}}(\mathbf{k N})$ & $\mathbf{c}(\mathbf{c m})$ & $\begin{array}{l}\mathbf{f}_{\mathrm{c}, 0(\mathbf{c a v})} \\
\mathbf{k N} / \mathbf{c m}^{2}\end{array}$ & $\mathbf{F}_{\mathbf{s}}(\mathbf{k N})$ & $\boldsymbol{\sigma}_{\mathrm{e}, 0} / \mathbf{f}_{\mathbf{y}=\mathbf{\eta}} \boldsymbol{\eta}_{\mathbf{o}}$ & $\boldsymbol{\beta}^{2}$ & $\boldsymbol{\beta}$ \\
\hline 2,5 & 1,6 & 1,5625 & 0,42 & 4,9 & 9,80 & 0,00 & 6,1 & $1,2 \mathrm{E}+13$ & 0,80 & $\begin{array}{c}2,87 \mathrm{E} \\
+12\end{array}$ & 1692647 \\
\hline 2,5 & 1,6 & 1,5625 & 0,49 & 4,9 & 9,04 & 0,18 & 6,1 & 1695,97 & 0,80 & $\begin{array}{c}457,8 \\
7\end{array}$ & 21,40 \\
\hline 2,5 & 1,6 & 1,5625 & 0,56 & 4,9 & 8,39 & 0,31 & 6,1 & 277,51 & 0,80 & 80,72 & 8,98 \\
\hline 2,5 & 1,6 & 1,5625 & 0,63 & 4,9 & 7,83 & 0,42 & 6,1 & 104,21 & 0,80 & 32,49 & 5,70 \\
\hline 2,5 & 1,6 & 1,5625 & 0,70 & 4,9 & 7,34 & 0,50 & 6,1 & 54,34 & 0,80 & 18,08 & 4,25 \\
\hline 2,5 & 1,6 & 1,5625 & 0,77 & 4,9 & 6,90 & 0,57 & 6,1 & 33,69 & 0,80 & 11,91 & 3,45 \\
\hline 2,5 & 1,6 & 1,5625 & 0,84 & 4,9 & 6,52 & 0,63 & 6,1 & 23,22 & 0,80 & 8,70 & 2,95 \\
\hline 2,5 & 1,6 & 1,5625 & 0,91 & 4,9 & 6,17 & 0,68 & 6,1 & 17,17 & 0,80 & 6,79 & 2,61 \\
\hline 2,5 & 1,6 & 1,5625 & 0,98 & 4,9 & 5,86 & 0,72 & 6,1 & 13,35 & 0,80 & 5,56 & 2,36 \\
\hline 2,5 & 1,6 & 1,5625 & 1,05 & 4,9 & 5,58 & 0,75 & 6,1 & 10,77 & 0,80 & 4,71 & 2,17 \\
\hline 2,5 & 1,6 & 1,5625 & 1,12 & 4,9 & 5,33 & 0,78 & 6,1 & 8,93 & 0,80 & 4,09 & 2,02 \\
\hline 2,5 & 1,6 & 1,5625 & 1,19 & 4,9 & 5,10 & 0,81 & 6,1 & 7,58 & 0,80 & 3,63 & 1,91 \\
\hline 2,5 & 1,6 & 1,5625 & 1,26 & 4,9 & 4,88 & 0,84 & 6,1 & 6,55 & 0,80 & 3,27 & 1,81 \\
\hline
\end{tabular}

TABELA100-Simulação matemática para determinação do valor da excentricidade e para carga de segundo limite das ligações cavilhadas, $\mathrm{d}=16 \mathrm{~mm}$; Espécie de Madeira: Pinus com impregnação

\begin{tabular}{|c|c|c|c|c|c|c|c|c|c|c|c|}
\hline$t(\mathrm{~cm})$ & $\mathrm{d}(\mathrm{cm})$ & $\beta_{\mathrm{ef}}=\mathrm{t} / \mathrm{d}$ & $\mathrm{e}(\mathrm{cm})$ & $\begin{array}{c}\mathrm{f}_{\mathrm{e}} \\
\mathrm{kN} / \mathrm{cm} \\
2\end{array}$ & $\mathrm{~F}_{\mathrm{w}}(\mathrm{kN})$ & $\mathrm{c}(\mathrm{cm})$ & $\begin{array}{l}\mathbf{f}_{\mathrm{c}, 0 \text { (cav) }} \\
\mathbf{k N} / \mathbf{c m}^{2}\end{array}$ & $F_{s}(k N)$ & $\sigma_{e, 0} / f_{y=} \eta_{o}$ & $\beta^{2}$ & $\beta$ \\
\hline 2,5 & 1,6 & 1,5625 & 0,42 & 6,5 & 13,00 & 0,00 & 6,1 & $1,2 \mathrm{E}+13$ & 1,07 & $\begin{array}{c}2,16 \mathrm{E} \\
+12\end{array}$ & 1469629 \\
\hline 2,5 & 1,6 & 1,5625 & 0,49 & 6,5 & 11,99 & 0,18 & 6,1 & 1695,97 & 1,07 & $\begin{array}{c}345,1 \\
6\end{array}$ & 18,58 \\
\hline 2,5 & 1,6 & 1,5625 & 0,56 & 6,5 & 11,13 & 0,31 & 6,1 & 277,51 & 1,07 & 60,85 & 7,80 \\
\hline 2,5 & 1,6 & 1,5625 & 0,63 & 6,5 & 10,38 & 0,42 & 6,1 & 104,21 & 1,07 & 24,49 & 4,95 \\
\hline 2,5 & 1,6 & 1,5625 & 0,70 & 6,5 & 9,73 & 0,50 & 6,1 & 54,34 & 1,07 & 13,63 & 3,69 \\
\hline 2,5 & 1,6 & 1,5625 & 0,77 & 6,5 & 9,16 & 0,57 & 6,1 & 33,69 & 1,07 & 8,98 & 3,00 \\
\hline 2,5 & 1,6 & 1,5625 & 0,84 & 6,5 & 8,65 & 0,63 & 6,1 & 23,22 & 1,07 & 6,55 & 2,56 \\
\hline 2,5 & 1,6 & 1,5625 & 0,91 & 6,5 & 8,19 & 0,68 & 6,1 & 17,17 & 1,07 & 5,12 & 2,26 \\
\hline 2,5 & 1,6 & 1,5625 & 0,98 & 6,5 & 7,78 & 0,72 & 6,1 & 13,35 & 1,07 & 4,19 & 2,05 \\
\hline 2,5 & 1,6 & 1,5625 & 1,05 & 6,5 & 7,41 & 0,75 & 6,1 & 10,77 & 1,07 & 3,55 & 1,88 \\
\hline 2,5 & 1,6 & 1,5625 & 1,12 & 6,5 & 7,07 & 0,78 & 6,1 & 8,93 & 1,07 & 3,08 & 1,76 \\
\hline 2,5 & 1,6 & 1,5625 & 1,19 & 6,5 & 6,76 & 0,81 & 6,1 & 7,58 & 1,07 & 2,74 & 1,65 \\
\hline 2,5 & 1,6 & 1,5625 & 1,26 & 6,5 & 6,48 & 0,84 & 6,1 & 6,55 & 1,07 & 2,47 & 1,57 \\
\hline
\end{tabular}


TABELA 101-Simulação matemática para determinação do valor da excentricidade e para carga de primeiro limite das ligações cavilhadas,

d=16mm; Espécie de Madeira: Ipê

\begin{tabular}{|c|c|c|c|c|c|c|c|c|c|c|c|}
\hline $\mathbf{t}(\mathbf{c m})$ & $\mathbf{d}(\mathbf{c m})$ & $\boldsymbol{\beta}_{\mathrm{ef}}=\mathbf{t} / \mathbf{d}$ & $\mathbf{e}(\mathbf{c m})$ & $\begin{array}{c}\sigma_{\mathrm{e}, \mathrm{o}} \\
\mathbf{k N / c m}\end{array}$ & $\mathbf{F}_{\mathbf{w}}(\mathbf{k N})$ & $\mathbf{c}(\mathbf{c m})$ & $\begin{array}{c}\mathbf{f}_{\mathbf{c}, 0(\mathbf{c a v})} \\
\mathbf{k N} / \mathbf{c m}^{2}\end{array}$ & $\mathbf{F}_{\mathbf{s}}(\mathbf{k N})$ & $\boldsymbol{\sigma}_{\mathrm{e}, 0} / \mathbf{f}_{\mathbf{y}}=\eta_{\mathbf{o}}$ & $\boldsymbol{\beta}^{2}$ & $\boldsymbol{\beta}$ \\
\hline 2,5 & 1,6 & 1,5625 & 0,42 & 7,3 & 14,60 & 0,00 & 8,2 & $1,5 \mathrm{E}+13$ & 0,89 & $\begin{array}{c}2,59 \mathrm{E} \\
+12\end{array}$ & 1607848 \\
\hline 2,5 & 1,6 & 1,5625 & 0,49 & 7,3 & 13,47 & 0,18 & 8,2 & 2279,83 & 0,89 & $\begin{array}{c}413,1 \\
4\end{array}$ & 20,33 \\
\hline 2,5 & 1,6 & 1,5625 & 0,56 & 7,3 & 12,50 & 0,31 & 8,2 & 373,05 & 0,89 & 72,84 & 8,53 \\
\hline 2,5 & 1,6 & 1,5625 & 0,63 & 7,3 & 11,66 & 0,42 & 8,2 & 140,09 & 0,89 & 29,32 & 5,41 \\
\hline 2,5 & 1,6 & 1,5625 & 0,70 & 7,3 & 10,93 & 0,50 & 8,2 & 73,04 & 0,89 & 16,31 & 4,04 \\
\hline 2,5 & 1,6 & 1,5625 & 0,77 & 7,3 & 10,28 & 0,57 & 8,2 & 45,29 & 0,89 & 10,75 & 3,28 \\
\hline 2,5 & 1,6 & 1,5625 & 0,84 & 7,3 & 9,71 & 0,63 & 8,2 & 31,21 & 0,89 & 7,85 & 2,80 \\
\hline 2,5 & 1,6 & 1,5625 & 0,91 & 7,3 & 9,20 & 0,68 & 8,2 & 23,08 & 0,89 & 6,13 & 2,48 \\
\hline 2,5 & 1,6 & 1,5625 & 0,98 & 7,3 & 8,73 & 0,72 & 8,2 & 17,94 & 0,89 & 5,01 & 2,24 \\
\hline 2,5 & 1,6 & 1,5625 & 1,05 & 7,3 & 8,32 & 0,75 & 8,2 & 14,47 & 0,89 & 4,25 & 2,06 \\
\hline 2,5 & 1,6 & 1,5625 & 1,12 & 7,3 & 7,94 & 0,78 & 8,2 & 12,01 & 0,89 & 3,69 & 1,92 \\
\hline 2,5 & 1,6 & 1,5625 & 1,19 & 7,3 & 7,59 & 0,81 & 8,2 & 10,19 & 0,89 & 3,28 & 1,81 \\
\hline 2,5 & 1,6 & 1,5625 & 1,26 & 7,3 & 7,27 & 0,84 & 8,2 & 8,80 & 0,89 & 2,95 & 1,72 \\
\hline
\end{tabular}

TABELA 102-Simulação matemática para determinação do valor da excentricidade e para carga de segundo limite das ligações cavilhadas, $\mathrm{d}=16 \mathrm{~mm}$; Espécie de Madeira: Ipê

\begin{tabular}{|c|c|c|c|c|c|c|c|c|c|c|c|}
\hline $\mathbf{t}(\mathbf{c m})$ & $\mathbf{d}(\mathbf{c m})$ & $\boldsymbol{\beta}_{\mathrm{ef}}=\mathbf{t} / \mathbf{d}$ & $\mathbf{e}(\mathbf{c m})$ & $\begin{array}{c}\mathrm{f}_{\mathrm{e}} \\
\mathrm{kN} / \mathbf{c m} \\
2\end{array}$ & $\mathbf{F}_{\mathbf{w}}(\mathbf{k N})$ & $\mathbf{c}(\mathbf{c m})$ & $\begin{array}{c}\mathbf{f}_{\mathrm{c}, 0(\mathbf{c a v})} \\
\mathbf{k N} / \mathbf{c m}^{2}\end{array}$ & $\mathbf{F}_{\mathbf{s}}(\mathbf{k N})$ & $\boldsymbol{\sigma}_{\mathrm{e}, 0} / \mathbf{f}_{\mathbf{y}=} \boldsymbol{\eta}_{\mathbf{o}}$ & $\boldsymbol{\beta}^{2}$ & $\boldsymbol{\beta}$ \\
\hline 2,5 & 1,6 & 1,5625 & 0,42 & 9,6 & 19,20 & 0,00 & 8,2 & $1,5 \mathrm{E}+13$ & 1,17 & $\begin{array}{c}1,97 \mathrm{E} \\
+12\end{array}$ & 1402074 \\
\hline 2,5 & 1,6 & 1,5625 & 0,49 & 9,6 & 17,71 & 0,18 & 8,2 & 2279,83 & 1,17 & $\begin{array}{c}314,1 \\
6\end{array}$ & 17,72 \\
\hline 2,5 & 1,6 & 1,5625 & 0,56 & 9,6 & 16,44 & 0,31 & 8,2 & 373,05 & 1,17 & 55,39 & 7,44 \\
\hline 2,5 & 1,6 & 1,5625 & 0,63 & 9,6 & 15,34 & 0,42 & 8,2 & 140,09 & 1,17 & 22,29 & 4,72 \\
\hline 2,5 & 1,6 & 1,5625 & 0,70 & 9,6 & 14,37 & 0,50 & 8,2 & 73,04 & 1,17 & 12,40 & 3,52 \\
\hline 2,5 & 1,6 & 1,5625 & 0,77 & 9,6 & 13,52 & 0,57 & 8,2 & 45,29 & 1,17 & 8,17 & 2,86 \\
\hline 2,5 & 1,6 & 1,5625 & 0,84 & 9,6 & 12,77 & 0,63 & 8,2 & 31,21 & 1,17 & 5,97 & 2,44 \\
\hline 2,5 & 1,6 & 1,5625 & 0,91 & 9,6 & 12,09 & 0,68 & 8,2 & 23,08 & 1,17 & 4,66 & 2,16 \\
\hline 2,5 & 1,6 & 1,5625 & 0,98 & 9,6 & 11,49 & 0,72 & 8,2 & 17,94 & 1,17 & 3,81 & 1,95 \\
\hline 2,5 & 1,6 & 1,5625 & 1,05 & 9,6 & 10,94 & 0,75 & 8,2 & 14,47 & 1,17 & 3,23 & 1,80 \\
\hline 2,5 & 1,6 & 1,5625 & 1,12 & 9,6 & 10,44 & 0,78 & 8,2 & 12,01 & 1,17 & 2,81 & 1,68 \\
\hline 2,5 & 1,6 & 1,5625 & 1,19 & 9,6 & 9,98 & 0,81 & 8,2 & 10,19 & 1,17 & 2,49 & 1,58 \\
\hline 2,5 & 1,6 & 1,5625 & 1,26 & 9,6 & 9,57 & 0,84 & 8,2 & 8,80 & 1,17 & 2,25 & 1,50 \\
\hline
\end{tabular}




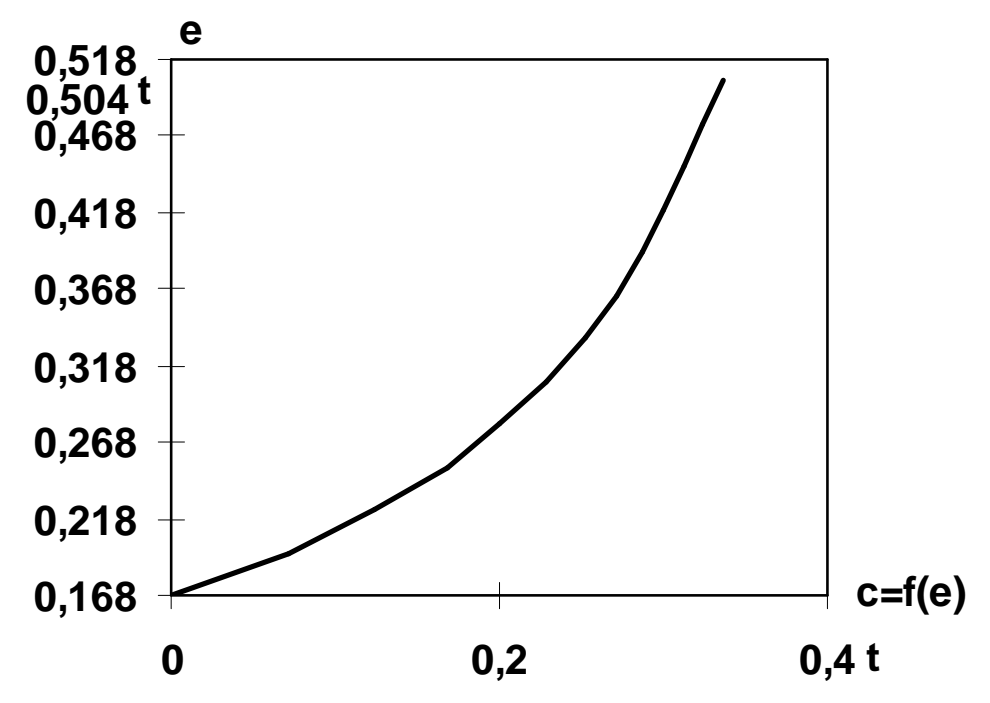

FIGURA 118 - Valores de c em função da excentricidade e no intervalo $\mathrm{t} / 6 \leq \mathrm{e} \leq \mathrm{t} / 2$

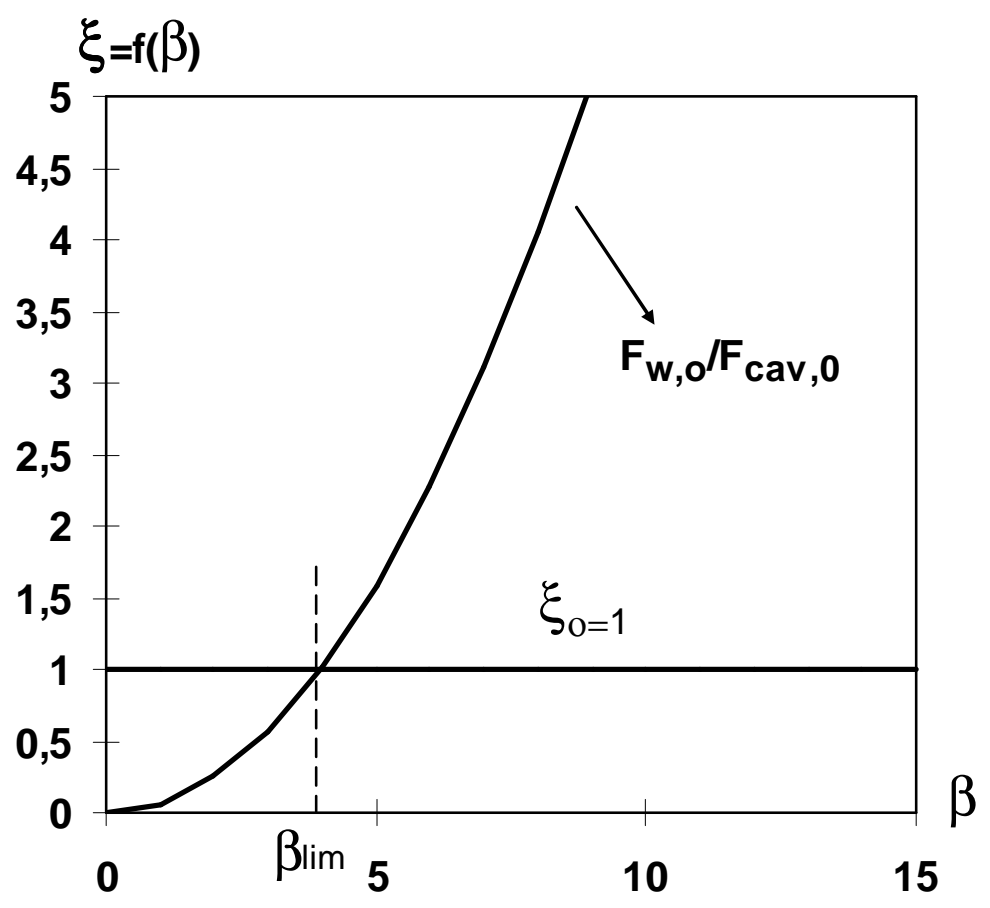

FIGURA 119 - Diagrama $\xi_{0} \times \beta$ e valor de $\beta_{\text {lim }} \eta_{0}=0,75$ para Pinus sem impregnação 


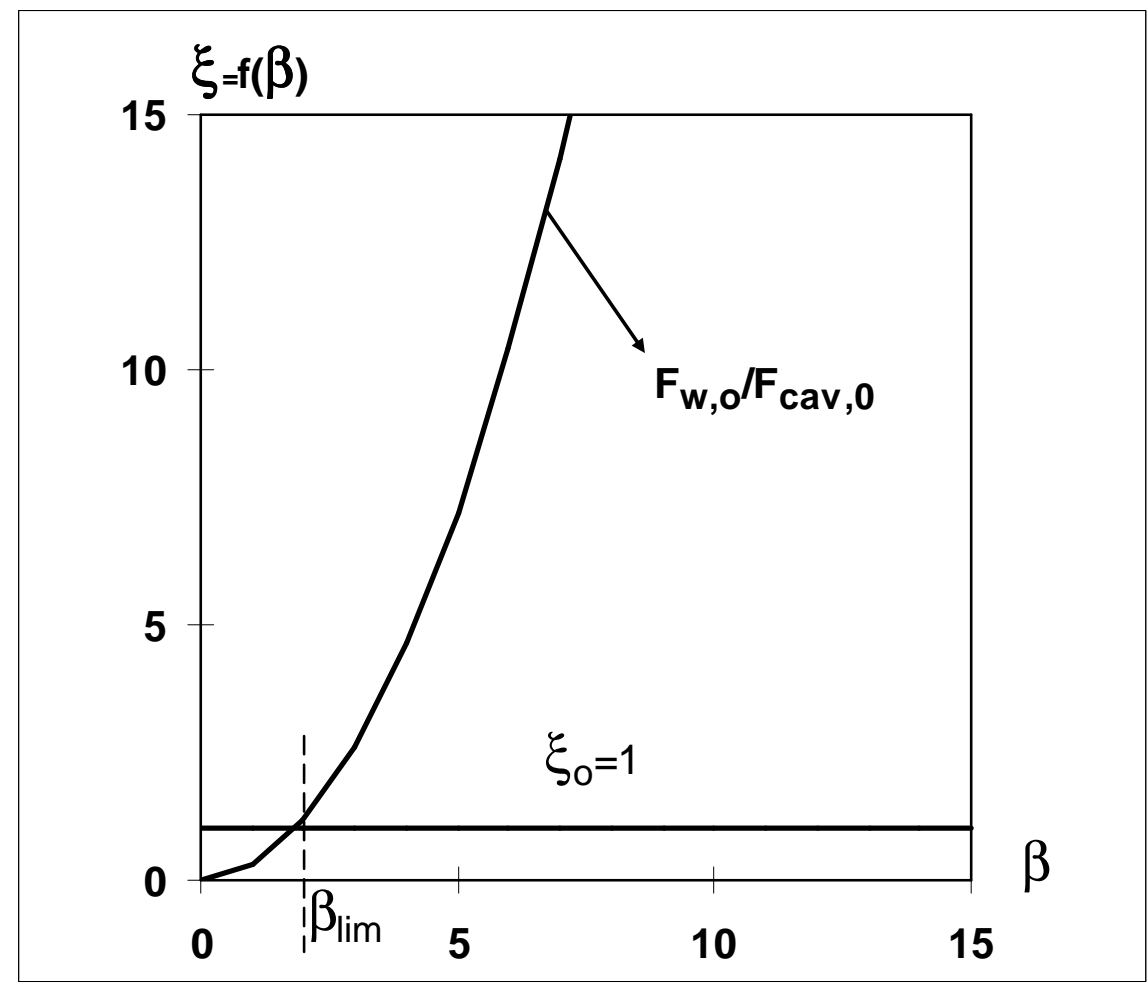

FIGURA 120 - Diagrama $\xi_{0} \times \beta$ e valor de $\beta_{\lim } \eta_{0}=0,80$ para Pinus com impregnação.

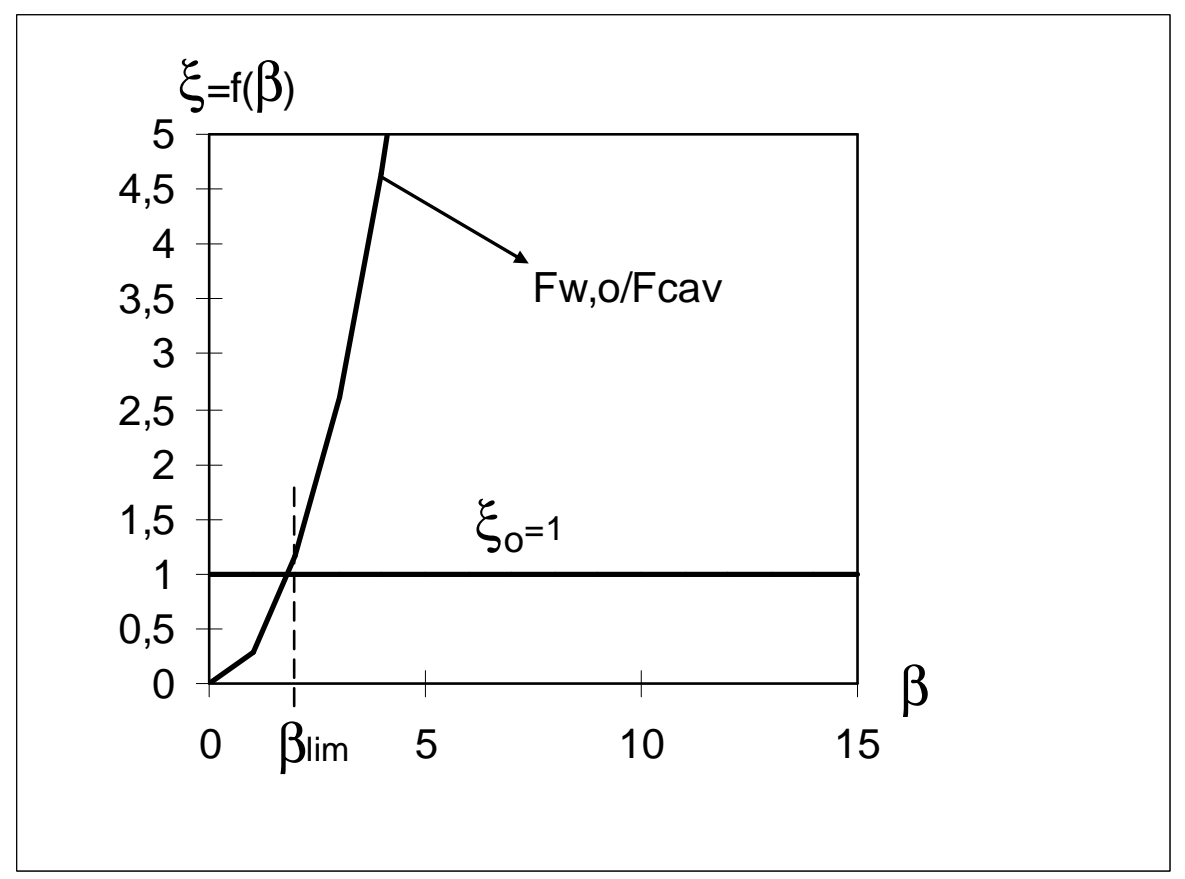

FIGURA 121 - Diagrama $\xi_{0} \times \beta$ e valor de $\beta_{\lim } \eta_{0}=0,89$ para o Ipê. 
Fw,o (kN)

Fcav

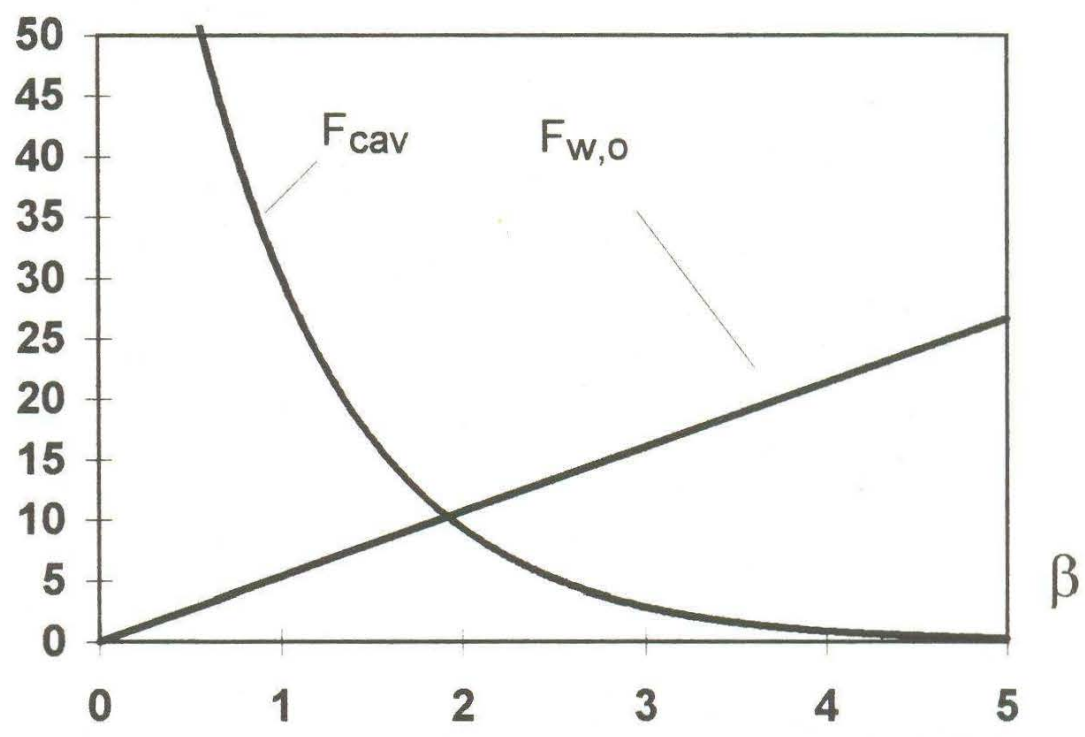

FIGURA 122-Cálculo da carga de primeiro limite da ligação Pinus sem impregnação.

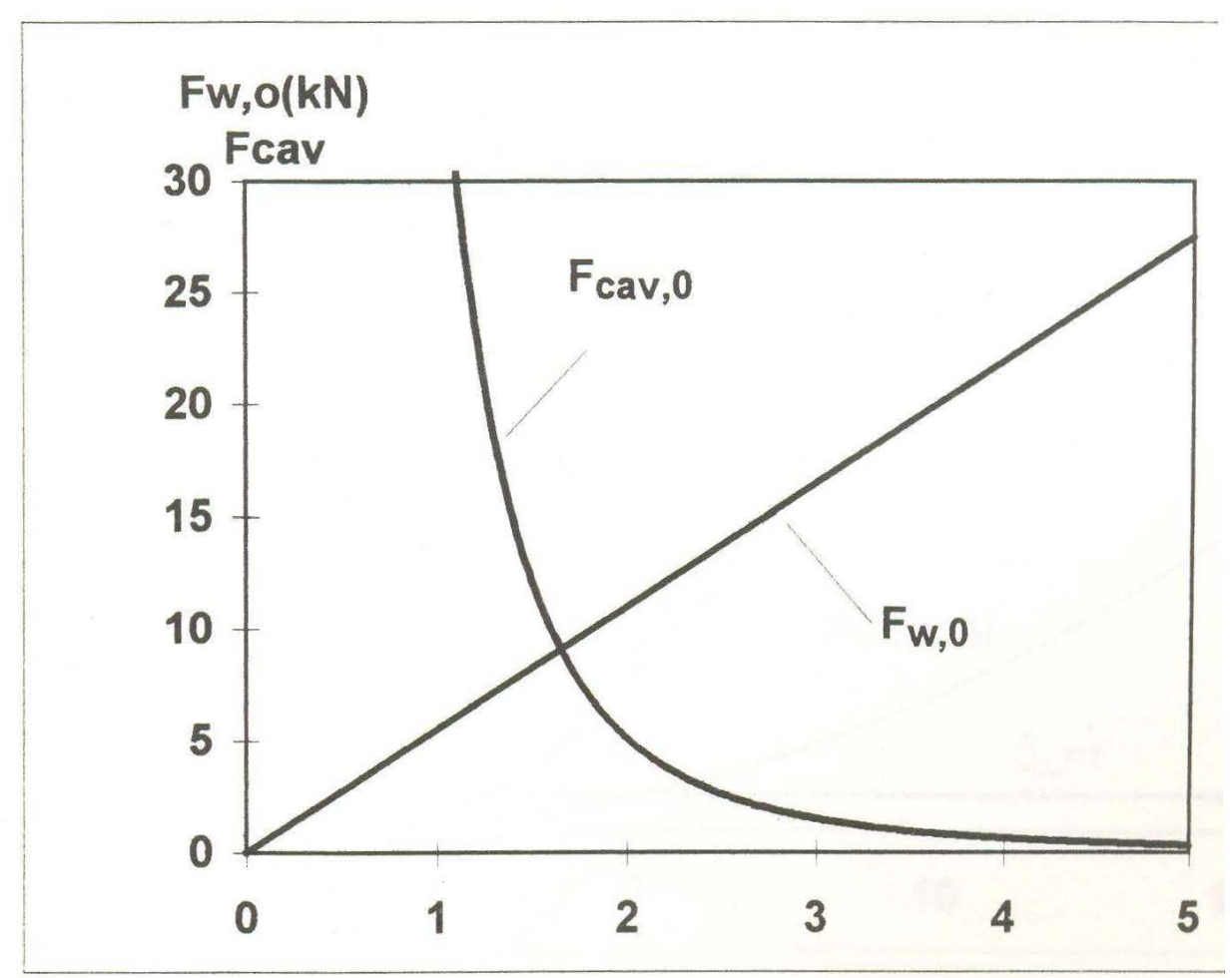

FIGURA 123-Cálculo da carga de primeiro limite da ligação Pinus com impregnação. 


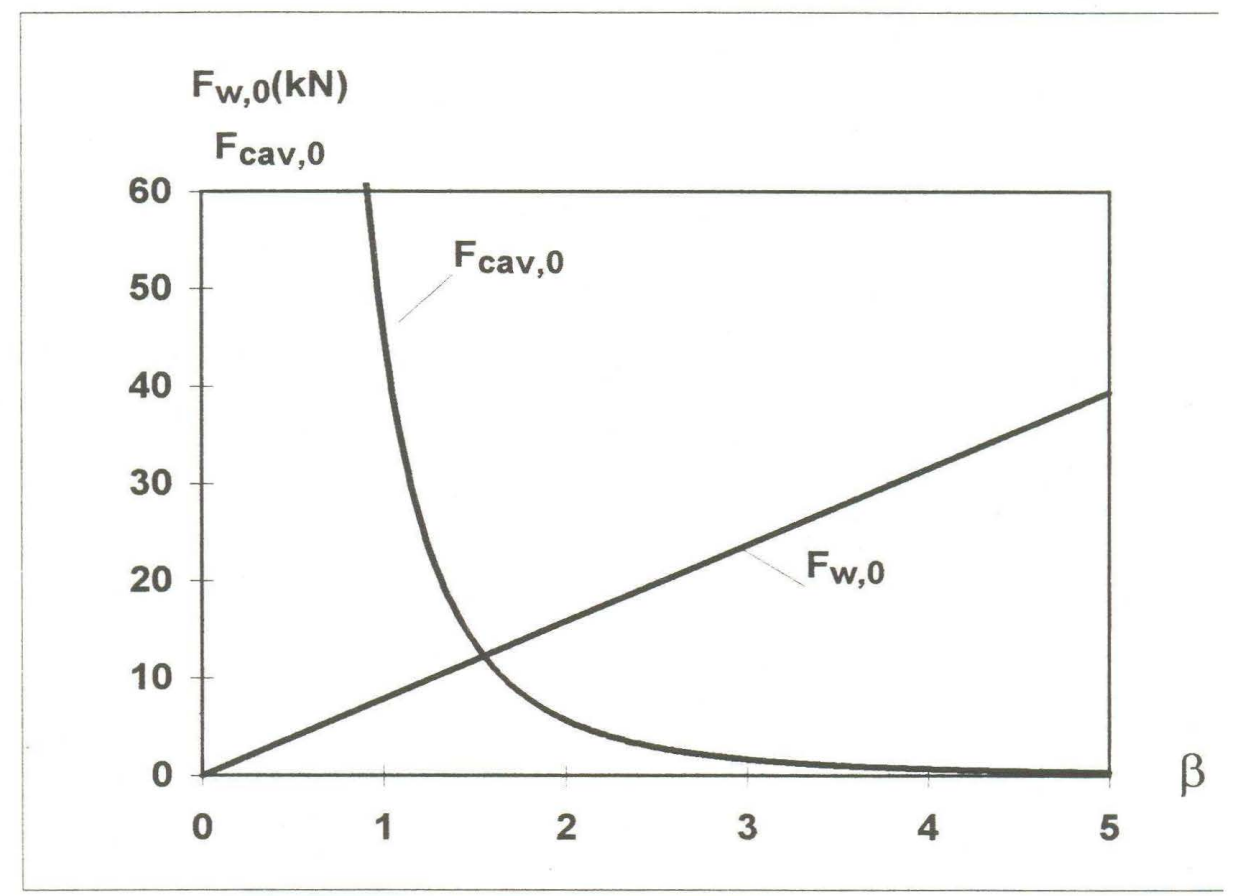

FIGURA 124-Cálculo da carga de primeiro limite da ligação Ipê.

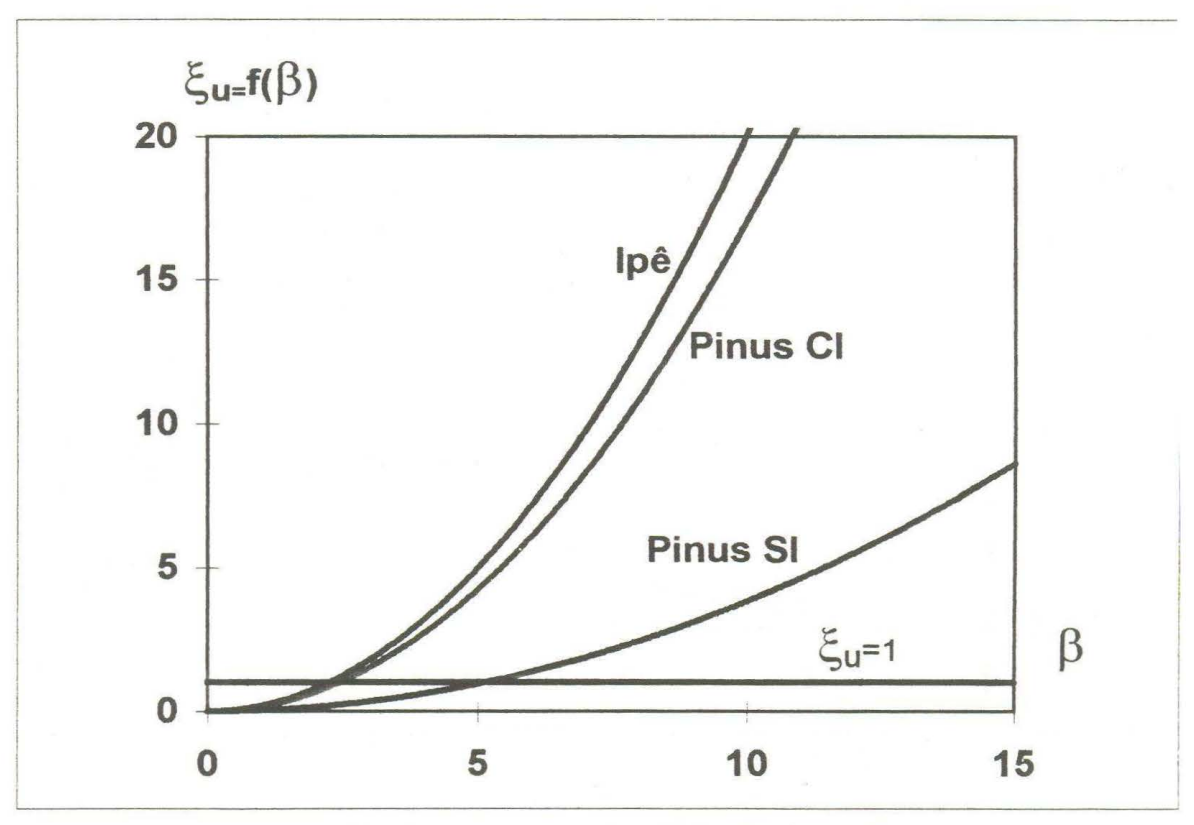

FIGURA 125 -Comportamento de $\xi u$ em função de $\beta$.

Carga de segundo limite Hipótese A. 


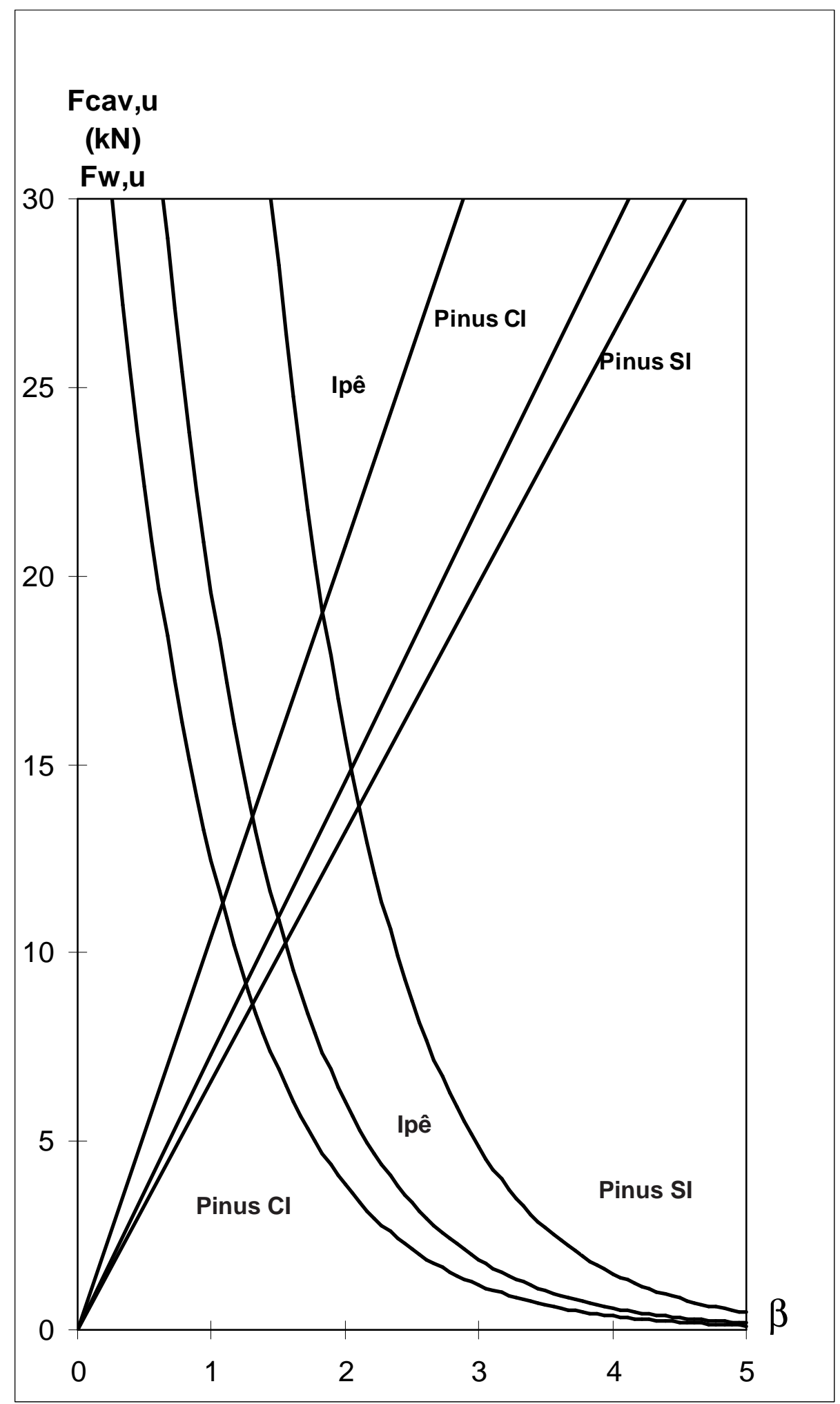

FIGURA 126 - Comportamento das funções $F_{\mathbf{w}, \mathbf{u}}$ e $F_{\mathbf{c a v}, \mathbf{u}}$ para carga de segundo limite Hipótese A 


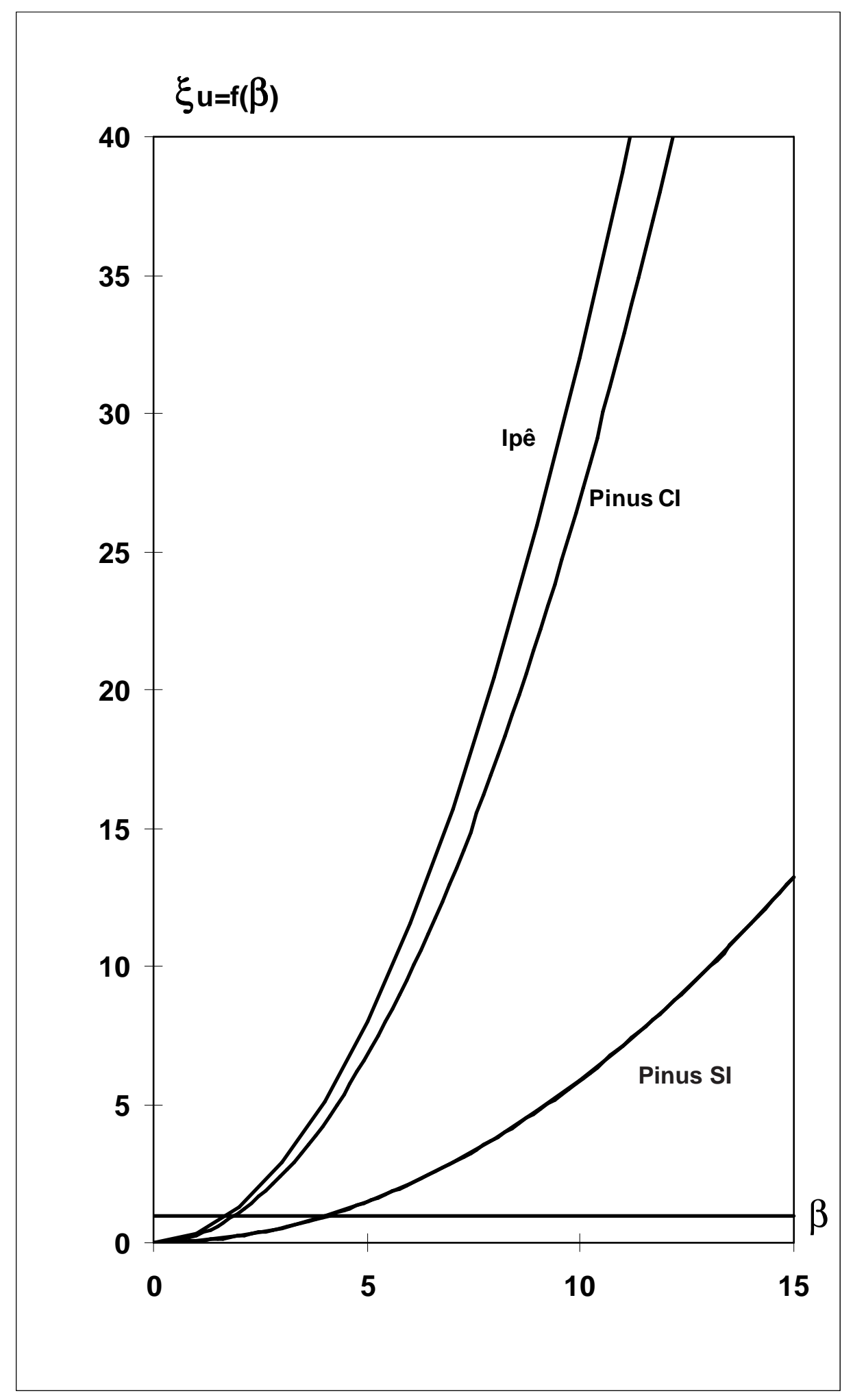

FIGURA 127 - Comportamento de $\xi_{\text {u em função de } \beta}$ Carga de segundo limite Hipótese B. 


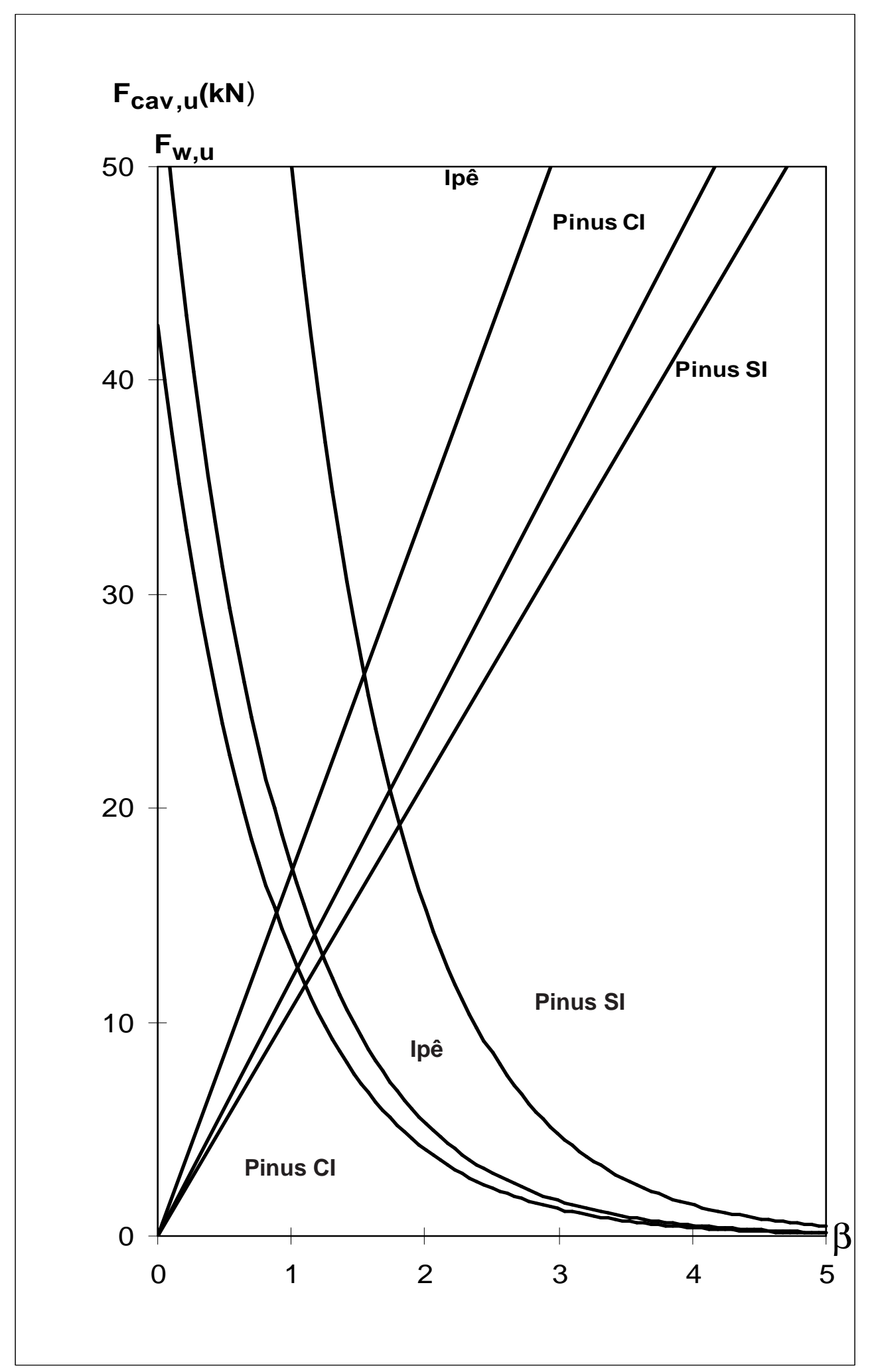

FIGURA 128 - Comportamento das funções $\mathbf{F}_{\mathbf{w}, \mathbf{u}} \mathbf{e} \mathbf{F}_{\mathbf{c a v}, \mathbf{u}}$ Carga de segundo limite Hipótese $B$. 
TABELA 103-Valores das cargas de primeiro limite em comparação com o resultados experimentais e com os valores normativos segundo a NBR 7190/96 das ligações cavilhadas impregnadas e não impregnadas no ensaio de compressão paralela às fibras.

ESPÉCIE: Pinus; $f\left(k N / \mathrm{cm}^{2}\right) ; F(k N)$

$\begin{array}{cccccccccc}\text { C.P. } & \mathbf{t} & \boldsymbol{\beta} & \mathbf{f}_{\mathbf{c} 90} & \boldsymbol{\beta}_{\text {lim }} & \mathbf{F}_{\mathbf{w}, \mathbf{0}} & \mathbf{F}_{\text {cav,0 }} & \mathbf{F}_{\text {oexp. }} & \mathbf{R}_{\mathbf{v d}, \mathbf{1}} & \text { OBS } \\ \text { CP16 } & 2,5 & 1,56 & 0,3 & 4,3 & 1,33 & - & 1,5 & 0,30 & \mathrm{SI} \\ \text { CPI16 } & 2,7 & 1,69 & 1,6 & 2,19 & 1,45 & - & 2 & 1,74 & \mathrm{Cl} \\ \text { CP18 } & 2,6 & 1,44 & 0,3 & 4,3 & 1,56 & - & 2,25 & 0,35 & \mathrm{SI} \\ \text { CPI18 } & 2,6 & 1,44 & 1,6 & 2,19 & 1,57 & - & 2,75 & 1,89 & \mathrm{Cl} \\ \text { CP20 } & 2,5 & 1,25 & 0,3 & 4,3 & 1,67 & - & 2,5 & 0,38 & \mathrm{SI} \\ \text { CPI20 } & 2,6 & 1,30 & 1,6 & 2,19 & 1,75 & - & 3,75 & 2,10 & \mathrm{Cl}\end{array}$

TABELA 104-Valores das cargas de segundo limite Hipótese $A$, em comparação com o resultados experimentais e com os valores normativos segundo a NBR 7190/96 das ligações cavilhadas impregnadas e não impregnadas no ensaio de compressão paralela às fibras.

ESPÉCIE: Pinus; $f\left(k N / \mathrm{cm}^{2}\right) ; F(k N)$

$\begin{array}{cccccccccc}\text { C.P. } & \mathbf{t} & \boldsymbol{\beta} & \mathbf{f}_{\mathbf{c 9 0}} & \boldsymbol{\beta}_{\mathbf{l i m}} & \mathbf{F}_{\mathbf{w}, \mathbf{0}} & \mathbf{F}_{\text {cav,0 }} & \mathbf{F}_{\text {uexp. }} & \mathbf{R}_{\mathbf{v d}, \mathbf{1}} & \text { OBS } \\ \text { CP16 } & 2,5 & 1,56 & 0,3 & 4,88 & 1,75 & - & 2,03 & 0,30 & \mathrm{SI} \\ \text { CPI16 } & 2,7 & 1,69 & 1,6 & 2,44 & 1,94 & - & 2,93 & 1,74 & \mathrm{Cl} \\ \text { CP18 } & 2,6 & 1,44 & 0,3 & 4,88 & 2,05 & - & 2,78 & 0,35 & \mathrm{SI} \\ \text { CPI18 } & 2,6 & 1,44 & 1,6 & 2,44 & 2,10 & - & 4,05 & 1,89 & \mathrm{Cl} \\ \text { CP20 } & 2,5 & 1,25 & 0,3 & 4,88 & 2,19 & - & 3,01 & 0,38 & \mathrm{SI} \\ \text { CPI20 } & 2,6 & 1,30 & 1,6 & 2,44 & 2,33 & - & 5,4 & 2,10 & \mathrm{Cl}\end{array}$

TABELA 105-Valores das cargas de segundo limite Hipótese $B$, em comparação com o resultados experimentais e com os valores normativos segundo a NBR 7190/96 das ligações cavilhadas impregnadas e não impregnadas no ensaio de compressão paralela às fibras.

ESPÉCIE: Pinus ; $f\left(k N / \mathrm{cm}^{2}\right) ; F(k N)$

\begin{tabular}{cccccccccc} 
C.P. & $\mathbf{t}$ & $\boldsymbol{\beta}$ & $\mathbf{f}_{\mathbf{c} 90}$ & $\boldsymbol{\beta}_{\text {lim }}$ & $\mathbf{F}_{\mathbf{w}, \mathbf{0}}$ & $\mathbf{F}_{\text {cav,00 }}$ & $\mathbf{F}_{\max }$ & $\mathbf{R}_{\mathbf{v d}, \mathbf{1}}$ & OBS \\
CP16 & 2,5 & 1,56 & 0,3 & 3,87 & 2,78 & - & 2,8 & 0,30 & $\mathrm{SI}$ \\
CPI16 & 2,7 & 1,69 & 1,6 & 1,95 & 3,18 & - & 3,98 & 1,74 & $\mathrm{Cl}$ \\
CP18 & 2,6 & 1,44 & 0,3 & 3,87 & 3,26 & - & 4,1 & 0,35 & $\mathrm{SI}$ \\
CPI18 & 2,6 & 1,44 & 1,6 & 1,95 & 3,44 & - & 5,35 & 1,89 & $\mathrm{Cl}$ \\
CP20 & 2,5 & 1,25 & 0,3 & 3,87 & 3,48 & - & 4,8 & 0,38 & $\mathrm{SI}$ \\
CPI20 & 2,6 & 1,30 & 1,6 & 1,95 & 3,83 & - & 7,35 & 2,10 & $\mathrm{Cl}$ \\
\hline
\end{tabular}


TABELA 106-Valores das cargas de primeiro limite em comparação com o resultados experimentais e com os valores normativos segundo a NBR 7190/96 das ligações cavilhadas impregnadas e não impregnadas no ensaio de compressão paralela às fibras.

ESPÉCIE: Ipê; $f\left(k N / \mathrm{cm}^{2}\right) ; F(k N)$

$\begin{array}{cccccccccc}\text { C.P. } & \mathbf{t} & \boldsymbol{\beta} & \mathbf{f}_{\mathbf{c 9 0}} & \boldsymbol{\beta}_{\mathbf{l i m}} & \mathbf{F}_{\mathbf{w}, \mathbf{0}} & \mathbf{F}_{\text {cav,00 }} & \mathbf{F}_{\text {oexp. }} & \mathbf{R}_{\mathbf{v d}, \mathbf{1}} & \text { OBS } \\ \text { P1 } & 2,3 & 1,44 & 2,4 & 2,06 & 1,77 & - & 1,25 & 2,23 & \text { SI } \\ \text { P2 } & 2,4 & 1,33 & 2,4 & 2,06 & 2,07 & - & 2,25 & 2,61 & \text { SI } \\ \text { P3 } & 2,45 & 1,23 & 2,4 & 2,06 & 2,35 & - & 2,75 & 2,96 & \text { SI }\end{array}$

TABELA 107-Valores das cargas de segundo limite Hipótese $A$, em comparação com o resultados experimentais e com os valores normativos segundo a NBR 7190/96 das ligações cavilhadas impregnadas e não impregnadas no ensaio de compressão paralela às fibras.

ESPÉCIE:Ipê; $f\left(k N / \mathrm{cm}^{2}\right) ; F(k N)$

$\begin{array}{cccccccccc}\text { C.P. } & \mathbf{t} & \boldsymbol{\beta} & \mathbf{f}_{\mathbf{c} 90} & \boldsymbol{\beta}_{\mathbf{l i m}} & \mathbf{F}_{\mathbf{W}, \mathbf{0}} & \mathbf{F}_{\text {cav,00}} & \mathbf{F}_{\text {uexp. }} & \mathbf{R}_{\mathbf{v d}, \mathbf{1}} & \text { OBS } \\ \text { P1 } & 2,3 & 1,44 & 2,4 & 2,34 & 2,38 & - & 2,64 & 2,23 & \text { SI } \\ \text { P2 } & 2,4 & 1,33 & 2,4 & 2,34 & 2,80 & - & 4,1 & 2,61 & \mathrm{Cl} \\ \text { P3 } & 2,45 & 1,23 & 2,4 & 2,34 & 3,18 & - & 4,96 & 2,96 & \mathrm{SI}\end{array}$

TABELA 108-Valores das cargas de segundo limite Hipótese $B$, em comparação com o resultados experimentais e com os valores normativos segundo a NBR 7190/96 das ligações cavilhadas impregnadas e não impregnadas no ensaio de compressão paralela às fibras.

ESPÉCIE: Ipê ; $f\left(k N / \mathrm{cm}^{2}\right) ; F(k N)$

$\begin{array}{cccccccccc}\text { C.P. } & \mathbf{t} & \boldsymbol{\beta} & \mathbf{f}_{\mathbf{c} 90} & \boldsymbol{\beta}_{\text {lim }} & \mathbf{F}_{\mathbf{w}, \mathbf{0}} & \mathbf{F}_{\mathbf{c a v}, \mathbf{0}} & \mathbf{F}_{\mathbf{m a x}} & \mathbf{R}_{\mathbf{v d}, \mathbf{1}} & \text { OBS } \\ \text { P1 } & 2,3 & 1,44 & 2,4 & 1,83 & 3,89 & - & 6,5 & 2,23 & \mathrm{SI} \\ \text { P2 } & 2,4 & 1,33 & 2,4 & 1,83 & 4,56 & - & 6,5 & 2,61 & \mathrm{Cl} \\ \text { P3 } & 2,45 & 1,23 & 2,4 & 1,83 & 5,17 & - & 7,58 & 2,96 & \mathrm{SI}\end{array}$




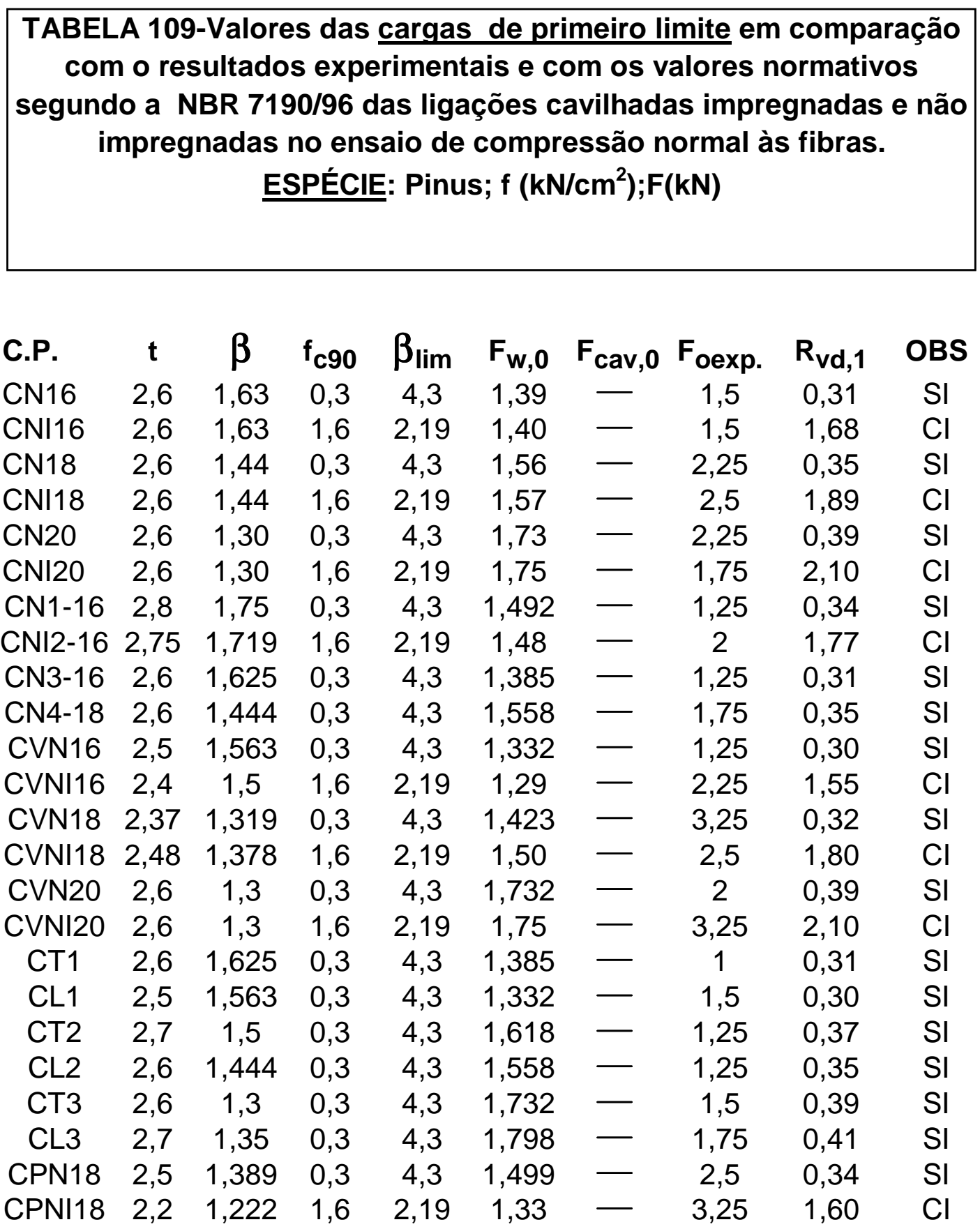


TABELA 110-Valores das cargas de segundo limite,Hipótese $A$, em comparação com o resultados experimentais e com os valores normativos segundo a NBR 7190/96 das ligações cavilhadas impregnadas e não impregnadas no ensaio de compressão normal às fibras.

ESPÉCIE: Pinus; $f\left(k N / \mathrm{cm}^{2}\right) ; F(k N)$

$\begin{array}{llllllllll}\text { C.P. } & t & \boldsymbol{B} & \mathrm{f}_{\mathrm{c} 90} & \boldsymbol{\beta}_{\mathrm{lim}} & \mathrm{F}_{\mathrm{w}, 0} & \mathrm{~F}_{\mathrm{cav}, 0} & F_{\text {uexp. }} & \mathbf{R}_{\mathrm{vd}, \mathbf{1}} & \text { OBS }\end{array}$ $\begin{array}{llllllllll}\text { CN16 } & 2,6 & 1,63 & 0,3 & 4,88 & 1,82 & - & 2,48 & 0,31 & \text { SI }\end{array}$ $\begin{array}{lllllllllll}\mathrm{CN} 16 & 2,6 & 1,63 & 1,6 & 2,44 & 1,86 & - & 2,45 & 1,68 & \mathrm{Cl}\end{array}$ $\begin{array}{llllllllll}\mathrm{CN} 18 & 2,6 & 1,44 & 0,3 & 4,88 & 2,05 & - & 2,78 & 0,35 & \mathrm{SI}\end{array}$ $\begin{array}{llllllllll}\mathrm{CN} 18 & 2,6 & 1,44 & 1,6 & 2,44 & 2,10 & - & 3,65 & 1,89 & \mathrm{Cl}\end{array}$ $\begin{array}{llllllllll}\text { CN20 } & 2,6 & 1,30 & 0,3 & 4,88 & 2,28 & - & 2,89 & 0,39 & \text { SI }\end{array}$ $\begin{array}{llllllllll}\mathrm{CNI} 20 & 2,6 & 1,30 & 1,6 & 2,44 & 2,33 & - & 3,21 & 2,10 & \mathrm{Cl}\end{array}$ $\begin{array}{llllllllll}\mathrm{CN} 1-16 & 2,8 & 1,75 & 0,3 & 4,88 & 1,962 & - & 1,78 & 0,34 & \mathrm{SI}\end{array}$ $\begin{array}{lllllllllll}\text { CNI2-16 } & 2,75 & 1,719 & 1,6 & 2,44 & 1,97 & - & 2,82 & 1,77 & \mathrm{Cl}\end{array}$ $\begin{array}{llllllllll}\text { CN3-16 } & 2,6 & 1,625 & 0,3 & 4,88 & 1,822 & - & 1,64 & 0,31 & \text { SI }\end{array}$ $\begin{array}{llllllllll}\mathrm{CN} 4-18 & 2,6 & 1,444 & 0,3 & 4,88 & 2,05 & - & 2,21 & 0,35 & \mathrm{SI}\end{array}$ $\begin{array}{llllllllll}\text { CVN16 } & 2,5 & 1,563 & 0,3 & 4,88 & 1,752 & - & 1,94 & 0,30 & \text { SI }\end{array}$ $\begin{array}{lllllllllll}\text { CVNI16 } & 2,4 & 1,5 & 1,6 & 2,44 & 1,72 & - & 2,79 & 1,55 & \mathrm{Cl}\end{array}$ $\begin{array}{llllllllll}\text { CVN18 } & 2,37 & 1,319 & 0,3 & 4,88 & 1,872 & - & 4,26 & 0,32 & \text { SI }\end{array}$ $\begin{array}{llllllllll}\text { CVNI18 } & 2,48 & 1,378 & 1,6 & 2,44 & 2,00 & - & 3,85 & 1,80 & \mathrm{Cl}\end{array}$ $\begin{array}{llllllllll}\text { CVN20 } & 2,6 & 1,3 & 0,3 & 4,88 & 2,278 & - & 2,91 & 0,39 & \text { SI }\end{array}$ $\begin{array}{lllllllllll}\text { CVNI20 } & 2,6 & 1,3 & 1,6 & 2,44 & 2,33 & - & 4,41 & 2,10 & \mathrm{Cl}\end{array}$ $\begin{array}{lllllllllll}\text { CT1 } & 2,6 & 1,625 & 0,3 & 4,88 & 1,822 & - & 1,52 & 0,31 & \text { SI }\end{array}$ $\begin{array}{llllllllll}\text { CL1 } & 2,5 & 1,563 & 0,3 & 4,88 & 1,752 & - & 1,92 & 0,30 & \text { SI }\end{array}$ $\begin{array}{llllllllll}\text { CT2 } & 2,7 & 1,5 & 0,3 & 4,88 & 2,129 & - & 2,01 & 0,37 & \text { SI }\end{array}$ $\begin{array}{llllllllll}\text { CL2 } & 2,6 & 1,444 & 0,3 & 4,88 & 2,05 & - & 1,73 & 0,35 & \text { SI }\end{array}$ $\begin{array}{llllllllll}\text { CT3 } & 2,6 & 1,3 & 0,3 & 4,88 & 2,278 & - & 1,98 & 0,39 & \text { SI }\end{array}$ $\begin{array}{llllllllll}\text { CL3 } & 2,7 & 1,35 & 0,3 & 4,88 & 2,365 & - & 1,98 & 0,41 & \text { SI }\end{array}$ $\begin{array}{llllllllll}\text { CPN18 } & 2,5 & 1,389 & 0,3 & 4,88 & 1,971 & - & 3,23 & 0,34 & \text { SI }\end{array}$ $\begin{array}{llllllllll}\text { CPNI18 } & 2,2 & 1,222 & 1,6 & 2,44 & 1,77 & - & 3,71 & 1,60 & C l\end{array}$ 

TABELA 111-Valores das cargas de segundo limite Hipótese $B$, em comparação com o resultados experimentais e com os valores normativos segundo a NBR 7190/96 das ligações cavilhadas impregnadas e não impregnadas no ensaio de compressão normal às fibras.
ESPÉCIE: Pinus; $f\left(k N / \mathrm{cm}^{2}\right) ; F(k N)$

$\begin{array}{lccccccccc}\text { C.P. } & \mathbf{t} & \boldsymbol{\beta} & \mathbf{f}_{\mathbf{c} 90} & \boldsymbol{\beta}_{\mathbf{l i m}} & \mathbf{F}_{\mathbf{w}, \mathbf{0}} & \mathbf{F}_{\mathbf{c a v}, \mathbf{0}} & \mathbf{F}_{\mathbf{m a x}} & \mathbf{R}_{\mathbf{v d}, \mathbf{1}} & \text { OBS } \\ \text { CN16 } & 2,6 & 1,63 & 0,3 & 3,87 & 2,90 & - & 3,38 & 0,31 & \mathrm{SI} \\ \text { CNI16 } & 2,6 & 1,63 & 1,6 & 1,97 & 3,06 & - & 3,2 & 1,68 & \mathrm{Cl} \\ \text { CN18 } & 2,6 & 1,44 & 0,3 & 3,87 & 3,26 & - & 3,9 & 0,35 & \mathrm{SI} \\ \text { CN118 } & 2,6 & 1,44 & 1,6 & 1,97 & 3,44 & - & 4,38 & 1,89 & \mathrm{Cl} \\ \text { CN20 } & 2,6 & 1,30 & 0,3 & 3,87 & 3,62 & - & 4,05 & 0,39 & \mathrm{SI} \\ \text { CNI20 } & 2,6 & 1,30 & 1,6 & 1,97 & 3,83 & - & 4,92 & 2,10 & \mathrm{Cl} \\ \text { CN1-16 } & 2,8 & 1,75 & 0,3 & 3,87 & 3,118 & - & 2,6 & 0,34 & \mathrm{SI} \\ \text { CNI2-16 } & 2,75 & 1,719 & 1,6 & 1,97 & 3,24 & - & 3,67 & 1,77 & \mathrm{Cl} \\ \text { CN3-16 } & 2,6 & 1,625 & 0,3 & 3,87 & 2,895 & - & 2,5 & 0,31 & \mathrm{SI} \\ \text { CN4-18 } & 2,6 & 1,444 & 0,3 & 3,87 & 3,257 & - & 3,17 & 0,35 & \mathrm{SI} \\ \text { CVN16 } & 2,5 & 1,563 & 0,3 & 3,87 & 2,784 & - & 3 & 0,30 & \mathrm{SI} \\ \text { CVNI16 } & 2,4 & 1,5 & 1,6 & 1,97 & 2,83 & - & 3,58 & 1,55 & \mathrm{Cl} \\ \text { CVN18 } & 2,37 & 1,319 & 0,3 & 3,87 & 2,974 & - & 6,2 & 0,32 & \mathrm{SI} \\ \text { CVNI18 } & 2,48 & 1,378 & 1,6 & 1,97 & 3,29 & - & 5,45 & 1,80 & \mathrm{Cl} \\ \text { CVN20 } & 2,6 & 1,3 & 0,3 & 3,87 & 3,619 & - & 4,25 & 0,39 & \mathrm{SI} \\ \text { CVNI20 } & 2,6 & 1,3 & 1,6 & 1,97 & 3,83 & - & 5,78 & 2,10 & \mathrm{Cl} \\ \text { CT11 } & 2,6 & 1,625 & 0,3 & 3,87 & 2,895 & - & 2,83 & 0,31 & \mathrm{SI} \\ \text { CL1 } & 2,5 & 1,563 & 0,3 & 3,87 & 2,784 & - & 3,7 & 0,30 & \mathrm{SI} \\ \text { CT2 } & 2,7 & 1,5 & 0,3 & 3,87 & 3,383 & - & 3,52 & 0,37 & \mathrm{SI} \\ \text { CL2 } & 2,6 & 1,444 & 0,3 & 3,87 & 3,257 & - & 3,3 & 0,35 & \mathrm{SI} \\ \text { CT3 } & 2,6 & 1,3 & 0,3 & 3,87 & 3,619 & - & 3,65 & 0,39 & \mathrm{SI} \\ \text { CL3 } & 2,7 & 1,35 & 0,3 & 3,87 & 3,758 & - & 3,3 & 0,41 & \mathrm{SI} \\ \text { CPN18 } & 2,5 & 1,389 & 0,3 & 3,87 & 3,132 & - & 4,58 & 0,34 & \mathrm{SI} \\ \text { CPNI18 } & 2,2 & 1,222 & 1,6 & 1,97 & 2,91 & - & 4,65 & 1,60 & \mathrm{Cl}\end{array}$


TABELA 112-Valores das cargas de primeiro limite, em comparação com o resultados experimentais e com os valores normativos segundo a NBR 7190/96 das ligações cavilhadas impregnadas e não impregnadas no ensaio de compressão normal às fibras.

ESPÉCIE: Ipê; f $\left(\mathrm{kN} / \mathrm{cm}^{2}\right) ; \mathrm{F}(\mathrm{kN})$

$\begin{array}{lccccccccc}\text { C.P. } & \mathbf{t} & \boldsymbol{\beta} & \mathbf{f}_{\mathbf{c 9 0}} & \boldsymbol{\beta}_{\mathbf{l i m}} & \mathbf{F}_{\mathbf{w}, \mathbf{0}} & \mathbf{F}_{\text {cav,0 }} & \mathbf{F}_{\text {oexp. }} & \mathbf{R}_{\mathbf{v d}, \mathbf{1}} & \text { OBS } \\ \text { N1 } & 2,4 & 1,50 & 2,4 & 2,06 & 1,84 & - & 2 & 2,32 & \text { SI } \\ \text { N2 } & 2,4 & 1,33 & 2,4 & 2,06 & 2,07 & - & 2,5 & 2,61 & \text { SI } \\ \text { N3 } & 2,45 & 1,23 & 2,4 & 2,06 & 2,35 & - & 3,25 & 2,96 & \text { SI }\end{array}$
TABELA 113-Valores das cargas de segundo limite Hipótese $A_{\text {, em }}$ comparação com o resultados experimentais e com os valores normativos segundo a NBR 7190/96 das ligações cavilhadas impregnadas e não impregnadas no ensaio de compressão normal às fibras.
ESPÉCIE:Ipê; $f\left(k N / \mathrm{cm}^{2}\right) ; F(k N)$

$\begin{array}{lccccccccc}\text { C.P. } & \mathbf{t} & \boldsymbol{\beta} & \mathbf{f}_{\mathbf{c} 90} & \boldsymbol{\beta}_{\text {lim }} & \mathbf{F}_{\mathbf{w}, \mathbf{0}} & \mathbf{F}_{\text {cav,00 }} & \text { Fuexp. } & \mathbf{R}_{\mathbf{v d}, \mathbf{1}} & \text { OBS } \\ \text { N1 } & 2,4 & 1,50 & 2,4 & 2,34 & 2,49 & - & 3,21 & 2,32 & \text { SI } \\ \text { N2 } & 2,4 & 1,33 & 2,4 & 2,34 & 2,80 & - & 4,14 & 2,61 & \text { SI } \\ \text { N3 } & 2,45 & 1,23 & 2,4 & 2,34 & 3,18 & - & 5,1 & 2,96 & \text { SI }\end{array}$

TABELA 114-Valores das cargas de segundo limite Hipótese $B$, em comparação com o resultados experimentais e com os valores normativos segundo a NBR 7190/96 das ligações cavilhadas impregnadas e não impregnadas no ensaio de compressão normal às fibras.

ESPÉCIE: Ipê; $f\left(k N / c^{2}\right) ; F(k N)$

\begin{tabular}{lccccccccc} 
C.P. & $\mathbf{t}$ & $\boldsymbol{\beta}$ & $\mathbf{f}_{\mathbf{c 9 0}}$ & $\boldsymbol{\beta}_{\text {lim }}$ & $\mathbf{F}_{\mathbf{w}, \mathbf{0}}$ & $\mathbf{F}_{\mathbf{c a v}, \mathbf{0}}$ & $\mathbf{F}_{\max }$ & $\mathbf{R}_{\mathbf{v d}, \mathbf{1}}$ & OBS \\
N1 & 2,4 & 1,50 & 2,4 & 1,95 & 4,06 & - & 6 & 2,32 & SI \\
N2 & 2,4 & 1,33 & 2,4 & 1,95 & 4,56 & - & 5,38 & 2,61 & SI \\
N3 & 2,45 & 1,23 & 2,4 & 1,95 & 5,17 & - & 6,4 & 2,96 & SI \\
\hline
\end{tabular}




\section{REFERÊNCIAS BIBLIOGRÁFICAS}

Serão listadas as referências contidas no texto em ordem alfabética pois também a parte estará listada a bibliografia consultada, e de igual modo irão figurar os trabalhos dos autores de maior relevância sobre o assunto em pauta.

1.AGNELLI, J.A.M. Obtenção de compostos polímero-madeira empregando madeiras nacionais. 33 a . Reunião Anual SBPC, D-2.3, 1981.

2.ALLINGER et al. Química Orgânica. Rio de Janeiro, Editora Guanabara Dois, 1978.

3.ALMEIDA, Pedro Afonso de Oliveira Almeida.Uniões Pregadas de Madeira.São Paulo, 1987. 141p. Dissertação (Mestrado)- Escola Politécnica, Universidade de São Paulo.

4.ALMEIDA, Pedro Afonso de Oliveira Almeida. Estruturas de grande porte de madeira composta.São Paulo, 1990. 277p. Tese (Doutorado)- Escola Politécnica, Universidade de São Paulo.

5.ALMEIDA ,P.A.O; FUSCO, P.B.; RODRIGUES, M.S. Fundamentos do método para a determinação das resistências das ligações pregadas ou parafusadas em Estruturas de Madeira.In:5 ENCONTRO BRASILEIRO EM MADEIRAS E EM ESTRUTURAS DE MADEIRA. 2., Belo Horizonte, 1995. Anais.Belo Horizonte, IBRAMEM, 1995. p.315-326. 
6.AMERICAN SOCIETY FOR TESTING AND MATERIALS.Mechanical fasteners in wood.Philadelphia, Pa.1977.

7.AMERICAN SOCIETY FOR TESTING AND MATERIALS.Standard methodos of testing small clear specimens of timber.Philadelphia, 1982.

8.ANDRIAMITANTSOA, L. Analyse des modélisations des assemblages bois cloués, application: panneaux de particules sur bois et bois sur bois. Annales de l'Institut Technique du Batiment et des Travaux Publics, p.1-12, jun.1990.

9.ASSOCIAÇÃO BRASILEIRA DE NORMAS TÉCNICAS. Cálculo e execução de estruturas de madeira. Rio de Janeiro, ABNT, 1982.

10. BARBEDO, C. apud SCHREYER. Estática das construções. vol III. Porto Alegre, Editora Globo, 1971.

11.BJORHOVDE et al., Connections in steel structures- Behaviour, strength and design, London, Elsevier Apllied Science, 1988.

12.BLASS et al. Timber structures in seismic regions RILEM, State-of-the-art report. Materials and Structures, vol 27, p. 157-184, 1994.

13. BODIG, J. \& JAYNE, B.A. Mechanics of wood and wood composites. New York, Van Nostrand Reinhold Company, 1982.

14. BRESLER et al. Diseño de estructuras de acero. Mexico, Editorial Limusa, 1978.

15.BRITISH STANDARDS INSTITUTION. Mechanically fastened joints in timber and wood-based materials.England, 1989. 
16.CALIL. C.; PFISTER, G. Treliças de Madeira para coberturas-Notas de aula SET 406-ESTRUTURAS DE MADEIRA.São Carlos, Escola de Engenharia de São Carlos, 1994.

17.CANADIAN STANDARDS ASSOCIATION.Engineering Design in Wood (Limit States Design). Toronto, 1989.

18.CÉSAR, S.F. As Estruturas Hauff de Madeira no Brasil.São Carlos, 1991.196p.Dissertação (Mestrado)- Escola de Engenharia de São Carlos, Universidade de São Paulo.

19.DEUTSCHES INSTITUT FÜR NORMUNG.Structural use of timberMechanically fastened joints.Berlin, 1988.

20.DEUTSCHES INSTITUT FÜR NORMUNG. Holzdübel.Berlin, 1989.

21.ECKELMAN, Carl A. Engineering concepts of single-pin dowel joint design. Forest Products Journal, vol. 19, n.12, p.52-60, 1969.

22.ECKELMAN, Carl A. Withdrawal strength of dowel joints: effect of shear strength, Forest Products Journal, vol. 29, n.1, p.48-52, 1979.

23.EHLBECK, J. \&EBERHART, O.Design of double-shear joints with nonmetalicc dowels. In: INTERNATIONAL COUNCIL FOR BUILDING RESEARCH STUDIES AND DOCUMENTATION WORKING COMISSION W18A- TIMBER STRUCTURES, Berlin.Meeting Twenty-Two, 1989. p.1-11.

24.EUROCODE N.5-COMISSION OF THE EUROPEAN COMMUNITIES. Design of timber structures.London, 1991. 
25. FURIATI, Marcos. Classsificação de peças estruturais de madeira. São Carlos, 1981. 132p. Dissertação (Mestrado )- Escola de Engenharia de São Carlos, Universidade de São Paulo.

26. GALPERIN et al. Manufacturing and properties of modified wood: a review of 25 years work. Holz/Forschung, vol.49, p.45-50, 1995.

27.GESUALDO, Francisco Antônio Romero. Ligação de peças estruturais de madeira através de cavilhas partidas de Eucalipto Citriodora.São Carlos, 1982.91p. Dissertação (Mestrado)- Escola de Engenharia de São Carlos, Universidade de São Paulo.

28.GESUALDO, Francisco Antônio Romero.Deformação das ligações nas estruturas de madeira. São Carlos, 1987.170p. Tese (Doutorado)-Escola de Engenharia de São Carlos, da Universidade de São Paulo.

29.GIORDANO, G. La moderna tecnica delle construzioni in legno.Milano, Editore Ulrico Hoepli, 1964.

30. HANSEN, H.J. Diseño moderno de estructuras de madera, México, Compañia Editorial Continental, 1961.

31.HELLMEISTER, João César. Sobre a determinação das características físicas da madeira. São Carlos, 1973.119p. Tese (Doutorado)-Escola de Engenharia de São Carlos, Universidade de São Paulo.

32.HILSON, B.O; WHALE, L.R.J. Developments in the design timber joints. The Structural Engineer, v.68, n.8, p.148-150,april 1990.

33.INSTITUTO BRASILEIRO DA MADEIRA E DAS ESTRUTURAS DE MADEIRA. Projeto da nova norma brasileira NBR 7190 "Projeto de estruturas de Madeira". São Paulo, Ibramem, 1995. 
34.JOHANSEN, K.W. Theory of timber connections. International Association for Bridge and Structural Engineering, vol.9, p.249-262, 1949.

35. KARLSEN, G.G. Wooden structures.Moscow, Mir Publishers, 1967.

36.LEITNER, R.J.As ligações em estruturas de madeira e, em especial, as ligações pregadas de peças estruturais de madeira de pinho.Curitiba, Faculdade de Engenharia do Paraná, 1952.

37. LIMA, M.F. Madeira- Para vencer grandes vãos. Téchne, São Paulo, n.11, p-15-17, jul/ago, 1994.

38.LUCHESE, J.A.; STAMATO, M.C. Ligações de peças de peroba rosa com parafusos de aço. In: II JORNADAS LUSO- BRASILEIRAS DE ENGENHARIA CIVIL DOMÍNIO-ESTRUTURAS,. Rio de janeiro, 1967.

39.MANRICH, Sati. O emprego de madeiras brasileiras na obtenção de compósitos polímero-madeira. São Carlos, 1984.184p.Dissertação (Mestrado)- Centro de Ciências e Tecnologia, Universidade Federal de São Carlos.

40. MANRICH, S.; AGNELLI, J.A.M. The effect of chemical treatment of wood and polymer characteristics on the properties of wood-polymer composites. Journal of Applied Polymer Science, vol. 37, p.1777-1790, 1989.

41. MANSON et al. Use of polymers in highway concrete. Washington, Transportation Research Board, 1978. ( National Cooperative Highway Research Program Report, 190 ).

42.McLAIN, T. E.; THANGJITHAM, S. Bolted wood-joint yield model. Journal of Structural Engineering, vol 109, n.8, p.1820-1835, 1983. 
43.MEYER, J.A. Wood-polymer materials. Advances in chemistry séries. Whashington,American Chemical Society, vol.207, p.257-320, 1984.

44.MEYER,J.A. \& LOOS, W.E.Processes of and products from, treating southern pine wood for modification of properties. Forest Products Journal, vol.19, n.12, p.32-38, december 1969.

45. MICROSOFT CORPORATION. Guia do usuário, Microsoft Excel versão 5.0. Cambridge, 1994.

46.NATIONAL FOREST PRODUCTS ASSOCIATION. Structural lumber, Glued Laminated Timber, Timber Piles, Connections. Washington, DC, 1992.

47. PAULA, Estevão V.Cavalcanti M. de. Viga Vierendeel de madeira. São Carlos, 1982. 164p. Dissertação ( Mestrado )- Escola de Engenharia de São Carlos. Universidade de São Paulo.

48.PIEDADE, Cesar Jr.Ligações de peças de Peroba Rosa e Pinho do Paraná com cavilhas de Eucalipto Citriodora. Botucatu, 1972.123p. Tese(Doutorado)- Departamento de Engenharia Rural, Faculdade de Ciências Médicas e Biológicas de Botucatu.

49.PRELORENTZOU, Pierre Antonie. Um estudo sobre ligações viga-coluna em estruturas de aço. São Carlos, 1991.221p.Dissertação (Mestrado)-Escola de Engenharia de São Carlos, Universidade de São Paulo.

50. PRYOR, W.A. Introdução ao estudo dos radicais livres, São Paulo, Editora Edgard Blucher, 1970, 132p. 
51.RAFF, R.A.V.; HERRICK, I.W.; ADAMS, M.F. Polymerization of Styrene and Styrene-Divinylbenzene in Wood. Forest Products Journal, p.260-262, July 1965.

52.SALES, Almir.Características de resistência mecânica e algumas espécies de Eucalipto do Estado de São Paulo. São Carlos, 1991.219p. Dissertação (Mestrado)-Escola de Engenharia de São Carlos, Universidade de São Paulo.

53.SHREVE, R.N.; BRINK, J.A. Indústrias de processos químicos. Rio de Janeiro, Editora Guanabara Dois, 1980.

54.SOLTIS, L.A.; HUBBARD, F. K.; WILKINSON, T.L. Bearing strength of bolted timber joints. Journal of Structural Engineering,vol.112, n.9, p.21412154, September 1986.

55.STALNAKER, J.J.; HARRIS, E.C.Structural design in wood.New York, Van Nostrand Reinhold, 1989.

56. TONISSI, José Luís. Madeira e seus derivados na construção. São Paulo, 1985. 137p. Dissertação (Mestrado )- Escola de Engenharia de São Carlos, Universidade de São Paulo.

57. WHALE, L.R.J.; SMITH, I.; LARSEN, H.O. Design of nailed and bolted joints for the revision of existing formulae in draft Eurocode 5 and the $\mathrm{CIB}$ CODE. In: INTERNATIONAL COUNCIL FOR BUILDING RESEARCH STUDIES AND DOCUMENTATION WORKING COMISSION W 18 ATIMBER STRUCTURES. Ireland. 1987. p.1-36.

58. ZAGOTTIS, D. Pontes e grandes estruturas: introdução da segurança no projeto estrutural. São Paulo, EPUSP, 1974. 
59.ZHANG, J.L; ECKELMAN. The bending moment resistance of singledowel corner joints in case construction. Forest Products Jornal, vol 43, n.6, p.19-24, June, 1993. 


\section{OBRAS CONSULTADAS}

1.ALLINGER et al.Química Orgânica.Rio de Janeiro, Editora Guanabara Dois, 1978.

2.ALMEIDA et al. Determinação das propriedades das madeiras para projeto de estruturas. São Paulo, EPUSP, 1996. (Boletim Técnico do Departamento de Engenharia de Estruturas e Fundações,BT/PEF/ 9604).

3.AMERICAN INSTITUTE OF TIMBER CONSTRUCTION . Timber Construction Manual, Second edition.Colorado, 1974.

4. ANDREWS, H. J. An introduction to timber engineering. London, Pergamon Press, 1967.

5. ASSOCIAÇÃO BRASILEIRA DE NORMAS TÉCNICAS. Símbolos gráficos para projetos de estruturas. Rio de Janeiro, ABNT, 1983.

6.AUNE, P. \& MALLORY, M.P. Lateral Load-Bearing capacity of nailed joints based on the yield theory-experimental verification, Madison, Forest Products Laboratory, 1986. ( Research Paper FPL 470).

7.BARDI, P.M. A Madeira desde o Pau-Brasil até a Celulose, Banco Sudameris, Arte e Cultura, São Paulo, Volume V, 1982.

8.BECKETT, D.\& MARSH, P. An introduction to structural design. London, Surrey University Press, 1974. 
9.BERGÓS, J. Maderas de construccion decoracion y artesena. Barcelona, Editorial Gustavo Gilli, 1951.

10.BILLMEYER, F.W, jr. Textbook of polymer science, Third Edition, New York, John Wiley \& Sons, 1984.

11.BLAKE, A. Pratical stress analysis in engineering design, Madison, Marcel Decker, inc., 1982.

12.BLASS et al. Timber structures in seismic regions Rilem state-of-the-art Report. Materials and Structures, n.27, p-157-184, 1994.

13.BOCCO, R.N.; TEXO, D.M. Construcciones normalizadas. sistema estructural de madera para viviendas uni y bifamiliares. Informes de la Construccion. vol.43, n. 418, p.53-59, 1992.

14.BUCHANAN, A.H.\& LAI, J.C. Glulam rivets in radiata pine. Canadian Journal of Civil Engineering. vol.21, n.2 , p.340-350, 1994.

15.CAMPOS, M.M.. Química orgânica -volume 1, São Paulo, Editora Edgard Blucher, 1976.

16.DERRY, T.K.; WILLIAMS, T.I. A short history of technology, London, Oxford University Press, 1960.

17.DESCH, H.E. Timber its structure and properties, London, Macmillan\& co Ltd, 1953.

18. DYER, D.B. Slip modulus in bolted timber joints. Canadian Journal of Civil Engineering, n. 19, p.960-964, 1992. 
19.ECKELMAN, C. A. How to design dowel joints, Lafayette, Agricultural experimental station, p.1-7, 1970 (Research Progress Report 373).

20.EMERSON \&FRIDLEY. Resistance of metal-plate-connected truss joints to dynamic loading, Forest Products Journal, vol.46, n.5, p-83-90,1996.

21. ERKI, M.A. Modelling the load-slip behaviour of timber joints with mechanical fasteners. Canadian Journal of Civil Engineering, n.18, p.607616, 1991.

22. FEIREIR, J. L. Woodworking for industry, USA, Chas. A. Bennett Co., Inc., 1971.

23. FELTRE, R. Química orgânica, São Paulo, Editora Moderna, 1995.

24. FONSECA et al. Estatística aplicada, São Paulo, Editora Atlas, 1991.

25. FONSECA, J. S. \& MARTINS, G. A. Curso de estatística. São Paulo, Editora Atlas, 1992.

26.FOREST PRODUCTS LABORATORY FOREST SERVICE.Wood Handbook:Wood as an Engineering Material.,Washington, DC, 1987.

27. FROMENT, G. Les bois de construction. Paris, Eyrolles, 1952.

28.FUSCO, P.B. Normalização dos Símbolos Gráficos para Projetos de Estruturas de Madeira, Boletim Técnico da Escola Politécnica da USP, BT/PEF/9310, p.1-12.1993. 
29. FUSCO, P.B.\& ALMEIDA, P.A.O. Estados limites das uniões pregadas de madeira. São Paulo, EPUSP, 1988. ( Publicação BT/PEF-8817).

30. FUSCO et al. Norma de projeto de estruturas de madeira. São Paulo, EPUSP, 1996. ( Boletim Técnico do Departamento de Engenharia de Estruturas e Fundações, BT/PEF/9602).

31. GESUALDO, Francisco Antônio Romero. Deformação das ligações nas estruturas de madeira. São Carlos,1987.170p. Tese(Doutorado)- Escola de Engenharia de São Carlos, Universidade de São Paulo.

32.GIORDANO, G. La moderna tecnica delle construzioni in legno, Milano, Editore Ulrico Hoepli, 1964.

33.GUITIÁN, R. Evolução dos conceitos de polímero e de polimerização.O moderno Plástico,São Paulo,n.246, p.38-42, agosto 1994.

34.HANSEN, H.J. Diseño moderno de Estructuras de Madera.México, Compañia Editorial Continental, 1961.

35.HELLMEISTER, João César. Sobre a determinação das características físicas da madeira. São Carlos, 1973.119p. Tese (Doutorado)-Escola de Engenharia de São Carlos, Universidade de São Paulo.

36. HILSON, B.O. \& WHALE, L.R.J. Developments in the design of timber joints. The Structural Engineer, vol.68, n. 8. p.148-150, 1990.

37. HOFFMANN, K. \& GRIESE, H. Construcciones con madera. Barcelona, Editorial Blume, 1967. 
38.INSTITUTO BRASILEIRO DA MADEIRA E DAS ESTRUTURAS DE MADEIRA. Projeto da nova norma brasileira NBR 7190- "PROJETO DE ESTRUTURAS DE MADEIRA". São Paulo, 1995.

39. ITANI, R.Y.\& FAHERTY, K. F. Structural wood research- state of the art and research needs. New York, ASCE, 1984.

40.KULAK, G.L.; FISHER, J.W.; STRUIK, J.H.A.Guide to design criteria for bolted and riveted joints.New York, John Wiley \&Sons, 1987.

41.LABORATÓRIO DE MADEIRAS E DE ESTRUTURAS DE MADEIRA. Madeira-determinação de suas características. São Carlos, 1988.

42.MANO, E.B.Introdução a Polímeros.São Paulo, Editora Edgard Blücher, 1985.

43.MANO, E.B. Polímeros como materiais de engenharia. São Paulo, Editora Edgard Blücher, 1991.

44. MARK et al. Encyclopédia of polymer science and engineering. New York, John Wiley, vol 16, 1989.

45.MATEUS, J.E.Bases para o dimensionamento de Estruturas de Madeira.Lisboa, LNEC, 1961.

46.McLAIN, T.E. Mechanical fastening of structural wood members-design and research status.ASCE, p.31-70, 1984.

47. MELCHIORRE, Armando. L'assemblage d'éléments structures au moyen d'adhésifs. Acier-stahl-steel, p.187-191, 1977. 
48. MERCER, J.G. Gllues, finger jointing, and methods of connecting structural components. The Structural Engineer, vol.60A, n.2, p.45-47, 1982.

49.MEYER, J.A. Treatment of wood-polymer systems using catalyst-heat techniques. Forest Products Journal, p.362-364, september 1965.

50.MOLITERNO, A.M.Caderno de Projetos de Telhados em Estruturas de Madeira. São Paulo, Editora Edgard Blücher, 1981.

51. MOREY, P.R. O crescimento das árvores. São Paulo, EPU/EDUSP, vol 19, 1980.

52.OBERG, F.R. Heavy timber construction. Illinois, American Technical Society, 1972.

53.OLIVA, Antônio Guitiérrez; La madera en la construccion. Informes de la Construccion, vol.35, n.358, p.5-8, 1984.

54.PAN, Z.R.et al. Mini-emulsion formation e polymerization of styrene.Polymer International,vol.30, n.2, p.259-264,1992.

55. PFEIL, W. Estruturas de madeira. Rio de Janeiro, LTC, 1994.

56. PRYOR, W.A. Introdução ao estudo dos radicais livrres, São Paulo, Editora Edgard Blucher, 1970, 132p.

57. RACHER, P. \& GALIMARD, P. Les assemblages de structures bois. Annales de L'Institut Technique Du Batiment Et Des Travaux Publics. n.504, p.29-36, 1992.

58. REVISTA DIRIGENTE CONSTRUTOR. A luta para divulgar a madeira. São Paulo, Novembro de 1987. Matéria de capa. 
59. SAMLAIC, J. As propriedades físicas e mecânicas da madeira. Revista da Madeira, n.386, p.6-12, 1984.

60.SEYMOUR, R.B.; CARRAHER, C.E.Polymer Chemistry -an introduction, second edition.New York, Marcel Decker, 1988.

61.SMITH, R. C. Principles and practices of heavy construction, PrenticeHall, New Jersey, 1976.

62. SOLTIS, L. A. \& WILKINSON, T.L. Bolted- Connection Design. Madison, Forest Products Laboratory, 1987. ( General Technical Report FPL-GTR-54).

63.SOUZA, J.B. Ciclo do carro de Bois no Brasil, Companhia Editora Nacional, São Paulo, 1958.

64.STALNAKER, J.J.; HARRIS, E.C.Structural design in wood.New York, Van Nostrand Reinhold, 1989.

65.TEZUKA, Y. Concretos polímeros, São Paulo, IPT, 1979.

66.THOMAS, Kenneth. Mechanical fasteners. The Structural Engineer,v.60A, n.2, p.47-51, 1982.

67.ULREY, H. F. Carpenters and builders library- tools. Steel square.Joinery. Indiana, 1970.

68. WANGAARD, F.F. The mechanical properties of wood. New York, John Wiley, 1950. 
69.ZELLER, Etienne. Performances des constructions en bois et maintenance. Annales de l'institut techinique du batiment et des travaux publics, N. 492, p.53-87, 1991.

70.ZHAN, John J. Design equations for multiple-fastener wood connections. Journal of Structural Engineering, vol.117, n.11, p.3477-3486, 1991.

71.ZHAN, John J. Reliability of bolted wood connections. Journal of Structural Engineering, vol. 118, n.12, p.3362-3376, 1992. 